Portland State University

PDXScholar

\title{
Hydrodynamic and Water Quality Modeling of the Chehalis River Using CE-QUAL-W2
}

Sarah Van Glubt

Portland State University

Follow this and additional works at: https://pdxscholar.library.pdx.edu/open_access_etds

Part of the Civil and Environmental Engineering Commons, and the Water Resource Management Commons

Let us know how access to this document benefits you.

\section{Recommended Citation}

Van Glubt, Sarah, "Hydrodynamic and Water Quality Modeling of the Chehalis River Using CE-QUAL-W2" (2017). Dissertations and Theses. Paper 3486.

https://doi.org/10.15760/etd.5370

This Thesis is brought to you for free and open access. It has been accepted for inclusion in Dissertations and Theses by an authorized administrator of PDXScholar. Please contact us if we can make this document more accessible: pdxscholar@pdx.edu. 
Hydrodynamic and Water Quality Modeling of the Chehalis River Using CE-QUAL-W2

by

Sarah Van Glubt

A thesis submitted in partial fulfillment of the requirements for the degree of

Master of Science

in

Civil and Environmental Engineering

Thesis Committee:

Scott Wells, Chair

Chris Berger

Gwynn Johnson

Portland State University

2017 
(C) 2016 Sarah Van Glubt 


\begin{abstract}
The Chehalis River Basin is located in the southwest region of Washington State, originating in the Olympic Mountains and flowing to Grays Harbor and the Pacific Ocean. The Chehalis River is over 125 miles, exists within five counties, and flows through agricultural, residential, industrial, and forest land areas. Four major rivers discharge to the Chehalis River, as well as many smaller creeks, five wastewater treatment plants, and groundwater flows.

Flooding is a major problem in the relatively flat areas surrounding the cities of Chehalis and Centralia, with severe consequences for property, safety and transportation. As a result, construction of a flood-control dam in the upper basin has been proposed. One major concern of constructing a dam is the potentially severe impacts to fish health and habitat. The Chehalis River has routinely violated water quality standards for primarily temperature and dissolved oxygen, and has had multiple water quality and Total Maximum Daily Load studies beginning in 1990.
\end{abstract}

CE-QUAL-W2, a two-dimensional (longitudinal and vertical) hydrodynamic and water quality model, was used to simulate the Chehalis River, including free flowing river stretches and stratified (in summer) lake-like stretches. The goals of this research were to assess the flood retention structure's impacts to water quality, as well as river responses to potential climate change scenarios.

In order to use the model to achieve these goals, calibration to field data for flow, temperature, and water quality constituents was performed. This involved developing 
meteorological data, riparian shading data, and flow, temperature, water quality records for all tributaries during the calibration period of January 1, 2013 to December 31, 2014. System cross-sectional geometry data were also required for the model grid. Because of the short travel time in the river, the model was sensitive to boundary condition data, wind speed, bathymetry, nutrient kinetics, and algae, epiphyton, and zooplankton kinetics.

Future conditions showed predictions of warmer water temperatures and slight changes to water quality conditions on the river. As fish in the area prefer cooler water temperatures, this could pose a threat to fish health and habitat. Flood retention structures also showed impacts to river temperature and water quality. Structures with the purpose of flood retention only (only operating during times of flooding) gave model predictions for daily maximum temperature higher than structures that employed flood retention and flow augmentation (operating during all times of the year). This suggested the management of flow passage or retention by the dam is important for water quality on the river.

As this research continues improvements will be made, particularly to temperature and water quality constituents. Additional data for the system would be beneficial to this process. Model predictions of temperature were sensitive to meteorological data, including cloud cover, which were largely estimated based on solar radiation. Additional meteorological data throughout the basin would be useful to temperature results. Temperature results were also sensitive to the model bathymetry, 
and additional investigations into segments widths and water depths may improve temperature predictions.

Water quality constituent data were largely lacking for the system. Many estimation techniques and approximations were used for input water quality constituents for the model upstream boundary and tributaries when little or no data were available, introducing uncertainty to the model. It was not possible to calibrate $\mathrm{pH}$ to field data because alkalinity data were essentially unavailable. However, other constituents had good agreement between model predictions and field data, including dissolved oxygen, nitrates, total phosphorus, and total suspended solids. 


\section{Acknowledgments}

A huge thank you to Dr. Scott Wells and Dr. Chris Berger for their continued teaching, assistance, availability, patience, and kindness. This project would not have been possible without them. 


\section{Table of Contents}

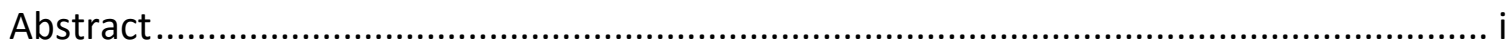

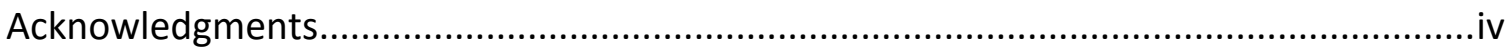

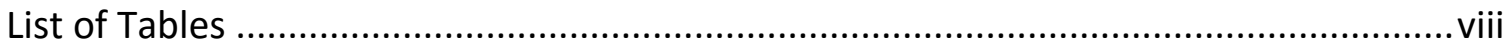

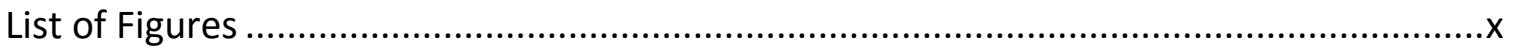

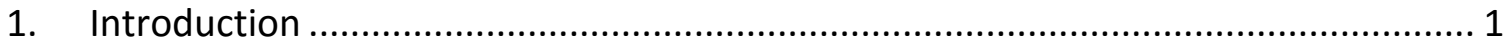

1.1. Chehalis River Basin Background ................................................................ 1

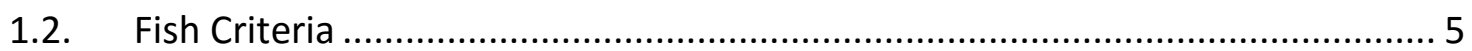

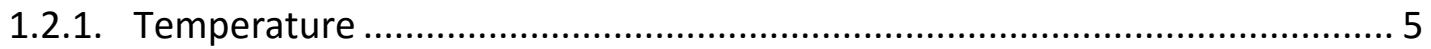

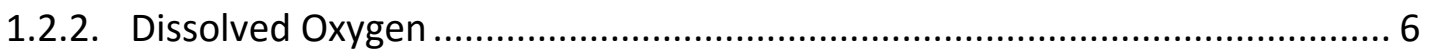

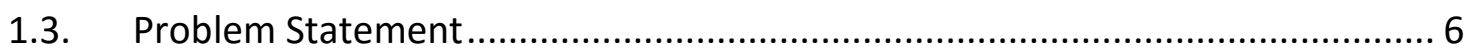

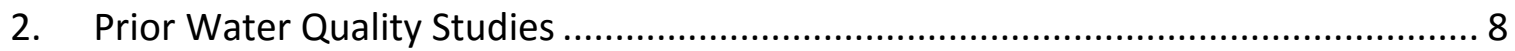

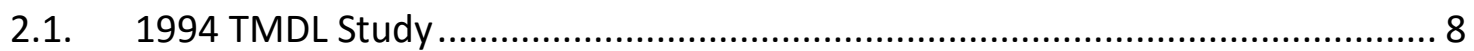

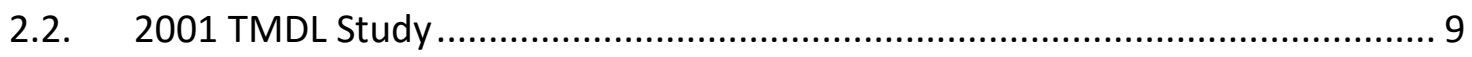

2.3. 2014 Anchor QEA Water Quality Studies Report ........................................ 12

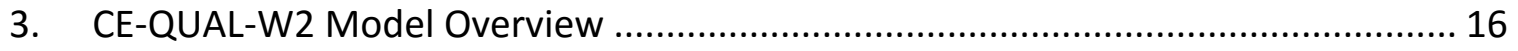

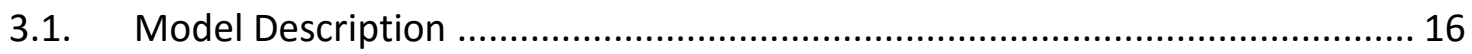

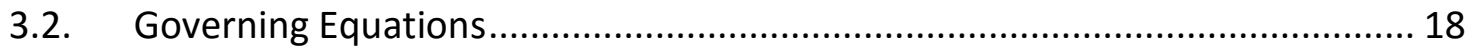

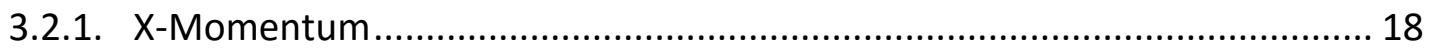

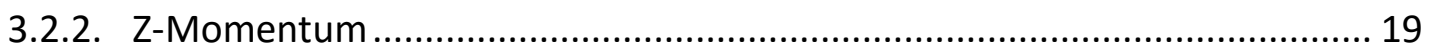

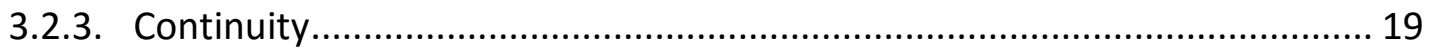

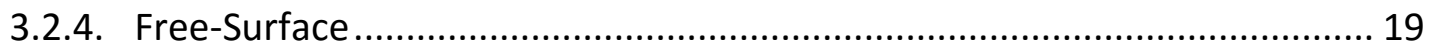

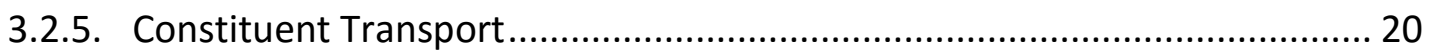

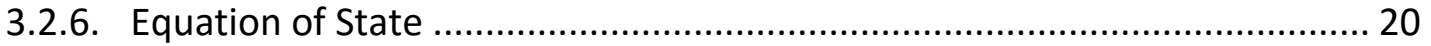

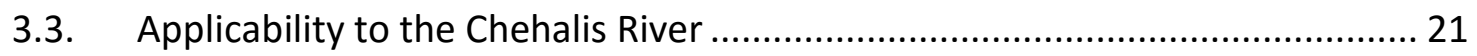

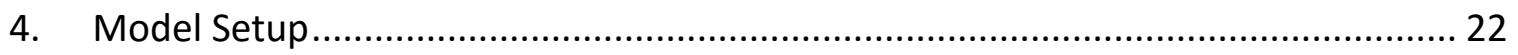

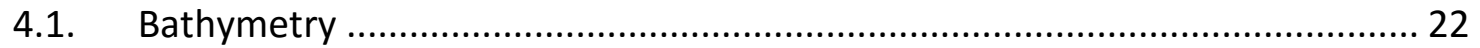

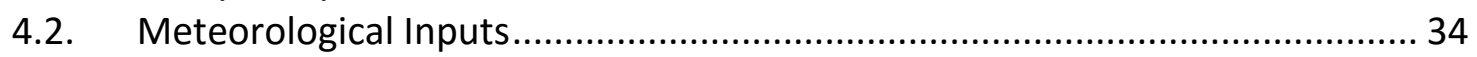

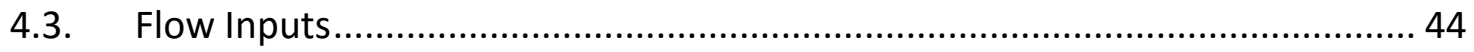

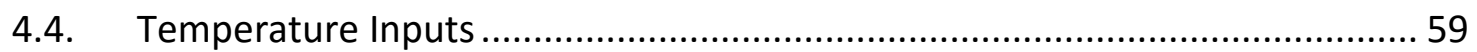

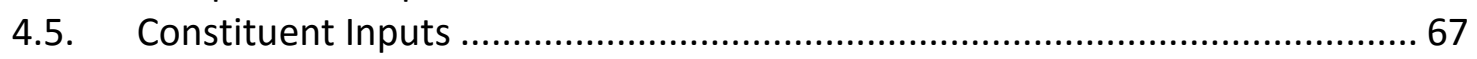

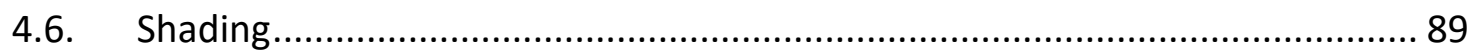

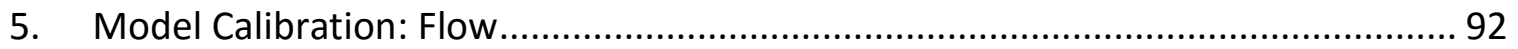

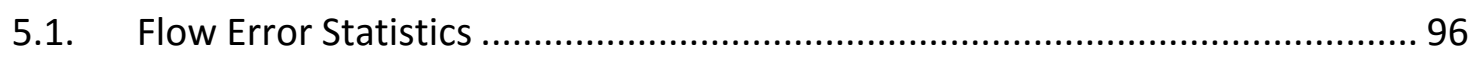

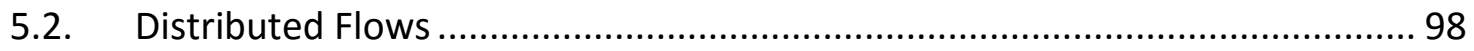

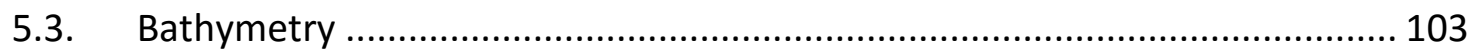

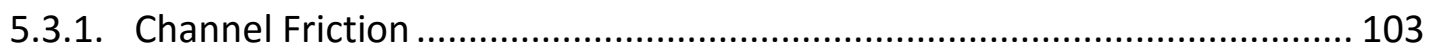

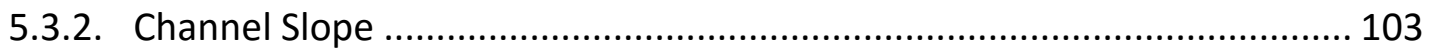

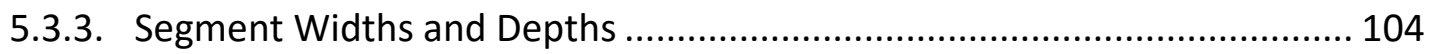

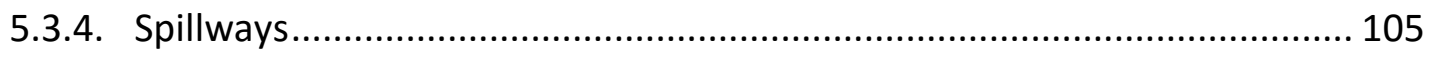

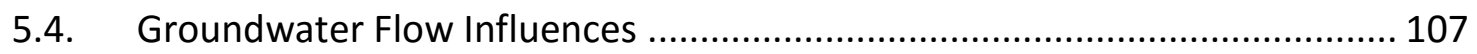




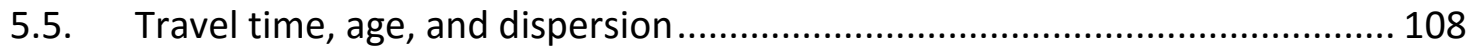

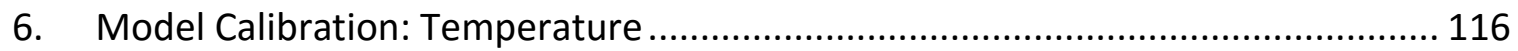

6.1. Temperature Error Statistics ................................................................ 134

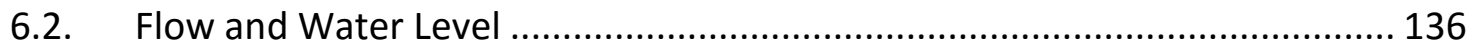

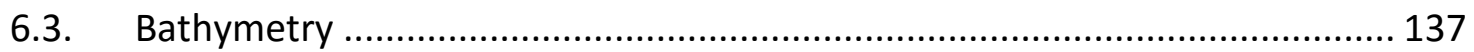

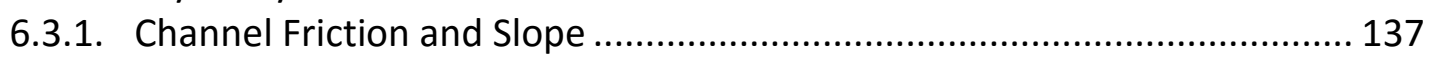

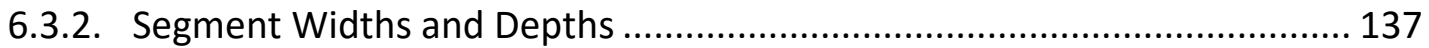

6.4. Boundary Condition Temperature ............................................................. 138

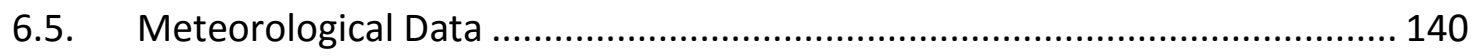

6.6. Wind Sheltering ..................................................................................... 141

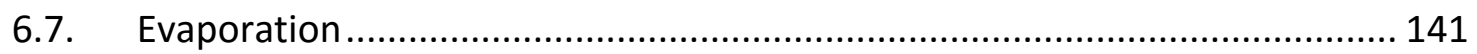

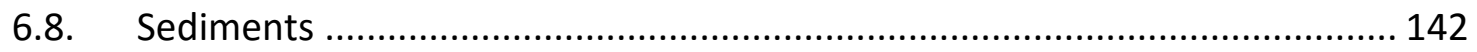

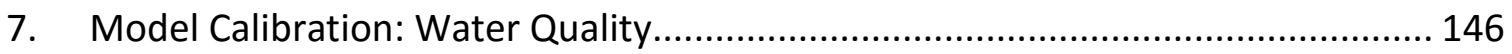

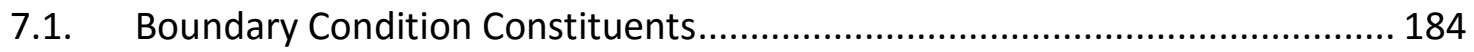

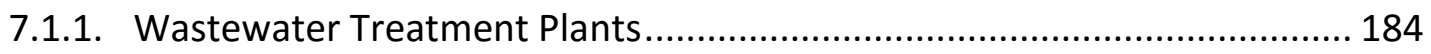

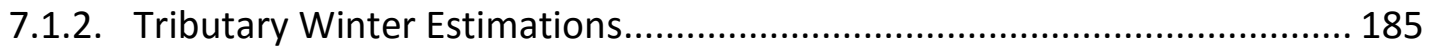

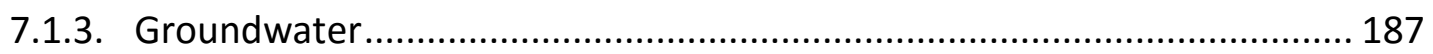

7.1.4. Locating Tributaries that Affected In-Stream Water Quality ...................... 188

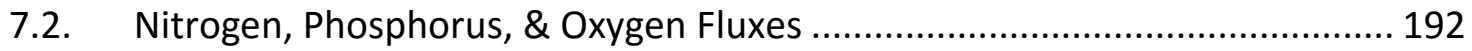

7.2.1. Algae, Epiphyton, \& Zooplankton Kinetics............................................ 203

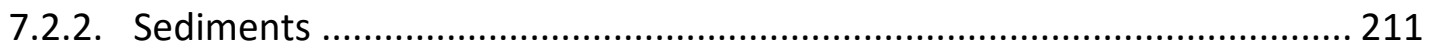

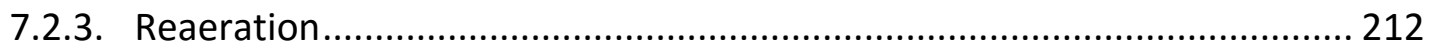

7.3. Comments About Model Predictions ........................................................ 213

7.4. Continuous Water Quality ...................................................................... 214

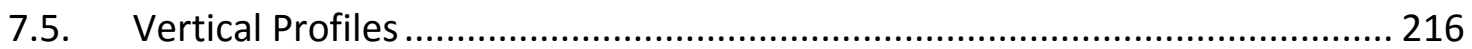

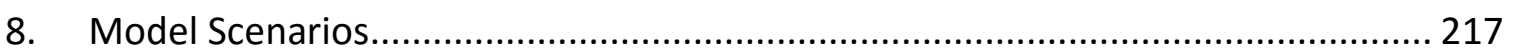

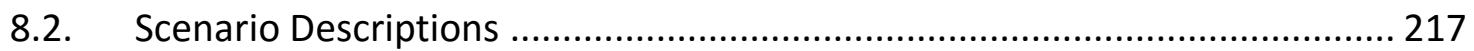

8.2.1. Flood Retention Only (FRO) ............................................................... 217

8.2.2. Flood Retention Flow Augmentation (FRFA) ....................................... 218

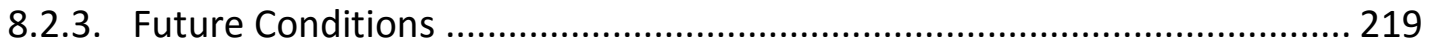

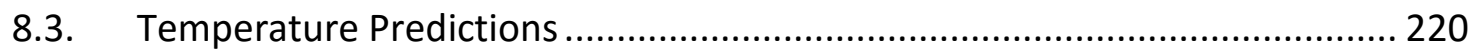

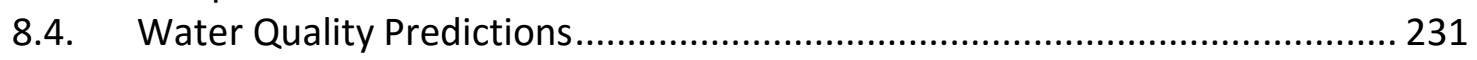

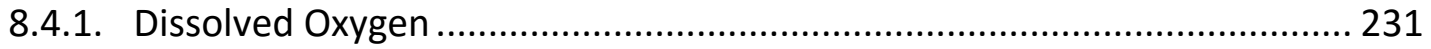

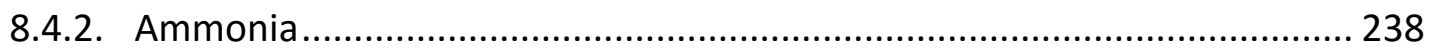

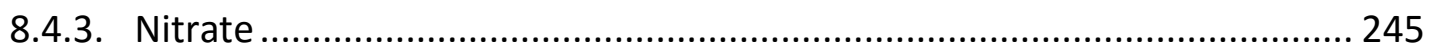

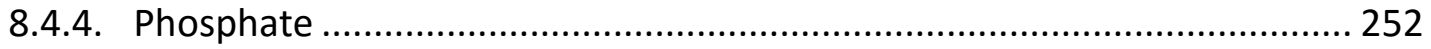

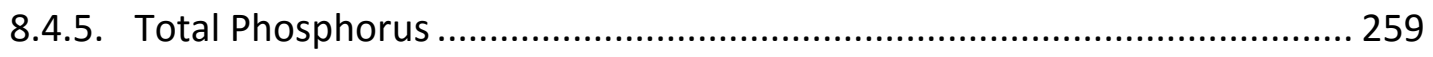

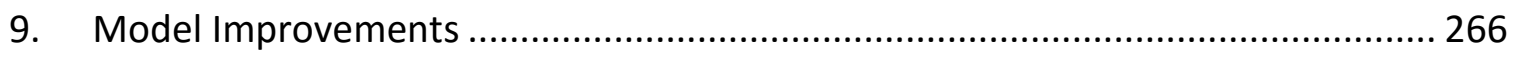

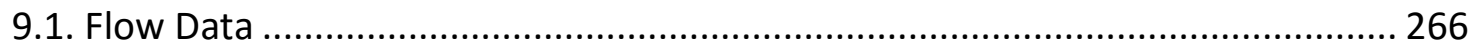

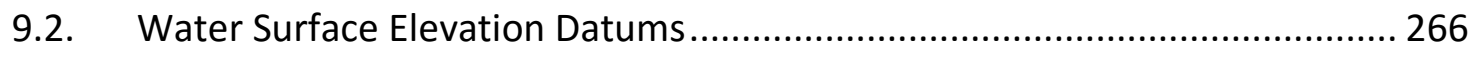

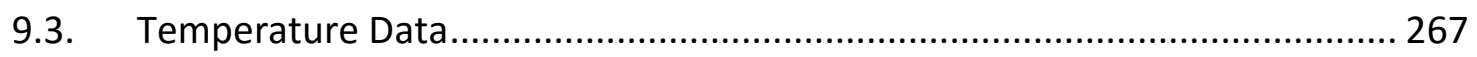

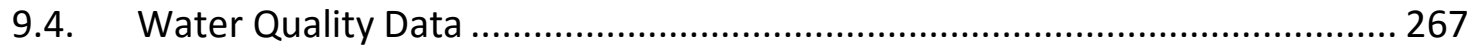




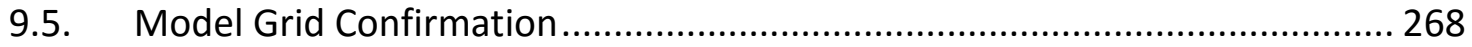

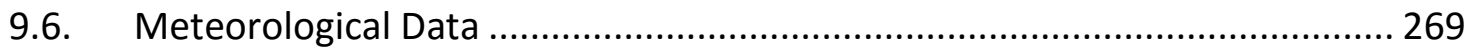

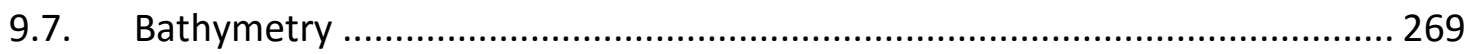

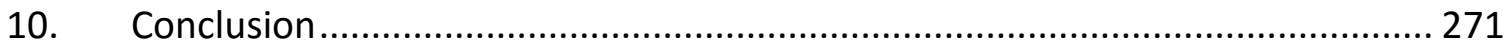

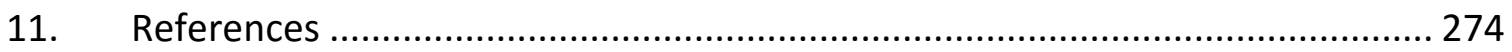

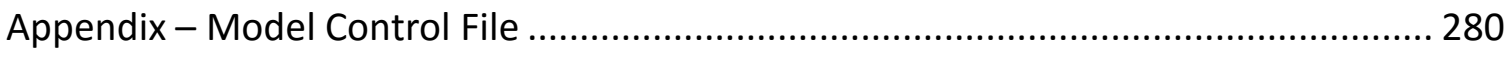




\section{List of Tables}

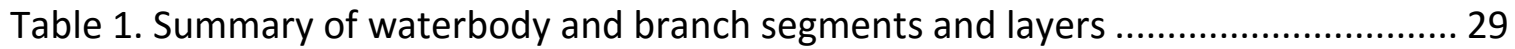

Table 2. Monitoring stations that provided meteorological data .................................. 35

Table 3. Air and Dew Temperature Regression Relationships for Minot Peak (MIPW)

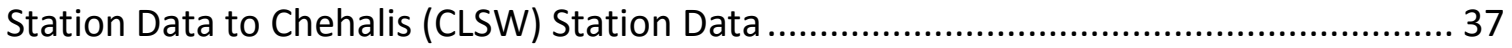

Table 4. River mile and segment locations for tributaries, dischargers, and groundwater

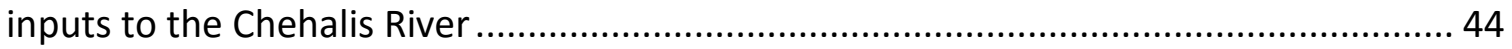

Table 5. Flow monitoring stations with measured or estimated flow data .................... 47 Table 6. Flow Regression Relationships for South Fork Chehalis River, Black River, and Elk Creek to Chehalis River at Doty or Grand Mound ...................................................... 49

Table 7. Drainage area values used to calculate flow for tributaries with missing data.. 52 Table 8. Monitoring stations used to develop model temperature inputs ......................60 Table 9. Temperature Regression Relationships for Upstream Boundary, Elk Creek, South Fork Chehalis River, Newaukum River, Skookumchuck River, and Black River ................ 62

Table 10. Monitoring stations that provided water quality data .................................. 69

Table 11. Flow and water surface elevation stations on the mainstem Chehalis River used to compare to model predictions ............................................................................. 92

Table 12. Error statistics for model comparisons to field data for flow at Doty, Grand

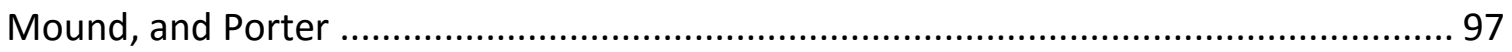

Table 13. Error statistics for model comparisons to field data for flow at Doty, Grand Mound, and Porter during the months of May through October 97 Table 14. Error statistics for model comparisons to field data for flow at Doty, Grand Mound, and Porter during the months of November through April.............................. 98 Table 15. Error statistics for model comparisons to water level data at Doty, Adna, Chehalis WWTP, Centralia, Grand Mound, Rochester, and Porter mainstem Chehalis River stations. 98

Table 16. Percent of mainstem Chehalis River flow attributed to groundwater throughout the model. 107

Table 17. Travel times for upstream pulse inputs to reach various downstream locations for various input pulse times 111 Table 18. Percent mixing at various segments throughout the model at various times during the model simulation 114

Table 19. Temperature stations on the mainstem Chehalis River used to compare to model predictions 116 Table 20. Mainstem Chehalis River vertical temperature profile collection locations and dates used in temperature calibration 118 Table 21. Error statistics for temperature comparisons between model predictions and field data along the mainstem Chehalis River ranging between upstream of Pe Ell and Porter, WA 134 
Table 22. Error statistics for daily maximum temperature comparisons between model predictions and field data along the mainstem Chehalis River ranging between upstream of Pe Ell and Porter, WA.................................................................................. 135

Table 23. Water quality stations on the mainstem Chehalis River used to compare to

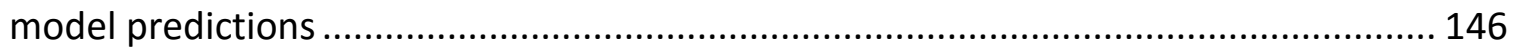

Table 24. Mainstem Chehalis River vertical dissolved oxygen profile collection locations and dates used in water quality calibration 147

Table 25. W2 Model Water Quality Parameters in the Chehalis River Model ............... 181

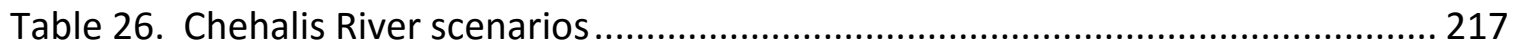

Table 27. Future conditions monthly flow multipliers (Hill, 2016) ............................. 219 


\section{List of Figures}

Figure 1. Study area with major tributaries, from near Doty to Porter, WA.................... 2 Figure 2. Upstream portion of the Chehalis River exhibiting steep gradients with riffles and pools

\section{3}

Figure 3. Middle portion of the Chehalis River near Centralia exhibiting slow, deep, lakelike conditions....

Figure 4. Lower portion of the Chehalis River near Porter exhibiting steeper gradients than the middle portion, with swift-moving water .......................................................... 4 Figure 5. Portion of the Chehalis River exhibiting step gradients with pools and riffles . 23 Figure 6 Portion of the Chehalis River exhibiting lake-like conditions ........................... 23 Figure 7. Longitudinal profile of the Chehalis River thalweg (vertical lines show model

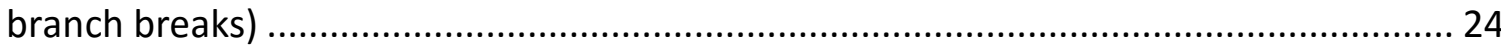

Figure 8. Longitudinal profile of the Chehalis River thalweg and the model grid bottom

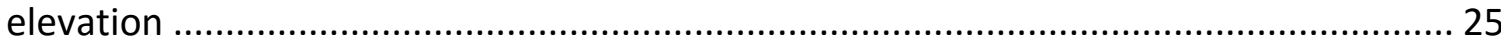

Figure 9. Example Chehalis River field cross section at river mile 77.92 used to calculate layer widths for model segment 140 . The CE-QUAL-W2 model widths are represented by

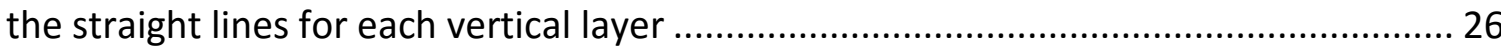
Figure 10. Example Chehalis River field cross section at river mile 76 used to calculate layer widths for model segment 151 . The CE-QUAL-W2 model widths are represented by the straight lines for each vertical layer 27

Figure 11. Aerial view of the entire model grid, showing active model segments along the

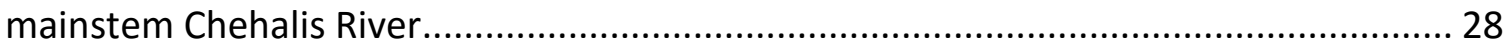

Figure 12. Model branch 1 side profile view, including all segments and layers ............. 30

Figure 13. Model branch 2 side profile view, including all segments and layers ............. 30

Figure 14. Model branch 3 side profile view, including all segments and layers ............. 31

Figure 15. Model branch 4 side profile view, including all segments and layers ............ 31

Figure 16. Model branch 5 side profile view, including all segments and layers ............ 32

Figure 17. Model branch 6 side profile view, including all segments and layers ............ 32

Figure 18. Model branch 7 side profile view, including all segments and layers ............ 33

Figure 19. Model branch 8 side profile view, including all segments and layers ............ 33

Figure 20. Model branch 9 side profile view, including all segments and layers ............. 34

Figure 21. Model branch 10 side profile view, including all segments and layers .......... 34

Figure 22. Meteorological stations near the Chehalis River that provided data, including Thrash Creek, HKFW, CLSW, Centralia-Chehalis Airport, and MIPW ............................ 36

Figure 23. Air temperature relationship between Minot Peak (MIPW) and Chehalis (CLSW) RAWS stations when both had data available .......................................................... 38

Figure 24. Dew point temperature relationship between Minot Peak (MIPW) and Chehalis (CLSW) RAWS stations when both had data available ............................................. 38

Figure 25. Meteorological data from the Thrash Creek station (including estimated values)

Figure 26. Meteorological data from the HKFW station (raw values only) ..................... 41 
Figure 27. Meteorological data from the CLSW station (including estimated values) .... 42 Figure 28. Meteorological data from the MIPW station (including estimated values) ... 43 Figure 29. Schematic of tributaries to the model reach of the Chehalis River and their corresponding river miles (WEST Consultants, 2011 and WADOE, 2001). Note: figure is not to scale. 46

Figure 30. Flow relationship between Chehalis River near Mahaffey Creek and Chehalis River at Doty when both gaging stations had data available 50 Figure 31. Flow relationship between Elk Creek and Chehalis River at Doty when both

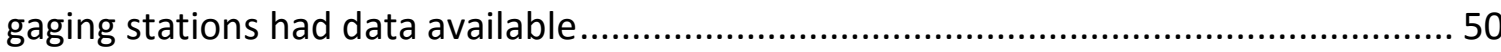
Figure 32. Flow relationship between South Fork Chehalis River and Chehalis River at Doty when both gaging stations had data available 51 Figure 33. Flow relationship between Black River and Chehalis River at Grand Mound when both gaging stations had data available 51 Figure 34. Input flow data where field data were available for Chehalis River at Mahaffey Creek (upstream boundary), Elk Creek, South Fork Chehalis River, Newaukum River, Salzer Creek, Skookumchuck River, and Black River .... 54 Figure 35. Input flow based on drainage area ratios to Newaukum River for Bunker Creek, Mill Creek, Stearns Creek, Dillenbaugh Creek, and China Creek. 55 Figure 36. Input flow based on drainage area ratios to Newaukum River for Scammon Creek, Prairie Creek, Lincoln Creek, Scatter Creek, and Independence Creek................. 56 Figure 37. Input flow based on drainage area ratios to Newaukum River for Garrard Creek, Rock Creek, Cedar Creek, Gibson Creek, and Porter Creek ......................................... 57 Figure 38. Input flow for the Pe Ell, Darigold, Chehalis, Centralia, and Grand Mound

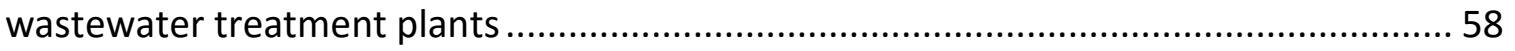

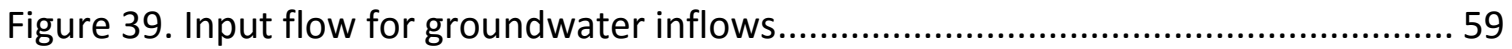
Figure 40. Temperature relationship between Chehalis River at upstream boundary station 11-UCH and Chehalis River Downstream of Darigold when both gaging stations had data available 63 Figure 41. Temperature relationship between South Fork Chehalis River and Chehalis River Downstream of Darigold when both gaging stations had data available 63 Figure 42. Input temperature data where field data were available for the upstream boundary (station 11-UCH), Elk Creek, South Fork Chehalis River, Newaukum River, Skookumchuck River, Scatter Creek, and Black River............................................... 65 Figure 43. Input temperature for the Pe Ell, Darigold, Centralia, Chehalis, and Grand

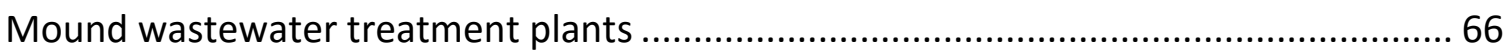

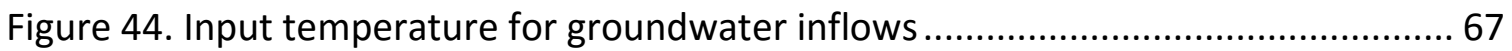
Figure 45. Input concentrations for ISS, PO4, NH3, and NO3 for tributaries with data available, including the upstream boundary, Elk Creek, South Fork Chehalis River, Newaukum River, Skookumchuck River, Black River, and Lincoln Creek ....................... 76 Figure 46. Input concentrations for TIC, alkalinity, algae, and DO for tributaries with data available, including the upstream boundary, Elk Creek, South Fork Chehalis River, Newaukum River, Skookumchuck River, Black River, and Lincoln Creek ....................... 77 
Figure 47. Input concentrations for LDOM, RDOM, LPOM, and RPOM for tributaries with data available, including the upstream boundary, Elk Creek, South Fork Chehalis River, Newaukum River, Skookumchuck River, Black River, and Lincoln Creek ....................... 78 Figure 48. Input concentrations for LDOM-P, RDOM-P. LPOM-P, and RPOM-P for tributaries with data available, including the upstream boundary, Elk Creek, South Fork Chehalis River, Newaukum River, Skookumchuck River, Black River, and Lincoln Creek 79 Figure 49. Input concentrations for LDOM-N, RDOM-N. LPOM-N, and RPOM-N for tributaries with data available, including the upstream boundary, Elk Creek, South Fork Chehalis River, Newaukum River, Skookumchuck River, Black River, and Lincoln Creek 80 Figure 50. Field data concentrations for $\mathrm{pH}, \mathrm{BOD5}$, and TSS used to calculate input water quality concentrations for Elk Creek, South Fork Chehalis River, Newaukum River, Skookumchuck River, Black River, and Lincoln Creek ................................................. 81 Figure 51. Field data concentrations for chlorophyll a, TKN, and TP used to calculate input water quality concentrations for Elk Creek, South Fork Chehalis River, Newaukum River, Skookumchuck River, Black River, and Lincoln Creek ................................................. 82 Figure 52. Model input concentrations for FC, ISS, PO4, and NH3 for the Pe Ell, Darigold, Centralia, Chehalis, and Grand Mound wastewater treatment plants ........................... 83 Figure 53. Model input concentrations for NO3, DO, TIC, and alkalinity for the Pe Ell, Darigold, Centralia, Chehalis, and Grand Mound wastewater treatment plants............ 84 Figure 54. Model input concentrations for dissolved, particulate, phosphorus, and nitrogen BOD for the Pe Ell, Darigold, Centralia, Chehalis, and Grand Mound wastewater treatment plants 85

Figure 55. Model input concentrations for groundwater reaches with data for TDS, PO4, $\mathrm{NH} 3, \mathrm{NO} 3, \mathrm{BOD}$, and DO 86

Figure 56. Model input concentrations for groundwater reaches with data for TIC, alkalinity, and the DOM and POM species (labile, refractory, phosphorus, and nitrogen)

Figure 57. Field groundwater data for $\mathrm{pH}, \mathrm{BOD5}$, and TP used to calculate input water quality concentrations 88

Figure 58. Left bank vegetation elevation for each segment input to the model in the shade file 90

Figure 59. Right bank vegetation elevation for each segment input to the model in the shade file 91 Figure 60. Longitudinal view of the mainstem Chehalis River flow and water surface elevation gaging stations used for flow calibration (vertical lines show model branch breaks)..... 93

Figure 61. Model flow predictions compared to Chehalis River field data at Doty, Grand Mound, and Porter 94 Figure 62. Model water surface elevation predictions compared to Chehalis River field data at Doty, Adna, Chehalis WWTP, and Centralia 95 Figure 63. Model water surface elevation predictions compared to Chehalis River field data at Grand Mound, Rochester, and Porter 96 
Figure 64. Distributed tributary flows input upstream of flow monitoring locations at Doty, Grand Mound, and Porter for model calibration 100 Figure 65. Water surface elevation at Porter versus distributed flow in branch 9 upstream of Porter. 101 Figure 66. Map and earth aerial views of ponds and oxbows adjacent to the Chehalis River near Chehalis and Centralia, WA where flooded water may be stored 102 Figure 67. Schematic of water and weir heights for a free flowing submerged weir used with the spillway equations (Cole and Wells, 2016)... 106 Figure 68. Resulting tracer magnitudes and timing along the river channel for tracer pulses

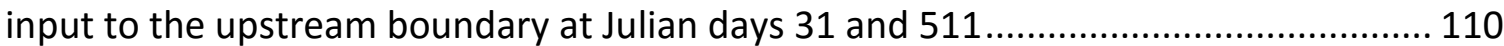
Figure 69. Travel times for tracer pulse peaks at various downstream locations.......... 112 Figure 70. Model-predicted water age throughout the model reach .......................... 113 Figure 71. Model-predicted TDS concentrations at various downstream locations after a constant input of $100 \mathrm{mg} / \mathrm{L}$ was added to the upstream boundary .... 115 Figure 72. Longitudinal view of the mainstem Chehalis River continuous and vertical temperature gaging stations used for temperature calibration (vertical lines show model branch breaks)

Figure 73. Model temperature predictions compared to field data at the mainstem Chehalis River stations: $11-\mathrm{UCH}$, upstream of Pe Ell, downstream of Pe Ell, 13-CH, at Woodstead, upstream of Elk Creek, and at Doty 122 Figure 74. Model temperature predictions compared to field data at the mainstem Chehalis River stations: $15-\mathrm{CH}$, at Dryad, at Rainbow Falls, 19-CH, at Ceres Hills Road, and at Adna.

Figure 75. Model temperature predictions compared to field data at the mainstem Chehalis River stations: 21-CH, near Newaukum Confluence, 22-CH, upstream of Darigold, downstream of Darigold, and upstream of Skookumchuck.... 124 Figure 76. Model temperature outputs versus field data collected at the mainstem Chehalis River stations: at Galvin Bridge, $17-\mathrm{CH}$, upstream of Black River, $18-\mathrm{CH}$, at Oakville, 23-CH, and at Porter 125 Figure 77. Model predictions of daily maximum temperatures compared to field data at the mainstem Chehalis River stations: 11-UCH, upstream of Pe Ell, downstream of Pe Ell, 13- $\mathrm{CH}$, at Woodstead, upstream of Elk Creek, and at Doty 126 Figure 78. Model predictions of daily maximum temperatures compared to field data at the mainstem Chehalis River stations: $15-\mathrm{CH}$, at Dryad, at Rainbow Falls, $19-\mathrm{CH}$, at Ceres Hills Road, and at Adna.... 127 Figure 79. Model predictions of daily maximum temperatures compared to field data at the mainstem Chehalis River stations: $21-\mathrm{CH}$, near Newaukum Confluence, 22-CH, upstream of Darigold, downstream of Darigold, and upstream of Skookumchuck....... 128 Figure 80 . Model predictions of daily maximum temperatures compared to field data at the mainstem Chehalis River stations: at Galvin Bridge, 17- $\mathrm{CH}$, upstream of Black River, 18- $\mathrm{CH}$, at Oakville, and at Porter 129 
Figure 81. Model versus field data vertical temperature profiles at the mainstem Chehalis River stations: at Route 6 Bridge, HL-14, and HL-13................................................ 130 Figure 82. Model versus field data vertical temperature profiles at the mainstem Chehalis River stations: HL-12, HL-11, HL-10, HL-9, and HL-8 ............................................. 131 Figure 83. Model versus field data vertical temperature profiles at the mainstem Chehalis River stations: HL-7, HL-6, HL-5, HL-4, and HL-3 132 Figure 84. Model versus field data vertical temperature profiles at the mainstem Chehalis River stations: HL-2, Mellen Road Bridge, and HL-1 ............................................. 133 Figure 85. Comparison of model versus field data at Dryad and Rainbow Falls for before and after bathymetry segment width changes were made ......................................... 138 Figure 86. Comparison of model versus field data temperature when boundary tributary temperatures were estimated using Newaukum River versus Chehalis River Downstream of Darigold WWTP data 139 Figure 87. Model temperature versus field data at downstream of Pe Ell, station $13-\mathrm{CH}$, at Woodstead, and at Doty when TSEDF equaled 0.3 .... 143 Figure 88. Model temperature versus field data at downstream of Pe Ell, station $13-\mathrm{CH}$, at Woodstead, and at Doty when TSEDF equaled 0.6 144 Figure 89. Model temperature versus field data at downstream of Pe Ell, station $13-\mathrm{CH}$, at

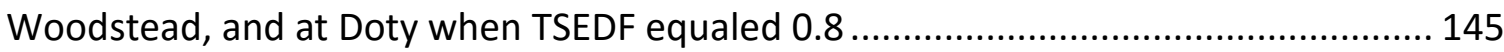
Figure 90. Longitudinal view of the mainstem Chehalis River water quality sample sites (vertical lines show model branch breaks). 148 Figure 91. Model dissolved oxygen predictions versus field data at upstream of Pe Ell, at Dryad, upstream of South Fork Chehalis River, at Adna, upstream of Newaukum River, and at Route 6 bridge 150

Figure 92. Model dissolved oxygen predictions versus field data at upstream of Skookumchuck River, at Galvin Road bridge, upstream of Black River, at Oakville, and at Porter. 151

Figure 93. Model ammonia predictions versus field data at upstream of Pe Ell, at Dryad, upstream of South Fork Chehalis River, at Adna, upstream of Newaukum River, and at Route 6 bridge. 152 Figure 94. Model ammonia predictions versus field data at upstream of Skookumchuck River, at Galvin Road bridge, upstream of Black River, at Oakville, and at Porter......... 153 Figure 95. Model nitrates predictions versus field data at upstream of Pe Ell, at Dryad, upstream of South Fork Chehalis River, at Adna, upstream of Newaukum River, and at Route 6 bridge. 154

Figure 96. Model nitrates predictions versus field data at upstream of Skookumchuck River, at Galvin Road bridge, upstream of Black River, at Oakville, and at Porter ........ 155 Figure 97. Model total Kjeldahl nitrogen predictions versus field data at upstream of Pe Ell, upstream of South Fork Chehalis River, at Adna, upstream of Newaukum River, and at Route 6 bridge. 156 Figure 98. Model total Kjeldahl nitrogen predictions versus field data at upstream of Skookumchuck River, at Galvin Road bridge, upstream of Black River, and at Oakville 157 
Figure 99. Model phosphate predictions versus field data at upstream of Pe Ell, downstream of Pe Ell, at Dryad, upstream of South Fork Chehalis River, at Adna, and upstream of Newaukum River 158 Figure 100. Model phosphate predictions versus field data at Route 6 bridge, upstream of Skookumchuck River, at Galvin Road bridge, upstream of Black River, at Oakville, and at Porter 159

Figure 101. Model total phosphorus predictions versus field data at upstream of Pe Ell, at Dryad, upstream of South Fork Chehalis River, at Adna, upstream of Newaukum River, and at Route 6 bridge ..... 160

Figure 102. Model total phosphorus predictions versus field data at upstream of Skookumchuck River, at Galvin Road bridge, upstream of Black River, at Oakville, and at Porter 161

Figure 103. Model chlorophyll a predictions versus field data at upstream of Pe Ell, upstream of South Fork Chehalis River, at Adna, upstream of Newaukum River, and at Route 6 bridge. 162

Figure 104. Model chlorophyll a predictions versus field data at upstream of Skookumchuck River, at Galvin Road bridge, upstream of Black River, and at Oakville 163 Figure 105. Model pH predictions versus field data at upstream of Pe Ell, at Dryad, upstream of South Fork Chehalis River, at Adna, upstream of Newaukum River, and at Route 6 bridge. 164

Figure 106. Model pH predictions versus field data at upstream of Skookumchuck River, at Galvin Road bridge, upstream of Black River, at Oakville, and at Porter .................. 165 Figure 107. Model TSS predictions versus field data at upstream of Pe Ell, at Dryad, upstream of South Fork Chehalis River, at Adna, upstream of Newaukum River, and at Route 6 bridge. 166 Figure 108. Model TSS predictions versus field data at upstream of Skookumchuck River, at Galvin Road bridge, upstream of Black River, at Oakville, and at Porter .................. 167 Figure 109. Model dissolved oxygen predictions versus continuous field data at the downstream of Pe Ell monitoring station .................................................................. 168 Figure 110. Model dissolved oxygen predictions versus continuous field data at the Route 6 Bridge monitoring station 169

Figure 111. Model dissolved oxygen predictions versus continuous field data at the Mellen Road Bridge monitoring station 170 Figure 112. Model chlorophyll a predictions versus continuous field data at the downstream of Pe Ell monitoring station 171 Figure 113. Model chlorophyll a predictions versus continuous field data at the Route 6 Bridge monitoring station ..... 172

Figure 114. Model chlorophyll a predictions versus continuous field data at the Mellen

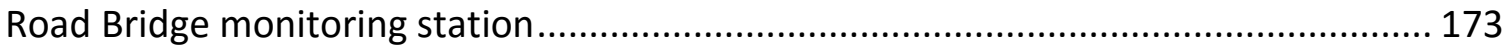
Figure 115. Model pH predictions versus continuous field data at the downstream of $\mathrm{Pe}$ Ell monitoring station. 174 
Figure 116. Model pH predictions versus continuous field data at the Route 6 Bridge

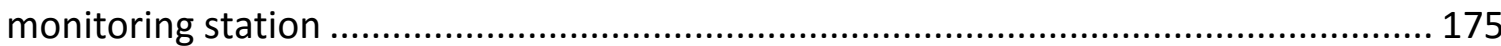

Figure 117. Model pH predictions versus continuous field data at the Mellen Road Bridge monitoring station 176

Figure 118. Model-predicted vertical dissolved oxygen profiles compared to field data at the monitoring stations: Route 6 Bridge, HL-14, and HL-13. 177 Figure 119. Model-predicted vertical dissolved oxygen profiles compared to field data at the monitoring stations: HL-12, HL-11, HL-10, HL-9 and HL-8 178 Figure 120. Model-predicted vertical dissolved oxygen profiles compared to field data at the monitoring stations: $\mathrm{HL}-7, \mathrm{HL}-6, \mathrm{HL}-5, \mathrm{HL}-4$ and $\mathrm{HL}-3$ 179 Figure 121. Model-predicted vertical dissolved oxygen profiles compared to field data at the monitoring stations: HL-2, Mellen Road Bridge, and HL-1. 180

Figure 122. TP model predictions compared to field data when previous technique was used to estimate OMP for Elk Creek 190

Figure 123. TP model predictions compared to field data when updated technique was used to estimate OMP for Elk Creek ................................................................................ 191

Figure 124. Dominant model-predicted NH4, NO3, and DO fluxes in waterbody 1 ...... 194 Figure 125. Dominant model-predicted NH4, NO3, and DO fluxes in waterbody 2 ..... 195 Figure 126. Dominant model-predicted NH4, NO3, and DO fluxes in waterbody 3 ...... 196 Figure 127. Dominant model-predicted NH4, NO3, and DO fluxes in waterbody 4 ...... 197 Figure 128. Dominant model-predicted NH4, NO3, and DO fluxes in waterbody 5 ...... 198 Figure 129. Dominant model-predicted NH4, NO3, and DO fluxes in waterbody 6 ...... 199 Figure 130. Dominant model-predicted NH4, NO3, and DO fluxes in waterbody 7 ..... 200 Figure 131. Dominant model-predicted NH4, NO3, and DO fluxes in waterbody 8 ..... 201 Figure 132. Dominant model-predicted NH4, NO3, and DO fluxes in waterbody 9 ..... 202 Figure 133. Algae growth limitation by phosphorus predicted by the model at upstream of Pe Ell, downstream of Pe Ell, Dryad, upstream of South Fork Chehalis River, Adna, and upstream of Newaukum River 205 Figure 134. Algae growth limitation by phosphorus predicted by the model at Route 6 Bridge, upstream of Skookumchuck River, Galvin Road Bridge, upstream of Black River, Oakville, and Porter 206 Figure 135. Algae growth limitation by nitrogen predicted by the model at upstream of $\mathrm{Pe}$ Ell, downstream of Pe Ell, Dryad, upstream of South Fork Chehalis River, Adna, and upstream of Newaukum River 207 Figure 136. Algae growth limitation by nitrogen predicted by the model at Route 6 Bridge, upstream of Skookumchuck River, Galvin Road Bridge, upstream of Black River, Oakville, and Porter 208 Figure 137. Algae growth limitation by light predicted by the model at upstream of Pe Ell, downstream of Pe Ell, Dryad, upstream of South Fork Chehalis River, Adna, and upstream of Newaukum River. 209 
Figure 138. Algae growth limitation by light predicted by the model at Route 6 Bridge, upstream of Skookumchuck River, Galvin Road Bridge, upstream of Black River, Oakville, and Porter 210

Figure 139. Cloud cover for Thrash Creek and CLSW during the times of continuous DO

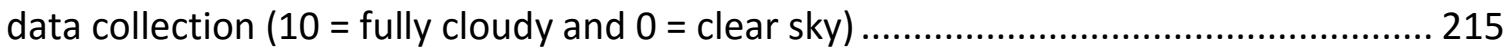
Figure 140. Model daily maximum temperature predictions upstream of Elk Creek for current conditions: baseline, FRO with no vegetative shading, FRO with riparian shading, FRFA scenario 1, and FRFA scenario 2 simulations. 221 Figure 141. Model daily maximum temperature predictions upstream of Elk Creek for future conditions: baseline, FRO with no vegetative shading, FRO with riparian shading, FRFA scenario 1, and FRFA scenario 2 simulations 222 Figure 142. Model daily maximum temperature predictions at Ceres Hills for current conditions: baseline, FRO with no vegetative shading, FRO with riparian shading, FRFA scenario 1, and FRFA scenario 2 simulations. 223 Figure 143. Model daily maximum temperature predictions at Ceres Hills for future conditions: baseline, FRO with no vegetative shading, FRO with riparian shading, FRFA scenario 1 , and FRFA scenario 2 simulations.

Figure 144. Model daily maximum temperature predictions upstream of the Newaukum River for current conditions: baseline, FRO with no vegetative shading, FRO with riparian shading, FRFA scenario 1 , and FRFA scenario 2 simulations

Figure 145. Model daily maximum temperature predictions upstream of the Newaukum River for future conditions: baseline, FRO with no vegetative shading, FRO with riparian shading, FRFA scenario 1, and FRFA scenario 2 simulations 226 Figure 146. Model daily maximum temperature predictions upstream of the Skookumchuck River for current conditions: baseline, FRO with no vegetative shading, FRO with riparian shading, FRFA scenario 1, and FRFA scenario 2 simulations 227 Figure 147. Model daily maximum temperature predictions upstream of the Skookumchuck River for future conditions: baseline, FRO with no vegetative shading, FRO with riparian shading, FRFA scenario 1, and FRFA scenario 2 simulations .... 228 Figure 148. Model daily maximum temperature predictions upstream of the Black River for current conditions: baseline, FRO with no vegetative shading, FRO with riparian shading, FRFA scenario 1, and FRFA scenario 2 simulations 229 Figure 149. Model daily maximum temperature predictions upstream of the Black River for future conditions: baseline, FRO with no vegetative shading, FRO with riparian shading, FRFA scenario 1, and FRFA scenario 2 simulations. 230 Figure 150. Model DO predictions for current conditions during summer 2013 at upstream of the South Fork Chehalis River and upstream of the Newaukum River for the scenarios: baseline, FRO with riparian shading, FRO with no shading, FRFA scenario 1, and FRFA scenario 2 232 Figure 151. Model DO predictions for current conditions during summer 2013 at upstream of the Skookumchuck River and upstream of the Black River for the scenarios: baseline, 
FRO with riparian shading, FRO with no shading, FRFA scenario 1, and FRFA scenario 2 233

Figure 152. Model DO predictions for current conditions during summer 2014 at upstream of the South Fork Chehalis River and upstream of the Newaukum River for the scenarios: baseline, FRO with riparian shading, FRO with no shading, FRFA scenario 1, and FRFA scenario 2 .....

Figure 153. Model DO predictions for current conditions during summer 2014 at upstream of the Skookumchuck River and upstream of the Black River for the scenarios: baseline, FRO with riparian shading, FRO with no shading, FRFA scenario 1, and FRFA scenario 2 235

Figure 154. Model DO predictions for future conditions during summer 2014 at upstream of the South Fork Chehalis River and upstream of the Newaukum River for the scenarios: baseline, FRO with riparian shading, FRO with no shading, FRFA scenario 1, and FRFA scenario 2 236

Figure 155. Model DO predictions for future conditions during summer 2014 at upstream of the Skookumchuck River and upstream of the Black River for the scenarios: baseline, FRO with riparian shading, FRO with no shading, FRFA scenario 1, and FRFA scenario 2

Figure 156. Model NH4 predictions for current conditions during summer 2013 at upstream of the South Fork Chehalis River and upstream of the Newaukum River for the scenarios: baseline, FRO with riparian shading, FRO with no shading, FRFA scenario 1, and FRFA scenario 2 239 Figure 157. Model NH4 predictions for current conditions during summer 2013 at upstream of the Skookumchuck River and upstream of the Black River for the scenarios: baseline, FRO with riparian shading, FRO with no shading, FRFA scenario 1, and FRFA scenario 2 .

Figure 158. Model NH4 predictions for current conditions during summer 2014 at upstream of the South Fork Chehalis River and upstream of the Newaukum River for the scenarios: baseline, FRO with riparian shading, FRO with no shading, FRFA scenario 1, and FRFA scenario 2 241 Figure 159. Model NH4 predictions for current conditions during summer 2014 at upstream of the Skookumchuck River and upstream of the Black River for the scenarios: baseline, FRO with riparian shading, FRO with no shading, FRFA scenario 1, and FRFA scenario 2 .....

Figure 160. Model NH4 predictions for future conditions during summer 2014 at upstream of the South Fork Chehalis River and upstream of the Newaukum River for the scenarios: baseline, FRO with riparian shading, FRO with no shading, FRFA scenario 1, and FRFA scenario 2 243 Figure 161. Model NH4 predictions for future conditions during summer 2014 at upstream of the Skookumchuck River and upstream of the Black River for the scenarios: baseline, FRO with riparian shading, FRO with no shading, FRFA scenario 1, and FRFA scenario 2 
Figure 162. Model NO3 predictions for current conditions during summer 2013 at upstream of the South Fork Chehalis River and upstream of the Newaukum River for the scenarios: baseline, FRO with riparian shading, FRO with no shading, FRFA scenario 1, and FRFA scenario 2

Figure 163. Model NO3 predictions for current conditions during summer 2013 at upstream of the Skookumchuck River and upstream of the Black River for the scenarios: baseline, FRO with riparian shading, FRO with no shading, FRFA scenario 1, and FRFA scenario 2

Figure 164. Model NO3 predictions for current conditions during summer 2014 at upstream of the South Fork Chehalis River and upstream of the Newaukum River for the scenarios: baseline, FRO with riparian shading, FRO with no shading, FRFA scenario 1, and FRFA scenario 2 248

Figure 165. Model NO3 predictions for current conditions during summer 2014 at upstream of the Skookumchuck River and upstream of the Black River for the scenarios: baseline, FRO with riparian shading, FRO with no shading, FRFA scenario 1, and FRFA scenario 2

Figure 166. Model NO3 predictions for future conditions during summer 2014 at upstream of the South Fork Chehalis River and upstream of the Newaukum River for the scenarios: baseline, FRO with riparian shading, FRO with no shading, FRFA scenario 1, and FRFA scenario 2 250

Figure 167. Model NO3 predictions for future conditions during summer 2014 at upstream of the Skookumchuck River and upstream of the Black River for the scenarios: baseline, FRO with riparian shading, FRO with no shading, FRFA scenario 1, and FRFA scenario 2 251

Figure 168. Model PO4 predictions for current conditions during summer 2013 at upstream of the South Fork Chehalis River and upstream of the Newaukum River for the scenarios: baseline, FRO with riparian shading, FRO with no shading, FRFA scenario 1, and FRFA scenario 2 253

Figure 169. Model PO4 predictions for current conditions during summer 2013 at upstream of the Skookumchuck River and upstream of the Black River for the scenarios: baseline, FRO with riparian shading, FRO with no shading, FRFA scenario 1, and FRFA scenario 2 .

Figure 170. Model PO4 predictions for current conditions during summer 2014 at upstream of the South Fork Chehalis River and upstream of the Newaukum River for the scenarios: baseline, FRO with riparian shading, FRO with no shading, FRFA scenario 1, and FRFA scenario 2 255 Figure 171. Model PO4 predictions for current conditions during summer 2014 at upstream of the Skookumchuck River and upstream of the Black River for the scenarios: baseline, FRO with riparian shading, FRO with no shading, FRFA scenario 1, and FRFA scenario 2 ..... 256

Figure 172. Model PO4 predictions for future conditions during summer 2014 at upstream of the South Fork Chehalis River and upstream of the Newaukum River for the scenarios: 
baseline, FRO with riparian shading, FRO with no shading, FRFA scenario 1, and FRFA scenario 2

Figure 173. Model PO4 predictions for future conditions during summer 2014 at upstream of the Skookumchuck River and upstream of the Black River for the scenarios: baseline, FRO with riparian shading, FRO with no shading, FRFA scenario 1, and FRFA scenario 2

Figure 174. Model TP predictions for current conditions during summer 2013 at upstream of the South Fork Chehalis River and upstream of the Newaukum River for the scenarios: baseline, FRO with riparian shading, FRO with no shading, FRFA scenario 1, and FRFA scenario 2 260

Figure 175. Model TP predictions for current conditions during summer 2013 at upstream of the Skookumchuck River and upstream of the Black River for the scenarios: baseline, FRO with riparian shading, FRO with no shading, FRFA scenario 1, and FRFA scenario 2

Figure 176. Model TP predictions for current conditions during summer 2014 at upstream of the South Fork Chehalis River and upstream of the Newaukum River for the scenarios: baseline, FRO with riparian shading, FRO with no shading, FRFA scenario 1, and FRFA scenario 2 262

Figure 177. Model TP predictions for current conditions during summer 2014 at upstream of the Skookumchuck River and upstream of the Black River for the scenarios: baseline, FRO with riparian shading, FRO with no shading, FRFA scenario 1, and FRFA scenario 2 263

Figure 178. Model TP predictions for future conditions during summer 2014 at upstream of the South Fork Chehalis River and upstream of the Newaukum River for the scenarios: baseline, FRO with riparian shading, FRO with no shading, FRFA scenario 1, and FRFA scenario 2 ..... 264

Figure 179. Model TP predictions for future conditions during summer 2014 at upstream of the Skookumchuck River and upstream of the Black River for the scenarios: baseline, FRO with riparian shading, FRO with no shading, FRFA scenario 1, and FRFA scenario 2 
1. Introduction

\subsection{Chehalis River Basin Background}

The Chehalis River Basin is located in the southwest region of Washington State. The drainage area to the Chehalis River is over 2000 square miles, with area existing within five counties: Lewis, Thurston, Grays Harbor, Pacific, and Cowlitz (WADOE, 2001). On the western end, the basin also overlaps with the Chehalis Tribal Reservation (Pickett, 1994). The Chehalis River originates in the Olympic Mountains and flows into Grays Harbor and the Pacific Ocean, totaling over 125 miles in length (USGS, 2013). The larger tributaries to the Chehalis River include the South Fork Chehalis River, Newaukum River, Skookumchuck River, and Black River. The smaller tributaries include many creeks, such as Elk, Bunker, Mill, Stearns, Salzer, China, Scammon, Lincoln, Prairie, Scatter, Independence, Garrard, Cedar, Rock, Gibson, and Porter. 


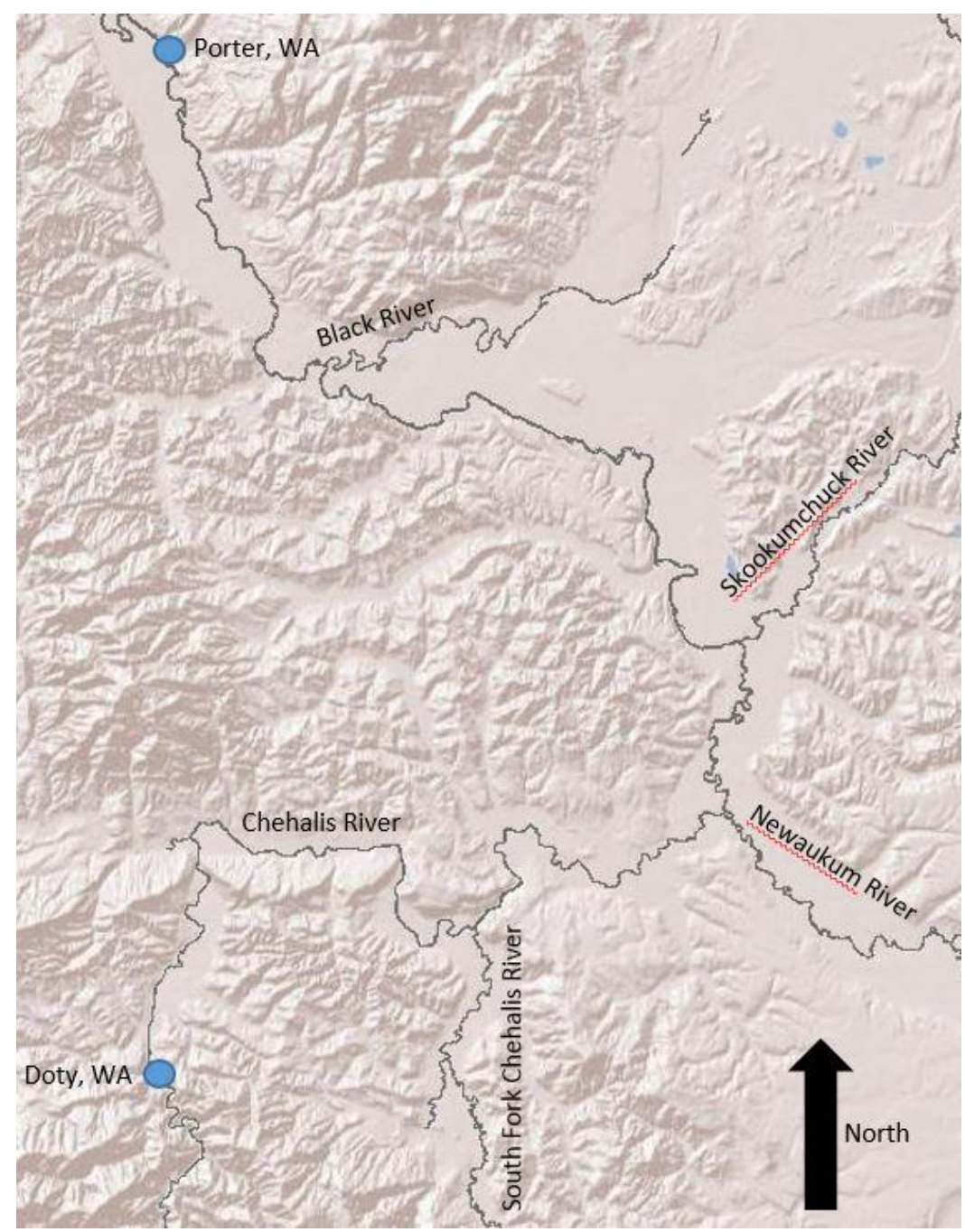

Figure 1. Study area with major tributaries, from near Doty to Porter, WA

The mainstem Chehalis River has three distinct reaches based on their unique physical characteristics of slope and depth. The upper reach, beginning near Pe Ell and extending to Chehalis, WA, has steep gradients with riffles and pools (Pickett, 1994). The middle reach, beginning near Chehalis, WA and extending to the Skookumchuck River, has slow, deep, lake-like conditions that at times exhibit stratification (Pickett, 1994). The lower reach, beginning near the Skookumchuck River and extending to Porter, WA, is similar to the upper reach, with faster velocities and riffles and pools (Pickett, 1994). 
Figure 2, Figure 3, and Figure 4 show examples of the different physical characteristics seen on the Chehalis River.

The land uses in the Chehalis river basin are diverse, including residential, agricultural, industrial, and logging and forest (WADOE, 2001). The river passes through urban areas, including the cities Centralia and Chehalis. In the study area, four municipal wastewater treatment plants (Pe Ell, Chehalis, Centralia, and Grand Mound) and one industrial wastewater treatment plant (Darigold) discharge to the river. Wastewater land application near the river is required as an alternative for the Darigold wastewater treatment plant during periods of low river flows.

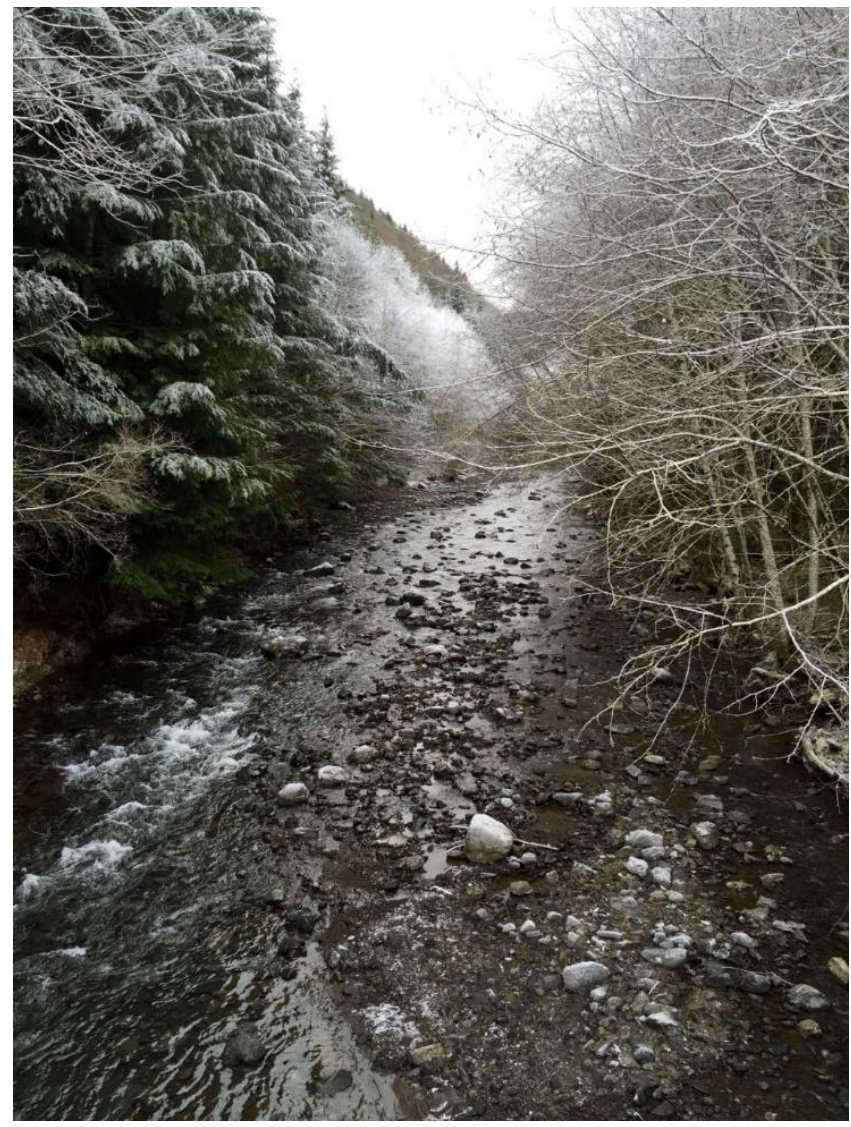

Figure 2. Upstream portion of the Chehalis River exhibiting steep gradients with riffles and pools 


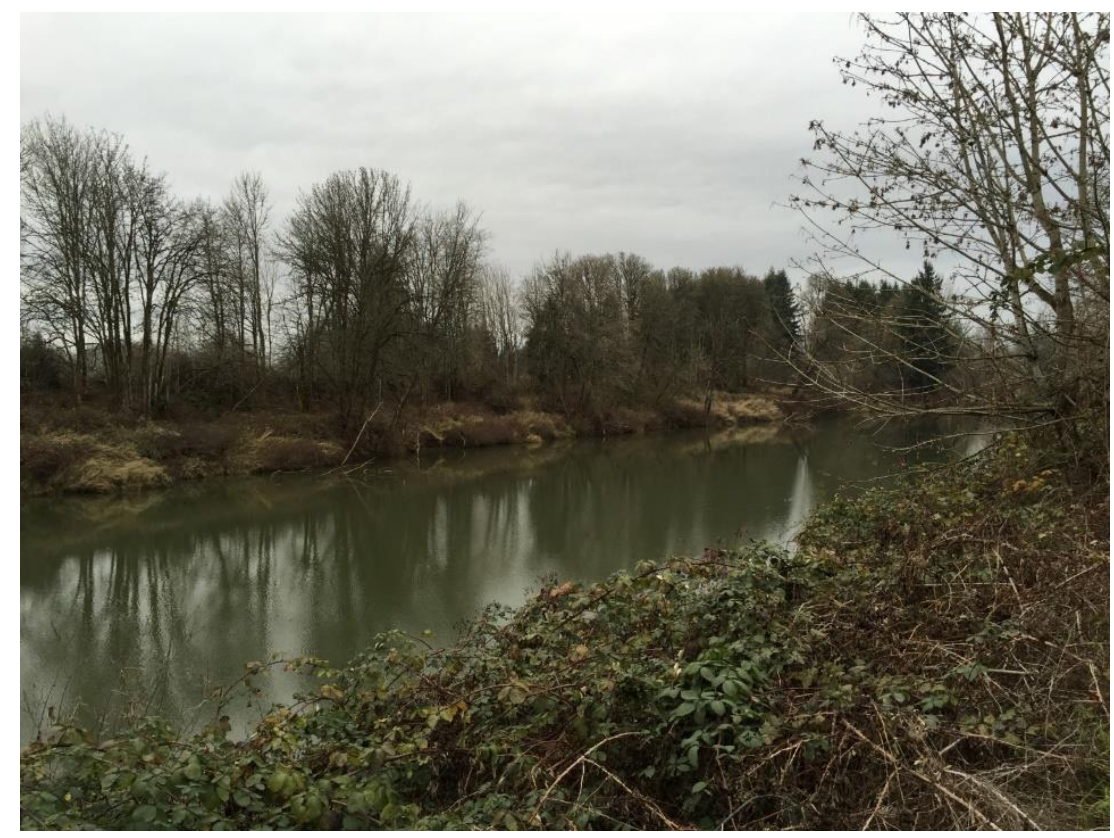

Figure 3. Middle portion of the Chehalis River near Centralia exhibiting slow, deep, lake-like conditions

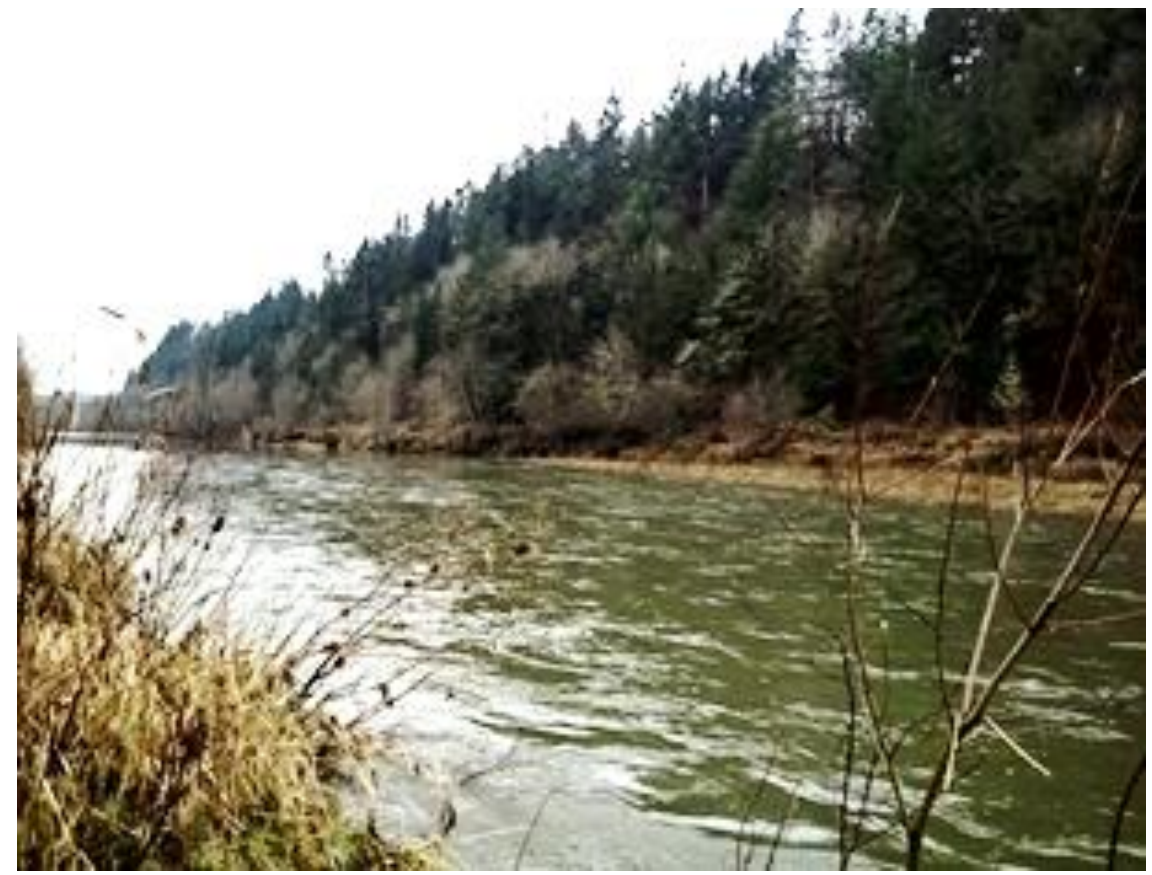

Figure 4. Lower portion of the Chehalis River near Porter exhibiting steeper gradients than the middle portion, with swift-moving water 


\subsection{Fish Criteria}

\subsubsection{Temperature}

Temperature considerations for the river are especially important because of concerns for fish. National and state regulations mandate temperatures that must not be exceeded on the Chehalis River. Water quality criteria are designed to ensure the health of two main fish groups (salmonids and warm-water) during two main life-stages (spawning and rearing) (Collyard and Von Prause, 2010).

Core summer habitat for salmonids include areas during the summer months that are used by salmonids for any of the following purposes: spawning, emergence, or adult holding; summer rearing by at least one adult salmonid; or foraging by an adult or subadult salmonid (Collyard and Von Prause, 2010). Salmonid spawning, rearing, or migration habitat include areas outside of the summer months that are used by salmon or trout for spawning and emergence (Collyard and Von Prause, 2010).

The criteria are based on the 7-day average of daily maximum temperature (7DADMax). For the Chehalis River, temperature criteria include (Anchor, 2014):

- For core summer salmonid habitat, the 7-DADMax may not exceed $16{ }^{\circ} \mathrm{C}$ between June $15^{\text {th }}$ to September $15^{\text {th }}$.

- For salmonid spawning, rearing, and migration habitat, 7-DADMax may not exceed $17.5^{\circ} \mathrm{C}$ between September $16^{\text {th }}$ to Jun $14^{\text {th }}$.

Additional supplemental criteria exist for areas used for salmonid spawning and incubation. Depending on the specific site, these criteria include (Collyard and Von Prause, 2010): 
- Between September $15^{\text {th }}$ to July $1^{\text {st }}$, the 7-DADMax may not exceed $13^{\circ} \mathrm{C}$.

- Between October $1^{\text {st }}$ to May $15^{\text {th }}$, the 7-DADMax may not exceed $13^{\circ} \mathrm{C}$.

- Between February $15^{\text {th }}$ to July $1^{\text {st }}$, the 7-DADMax may not exceed $13^{\circ} \mathrm{C}$.

These standards were created because generally salmonid fish species in the Pacific Northwest thrive in cooler water.

\subsubsection{Dissolved Oxygen}

Dissolved oxygen (DO) is another important water quality constituent for fish survival and health. The criteria for DO are based on fish type and life stage similarly to temperature. For the Chehalis River, the criteria include (Collyard and Von Prause, 2010):

- For core summer salmonid habitat, the lowest daily minimum DO may not be less than $9.5 \mathrm{mg} / \mathrm{L}$ between June $15^{\text {th }}$ to September $15^{\text {th }}$.

- For salmonid spawning, rearing, and migration habitat, the lowest daily minimum DO may not be less than $8.0 \mathrm{mg} / \mathrm{L}$ between September $16^{\text {th }}$ to June $14^{\text {th }}$.

\subsection{Problem Statement}

Frequent flooding is a major problem for the Chehalis River Basin. Since 1945 there have been 45 floods. Of these, five of the ten worst took place in 1996 (twice), 2006, 2007, and 2009 (Pickett, 2015). The 2007 flood was about the magnitude of a 500-year flood (Pickett, 2015). The flooding has severe consequences for residential and commercial property, safety, and transportation. Interstate- 5 has been shut down multiple times as a result of flooding (Pickett, 2015). These flood events led the legislature to create the Chehalis River Basin Flood Authority (CRBFA) in 2008 (Pickett, 2015). The CRBFA has largely focused on investigating the implementation of dams in the upper basin as a flood control technique (Pickett, 2015). 
One major concern of dam implementation is the potentially severe impacts on fish and habitat (Pickett, 2015). The Chehalis River has routinely violated water quality standards for temperature and dissolved oxygen, resulting in multiple water quality and Total Maximum Daily Load (TMDL) studies beginning in 1990. DO is crucial for the survival and health of fish and other aquatic species. Many factors impact DO levels, such as loadings of nutrients, especially nitrogen and phosphorus; amount of organic matter; algae and epiphyton growth and respiration; and season and time of day. In the Chehalis system, DO and temperature are particularly of concern in the area of the river near Centralia and Chehalis, where the water becomes deep and slow. Juvenile and adult salmonids require cool water temperatures for survival and health. System geometry, such as velocity and depth, as well as riparian vegetative shade, impact the temperature of a river (WADOE, 2016j). Cooler water temperatures generally result in higher DO levels (WADOE, 2016j). 


\section{Prior Water Quality Studies}

\subsection{TMDL Study}

The Chehalis River basin has a history of areas with low dissolved oxygen levels. Thermally stratified regions of the Chehalis River near Centralia, WA have exhibited hypoxic and anoxic conditions in the deeper portions of the water column. The Chehalis River and many of its tributaries have violated water quality standards for dissolved oxygen, temperature, and fecal coliform multiple times.

The purpose of this study (Pickett, 1994) was to evaluate the Chehalis River and the loading sources that resulted in these low DO levels. Data for hydrodynamics, temperature, dissolved oxygen, and other water quality parameters were collected and the mainstem Chehalis River was modeled using WASP5 (EPA). Point sources to the river included National Pollutant Discharge Elimination System (NPDES) regulated sources, including wastewater treatment plants. Non-point sources resulted from land use related to commercial, residential, timber, and waste land-application activities. Additionally, the Centralia Landfill adjacent to Salzer Creek could potentially impact the Chehalis River via groundwater, storm water, or leachate interactions from the site. The landfill was designated as a CERCLA (Superfund) site.

WASP5 is a time-dependent three-dimensional model for oxygen, nutrients, biochemical oxygen demand (BOD), phytoplankton, and conservative parameters. In this case, a steady state mode of the model was implemented. Various nutrients, including 
ammonia-nitrogen, nitrate-nitrogen, ortho-phosphate, phytoplankton-carbon, BOD, DO, organic nitrogen, and organic phosphorus were modeled.

Modeling of the Chehalis river using WASP5 indicated that conditions existing during the time of the study would not allow dissolved oxygen standards to be met during midsummer and early fall. Even if no additional loadings beyond natural background levels existed, model predictions of dissolved oxygen levels showed that water quality standards would still be violated. The DO concentrations in the upper and lower portions of the study area were always predicted to be too low during mid-summer, while in the middle Centralia reach DO concentrations were predicted to be too low during early fall.

\section{2. $2001 \mathrm{TMDL}$ Study}

The most recent TMDL study is from 2001 (WADOE), conducted due to temperature criteria exceedances. Temperature exceedances have been partially due to inadequate riparian shading, with industrial and municipal discharges also playing a small role. At the time of this TMDL, the upper Chehalis River basin streams were required not to exceed $18{ }^{\circ} \mathrm{C}$ due to human impacts. If the temperature exceeded $18{ }^{\circ} \mathrm{C}$ due to natural causes, then human induced temperature increase could not exceed 0.3 additional ${ }^{\circ} \mathrm{C}$.

While river shading data were not widely available, the study estimated that over 30 percent of natural riparian vegetation had been depleted. The solar radiation loading capacity for this study was evaluated as the amount of shade necessary to reduce river temperature values to meet standards. Promoting riparian vegetation would give additional environmental benefits, such as bank stability, reduction of sediment 
transport, and increased groundwater recharge capacity of the river. Unfortunately, for three major tributaries to the Chehalis River (South Fork Chehalis River, Newaukum River, and Black River) solely increasing riparian vegetative shade to achievable levels still would not allow temperature standards to be met. This was largely because these tributaries had wide and shallow sections, with slow velocities allowing excess heating. In these cases, reducing river width-to-depth ratios would be important for temperature reduction.

River temperature is very important to the health of many fish species, and adverse impacts are seen in the Chehalis River when stream temperatures increase. For example, there was a reduction in the quality of habitat salmonid fish required for spawning and rearing during summer periods of excessive temperatures. Bull trout were classified as threatened by the U.S. Fish and Wildlife Services and Coho salmon were listed as a potential addition to the federal Endangered Species Act by the National Marine Fisheries Service. In fact, the first TMDL for this basin was motivated largely as a result of a fish kill in 1989 on the Black River.

In determining the necessary amounts of riparian shading to reduce water temperatures, this study made some key assumptions: (1) river flow would not be reduced during critical low-flow periods and (2) the channel morphology would be improved due to riparian vegetation restoration efforts. Using monitoring stations along the river, clear seasonal temperature patterns were seen. The months of June and July were the times when temperature criteria were most often violated. 
SNTEMP was the model this study used to predict how altering certain parameters affected stream temperature. SNTEMP is a steady state, one-dimensional heat transport model. The model SSSHADE was used in this study to estimate stream shading as a result of riparian characteristics. Maximum daily stream temperature was found to be most sensitive to changes in air temperature, followed by humidity, then solar radiation. Except for the Chehalis River headwater reach, all other streams in the basin were determined to need increased shading between $12 \%$ and $42 \%$ to meet temperature criteria.

The TMDL resulted in several requirements for the river: additional withdrawals from the Chehalis River may not be allowed during critical low-flow times; processes influencing channel morphology must remain the same for all streams except for the South Fork Chehalis River, Newaukum River, and Black River, where these processes need to be altered in order to improve channel morphology; sediment transport must be maintained or reduced; watershed hydrology, including flow magnitudes and timing, must not change any further than has already occurred; and the temperature and flow conditions for incoming tributaries to the Chehalis River must not get worse. During critical low-flow periods, temperature restrictions for dischargers become more extreme. The critical period for all existing point dischargers, except Darigold, begins the day after the seven-day average flow drops below $1000 \mathrm{cfs}$. This period ends the day after this average increases above 1000 cfs and the Centralia Reach daily flow is observed to be more than 2,500 cfs on at least one of the previous seven days. For Darigold, the critical 
period begins when the Centralia Reach flow is observed as less than $500 \mathrm{cfs}$ and ends when the Centralia Reach flow increases above 1000 cfs.

\subsection{Anchor QEA Water Quality Studies Report}

Constructing a dam in the Chehalis Basin could have many benefits for flood control but impacts on aquatic species. In order to determine the effects from a potential dam, the baseline conditions of the system were evaluated. Multiple water quality studies were conducted within this report (Anchor QEA, 2014) to look specifically at temperature, dissolved oxygen, and water quality in the mainstem Chehalis River. Additionally, nutrient and biochemical oxygen demand from the larger tributaries were monitored. These data could be used to recalibrate existing HEC-RAS and CE-QUAL-W2 models, and evaluate fish habitat and aquatic species impact.

Multiple temperature probes were employed in the summer of 2013, some with adjacent air temperature monitors. Low flow surveys were conducted in the summers of 2013 and 2014 with the goal of characterizing nutrient and BOD loadings along the river. Summer low flow surveys included mainstem data collected just upstream of the larger tributaries. Many detailed water quality profiles were collected in July, 2014 near Centralia, WA, where stratification exists. Groundwater wells were monitored for temperature in reaches identified to be the most highly contributing to river flow. Lastly, meteorological data were collected due to its impact on modeling temperature. Data for wind speed and direction, relative humidity, air temperature, precipitation and incident solar radiation were collected. 
Notably, all temperature monitoring locations in areas identified as important summer salmonid habitat had temperature criteria exceedances above $16{ }^{\circ} \mathrm{C}$ for the entire 2013 summer period and most of the 2014 summer period. Additionally, spawning and incubation criteria for fall, spring, and early summer were exceeded in the following year during early fall and early summer. However, the reaches and tributaries identified as areas important for salmon spawning, rearing, and migration habitat generally remained below temperature criteria during fall and spring. Spatially, temperature increased from upstream to downstream, though was variable depending on specific conditions such as meteorology and inflowing tributaries. Generally, Elk Creek and South Fork Chehalis River were not determined to have significant impacts on the mainstem Chehalis River temperature. The Skookumchuck River and Black River temperatures were typically lower than at the mainstem confluence locations. The tributaries in the upper Chehalis River reaches were determined to have the most adverse temperature effects.

The three low-flow surveys recorded diurnal patterns of temperature, $\mathrm{DO}, \mathrm{pH}$, turbidity, and chlorophyll a. Generally, diurnal variations of temperature, DO, and pH were larger at Pe Ell than in the Centralia reach. At Pe Ell, the temperature criterion was exceeded for the two sampling days. Highest DO values were seen during the day, and the lowest during the night at Pe Ell. The lowest DO values did not meet the criterion. Similar patterns were seen for $\mathrm{pH}$. These patterns suggest photosynthesis and respiration cycles had an impact on DO and pH. Specifically, algae were a more likely contributor to these trends, rather than phytoplankton, due to the fact that turbidity and chlorophyll a 
concentrations were nearly zero. At the Centralia reach monitoring locations, similar diurnal trends to Pe Ell were observed for DO, though not for $\mathrm{pH}$. In the Centralia reach, moderate chlorophyll a concentrations were observed. Additionally, in the Centralia reach stratification was observed that resulted in a decline of $\mathrm{DO}$ and $\mathrm{pH}$ in deeper pools, even during well-mixed times. The turbidity levels were low at these locations, suggesting photosynthesis could take place where water was shallow enough. However, photosynthesis did not generally have a significant impact on DO and $\mathrm{pH}$. Spatially, DO generally decreased moving downstream, and often did not meet the summer salmonid criterion and the salmonid spawning, rearing, and migration criterion. $\mathrm{PH}$, turbidity, and chlorophyll a levels were generally within the applicable criterion.

Thermal stratification was seen between river miles 67 and 70 in the Centralia reach. The most extreme thermal stratification was seen at the deepest reach at river mile 69.25 and showed a surface to bottom temperature difference of $7^{\circ} \mathrm{C}$. Similar DO trends were seen. In upstream locations where no stratification existed, DO values were higher. PH values outside of the stratification area were typically between 6.5 and 8.5. Generally, turbidity was low near the surface, and increased with depth, though never exceeded the criterion.

Solar heating was the main contributor to water temperature, and was a function of riparian vegetation, topography, and channel geomorphology. LiDAR data concluded vegetative shading density was $20 \%$ in forested areas and $50 \%$ in urban areas. More shading cover would reduce river temperatures. Generally, DO is plentiful in the river, 
except where stratification occurs, leading to nearly anoxic levels near the bottom of the channel. PH and turbidity levels were within the aquatic life use criteria throughout the study area. 


\section{CE-QUAL-W2 Model Overview}

\subsection{Model Description}

CE-QUAL-W2 is a two-dimensional (longitudinal and vertical) hydrodynamic and water quality model applicable to surface waterbodies, such as rivers, reservoirs, lakes, and estuaries (Cole and Wells, 2016). The Version 3 model to Version 3.5 model was developed by a collaboration between the U.S. Army Corps of Engineers and the Water Quality Research Group at Portland State University. Since Version 3.5, the model is now maintained by the Water Quality Research Group at Portland State. The hydrodynamic capabilities of the model include predictions of flow, water surface elevation, velocities, and temperature. The water quality state variables include (Cole and Wells, 2016):

1. any number of generic constituents defined by a 0 and/or a 1 st order decay rate and/or a settling velocity and/or an Arrhenius temperature rate multiplier that can be used to define any number of the following:
a. conservative tracer(s)
b. water age or hydraulic residence time
c. $\mathrm{N}_{2}$ gas and \%Total Dissolved Gas
d. coliform bacteria(s)
e. contaminant(s)

2. any number of inorganic suspended solids groups

3. any number of phytoplankton groups

4. any number of periphyton/epiphyton groups

5. any number of CBOD groups

6. any number of submerged macrophyte groups

7. ammonium

8. nitrate+nitrite

9. bioavailable phosphorus (commonly represented by orthophosphate or soluble reactive phosphorus)

10. silica (dissolved and particulate)

11. labile dissolved organic matter

12. refractory dissolved organic matter

13. labile particulate organic matter 
14. refractory particulate organic matter

15. total inorganic carbon

16. alkalinity

17. iron and manganese

18. dissolved oxygen

19. organic sediments

20. gas entrainment

21. any number of macrophyte groups

22. any number of zooplankton groups

23. labile dissolved organic matter-P

24. refractory dissolved organic matter-P

25 . labile particulate organic matter-P

26. refractory particulate organic matter- $P$

27. labile dissolved organic matter- $\mathrm{N}$

28. refractory dissolved organic matter- $\mathrm{N}$

29. labile particulate organic matter-N

30. refractory particulate organic matter- $\mathrm{N}$

31. Sediment and water column $\mathrm{CH} 4$

32. Sediment and water column H2S

33. Sediment and water column $\mathrm{SO} 4$

34. Sediment and water column Sulfide

35. Sediment and water column $\mathrm{FeOOH}(\mathrm{s})$

36. Sediment and water column $\mathrm{Fe}+2$

37. Sediment and water column $\mathrm{MnO} 2$ (s)

38. Sediment and water column $\mathrm{Mn}+2$

39. Sediment organic $P$, sediment $\mathrm{PO} 4$

40. Sediment organic N, sediment NO3, sediment NH4

41. Sediment Temperature

42. Sediment $\mathrm{pH}$

43. Sediment alkalinity

44. Sediment Total inorganic $C$

45. Sediment organic $C$

46. Turbidity correlation to Suspended solids

Additionally, many derived variables are computed, such as $\mathrm{pH}$, Total $\mathrm{P}$, Total $\mathrm{N}$, $\mathrm{CBOD}_{\text {total, }}$ and total organic carbon (Cole and Wells, 2016).

CE-QUAL-W2 allows the user to include multiple branches, variable layer heights, time-varying boundary conditions, inputs from point or non-point sources, outflows or 
withdrawals from the system, and calculations of ice-cover (Cole and Wells, 2016). The hydrodynamic and constituent transport equations are averaged laterally for each layer. Turbulent time-averaged equations employ the Boussinesq and hydrostatic approximations. Vertical velocity is assumed negligible compared to longitudinal velocity. Momentum dispersion, the Coriolis effect, and viscous shear in the fluid domain are neglected. Atmospheric pressure is assumed to be $1 \mathrm{~atm}$ and not to vary spatially. Partial differential equations are solved using the finite difference method (Cole and Wells, 2016).

\subsection{Governing Equations}

\subsubsection{X-Momentum}

$$
\frac{\partial U B}{\partial t}+\frac{\partial U U B}{\partial x}+\frac{\partial W U B}{\partial z}=-\frac{1}{\rho} \frac{\partial B P}{\partial x}+\frac{\partial\left(B A_{x} \frac{\partial U}{\partial x}\right)}{\partial x}+\frac{\partial B \tau_{x}}{\partial z}
$$

Where

$$
\begin{aligned}
& U=\text { longitudinal, laterally averaged velocity }, \mathrm{m} / \mathrm{s} \\
& B=\text { water body width }, \mathrm{m} \\
& \mathrm{t}=\text { time }, \mathrm{s} \\
& \mathrm{X}=\text { longitudinal Cartesian coordinate } \\
& \mathrm{z}=\text { vertical Cartesian coordinate } \\
& W=\text { vertical, laterally averaged velocity, } \mathrm{m} / \mathrm{s} \\
& \rho=\text { density, } \mathrm{kg} / \mathrm{m}^{3}
\end{aligned}
$$


$\mathrm{P}=$ pressure, $\mathrm{N} / \mathrm{m}^{2}$

$A_{x}=$ longitudinal momentum dispersion coefficient, $\mathrm{m}^{2} / \mathrm{s}^{2}$

$\tau_{\mathrm{x}}=$ shear stress per unit mass, $\mathrm{m}^{2} / \mathrm{s}^{2}$

\subsubsection{Z-Momentum}

$$
0=g-\frac{1}{\rho} \frac{\partial P}{\partial z}
$$

Where

$$
\mathrm{g}=\text { acceleration due to gravity, } \mathrm{m} / \mathrm{s}^{2}
$$

\subsubsection{Continuity}

$$
\frac{\partial U B}{\partial x}+\frac{\partial W B}{\partial z}=q B
$$

Where

$$
q=\text { lateral boundary inflow or outflow, } \mathrm{m}^{3} / \mathrm{s}
$$

\subsubsection{Free-Surface}

$$
\frac{\partial B_{\eta} \eta}{\partial t}=\frac{\partial}{\partial x} \int_{\eta}^{h} U B d z-\int_{\eta}^{h} q B d z
$$

Where

$$
\begin{aligned}
& B_{\eta}=\text { spatially and temporally varying surface width, } m \\
& \eta=\text { free water surface location, } m \\
& h=\text { total depth, } m
\end{aligned}
$$




\subsubsection{Constituent Transport}

$$
\frac{\partial B \varphi}{\partial t}+\frac{\partial U B \varphi}{\partial x}+\frac{\partial W B \varphi}{\partial z}-\frac{\partial\left(B D_{x} \frac{\partial \varphi}{\partial x}\right)}{\partial x}-\frac{\partial\left(B D_{z} \frac{\partial \varphi}{\partial z}\right)}{\partial z}=q_{\varphi} B+S_{k} B
$$

Where

$\phi=$ laterally averaged constituent concentration, $\mathrm{mg} / \mathrm{L}$

$D_{x}=$ longitudinal temperature and constituent dispersion coefficient, $\mathrm{m}^{2} / \mathrm{s}$

$D_{z}=$ vertical temperature and constituent dispersion coefficient, $\mathrm{m}^{2} / \mathrm{s}$

$q_{\phi}=$ lateral inflow or outflow mass flow rate of constituent per unit

volume, $\mathrm{mg} / \mathrm{L} / \mathrm{s}$

$S_{k}=$ kinetics source/sink term for constituent

\subsubsection{Equation of State}

$$
\rho=f\left(T, \varphi_{T D S}, \varphi_{S S}\right)
$$

Where

$$
\begin{aligned}
& \mathrm{T}=\text { temperature, }{ }^{\circ} \mathrm{C} \\
& \phi_{\mathrm{TDS}}=\text { total dissolved solids concentration, } \mathrm{mg} / \mathrm{L} \\
& \phi_{\mathrm{SS}}=\text { suspended solids concentration, } \mathrm{mg} / \mathrm{L}
\end{aligned}
$$

For a detailed description of the assumptions and processes in the derivation of these equations, and for other equations used in CE-QUAL-W2, see the user manual (Cole and Wells, 2016). 


\subsection{Applicability to the Chehalis River}

It was important to use a two-dimensional model for the Chehalis River system because of stratification effects seen in the deep pools in the Centralia reach. These could not be accurately described with a one-dimensional model. CE-QUAL-W2 was also employed to model the potential upstream reservoir, allowing for an easy transition between the output data from the reservoir model to the downstream mainstem Chehalis River model. This also helped to assure uniformity between the modeling techniques used for the reservoir and the downstream mainstem Chehalis River. 


\section{Model Setup}

\subsection{Bathymetry}

The Chehalis River was modeled from upstream of Pe Ell at the proposed dam site (river mile 108) to Porter, WA (river mile 33.3). Only the mainstem Chehalis River was modeled and was discretized into 10 model branches and 9 waterbodies. The physical characteristics of the river varied widely, and multiple branches allowed for separate characteristics (such as branch slope) unique to each branch to be implemented in the model. The upstream reaches had steep gradients with riffles and pools (see Figure 5), while the middle portion near Centralia had slow and deep lake-like conditions (see Figure 6). The longitudinal profile of the river thalweg in Figure 7 shows the varying slopes along the Chehalis River and the locations of the model branches and waterbodies. Figure 8 shows the bottom elevation of the model grid compared to the longitudinal profile of the river thalweg. 


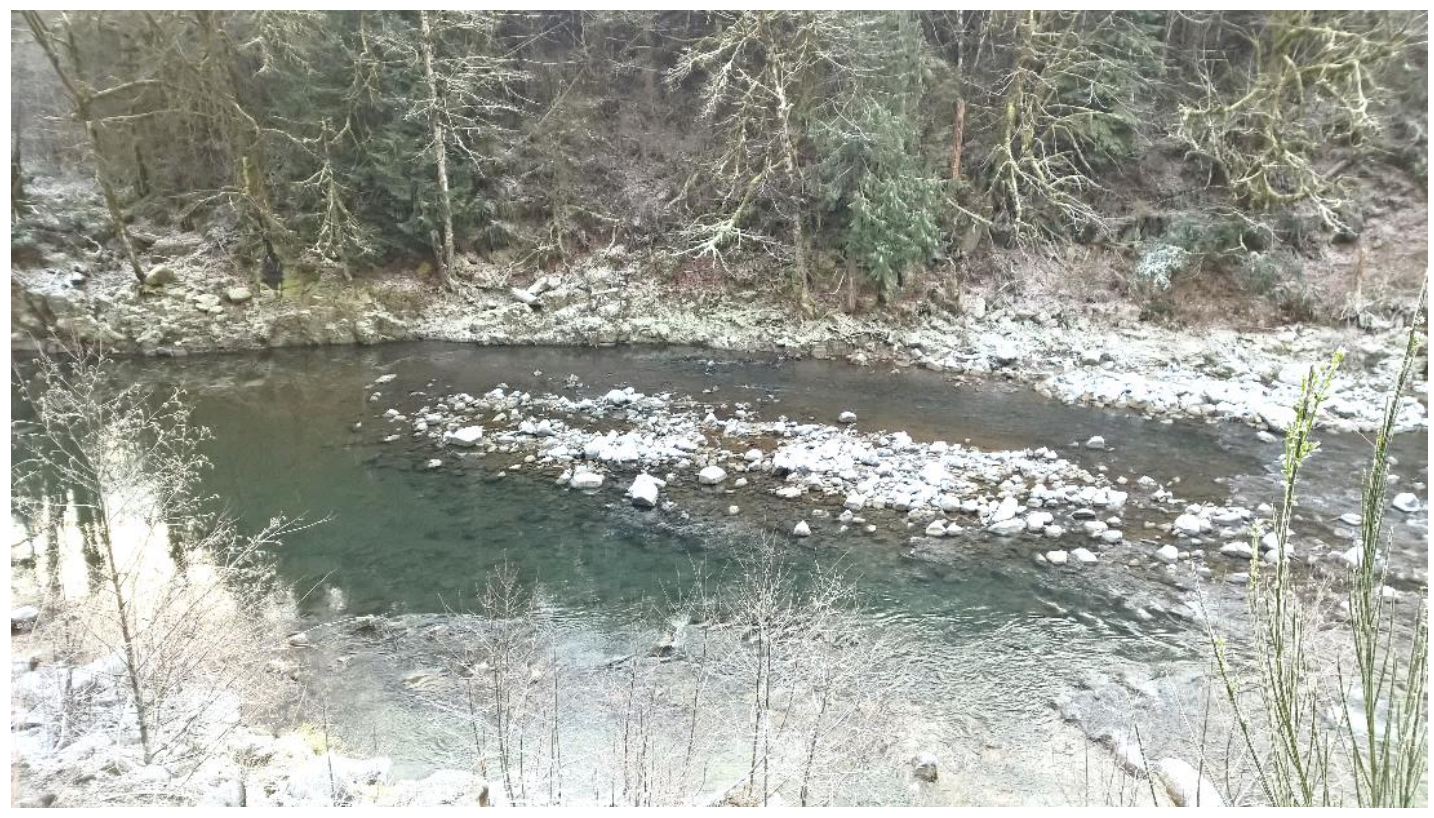

Figure 5. Portion of the Chehalis River exhibiting step gradients with pools and riffles

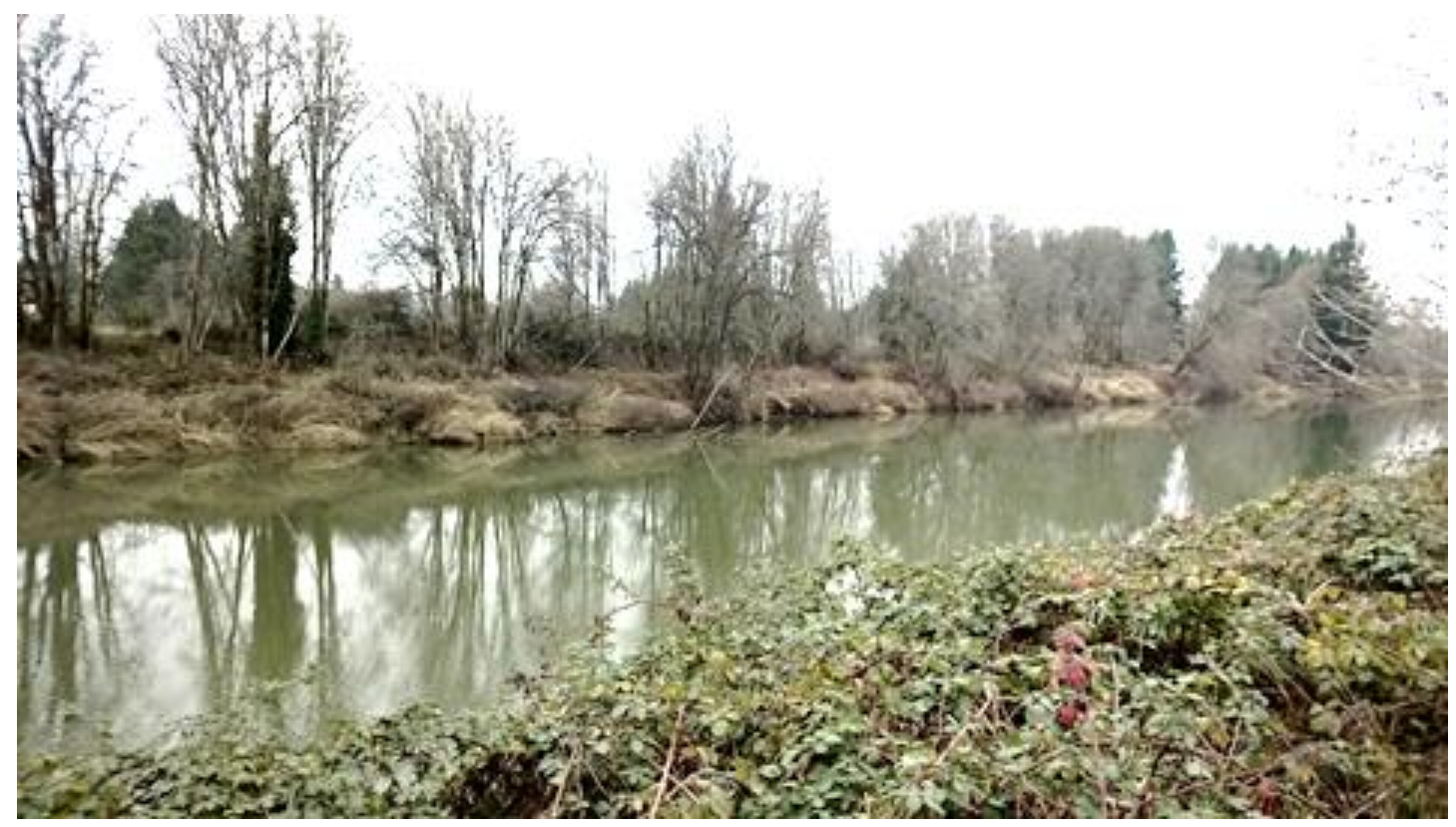

Figure 6 Portion of the Chehalis River exhibiting lake-like conditions 


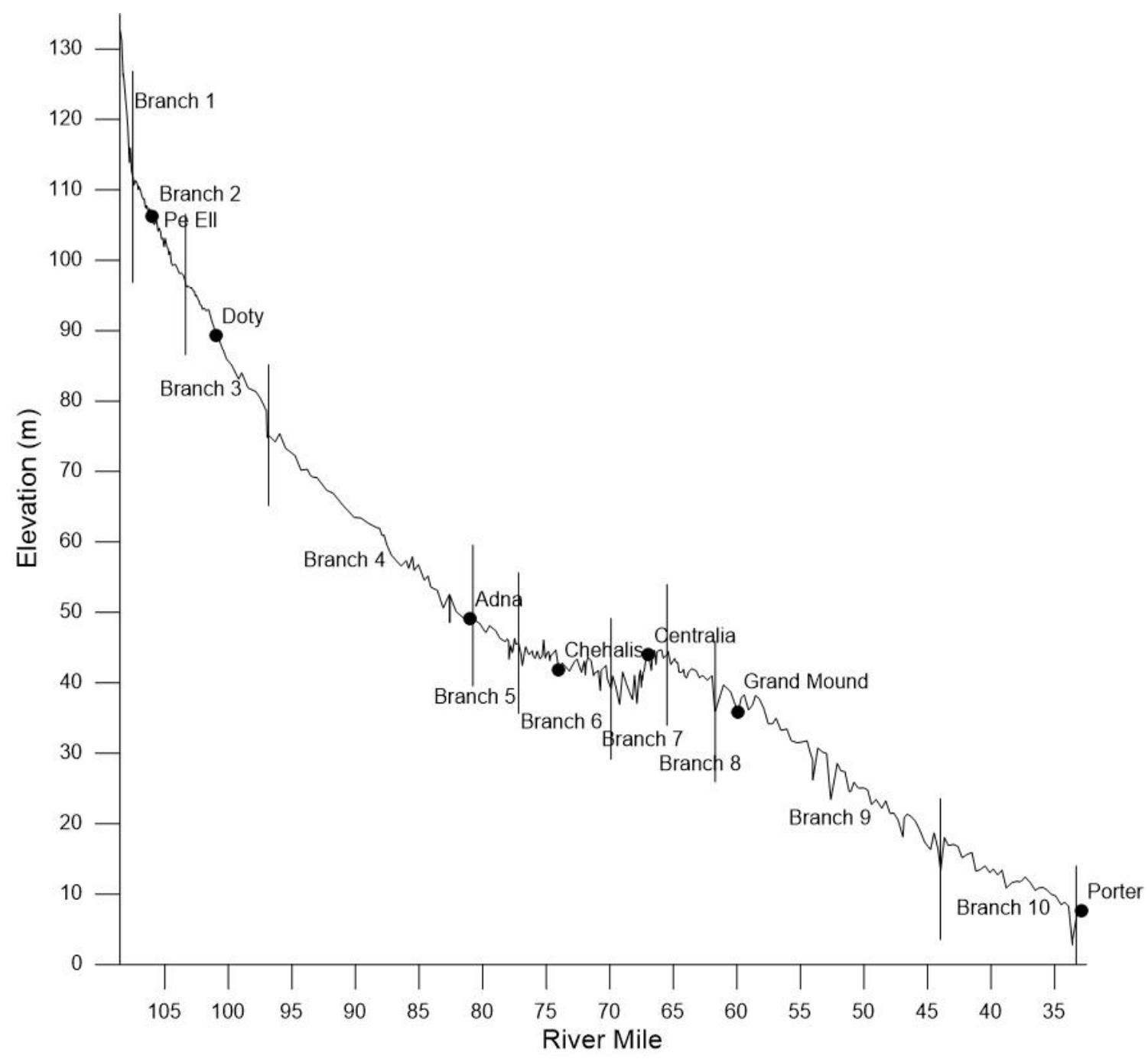

Figure 7. Longitudinal profile of the Chehalis River thalweg (vertical lines show model branch breaks) 


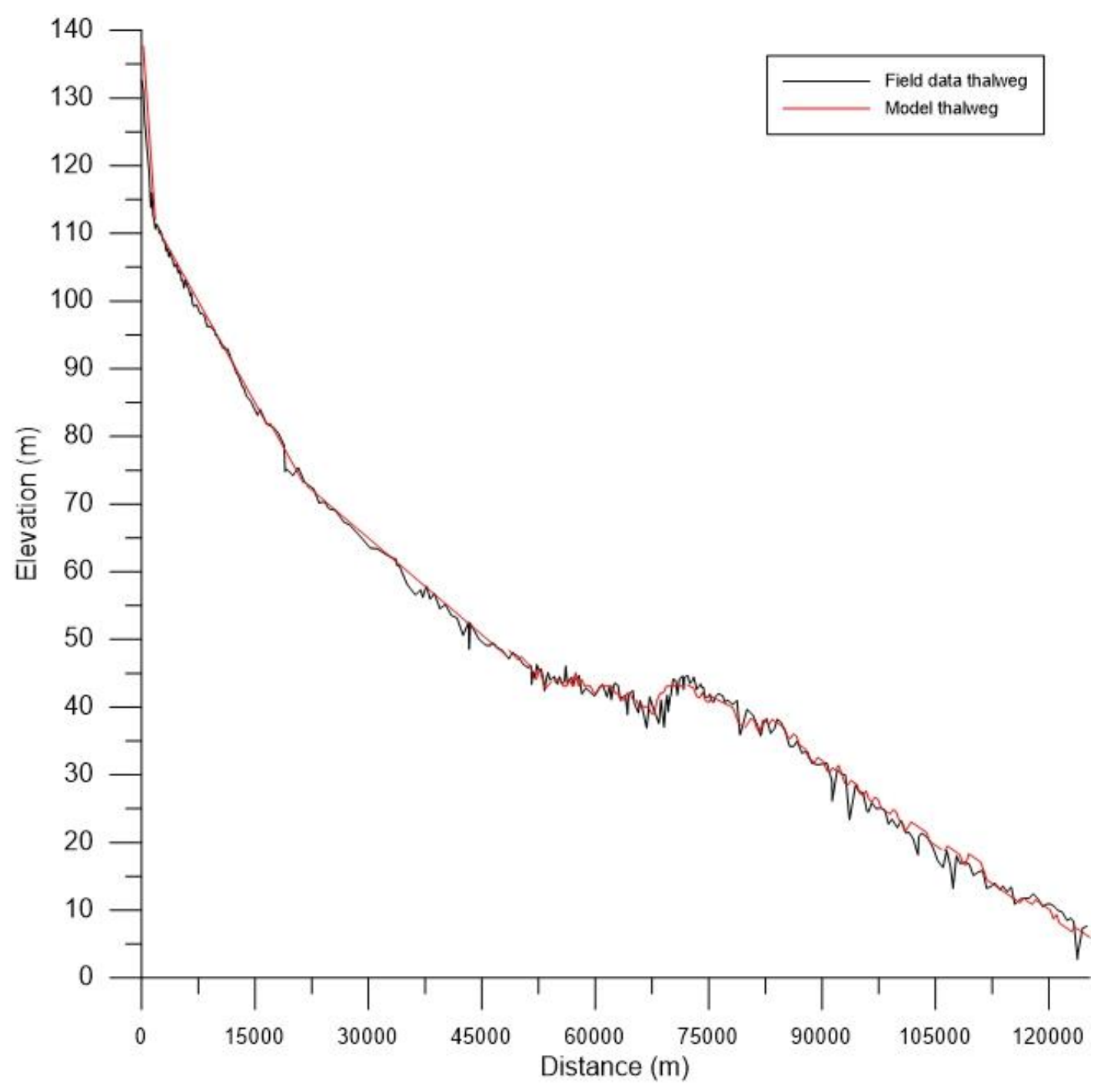

Figure 8. Longitudinal profile of the Chehalis River thalweg and the model grid bottom elevation

The model grid was developed based on river cross section data provided by Anchor QEA (2012). This included station and elevation data for over 350 cross sections along the Chehalis River. The model grid consisted of 322 longitudinal segments of $400 \mathrm{~m}$ length, each with 20 vertical layers of $1 \mathrm{~m}$ thickness. Field cross section data were interpolated to determine layer widths in each model segment. Examples of field cross section data used to calculate model segment layer widths can be seen in Figure 9 for 
model segment 140 at river mile 77.92, and Figure 10 for model segment 151 at river mile 76. Figure 11 shows an aerial view of all active model segments along the mainstem Chehalis River.

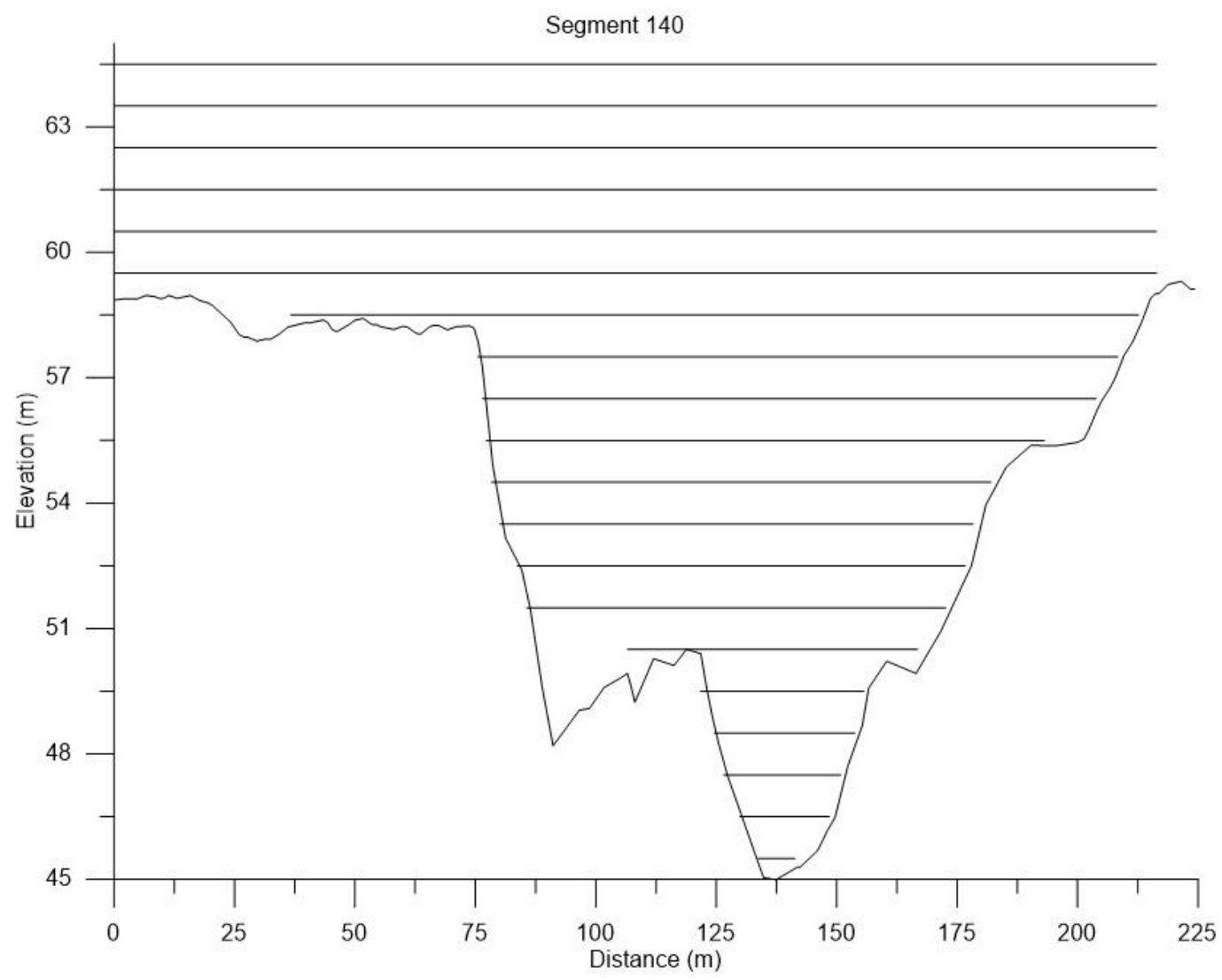

Figure 9. Example Chehalis River field cross section at river mile 77.92 used to calculate layer widths for model segment 140 . The CE-QUAL-W2 model widths are represented by the straight lines for each vertical layer 
Segment 151

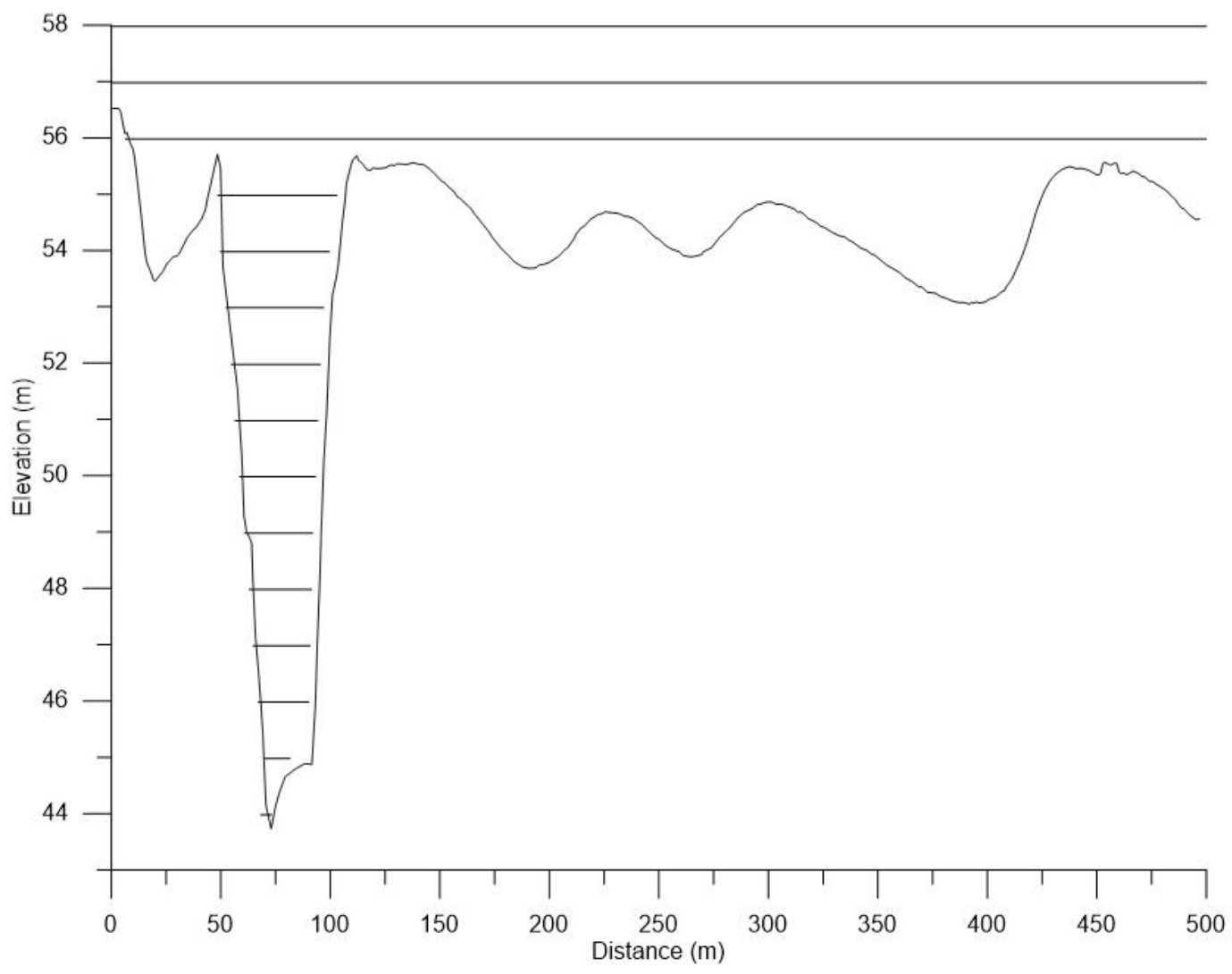

Figure 10. Example Chehalis River field cross section at river mile 76 used to calculate layer widths for model segment 151. The CE-QUAL-W2 model widths are represented by the straight lines for each vertical layer 


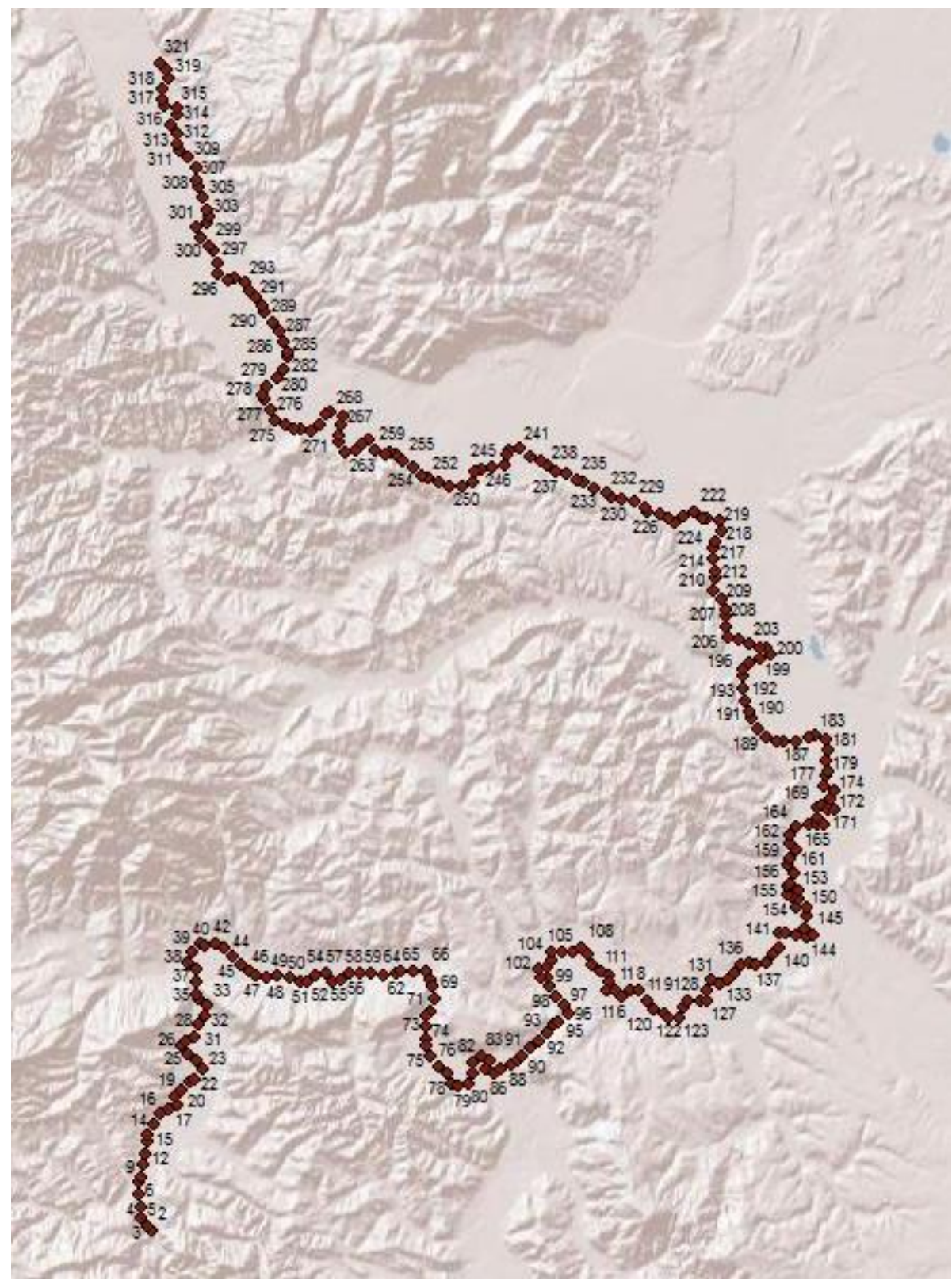

Figure 11. Aerial view of the entire model grid, showing active model segments along the mainstem Chehalis River

Field cross sectional data were also used to identify active layers of each model segment and calculate channel slope. Elevation data used in the model were referenced to the NAVD88 datum. Initial water surface depths were set to 2 meters ( 6.6 feet) for each segment. Table 1 gives a summary of the waterbody and branch segments and layer 
dimensions. Figure 12, Figure 13, Figure 14, Figure 15, Figure 16, Figure 17, Figure 18, Figure 19, Figure 20, and Figure 21 show the model side profile for branch 1, branch 2, branch 3, branch 4, branch 5, branch 6, branch 7, branch 8, branch 9, and branch 10, respectively.

Table 1. Summary of waterbody and branch segments and layers

\begin{tabular}{|c|c|c|c|c|c|c|c|c|}
\hline $\begin{array}{c}\text { Water - } \\
\text { body }\end{array}$ & Branch & $\begin{array}{c}\text { Starting } \\
\text { Active } \\
\text { Segment }\end{array}$ & $\begin{array}{c}\text { Ending } \\
\text { Active } \\
\text { Segment }\end{array}$ & $\begin{array}{c}\text { Branch } \\
\text { Length } \\
(\mathrm{m})\end{array}$ & $\begin{array}{c}\text { Number } \\
\text { of } \\
\text { layers }\end{array}$ & $\begin{array}{c}\text { Vertical } \\
\text { layer } \\
\text { Thickness } \\
(\mathrm{m})\end{array}$ & SLOPE & SLOPEC \\
\hline 1 & 1 & 2 & 6 & 2000 & 20 & 1 & 0.01600 & 0.003 \\
\hline 2 & 2 & 9 & 28 & 8000 & 20 & 1 & 0.00200 & 0.0004 \\
\hline 3 & 3 & 31 & 59 & 11600 & 20 & 1 & 0.00200 & 0.0006 \\
\hline 4 & 4 & 62 & 128 & 26400 & 20 & 1 & 0.00095 & 0.00095 \\
\hline 5 & 5 & 131 & 145 & 6000 & 20 & 1 & 0.00118 & 0.00055 \\
\hline 6 & 6 & 148 & 174 & 10800 & 20 & 1 & 0.00000 & 0.00000 \\
\hline 7 & 7 & 177 & 193 & 6800 & 20 & 1 & 0.00000 & 0.00000 \\
\hline 8 & 9 & 196 & 214 & 7200 & 20 & 1 & 0.00055 & 0.00055 \\
\hline 9 & 10 & 217 & 282 & 26000 & 20 & 1 & 0.00076 & 0.00076 \\
\hline & & & 321 & 19200 & 20 & 1 & 0.00077 & 0.00077 \\
\hline
\end{tabular}




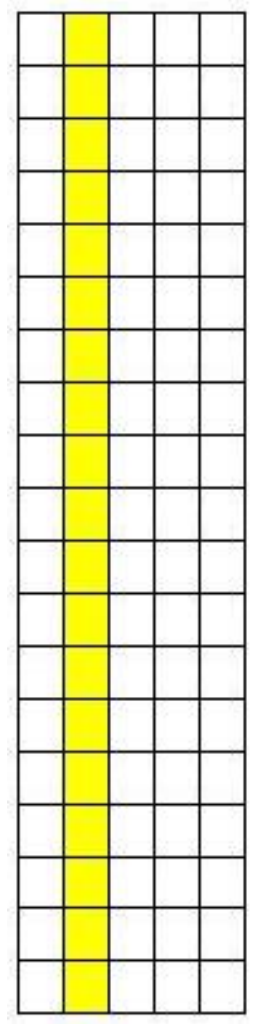

Figure 12. Model branch 1 side profile view, including all segments and layers

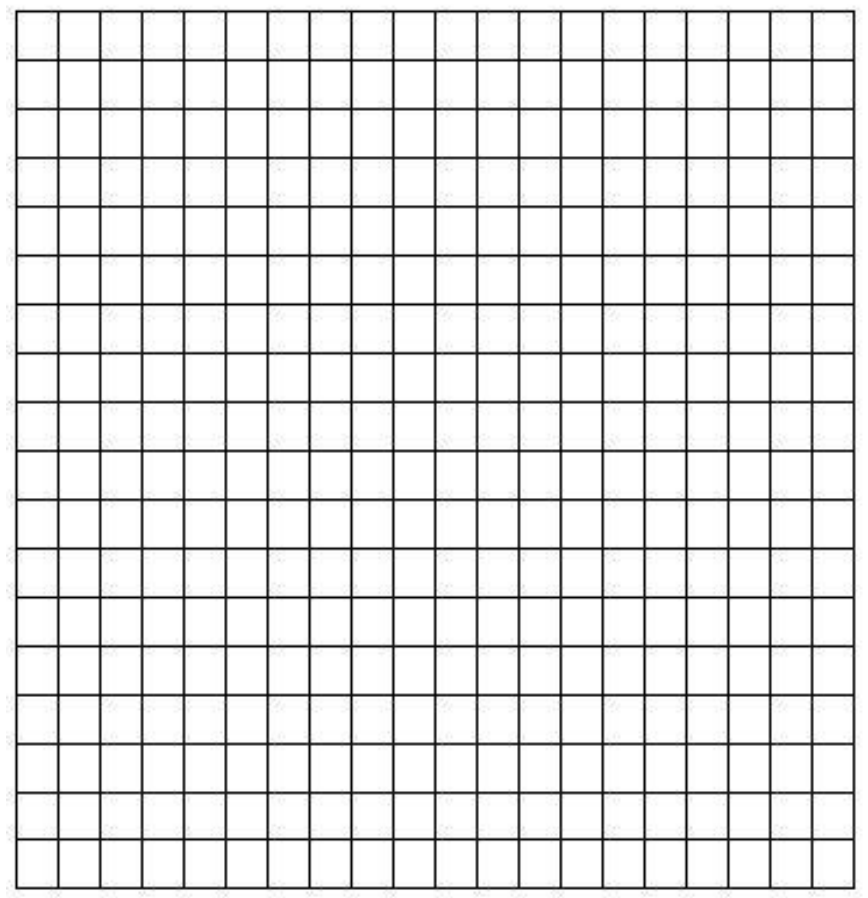

Figure 13. Model branch 2 side profile view, including all segments and layers 


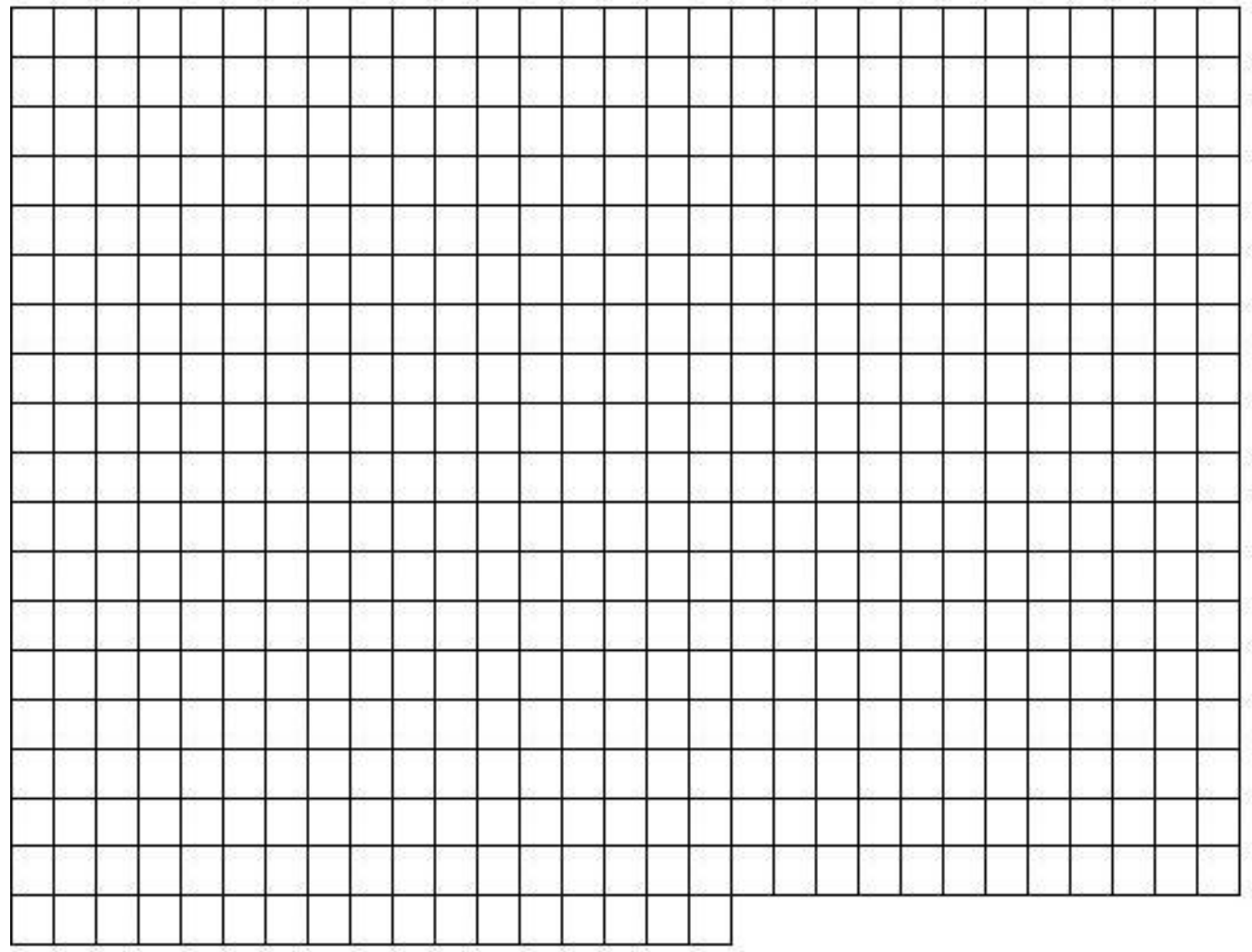

Figure 14. Model branch 3 side profile view, including all segments and layers

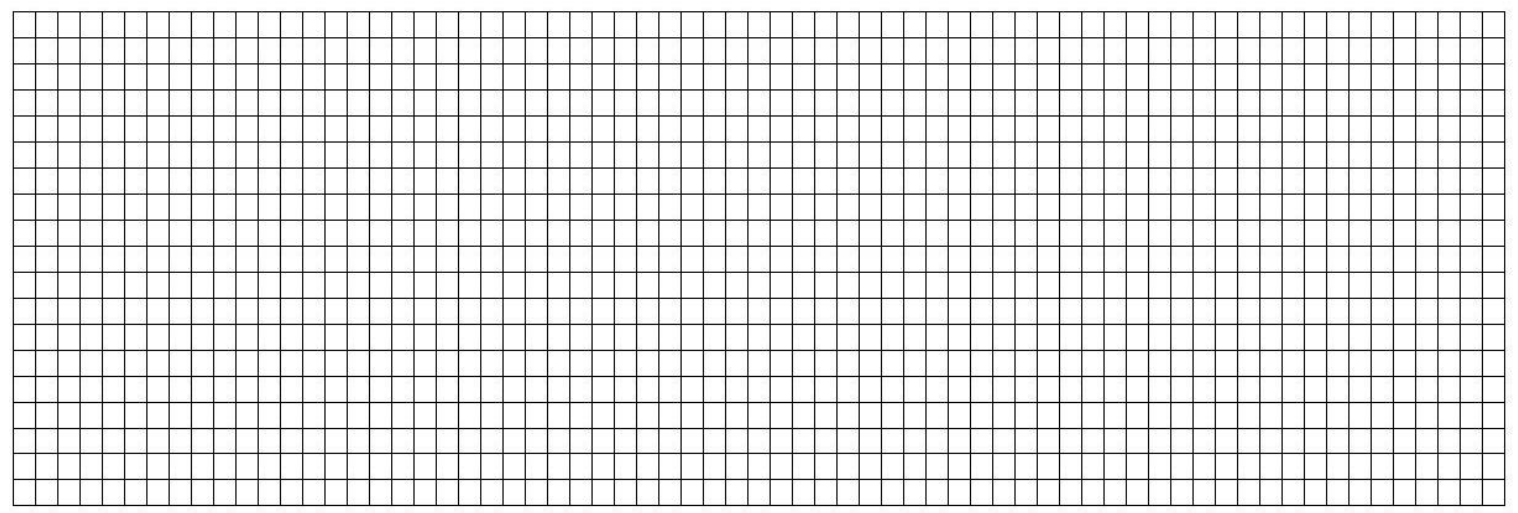

Figure 15. Model branch 4 side profile view, including all segments and layers 


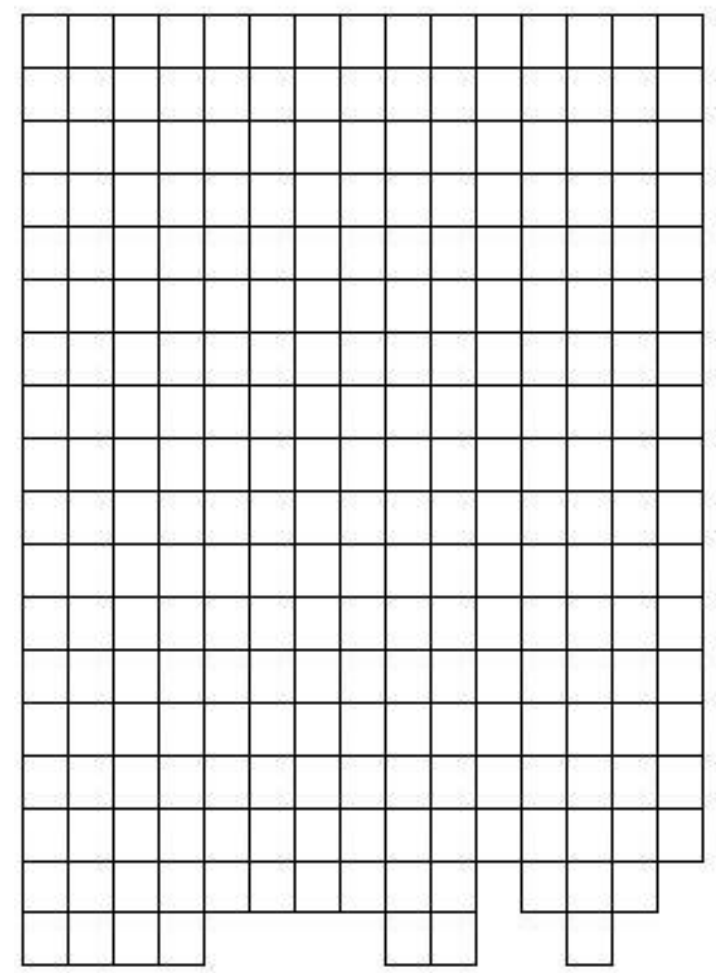

Figure 16. Model branch 5 side profile view, including all segments and layers

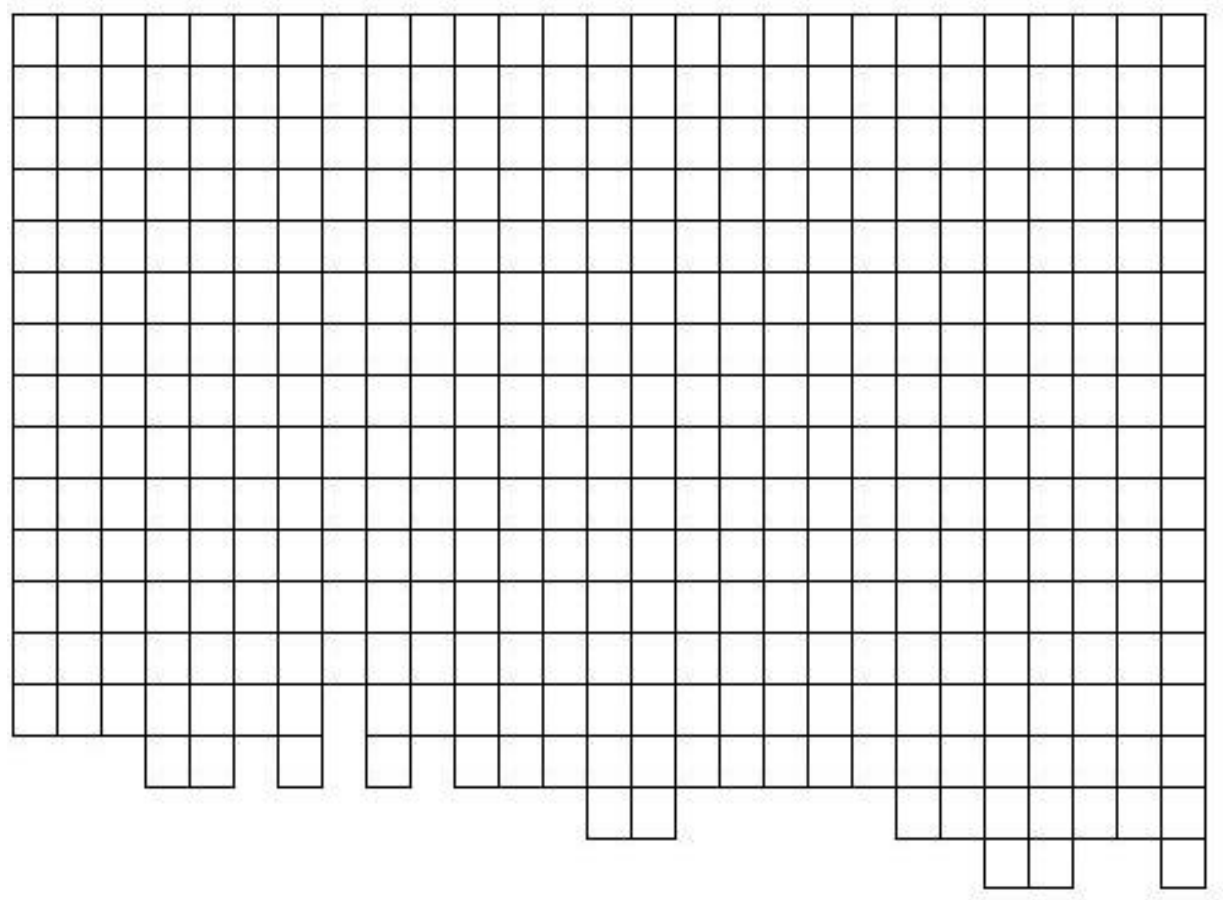

Figure 17. Model branch 6 side profile view, including all segments and layers 


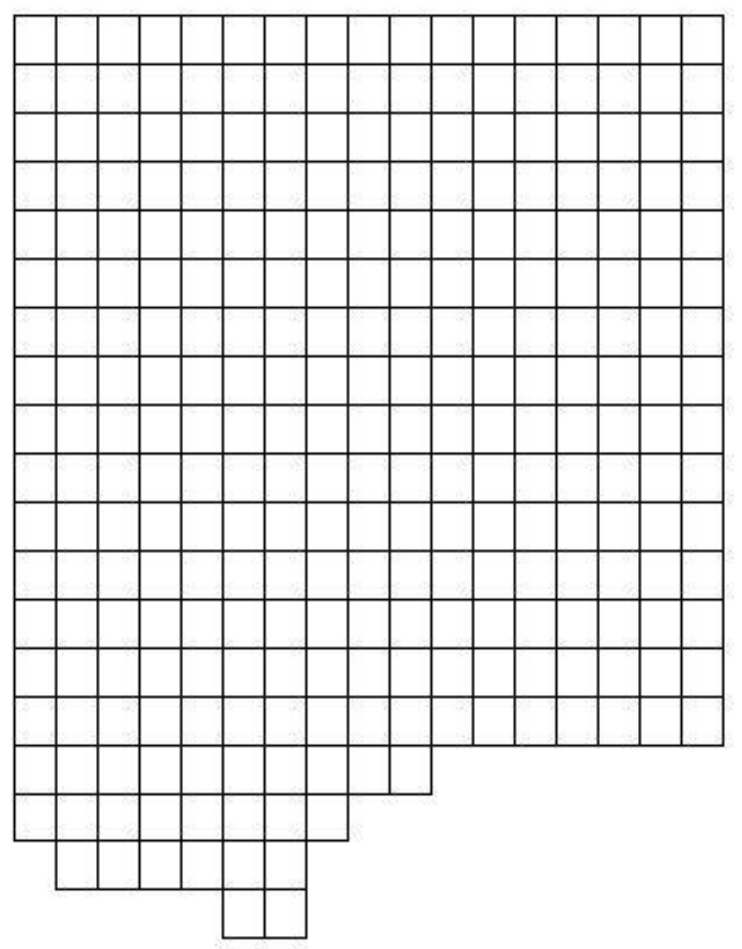

Figure 18. Model branch 7 side profile view, including all segments and layers

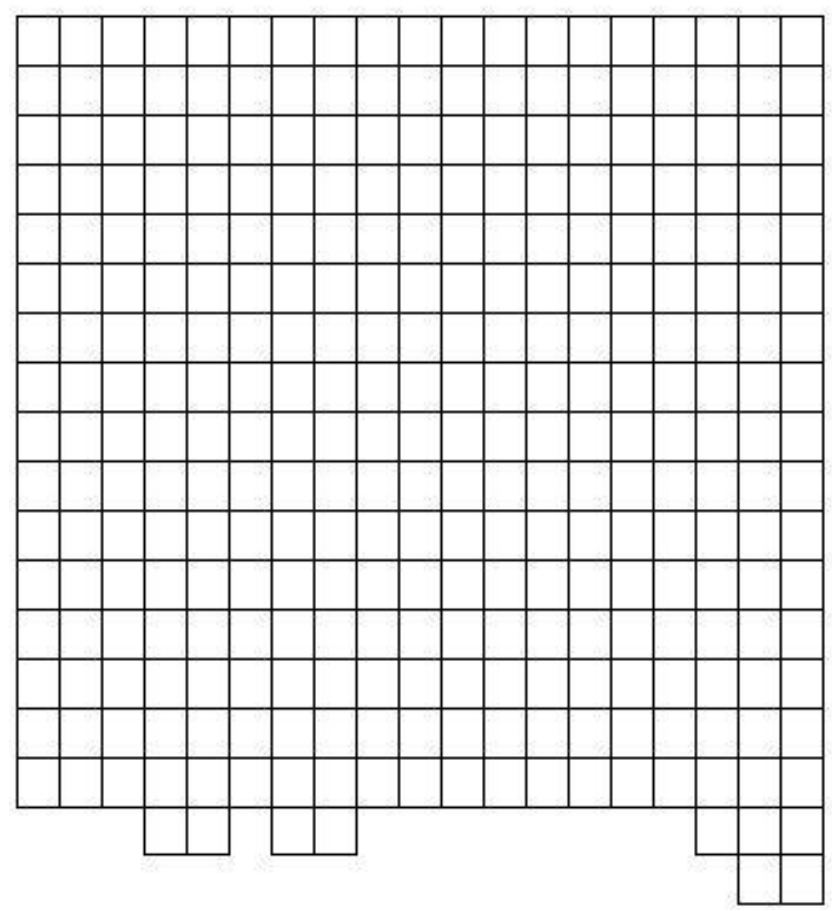

Figure 19. Model branch 8 side profile view, including all segments and layers 


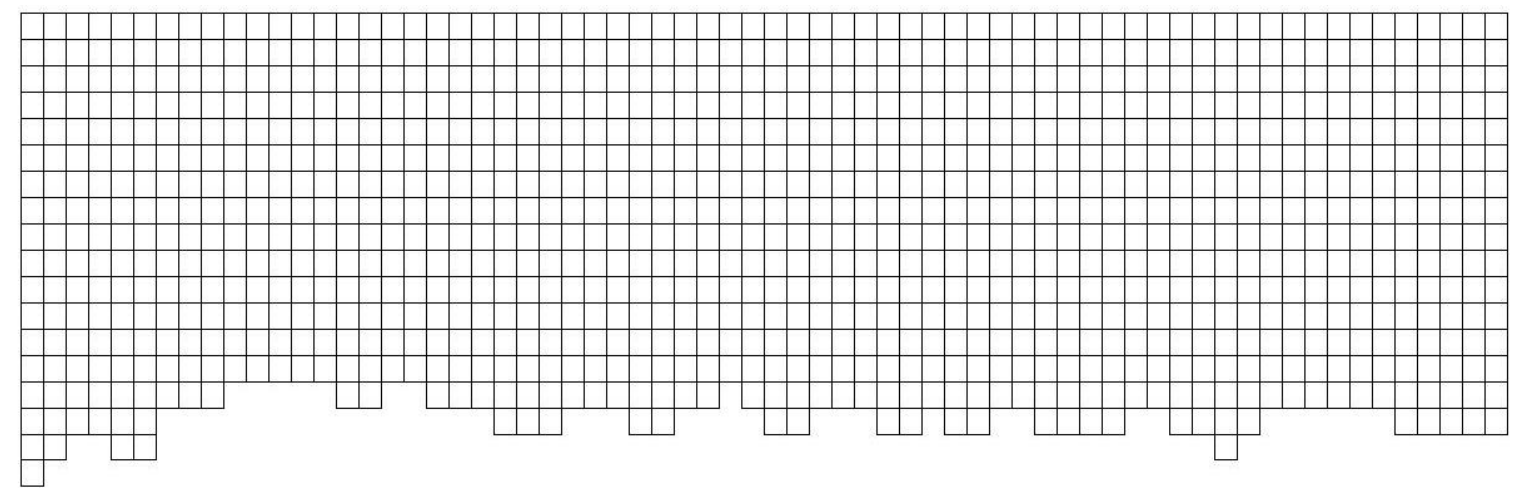

Figure 20. Model branch 9 side profile view, including all segments and layers

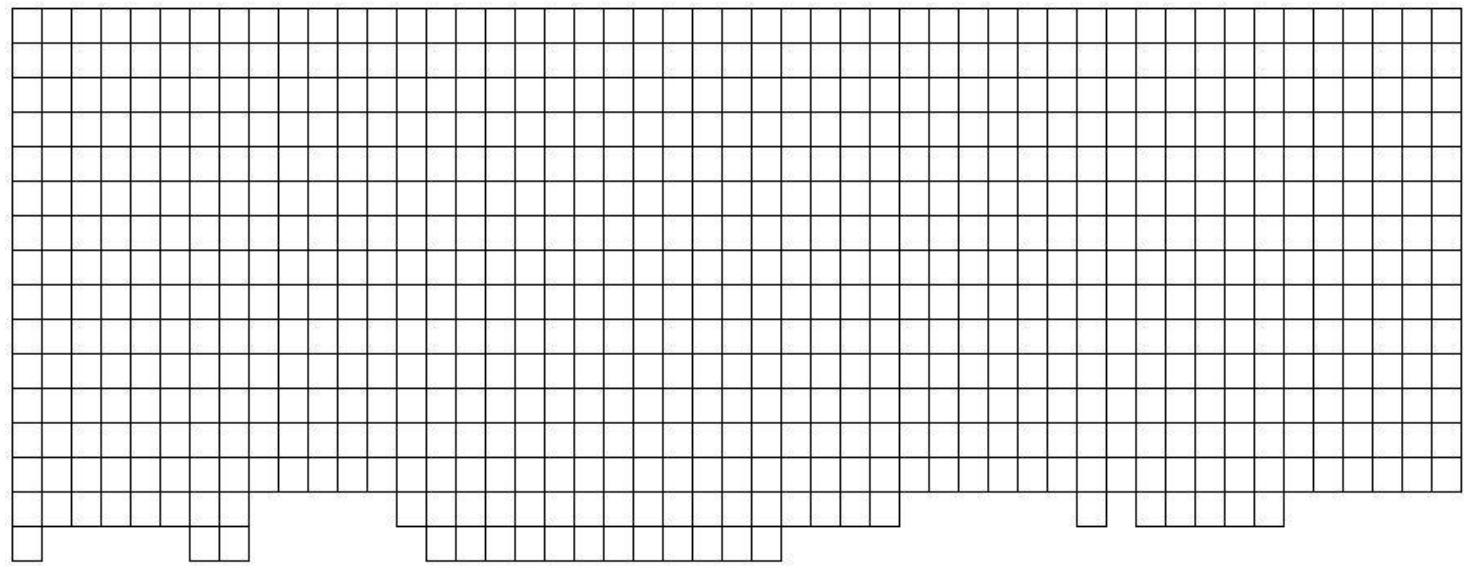

Figure 21. Model branch 10 side profile view, including all segments and layers

\subsection{Meteorological Inputs}

Meteorological parameters used in this study included air temperature, dew point temperature, wind speed, wind direction, cloud cover, and solar radiation. CE-QUAL-W2 has the capability to internally calculate solar radiation based on cloud cover data and latitude and longitude.

One source of meteorological data was the Remote Automatic Weather Stations (RAWS, 2014) database, with hourly data available (Bowman, 2016 and Breckner, 2016). 
Another source of meteorological data was Chehalis River Basin Flood Authority (CRBFA, 2016) at Thrash Creek near the proposed dam site, with data available at 15-minute frequency. Lastly, the National Oceanic and Atmospheric Administration (NOAA, 2015) provided data from the Chehalis-Centralia meteorological station. Table 2 lists the stations used to create input meteorological files.

Table 2. Monitoring stations that provided meteorological data

\begin{tabular}{|c|c|c|c|c|c|c|}
\hline Organization & $\begin{array}{l}\text { Station } \\
\text { ID }\end{array}$ & State Name & Location & $\begin{array}{c}\text { Dates } \\
\text { with data }\end{array}$ & $\begin{array}{c}\text { Waterbodies } \\
\text { applied to in } \\
\text { model }\end{array}$ & $\begin{array}{c}\text { River Miles } \\
\text { applied to } \\
\text { in model }\end{array}$ \\
\hline CRBFA & $\begin{array}{l}\text { Thrash } \\
\text { Creek }\end{array}$ & Thrash Creek & $\begin{array}{l}\text { Near Pe } \\
\text { Ell }\end{array}$ & $\begin{array}{l}1 / 1 / 13- \\
12 / 31 / 15\end{array}$ & $1 \& 2$ & $108-102$ \\
\hline RAWS & HKFW & $\begin{array}{c}\text { Huckleberry } \\
\text { Ridge }\end{array}$ & $\begin{array}{l}\text { Near Pe } \\
\text { Ell }\end{array}$ & $\begin{array}{l}4 / 2 / 13- \\
12 / 31 / 15\end{array}$ & - & - \\
\hline RAWS & CLSW & Chehalis & $\begin{array}{c}\text { Near } \\
\text { Chehalis }\end{array}$ & $\begin{array}{l}1 / 1 / 13- \\
12 / 31 / 15\end{array}$ & $3,4,5,6, \& 7$ & $102-61.7$ \\
\hline NOAA & KCLS & $\begin{array}{c}\text { Chehalis- } \\
\text { Centralia Airport }\end{array}$ & $\begin{array}{c}\text { Chehalis, } \\
\text { WA }\end{array}$ & $\begin{array}{l}1 / 1 / 13- \\
12 / 31 / 15\end{array}$ & - & - \\
\hline RAWS & MIPW & Minot Peak & $\begin{array}{l}\text { Near } \\
\text { Porter }\end{array}$ & $\begin{array}{l}4 / 9 / 13- \\
12 / 31 / 15\end{array}$ & $8 \& 9$ & $61.7-33.3$ \\
\hline
\end{tabular}

The CRBFA Thrash Creek gage data were applied to model waterbodies 1 and 2; the RAWS Chehalis gage data were applied to waterbodies 3, 4, 5, 6, and 7; and the RAWS Minot Peak gage data were applied to waterbodies 8 and 9 . While the RAWS Huckleberry Ridge station and Chehalis-Centralia Airport station data were not used in model input files, they were used to evaluate and compare to the other meteorological stations. Both RAWS and CRBFA had a meteorological data site near Pe Ell. The CRBFA site was used to be consistent with other modeling projects of the Chehalis River and because of its proximity to the upstream boundary. The CLSW station data were used rather than the 
airport because CLSW collected data at shorter time intervals. Figure 22 shows the locations of the meteorological stations in relation to the model grid.

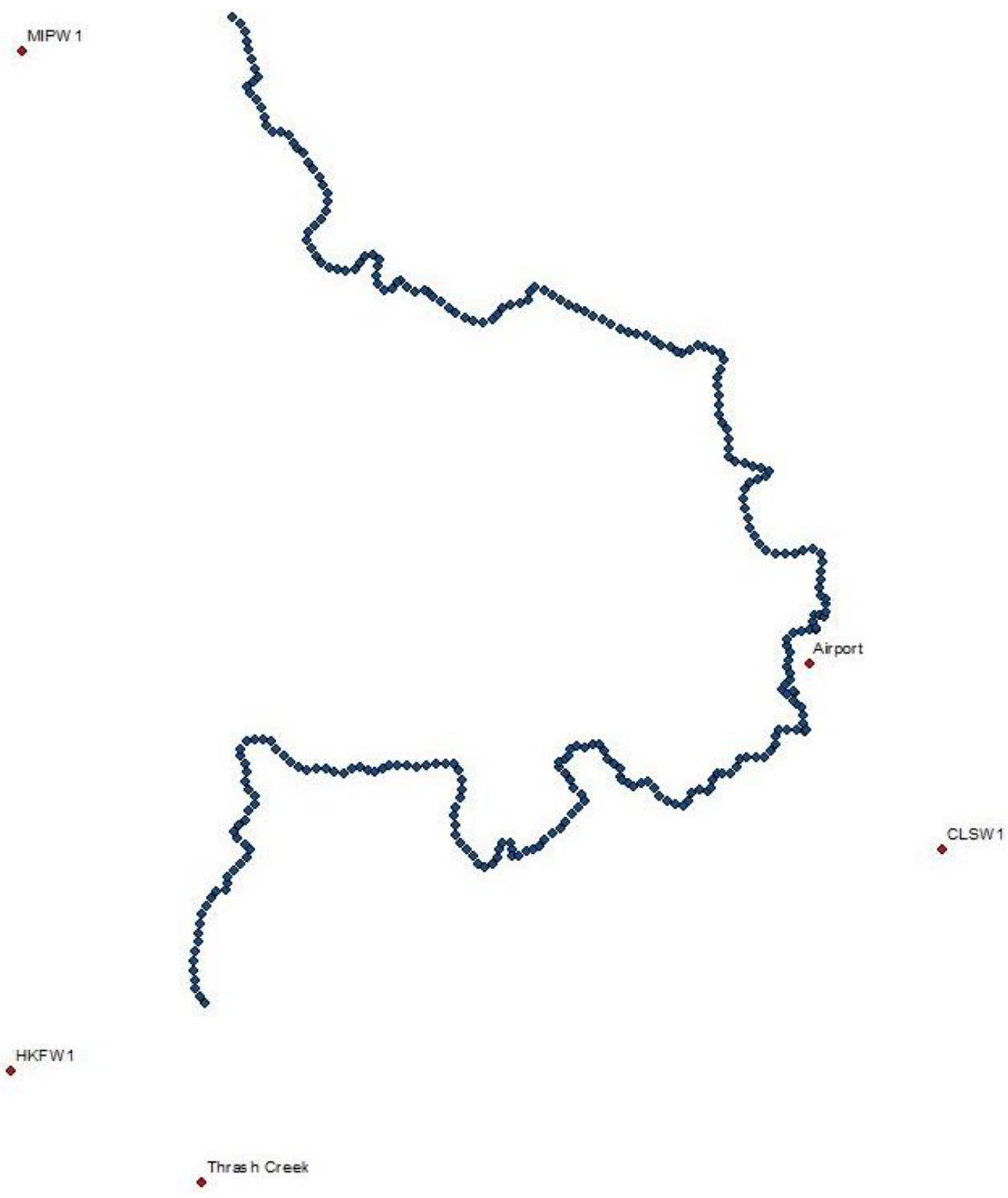

Figure 22. Meteorological stations near the Chehalis River that provided data, including Thrash Creek, HKFW, CLSW, Centralia-Chehalis Airport, and MIPW 
Since data were required for the entire model time period of January 1, 2013 to December 31, 2014, there were many data gaps that needed to be filled. Linear interpolation was employed to fill in missing data for short time gaps, on the order of hours. For some longer temporal gaps data from another station were used. For example, the first months of the MIPW data set were unavailable, so values from the CLSW data set were used. For other longer time gaps, linear correlation relationships with another station's data were created and used to estimate missing data:

1. For times when both stations had data available, a linear regression equation was created between a station with missing data and the closest station with a full data set.

2. This relationship was used to estimate values for the station with missing data during times when data were unavailable.

Regression relationships were created for air and dew point temperature between the MIPW and CLSW monitoring stations. These regression equations can be viewed in Table 3 and plots of the regression relationships are shown in Figure 23 and Figure 24 for air and dew temperature, respectively.

Table 3. Air and Dew Temperature Regression Relationships for Minot Peak (MIPW) Station Data to Chehalis (CLSW) Station Data

\begin{tabular}{|c|c|c|}
\hline Station with missing data & Regression Equation & $\mathrm{R}^{2}$ Value \\
\hline Minot Peak (MIPW) & Tair $_{M I P W}=0.6559 *$ Tair $_{C L S W}+1.7891$ & 0.6562 \\
\hline Minot Peak (MIPW) & Tdew $_{M I P W}=0.6265 *$ Tdew $_{C L S W}+1.8753$ & 0.4879 \\
\hline
\end{tabular}




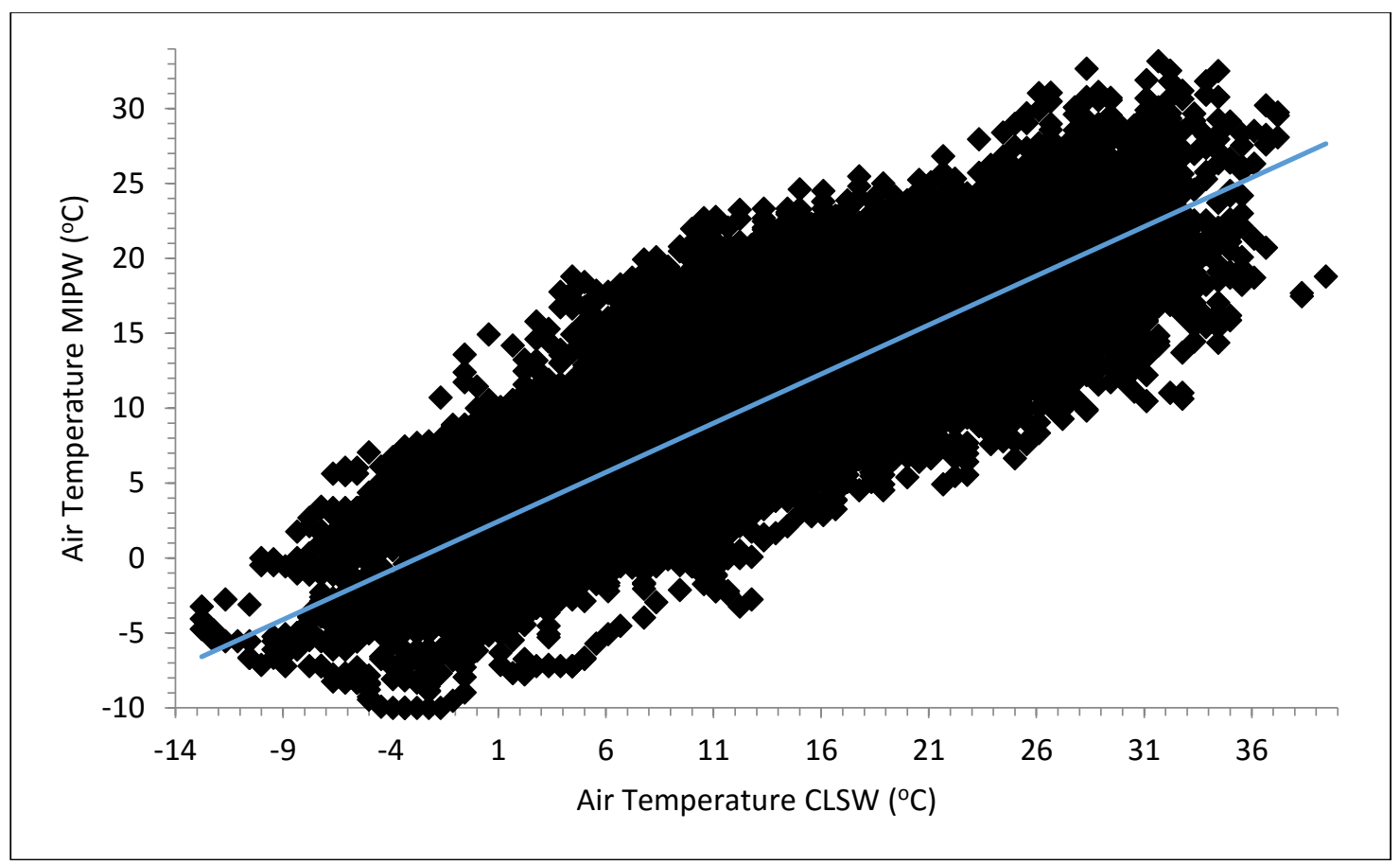

Figure 23. Air temperature relationship between Minot Peak (MIPW) and Chehalis (CLSW) RAWS stations when both had data available

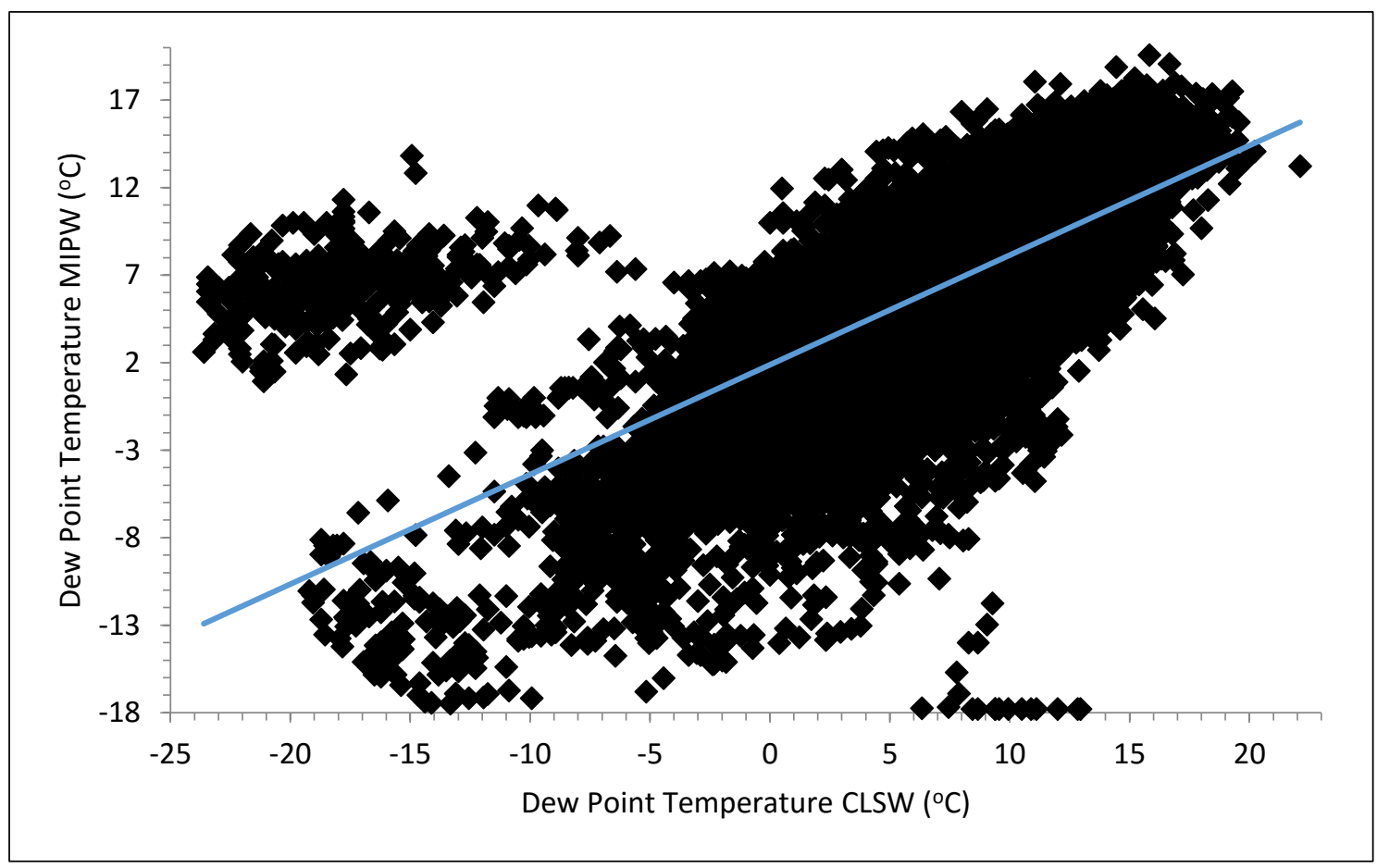

Figure 24. Dew point temperature relationship between Minot Peak (MIPW) and Chehalis (CLSW) RAWS stations when both had data available 
Cloud cover values were missing for the RAWS stations. These were estimated using solar radiation data. First, theoretical clear sky solar radiation based on latitude and longitude were calculated using code from CE-QUAL-W2 (Cole and Wells, 2016). Then, cloud cover was calculated by comparing solar radiation data with theoretical clear sky solar radiation using (Cole and Wells, 2016):

$$
\varphi_{s_{-} \text {data }}=\varphi_{s_{-} \text {clearsky }}\left(1-0.65 C^{2}\right)
$$

Where

$\phi_{\text {s_data }_{-}}$is the real short wave solar radiation

$\phi_{\text {s_clearsky }}$ is the theoretical clear sky short wave solar radiation

$C$ is the fraction of cloud cover between 0 and 1

Meteorological data including air temperature, dew point temperature, wind speed, wind direction, cloud cover, and solar radiation, for the Thrash Creek, HKFW, CLSW, and MIPW stations are shown in Figure 25, Figure 26, Figure 27, and Figure 28, respectively. 

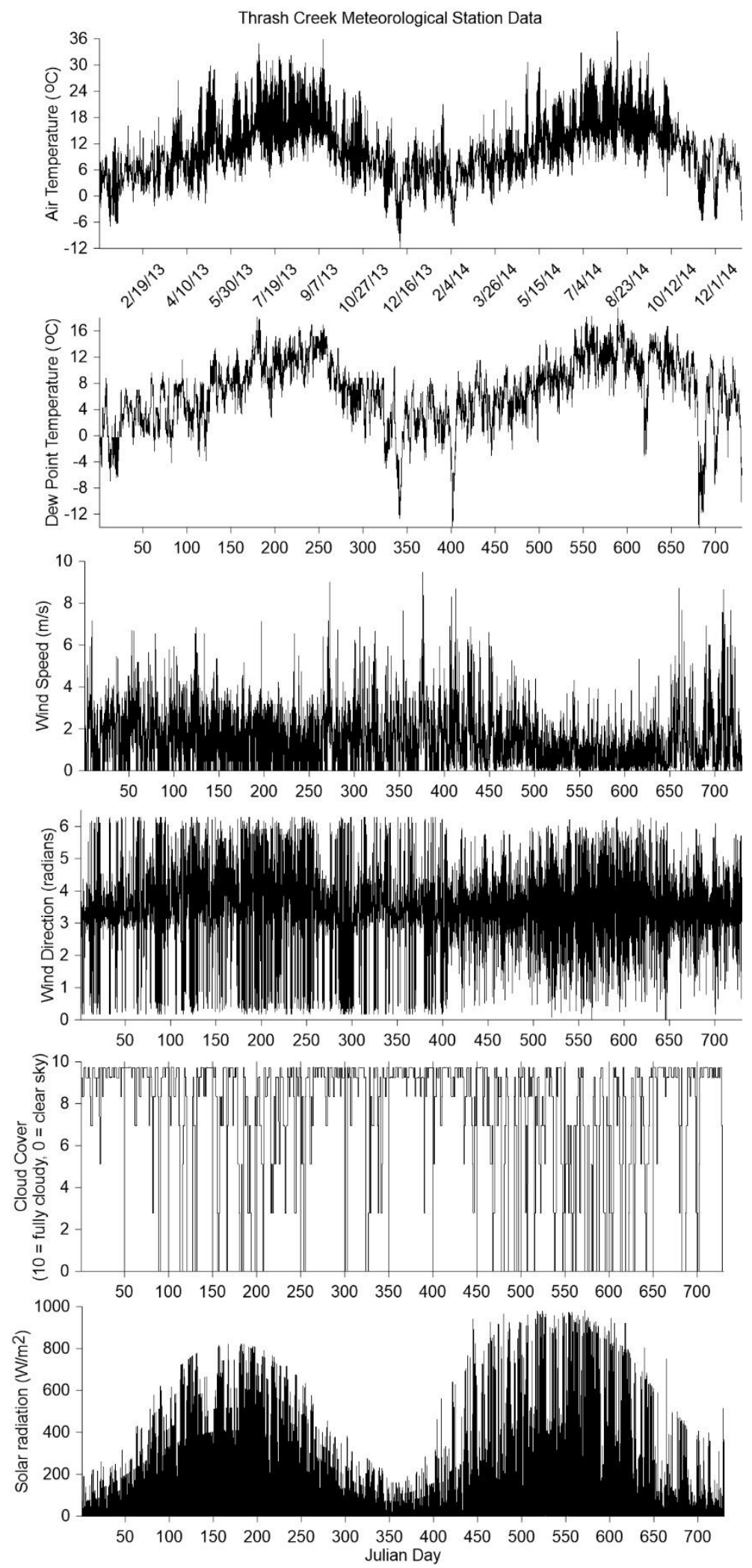

Figure 25. Meteorological data from the Thrash Creek station (including estimated values) 

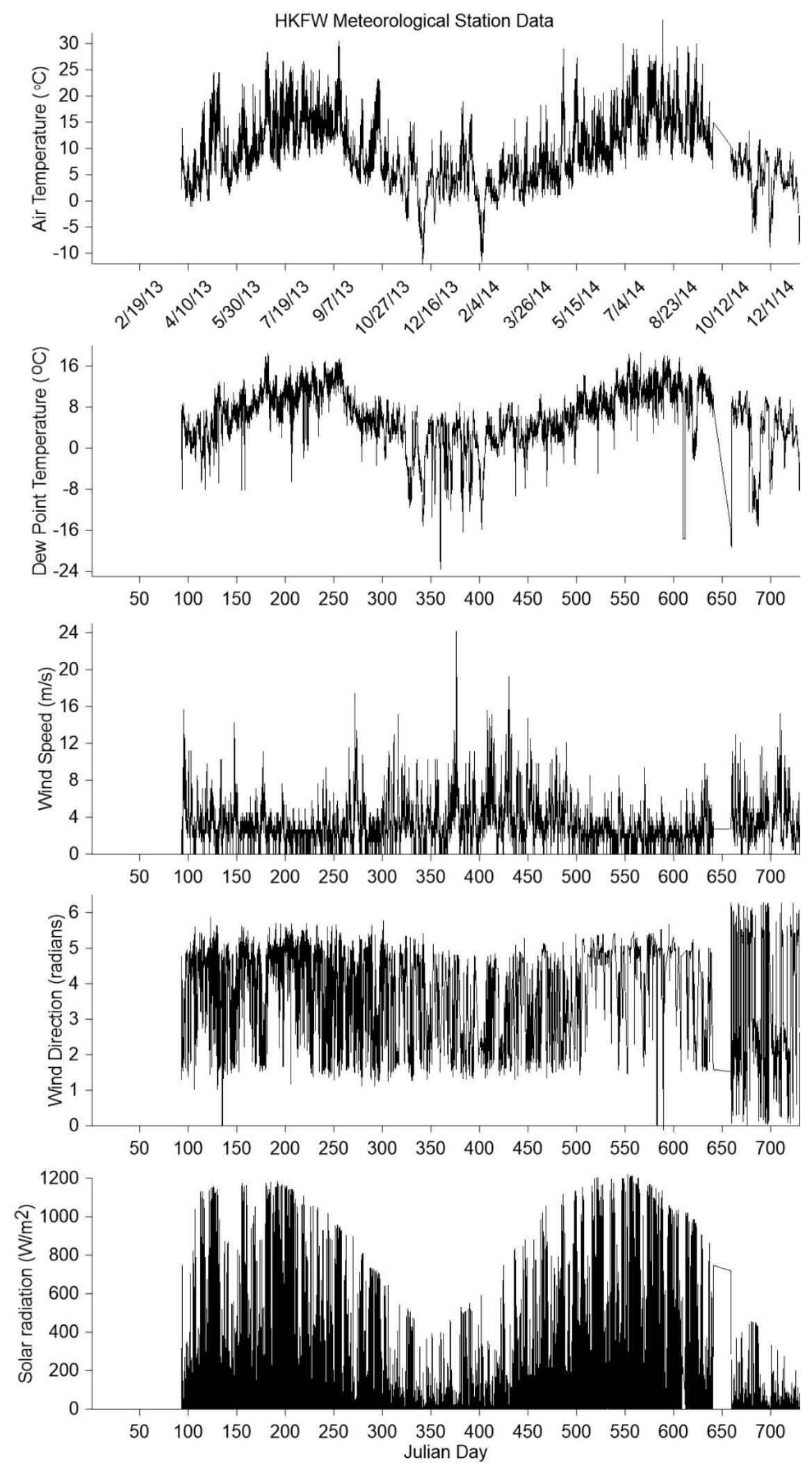

Figure 26. Meteorological data from the HKFW station (raw values only) 

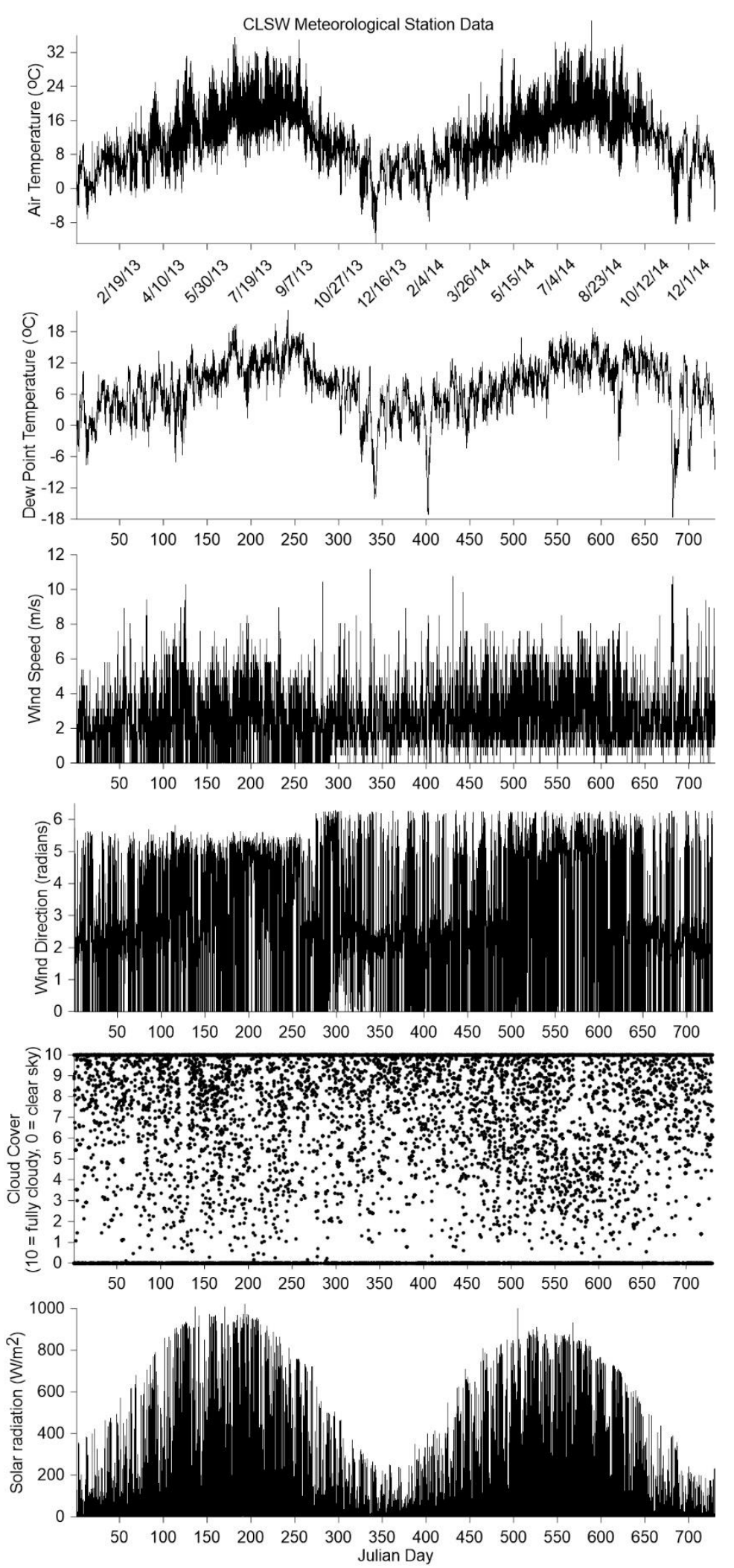

Figure 27. Meteorological data from the CLSW station (including estimated values) 

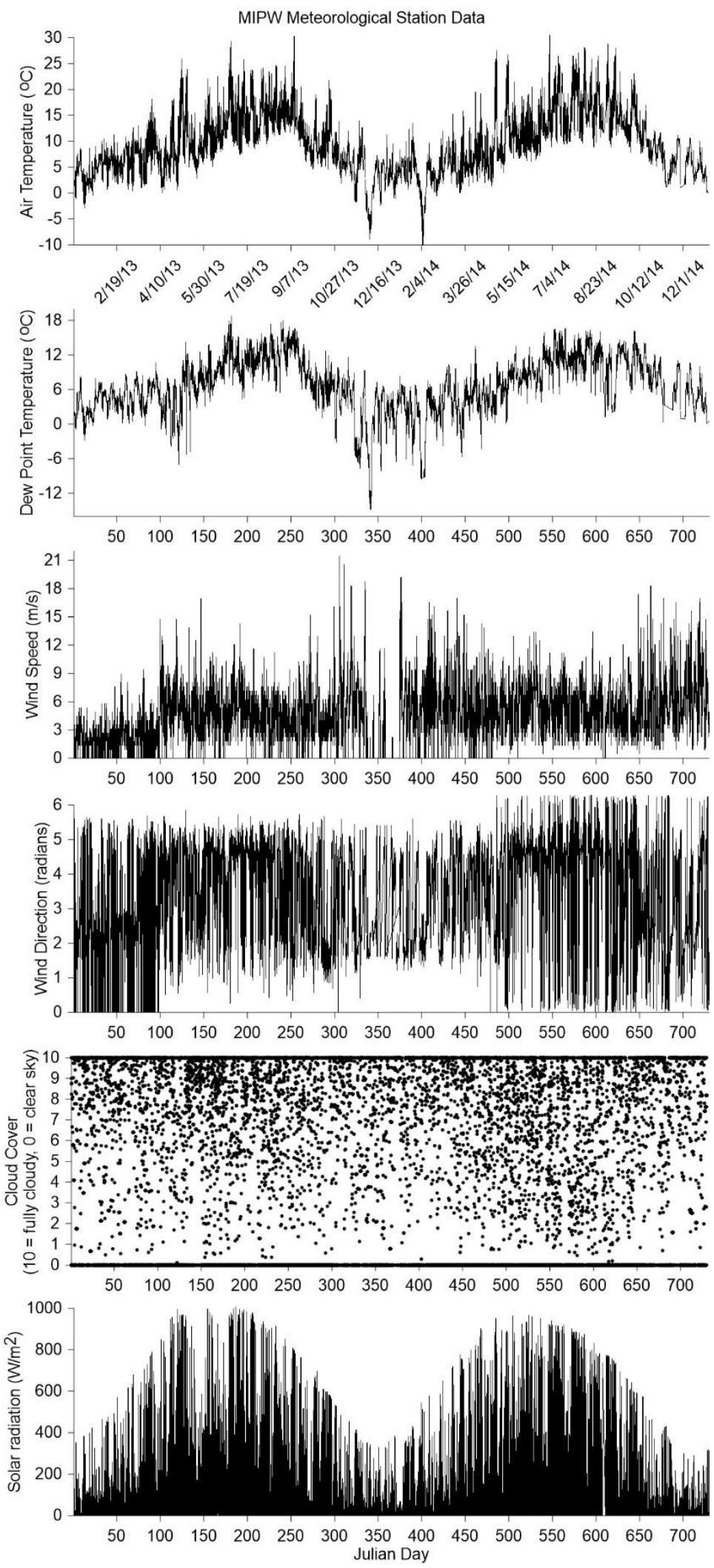

Figure 28. Meteorological data from the MIPW station (including estimated values) 


\subsection{Flow Inputs}

Many tributaries discharge to the mainstem Chehalis River within the model reach.

The larger tributaries include the Newaukum River, Skookumchuck River, South Fork Chehalis River and Black River. The smaller tributaries include Bunker, Mill, Stearns, Dillenbaugh, Salzer, China, Scammon, Prairie, Lincoln, Scatter, Independence, Garrard, Rock, Cedar, Gibson, and Porter creeks. Five wastewater treatment plants (WWTP) discharge to the river. Four are municipal (Pe Ell, Centralia, Chehalis, and Grand Mound), while the other is industrial (Darigold, Inc.). Groundwater inputs also occur along the Chehalis River, starting upstream of Elk Creek and continuing until the downstream boundary at Porter. The river mile and model segment locations of the tributaries, dischargers, and groundwater inputs can be seen in Table 4. A schematic of of the tributaries and dischargers entering the Chehalis River can be seen in Figure 29.

Table 4. River mile and segment locations for tributaries, dischargers, and groundwater inputs to the Chehalis River

\begin{tabular}{|c|c|c|}
\hline Description & Model Segment & River Mile \\
\hline Pe Ell WWTP & 15 & 107 \\
\hline Elk Creek & 38 & 100 \\
\hline South Fork Chehalis River & 89 & 88 \\
\hline Bunker Creek & 105 & 85 \\
\hline Stearns Creek & 134 & 78.1 \\
\hline Mill Creek & 135 & 78 \\
\hline Newaukum River & 145 & 75.2 \\
\hline Darigold WWTP & 150 & 75 \\
\hline Dillenbaugh Creek & 150 & 74.4 \\
\hline Chehalis WWTP & 150 & 74.3 \\
\hline Salzer Creek & 171 & 69.2 \\
\hline China Creek & 181 & 67.5 \\
\hline Skookumchuck River & 182 & 66.8 \\
\hline
\end{tabular}




\begin{tabular}{|c|c|c|}
\hline Description & Model Segment & River Mile \\
\hline Scammon Creek & 187 & 65.5 \\
\hline Lincoln Creek & 205 & 61.8 \\
\hline Centralia WWTP & 207 & 61.25 \\
\hline Grand Mound WWTP & 218 & 59.17 \\
\hline Prairie Creek & 222 & 58.2 \\
\hline Scatter Creek & 236 & 55.2 \\
\hline Independence Creek & 250 & 50 \\
\hline Black River & 267 & 47 \\
\hline Garrard Creek & 275 & 44.9 \\
\hline Rock Creek & 300 & 39.3 \\
\hline Cedar Creek & 302 & 38.7 \\
\hline Gibson Creek & 308 & 37.3 \\
\hline Porter Creek & 321 & 33.3 \\
\hline $\begin{array}{c}\text { Groundwater - Upstream of Elk Creek } \\
\text { to downstream Boundary at Porter }\end{array}$ & $35-321$ & $101.9-33.3$ \\
\hline
\end{tabular}




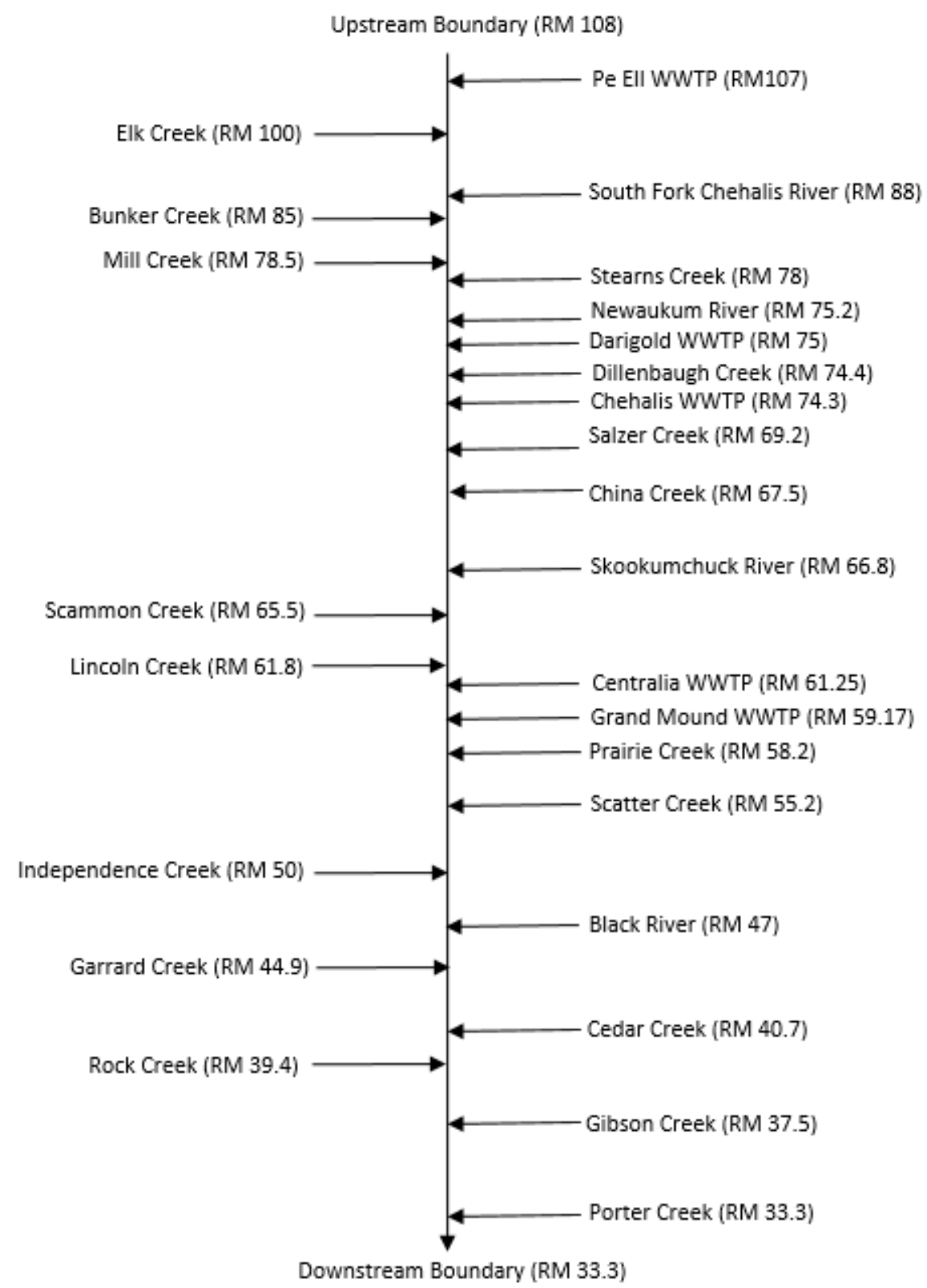

Figure 29. Schematic of tributaries to the model reach of the Chehalis River and their corresponding river miles (WEST Consultants, 2011 and WADOE, 2001). Note: figure is not to scale.

Flow and stage data were available from multiple monitoring stations along the mainstem Chehalis River and for some of the tributaries. Flow data were made available by USGS (2014), WADOE (2014), and Thurston County (2014). WWTP data were provided by the WADOE National Pollutant Discharge Elimination System (NPDES) permit database 
and also directly from some of the wastewater treatment plant managers (NPDES, 2016;

Phelps, 2016; Hillock, 2016; Bilhimer, 2016; Zentner, 2016; and Patching, 2016).

Groundwater is generally a flow source to the river and varies along the channel. Multiple studies have been conducted that give average groundwater flow values for various reaches of the Chehalis River. These include a TMDL study (Erickson, 1993), an aquifer characterization study (Garrigues, et al., 1998), a Centralia-Chehalis area groundwater study (Pitz et al., 2005), a seepage investigation in the Chehalis River basin (Ely, et al., 2008), and a groundwater/surface water study in the Chehalis River basin (Gendaszek, 2011). Flow data from these studies were generally given as gains and losses of flow for various reaches along the Chehalis River. The most recent data were used from the Gendaszek (2011) report when possible, and then from the Ely, et al. (2008) report to fill in data gaps. Due to lack of continuous data, the estimates of the groundwater flow from these studies were assumed constant over time. These flows were allocated to each applicable model segment, acting as many individual point tributaries. Table 5 lists the stations that provided flow data for tributaries, dischargers, and groundwater inputs.

Table 5. Flow monitoring stations with measured or estimated flow data

\begin{tabular}{|c|c|c|}
\hline Organization & Station ID & Description \\
\hline USGS & 12019310 & Chehalis River above Mahaffey Creek \\
\hline USGS & 12020000 & Chehalis River near Doty, WA \\
\hline USGS & 12020525 & Elk Creek below Deer Creek near Doty, WA \\
\hline USGS & 12020800 & South Fork Chehalis River near Wildwood, WA \\
\hline USGS & 12025000 & Newaukum River near Chehalis, WA \\
\hline USGS & 12026400 & Skookumchuck River near Bucoda, WA \\
\hline USGS & 12027500 & Chehalis River near Grand Mound, WA \\
\hline USGS & 12031000 & Chehalis River at Porter, WA \\
\hline Thurston County & $55 a$ & Scatter Creek at James Road \\
\hline WADOE & $23 E 060$ & Black River at Hwy 12 \\
\hline
\end{tabular}




\begin{tabular}{|c|c|c|}
\hline Organization & Station ID & Description \\
\hline WADOE & $23 \mathrm{H} 060$ & Salzer Creek at Airport Road \\
\hline WADOE NPDES & WA0020192 & Pe Ell WWTP \\
\hline WADOE NPDES & WA0037478 & Darigold WWTP \\
\hline WADOE NPDES & WA0021105 & Chehalis WWTP \\
\hline WADOE NPDES & WA0020982 & Centralia WWTP \\
\hline WADOE NPDES & WA0042099 & Grand Mound WWTP \\
\hline USGS & Reach T (Ely, et al.) & Groundwater river mile $101.9-100.5$ \\
\hline USGS & Reach S (Ely, et al.) & Groundwater river mile $100.5-97.9$ \\
\hline USGS & Reach R (Ely, et al.) & Groundwater river mile $97.9-93.8$ \\
\hline USGS & Reach Q (Ely, et al.) & Groundwater river mile $93.8-90.2$ \\
\hline USGS & Reach P (Ely, et al.) & Groundwater river mile $90.2-86$ \\
\hline USGS & Reach O (Ely, et al.) & Groundwater river mile $86-79.9$ \\
\hline USGS & Reach N (Ely, et al.) & Groundwater river mile $79.9-75.1$ \\
\hline USGS & Reach A (Gendaszek) & Groundwater river mile $75.1-66.7$ \\
\hline USGS & Reach B (Gendaszek) & Groundwater river mile $66.7-64.2$ \\
\hline USGS & Reach C (Gendaszek) & Groundwater river mile $64.2-61.4$ \\
\hline USGS & Reach D (Gendaszek) & Groundwater river mile $61.4-59.9$ \\
\hline USGS & Reach E (Gendaszek) & Groundwater river mile $59.9-58.8$ \\
\hline USGS & Reach F (Gendaszek) & Groundwater river mile $58.8-57.1$ \\
\hline USGS & Reach G (Gendaszek) & Groundwater river mile $57.1-55.7$ \\
\hline USGS & Reach H (Gendaszek) & Groundwater river mile $55.7-54.2$ \\
\hline USGS & Reach I (Gendaszek) & Groundwater river mile $54.2-52.5$ \\
\hline USGS & Reach J (Gendaszek) & Groundwater river mile $52.5-51.5$ \\
\hline USGS & Reach K (Gendaszek) & Groundwater river mile $51.5-50.2$ \\
\hline USGS & Reach L (Gendaszek) & Groundwater river mile $50.2-49.1$ \\
\hline USGS & Reach M (Gendaszek) & Groundwater river mile $49.1-47.9$ \\
\hline USGS & Reach N (Gendaszek) & Groundwater river mile $47.9-47.1$ \\
\hline USGS & Reach O (Gendaszek) & Groundwater river mile $47.1-46.1$ \\
\hline USGS & Reach P (Gendaszek) & Groundwater river mile $46.1-45$ \\
\hline USGS & Reach Q (Gendaszek) & Groundwater river mile $45-44$ \\
\hline USGS & Reach R (Gendaszek) & Groundwater river mile $44-42.3$ \\
\hline USGS & Reach E (Ely, et al.) & Groundwater river mile $42.3-34$ \\
\hline USGS & Reach D (Ely, et al.) & Groundwater river mile $34-33.3$ \\
\hline
\end{tabular}

Flow data were required for the entire model time period of January 1, 2013 to

December 31, 2014, and gaps needed to be filled when necessary. The nearest mainstem

flow monitoring station to the upstream boundary was located on the Chehalis River near

Mahaffey Creek (USGS 12019310), with 15-minute frequency flow values. The Chehalis

River at Mahaffey Creek, South Fork Chehalis River, Black River, and Elk Creek had flow 
records available, though sometimes with sizable data gaps on the order of months. Correlations were developed in order to fill in these gaps, following the same procedure as the meteorological data. The flow regression equations for Chehalis River near Mahaffey Creek, Elk Creek, South Fork Chehalis River, and Black River are shown in Table 6. Plots of the regression relationships can be seen in Figure 30, Figure 31, Figure 32, and Figure 33 for Chehalis River near Mahaffey Creek, Elk Creek, South Fork Chehalis River, and Black River, respectively.

Table 6. Flow Regression Relationships for South Fork Chehalis River, Black River, and Elk Creek to Chehalis River at Doty or Grand Mound

\begin{tabular}{|c|c|c|}
\hline Tributary & Regression Equation & $\mathrm{R}^{2}$ Value \\
\hline $\begin{array}{c}\text { Upstream boundary (Chehalis } \\
\text { River at Mahaffey Creek) }\end{array}$ & $Q_{\text {Ch R. Mahaffey }}=0.8262 * Q_{\text {Chehalis@Doty }}-0.3337$ & 0.98 \\
\hline Elk Creek & $Q_{\text {Elk Creek }}=0.2659 * Q_{\text {Chehalis@Doty }}+2.4474$ & 0.8558 \\
\hline South Fork Chehalis River & $Q_{\text {SF Chehalis }}=0.1717 * Q_{\text {Chehalis@Doty }}+1.0654$ & 0.8232 \\
\hline Black River & $Q_{\text {Black }}=0.9034 * Q_{\text {Chehalis@Grand Mound }}+3.6102$ & 0.6611 \\
\hline
\end{tabular}




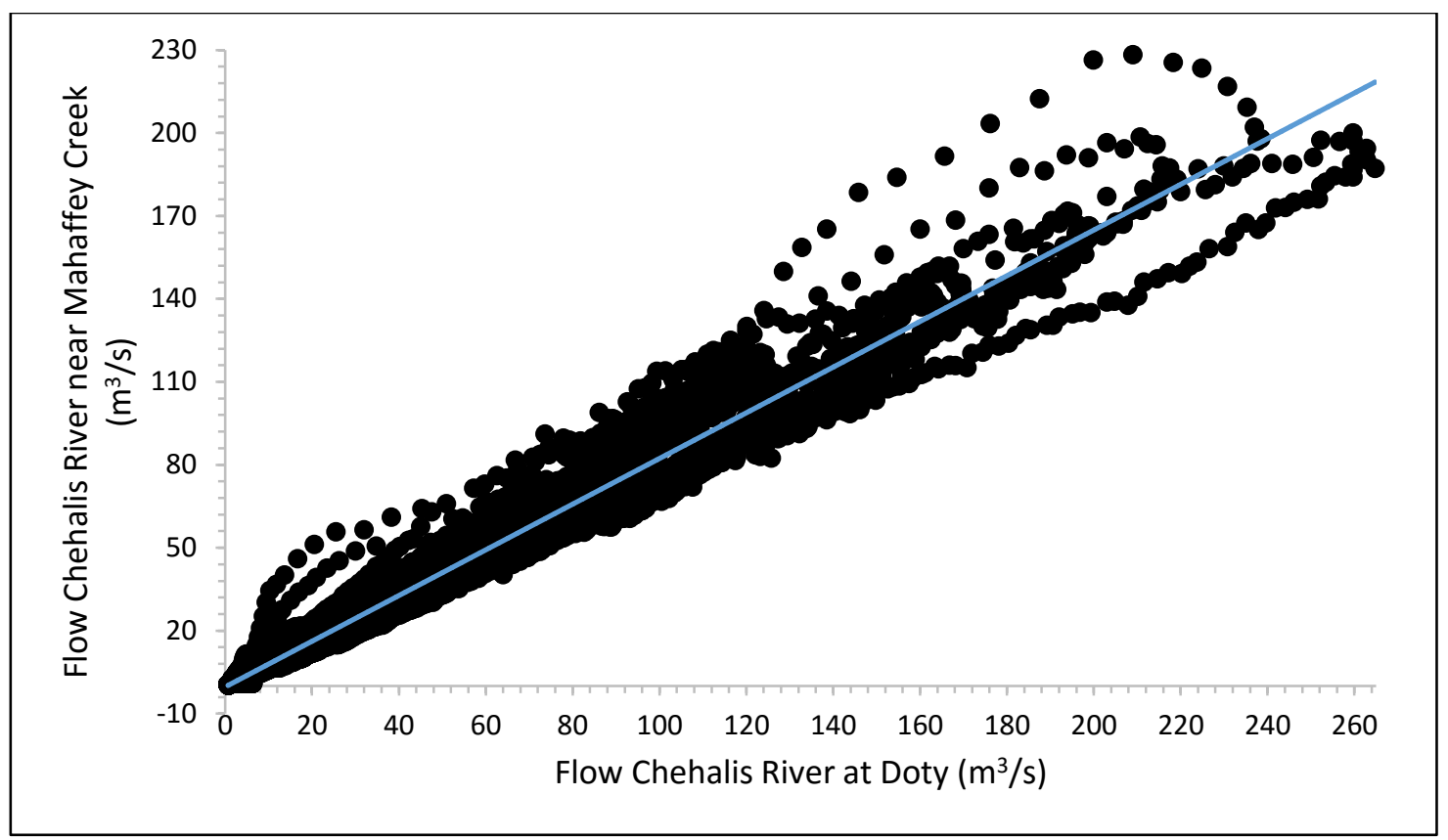

Figure 30. Flow relationship between Chehalis River near Mahaffey Creek and Chehalis River at Doty when both gaging stations had data available

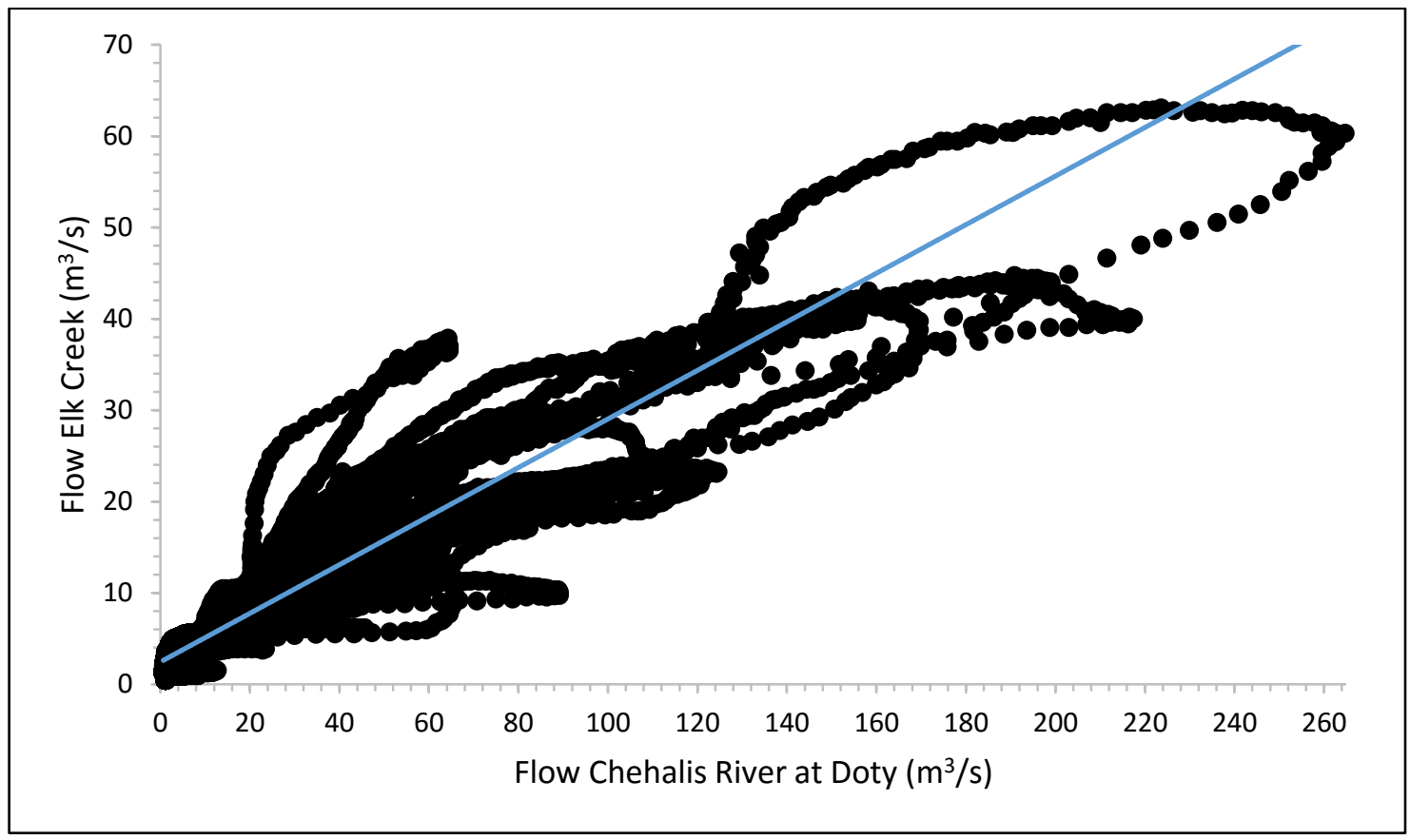

Figure 31. Flow relationship between Elk Creek and Chehalis River at Doty when both gaging stations had data available 


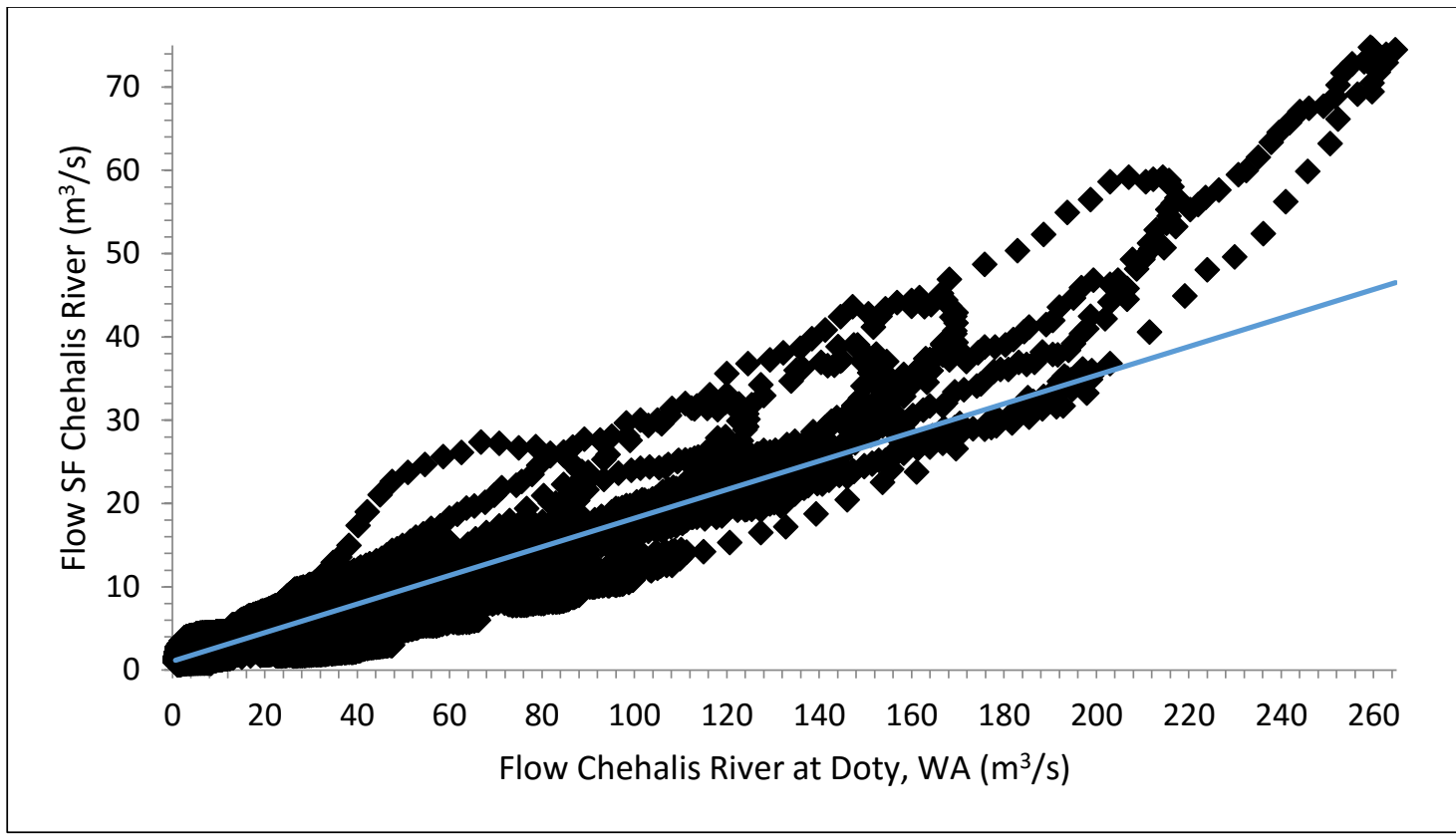

Figure 32. Flow relationship between South Fork Chehalis River and Chehalis River at Doty when both gaging stations had data available

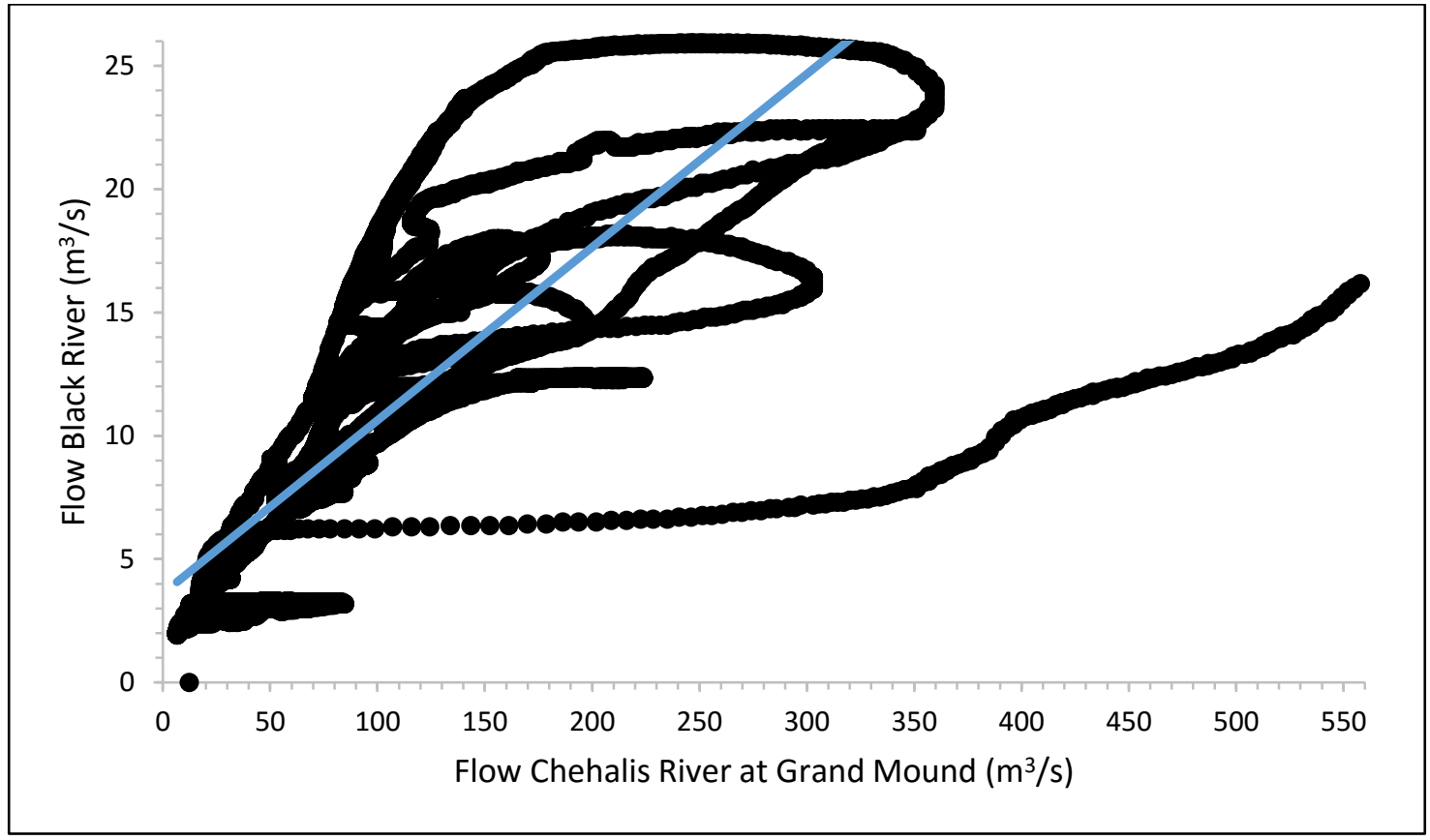

Figure 33. Flow relationship between Black River and Chehalis River at Grand Mound when both gaging stations had data available 
Many of the smaller tributaries - including Bunker, Mill, Stearns, Dillenbaugh, Salzer, China, Scammon, Prairie, Lincoln, Scatter, Independence, Garrard, Rock, Cedar, Gibson, and Porter creeks - had little to no flow data available during the model time period, and hence it was not possible to create a regression relationship. In this case, gaged flow data from another tributary and a ratio of drainage area of the ungaged station to the drainage area of the gaged station was employed to estimate the missing tributary flow following the equation below (Anchor QEA, 2012 and WEST Consultants, 2011). The Newaukum River data set was used as the gaged data set since this tributary had data available for the entire model time period. The drainage area values were provided by USGS (2016). Table 7 shows the tributary gaging stations and corresponding drainage areas used to employ this method.

$$
Q_{\text {ungaged }}=Q_{\text {gaged }} \times \frac{\text { Drainage Area }}{\text { Draingaged }}
$$

Table 7. Drainage area values used to calculate flow for tributaries with missing data

\begin{tabular}{|c|c|c|}
\hline Station ID & Station Name & Drainage Area $\left(\mathrm{mi}^{2}\right)$ \\
\hline USGS 12019310 & Chehalis River above Mahaffey Creek near Pe Ell, WA & 68.9 \\
\hline USGS 12010000 & Chehalis River at Doty, WA & 113 \\
\hline USGS 12025000 & Newaukum River & 155 \\
\hline USGS 12022010 & Bunker Creek above Deep Creek near Bunker, WA & 20.7 \\
\hline USGS 12022500 & Stearns Creek near Napavine, WA & 14.1 \\
\hline USGS 12023400 & Mill Creek at Littell, WA & 6.17 \\
\hline USGS 12025075 & Dillenbaugh Creek below Berwick Creek near Chehalis, WA & 12.4 \\
\hline USGS 12025330 & Salzer Creek & 16.5 \\
\hline USGS 12025530 & China creek near Centralia, WA & 1.58 \\
\hline USGS 12026670 & Scammon creek at Cooks Hill Road near Centralia, WA & 5.13 \\
\hline LNC-CRK & Lincoln Creek & 19.3 \\
\hline USGS 12027200 & Lincoln creek at RM 1.6 near Galvin, WA & 37.1 \\
\hline USGS 12027540 & Prairie creek near Grand Mound, WA & 3.76 \\
\hline
\end{tabular}




\begin{tabular}{|c|c|c|}
\hline Station ID & Station Name & Drainage Area $\left(\mathrm{mi}^{2}\right)$ \\
\hline USGS 12028150 & Independence Creek & 13.2 \\
\hline USGS 12029325 & Garrard Creek & 11 \\
\hline USGS 12030000 & Rock Creek & 24.8 \\
\hline USGS 12030500 & Cedar Creek & 38.2 \\
\hline USGS 12030550 & Gibson Creek & 6.96 \\
\hline USGS 12030950 & Porter Creek & 39.8 \\
\hline
\end{tabular}

Figure 34 shows the input flow to the model for tributaries with data available, including those where regression estimation techniques were employed. Figure 35, Figure 36, and Figure 37 show the input flow for tributaries where flow values were estimated from drainage areas and Newaukum River data. Figure 38 shows the input flows from the WWTP dischargers, and Figure 39 shows the input flows for groundwater sources to the Chehalis River. 

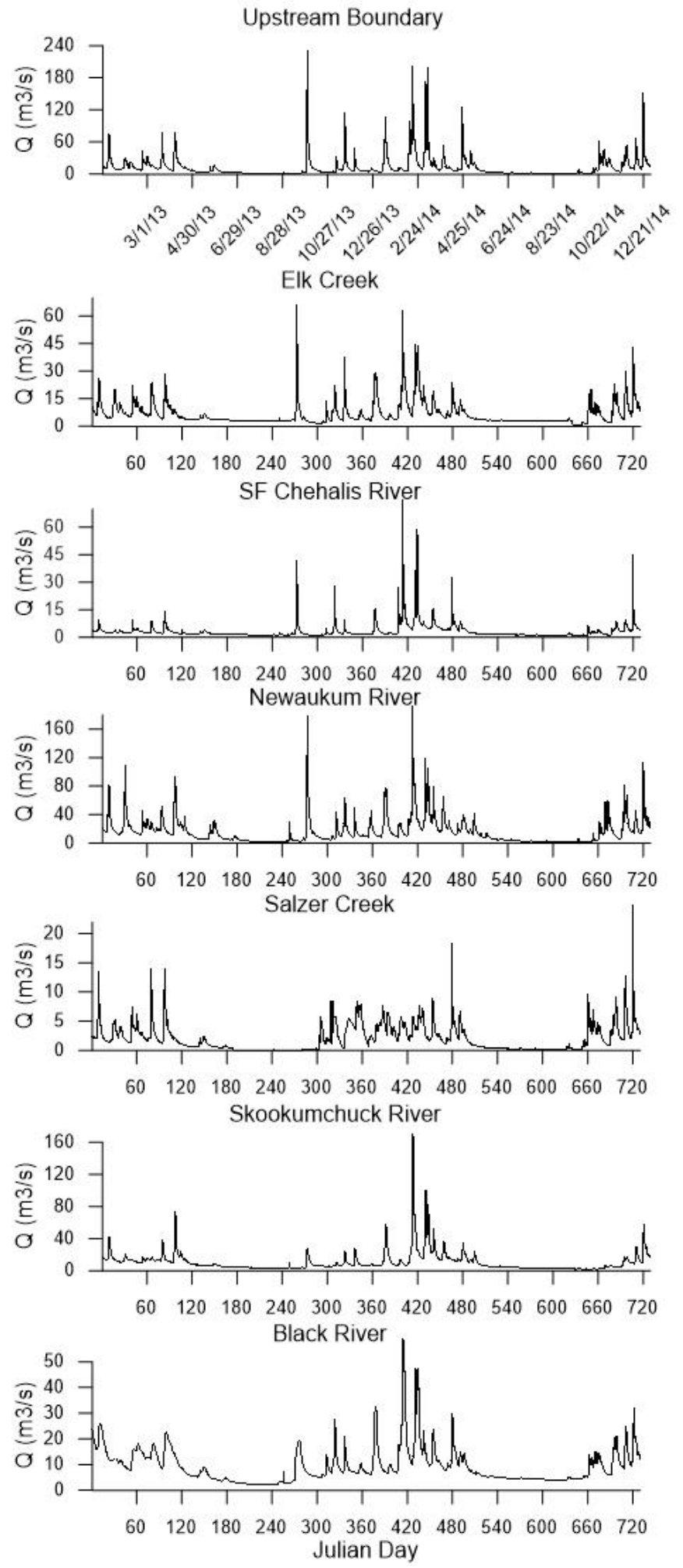

Figure 34. Input flow data where field data were available for Chehalis River at Mahaffey Creek (upstream boundary), Elk Creek, South Fork Chehalis River, Newaukum River, Salzer Creek, Skookumchuck River, and Black River 

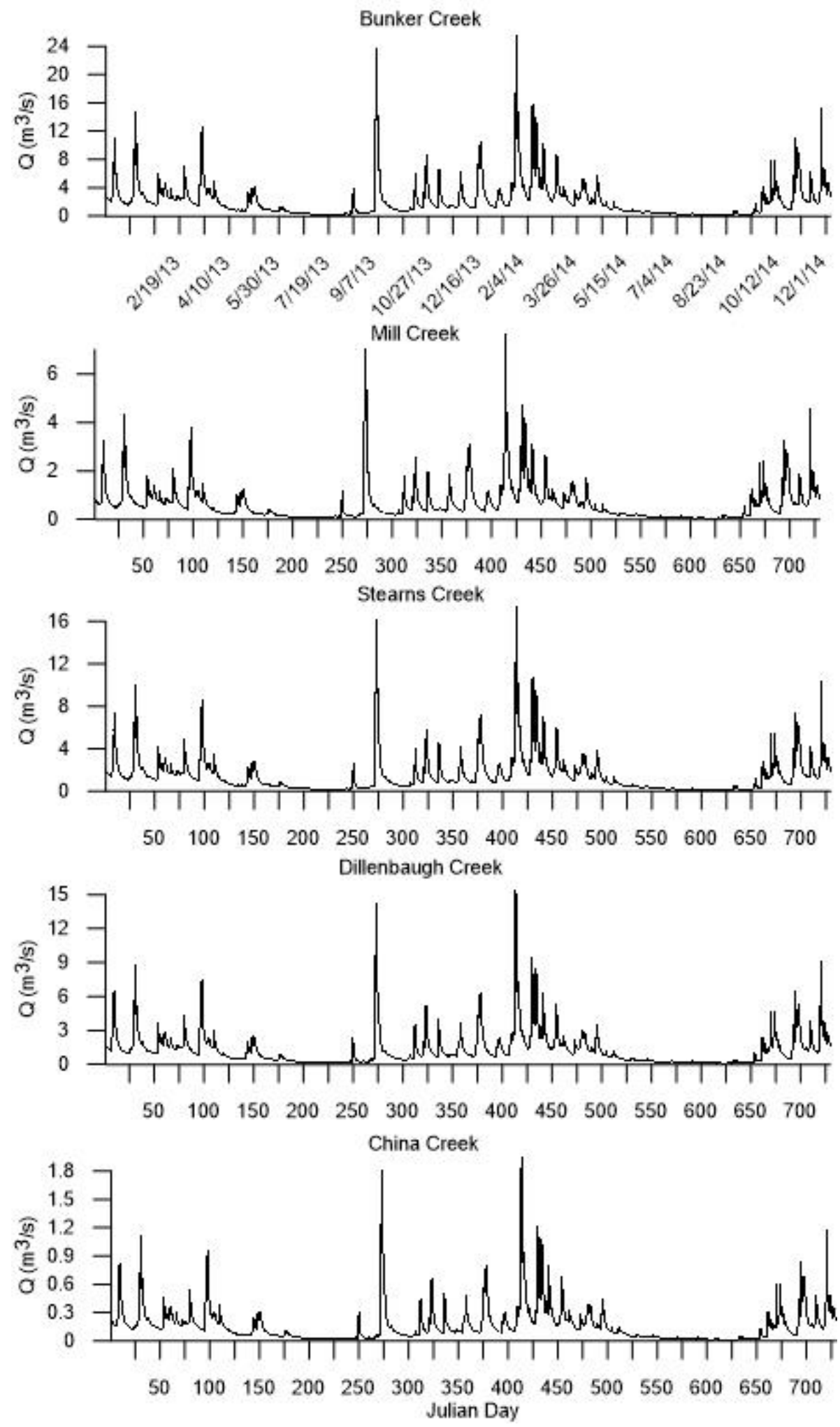

Figure 35. Input flow based on drainage area ratios to Newaukum River for Bunker Creek, Mill Creek, Stearns Creek, Dillenbaugh Creek, and China Creek 

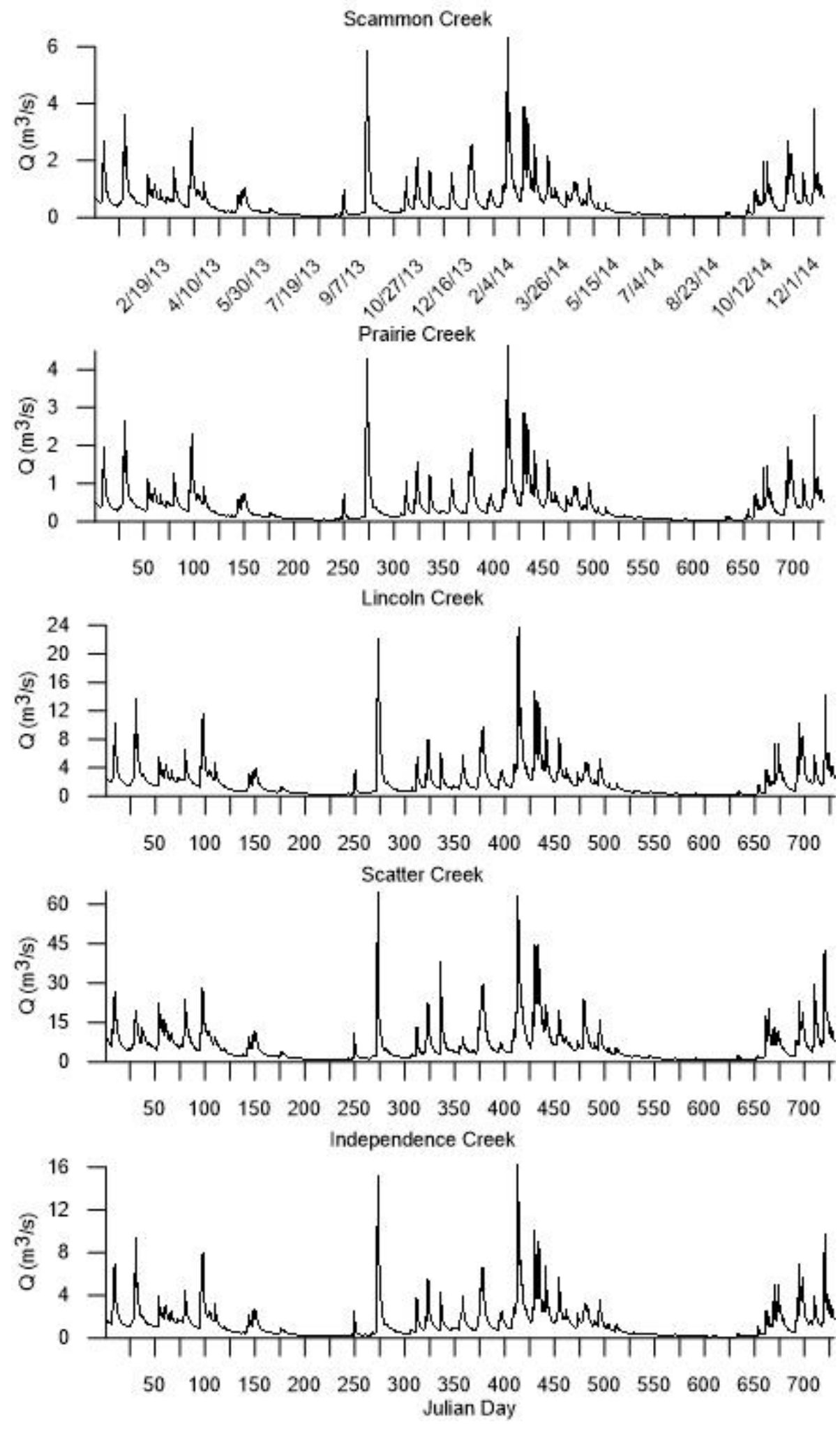

Figure 36. Input flow based on drainage area ratios to Newaukum River for Scammon Creek, Prairie Creek, Lincoln Creek, Scatter Creek, and Independence Creek 

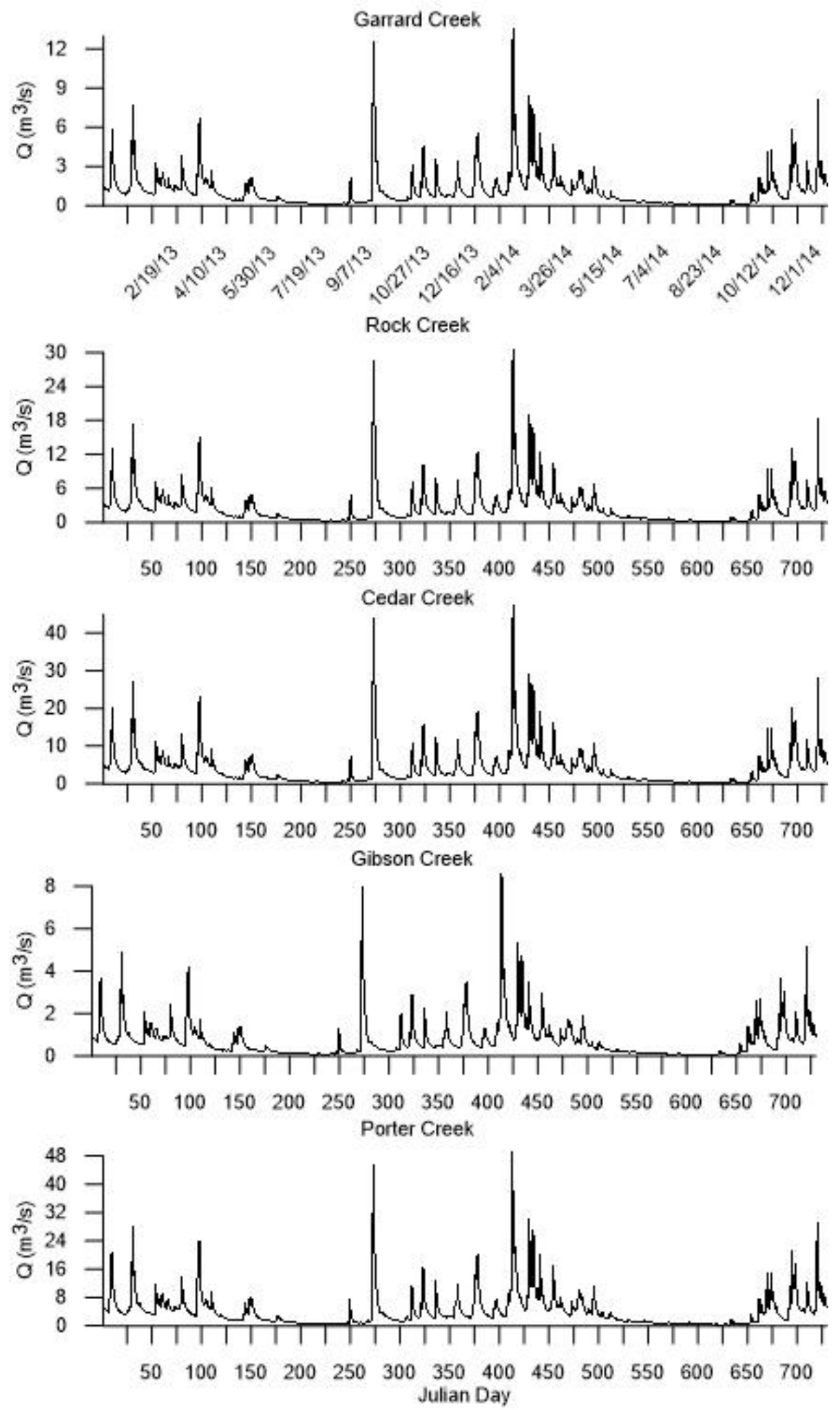

Figure 37. Input flow based on drainage area ratios to Newaukum River for Garrard Creek, Rock Creek, Cedar Creek, Gibson Creek, and Porter Creek 

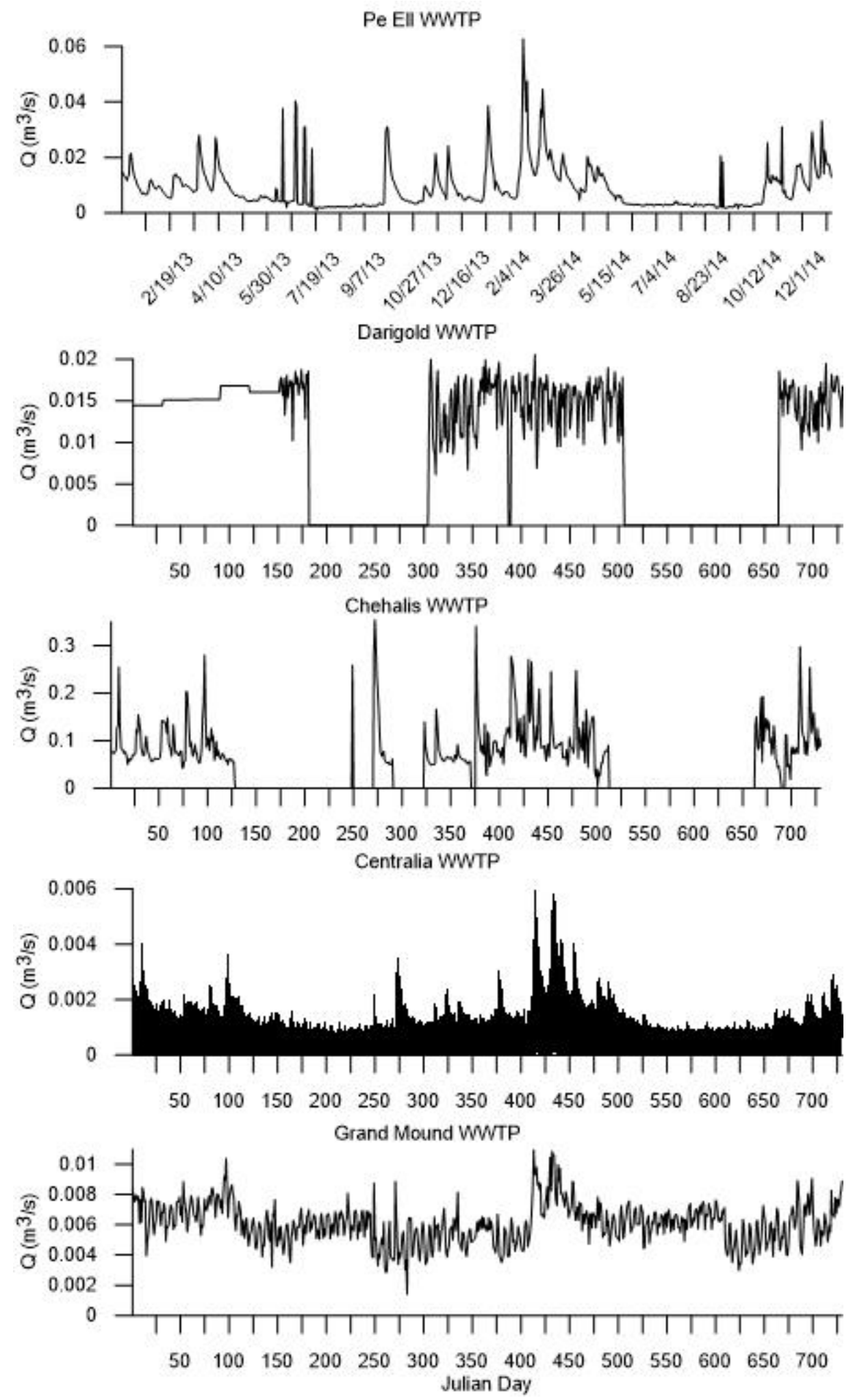

Figure 38. Input flow for the Pe Ell, Darigold, Chehalis, Centralia, and Grand Mound wastewater treatment plants 


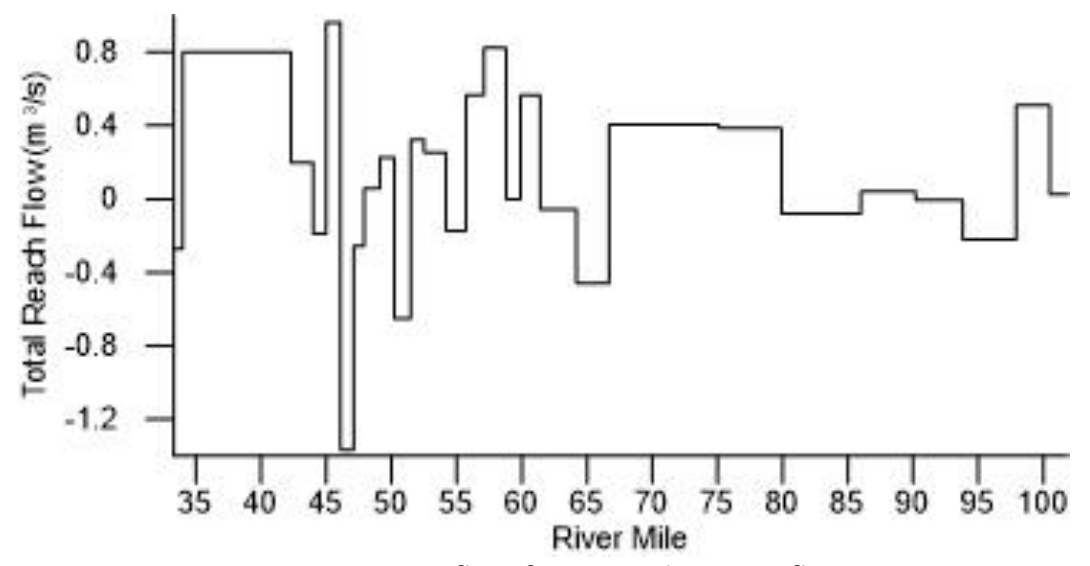

Figure 39. Input flow for groundwater inflows

\subsection{Temperature Inputs}

Temperature data were also required for the entire model time period for all input flows. Temperature data were available from measurement locations along the mainstem Chehalis River as well as for some of the tributaries. Temperature data were made available by WADOE (2014), Anchor QEA (2014), Washington Department of Fish and Wildlife (WDFW 2014), and Thurston County (2014). WWTP data were provided by the WADOE NPDES permit data base as well as directly from some plant managers (NPDES 2003a, 2003b, 2010, 2011, 2012; Phelps, 2016; Hillock, 2016; Bilhimer, 2016; Zentner, 2016; and Patching, 2016). Groundwater temperature data were provided from the Chehalis River TMDL study (Erickson, 1993), where temperature data were provided for various reaches of groundwater interacting with the Chehalis River. Groundwater temperature data collected from the wells closest to the river for each reach were used. Table 8 lists the gaging stations that were used for the model temperature for tributaries, dischargers, and groundwater inputs. 
Table 8. Monitoring stations used to develop model temperature inputs

\begin{tabular}{|c|c|c|c|}
\hline Organization & Station ID & Description & Dates with data \\
\hline Anchor QEA & CHL-PEL-US & Chehalis Upstream of Pe Ell & $7 / 31 / 13-3 / 26 / 14$ \\
\hline Anchor QEA & CHL-PEL-DS & Chehalis Downstream of Pe Ell & $7 / 31 / 13-7 / 30 / 14$ \\
\hline Anchor QEA & CHL- & Chehalis at Woodstead Farm 01 & $7 / 2 / 13-10 / 28 / 13$ \\
\hline Anchor QEA & CHL-DOTY & Chehalis at Doty & $7 / 3 / 13-10 / 16 / 13$ \\
\hline Anchor QEA & ELK-CRK & Elk Creek & $7 / 31 / 13-3 / 26 / 14$ \\
\hline Anchor QEA & CHL-RAINBOW- & Chehalis at Rainbow Falls & $7 / 2 / 13-10 / 16 / 13$ \\
\hline Anchor QEA & CHL-CERES-HILLS & Chehalis at Ceres Hill Road & $7 / 3 / 13-10 / 16 / 13$ \\
\hline Anchor QEA & SF-CHL-MOUTH & South Fork Mouth & $7 / 31 / 13-3 / 26 / 14$ \\
\hline Anchor QEA & CHL-ADNA & Chehalis Near Adna & $7 / 31 / 13-7 / 21 / 14$ \\
\hline Anchor QEA & CHL-US-NWK & $\begin{array}{c}\text { Chehalis Upstream of Newaukum } \\
\text { Confluence }\end{array}$ & $7 / 31 / 13-3 / 26 / 14$ \\
\hline Anchor QEA & NWK-MOUTH & Newaukum Mouth & $9 / 18 / 13-7 / 21 / 14$ \\
\hline Anchor QEA & SKM-MOUTH & Skookumchuck Mouth & $9 / 5 / 13-10 / 15 / 13$ \\
\hline Anchor QEA & CHL-GLV & Chehalis at Galvin Bridge & $7 / 30 / 13-7 / 21 / 14$ \\
\hline Anchor QEA & CHL-US-BLK & Chehalis Upstream of Black River & $7 / 30 / 13-7 / 22 / 14$ \\
\hline Anchor QEA & BLK-RT12 & Black River Mouth & $9 / 5 / 13-7 / 22 / 14$ \\
\hline Anchor QEA & CHL-OAK & Chehalis at Oakville & $7 / 30 / 13-7 / 22 / 14$ \\
\hline WDFW & $11-\mathrm{UCH}$ & Upper Chehalis & $6 / 9 / 14-9 / 15 / 15$ \\
\hline WDFW & 3-UCH & Upper Chehalis & $5 / 15 / 14-9 / 15 / 15$ \\
\hline WDFW & $13-\mathrm{CH}$ & Chehalis mainstem & $6 / 10 / 14-9 / 15 / 15$ \\
\hline WDFW & 4-UCH & Upper Chehalis & $5 / 15 / 14-9 / 15 / 15$ \\
\hline WDFW & $15-\mathrm{CH}$ & Chehalis mainstem & $6 / 10 / 14-10 / 14 / 14$ \\
\hline WDFW & $19-\mathrm{CH}$ & Chehalis mainstem & $6 / 18 / 14-9 / 2 / 15$ \\
\hline WDFW & $21-\mathrm{CH}$ & Upper Chehalis & $6 / 11 / 14-9 / 2 / 15$ \\
\hline WDFW & NEW-1 & Newaukum & $7 / 15 / 14-9 / 4 / 15$ \\
\hline WDFW & $22-\mathrm{CH}$ & Upper Chehalis & $6 / 11 / 14-8 / 5 / 15$ \\
\hline WDFW & $16-\mathrm{CH}$ & Chehalis mainstem & $6 / 10 / 14-9 / 3 / 15$ \\
\hline WDFW & $17-\mathrm{CH}$ & Chehalis mainstem & $6 / 10 / 14-9 / 1 / 15$ \\
\hline WDFW & $18-\mathrm{CH}$ & Chehalis mainstem & $6 / 10 / 14-8 / 26 / 15$ \\
\hline WDFW & $23-\mathrm{CH}$ & Chehalis mainstem & $7 / 15 / 14-8 / 17 / 15$ \\
\hline $\begin{array}{l}\text { Thurston } \\
\text { County }\end{array}$ & $55 a$ & Scatter Creek at James Road & $1 / 1 / 13-5 / 19 / 15$ \\
\hline WADOE & $23 \mathrm{~A} 160$ & Chehalis River at Dryad & $\begin{array}{c}\text { 7/1/13 - 9/18/13, } \\
6 / 24 / 14-9 / 23 / 14, \& \\
5 / 19 / 15-9 / 15 / 15\end{array}$ \\
\hline WADOE & $23 \mathrm{~A} 070$ & Chehalis River at Porter & $\begin{array}{c}10 / 23 / 12-6 / 25 / 13 \& \\
9 / 18 / 13-5 / 26 / 15\end{array}$ \\
\hline $\begin{array}{l}\text { WADOE } \\
\text { NPDES }\end{array}$ & WA0020192 & Pe Ell WWTP & $1 / 1 / 13-12 / 31 / 14$ \\
\hline $\begin{array}{l}\text { WADOE } \\
\text { NPDES }\end{array}$ & WA0037478 & Darigold WWTP & $\begin{array}{l}1 / 1 / 13-9 / 30 / 13, \& \\
11 / 1 / 13-12 / 31 / 14\end{array}$ \\
\hline
\end{tabular}




\begin{tabular}{|c|c|c|c|}
\hline $\begin{array}{c}\text { Organization } \\
\begin{array}{c}\text { WADOE } \\
\text { NPDES }\end{array}\end{array}$ & Station ID & Description & Dates with data \\
\hline $\begin{array}{c}\text { WADOE } \\
\text { NPDES }\end{array}$ & WA0020982 & Chehalis WWTP & $1 / 1 / 13-12 / 31 / 14$ \\
\hline $\begin{array}{c}\text { WADOE } \\
\text { NPDES }\end{array}$ & WA0042099 & Centralia WWTP & $1 / 1 / 13-12 / 31 / 14$ \\
\hline $\begin{array}{c}\text { Darigold } \\
\text { WWTP }\end{array}$ & 41 & Chehalis River Upstream Darigold & $1 / 1 / 13-11 / 30 / 15$ \\
\hline $\begin{array}{c}\text { Darigold } \\
\text { WWTP }\end{array}$ & 40 & WWTP & $1 / 1 / 13-12 / 31 / 14$ \\
\hline WADOE & DW03 & GW - Bunker Creek to Adna & $1 / 1 / 13-11 / 30 / 15$ \\
\hline WADOE & DW08 & GW - Adna to Claquato & 1993 \\
\hline WADOE & DW07 & GW - Claquato to Golf Course & 1993 \\
\hline WADOE & DW15 & GW - Golf Course to Mellen Street & 1993 \\
\hline WADOE & DW18 & GW - Centralia/Fords Prairie & 1993 \\
\hline WADOE & DW27 & GW - Grand Mound to Oakville & 1993 \\
\hline
\end{tabular}

Temperature data gaps were filled using the same regression procedure as for meteorological data by creating correlations between stations with missing data and stations with complete data sets. The Chehalis River downstream of Darigold WWTP and the Chehalis River upstream of Darigold WWTP gages had data for the entire model time period and hence were used for correlations with other incomplete data series. However, the regression relationships using the Chehalis River downstream of Darigold WWTP gage to fill in missing data had higher coefficient of determination $\left(R^{2}\right)$ values than when using data from the upstream site. For this reason, the downstream site was used rather than the upstream to fill missing data. The exceptions to this were when closer temperature gages had data available. For Elk Creek this was 4-UCH and for Black River this was 18-CH. When these closer gages did not have data, the downstream Darigold gage was used.

The closest temperature measurement station to the upstream boundary was 11$\mathrm{UCH}$. When possible, data from 11-UCH was used. The next closest stations were $\mathrm{CHL}-$ 
PEL-US and 3-UCH, which were close together and were located in the same model segment (length $400 \mathrm{~m}$ ). A data set including temperature data from CHL-PEL-US from $1 / 1 / 13$ to $5 / 14 / 14$ and $3-\mathrm{UCH}$ from $5 / 15 / 15$ to $9 / 15 / 15$ was created. One regression relationship was formed between 11-UCH and the CHL-PEL-US and 3-UCH data set. This relationship was used to estimate upstream boundary temperatures when CHL-PEL-US and 3-UCH had data. A second regression relationship was created between 11-UCH and Chehalis River Downstream of Darigold WWTP and was used to estimate upstream boundary temperatures for the remainder of the model time period.

The temperature linear regression relationships for Chehalis River near the upstream boundary (station 11-UCH), Elk Creek, South Fork Chehalis River, Newaukum River, Skookumchuck River, and Black River are shown in Table 9. Example plots of the regression relationships are shown for the Chehalis River upstream boundary and South Fork Chehalis River in Figure 40 and Figure 41, respectively.

Table 9. Temperature Regression Relationships for Upstream Boundary, Elk Creek, South Fork Chehalis River, Newaukum River, Skookumchuck River, and Black River

\begin{tabular}{|c|c|c|}
\hline Tributary & Regression Equation & $\mathrm{R}^{2}$ Value \\
\hline $\begin{array}{l}\text { Upstream boundary } \\
\text { (station 11-UCH) }\end{array}$ & $\begin{array}{c}Q_{C h R .(11-U C H)}=1.0191 * Q_{C H L-P E L-U S \& 3-U C H}-0.5085 \\
Q_{C h R .(11-U C H)}=0.8252 * Q_{C h R . D S \text { Darigold }}+0.6678\end{array}$ & $\begin{array}{l}0.978 \\
0.957\end{array}$ \\
\hline Elk Creek & $\begin{array}{c}T_{\text {Elk Creek }}=0.7681 * T_{\text {Ch R. }(4-U C H)}+1.7319 \\
Q_{\text {Elk Creek }}=0.7479 * Q_{\text {Ch R.DS Darigold }}+1.6611\end{array}$ & $\begin{array}{l}0.974 \\
0.971\end{array}$ \\
\hline South Fork Chehalis River & $Q_{S F \text { Chehalis }}=0.9657 * Q_{\text {ChR.DS Darigold }}+0.5376$ & 0.989 \\
\hline Newaukum River & $Q_{\text {Newaukum R. }}=0.975 * Q_{\text {ChR.DS Darigold }}+0.3016$ & 0.987 \\
\hline Skookumchuck River & $Q_{\text {Skookumchuck R. }}=0.6538 * Q_{\text {Ch R.DS Darigold }}+4.9754$ & 0.974 \\
\hline Black River & $\begin{array}{c}T_{\text {Black }}=0.7406 * T_{\text {ChR.(18-CH })}+3.2796 \\
Q_{\text {Black }}=0.832 * Q_{\text {Ch R.DS Darigold }}+2.2174\end{array}$ & $\begin{array}{l}0.836 \\
0.968\end{array}$ \\
\hline
\end{tabular}




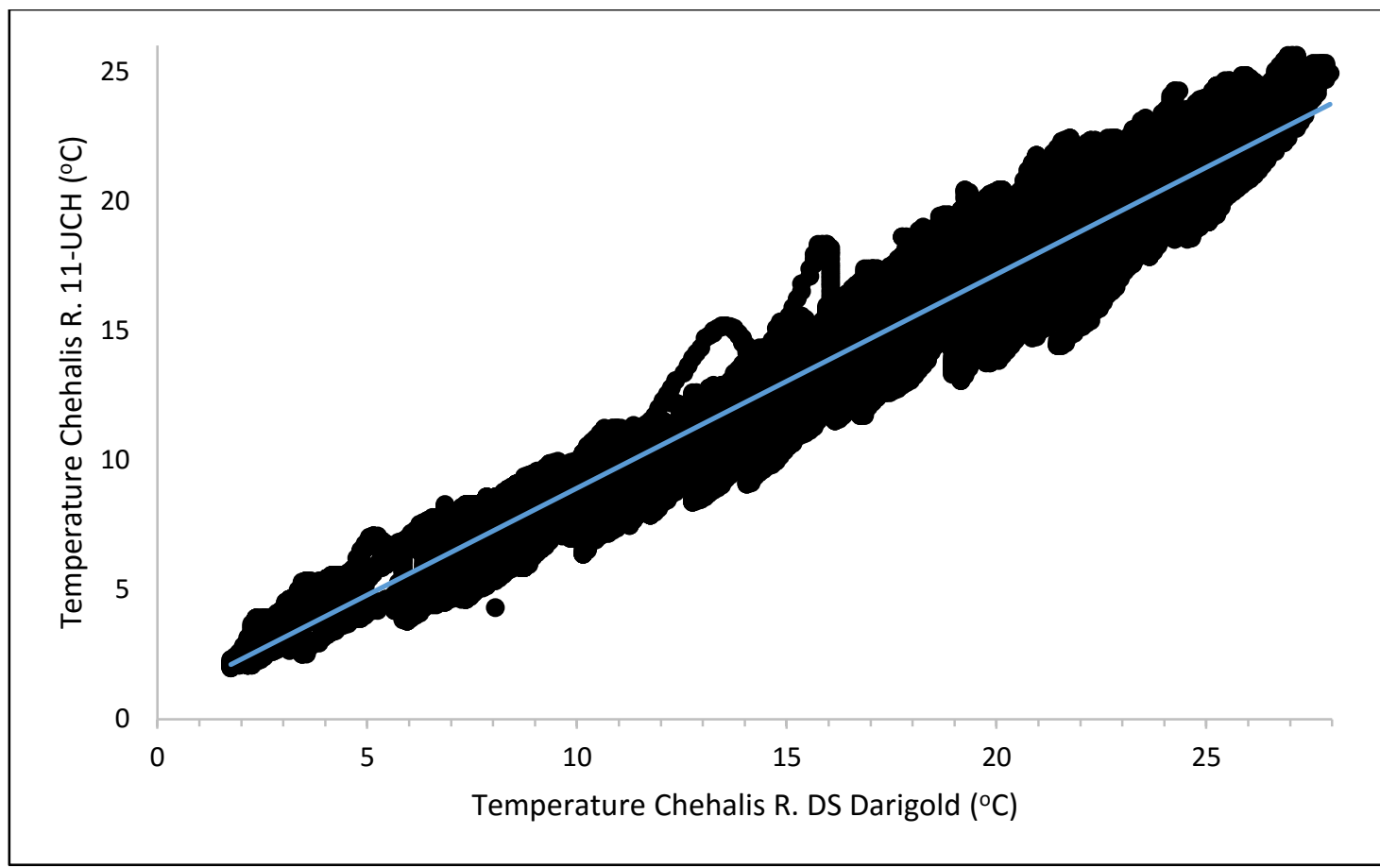

Figure 40. Temperature relationship between Chehalis River at upstream boundary station 11-UCH and Chehalis River Downstream of Darigold when both gaging stations had data available

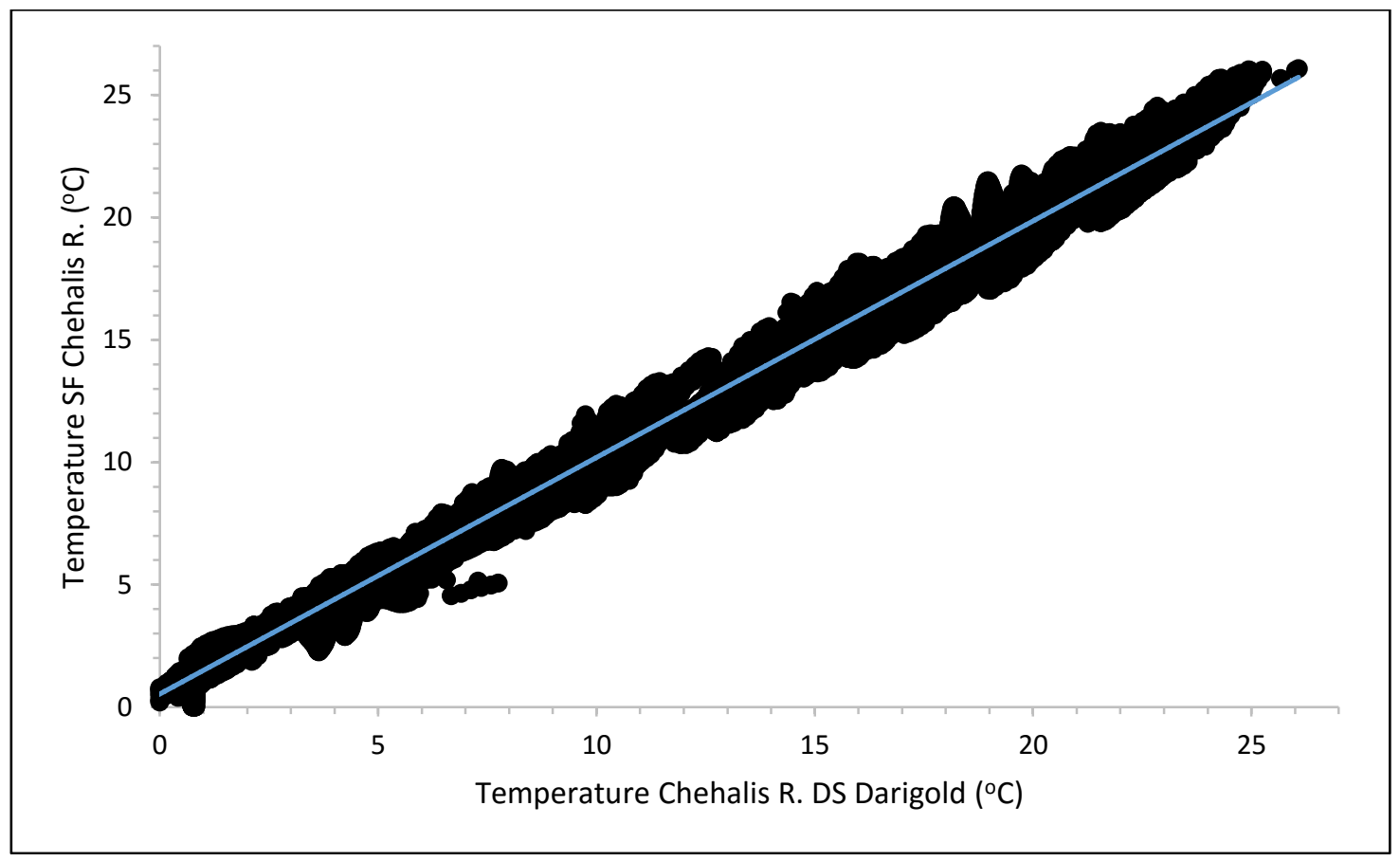

Figure 41. Temperature relationship between South Fork Chehalis River and Chehalis River Downstream of Darigold when both gaging stations had data available 
For tributaries where no data were available it was not possible to create a regression relationship to estimate temperature values. In these cases, the input temperature file from another tributary with similar flow magnitudes was used instead.

Groundwater reaches typically had one data value for temperature available, and sometimes no data. In order to estimate seasonal variation in groundwater temperature, $2{ }^{\circ} \mathrm{C}$ was added to the groundwater temperature data during the summer months.

Figure 42 shows input temperature to the model for tributaries with data available, including those where regression estimation techniques were employed. Figure 43 shows the input temperature for the wastewater treatment plants, and Figure 44 shows the temperature input data for the groundwater sources. 

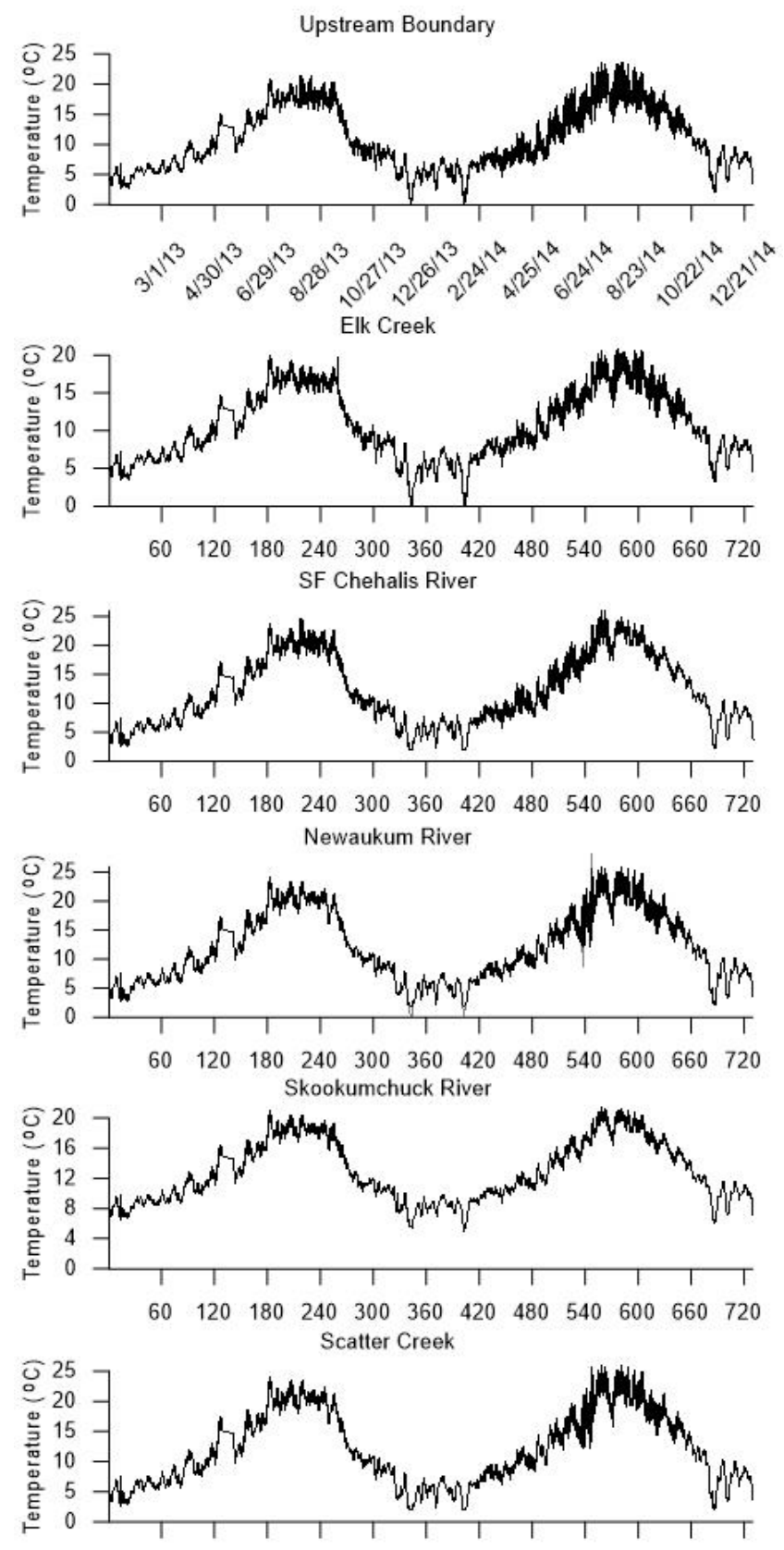

$\begin{array}{llllllllllll}60 & 120 & 180 & 240 & 300 & 360 & 420 & 480 & 540 & 600 & 660 & 720\end{array}$

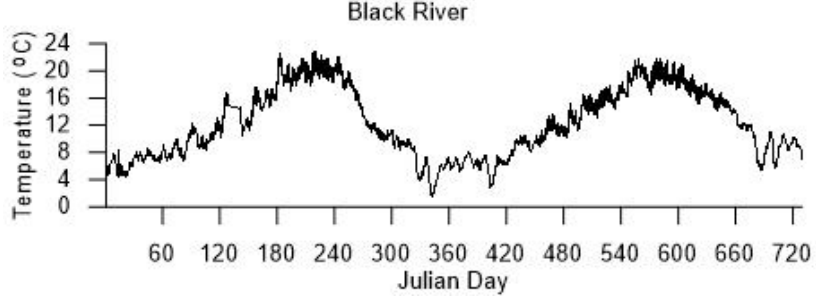

Figure 42. Input temperature data where field data were available for the upstream boundary (station 11UCH), Elk Creek, South Fork Chehalis River, Newaukum River, Skookumchuck River, Scatter Creek, and Black River 

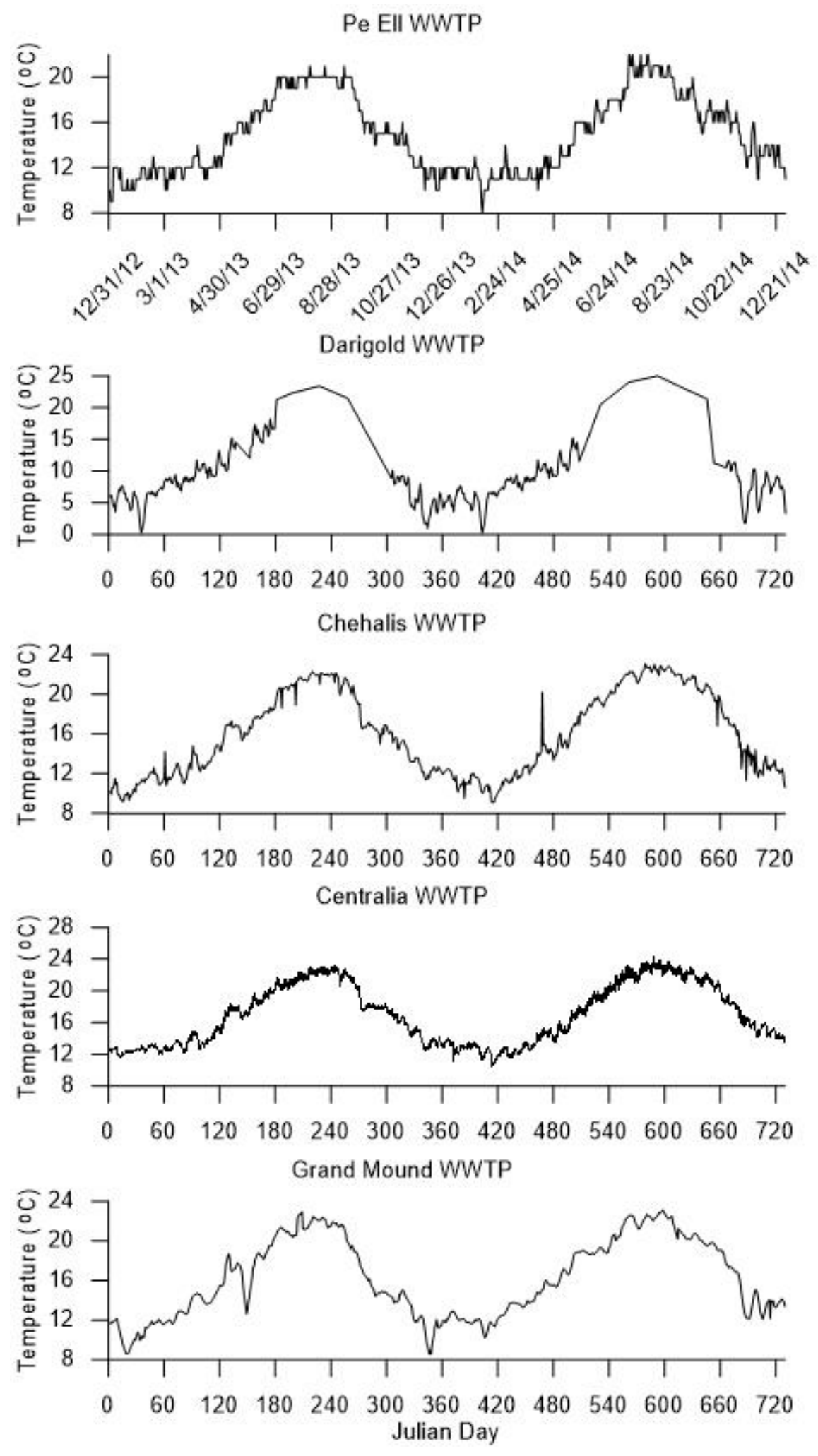

Figure 43. Input temperature for the Pe Ell, Darigold, Centralia, Chehalis, and Grand Mound wastewater treatment plants 


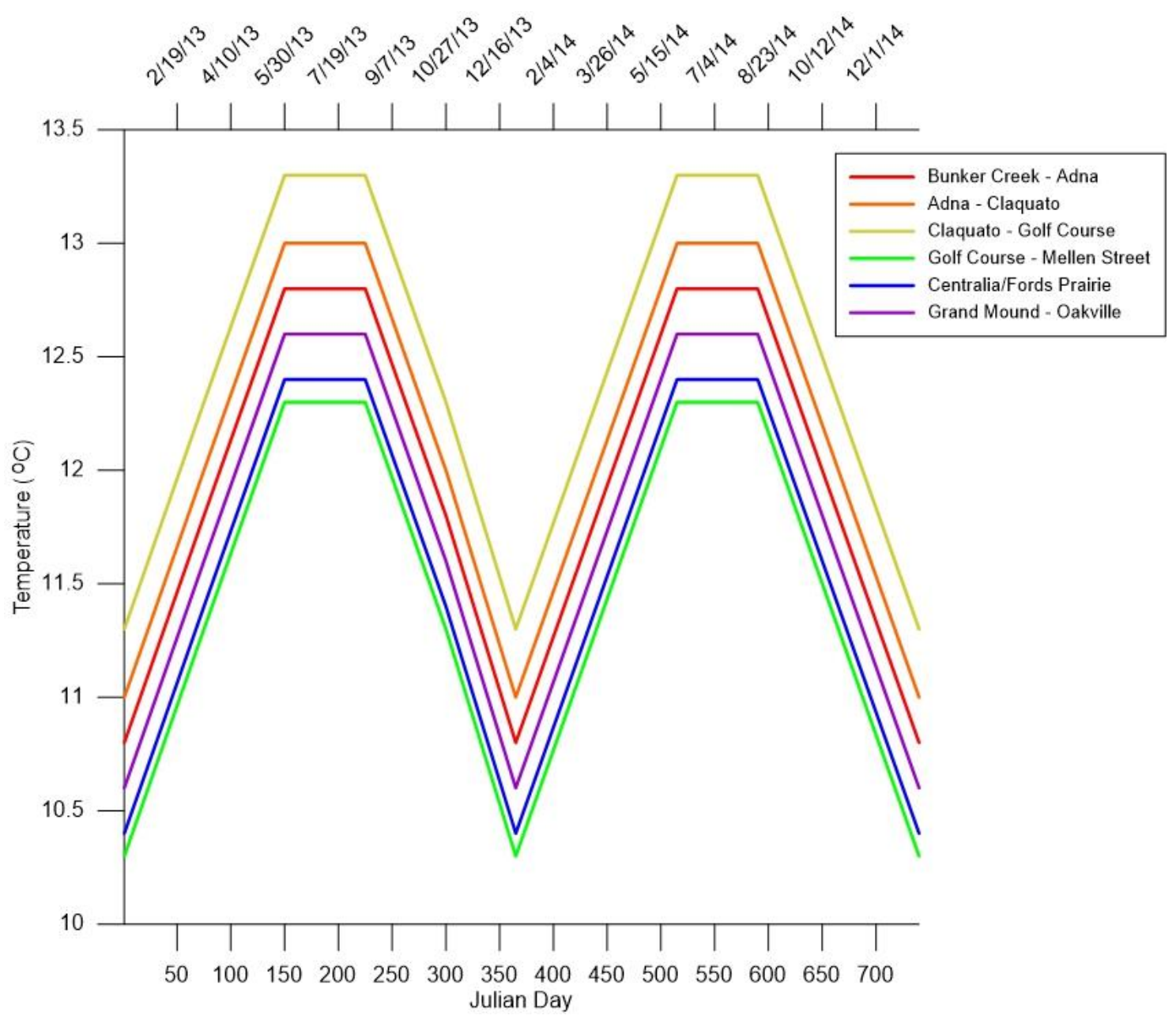

Figure 44. Input temperature for groundwater inflows

\subsection{Constituent Inputs}

The water quality state variables modeled included:

- Total dissolved solids (TDS)

- Fecal coliform (FC)

- Inorganic suspended solids (ISS)

- Phosphate (PO4)

- Ammonia (NH3)

- Nitrates (NO3)

- Labile dissolved organic matter (LDOM)

- Refractory dissolved organic matter (RDOM) 
- Labile particulate organic matter (LPOM)

- Refractory particulate organic matter (RPOM)

- Biochemical oxygen demand (BOD)

- Biochemical oxygen demand as phosphorus (BOD-P)

- Biochemical oxygen demand as nitrogen (BOD-N)

- Algae

- Dissolved oxygen (DO)

- Alkalinity (alk)

- Zooplankton

- LDOM as phosphorus (LDOM-P)

- RDOM as phosphorus (RDOM-P)

- LPOM as phosphorus (LPOM-P)

- RPOM as phosphorus (RPOM-P)

- LDOM as nitrogen (LDOM-N)

- RDOM as nitrogen (RDOM-N)

- LPOM as nitrogen (LPOM-N)

- RPOM as nitrogen (RPOM-N)

Data were needed for the entire model time period for all flow inputs for all water quality state variables. Some water quality data for various locations along the Chehalis mainstem were available from WADOE (2014) and Anchor QEA (2014). Some of the tributaries had data available from Anchor QEA (2014), including the Newaukum River, Skookumchuck River, South Fork Chehalis River, Black River, Elk creek, and Lincoln Creek. Water quality data for the mainstem Chehalis River and the tributaries were generally point data collected during the summer months, often with only two or three samples collected for a given constituent over the course of the years 2013 and 2014 . Some water quality data were available for the wastewater treatment plants and were made available by the WADOE NPDES permit database (2014) and directly from the wastewater treatment plant managers, as either daily point data or monthly averages (Phelps, 2016; 
Hillock, 2016; Bilhimer, 2016; Zentner, 2016; and Patching, 2016). Groundwater water quality data were provided from the Chehalis River TMDL (Erickson, 1993). Table 10 lists the stations that provided water quality data.

Table 10. Monitoring stations that provided water quality data

\begin{tabular}{|c|c|c|c|}
\hline Organization & Station ID & Description & Dates with data \\
\hline Anchor QEA & CHL-PEL-US & Chehalis Upstream of Pe Ell & $8 / 6 / 13,9 / 17 / 13,1 / 27 / 14, \& 7 / 22 / 14$ \\
\hline Anchor QEA & ELK-CRK & Elk Creek & $8 / 6 / 13,9 / 17 / 13,7 / 22 / 14, \& 7 / 30 / 14$ \\
\hline Anchor QEA & SF-CHL-MOUTH & South Fork Mouth & $8 / 6 / 13,9 / 17 / 13, \& 7 / 22 / 14$ \\
\hline Anchor QEA & NWK-MOUTH & Newaukum Mouth & $8 / 6 / 13,9 / 17 / 13, \& 7 / 22 / 14$ \\
\hline Anchor QEA & SKM-MOUTH & Skookumchuck Mouth & $8 / 6 / 13,9 / 17 / 13, \& 7 / 22 / 14$ \\
\hline Anchor QEA & LNC-CRK & Lincoln Creek & $8 / 6 / 13,9 / 17 / 13,7 / 22 / 14, \& 7 / 30 / 14$ \\
\hline Anchor QEA & BLK-RT12 & Black River Mouth & $8 / 6 / 13,9 / 17 / 13, \& 7 / 22 / 14$ \\
\hline $\begin{array}{l}\text { WADOE } \\
\text { NPDES }\end{array}$ & WA0020192 & Pe Ell WWTP & $1 / 1 / 13-12 / 31 / 14$ \\
\hline $\begin{array}{l}\text { WADOE } \\
\text { NPDES }\end{array}$ & WA0037478 & Darigold WWTP & $\begin{array}{c}1 / 1 / 13-9 / 30 / 13, \& 11 / 1 / 13- \\
12 / 31 / 14\end{array}$ \\
\hline $\begin{array}{l}\text { WADOE } \\
\text { NPDES }\end{array}$ & WA0021105 & Chehalis WWTP & $1 / 1 / 13-12 / 31 / 14$ \\
\hline $\begin{array}{l}\text { WADOE } \\
\text { NPDES }\end{array}$ & WA0020982 & Centralia WWTP & $1 / 1 / 13-12 / 31 / 14$ \\
\hline $\begin{array}{l}\text { WADOE } \\
\text { NPDES }\end{array}$ & WA0042099 & Grand Mound WWTP & $1 / 1 / 13-12 / 31 / 14$ \\
\hline WADOE & DW03 & $\begin{array}{c}\text { GW Bunker Creek to Adna } \\
\text { reach }\end{array}$ & $\begin{array}{c}11 / 17 / 92,11 / 18 / 92,12 / 1 / 92 \\
12 / 2 / 92, \& 12 / 8 / 92\end{array}$ \\
\hline WADOE & DW08 & GW Adna to Claquato reach & $\begin{array}{c}11 / 17 / 92,11 / 18 / 92,12 / 1 / 92 \\
12 / 2 / 92, \& 12 / 8 / 92 \\
\end{array}$ \\
\hline WADOE & DW07 & $\begin{array}{c}\text { GW Claquato to Golf Course } \\
\text { reach }\end{array}$ & $\begin{array}{c}11 / 17 / 92,11 / 18 / 92,12 / 1 / 92 \\
12 / 2 / 92, \& 12 / 8 / 92\end{array}$ \\
\hline WADOE & DW15 & $\begin{array}{l}\text { GW Golf Course to Mellen } \\
\text { Street reach }\end{array}$ & $\begin{array}{c}11 / 17 / 92,11 / 18 / 92,12 / 1 / 92 \\
12 / 2 / 92, \& 12 / 8 / 92\end{array}$ \\
\hline WADOE & DW18 & $\begin{array}{c}\text { GW Centralia/Fords Prairie } \\
\text { reach }\end{array}$ & $\begin{array}{c}11 / 17 / 92,11 / 18 / 92,12 / 1 / 92 \\
12 / 2 / 92, \& 12 / 8 / 92\end{array}$ \\
\hline WADOE & DW27 & $\begin{array}{l}\text { GW Grand Mound to } \\
\text { Oakville }\end{array}$ & $\begin{array}{c}11 / 17 / 92,11 / 18 / 92,12 / 1 / 92 \\
12 / 2 / 92, \& 12 / 8 / 92 \\
\end{array}$ \\
\hline WADOE & AHL145 & $\begin{array}{l}\text { GW Chehalis R. at Pranther } \\
\text { Rd. }\end{array}$ & $\begin{array}{c}10 / 05,5 / 10 / 04,6 / 7 / 04,7 / 6 / 04 \\
8 / 4 / 04,8 / 31 / 04, \& 10 / 4 / 04 \\
\end{array}$ \\
\hline WADOE & AHL144 & $\begin{array}{c}\text { GW Chehalis R. above WWTP } \\
\text { outfall }\end{array}$ & $\begin{array}{c}\text { 5/10/04, 6/7/04, 7/6/04, 8/4/04, } \\
8 / 31 / 04, \& 10 / 4 / 04\end{array}$ \\
\hline WADOE & AHL143 & GW Chehalis R. & $5 / 10 / 04,6 / 7 / 04,7 / 6 / 04, \& 10 / 4 / 04$ \\
\hline WADOE & AHL142 & GW Chehalis R. at Galvin Rd. & $5 / 11 / 04$ \\
\hline
\end{tabular}




\begin{tabular}{|c|c|c|c|}
\hline Organization & Station ID & Description & Dates with data \\
\hline WADOE & ABK199 & GW Chehalis R. at Mellen St. & $\begin{array}{r}5 / 11 / 04,6 / 15 / 04,7 / 8 / 04,8 / 3 / 04, \\
9 / 2 / 04, \& 10 / 6 / 04\end{array}$ \\
\hline WADOE & ABK198 & GW Chehalis R. nr. Airport & $5 / 12 / 04 \& 6 / 9 / 04$ \\
\hline WADOE & AHL146 & $\begin{array}{c}\text { GW Chehalis R. nr. Airport } \\
\text { Rd. }\end{array}$ & $\begin{array}{c}6 / 9 / 04,7 / 8 / 04,8 / 3 / 04,9 / 2 / 04, \\
10 / 6 / 04, \& 10 / 6 / 04\end{array}$ \\
\hline WADOE & ABK197 & $\begin{array}{c}\text { GW Chehalis R. at State Rte. } \\
6\end{array}$ & $\begin{array}{c}5 / 12 / 04,6 / 9 / 04,7 / 7 / 04,8 / 3 / 04, \\
9 / 1 / 04, \& 10 / 5 / 04\end{array}$ \\
\hline
\end{tabular}

In order to estimate the state variables of the CE-QUAL-W2 model, many conversions were made from measured to field data. When field data were not available, reasonable estimates were made for a given constituent. The assumptions and estimations employed for the input model constituents are outlined below, including the equations used for making calculations.

- $\quad$ TDS, FC, and BOD were assumed zero for tributaries with no data available.

- To convert 5-day $\mathrm{BOD}\left(\mathrm{BOD}_{5}\right)$ field data to ultimate $\mathrm{BOD}(\mathrm{BOD} \cup)$, the following typical relationship was used (Cole and Wells, 2016) assuming a BOD dcay rate of 0.1 day $^{-1}$ :

$$
B O D_{u}=2.54 * B O D_{5}
$$

BOD $u$ was assumed to be $50 \%$ dissolved (BOD $u$ dissolved) and $50 \%$ particulate (BODu particulate).

- Organic matter (OM) was calculated by (Cole and Wells, 2016):

$$
O M=\frac{B O D_{u}}{1.4}
$$

- PO4 was assumed to equal $1 \%$ of the OM concentration when no data were available. 
- When NO3 data were not available for the wastewater treatment plants, values between 0.5 and $1 \mathrm{mg} / \mathrm{L}$ were used.

- Algae concentrations (dry weight biomass concentration) were calculated by:

$$
\text { Algae }=0.1 * \text { Chlorophyll a }
$$

- Algae concentrations were assumed to be $1 \%$ phosphorus (AlgaeP) and $8 \%$ nitrogen (AlgaeN).

- Chlorophyll a concentrations for groundwater were assumed to be zero, and so algae, algaeP, and algaeN concentrations were also assumed to be zero.

- ISS were calculated by (Cole and Wells, 2016):

$$
I S S=T S S-\frac{B O D_{U \text { particulate }}}{1.4}-\text { algae }
$$

- TSS was assumed zero for groundwater flows, and hence ISS was also assumed zero.

- Dissolved organic matter (DOM) was calculated by (Cole and Wells, 2016):

$$
D O M=\frac{B O D_{U \text { dissolved }}}{1.4}
$$

- Particulate organic matter (POM) was calculated by (Cole and Wells, 2016):

$$
P O M=\frac{B O D_{U \text { particulate }}}{1.4}
$$

- DOM was assumed to be $50 \%$ labile (LDOM) and 50\% refractory (RDOM), and POM was also assumed to be $50 \%$ labile (LPOM) and refractory (RPOM). However, for groundwater inflows, POM was zero, implying all OM was dissolved.

- Organic matter as phosphorus (OMP) was calculated by: 


$$
O M P=T P-P 04-\text { AlgaeP }
$$

Where TP is total phosphorus.

- OMP was assumed to be equally portioned as labile dissolved LDOM-P, RDOM-P, LPOM-P, RPOM-P. LDOM, RDOM, LPOM, and RPOM concentrations were assumed to be $8 \%$ nitrogen.

- Total nitrogen (TN) was calculated by:

$$
T N=T K N+N O 3
$$

Where TKN is total Kjeldahl nitrogen, and equals the sum of ammonia and organic matter as nitrogen.

- Organic matter as nitrogen (OMN) was calculated by:

$$
O M N=T N-N H 3-N O 3-A l g a e N
$$

- OMN was assumed to be equally portioned as labile dissolved LDOM-N, RDOM-N, LPOM-N, RPOM-N. LDOM, RDOM, LPOM, and RPOM concentrations were assumed to be $1 \%$ phosphorus.

- Some of the fact sheets for the wastewater treatment plants included alkalinity for the Chehalis River near to the plats. Alkalinity for tributaries were assumed to be an average of these values when no data were available.

- No zooplankton data were available. Zooplankton concentrations were estimated as $0.01 \mathrm{mg} / \mathrm{L}$ for tributaries. Zooplankton was assumed to have zero concentration for groundwater inflows. 
Techniques for computing $\mathrm{pH}$, alkalinity, or total inorganic carbon are outlined below (Wells, 2016):

Alkalinity $[A L K]$ is usually given in units of $\mathrm{mg} / \mathrm{L}$ as $\mathrm{CaCO}_{3}$. By dividing by 50,000 the units are converted to moles/L. The model uses units of $\mathrm{mg} / \mathrm{L}$ as $\mathrm{C}$ for total inorganic $\mathrm{C}$ $\left[\mathrm{C}_{\mathrm{T}}\right.$ ] and can be converted to moles/L by dividing by $12,000 . \mathrm{C}_{\mathrm{T}}$ (in moles/L) is defined as:

$$
C_{T}=\left[\mathrm{H}_{2} \mathrm{CO}_{3}\right]+\left[\mathrm{HCO}_{3}^{-}\right]+\left[\mathrm{CO}_{3}^{-2}\right]
$$

Following equilibrium chemistry (see Stumm and Morgan, 1986), the alkalinity is then defined as:

$$
[A L K]=C_{T}\left(\alpha_{1}+2 \alpha_{2}\right)+\frac{K_{w}}{\left[H^{+}\right]}-\left[H^{+}\right]
$$

Where

$$
\begin{aligned}
& \alpha_{1}=\left(\frac{\left[H^{+}\right]}{K_{1}}+1+\frac{K_{2}}{\left[H^{+}\right]}\right)^{-1} \\
& \alpha_{2}=\left(\frac{\left[H^{+}\right]^{2}}{K_{1} K_{2}}+1+\frac{\left[H^{+}\right]}{K_{2}}\right)^{-1} \\
& \mathrm{~K}_{\mathrm{w}}=10^{-14} \mathrm{~mol}^{2} / \mathrm{L}^{2} \text { at } 25^{\circ} \mathrm{C} \\
& \left.\mathrm{K}_{\mathrm{w}}=10^{[-5242.39} \frac{\mathrm{T}}{}+35.3944-0.00835 \mathrm{~T}+11.8261 \log _{10}(\mathrm{~T})\right] \\
& \mathrm{K}_{1}=10^{-6.419} \mathrm{~mol} / \mathrm{L} \text { at } 15^{\circ} \mathrm{C} \\
& \mathrm{K}_{1}=10^{\left(-3404.71 / \mathrm{T}+14.8435-0.032786^{*} \mathrm{~T}\right)} \\
& \mathrm{K}_{2}=10^{-10.430} \mathrm{~mol} / \mathrm{L} \text { at } 15^{\circ} \mathrm{C}
\end{aligned}
$$




$$
\begin{aligned}
& \mathrm{K}_{2}=10^{(-2902.39 / \mathrm{T}+6.498-0.02379 * \mathrm{~T})} \\
& \mathrm{T}=\text { temperature }\left({ }^{\circ} \mathrm{C}\right) \\
& {\left[\mathrm{H}^{+}\right]=\text {hydrogen ion concentration }} \\
& \mathrm{pH}=-\log \left[\mathrm{H}^{+}\right]
\end{aligned}
$$

These equations assume the activity corrections for the species concentrations are unity, implying that the inflowing water has a low TDS. By knowing any 2 of the 3 components $-\mathrm{pH}$, alkalinity, or total inorganic carbon - the above equations allow for the computation of the other.

For times when data for a constituent were not available for a tributary or groundwater inflow, averages or medians of the other values were used as an estimate. Tributaries that did not have any water quality data available used an input water quality constituent file from the nearest tributary with data available. For wastewater treatment plants with no data for a constituent, reasonable or typical values were used as an estimate. For reaches of the river with no groundwater data available, data from the closest reach were used.

Input constituent data for ISS, PO4, NH3, and NO3 are shown in Figure 45. Input constituent data for TIC, alkalinity, algae, and DO are shown in Figure 46. Input constituent data for LDOM, RDOM, LPOM, and RPOM are shown in Figure 47. Input constituent data for LDOM-P, RDOM-P, LPOM-P, and RPOM-P are shown in Figure 48. Input constituent data for LDOM-N, RDOM-N, LPOM-N, and RPOM-N are shown in Figure 49. Figure 50 shows tributary field data for $\mathrm{pH}, \mathrm{BOD5}$, and TSS while Figure 51 shows 
tributary field data for chlorophyll a, TKN, and TP that were used to calculate constituents with the equations outlined above.

Figure 52 shows model input data for the wastewater treatment plants for FC, ISS, PO4, and NH3, while Figure 53 shows NO3, DO, TIC, and alkalinity. Figure 54 shows the wastewater treatment plant BOD species, including dissolved, particulate, phosphorus, and nitrogen.

Figure 55 shows input constituent data for TDS, PO4, NH3, NO3, BOD and DO for the groundwater inflows. Figure 56 shows data for TIC, alkalinity, and the DOM and POM species (labile, refractory, phosphorus, and nitrogen) for the groundwater inflows. Figure 57 shows field data for $\mathrm{pH}, \mathrm{BOD5}$, and TP used to calculate groundwater constituent concentrations with the equations described above. 

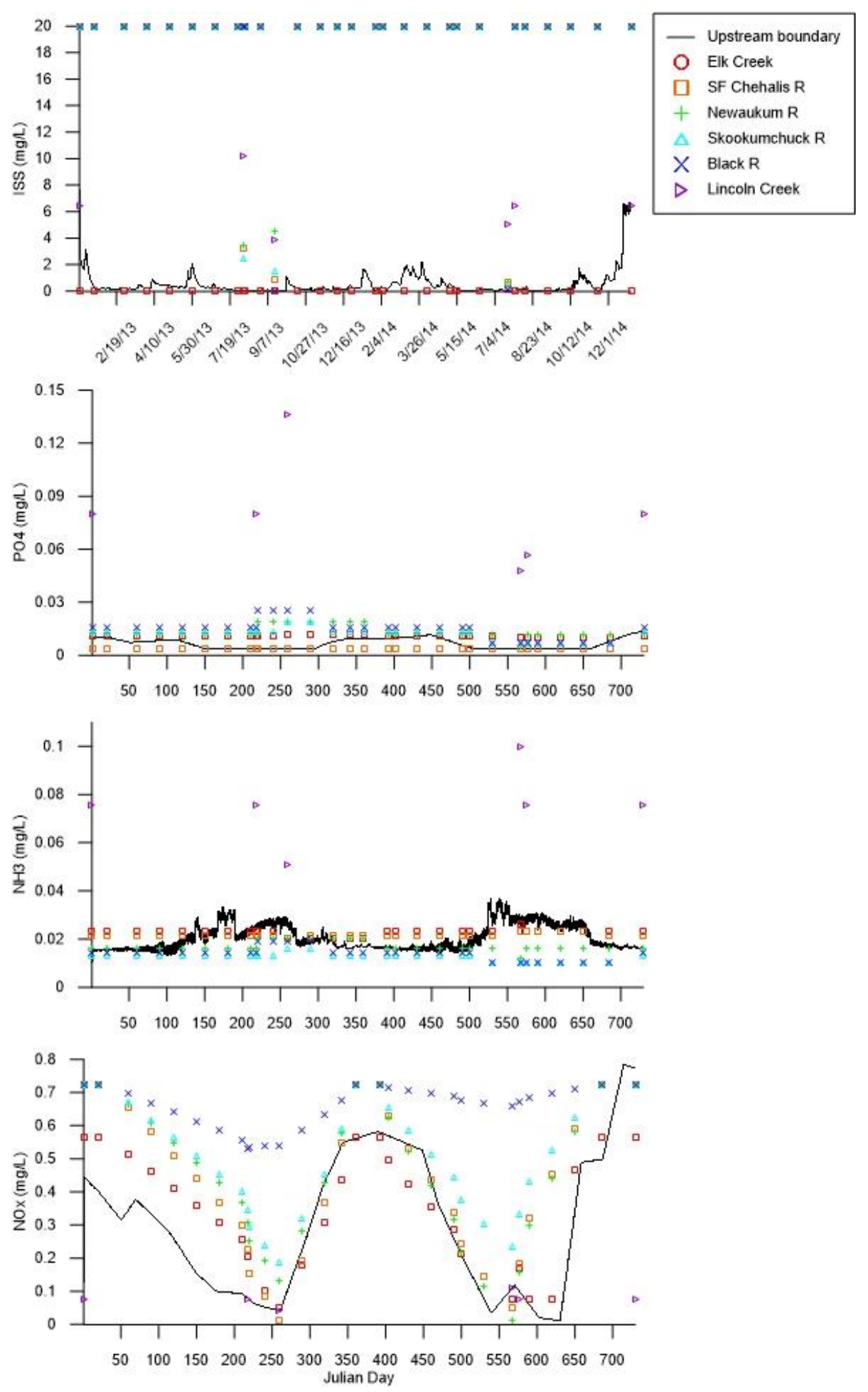

Figure 45. Input concentrations for ISS, $\mathrm{PO} 4, \mathrm{NH} 3$, and $\mathrm{NO} 3$ for tributaries with data available, including the upstream boundary, Elk Creek, South Fork Chehalis River, Newaukum River, Skookumchuck River, Black River, and Lincoln Creek 

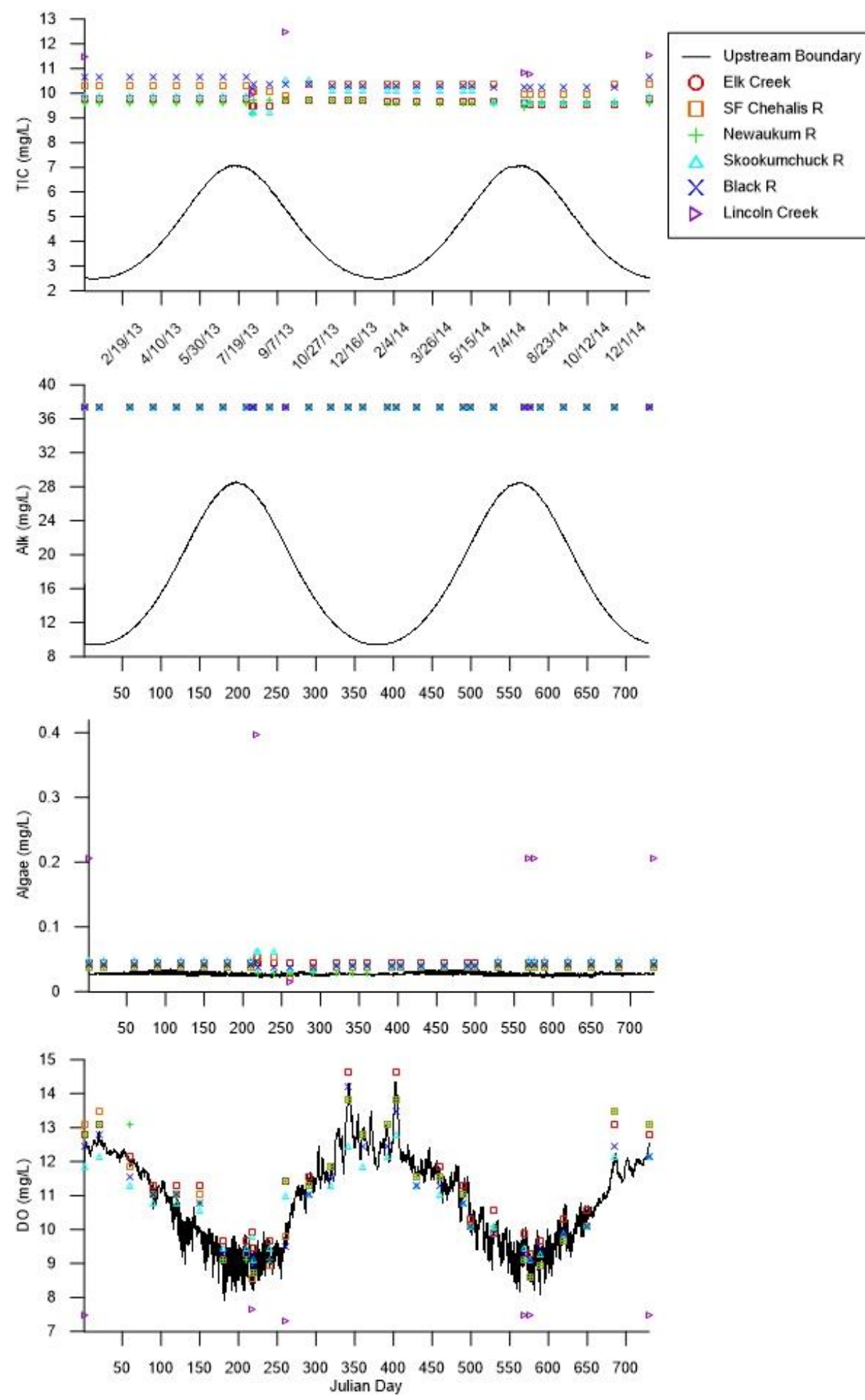

Figure 46. Input concentrations for TIC, alkalinity, algae, and DO for tributaries with data available, including the upstream boundary, Elk Creek, South Fork Chehalis River, Newaukum River, Skookumchuck River, Black River, and Lincoln Creek 

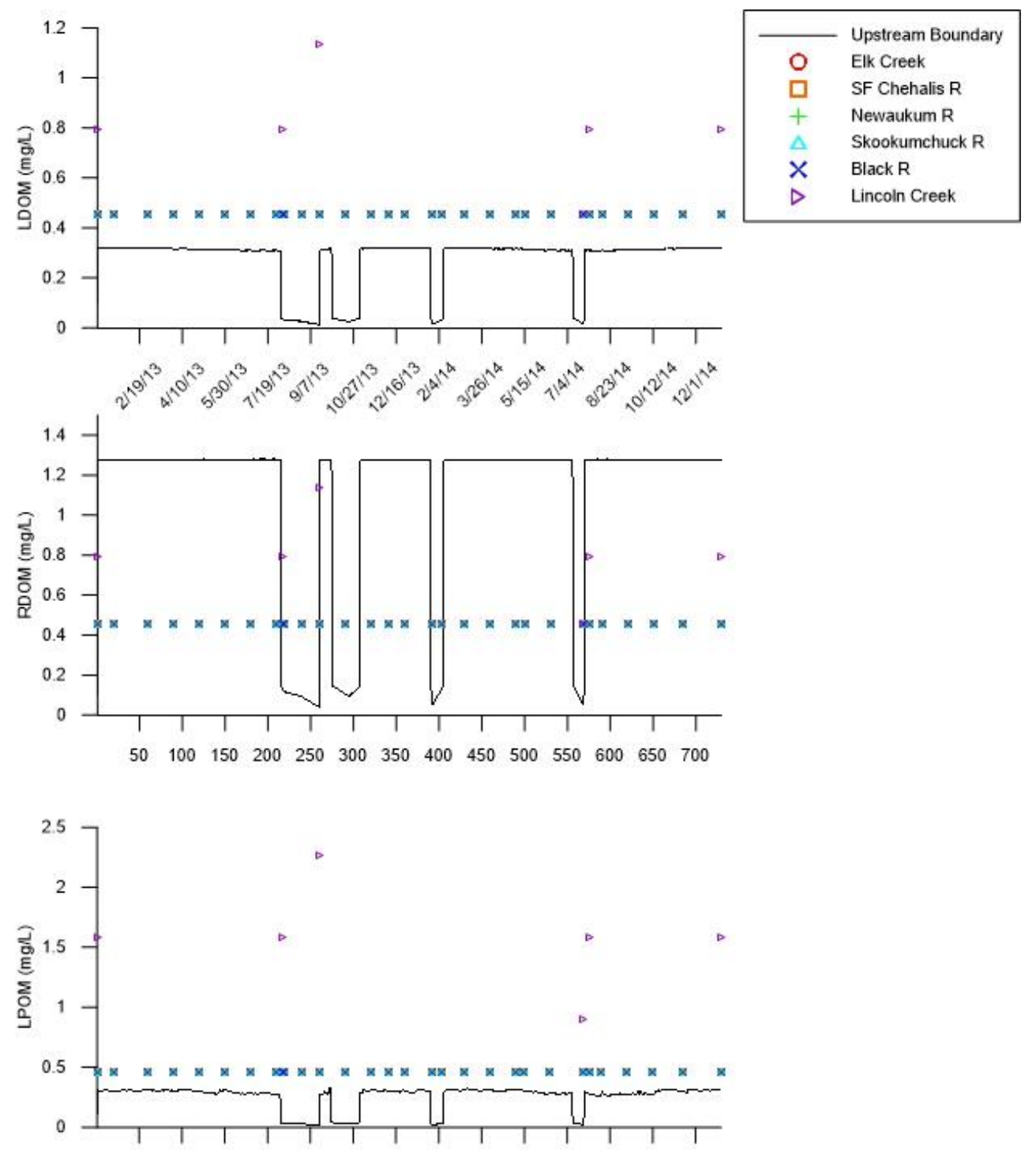

$\begin{array}{llllllllllllll}50 & 100 & 150 & 200 & 250 & 300 & 350 & 400 & 450 & 500 & 550 & 600 & 650 & 700\end{array}$

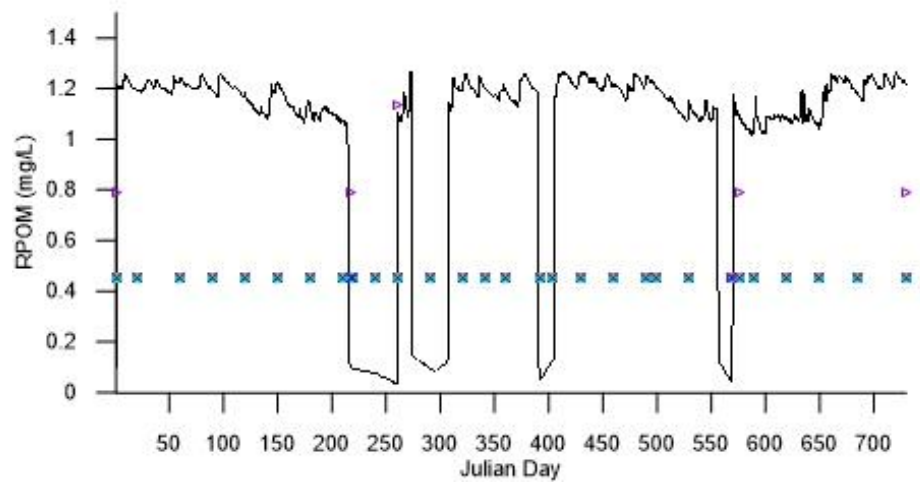

Figure 47. Input concentrations for LDOM, RDOM, LPOM, and RPOM for tributaries with data available, including the upstream boundary, Elk Creek, South Fork Chehalis River, Newaukum River, Skookumchuck River, Black River, and Lincoln Creek 

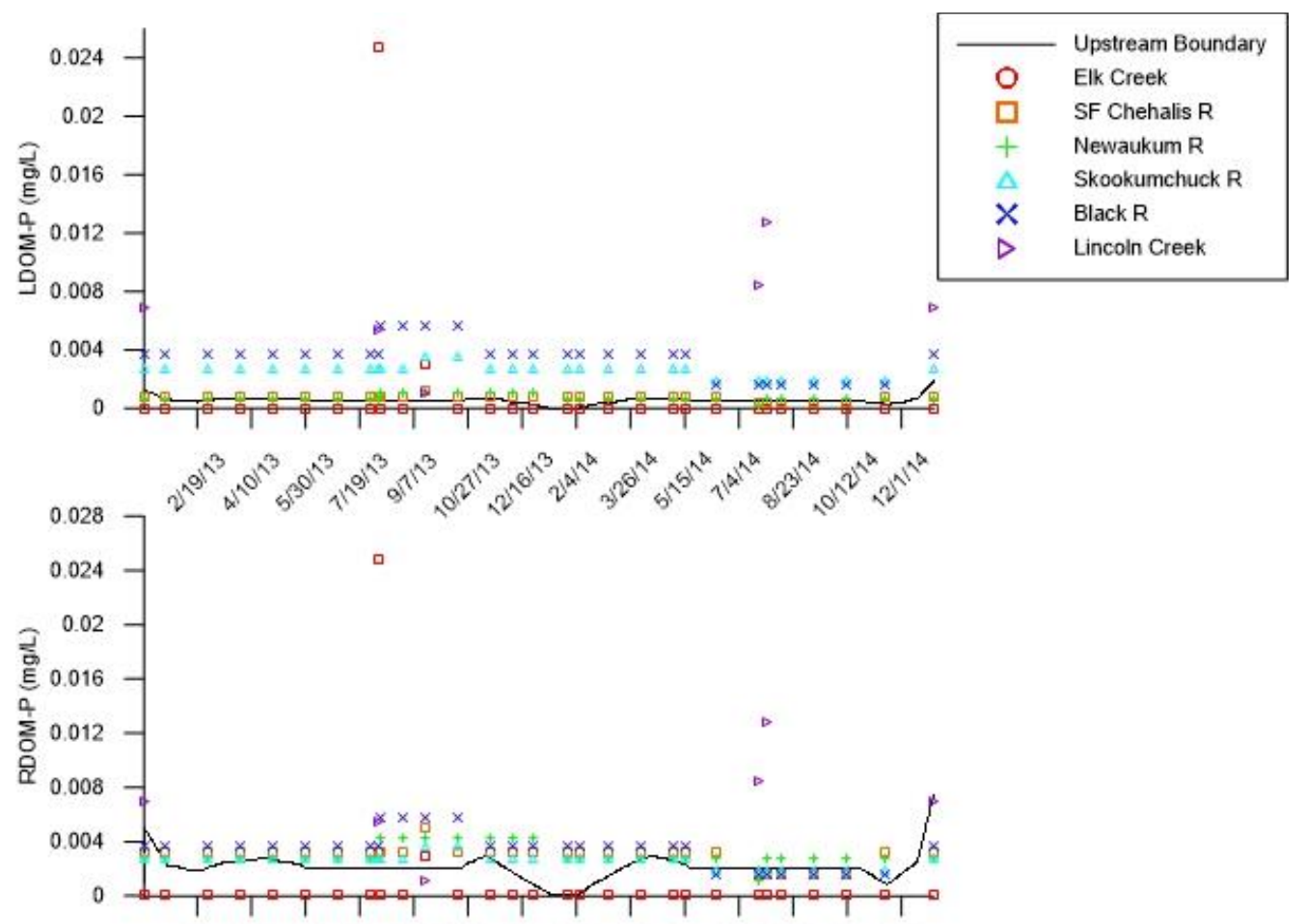

$\begin{array}{llllllllllllll}50 & 100 & 150 & 200 & 250 & 300 & 350 & 400 & 450 & 500 & 550 & 600 & 650 & 700\end{array}$
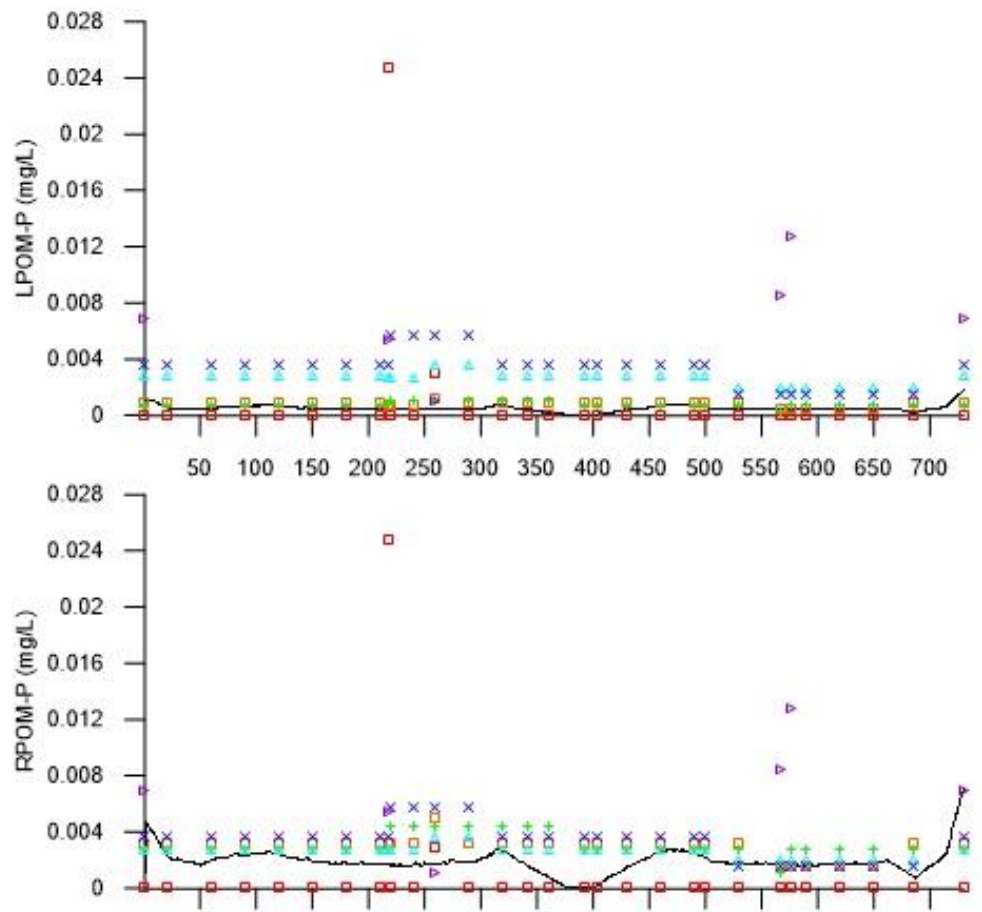

$\begin{array}{llllllllllllll}50 & 100 & 150 & 200 & 250 & 300 & 350 & 400 & 450 & 500 & 550 & 600 & 650 & 700\end{array}$ Julian Day

Figure 48. Input concentrations for LDOM-P, RDOM-P. LPOM-P, and RPOM-P for tributaries with data available, including the upstream boundary, Elk Creek, South Fork Chehalis River, Newaukum River, Skookumchuck River, Black River, and Lincoln Creek 

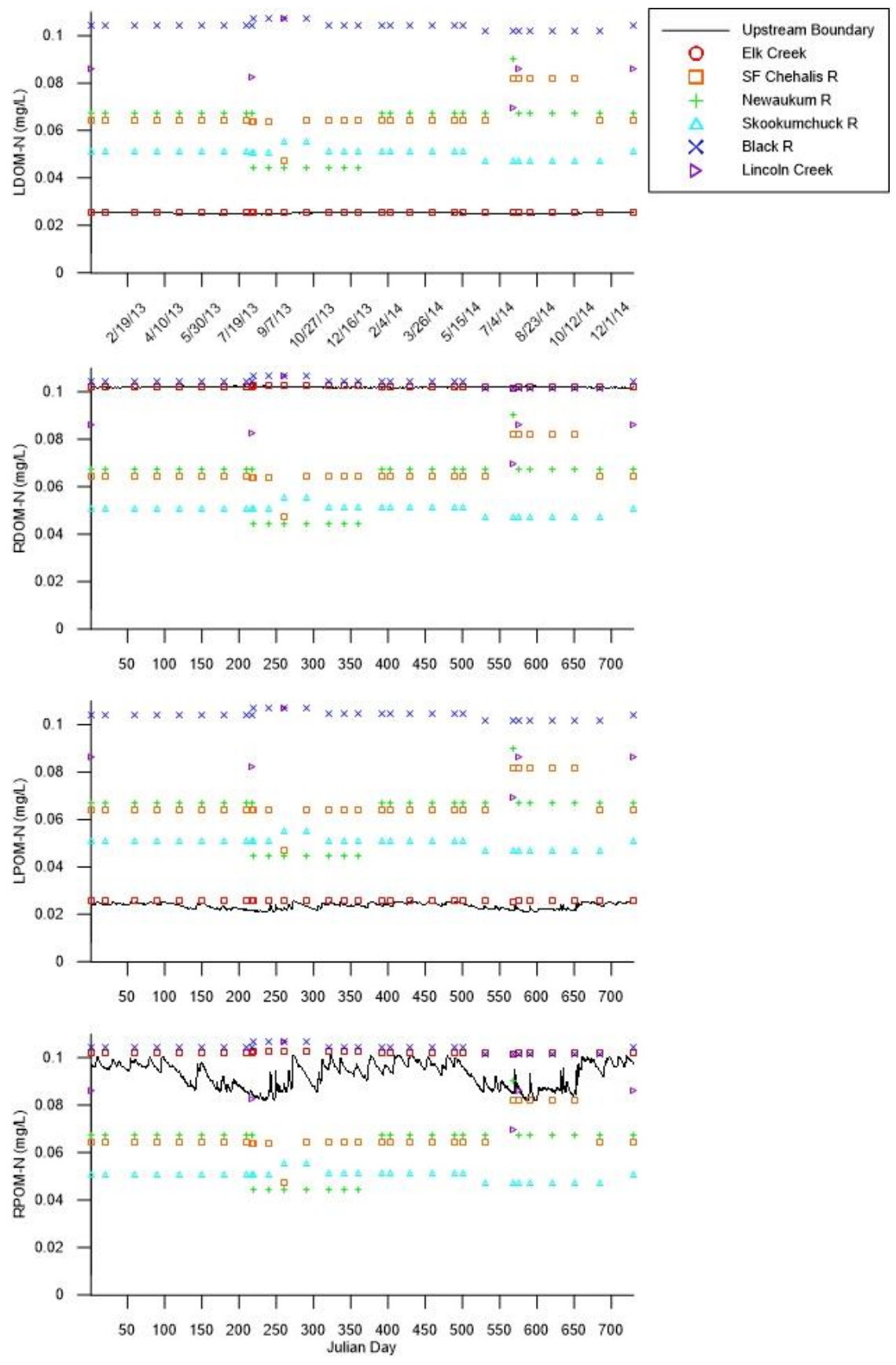

Figure 49. Input concentrations for LDOM-N, RDOM-N. LPOM-N, and RPOM-N for tributaries with data available, including the upstream boundary, Elk Creek, South Fork Chehalis River, Newaukum River, Skookumchuck River, Black River, and Lincoln Creek 

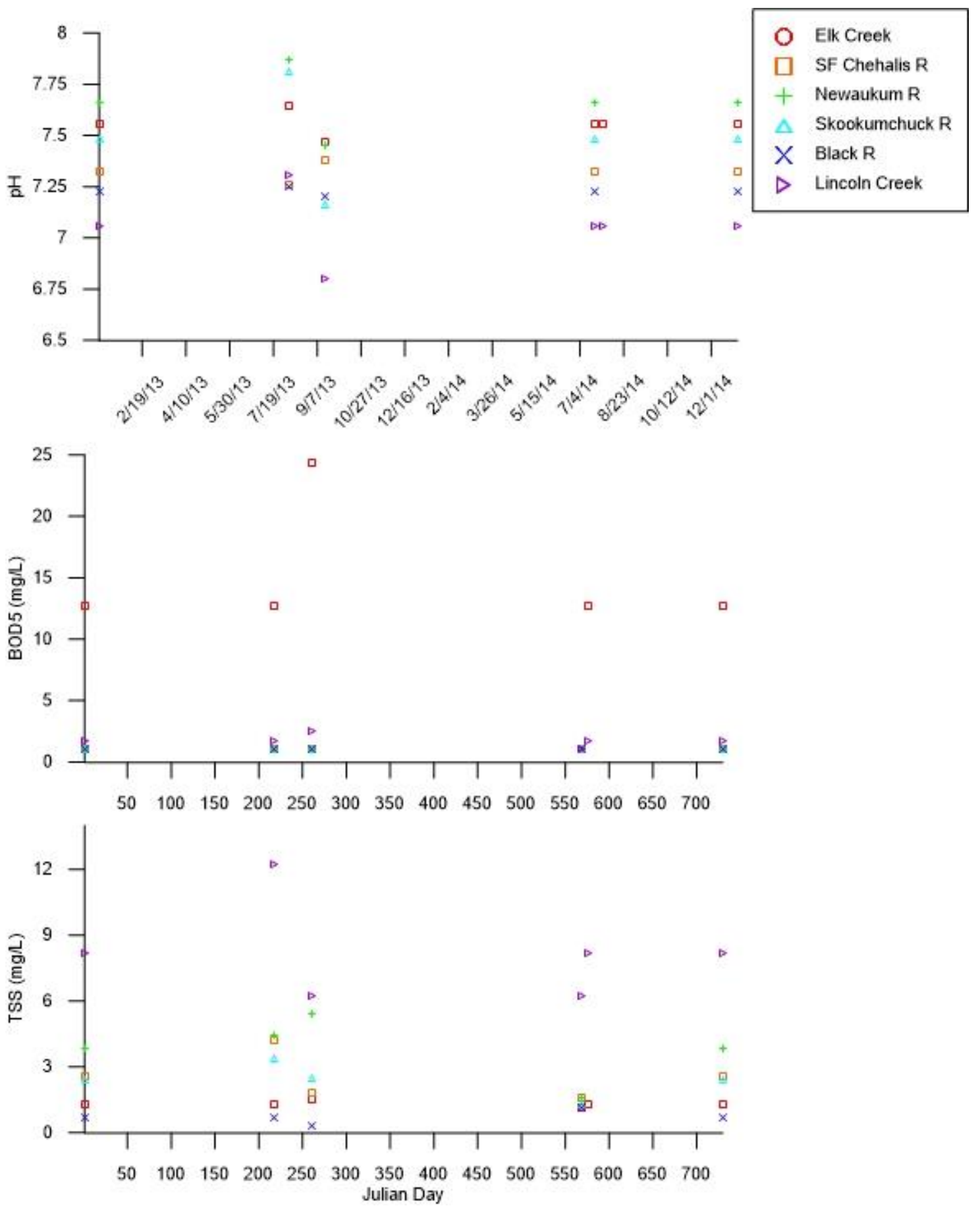

Figure 50. Field data concentrations for $\mathrm{pH}, \mathrm{BOD5}$, and TSS used to calculate input water quality concentrations for Elk Creek, South Fork Chehalis River, Newaukum River, Skookumchuck River, Black River, and Lincoln Creek 

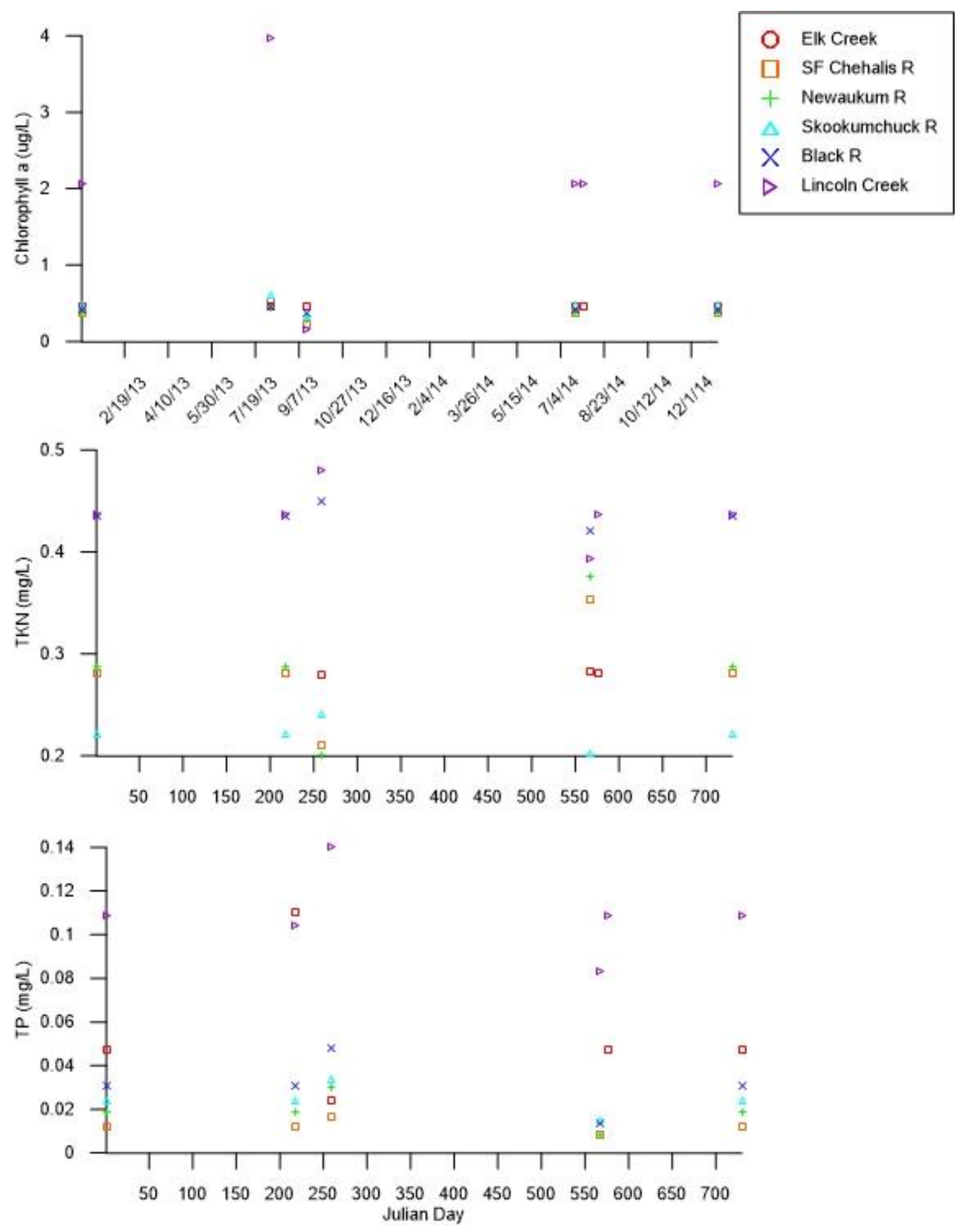

Figure 51. Field data concentrations for chlorophyll a, TKN, and TP used to calculate input water quality concentrations for Elk Creek, South Fork Chehalis River, Newaukum River, Skookumchuck River, Black River, and Lincoln Creek 

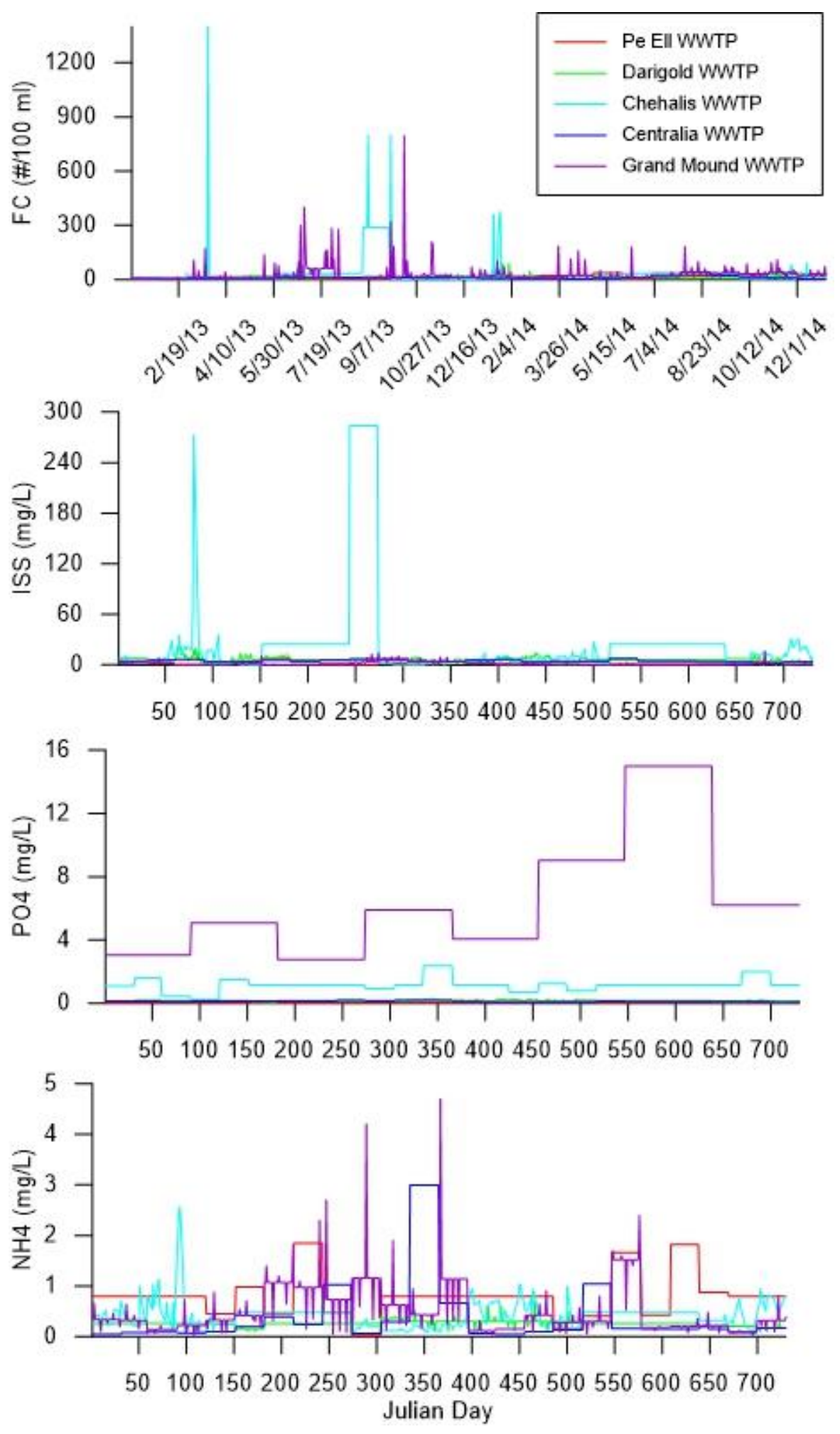

Figure 52. Model input concentrations for FC, ISS, PO4, and NH3 for the Pe Ell, Darigold, Centralia, Chehalis, and Grand Mound wastewater treatment plants 

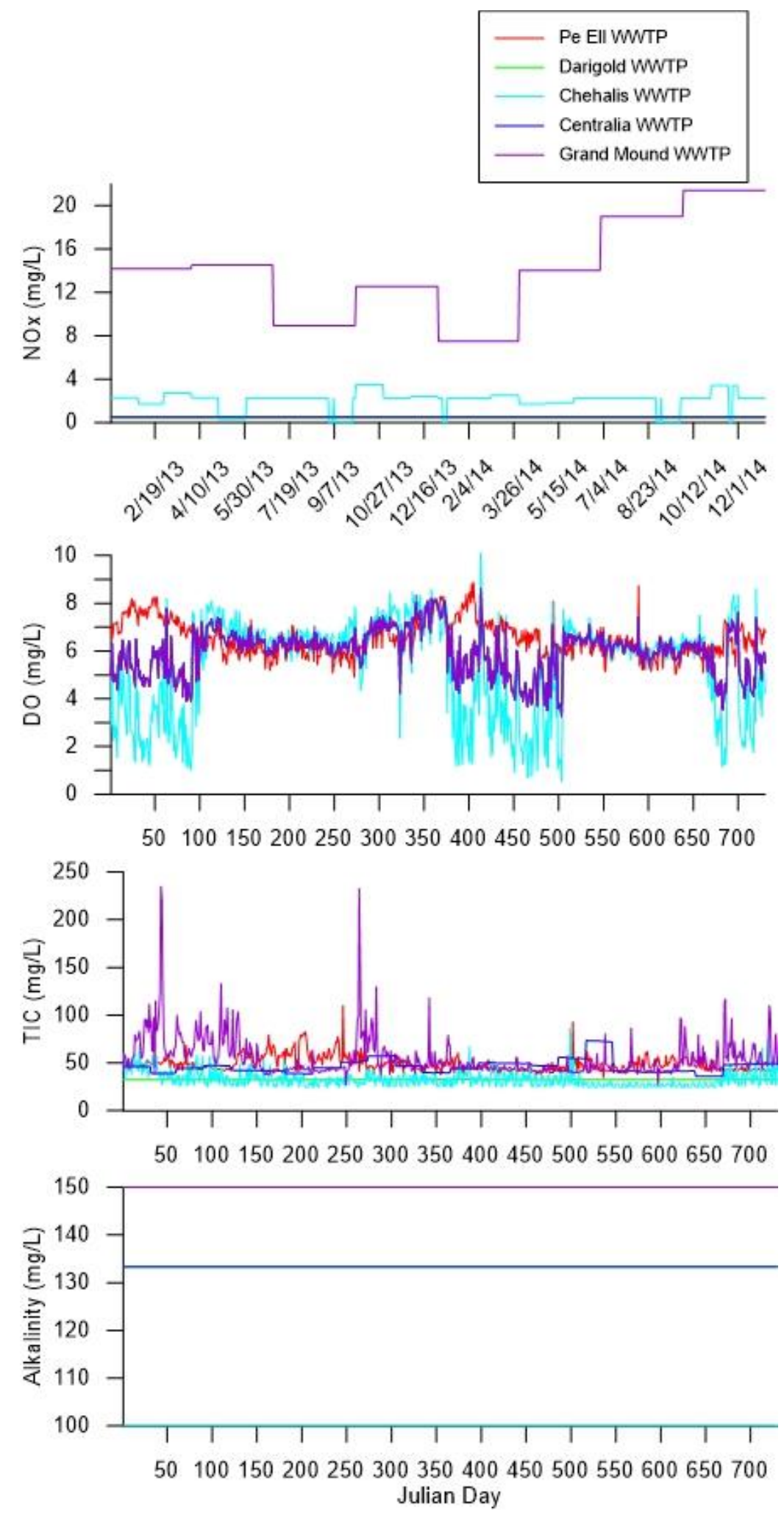

Figure 53. Model input concentrations for NO3, DO, TIC, and alkalinity for the Pe Ell, Darigold, Centralia, Chehalis, and Grand Mound wastewater treatment plants 

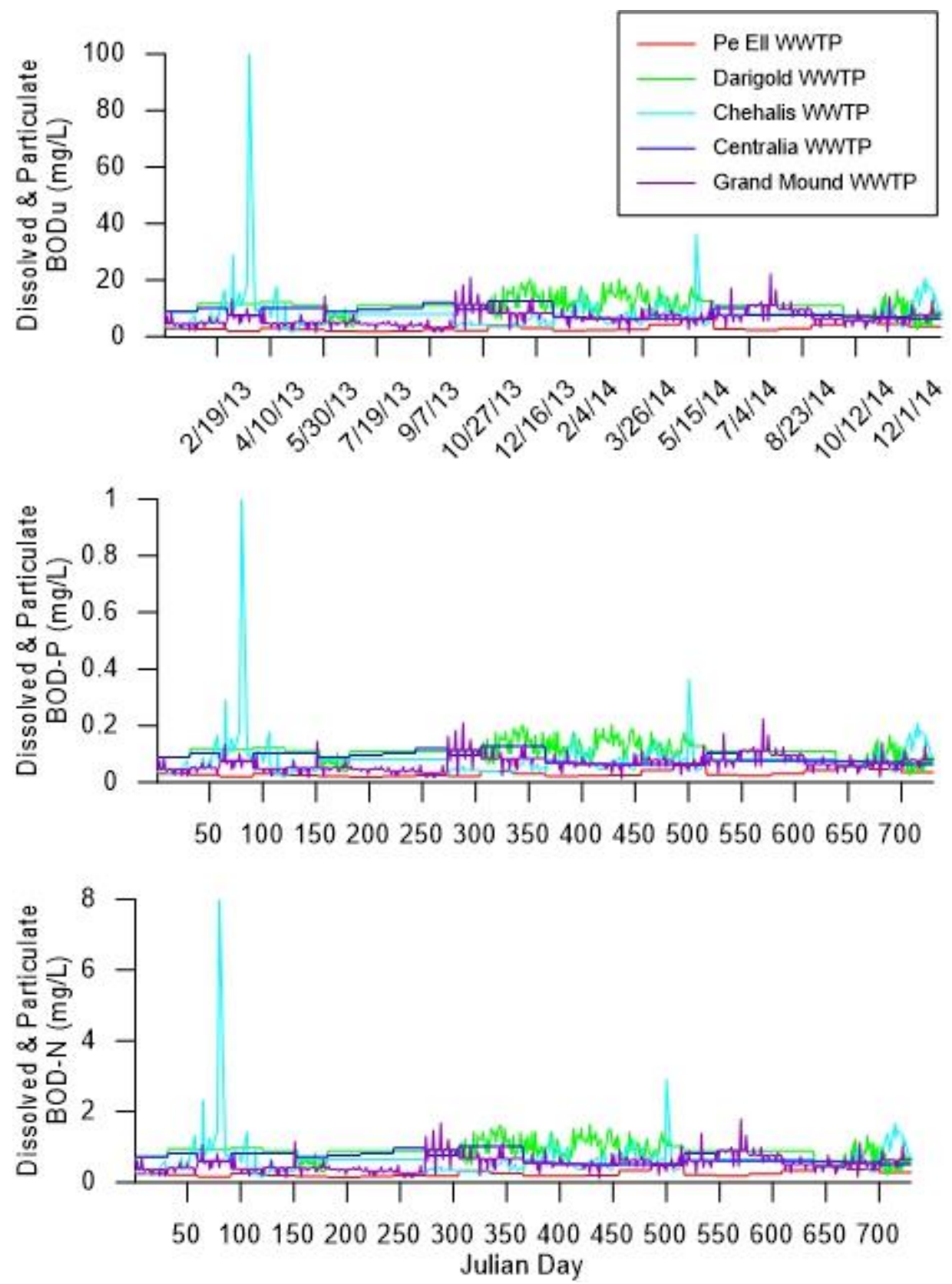

Figure 54. Model input concentrations for dissolved, particulate, phosphorus, and nitrogen BOD for the Pe Ell, Darigold, Centralia, Chehalis, and Grand Mound wastewater treatment plants 

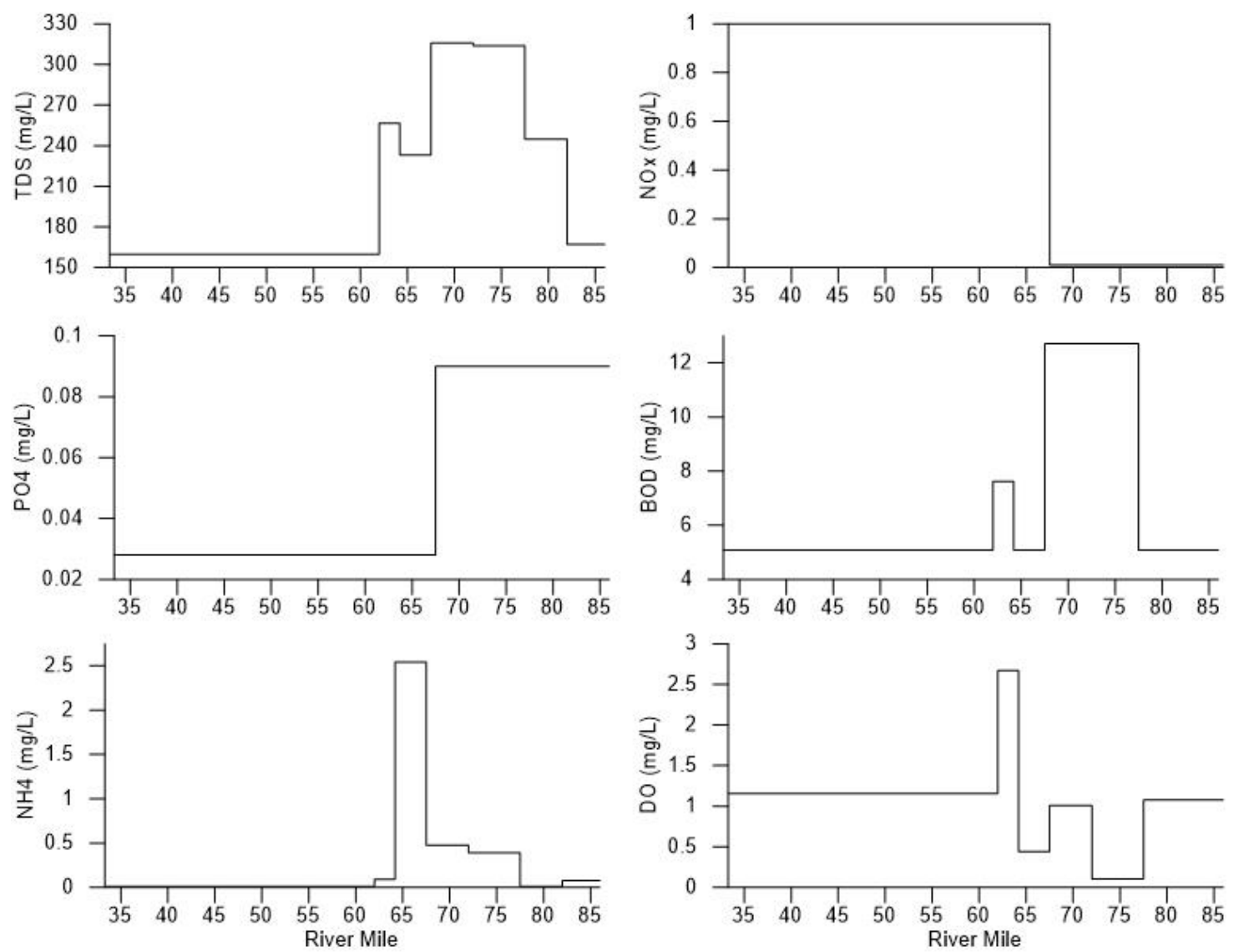

Figure 55. Model input concentrations for groundwater reaches with data for TDS, PO4, NH3, NO3, BOD, and DO 

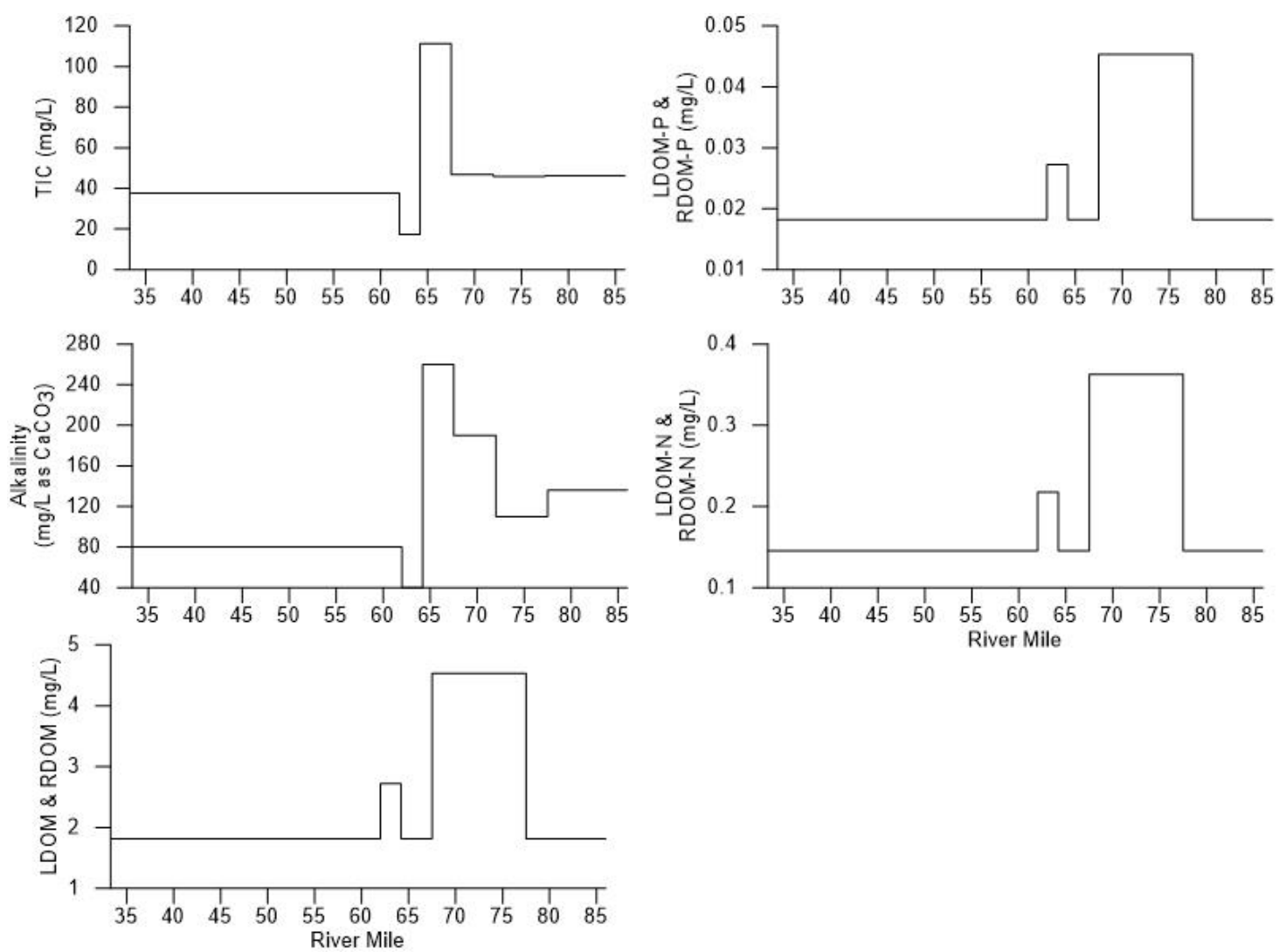

Figure 56. Model input concentrations for groundwater reaches with data for TIC, alkalinity, and the DOM and POM species (labile, refractory, phosphorus, and nitrogen) 

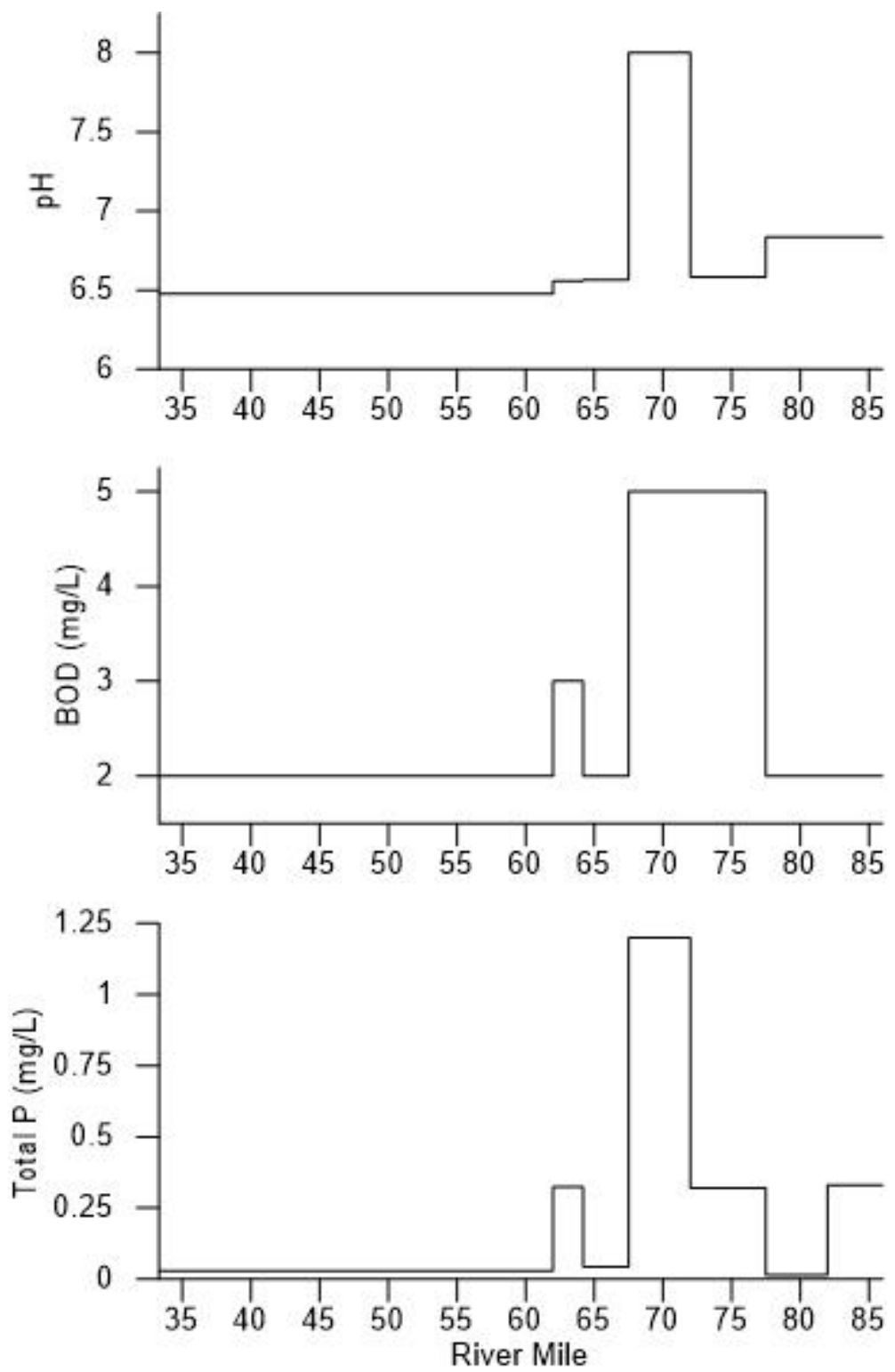

Figure 57. Field groundwater data for $\mathrm{pH}, \mathrm{BOD} 5$, and TP used to calculate input water quality concentrations 


\subsection{Shading}

CE-QUAL-W2 requires shading information for each model segment, including left and right bank vegetation elevation, distance to left and right bank vegetation, left and right bank shade reduction factors for leaf on and leaf off conditions, and Julian days when the shade reduction factors apply. The shade reduction factors specified the opacity of the vegetation.

A shading study conducted by Stillwater Sciences for Anchor QEA provided all shading data along the Chehalis River (Merrill, 2014). The data collected in this study were interpolated to the locations of the model segments. Increased shading had a cooling effect on river temperature, while the opposite was true for decreased shading. The upstream, steep gradient portion was especially shaded. Figure 58 and Figure 59 show the elevations of vegetation on the left and right banks of the channel along the thalweg of the Chehalis River, respectively. 


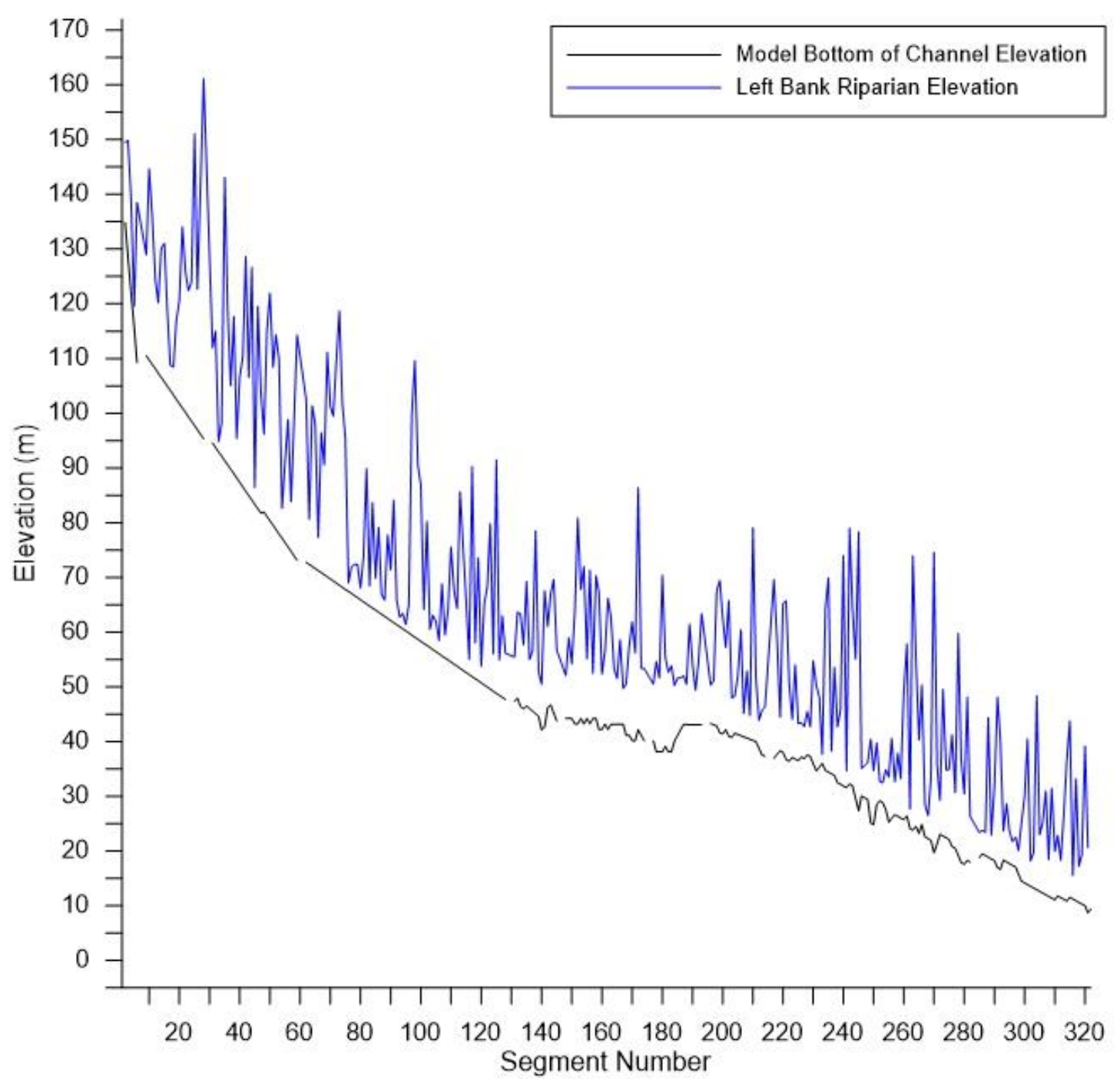

Figure 58. Left bank vegetation elevation for each segment input to the model in the shade file 


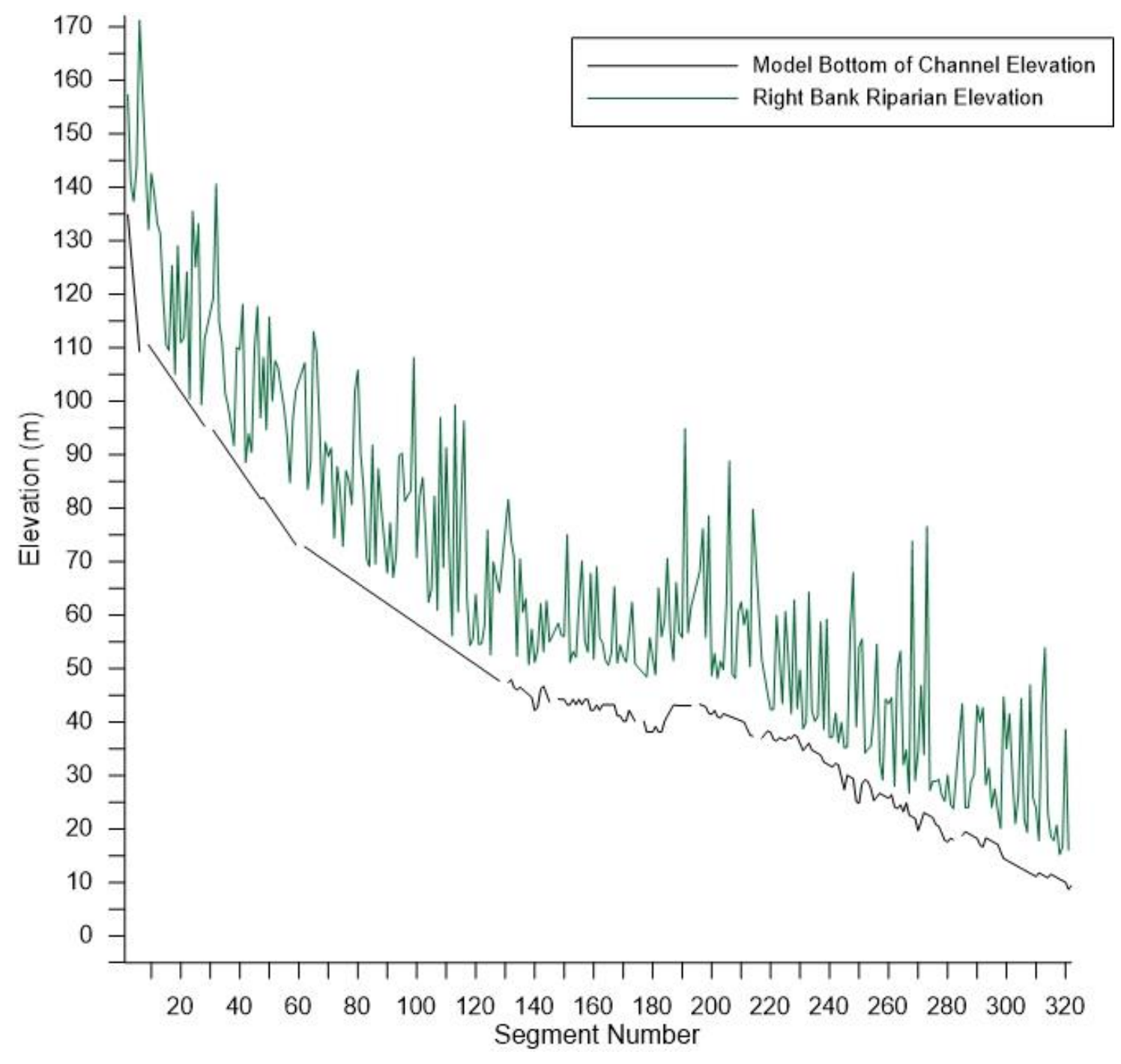

Figure 59. Right bank vegetation elevation for each segment input to the model in the shade file 


\section{Model Calibration: Flow}

The model calibration of flow rate began with upstream portions of the model and moved downstream. By comparing model flow predictions to field flow data along the mainstem of the Chehalis River, locations of excesses and deficiencies of flow were determined. Flow and water level data from the mainstem Chehalis River collected by USGS (2016a, 2016b, 2016c, 2016d, 2016e, 2016h, 2016i) were used for model-data comparisons during the model simulation years 2013 and 2014. Table 11 lists these flow gaging stations. Figure 60 gives a longitudinal view of the locations of the flow and water surface elevation calibration gaging stations along the Chehalis River.

Table 11. Flow and water surface elevation stations on the mainstem Chehalis River used to compare to model predictions

\begin{tabular}{|c|c|c|c|c|}
\hline Organization & Station ID & Description & $\begin{array}{c}\text { Data Type } \\
\text { Provided }\end{array}$ & $\begin{array}{c}\text { Model } \\
\text { Segment }\end{array}$ \\
\hline USGS & 12020000 & Chehalis River near Doty, WA & $\begin{array}{c}\text { Flow \& } \\
\text { water level }\end{array}$ & 32 \\
\hline USGS & 12021800 & Chehalis River near Adna, WA & Water level & 97 \\
\hline USGS & 12025100 & Chehalis River at Chehalis WWTP & Water level & 150 \\
\hline USGS & 12025500 & Chehalis River at Centralia, WA & Water level & 181 \\
\hline USGS & 12027500 & Chehalis River near Grand & Flow \& & 213 \\
\hline USGS & 12028060 & Chehalis River near Rochester, & Water level & 238 \\
\hline USGS & 12031000 & Chehalis River at Porter, WA & $\begin{array}{c}\text { Flow \& } \\
\text { water level }\end{array}$ & 321 \\
\hline
\end{tabular}




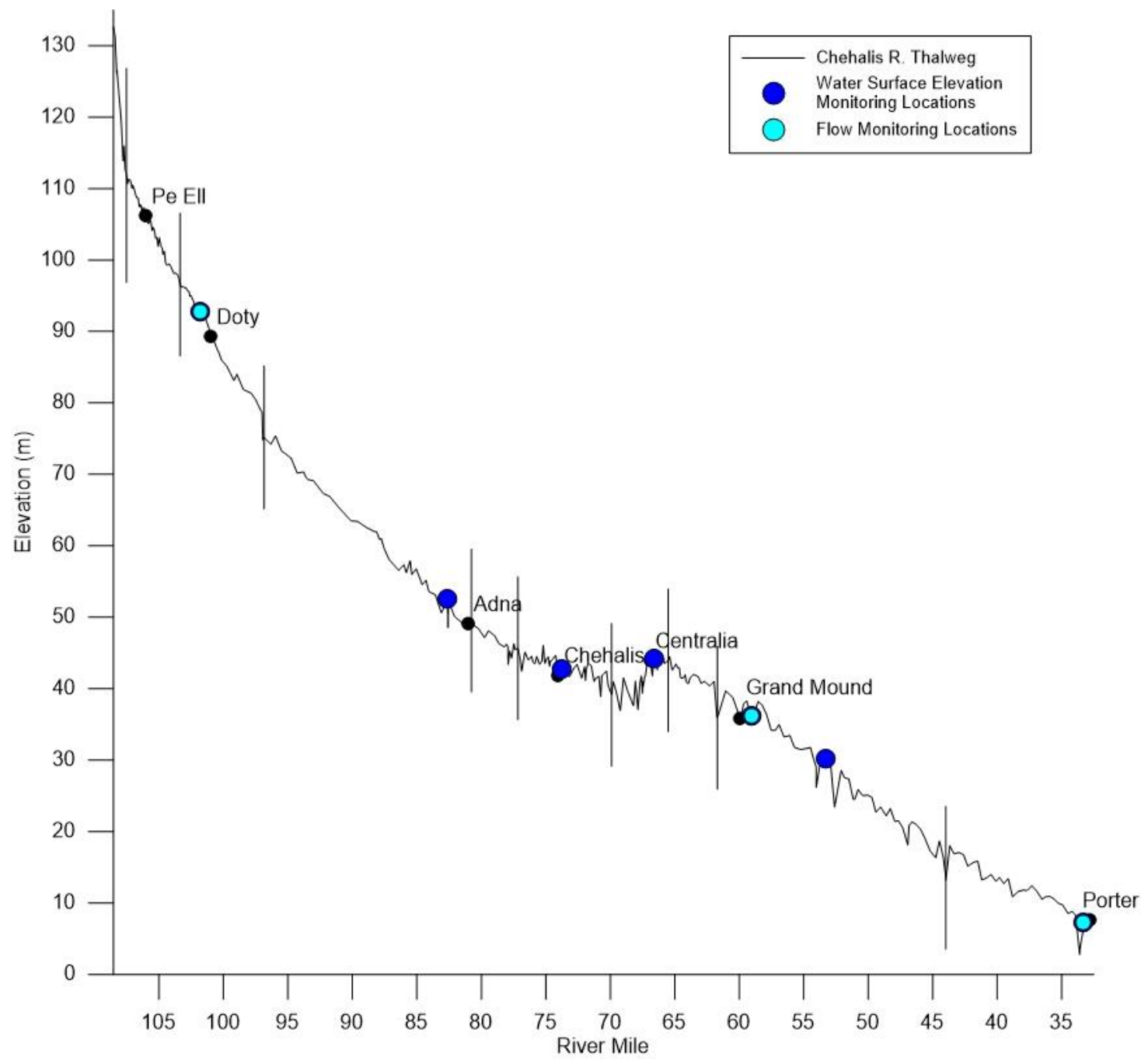

Figure 60. Longitudinal view of the mainstem Chehalis River flow and water surface elevation gaging stations used for flow calibration (vertical lines show model branch breaks)

Figure 61 shows model predictions of flow compared to field data collected at Doty, Grand Mound, and Porter. Figure 62 shows the model water surface elevation predictions compared to field data for gaging stations at Doty, Adna, Chehalis WWTP, and Centralia. Figure 63 shows the water surface elevation comparisons at Grand Mound, Rochester, and Porter. Many water elevation data sets had datums that were not clearly defined or were not tied to a national standard datum. This made it difficult to know whether the 
water surface elevations predicted by both the model and the field data were all referenced to the same datum.
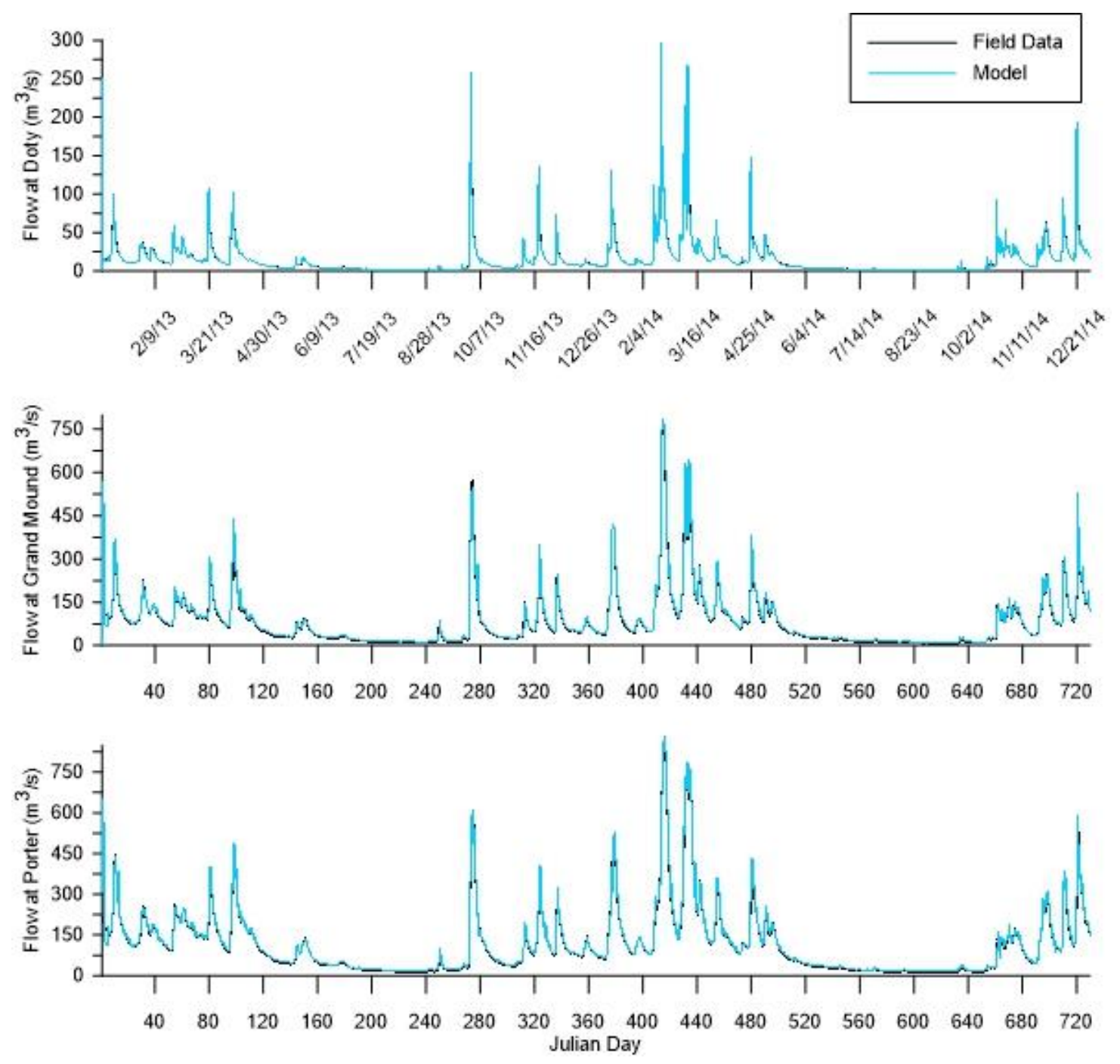

Figure 61. Model flow predictions compared to Chehalis River field data at Doty, Grand Mound, and Porter 

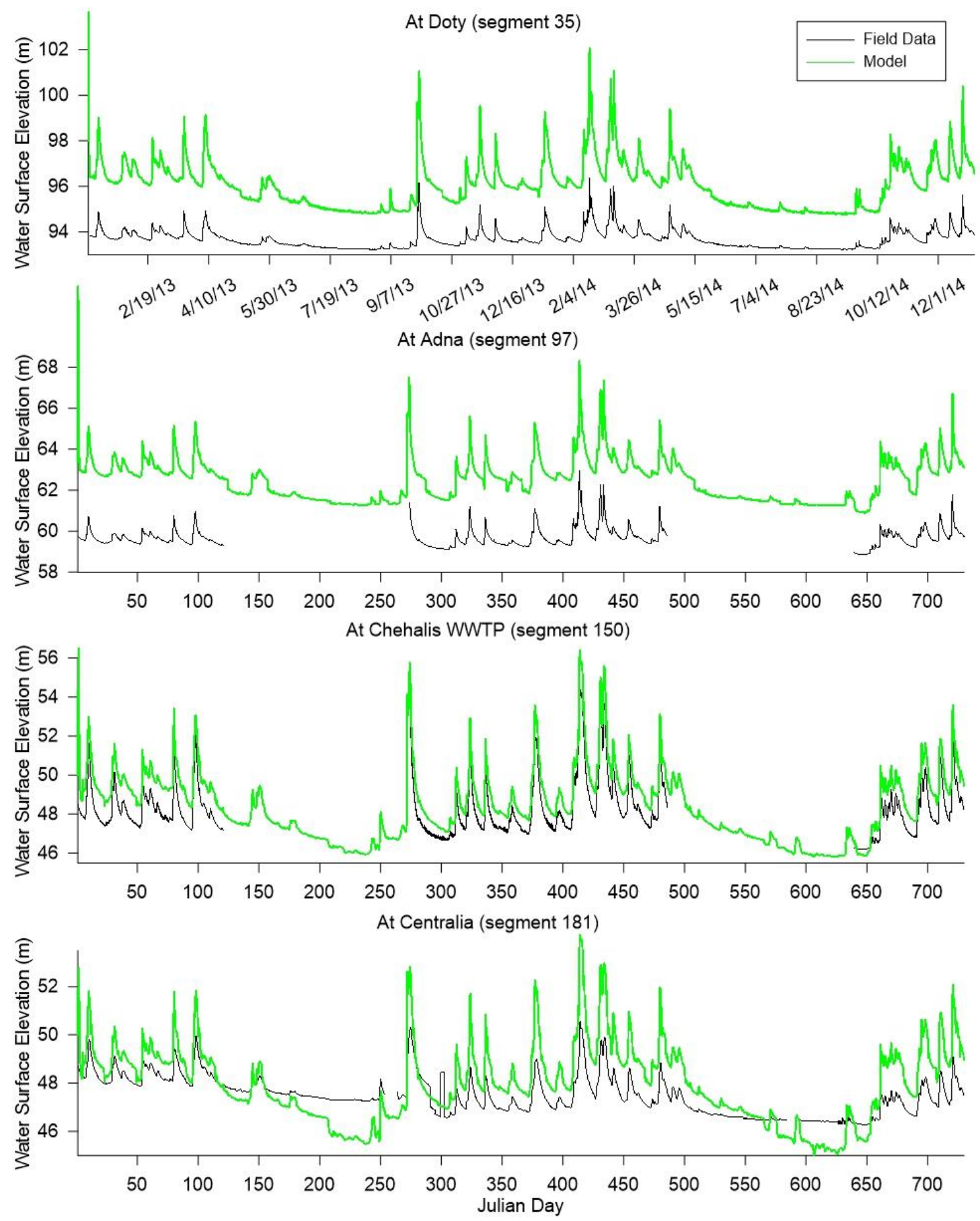

Figure 62. Model water surface elevation predictions compared to Chehalis River field data at Doty, Adna, Chehalis WWTP, and Centralia 

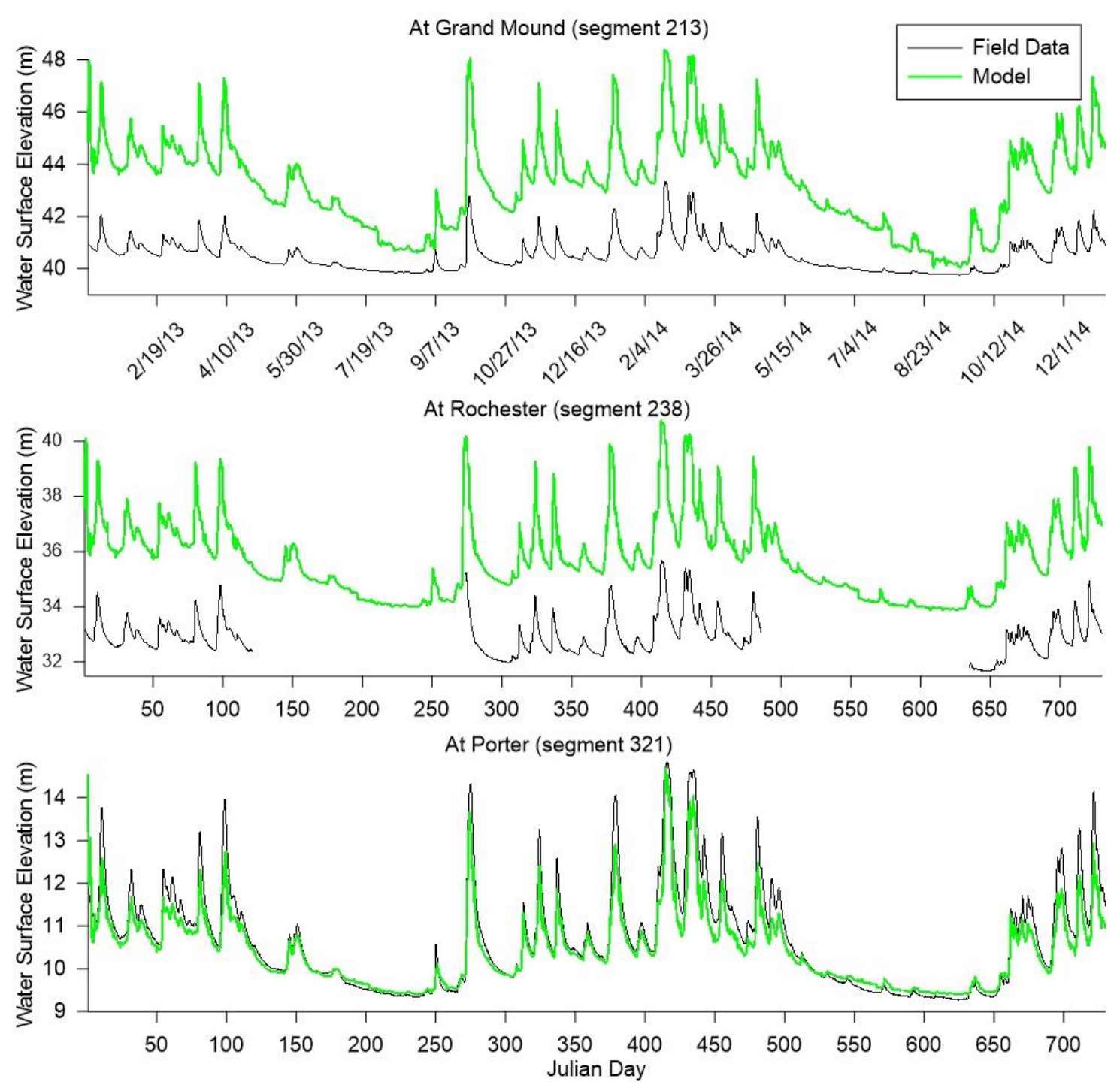

Figure 63. Model water surface elevation predictions compared to Chehalis River field data at Grand Mound, Rochester, and Porter

\subsection{Flow Error Statistics}

The closeness of model predicted flow to field data was evaluated through error statistics, including mean error (ME), absolute mean error (AME), and root mean square error (RMSE). These were calculated using the equations described below.

$$
M E=\frac{1}{N} \Sigma\left(Q_{\text {model }}-Q_{\text {field data }}\right)
$$


Where

$\mathrm{N}$ is the number of model-field data comparisons

$Q_{\text {model }}$ is the model flow output value

Qfield data is the field flow data value

$$
\begin{aligned}
A M E & =\frac{1}{N} \Sigma\left|\left(Q_{\text {model }}-Q_{\text {field data }}\right)\right| \\
R M S E & =\sqrt{\frac{1}{N} \Sigma\left(Q_{\text {model }}-Q_{\text {field data }}\right)^{2}}
\end{aligned}
$$

Error statistics for model flow predictions compared to field data at Doty, Grand Mound, and Porter are shown in Table 12. Error statistics for flow predictions at the same locations during the dry season months of May through October can be seen in Table 13. Error statistics for flow predictions at the same locations during the wet season months of November through April can be seen in Table 14. Error statics for model predicted water level compared to field data at Doty, Adna, Chehalis WWTP, Centralia, Grand Mound, Rochester, and Porter mainstem Chehalis River stations are shown in Table 15.

Table 12. Error statistics for model comparisons to field data for flow at Doty, Grand Mound, and Porter

\begin{tabular}{|c|c|c|c|c|}
\hline Location & $\begin{array}{c}\text { Number of Model- } \\
\text { Data Comparisons }\end{array}$ & $\begin{array}{c}\text { Mean Error } \\
\left(\mathrm{m}^{3} / \mathrm{s}\right)\end{array}$ & $\begin{array}{c}\text { Absolute Mean } \\
\text { Error }\left(\mathrm{m}^{3} / \mathrm{s}\right)\end{array}$ & $\begin{array}{c}\text { Root Mean Square } \\
\text { Error }\left(\mathrm{m}^{3} / \mathrm{s}\right)\end{array}$ \\
\hline Doty & 69880 & 0.07 & 0.67 & 4.40 \\
\hline Grand Mound & 68732 & 0.50 & 3.77 & 16.3 \\
\hline Porter & 68839 & 2.00 & 7.54 & 22.0 \\
\hline
\end{tabular}

Table 13. Error statistics for model comparisons to field data for flow at Doty, Grand Mound, and Porter during the months of May through October

\begin{tabular}{|c|c|c|c|c|}
\hline Location & $\begin{array}{c}\text { Number of Model- } \\
\text { Data Comparisons }\end{array}$ & $\begin{array}{c}\text { Mean Error } \\
\left(\mathrm{m}^{3} / \mathrm{s}\right)\end{array}$ & $\begin{array}{c}\text { Absolute Mean } \\
\text { Error }\left(\mathrm{m}^{3} / \mathrm{s}\right)\end{array}$ & $\begin{array}{c}\text { Root Mean Square } \\
\text { Error }\left(\mathrm{m}^{3} / \mathrm{s}\right)\end{array}$ \\
\hline Doty & 35138 & -0.05 & 0.29 & 1.36 \\
\hline Grand Mound & 34946 & 0.02 & 1.19 & 5.32 \\
\hline Porter & 34072 & 2.69 & 5.48 & 14.5 \\
\hline
\end{tabular}


Table 14. Error statistics for model comparisons to field data for flow at Doty, Grand Mound, and Porter during the months of November through April

\begin{tabular}{|c|c|c|c|c|}
\hline Location & $\begin{array}{c}\text { Number of Model- } \\
\text { Data Comparisons }\end{array}$ & $\begin{array}{c}\text { Mean Error } \\
\left(\mathrm{m}^{3} / \mathrm{s}\right)\end{array}$ & $\begin{array}{c}\text { Absolute Mean } \\
\text { Error }\left(\mathrm{m}^{3} / \mathrm{s}\right)\end{array}$ & $\begin{array}{c}\text { Root Mean Square } \\
\text { Error }\left(\mathrm{m}^{3} / \mathrm{s}\right)\end{array}$ \\
\hline Doty & 34362 & 0.18 & 1.05 & 6.13 \\
\hline Grand Mound & 33406 & 1.01 & 6.48 & 22.8 \\
\hline Porter & 34387 & 1.24 & 9.51 & 27.5 \\
\hline
\end{tabular}

Table 15. Error statistics for model comparisons to water level data at Doty, Adna, Chehalis WWTP, Centralia, Grand Mound, Rochester, and Porter mainstem Chehalis River stations

\begin{tabular}{|c|c|c|c|c|}
\hline Location & $\begin{array}{c}\text { Number of Model- } \\
\text { Data Comparisons }\end{array}$ & $\begin{array}{c}\text { Mean Error } \\
(\mathrm{m})\end{array}$ & $\begin{array}{c}\text { Absolute Mean } \\
\text { Error }(\mathrm{m})\end{array}$ & $\begin{array}{c}\text { Root Mean Square } \\
\text { Error }(\mathrm{m})\end{array}$ \\
\hline Doty & 69793 & -0.279 & 0.663 & 0.806 \\
\hline Adna & 40608 & -3.06 & 3.08 & 3.225 \\
\hline Chehalis WWTP & 40608 & 0.993 & 1.00 & 1.09 \\
\hline Centralia & 32187 & 0.198 & 0.709 & 0.860 \\
\hline Grand Mound & 68740 & 0.463 & 0.725 & 0.877 \\
\hline Rochester & 40608 & 1.21 & 1.21 & 1.24 \\
\hline Porter & 68847 & -0.223 & 0.287 & 0.421 \\
\hline
\end{tabular}

\subsection{Distributed Flows}

The process of adding or subtracting flow was based on comparisons of model predictions to field data at the 3 gages: Doty, Grand Mound, and Porter. The flow error was calculated as field data minus model predicted flow rate for every time field data were available. While all tributaries, dischargers, and groundwater inflows were taken into account with input flow files, not all flow dynamics could be captured this way. For example, there may have been flow inputs to the river in the form of storm events and overland flow. Or there may have been ungaged agricultural withdrawals from the river. In addition to a lack of data for the magnitude of these flow sources and sinks, the precise locations are also unknown. For this reason, the flow error was added or subtracted to 
the model as distributed flow along the model branch upstream of the gage location of comparison.

Distributed flows helped to keep the model hydrated, particularly during the summer months when flow in the river became very low and the model was prone to dry up. This was a multiple-iteration process until model predicted flows were in agreement with field data at Doty. First, flow calibration with distributed flows was conducted at Doty, the most upstream flow gage station. Once the Doty location was properly calibrated, the same method was employed for the Grand Mound location. Then, once the Grand Mound location was properly calibrated, the same method was repeated for the Porter gage at the downstream model boundary. Figure 64 shows the distributed tributary flows added to the branches upstream of the flow monitoring locations as part of the calibration process. 

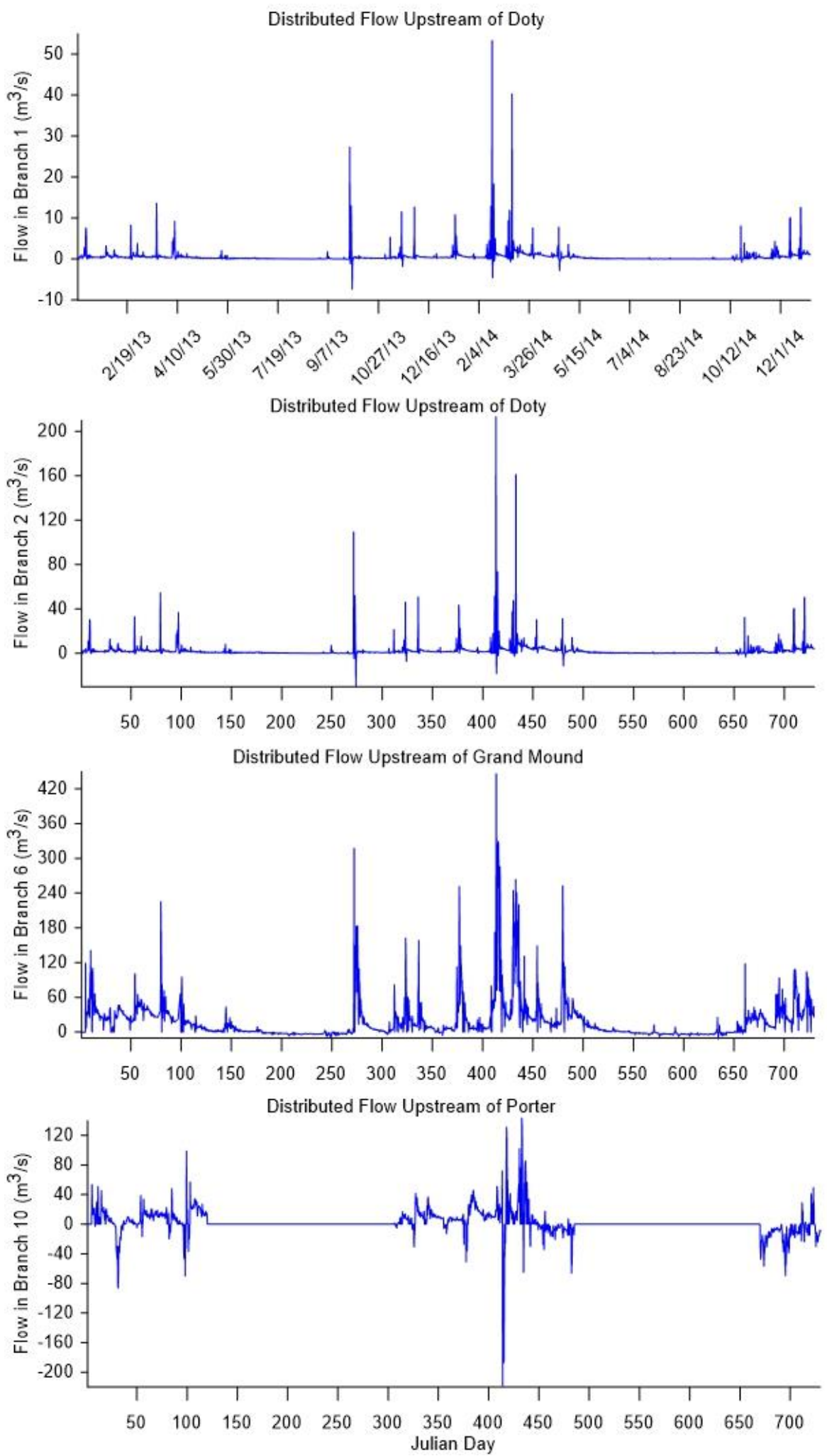

Figure 64. Distributed tributary flows input upstream of flow monitoring locations at Doty, Grand Mound, and Porter for model calibration 
In general, the distributed flows represented ungaged inflows during storm events. At multiple times the distributed flows for the branch upstream of Porter had large negative magnitudes. There were no clear indications that these large withdrawals were as a result of irrigation. The timing of the large distributed flows in branch 10 happened at times near to when peak water surface elevation occurred at Porter, generally during winter months. Figure 65 shows how water surface elevation varies with distributed flows in branch 10. This figure shows that generally, larger magnitudes of distributed flows correspond to peak water surface elevations.

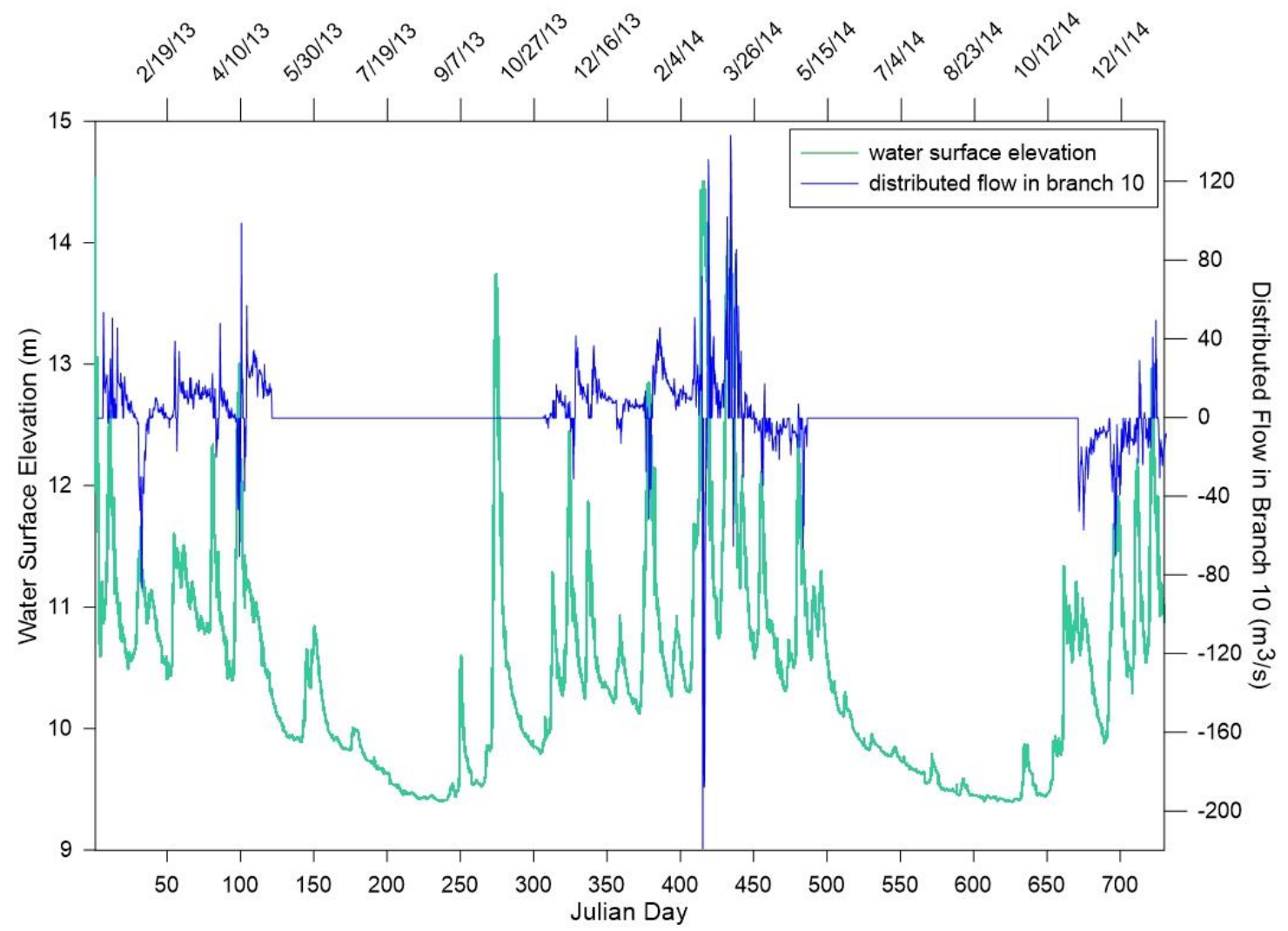

Figure 65. Water surface elevation at Porter versus distributed flow in branch 9 upstream of Porter 
It is thought that storm events resulting in large volumes of overland flow account for the large positive distributed flow values, raising the water surface elevations. Once the water reaches bank-full levels, the water spills out of the river channel flooding the surrounding land, accounting for the large negative distributed flow values. The water spilling out of the river could be draining to natural storage, such as nearby ponds or oxbows. Figure 66 shows examples of many such features located near the Chehalis River.
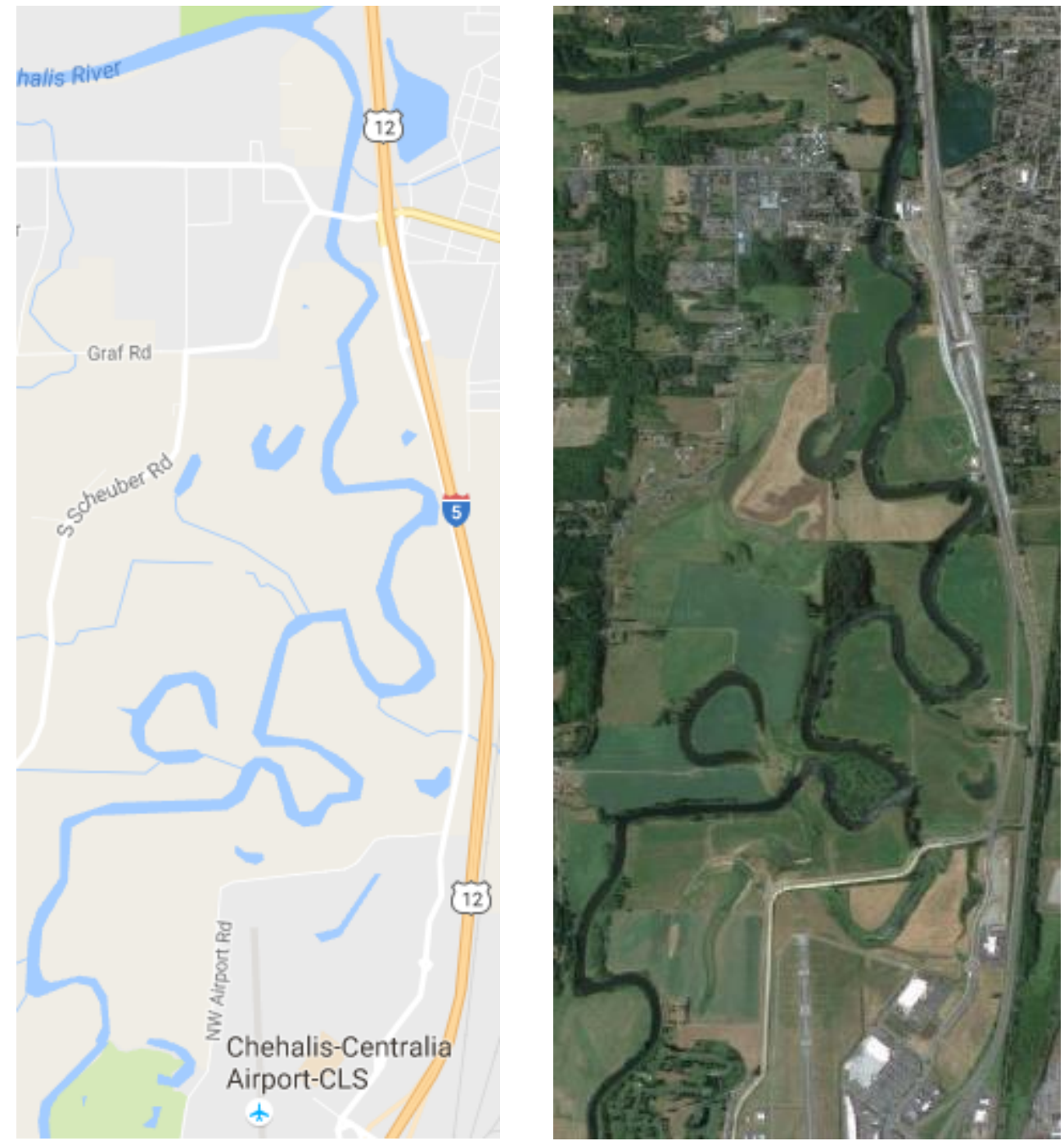

Figure 66. Map and earth aerial views of ponds and oxbows adjacent to the Chehalis River near Chehalis and Centralia, WA where flooded water may be stored 
It is important to note that while the distributed flow was implemented in the branch upstream of Porter, the flow could actually be occurring anywhere between the next upstream calibration station at Grand Mound and the station at Porter, in branches 7 to 10. With a more detailed description of the basin, the distributed flows could be more accurately placed. This is true for all flow calibration locations.

\subsection{Bathymetry}

The bathymetry, including channel friction, channel slope, and segment depths and widths, all impacted the flow calibration.

\subsubsection{Channel Friction}

A manning's friction coefficient was specified for every model segment. Increasing friction slowed the travel time of water through the system and increased water depths, keeping the system hydrated during the low flow summer months. This was especially important for the upstream locations where gradients were very steep and water flushed through quickly. Similarly, decreasing friction had the opposite effect of causing water level to decrease and move more quickly through the system. Matching magnitudes as well as timing of flow peaks was important to accurately describe the system. Altering friction helped to match timing of peak flows to field data.

\subsubsection{Channel Slope}

Each branch in the model had a specified channel slope. This gave the general slope of the branch, for all segments it included. However, the slope may not accurately 
capture the hydraulic gradient slope due to real channel characteristics, such as falls, riffles, or other features (Cole and Wells, 2016). Because of this, a separate variable, SLOPEC, was specified for each branch and represented the hydraulic equivalent slope. This variable was used to calculate fluid acceleration in the momentum equations (Cole and Wells, 2016).

Similar to friction, increasing or decreasing SLOPEC either quickened or slowed water moving through the system. This affected timing of flow peaks, water surface levels, and keeping the model hydrated during low flow summer months. In the Centralia reach where the river is slow and deep, the model slope was essentially zero.

\subsubsection{Segment Widths and Depths}

Model instabilities were more likely to occur when segment depths changed rapidly from one segment to the next. For example, when water moved through segments that were very wide and deep to segments that were suddenly narrow and shallow, water backed up behind this constriction which may not have been the case in reality. Conversely, when water moved through segments that were very narrow and shallow to segments that were suddenly very wide and deep, sometimes the model could dry up under some flow conditions. Scenarios such as these made it necessary to smooth some widths and depths in the bathymetry files so that transitions between wide, narrow, deep, and shallow segments were not abrupt. Additionally, very small widths in segments, such as $5 \mathrm{~m}$ or less, required the model to use a smaller time step because of numerical stability 
considerations. By removing some very small bottom layers in the bathymetry files, shorter model run times were achieved.

\subsubsection{Spillways}

Weirs were added at the end of some branches. These had crest elevations that could be raised slightly so that water backed up behind them, allowing the upstream locations to remain more hydrated. The spillways also had a set of user-defined coefficients that affected the way water moved over the spillway and between branches, giving either a retaining or flushing effect. In general, most of the spillways between branches were set so that the spillway crest was on the bottom elevation of the channel. The spillways had the following power functions describing behavior for free flowing conditions and submerged conditions (Cole and Wells, 2016):

$$
Q=\alpha_{1} \Delta h^{\beta_{1}} \text { Free flowing conditions }
$$

Where

$\alpha_{1}$ and $\beta_{1}$ are empirical coefficients

$\Delta \mathrm{h}$ is the difference between the upstream head and spillway crest elevation

$$
Q=\alpha_{2} \Delta h^{\beta_{2}} \text { Submerged conditions }
$$

Where

$\alpha_{2}$ and $\beta_{2}$ are empirical coefficients

$\Delta \mathrm{h}$ is the difference between the upstream head and downstream head 
First, $\alpha_{1}$ was calculated by using the equation for a broad crested weir (Cole and Wells, 2016):

$$
\alpha_{1}=C_{D} C_{v} \frac{2}{3} \sqrt{2 g} W
$$

Where

$C_{D}$ is a discharge coefficient $(0.84$ to 1.06$)$

$C_{v}$ is a velocity coefficient (1.0 to 1.2$)$

$\mathrm{g}$ is gravitational acceleration

W is channel width

Figure 67 shows a schematic describing the water and weir heights used in the previous equations. The coefficients $C_{D}$ and $C_{V}$ were assumed to equal 1 . Width $W$ was calculated as the average bottom three layer widths of the segment where the spillway was located, since these layers were the most commonly occupied by water.

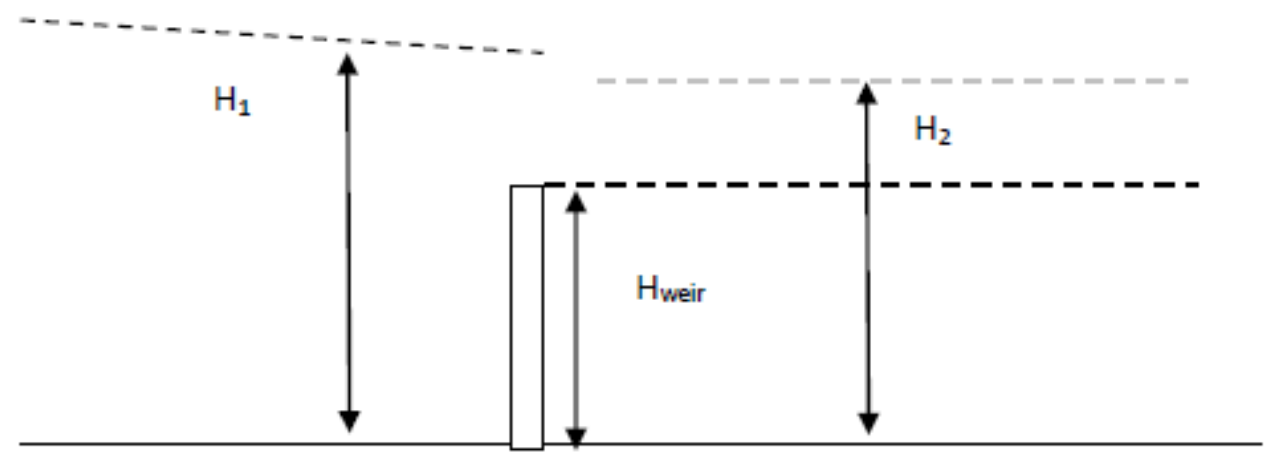

Figure 67. Schematic of water and weir heights for a free flowing submerged weir used with the spillway equations (Cole and Wells, 2016)

Following the methodology outlined in the CE-QUAL-W2 user manual (Cole and Wells, 2016), at a given flow value $Q$, the previous equations can be combined to give: 


$$
\alpha_{2}=\frac{\alpha_{1}\left(H_{1}-H_{\text {weir }}\right)^{\beta_{1}-\beta_{2}}}{0.33^{\beta_{2}}}
$$

$\beta_{1}$ and $\beta_{2}$ were set equal to each other. This implied:

$$
\alpha_{2}=\frac{\alpha_{1}}{0.33^{\beta_{2}}}
$$

By using this process, the spillway or weir coefficients for free flowing and submerged flow were set.

\subsection{Groundwater Flow Influences}

Groundwater flow magnitudes varied by location. The influence of these flows were assessed by determining how they compared to flow along the mainstem channel. Modelpredicted flow values were viewed within each groundwater reach. Then, the percent of the mainstem Chehalis River flow attributed to groundwater was computed. Groundwater flows accounted for a larger portion of the mainstem river during the summer seasons than during the winter seasons. Table 16 shows how the percent of mainstem Chehalis River flow attributed to groundwater varied by season, and for the entire model duration. Negative values are indicative of groundwater losses, or flow moving from the river to an aquifer.

Table 16. Percent of mainstem Chehalis River flow attributed to groundwater throughout the model

\begin{tabular}{|c|c|c|c|c|c|c|}
\cline { 3 - 7 } \multicolumn{2}{c|}{} & \multicolumn{5}{c|}{ \% of Mainstem Chehalis River Flow } \\
\hline $\begin{array}{c}\text { Groundwater Reach } \\
\text { Segment Range }\end{array}$ & $\begin{array}{c}\text { Groundwater Reach } \\
\text { Gain/Loss (m3/s) }\end{array}$ & Winter & Spring & Summer & Fall & Overall \\
\hline $35-37$ & 0.025 & 0.17 & 0.36 & 2.03 & 0.47 & 0.77 \\
\hline $38-47$ & 0.510 & 0.02 & 0.04 & 0.11 & 0.06 & 0.06 \\
\hline $48-66$ & -0.221 & -0.95 & -1.66 & -4.73 & -2.31 & -2.43 \\
\hline $67-80$ & -0.003 & -0.01 & -0.02 & -0.06 & -0.03 & -0.03 \\
\hline $81-97$ & 0.040 & 0.15 & 0.25 & 0.67 & 0.34 & 0.36 \\
\hline
\end{tabular}




\begin{tabular}{|c|c|c|c|c|c|c|}
\hline \multirow[b]{2}{*}{$\begin{array}{c}\text { Groundwater Reach } \\
\text { Segment Range }\end{array}$} & \multirow[b]{2}{*}{$\begin{array}{l}\text { Groundwater Reach } \\
\text { Gain/Loss }(\mathrm{m} 3 / \mathrm{s})\end{array}$} & \multicolumn{5}{|c|}{$\%$ of Mainstem Chehalis River Flow } \\
\hline & & Winter & Spring & Summer & Fall & Overall \\
\hline $98-122$ & -0.082 & -0.28 & -0.47 & -1.32 & -0.66 & -0.69 \\
\hline $123-143$ & 0.388 & 1.34 & 2.28 & 6.10 & 2.93 & 3.19 \\
\hline $144-181$ & 0.404 & 0.62 & 1.17 & 5.41 & 1.84 & 2.28 \\
\hline $182-191$ & -0.460 & -0.50 & -0.96 & -5.33 & -1.63 & -2.13 \\
\hline $192-204$ & -0.056 & -0.06 & -0.12 & -0.66 & -0.20 & -0.05 \\
\hline $205-210$ & 0.565 & 0.59 & 1.12 & 6.13 & 1.91 & 2.46 \\
\hline $211-214$ & 0.823 & 0.84 & 1.60 & 8.17 & 2.64 & 3.35 \\
\hline $224-229$ & 0.567 & 0.56 & 1.08 & 5.31 & 1.75 & 2.20 \\
\hline $230-235$ & -0.174 & -0.17 & -0.33 & -1.66 & -0.54 & -0.68 \\
\hline $236-242$ & 0.255 & 0.23 & 0.45 & 2.26 & 0.74 & 0.93 \\
\hline $243-246$ & 0.326 & 0.29 & 0.57 & 2.85 & 0.94 & 1.17 \\
\hline $247-251$ & -0.652 & -0.57 & -1.16 & -5.88 & -1.91 & -2.41 \\
\hline $252-255$ & 0.227 & 0.20 & 0.40 & 2.09 & 0.67 & 0.85 \\
\hline $256-260$ & 0.058 & 0.05 & 0.10 & 0.53 & 0.17 & 0.22 \\
\hline $261-264$ & -0.256 & -0.22 & -0.46 & -2.52 & -0.79 & -1.01 \\
\hline $265-268$ & -1.368 & -1.06 & -2.16 & -10.52 & -3.41 & -4.34 \\
\hline $269-272$ & 0.962 & 0.74 & 1.50 & 7.07 & 2.34 & 2.94 \\
\hline $273-276$ & -0.190 & -0.14 & -0.29 & -1.38 & -0.46 & -0.57 \\
\hline $277-285$ & 0.197 & 0.15 & 0.30 & 1.45 & 0.48 & 0.60 \\
\hline $286-318$ & 0.799 & 0.56 & 1.14 & 5.36 & 1.78 & 2.23 \\
\hline \multirow[t]{2}{*}{$319-321$} & -0.272 & -0.19 & -0.39 & -1.84 & -0.61 & -0.76 \\
\hline & Average: & 0.09 & 0.17 & 0.76 & 0.25 & 0.33 \\
\hline
\end{tabular}

\subsection{Travel time, age, and dispersion}

The time it took for a parcel of water to travel through the entire length of the model reach was evaluated by using a tracer. Tracer inputs of $100 \mathrm{mg} / \mathrm{L}$ were added over 2.4 hours to the upstream boundary every 30 days. Then the time for each tracer pulse peak to reach various downstream segments was found. The difference between the time a pulse peak appeared at a downstream location and the time it was originally input to the upstream boundary was the travel time. Figure 68 shows examples of how the tracer peak 
magnitudes decreased and time of peak occurrence became later moving downstream. Table 17 gives example values of travel time for various locations in the model and Figure 69 shows how travel time increases moving downstream for various initial upstream input pulse times. 

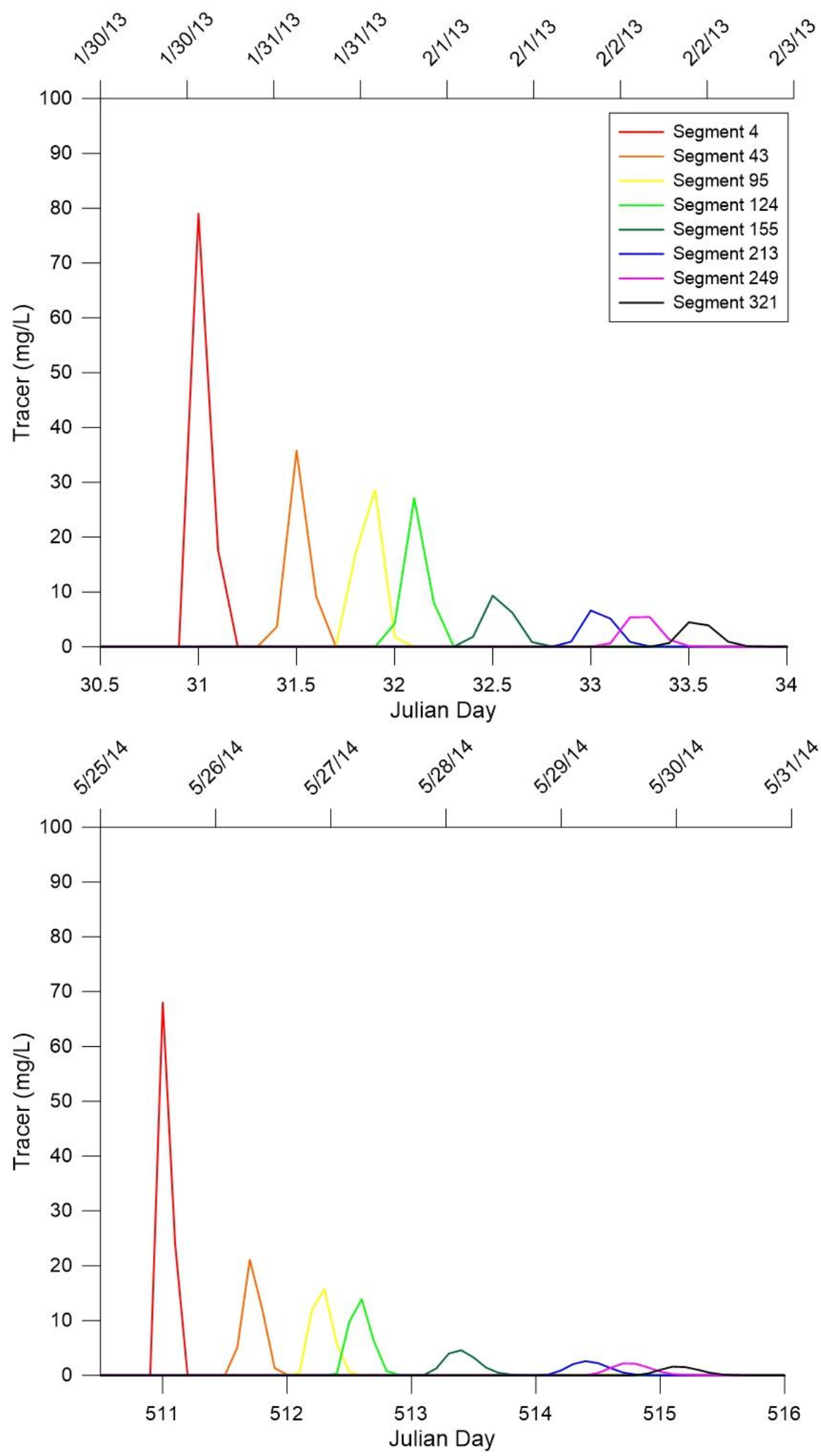

Figure 68. Resulting tracer magnitudes and timing along the river channel for tracer pulses input to the upstream boundary at Julian days 31 and 511 
Table 17. Travel times for upstream pulse inputs to reach various downstream locations for various input pulse times

\begin{tabular}{|c|c|c|c|c|c|}
\hline \multirow[b]{2}{*}{$\begin{array}{l}\text { Initial Upstream } \\
\text { Pulse Julian Day }\end{array}$} & \multicolumn{5}{|c|}{ Travel Time (days) } \\
\hline & Segment 43 & Segment 124 & Segment 193 & Segment 249 & Segment 321 \\
\hline 1 & 0.7 & 1.2 & 2.1 & 2.6 & 2.9 \\
\hline 31 & 0.5 & 1.1 & 1.9 & 2.3 & 2.5 \\
\hline 61 & 0.5 & 1.1 & 1.9 & 2.3 & 2.6 \\
\hline 91 & 0.7 & 1.5 & 2.9 & 3.3 & 3.7 \\
\hline 121 & 0.7 & 1.6 & 3.2 & 3.7 & 4.1 \\
\hline 151 & 0.5 & 1.3 & 2.5 & 3 & 3.3 \\
\hline 181 & 0.7 & 1.7 & 3.9 & 4.6 & 5.1 \\
\hline 211 & 1 & 2 & 5 & 5.6 & 6.1 \\
\hline 241 & 0.9 & 1.8 & 4.9 & 5.5 & 5.9 \\
\hline 271 & 0.5 & 1 & 1.6 & 2 & 2.3 \\
\hline 301 & 0.7 & 1.7 & 4.2 & 4.8 & 5.3 \\
\hline 331 & 0.6 & 1.5 & 2.9 & 3.4 & 3.8 \\
\hline 361 & 0.7 & 1.5 & 2.9 & 3.4 & 3.7 \\
\hline 391 & 0.7 & 1.6 & 3.2 & 3.7 & 4 \\
\hline 421 & 0.5 & 1.15 & 2 & 2.4 & 2.7 \\
\hline 451 & 0.6 & 1.3 & 2.2 & 2.6 & 2.8 \\
\hline 481 & 0.4 & 1 & 1.7 & 2.1 & 2.4 \\
\hline 511 & 0.7 & 1.6 & 3.2 & 3.7 & 4.1 \\
\hline 541 & 0.8 & 1.8 & 4.1 & 4.7 & 5.1 \\
\hline 571 & 0.8 & 1.7 & 4.7 & 5.3 & 5.8 \\
\hline 601 & 1.2 & 2.2 & 5.5 & 6.2 & 6.75 \\
\hline 631 & 1.2 & 2.1 & 4.7 & 5.2 & 5.6 \\
\hline 661 & 0.4 & 0.9 & 1.6 & 1.9 & 2.2 \\
\hline 691 & 0.5 & 1.2 & 2.1 & 2.4 & 2.7 \\
\hline 721 & 0.4 & 0.9 & 1.5 & 2 & 2.3 \\
\hline
\end{tabular}




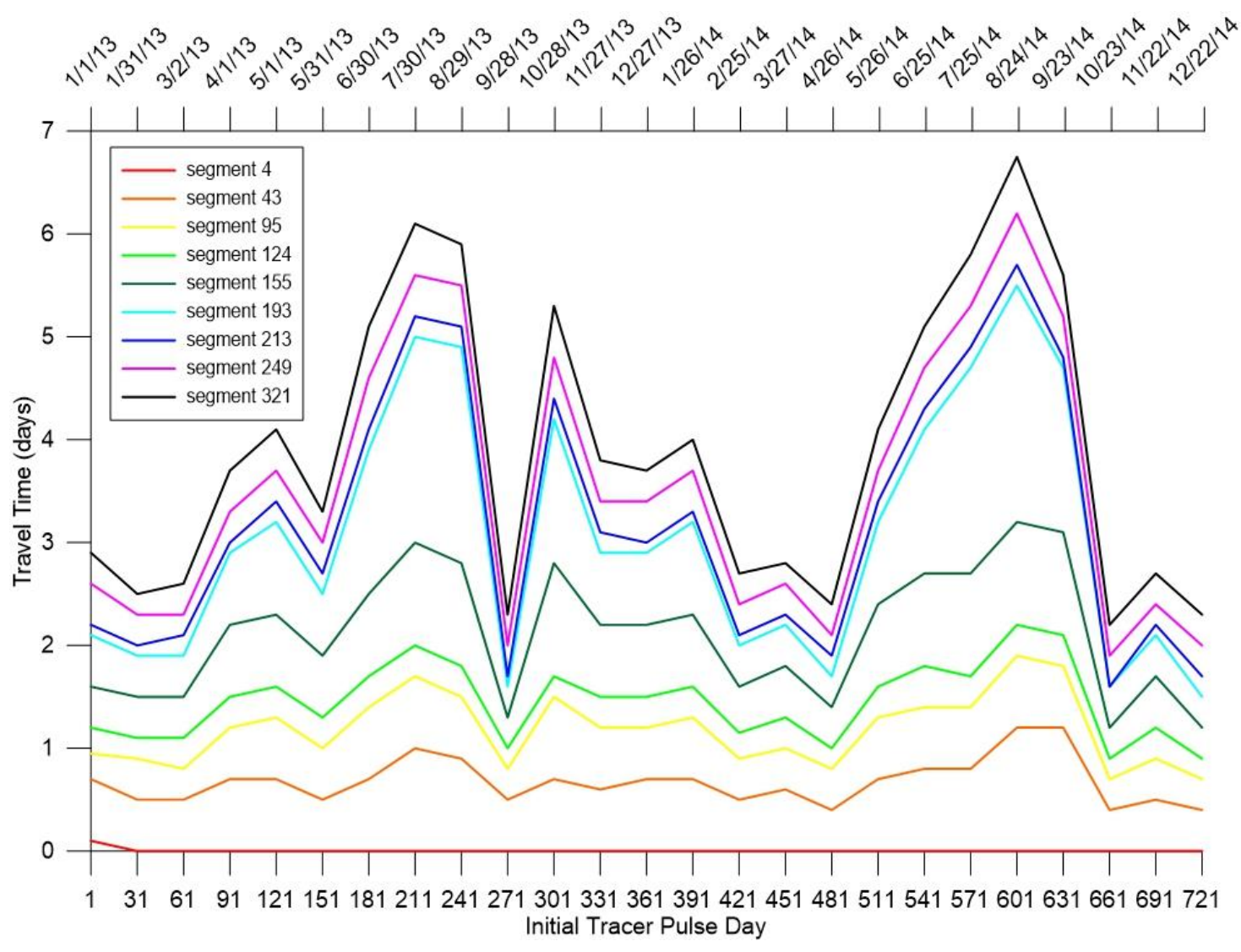

Figure 69. Travel times for tracer pulse peaks at various downstream locations

Water age is a measure of how long water has been in the system, and is similar to travel time in that it is a function of how quickly water moves through the system. However, flow inputs from tributaries or groundwater are set to "new" water or zero water age when they enter the river. For example, the water age may be lower for a segment just downstream of a major tributary than for a segment just upstream of a major tributary. This is because the new flow coming in from the major tributary mixes with the flow already in the mainstem river and reduces the water age. This implies water age will generally be less than travel time. Figure 70 shows how water age generally increases moving downstream, though it is influenced by boundary flows. 


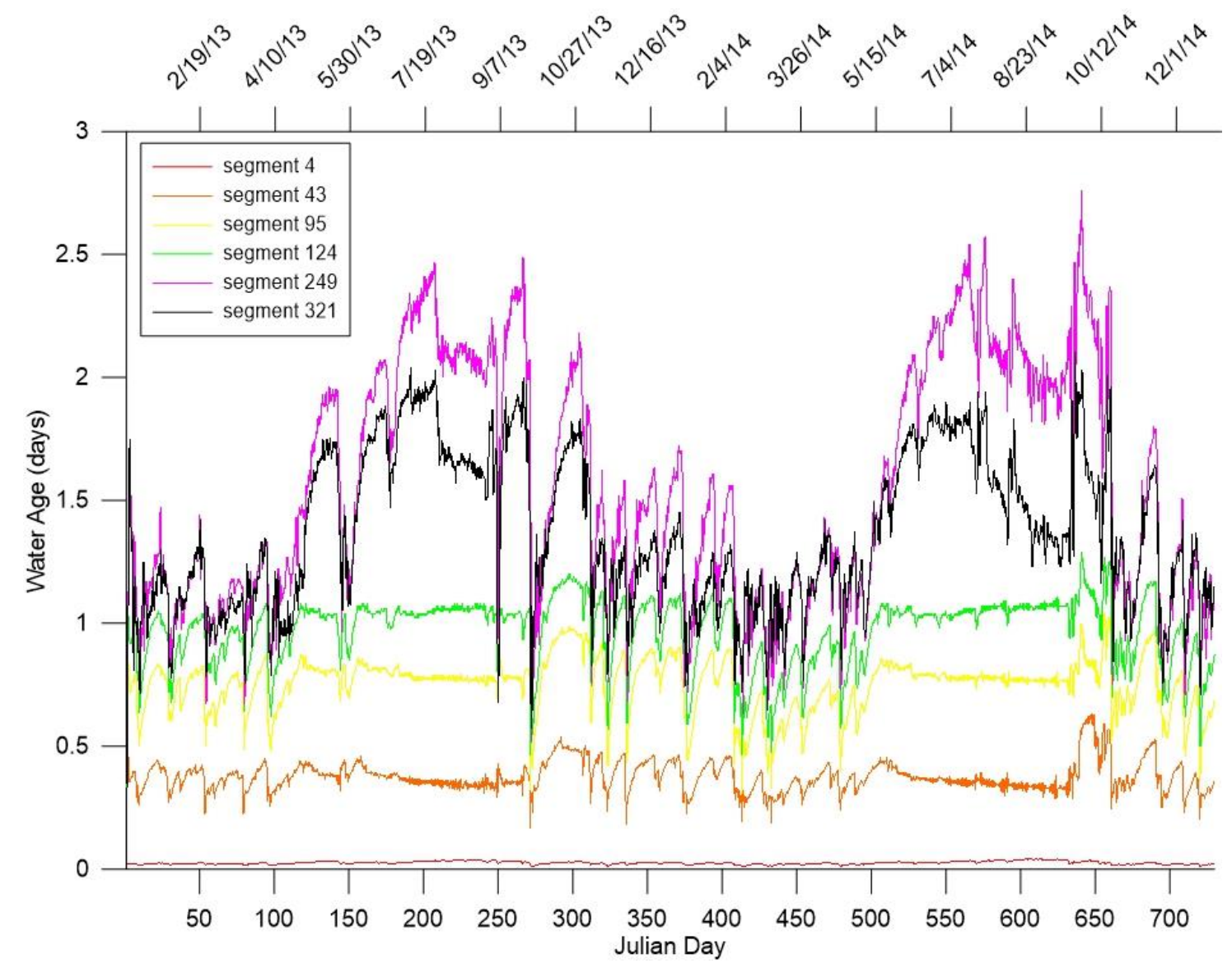

Figure 70. Model-predicted water age throughout the model reach

The mount of mixing taking place in the system was evaluated using TDS. TDS is conservative, so any decrease in concentration can be attributed to dilution. All input TDS values were set to zero except for the upstream boundary, which was set to a constant $100 \mathrm{mg} / \mathrm{L}$ throughout the entire model time period. The amount that TDS decreasesd moving downstream was how much dilution was taking place. Table 18 gives example values of percent mixing at various downstream locations at various times throughout the model simulation. Percent mixing was evaluated as the percent of the difference between the remaining TDS concentration compared to the initial $100 \mathrm{mg} / \mathrm{L}$ input at the upstream 
boundary. Figure 71 shows how TDS and mixing change moving downstream. Generally, mixing increased and TDS concentration decreased moving downstream as more mixing and dilution processes occurred along the channel.

Table 18. Percent mixing at various segments throughout the model at various times during the model simulation

\begin{tabular}{|c|c|c|c|c|c|}
\hline \multirow[b]{2}{*}{$\begin{array}{c}\text { Julian } \\
\text { Day }\end{array}$} & \multicolumn{5}{|c|}{$\%$ Mixing } \\
\hline & $\begin{array}{c}\text { Segment } \\
43 \\
\end{array}$ & $\begin{array}{c}\text { Segment } \\
124 \\
\end{array}$ & $\begin{array}{c}\text { Segment } \\
193 \\
\end{array}$ & $\begin{array}{c}\text { Segment } \\
249 \\
\end{array}$ & $\begin{array}{c}\text { Segment } \\
321 \\
\end{array}$ \\
\hline 1 & 43 & 43 & 43 & 43 & 43 \\
\hline 31 & 50.3 & 60.3 & 86.9 & 90.6 & 94.7 \\
\hline 61 & 33.4 & 61 & 87.2 & 88 & 91.6 \\
\hline 91 & 46.6 & 57.6 & 86.2 & 88.2 & 90.5 \\
\hline 121 & 49.5 & 58.9 & 85.8 & 90 & 91.5 \\
\hline 151 & 32.5 & 51.1 & 84 & 87.4 & 91.4 \\
\hline 181 & 59 & 68.4 & 88.1 & 91.4 & 93.7 \\
\hline 211 & 77.7 & 84.6 & 94.3 & 95.9 & 97.5 \\
\hline 241 & 82.2 & 84.2 & 94.9 & 97.1 & 98.1 \\
\hline 271 & 59.3 & 69.4 & 82.3 & 85.8 & 91.6 \\
\hline 301 & 50.2 & 63.9 & 87.4 & 90.3 & 93.1 \\
\hline 331 & 45.8 & 56.4 & 86.1 & 85.9 & 88.9 \\
\hline 361 & 51.7 & 61.3 & 85.9 & 87.8 & 92.4 \\
\hline 391 & 52.8 & 62.4 & 88.2 & 88.5 & 92.9 \\
\hline 421 & 47.8 & 58 & 85.8 & 87.8 & 91.1 \\
\hline 451 & 62.9 & 75 & 91.5 & 92.5 & 93.8 \\
\hline 481 & 27.5 & 38.1 & 77.3 & 75.9 & 83.9 \\
\hline 511 & 54.4 & 63.9 & 87.6 & 90.0 & 92.2 \\
\hline 541 & 71.7 & 80.6 & 90.4 & 93.5 & 95.3 \\
\hline 571 & 57.1 & 74.2 & 93.3 & 94.9 & 97.6 \\
\hline 601 & 81.5 & 87.6 & 94.6 & 96.7 & 98.1 \\
\hline 631 & 89.4 & 91.3 & 96 & 97.8 & 99.0 \\
\hline 661 & 24.8 & 53.1 & 80.1 & 84.3 & 87 \\
\hline 691 & 60.9 & 57.8 & 87 & 88.4 & 91.8 \\
\hline 721 & 26.3 & 44.8 & 77.8 & 89.5 & 91.9 \\
\hline
\end{tabular}




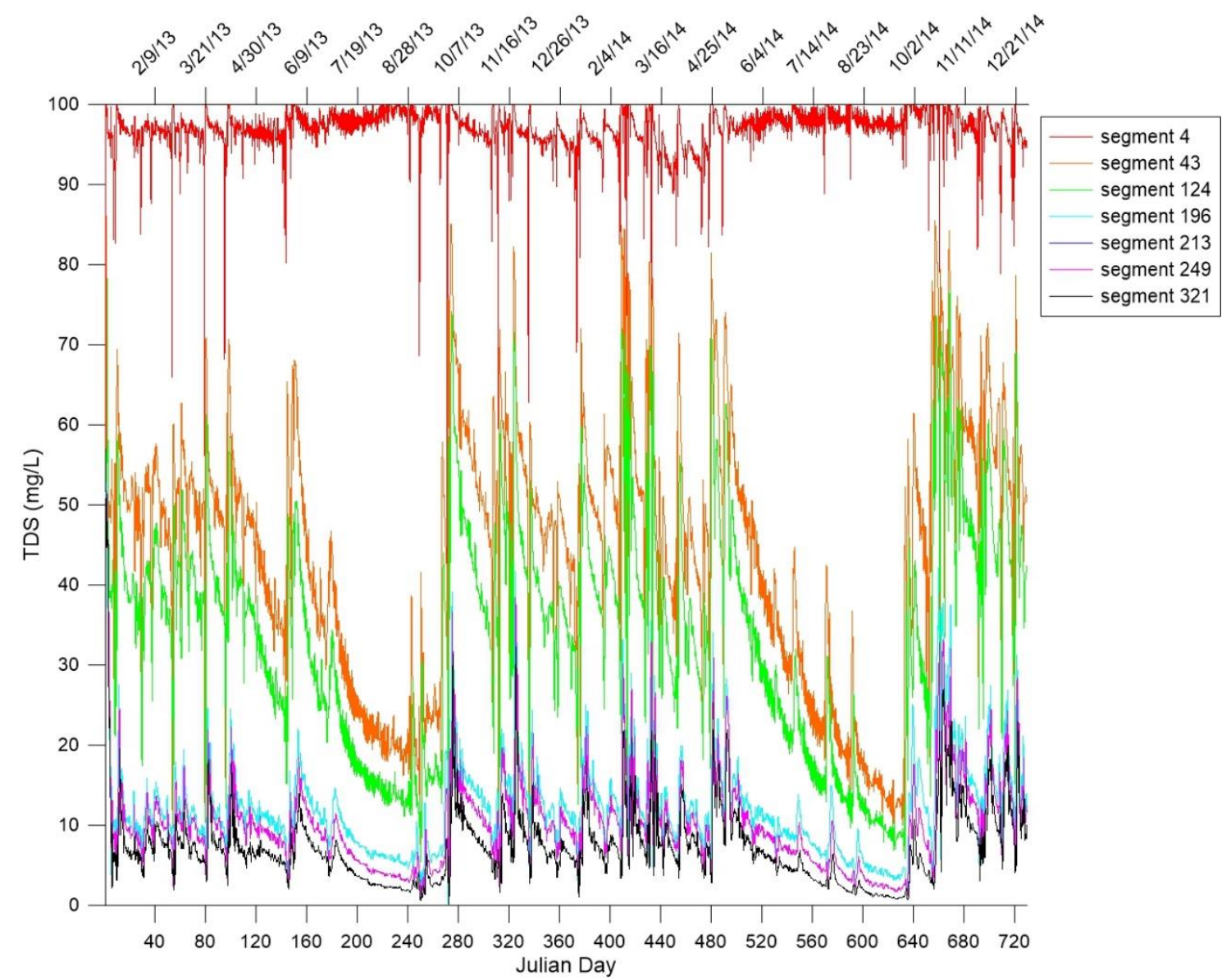

Figure 71. Model-predicted TDS concentrations at various downstream locations after a constant input of $100 \mathrm{mg} / \mathrm{L}$ was added to the upstream boundary 


\section{Model Calibration: Temperature}

Temperature was highly dependent on water depths and travel time, and hence was calibrated after the flow rate calibration was finalized. Many water quality state variables were temperature dependent, so it was also important to calibrate temperature before water quality. Similar to flow calibration, field temperature data along the mainstem of the Chehalis River were compared to model predictions moving from upstream to downstream. Table 19 lists the continuous temperature stations on the mainstem Chehalis River that were used to compare to model predictions.

Vertical temperature profile data were provided by Anchor QEA (2014). These data were collected at specific dates in the deeper lake-like region of the river near Chehalis and Centralia, WA. Table 20 lists the vertical temperature stations, locations, and dates when data were collected on the Chehalis River.

Figure 72 shows a longitudinal view of the locations of the mainstem continuous and vertical temperature stations along the Chehalis River.

Table 19. Temperature stations on the mainstem Chehalis River used to compare to model predictions

\begin{tabular}{|c|c|c|c|c|c|}
\hline Organization & Station ID & Description & Dates with data & $\begin{array}{c}\text { Model } \\
\text { Segment }\end{array}$ & $\begin{array}{c}\text { River } \\
\text { Mile }\end{array}$ \\
\hline WDFW & $11-U C H$ & Upper Chehalis & $6 / 9 / 14-9 / 15 / 15$ & 4 & 108 \\
\hline WDFW & $3-U C H$ & $\begin{array}{c}\text { Upper Chehalis } \\
\text { Chehalis mainstem }\end{array}$ & $5 / 15 / 14-9 / 15 / 15$ & 12 & 108 \\
\hline Anchor QEA & CHL-PEL-US & $\begin{array}{c}\text { Chehalis Upstream of } \\
\text { Pe Ell }\end{array}$ & $7 / 31 / 13-3 / 26 / 14$ & 12 & 107 \\
\hline Anchor QEA & CHL-PEL-DS & $\begin{array}{c}\text { Chehalis Downstream } \\
\text { of Pe Ell }\end{array}$ & $7 / 31 / 13-7 / 30 / 14$ & 15 & 106 \\
\hline WDFW & $13-C H$ & Chehalis mainstem & $6 / 10 / 14-9 / 15 / 15$ & 19 & 105 \\
\hline Anchor QEA & $\begin{array}{c}\text { CHL- } \\
\text { WOODSTEAD }\end{array}$ & Woodstead farm 01 & $7 / 2 / 13-10 / 28 / 13$ & 24 & 103 \\
\hline WDFW & $4-U C H$ & Upper Chehalis & $5 / 15 / 14-9 / 15 / 15$ & 36 & 102 \\
\hline
\end{tabular}




\begin{tabular}{|c|c|c|c|c|c|}
\hline Organization & Station ID & Description & Dates with data & $\begin{array}{c}\text { Model } \\
\text { Segment }\end{array}$ & $\begin{array}{l}\text { River } \\
\text { Mile }\end{array}$ \\
\hline Anchor QEA & CHL-DOTY & Chehalis at Doty & $7 / 3 / 13-10 / 16 / 13$ & 36 & 101 \\
\hline WADOE & 23A160 & $\begin{array}{c}\text { Chehalis River at } \\
\text { Dryad }\end{array}$ & $\begin{array}{c}7 / 1 / 13-9 / 18 / 13 \\
6 / 24 / 14-9 / 23 / 14 \\
\& 5 / 19 / 15-9 / 15 / 15\end{array}$ & 48 & 99.5 \\
\hline WDFW & $15-\mathrm{CH}$ & Chehalis mainstem & $6 / 10 / 14-10 / 14 / 14$ & 47 & 99 \\
\hline Anchor QEA & $\begin{array}{l}\text { CHL-RAINBOW- } \\
\text { FALLS } \\
\end{array}$ & $\begin{array}{l}\text { Chehalis at Rainbow } \\
\text { Falls }\end{array}$ & $7 / 2 / 13-10 / 16 / 13$ & 50 & 97.1 \\
\hline WDFW & $19-\mathrm{CH}$ & Chehalis mainstem & $6 / 18 / 14-9 / 2 / 15$ & 64 & 95.5 \\
\hline Anchor QEA & CHL-CERES-HILLS & $\begin{array}{c}\text { Chehalis at Ceres Hill } \\
\text { Road }\end{array}$ & $7 / 3 / 13-10 / 16 / 13$ & 81 & 90.1 \\
\hline Anchor QEA & CHL-ADNA & Chehalis Near Adna & $7 / 31 / 13-7 / 21 / 14$ & 119 & 81 \\
\hline WDFW & $21-\mathrm{CH}$ & Upper Chehalis & $6 / 11 / 14-9 / 2 / 15$ & 124 & 80.6 \\
\hline Anchor QEA & CHL-US-NWK & $\begin{array}{c}\text { Chehalis Upstream of } \\
\text { Newaukum } \\
\text { Confluence }\end{array}$ & $7 / 31 / 13-3 / 26 / 14$ & 144 & 75.4 \\
\hline WDFW & $22-\mathrm{CH}$ & Upper Chehalis & $6 / 11 / 14-8 / 5 / 15$ & 145 & 75.3 \\
\hline $\begin{array}{l}\text { Darigold } \\
\text { WWTP }\end{array}$ & 41 & $\begin{array}{c}\text { Chehalis River } \\
\text { Upstream Darigold } \\
\text { WWTP }\end{array}$ & $1 / 1 / 13-11 / 30 / 15$ & 149 & 74.7 \\
\hline $\begin{array}{l}\text { Darigold } \\
\text { WWTP }\end{array}$ & 40 & $\begin{array}{c}\text { Chehalis River } \\
\text { Downstream Darigold } \\
\text { WWTP }\end{array}$ & $1 / 1 / 13-11 / 30 / 15$ & 150 & 74.65 \\
\hline WDFW & $16-\mathrm{CH}$ & Chehalis mainstem & $6 / 10 / 14-9 / 3 / 15$ & 180 & 66.7 \\
\hline Anchor QEA & CHL-GLV & $\begin{array}{c}\text { Chehalis at Galvin } \\
\text { Bridge }\end{array}$ & $7 / 30 / 13-7 / 21 / 14$ & 196 & 64.1 \\
\hline WDFW & $17-\mathrm{CH}$ & Chehalis mainstem & $6 / 10 / 14-9 / 1 / 15$ & 213 & 60.1 \\
\hline Anchor QEA & CHL-US-BLK & $\begin{array}{c}\text { Chehalis Upstream of } \\
\text { Black River }\end{array}$ & $7 / 30 / 13-7 / 22 / 14$ & 238 & 54.2 \\
\hline WDFW & $18-\mathrm{CH}$ & Chehalis mainstem & $6 / 10 / 14-8 / 26 / 15$ & 249 & 50.5 \\
\hline Anchor QEA & CHL-OAK & Chehalis at Oakville & $7 / 30 / 13-7 / 22 / 14$ & 287 & 42.3 \\
\hline WDFW & $23-\mathrm{CH}$ & Chehalis mainstem & $7 / 15 / 14-8 / 17 / 15$ & 287 & 41.3 \\
\hline WADOE & $23 \mathrm{~A} 070$ & $\begin{array}{c}\text { Chehalis River at } \\
\text { Porter }\end{array}$ & $\begin{array}{l}10 / 23 / 12-6 / 25 / 13 \\
\& 9 / 18 / 13-5 / 26 / 15\end{array}$ & 321 & 33.3 \\
\hline
\end{tabular}


Table 20. Mainstem Chehalis River vertical temperature profile collection locations and dates used in temperature calibration

\begin{tabular}{|c|c|c|c|c|}
\hline Organization & Station ID & Description & Dates with data & $\begin{array}{c}\text { Model } \\
\text { Segment }\end{array}$ \\
\hline Anchor QEA & CHL-RT6-BR & $\begin{array}{c}\text { Chehalis R. at RT6 } \\
\text { Bridge at RM 75.31 }\end{array}$ & $\begin{array}{c}8 / 7 / 13,9 / 18 / 13, \\
\& 7 / 23 / 14\end{array}$ & 149 \\
\hline Anchor QEA & HL-14 & Chehalis R. at RM 74.5 & $7 / 31 / 14$ & 150 \\
\hline Anchor QEA & HL-13 & Chehalis R. at RM 73.75 & $7 / 31 / 14$ & 153 \\
\hline Anchor QEA & HL-12 & Chehalis R. at RM 73 & $7 / 31 / 14$ & 157 \\
\hline Anchor QEA & HL-11 & Chehalis R. at RM 72.5 & $7 / 31 / 14$ & 158 \\
\hline Anchor QEA & HL-10 & Chehalis R. at RM 74.25 & $7 / 31 / 14$ & 160 \\
\hline Anchor QEA & HL-9 & Chehalis R. at RM 71.5 & $7 / 31 / 14$ & 162 \\
\hline Anchor QEA & HL-8 & Chehalis R. at RM 71 & $7 / 31 / 14$ & 164 \\
\hline Anchor QEA & HL-7 & Chehalis R. at RM 70.5 & $7 / 31 / 14$ & 166 \\
\hline Anchor QEA & HL-6 & Chehalis R. at RM 70 & $7 / 31 / 14$ & 168 \\
\hline Anchor QEA & HL-5 & Chehalis R. at RM 69.25 & $7 / 31 / 14$ & 171 \\
\hline Anchor QEA & HL-4 & Chehalis R. at RM 68.75 & $7 / 31 / 14$ & 173 \\
\hline Anchor QEA & HL-3 & Chehalis R. at RM 68.25 & $7 / 31 / 14$ & 177 \\
\hline Anchor QEA & HL-2 & Chehalis R. at RM 67.75 & $7 / 31 / 14$ & 179 \\
\hline Anchor QEA & CHL-US-SKM & $\begin{array}{c}\text { Chehalis R. at Mellen } \\
\text { Road Bridge at RM 66.7 }\end{array}$ & $8 / 7 / 13,9 / 18 / 13$, & 180 \\
\hline Anchor QEA & HL-1 & Chehalis R. at RM 67.25 & $7 / 31 / 14$ & 181 \\
\hline
\end{tabular}




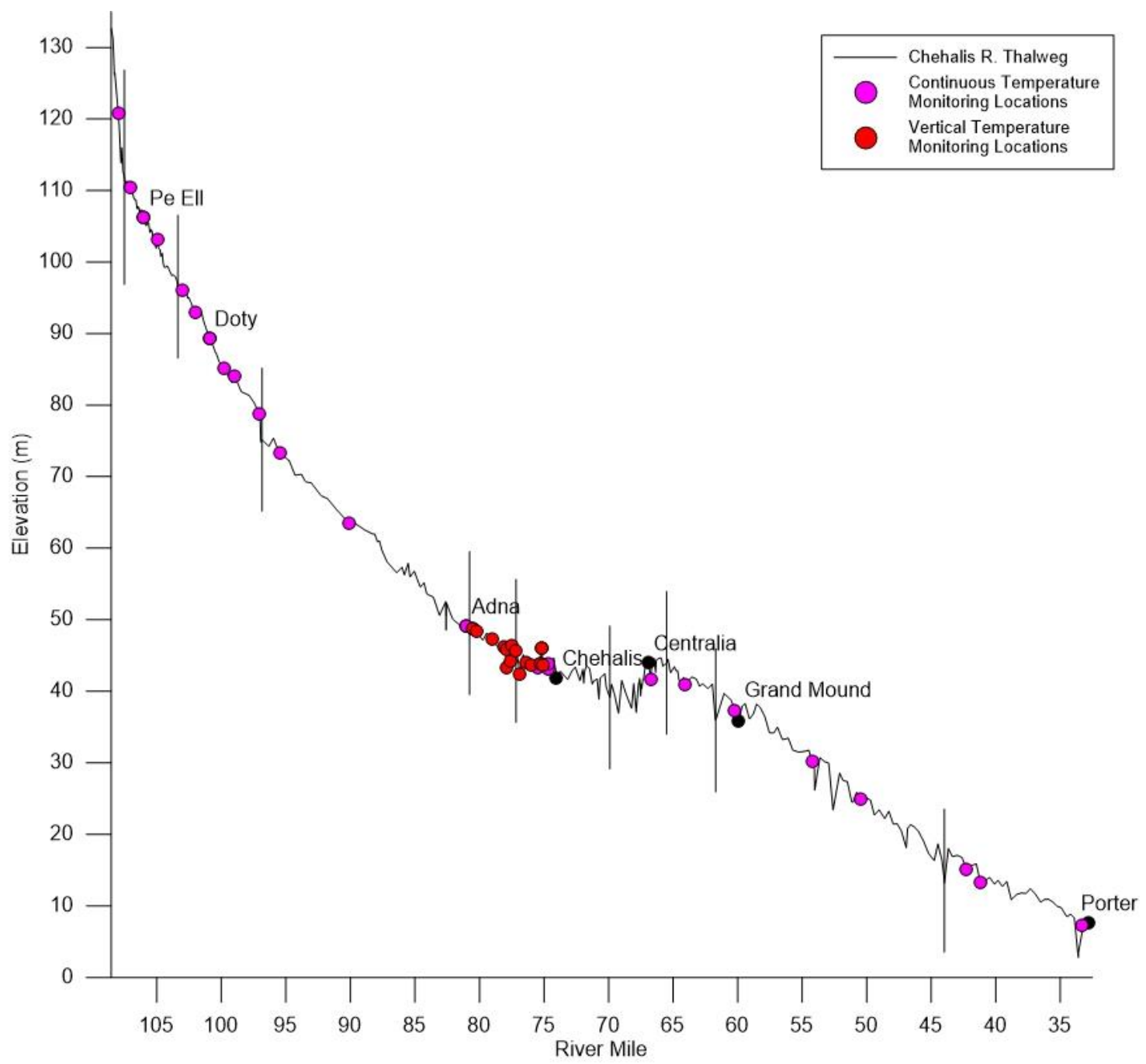

Figure 72. Longitudinal view of the mainstem Chehalis River continuous and vertical temperature gaging stations used for temperature calibration (vertical lines show model branch breaks)

Figure 73 shows model predicted temperature versus field data along the mainstem Chehalis River at the stations: 11-UCH, upstream of Pe Ell, downstream of Pe Ell, 13-CH, at Woodstead, upstream of Elk Creek, and at Doty. Figure 74 shows model predicted temperature versus field data along the mainstem Chehalis River at the stations: $15-\mathrm{CH}$, at Dryad, at Rainbow Falls, 19-CH, at Ceres Hills Road, and at Adna. Figure 75 shows model predicted temperature versus field data along the mainstem Chehalis River at the 
stations: 21-CH, near Newaukum Confluence, 22-CH, upstream of Darigold, downstream of Darigold, and upstream of Skookumchuck. Figure 76 shows model predicted temperature versus field data along the mainstem Chehalis River at the stations: at Galvin Bridge, 17-CH, upstream of Black River, 18-CH, at Oakville, 23-CH, and at Porter.

Since daily maximum temperatures are critical for fish habitat, the model predicted daily maximum was compared to daily maximum field temperatures as well. Figure 77 shows model predicted daily maximum temperature versus field data along the mainstem Chehalis River at the stations: 11-UCH, upstream of Pe Ell, downstream of Pe Ell, 13-CH, at Woodstead, upstream of Elk Creek, and at Doty. Figure 78 shows model predicted daily maximum temperature versus field data along the mainstem Chehalis River at the stations: 15- $\mathrm{CH}$, at Dryad, at Rainbow Falls, 19-CH, at Ceres Hills Road, and at Adna. Figure 79 shows model predicted daily maximum temperature versus field data along the mainstem Chehalis River at the stations: 21- $\mathrm{CH}$, near Newaukum Confluence, 22- $\mathrm{CH}$, upstream of Darigold, downstream of Darigold, and upstream of Skookumchuck. Figure 80 shows model predicted daily maximum temperature versus field data along the mainstem Chehalis River at the stations: at Galvin Bridge, 17- $\mathrm{CH}$, upstream of Black River, 18- $\mathrm{CH}$, at Oakville, 23- $\mathrm{CH}$, and at Porter.

Figure 81 shows the model predicted vertical temperature profiles versus field data at the stations: at Route 6 Bridge, $\mathrm{HL}-14$, and HL-13. Figure 82 shows the model predicted vertical temperature profiles versus field data at the stations: HL-12, HL-11, HL-10, HL-9, and HL-8. Figure 83 shows the model predicted vertical temperature profiles versus field 
data at the stations: HL-7, HL-6, HL-5, HL-4, and HL-3. Figure 84 shows the model predicted vertical temperature profiles versus field data at the stations: HL-2, at Mellen Road Bridge, and HL-1. 

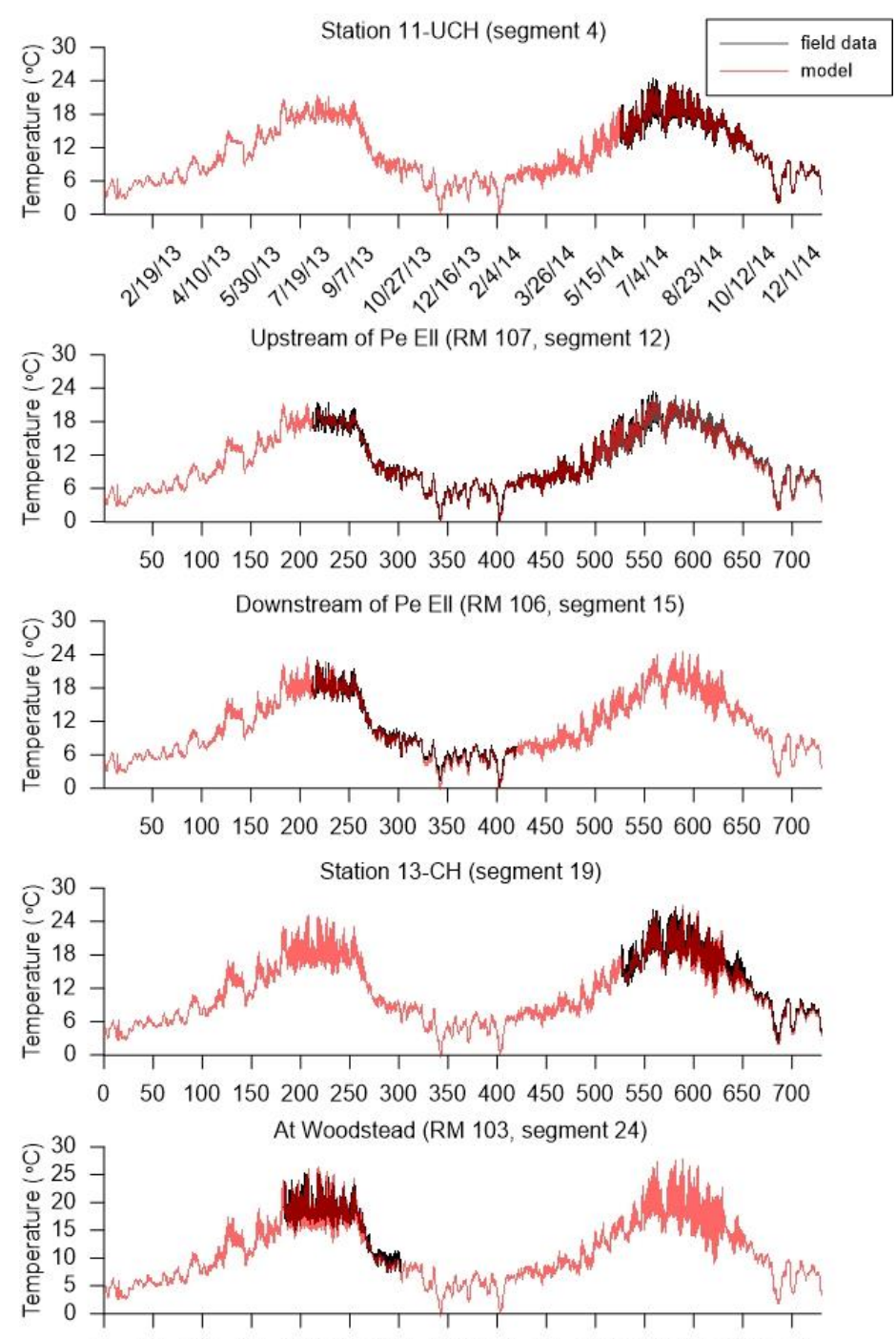

$0 \quad 50 \quad 100150200250300350400450500550600650700$
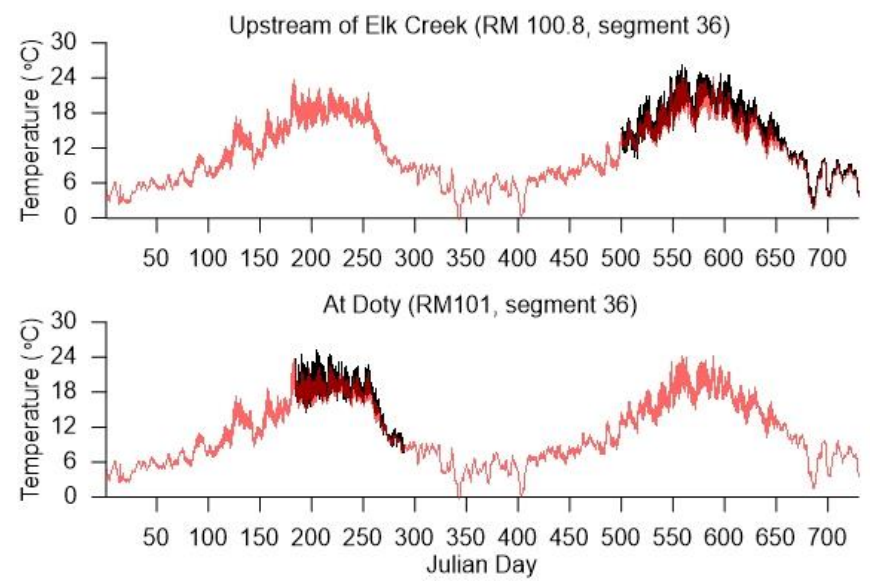

Figure 73. Model temperature predictions compared to field data at the mainstem Chehalis River stations: 11-UCH, upstream of Pe Ell, downstream of Pe Ell, 13-CH, at Woodstead, upstream of Elk Creek, and at Doty 

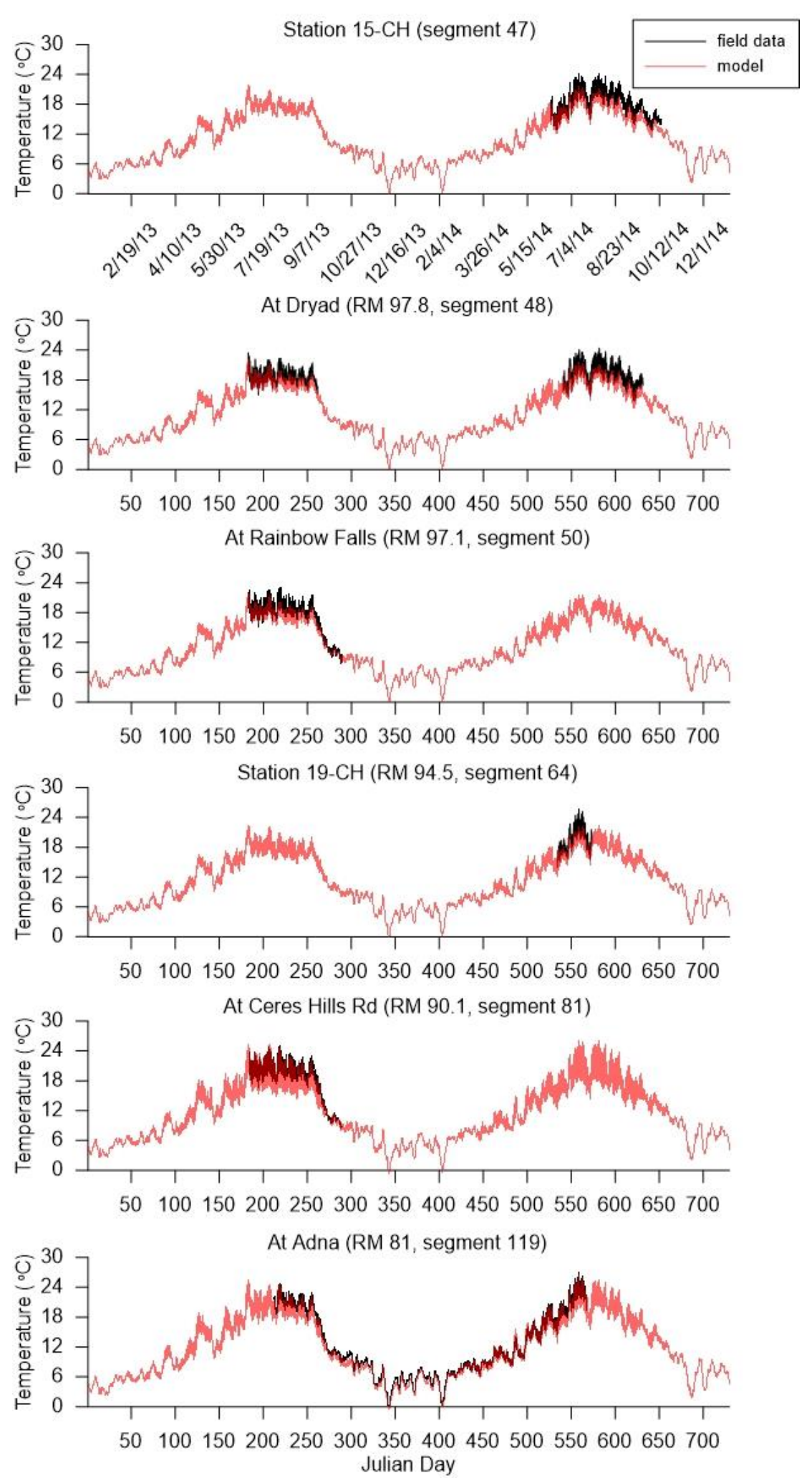

Figure 74. Model temperature predictions compared to field data at the mainstem Chehalis River stations: 15- $\mathrm{CH}$, at Dryad, at Rainbow Falls, 19-CH, at Ceres Hills Road, and at Adna 

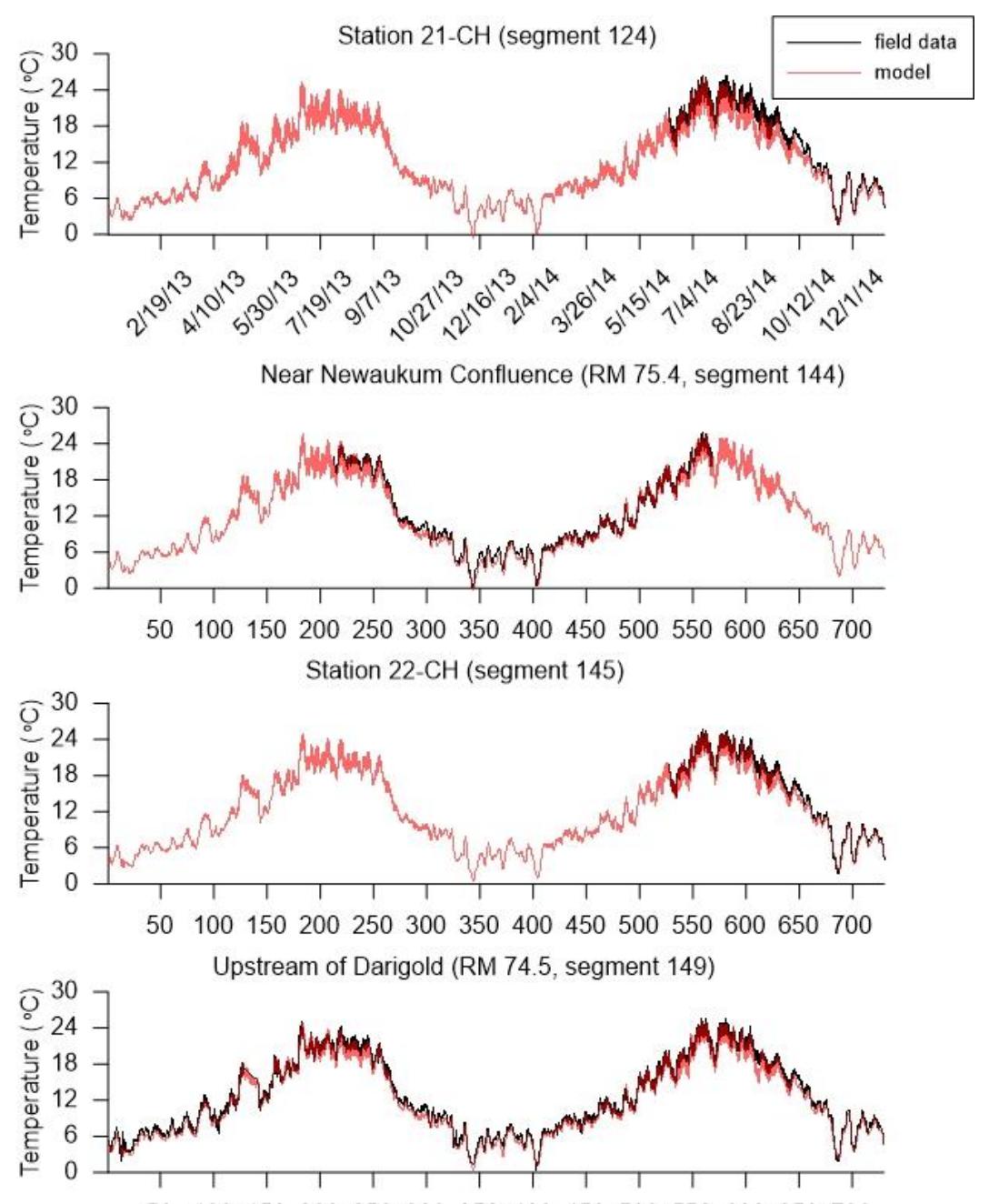

50100150200250300350400450500550600650700
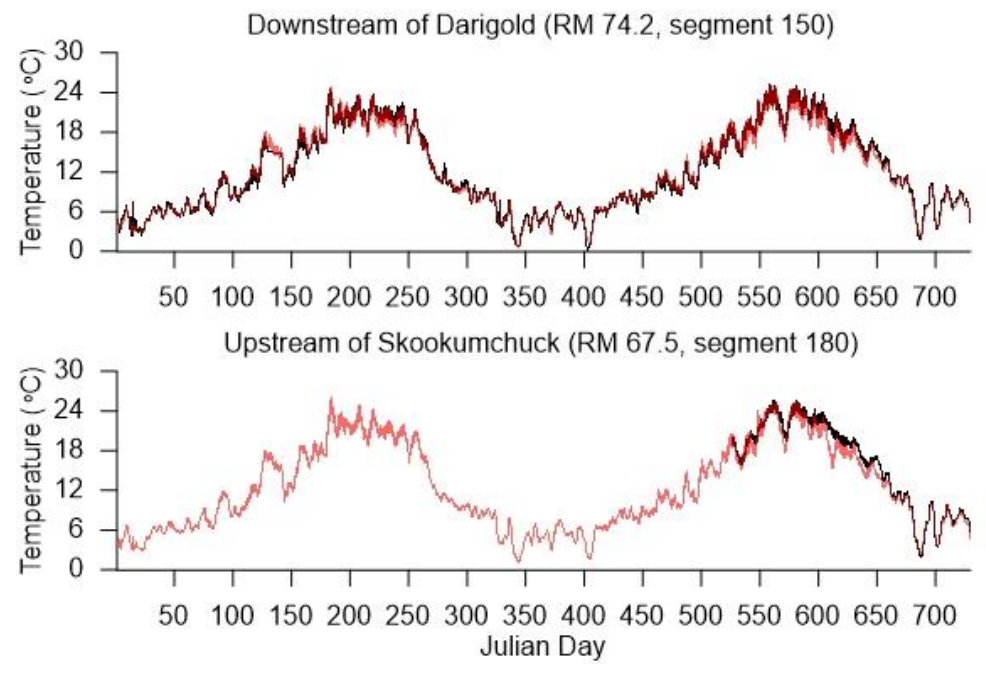

Figure 75. Model temperature predictions compared to field data at the mainstem Chehalis River stations: 21- $\mathrm{CH}$, near Newaukum Confluence, 22-CH, upstream of Darigold, downstream of Darigold, and upstream of Skookumchuck 

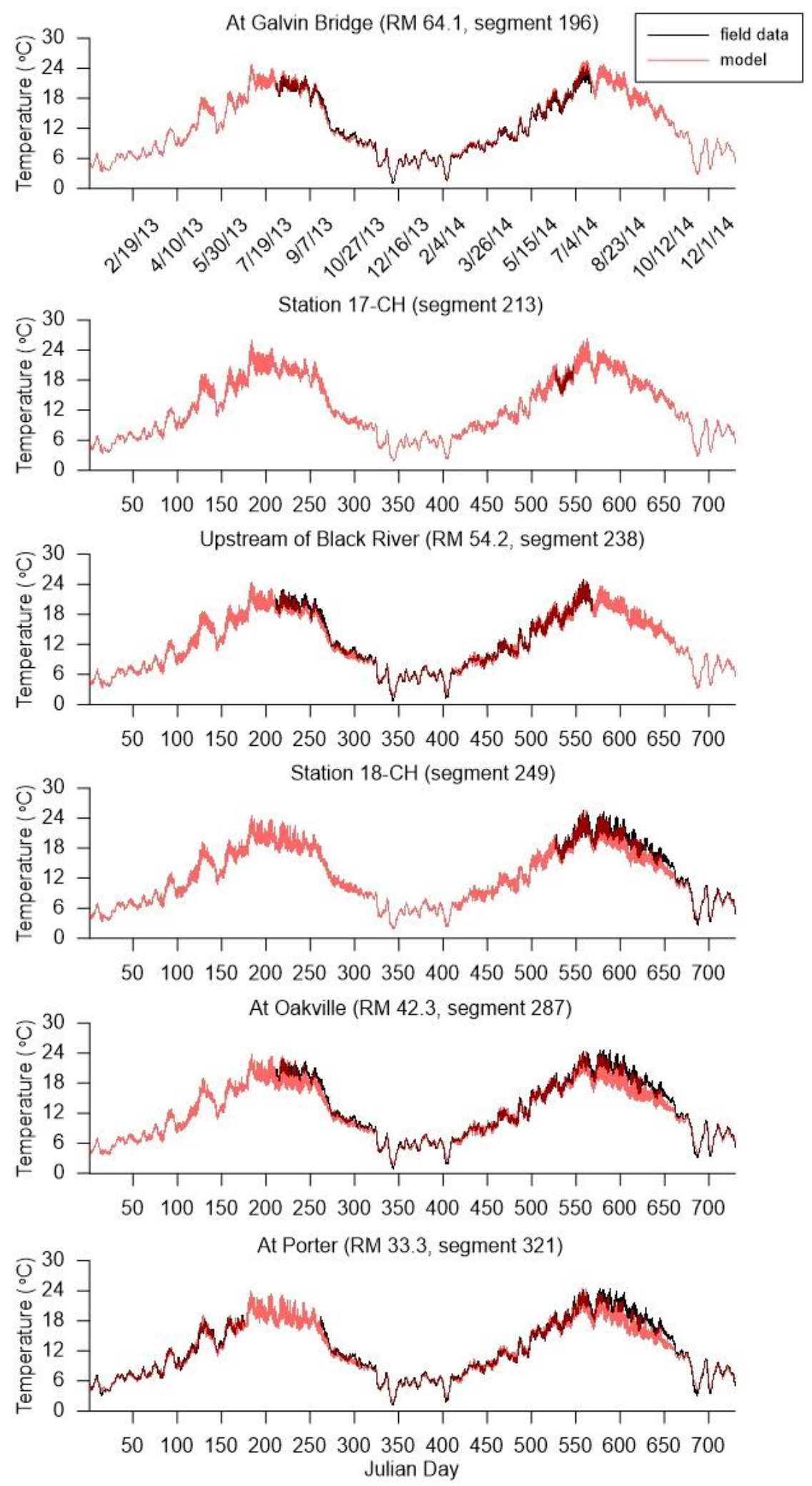

Figure 76. Model temperature outputs versus field data collected at the mainstem Chehalis River stations: at Galvin Bridge, 17-CH, upstream of Black River, $18-\mathrm{CH}$, at Oakville, 23-CH, and at Porter 

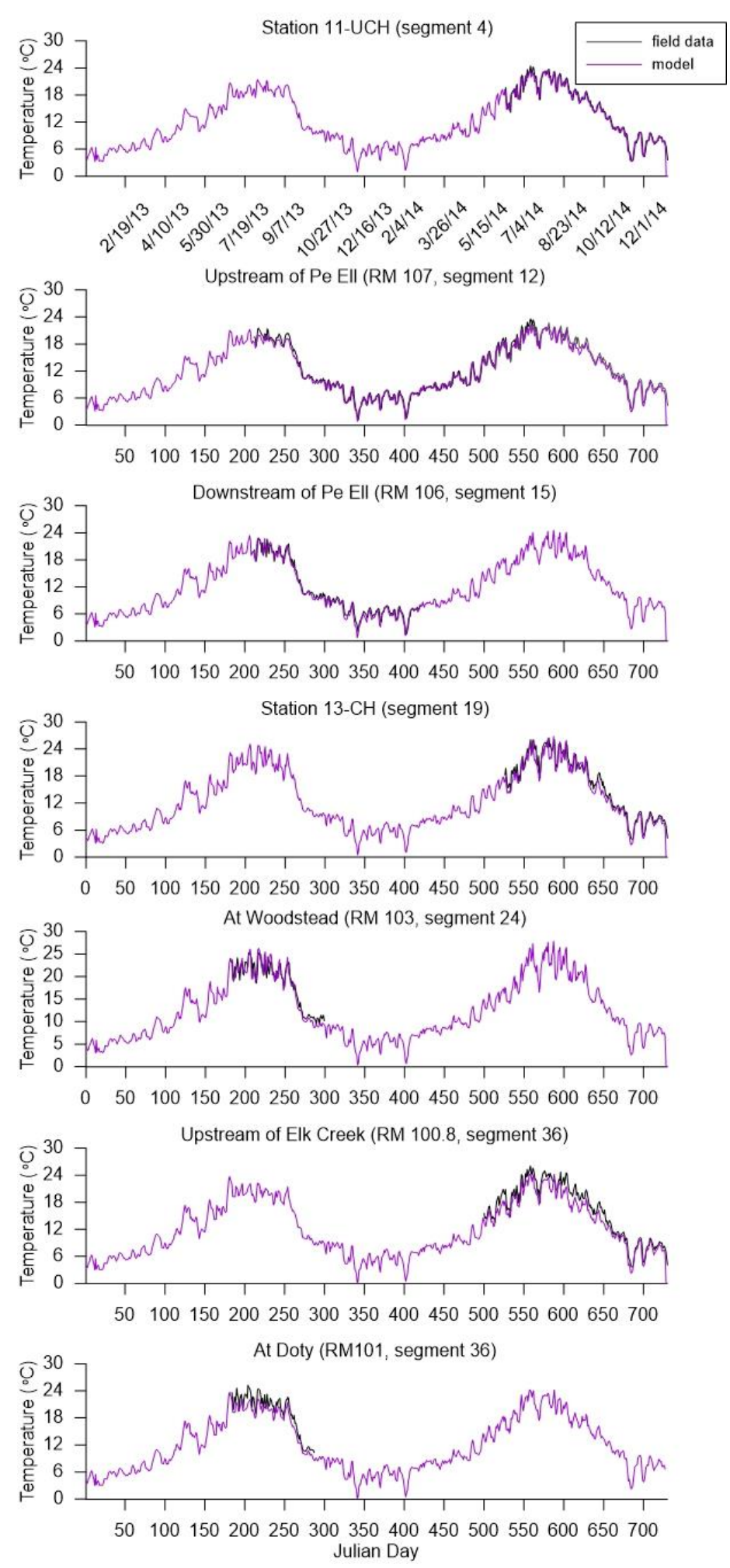

Figure 77. Model predictions of daily maximum temperatures compared to field data at the mainstem Chehalis River stations: 11-UCH, upstream of Pe Ell, downstream of Pe Ell, 13-CH, at Woodstead, upstream of Elk Creek, and at Doty 

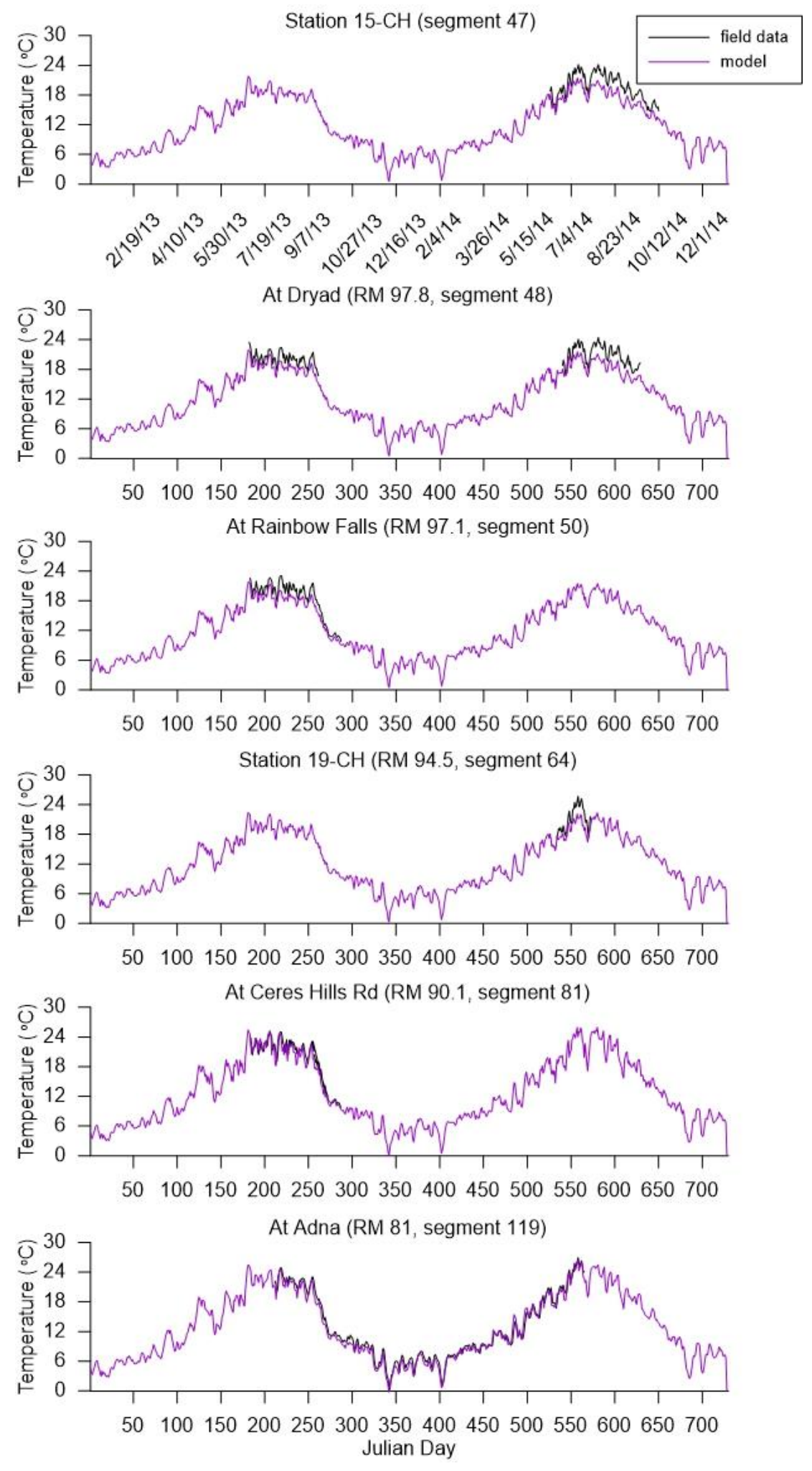

Figure 78. Model predictions of daily maximum temperatures compared to field data at the mainstem Chehalis River stations: $15-\mathrm{CH}$, at Dryad, at Rainbow Falls, $19-\mathrm{CH}$, at Ceres Hills Road, and at Adna 

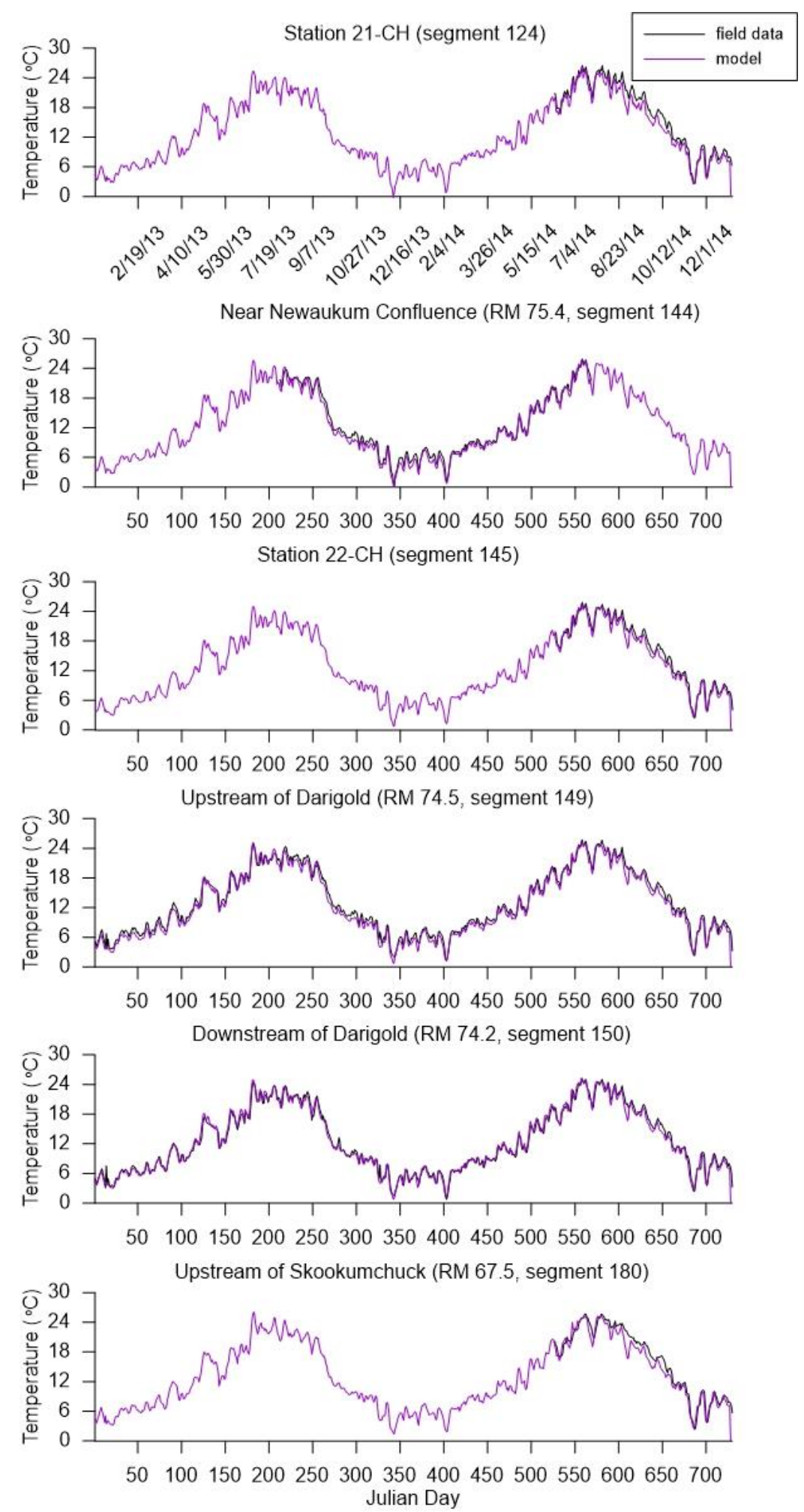

Figure 79. Model predictions of daily maximum temperatures compared to field data at the mainstem Chehalis River stations: 21-CH, near Newaukum Confluence, 22-CH, upstream of Darigold, downstream of Darigold, and upstream of Skookumchuck 

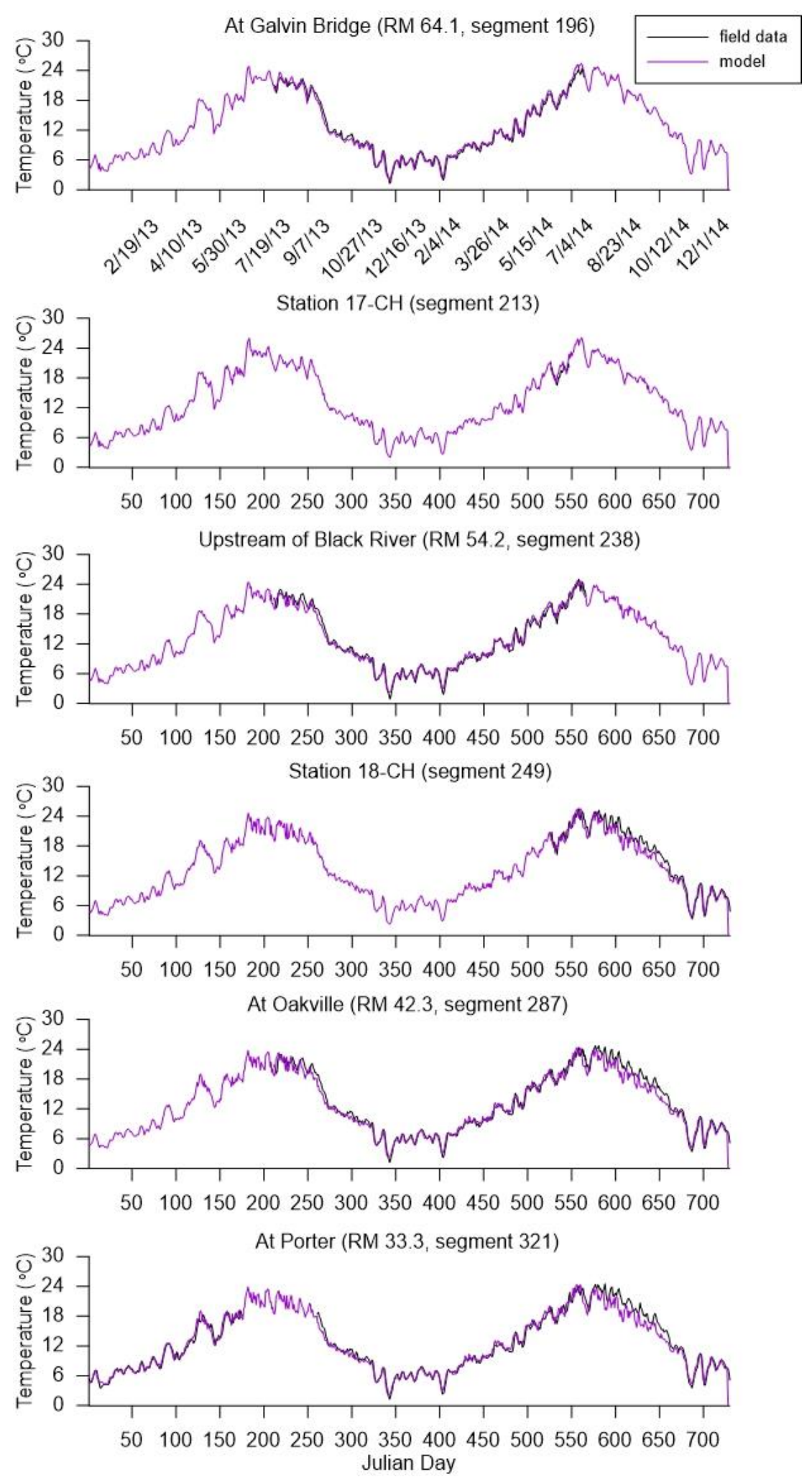

Figure 80. Model predictions of daily maximum temperatures compared to field data at the mainstem Chehalis River stations: at Galvin Bridge, 17- $\mathrm{CH}$, upstream of Black River, 18- $\mathrm{CH}$, at Oakville, and at Porter 


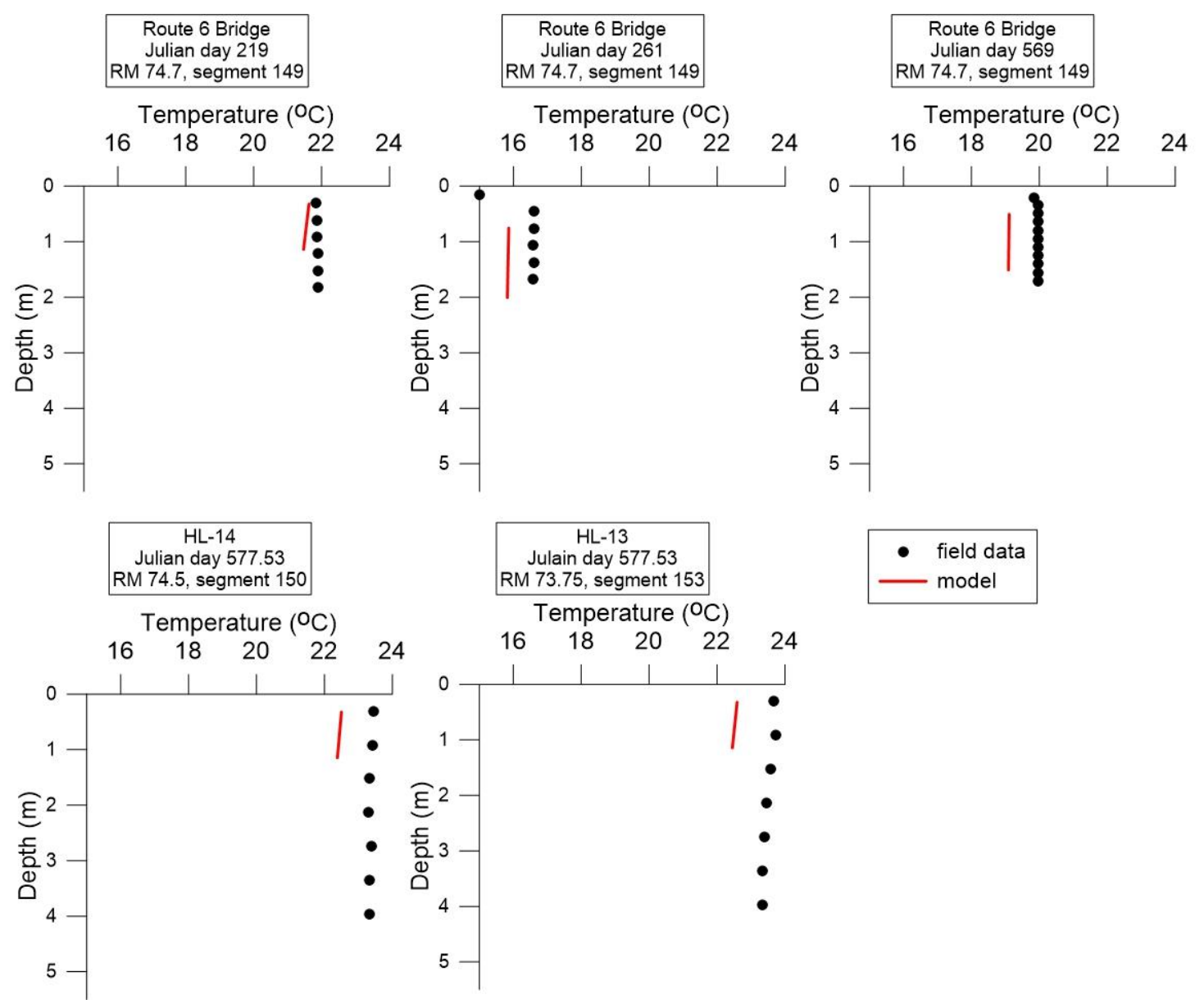

Figure 81. Model versus field data vertical temperature profiles at the mainstem Chehalis River stations: at Route 6 Bridge, $\mathrm{HL}-14$, and HL-13 


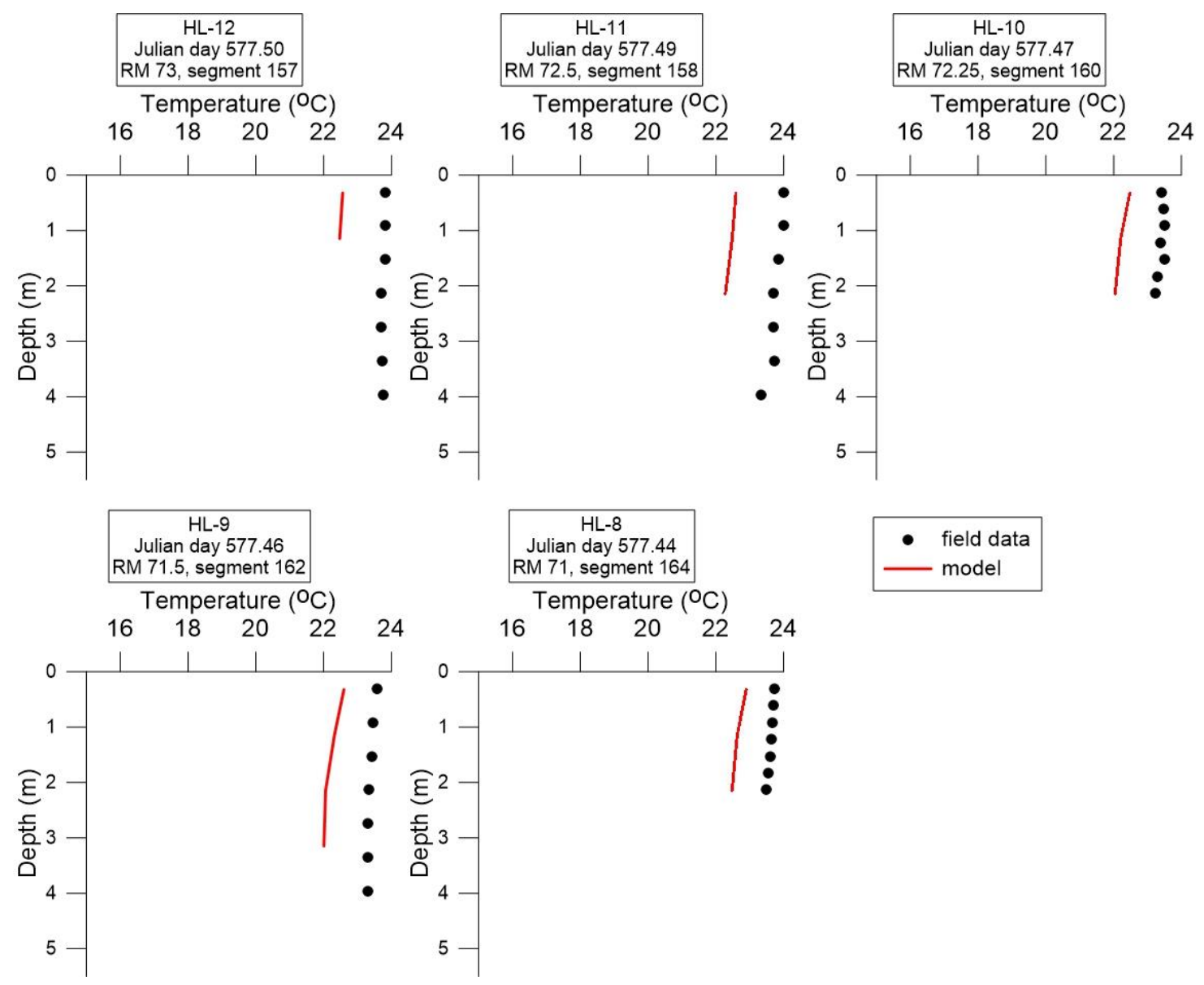

Figure 82. Model versus field data vertical temperature profiles at the mainstem Chehalis River stations:

HL-12, HL-11, HL-10, HL-9, and HL-8 


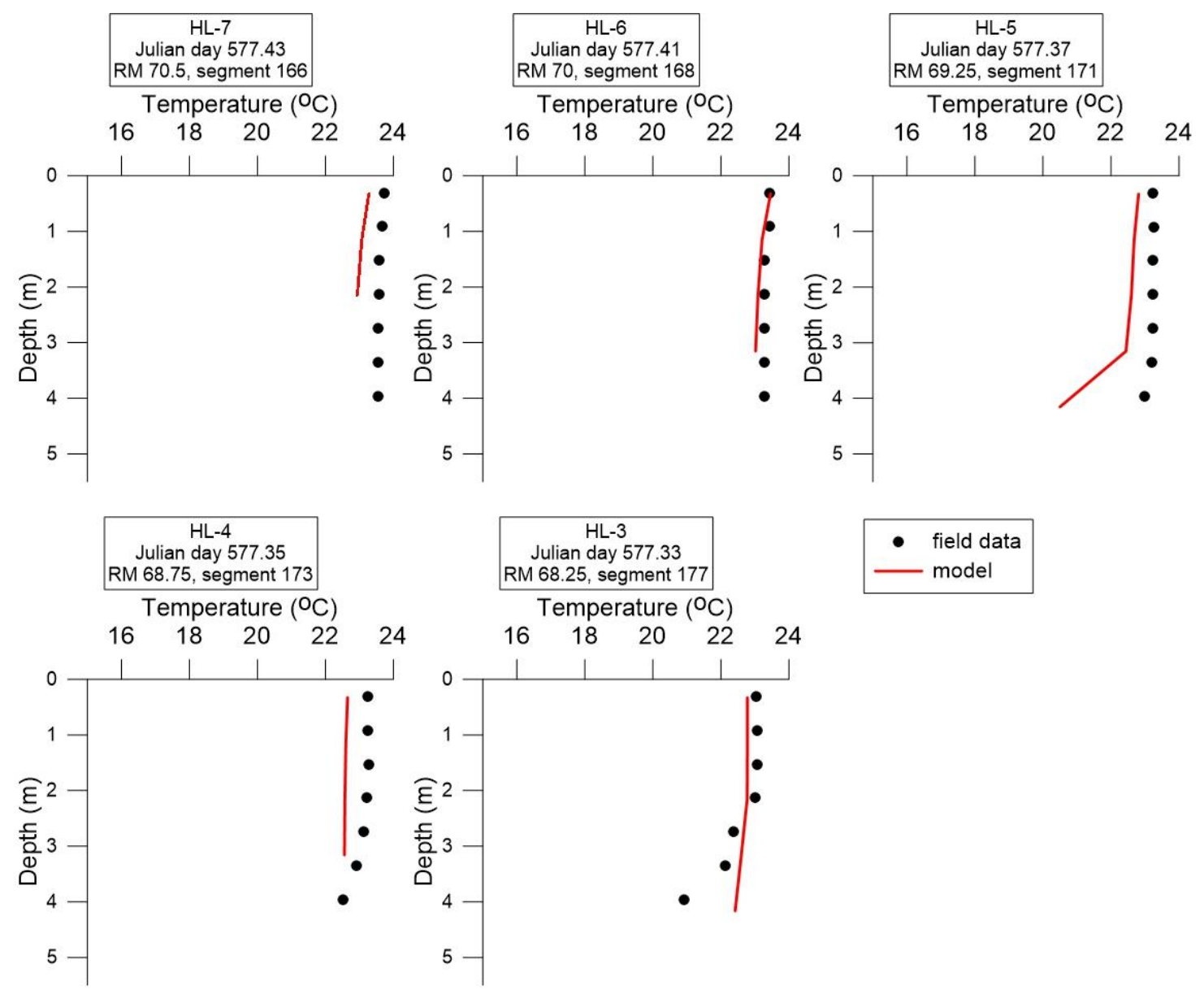

Figure 83. Model versus field data vertical temperature profiles at the mainstem Chehalis River stations: $\mathrm{HL}-7, \mathrm{HL}-6, \mathrm{HL}-5, \mathrm{HL}-4$, and HL-3 

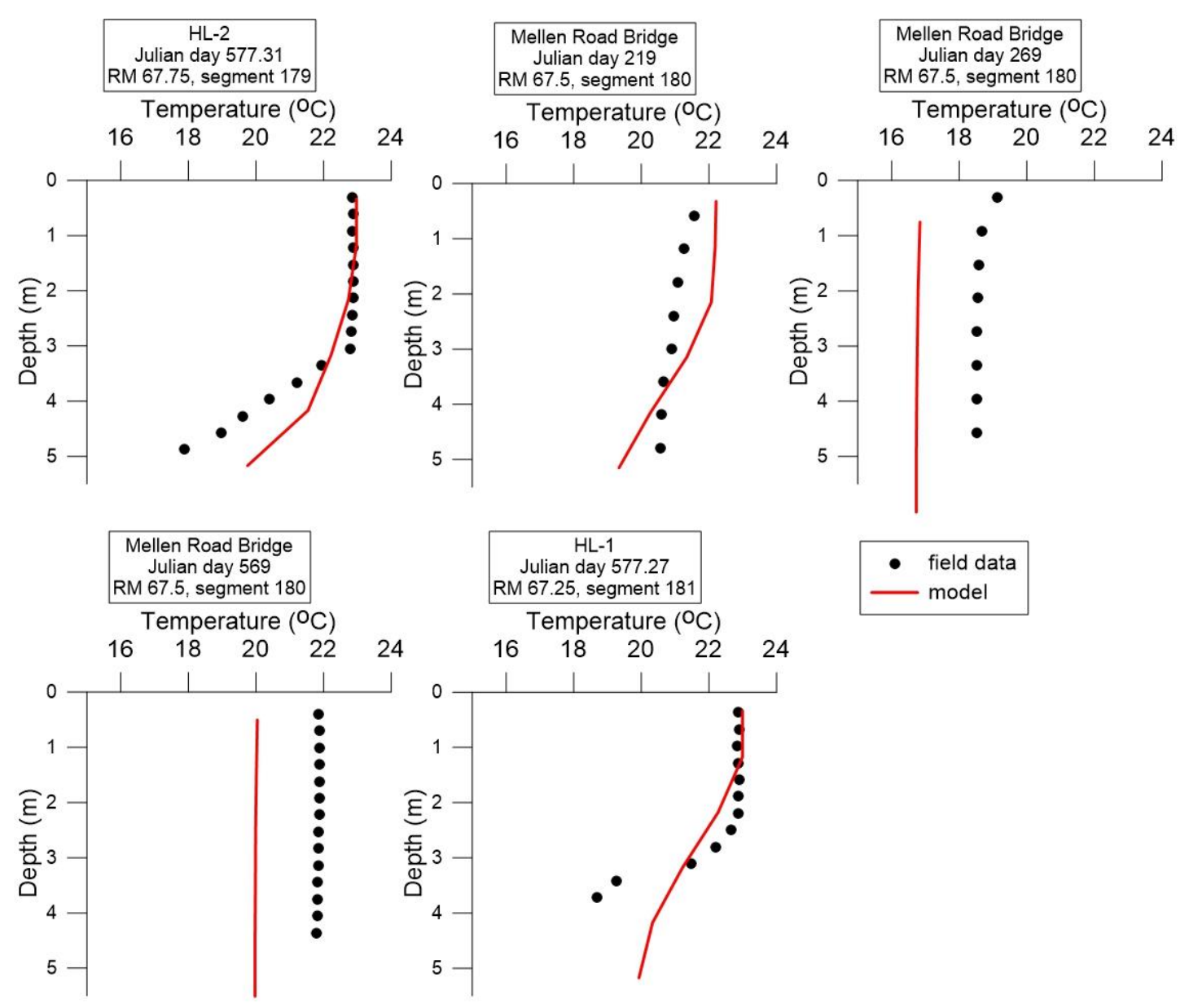

Figure 84. Model versus field data vertical temperature profiles at the mainstem Chehalis River stations:

$\mathrm{HL}-2$, Mellen Road Bridge, and HL-1 


\subsection{Temperature Error Statistics}

The closeness of model predicted temperature to field data was evaluated with error statistics, following the same procedure as with flow. Weighted average mean error, absolute mean error, and root mean square error values were computed using

$$
\begin{aligned}
M E_{\text {weighted }} & =\frac{\Sigma(M E \times N)}{\Sigma N} \\
A M E_{\text {weighted }} & =\frac{\Sigma(A M E \times N)}{\Sigma N} \\
R M S E_{\text {weighted }} & =\frac{\Sigma(R M S E \times N)}{\Sigma N}
\end{aligned}
$$

Table 21 shows error statistics for model predicted temperature values compared to field data at stations along the mainstem Chehalis River ranging between upstream of Pe Ell and Porter, WA. The error statistics for comparisons of model predicted daily maximum temperatures to field data is shown in Table 22 . The model is continuously improving, and as such these results are current, though not final. After further model improvements these errors are expected to decrease. The current results show the model was generally too cold at most locations, especially during the summer months.

Table 21. Error statistics for temperature comparisons between model predictions and field data along the mainstem Chehalis River ranging between upstream of Pe Ell and Porter, WA

\begin{tabular}{|c|c|c|c|c|}
\hline Location & $\begin{array}{c}\text { Number of } \\
\text { Model-Data } \\
\text { Comparisons }\end{array}$ & $\begin{array}{c}\text { Mean Error } \\
\left({ }^{\circ} \mathrm{C}\right)\end{array}$ & $\begin{array}{c}\text { Absolute } \\
\text { Mean Error } \\
\left({ }^{\circ} \mathrm{C}\right)\end{array}$ & $\begin{array}{c}\text { Root Mean } \\
\text { Square Error } \\
\left({ }^{\circ} \mathrm{C}\right)\end{array}$ \\
\hline 11-UCH & 9810 & 0.067 & 0.25 & 0.435 \\
\hline Upstream Pe Ell & 17051 & -0.031 & 0.402 & 0.616 \\
\hline Upstream of Pe Ell as well & 11006 & -0.163 & 0.556 & 0.679 \\
\hline Downstream Pe Ell & 17486 & -0.037 & 0.824 & 1.15 \\
\hline Station 13-CH & 9764 & -0.680 & 1.01 & 1.42 \\
\hline At Woodstead & 11372 & -0.591 & 1.03 & 1.30 \\
\hline
\end{tabular}




\begin{tabular}{|c|c|c|c|c|}
\hline Location & $\begin{array}{c}\text { Number of } \\
\text { Model-Data } \\
\text { Comparisons }\end{array}$ & $\begin{array}{c}\text { Mean Error } \\
\left({ }^{\circ} \mathrm{C}\right)\end{array}$ & $\begin{array}{c}\text { Absolute } \\
\text { Mean Error } \\
\left({ }^{\circ} \mathrm{C}\right)\end{array}$ & $\begin{array}{c}\text { Root Mean } \\
\text { Square Error } \\
\left({ }^{\circ} \mathrm{C}\right)\end{array}$ \\
\hline At Doty & 10107 & -0.810 & 1.12 & 1.44 \\
\hline Upstream Elk Creek & 11004 & -0.900 & 1.08 & 1.43 \\
\hline Station 15-CH & 6036 & -1.89 & 1.89 & 2.03 \\
\hline At Dryad & 8166 & -1.70 & 1.71 & 1.86 \\
\hline At Rainbow Falls & 30619 & -1.22 & 1.28 & 1.52 \\
\hline $\begin{array}{c}\text { Between Rainbow Falls } \\
\text { and Ceres Hills Road }\end{array}$ & 1876 & -1.71 & 1.71 & 1.84 \\
\hline At Ceres Hills Road & 10113 & -1.42 & 1.49 & 1.76 \\
\hline At Adna & 17043 & -0.796 & 0.883 & 1.10 \\
\hline Station 21-CH & 13430 & -1.26 & 1.32 & 1.59 \\
\hline Upstream of Newaukum & 17082 & -0.698 & 0.838 & 1.024 \\
\hline Station 22-CH & 9709 & -0.818 & 0.885 & 1.08 \\
\hline Upstream of Darigold & 60920 & -0.632 & 0.719 & 0.854 \\
\hline Downstream of Darigold & 64513 & -0.125 & 0.452 & 0.600 \\
\hline Upstream Skookumchuck & 9764 & -0.814 & 0.937 & 1.26 \\
\hline At Galvin Bridge & 17090 & 0.052 & 0.354 & 0.481 \\
\hline Station 17-CH & 984 & 0.002 & 0.653 & 0.787 \\
\hline Upstream Black River & 17142 & -0.221 & 0.530 & 0.714 \\
\hline Station 18-CH & 9757 & -0.988 & 1.19 & 1.54 \\
\hline At Oakville & 16894 & -0.445 & 0.683 & 0.963 \\
\hline Near Oakville & 8080 & -1.20 & 1.36 & 1.73 \\
\hline At Porter & 30909 & -0.410 & 0.693 & 1.05 \\
\hline Weighted Average Error statistics: & -0.58 & 0.818 & 1.04 \\
\hline
\end{tabular}

Table 22. Error statistics for daily maximum temperature comparisons between model predictions and field data along the mainstem Chehalis River ranging between upstream of Pe Ell and Porter, WA

\begin{tabular}{|c|c|c|c|c|}
\hline Location & $\begin{array}{c}\text { Number of } \\
\text { Model-Data } \\
\text { Comparisons }\end{array}$ & $\begin{array}{c}\text { Mean Error } \\
\left({ }^{\circ} \mathrm{C}\right)\end{array}$ & $\begin{array}{c}\text { Absolute } \\
\text { Mean Error } \\
\left({ }^{\circ} \mathrm{C}\right)\end{array}$ & $\begin{array}{c}\text { Root Mean } \\
\text { Square Error } \\
\left({ }^{\circ} \mathrm{C}\right)\end{array}$ \\
\hline 11-UCH & 204 & -0.194 & 0.738 & 0.985 \\
\hline Upstream Pe Ell & 354 & -0.315 & 0.716 & 0.908 \\
\hline Upstream of Pe Ell as well & 228 & -0.421 & 0.800 & 1.03 \\
\hline Downstream Pe Ell & 362 & 0.470 & 1.18 & 1.70 \\
\hline Station 13-CH & 202 & -0.824 & 1.17 & 1.48 \\
\hline At Woodstead & 116 & -0.422 & 1.20 & 1.46 \\
\hline At Doty & 103 & -1.65 & 1.69 & 1.92 \\
\hline Upstream Elk Creek & 228 & -1.50 & 1.56 & 1.83 \\
\hline Station 15-CH & 124 & -2.25 & 2.28 & 2.48 \\
\hline
\end{tabular}




\begin{tabular}{|c|c|c|c|c|}
\hline Location & $\begin{array}{c}\text { Number of } \\
\text { Model-Data } \\
\text { Comparisons }\end{array}$ & $\begin{array}{c}\text { Mean Error } \\
\left({ }^{\circ} \mathrm{C}\right)\end{array}$ & $\begin{array}{l}\text { Absolute } \\
\text { Mean Error } \\
\left({ }^{\circ} \mathrm{C}\right)\end{array}$ & $\begin{array}{c}\text { Root Mean } \\
\text { Square Error } \\
\left({ }^{\circ} \mathrm{C}\right)\end{array}$ \\
\hline At Dryad & 169 & -2.08 & 2.10 & 2.31 \\
\hline At Rainbow Falls & 104 & -1.59 & 1.59 & 1.83 \\
\hline $\begin{array}{l}\text { Between Rainbow Falls } \\
\text { and Ceres Hills Road }\end{array}$ & 40 & -1.99 & 2.07 & 2.39 \\
\hline At Ceres Hills Road & 107 & -0.639 & 1.15 & 1.46 \\
\hline At Adna & 353 & -0.459 & 0.799 & 0.998 \\
\hline Station $21-\mathrm{CH}$ & 201 & -1.18 & 1.27 & 1.51 \\
\hline Upstream of Newaukum & 356 & -0.587 & 0.776 & 0.944 \\
\hline Station $22-\mathrm{CH}$ & 201 & -0.668 & 0.906 & 1.11 \\
\hline Upstream of Darigold & 706 & -0.615 & 0.801 & 0.962 \\
\hline Downstream of Darigold & 703 & -0.125 & 0.579 & 0.780 \\
\hline Upstream Skookumchuck & 202 & -0.894 & 1.16 & 1.41 \\
\hline At Galvin Bridge & 354 & 0.073 & 0.589 & 0.733 \\
\hline Station $17-\mathrm{CH}$ & 22 & 0.647 & 1.09 & 1.25 \\
\hline Upstream Black River & 355 & -0.030 & 0.645 & 0.832 \\
\hline Station $18-\mathrm{CH}$ & 202 & -0.812 & 1.15 & 1.49 \\
\hline At Oakville & 351 & -0.179 & 0.692 & 0.920 \\
\hline Near Oakville & 167 & -0.987 & 1.24 & 1.60 \\
\hline At Porter & 643 & -0.261 & 0.759 & 1.08 \\
\hline \multicolumn{2}{|c|}{ Weighted Average Error statistics: } & -0.517 & 0.944 & 1.19 \\
\hline
\end{tabular}

\subsection{Flow and Water Level}

Flow volumes, depth, and timing were important to temperature calibration, so it was important that flow and water level calibration was as accurate as possible. Areas that were too shallow were often too warm and areas that were too deep were often too cool. Accurate depth preditions were necessary for capturing stratification dynamics. Travel time through the system was important, as water that moved slowly had more time to heat up, while water that moved through the system more quickly had less time to absorb solar radiation. 


\subsection{Bathymetry}

\subsubsection{Channel Friction and Slope}

Similar to flow calibration, channel friction and slope impacted the timing of peak temperature values. The timing and magnitude of temperature was important for calibration in order to accurately describe the temperature variation.

\subsubsection{Segment Widths and Depths}

Ensuring the widths of the segment layers were realistic was also important for temperature calibration. Since widths were calculated through interpolation and averaging of field data to model segment locations, it was important to hand check many cross sections and ensure that field data and model estimates of segment geometry were similar. Unrealistic layer widths impacted water depths and temperature. This was especially important for the vertical temperature profiles and continuous monitoring stations during the low flow summer months. Sometimes narrow segment widths caused the water to be deep, so that diurnal temperature swings were not as large as seen in field data. Or conversely, sometimes wide segment widths resulted in shallow water that had diurnal swings in temperature greater than field data showed. Figure 85 shows how widening the lower layers in the bathymetry around the stations at Dryad and Rainbow Falls decreased water depths and resulted in temperature values closer to field data during the summer of 2013. 

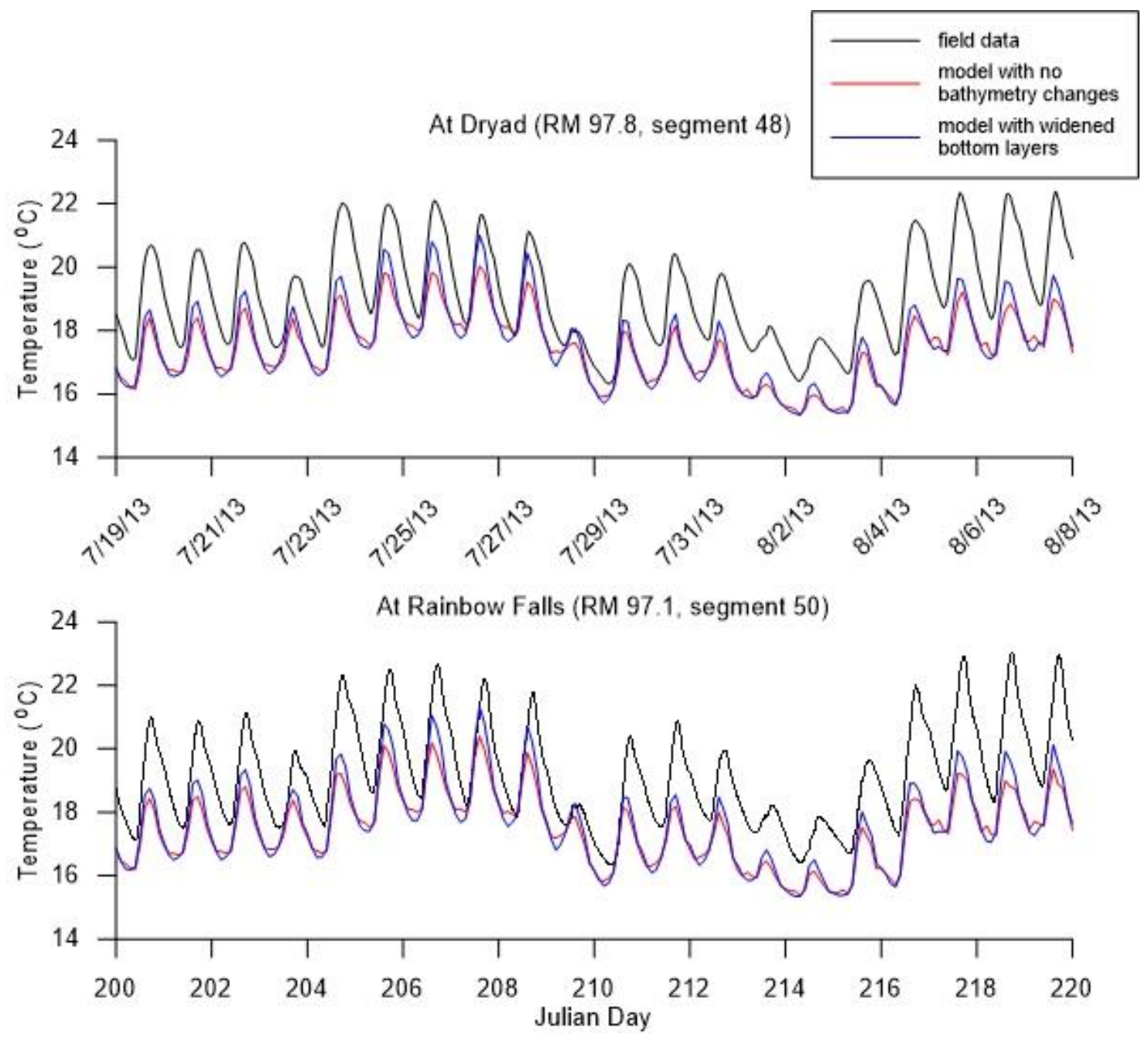

Figure 85. Comparison of model versus field data at Dryad and Rainbow Falls for before and after bathymetry segment width changes were made

\subsection{Boundary Condition Temperature}

Accurate input temperature values were important for temperature calibration. Ensuring field data quality and using appropriate temperature estimation techniques was important to this process, especially since so many tributaries lacked temperature field data. For example, the Newaukum River was originally used to create regression relationships to estimate missing tributary data. However, this tributary followed 
different trends than other tributaries with the timing of peak and minimum temperatures. This lead to poor results when comparing model temperature predictions to field data. Choosing a different temperature gage on the mainstem Chehalis River produced a vast improvement to temperature results. Figure 86 shows the sensitivity of the model to boundary tributary temperature inputs, giving very different results when missing tributary data were estimated using regression to the Newaukum River versus regression to the Chehalis River Downstream of Darigold WWTP.
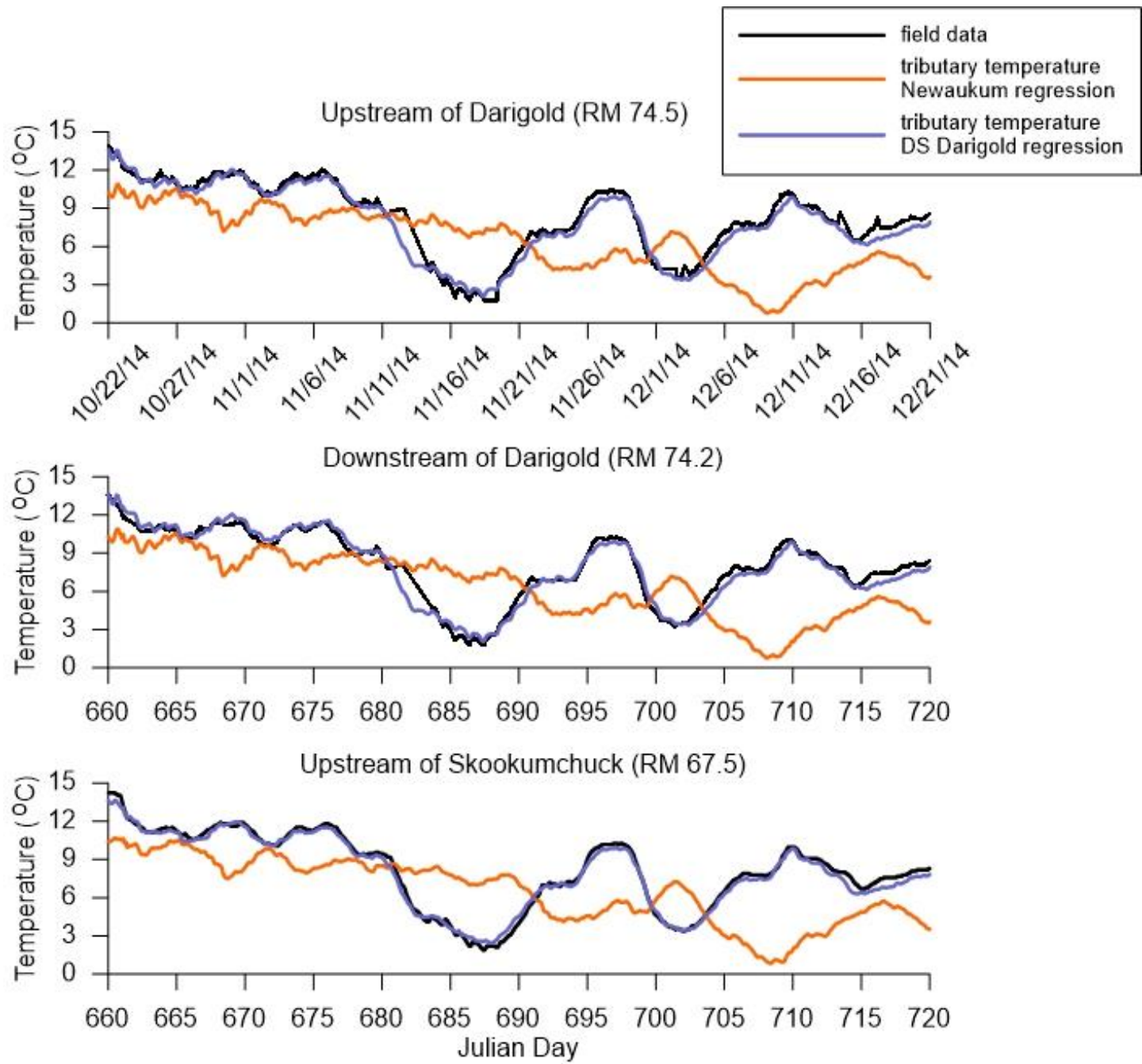

Figure 86. Comparison of model versus field data temperature when boundary tributary temperatures were estimated using Newaukum River versus Chehalis River Downstream of Darigold WWTP data 
Input temperature values for groundwater also impacted model temperature predictions, especially during the low flow summer months when the cold groundwater accounted for a larger portion of the mainstem flow. Very little temperature data were available for groundwater, with usually only one value for a given reach or no data at all. Thus, seasonal variations in groundwater temperatures were not known. Originally, a single data value was used for groundwater during the entire model simulation. However, adding $2{ }^{\circ} \mathrm{C}$ to groundwater inputs during the summer months aided the model in staying warm enough during these seasons.

\subsection{Meteorological Data}

Meteorological data, such as cloud cover, wind speed, and solar radiation also impacted resulting temperatures predictions. CE-QUAL-W2 was set to interpolate between meteorological input data values, so having small time intervals between values was important. Hence, meteorological data gaps were often filled to improve the temperature calibration.

Cloud cover was important for temperature calibration. When the Thrash Creek cloud cover data set was implemented for the entire system, resulting water temperatures were much too cold. Thrash Creek is located higher at a higher elevation near the upstream boundary, so is generally cloudier than the lower reaches of the river. Estimating cloud cover based off of solar radiation improved model temperature values. 


\subsection{Wind Sheltering}

A wind sheltering function was available in the model that either amplified or reduced the input wind speed values by a multiplier. For example, a wind sheltering coefficient of 0.5 meant the model would use only half the input wind speed in calculations of longitudinal momentum and evaporation. This took into account sheltering characteristics of the river surroundings, such as topography and wind breaks from trees. This was most important in the slow, deep, lake-like section where the river was more sensitive to wind effects. Reducing wind had a warming effect by decreasing summer evaporation.

\subsection{Evaporation}

Evaporation coefficients were specified for each waterbody, and the amount of evaporation was a function of wind speed. Evaporation was computed from:

$f(W)=a+b W^{C}$ (Cole and Wells, 2016)

Where

$\mathrm{f}(\mathrm{W})$ is a wind speed function in $\mathrm{W} \mathrm{m}^{-2} \mathrm{~mm} \mathrm{Hg}^{-1}$

$a, b$, and c are empirical coefficients

$\mathrm{W}$ is the wind speed measured $2 \mathrm{~m}$ above the ground

Default model coefficients according to Edinger, et al (1974) as listed in the CE-QUALW2 user manual (Cole and Wells, 2016) were initially employed. The a coefficient equaled $9.2 \mathrm{~W} \mathrm{~m}^{-2} \mathrm{mmHg}^{-1}$, the $\mathrm{b}$ coefficient equaled $0.46 \mathrm{~W} \mathrm{~m}^{-2} \mathrm{mmHg}^{-1}$, and the coefficient 
equaled 2.0. The a coefficient was then decreased to $4.5 \mathrm{~W} \mathrm{~m}^{-2} \mathrm{mmHg}^{-1}$ in order to aid the model in staying warm during the summer monhts.

\subsection{Sediments}

The loss of short wave solar radiation to the channel bottom can affect water temperature predictions. CE-QUAL-W2 allows the user to specify how much incident solar radiation that makes it to the sediments is reradiated back into the water column or absorbed. This was adjusted by altering the TSEDF coefficient, which can range from 0 to 1. When TSEDF equals 1 all incident solar radiation that hits the bottom of the channel is reflected back and available for absorption in the water column. When TSEDF equals 0 all short-wave solar radiation that reaches the bottom of the channel is lost to the sediments (Cole and Wells, 2016). A high TSEDF had a warming effect, while a low TSEDF had a cooling effect. Figure 87 , Figure 88 , and Figure 89 show model sensitivity to changes in TSEDF values when TSEDF equaled $0.3,0.6$, and 0.8 respectively, at the mainstem Chehalis River stations: downstream of Pe Ell, station 13-CH, at Woodstead, and at Doty. Peak temperatures increased as a result of increasing TSEDF. 

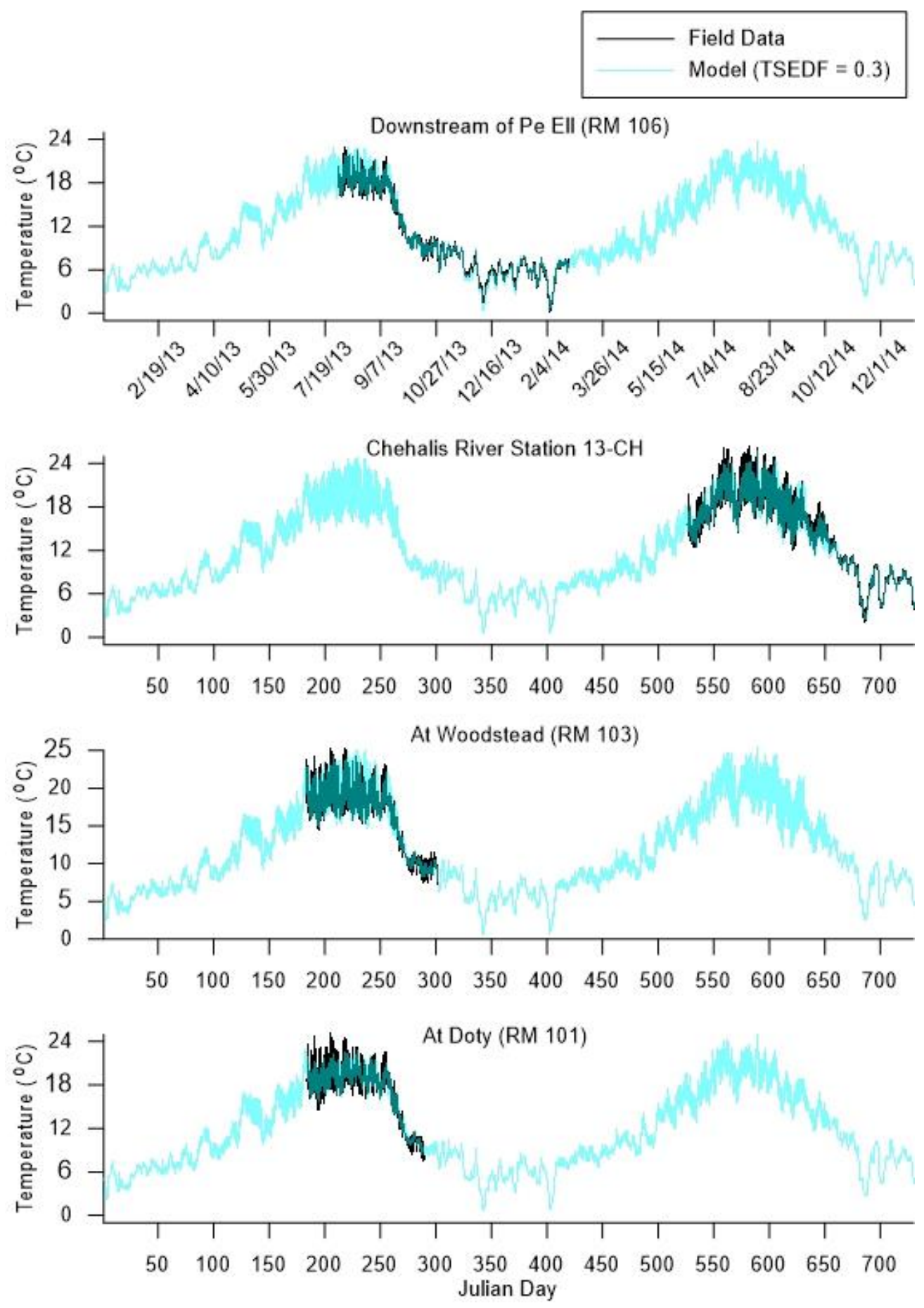

Figure 87. Model temperature versus field data at downstream of Pe Ell, station 13-CH, at Woodstead, and at Doty when TSEDF equaled 0.3 


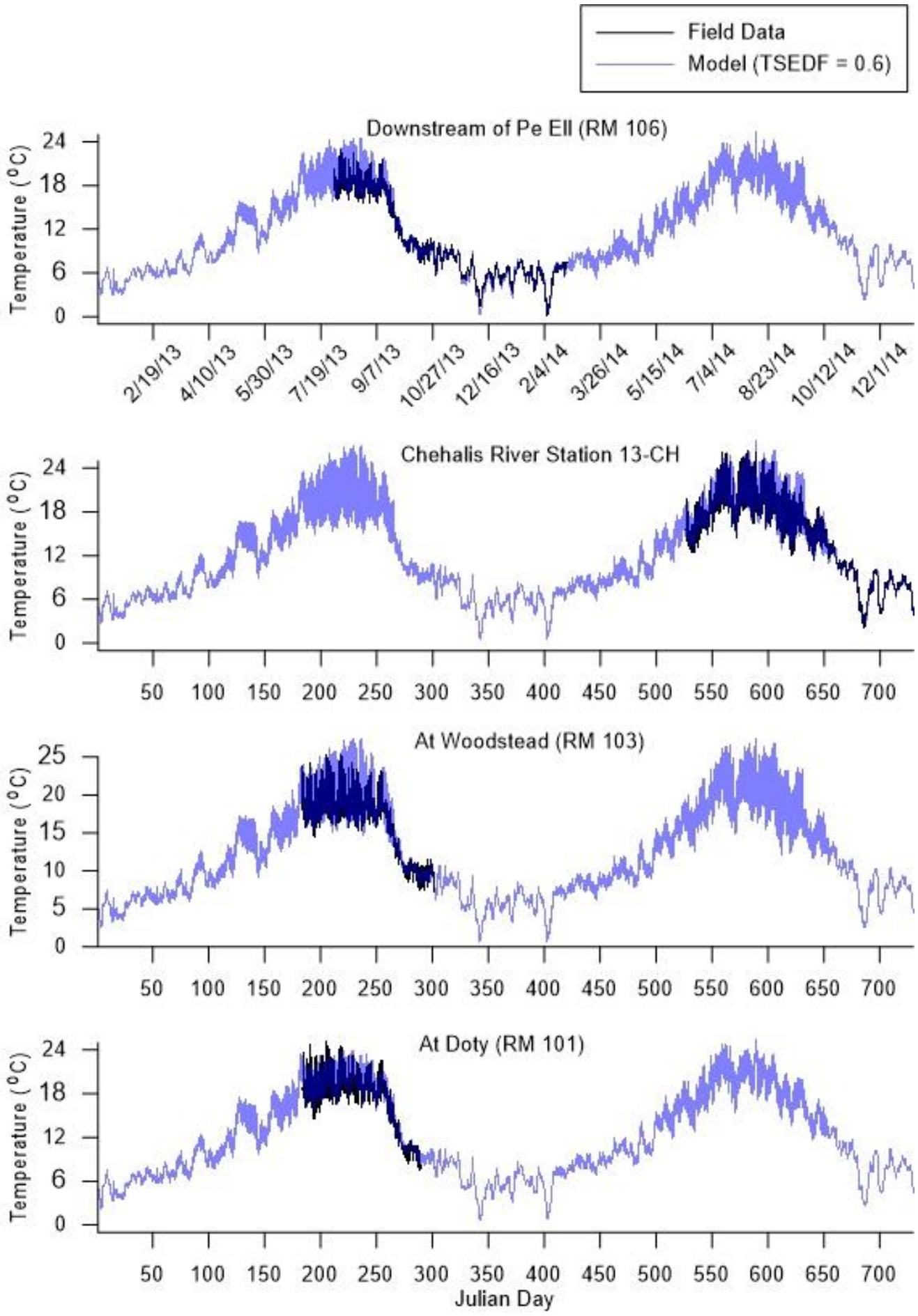

Figure 88. Model temperature versus field data at downstream of Pe Ell, station $13-\mathrm{CH}$, at Woodstead, and at Doty when TSEDF equaled 0.6 


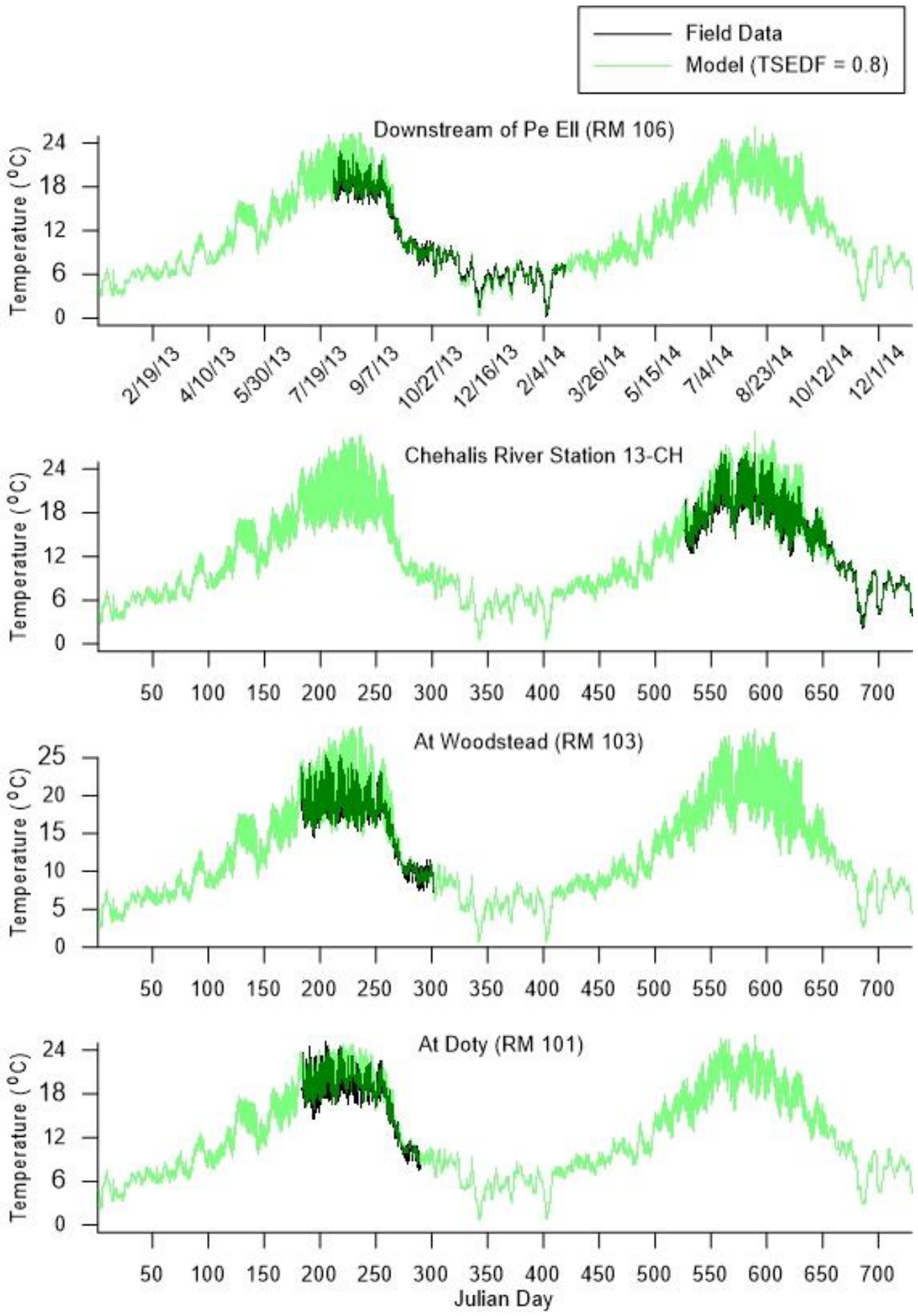

Figure 89. Model temperature versus field data at downstream of Pe Ell, station 13-CH, at Woodstead, and at Doty when TSEDF equaled 0.8 


\section{Model Calibration: Water Quality}

Similar to flow and temperature calibration, model predictions of water quality constituents were compared to mainstem Chehalis River field data. Data were provided from Anchor QEA (2014) and WADOE (2016g, 2016h). Table 23 lists the water quality sample sites on the mainstem Chehalis River used for comparisons of model predictions and field data. Table 24 lists the vertical dissolved oxygen stations, locations, and dates when data were collected on the Chehalis River. Figure 90 shows a longitudinal view of water quality sample sites along the river.

Table 23. Water quality stations on the mainstem Chehalis River used to compare to model predictions

\begin{tabular}{|c|c|c|c|c|c|}
\hline Organization & Station ID & Description & Data available & $\begin{array}{c}\text { Model } \\
\text { Segment }\end{array}$ & $\begin{array}{l}\text { River } \\
\text { Mile }\end{array}$ \\
\hline Anchor QEA & CHL-PEL-US & $\begin{array}{c}\text { Chehalis Upstream of } \\
\text { Pe Ell }\end{array}$ & $\begin{array}{c}\mathrm{DO}, \mathrm{FC}, \mathrm{NH} 3, \mathrm{NO}, \\
\text { OrthoP, } \mathrm{pH}, \mathrm{TP}, \& \mathrm{TSS}\end{array}$ & 12 & 107 \\
\hline Anchor QEA & CHL-PEL-DS & $\begin{array}{c}\text { Chehalis } \\
\text { Downstream of Pe Ell }\end{array}$ & OrthoP & 15 & 106 \\
\hline WADOE & $23 \mathrm{~A} 160$ & $\begin{array}{c}\text { Chehalis River at } \\
\text { Dryad }\end{array}$ & $\begin{array}{c}\mathrm{DO}, \mathrm{FC}, \mathrm{NH} 3, \mathrm{NO}, \\
\text { OrthoP, } \mathrm{pH}, \mathrm{TP}, \& \mathrm{TSS}\end{array}$ & 48 & 99.5 \\
\hline Anchor QEA & CHL-US-SF & $\begin{array}{c}\text { Chehalis River } \\
\text { Upstream of South } \\
\text { Fork }\end{array}$ & $\begin{array}{c}\text { BOD, chl-a, DO, NH3, } \\
\text { NO3, OrthoP, pH, } \\
\text { TKN, TP, \& TSS }\end{array}$ & 81 & 90 \\
\hline Anchor QEA & CHL-ADNA & Chehalis Near Adna & $\begin{array}{c}\text { BOD, chl-a, DO, NH3, } \\
\text { NO3, OrthoP, pH, } \\
\text { TKN, TP, \& TSS }\end{array}$ & 119 & 81 \\
\hline Anchor QEA & CHL-US-NWK & $\begin{array}{c}\text { Chehalis Upstream of } \\
\text { Newaukum } \\
\text { Confluence }\end{array}$ & $\begin{array}{c}\text { BOD, chl-a, DO, NH3, } \\
\text { NO3, OrthoP, pH, } \\
\text { TKN, TP, \& TSS }\end{array}$ & 144 & 75.4 \\
\hline Anchor QEA & CHL-RT6-BR & $\begin{array}{c}\text { Chehalis at RT6 } \\
\text { Bridge }\end{array}$ & $\begin{array}{c}\text { BOD, chl-a, DO, NH3, } \\
\text { NO3, OrthoP, pH, } \\
\text { TKN, TP, \& TSS }\end{array}$ & 149 & 74.7 \\
\hline Anchor QEA & CHL-US-SKM & $\begin{array}{c}\text { Chehalis at Mellen } \\
\text { Road Bridge }\end{array}$ & $\begin{array}{c}\text { BOD, chl-a, DO, NH3, } \\
\text { NO3, OrthoP, pH, } \\
\text { TKN, TP, \& TSS }\end{array}$ & 180 & 67.5 \\
\hline Anchor QEA & CHL-GLV & $\begin{array}{c}\text { Chehalis at Galvin } \\
\text { Bridge }\end{array}$ & $\begin{array}{c}\text { BOD, chl-a, DO, NH3, } \\
\text { NO3, OrthoP, pH, } \\
\text { TKN, TP, \& TSS }\end{array}$ & 196 & 64.1 \\
\hline
\end{tabular}




\begin{tabular}{|c|c|c|c|c|c|}
\hline Organization & Station ID & Description & Data available & $\begin{array}{c}\text { Model } \\
\text { Segment }\end{array}$ & $\begin{array}{c}\text { River } \\
\text { Mile }\end{array}$ \\
\hline Anchor QEA & CHL-US-BLK & $\begin{array}{c}\text { Chehalis Upstream of } \\
\text { Black River }\end{array}$ & $\begin{array}{c}\text { BOD, chl-a, DO, NH3, } \\
\text { NO3, OrthoP, pH, } \\
\text { TKN, TP, \& TSS }\end{array}$ & 238 & 54.2 \\
\hline Anchor QEA & CHL-OAK & Chehalis at Oakville & $\begin{array}{c}\text { BOD, chl-a, DO, NH3, } \\
\text { NO3, OrthoP, pH, } \\
\text { TKN, TP, \& TSS }\end{array}$ & 287 & 42.3 \\
\hline WADOE & 23A070 & $\begin{array}{c}\text { Chehalis River at } \\
\text { Porter }\end{array}$ & $\begin{array}{c}\text { DO, FC, NH3, NO3, } \\
\text { OrthoP, pH, TP, \& TSS }\end{array}$ & 321 & 33.3 \\
\hline
\end{tabular}

Table 24. Mainstem Chehalis River vertical dissolved oxygen profile collection locations and dates used in water quality calibration

\begin{tabular}{|c|c|c|c|c|}
\hline Organization & Station ID & Description & Dates with data & $\begin{array}{c}\text { Model } \\
\text { Segment }\end{array}$ \\
\hline Anchor QEA & CHL-RT6-BR & $\begin{array}{c}\text { Chehalis R. at RT6 } \\
\text { Bridge at RM 75.31 }\end{array}$ & $\begin{array}{c}8 / 7 / 13,9 / 18 / 13, \\
\& 7 / 23 / 14\end{array}$ & 149 \\
\hline Anchor QEA & HL-14 & Chehalis R. at RM 74.5 & $7 / 31 / 14$ & 150 \\
\hline Anchor QEA & HL-13 & Chehalis R. at RM 73.75 & $7 / 31 / 14$ & 153 \\
\hline Anchor QEA & HL-12 & Chehalis R. at RM 73 & $7 / 31 / 14$ & 157 \\
\hline Anchor QEA & HL-11 & Chehalis R. at RM 72.5 & $7 / 31 / 14$ & 158 \\
\hline Anchor QEA & HL-10 & Chehalis R. at RM 74.25 & $7 / 31 / 14$ & 160 \\
\hline Anchor QEA & HL-9 & Chehalis R. at RM 71.5 & $7 / 31 / 14$ & 162 \\
\hline Anchor QEA & HL-8 & Chehalis R. at RM 71 & $7 / 31 / 14$ & 164 \\
\hline Anchor QEA & HL-7 & Chehalis R. at RM 70.5 & $7 / 31 / 14$ & 166 \\
\hline Anchor QEA & HL-6 & Chehalis R. at RM 70 & $7 / 31 / 14$ & 168 \\
\hline Anchor QEA & HL-5 & Chehalis R. at RM 69.25 & $7 / 31 / 14$ & 171 \\
\hline Anchor QEA & HL-4 & Chehalis R. at RM 68.75 & $7 / 31 / 14$ & 173 \\
\hline Anchor QEA & HL-3 & Chehalis R. at RM 68.25 & $7 / 31 / 14$ & 177 \\
\hline Anchor QEA & HL-2 & Chehalis R. at RM 67.75 & $7 / 31 / 14$ & 179 \\
\hline Anchor QEA & CHL-US-SKM & $\begin{array}{c}\text { Chehalis R. at Mellen } \\
\text { Road Bridge at RM 66.7 }\end{array}$ & $8 / 7 / 13,9 / 18 / 13$, & 180 \\
\hline Anchor QEA & HL-1 & Chehalis R. at RM 67.25 & $7 / 31 / 14$ & 181 \\
\hline
\end{tabular}




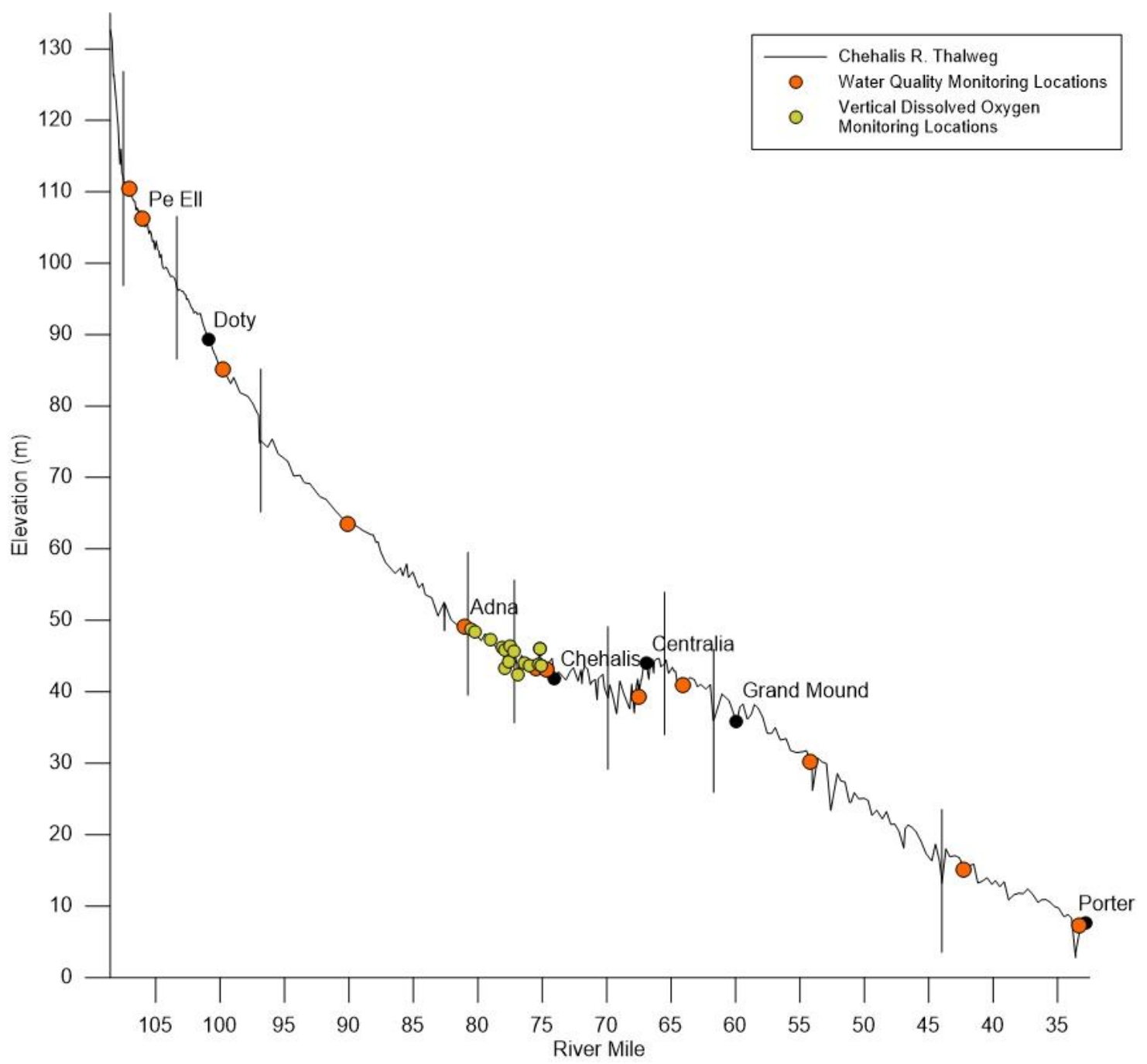

Figure 90. Longitudinal view of the mainstem Chehalis River water quality sample sites (vertical lines show model branch breaks)

Figure 91 through Figure 108 show the model results compared to field data for dissolved oxygen, chlorophyll a, ammonia, nitrates, total Kjeldahl nitrogen, phosphate, total phosphorus, $\mathrm{pH}$, and total suspended solids at upstream of Pe Ell, downstream of Pe Ell, at Dryad, upstream of the South Fork Chehalis River, at Adna, upstream of the Newaukum River, at Route 6 bridge, upstream of Skookumchuck River, at Galvin Road bridge, upstream of Black River, at Oakville, and at Porter. 
Continuous data were available for $\mathrm{DO}$, chlorophyll a, and $\mathrm{pH}$ during select days at the monitoring stations: downstream of Pe Ell, Route 6 Bridge, and Mellen Road Bridge. Model DO comparisons to continuous data are shown in Figure 109, Figure 110, and Figure 111 at the downstream of Pe Ell, Route 6 Bridge, and Mellen Road Bridge stations respectively. Model chlorophyll a comparisons to continuous data are shown in Figure 112, Figure 113, and Figure 114 at the downstream of Pe Ell, Route 6 Bridge, and Mellen Road Bridge stations respectively. Model pH comparisons to continuous data are shown in Figure 115, Figure 116, and Figure 117 at the downstream of Pe Ell, Route 6 Bridge, and Mellen Road Bridge respectively.

Vertical profile data were available at the same locations as temperature. Figure 118 shows model-predicted dissolved oxygen profiles compared to field data at the monitoring stations: Route 6 Bridge, HL-14, and HL-13. Figure 119 shows model-predicted dissolved oxygen profiles compared to field data at the monitoring stations: HL-12, HL11, HL-10, HL-9, and HL-8. Figure 120 shows model-predicted dissolved oxygen profiles compared to field data at the monitoring stations: HL-7, HL-6, HL-5, HL-4, and HL-3. Figure 121 shows model-predicted dissolved oxygen profiles compared to field data at the monitoring stations: HL-2, HL-1, and Mellen Road Bridge. 

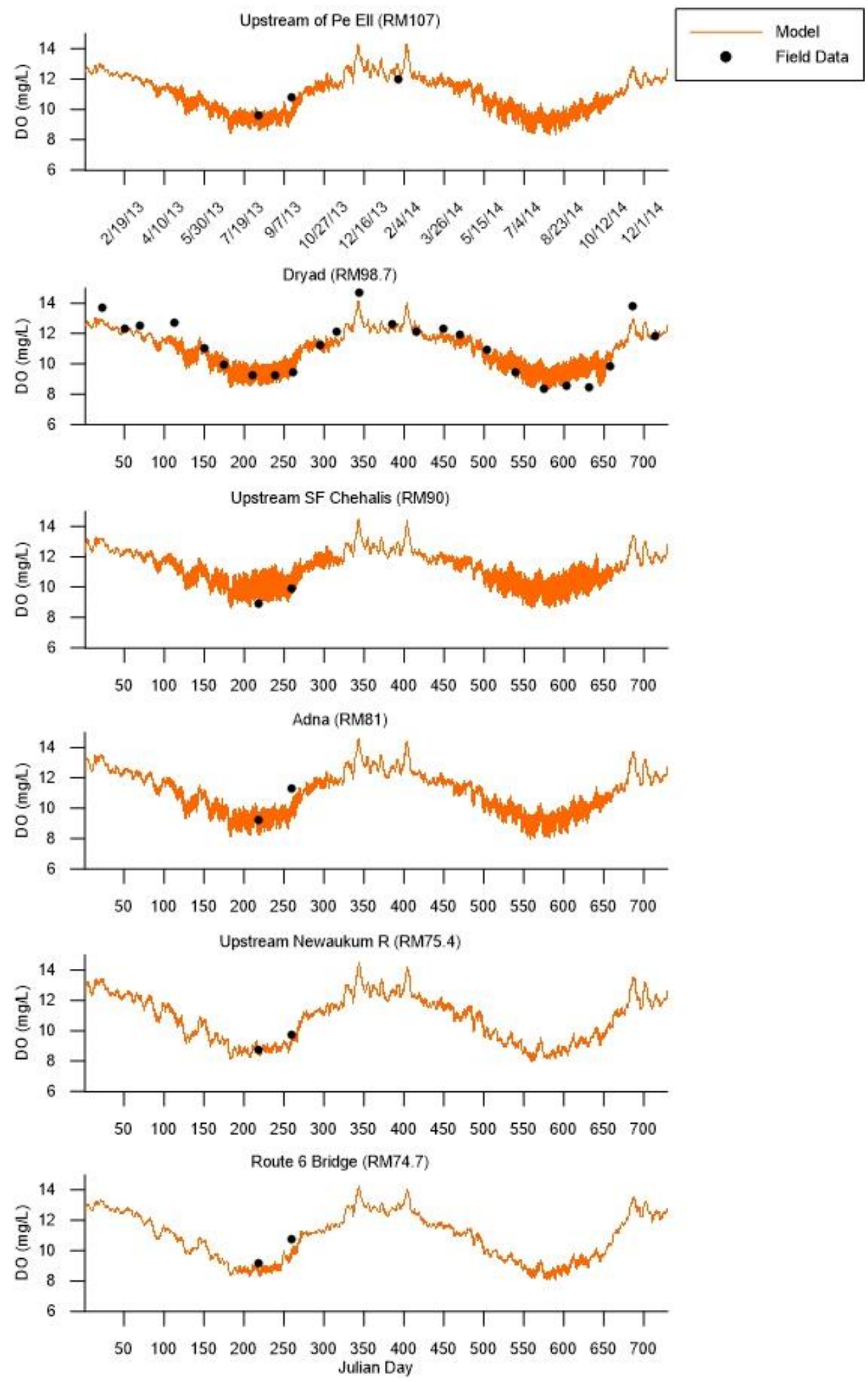

Figure 91. Model dissolved oxygen predictions versus field data at upstream of Pe Ell, at Dryad, upstream of South Fork Chehalis River, at Adna, upstream of Newaukum River, and at Route 6 bridge 

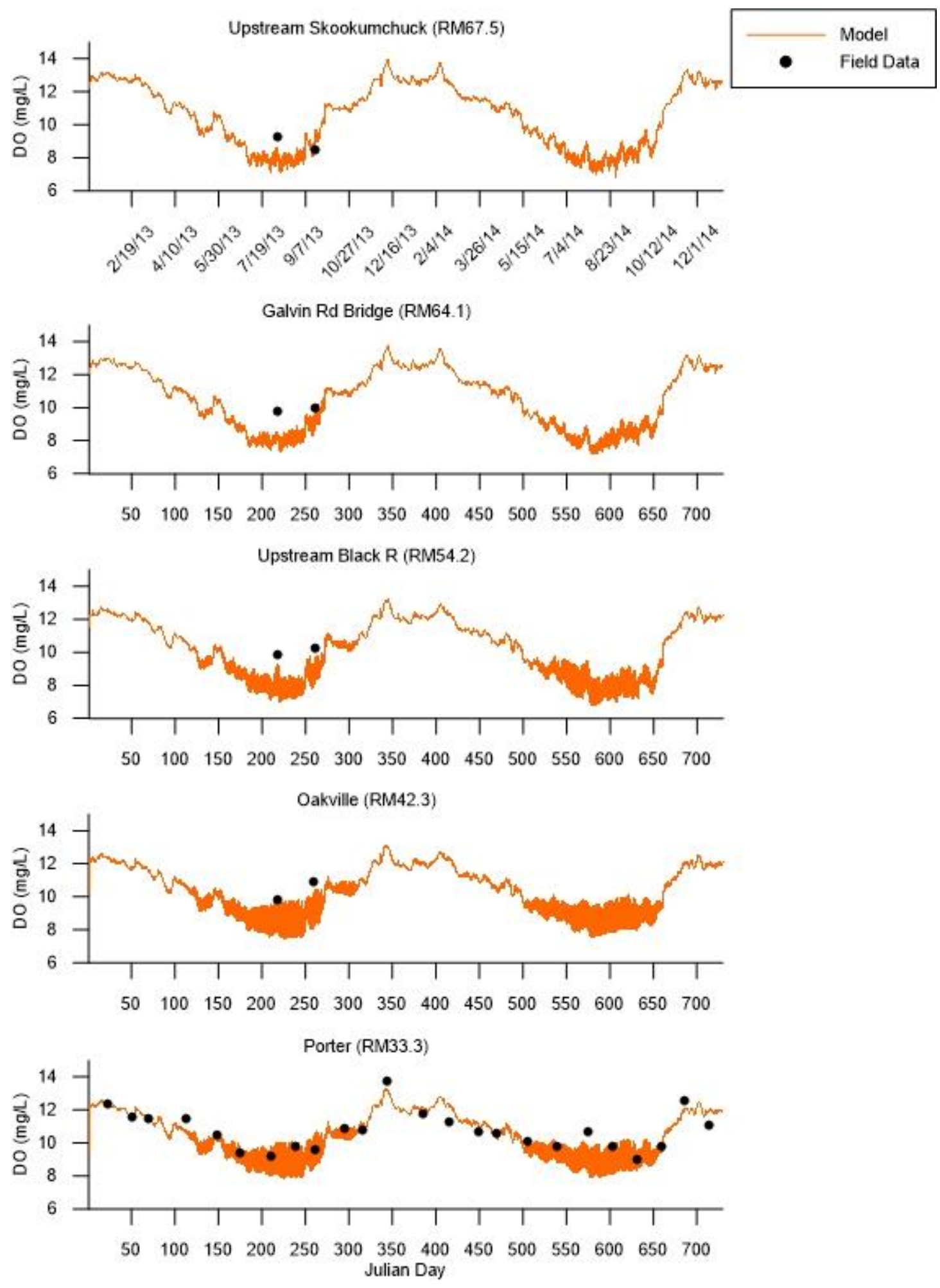

Figure 92. Model dissolved oxygen predictions versus field data at upstream of Skookumchuck River, at Galvin Road bridge, upstream of Black River, at Oakville, and at Porter 

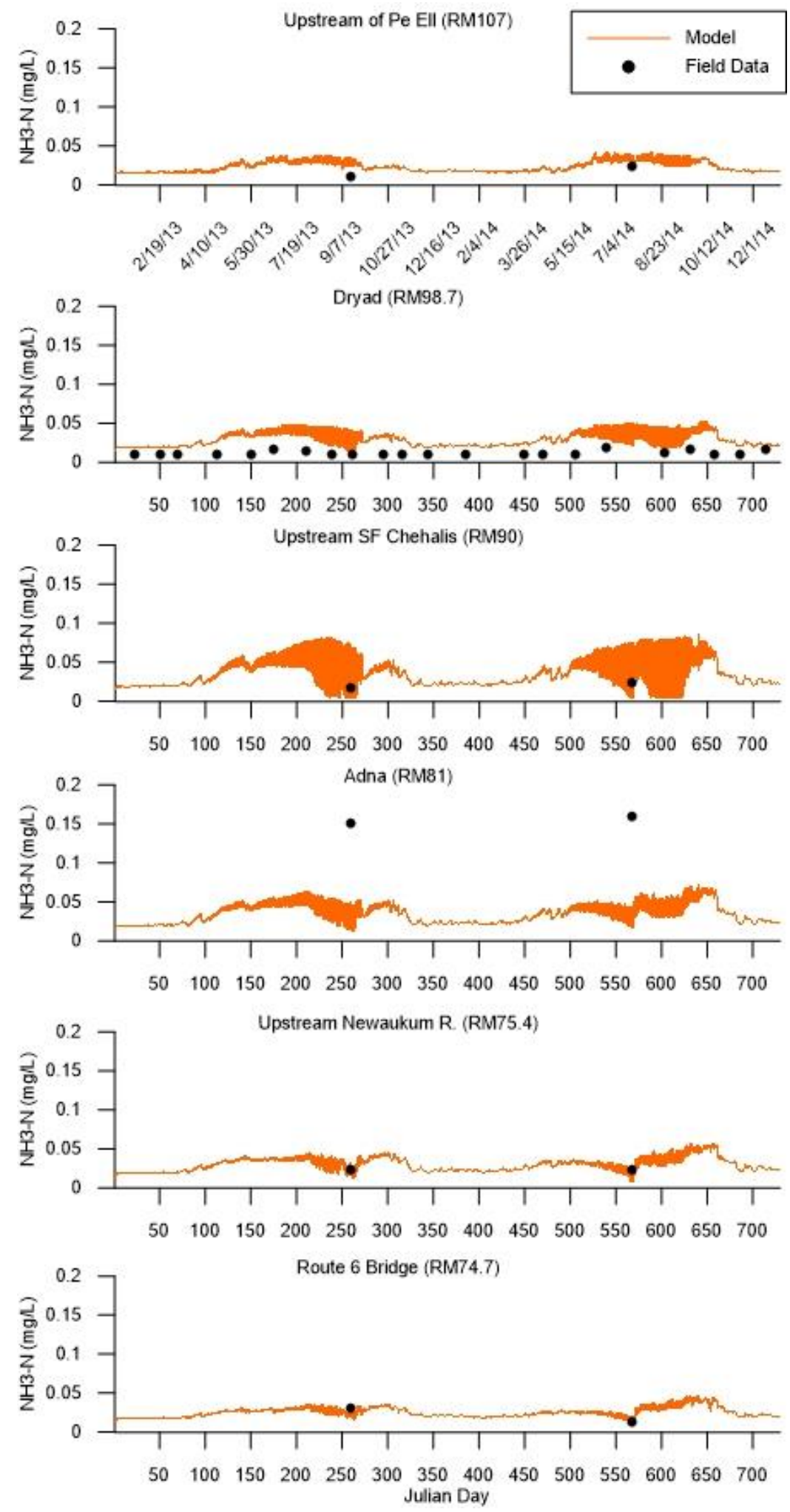

Figure 93. Model ammonia predictions versus field data at upstream of Pe Ell, at Dryad, upstream of South Fork Chehalis River, at Adna, upstream of Newaukum River, and at Route 6 bridge 

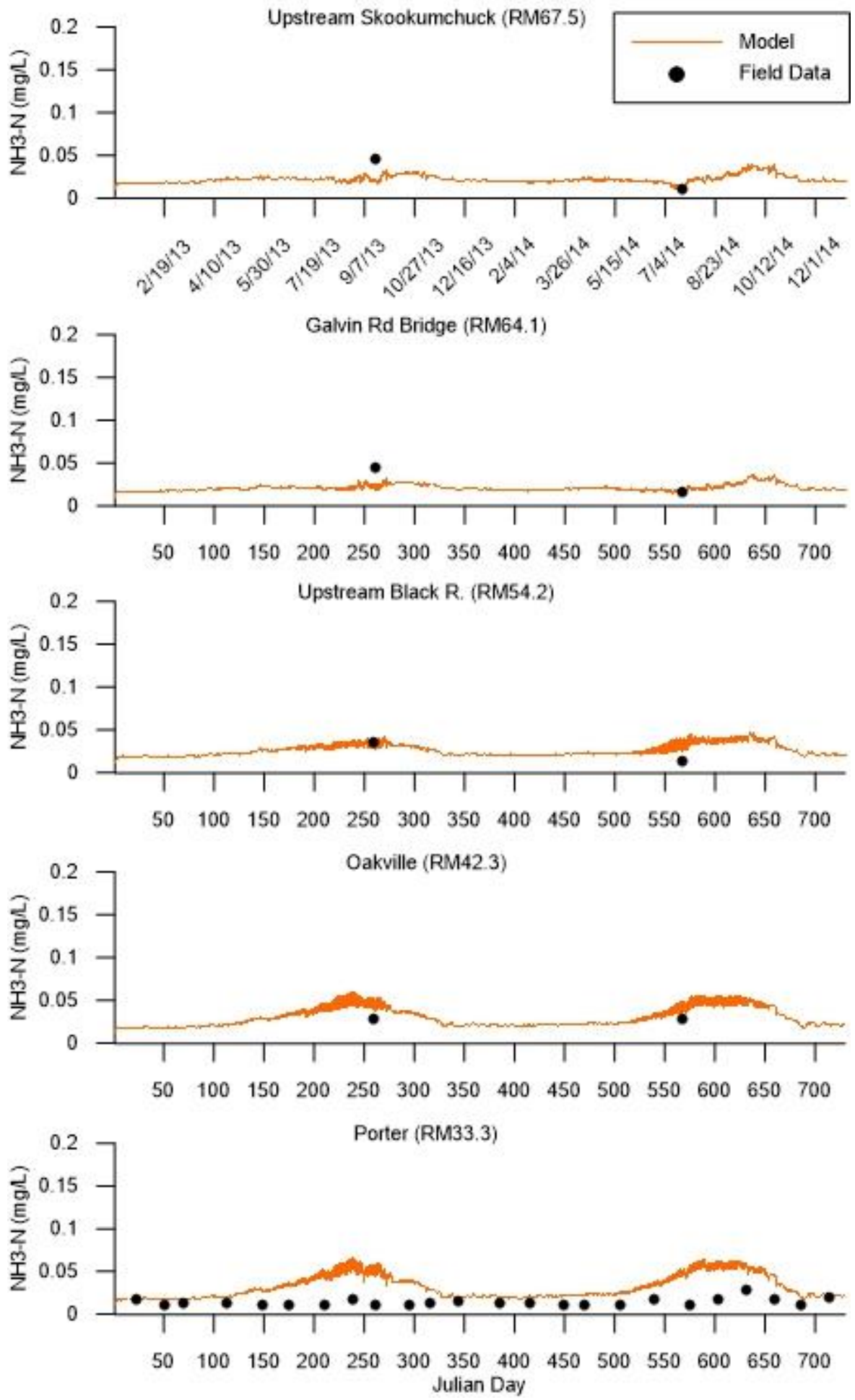

Figure 94. Model ammonia predictions versus field data at upstream of Skookumchuck River, at Galvin Road bridge, upstream of Black River, at Oakville, and at Porter 

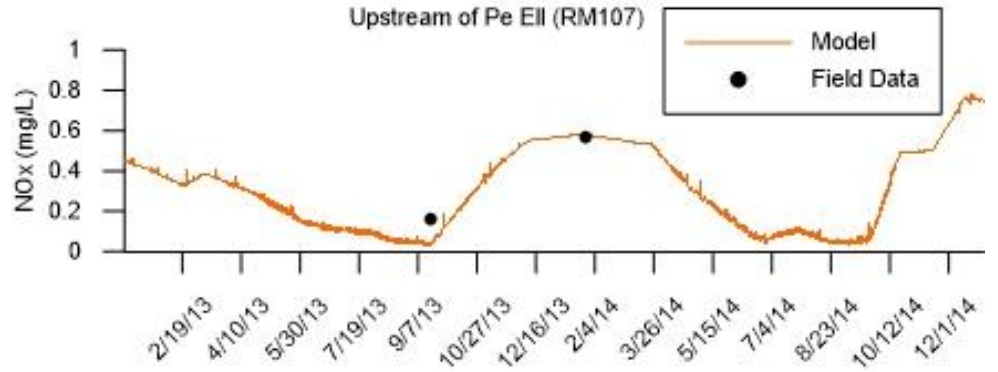

Dryad (RM98.7)
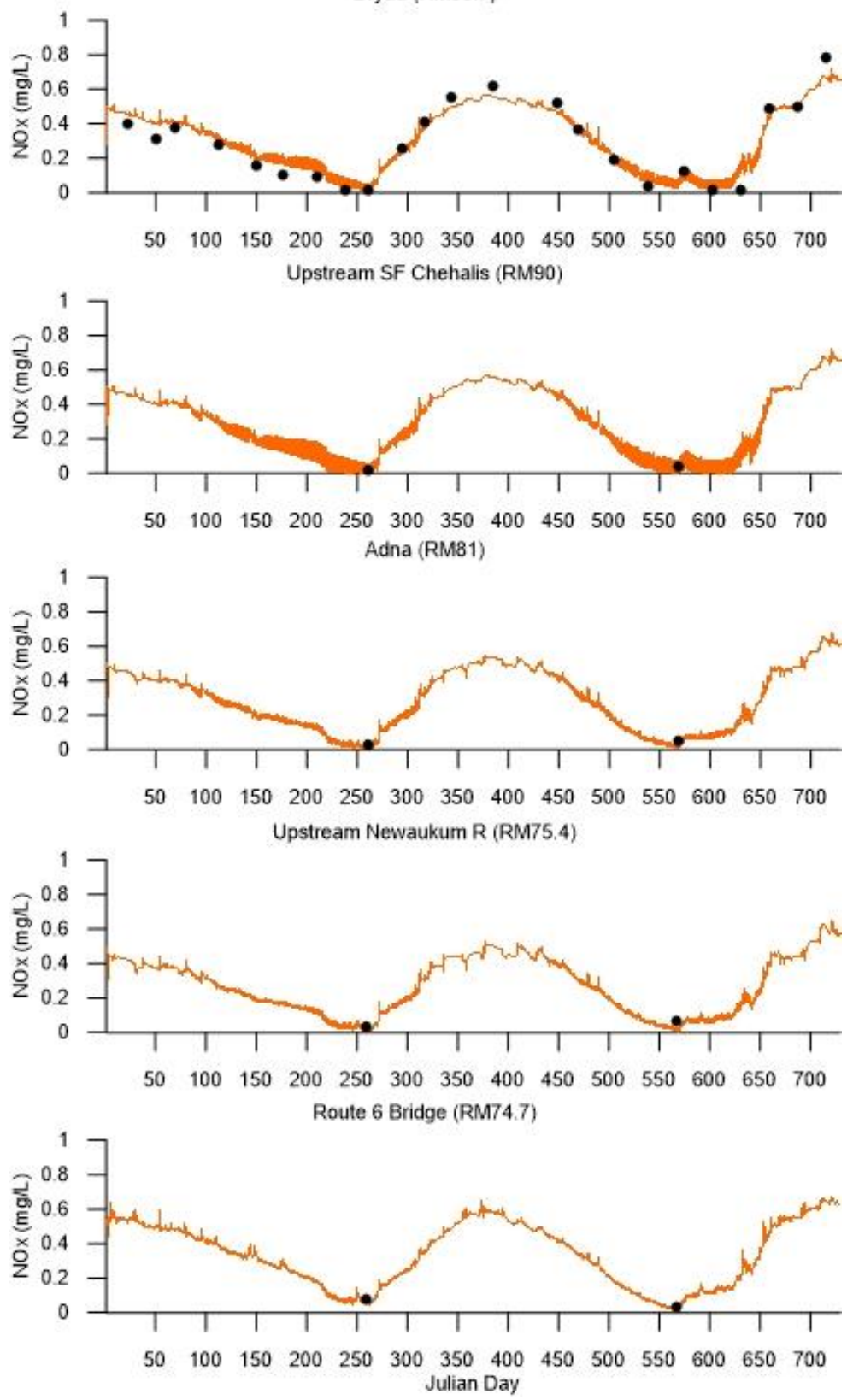

Figure 95. Model nitrates predictions versus field data at upstream of Pe Ell, at Dryad, upstream of South Fork Chehalis River, at Adna, upstream of Newaukum River, and at Route 6 bridge 

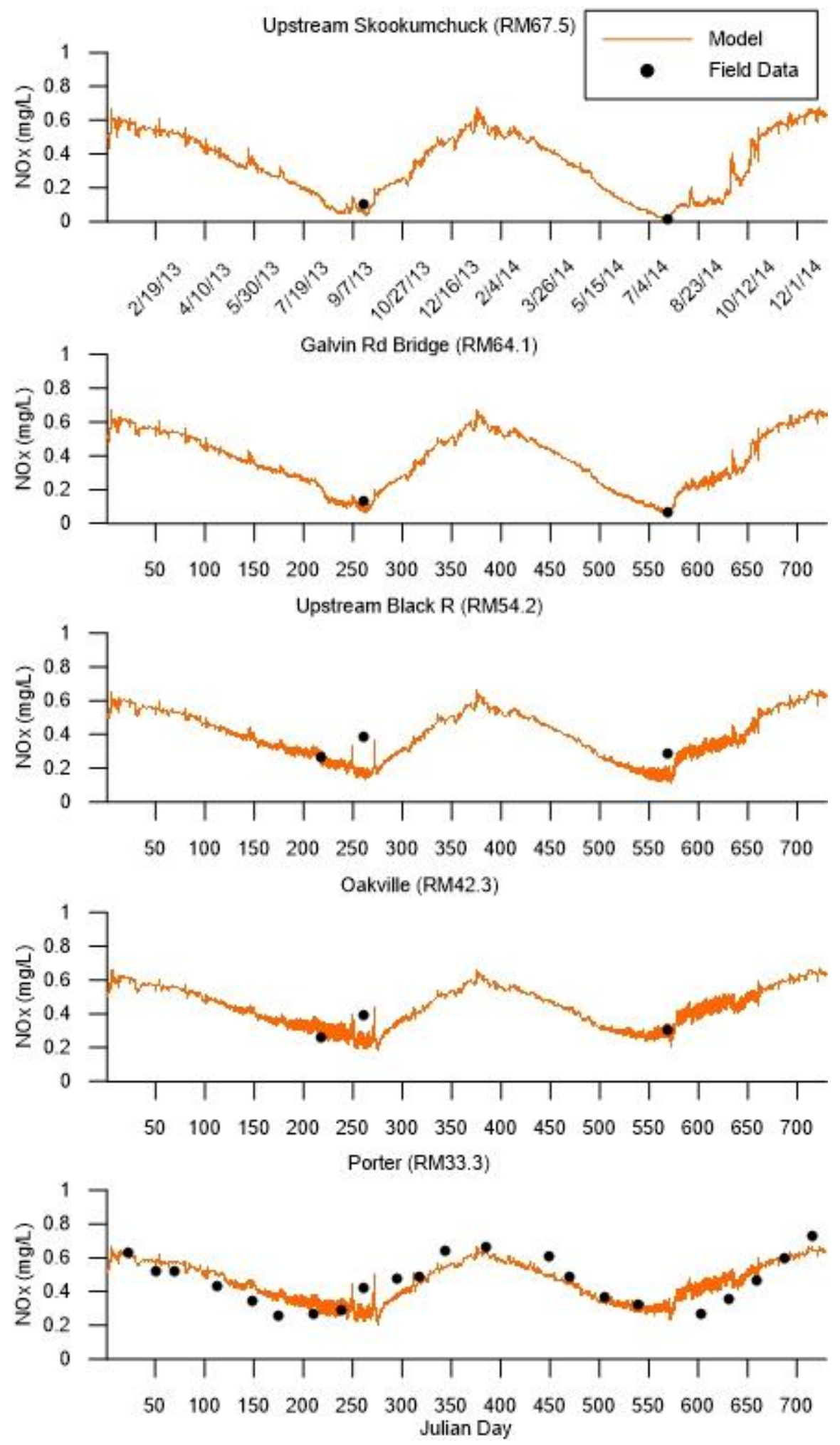

Figure 96. Model nitrates predictions versus field data at upstream of Skookumchuck River, at Galvin Road bridge, upstream of Black River, at Oakville, and at Porter 

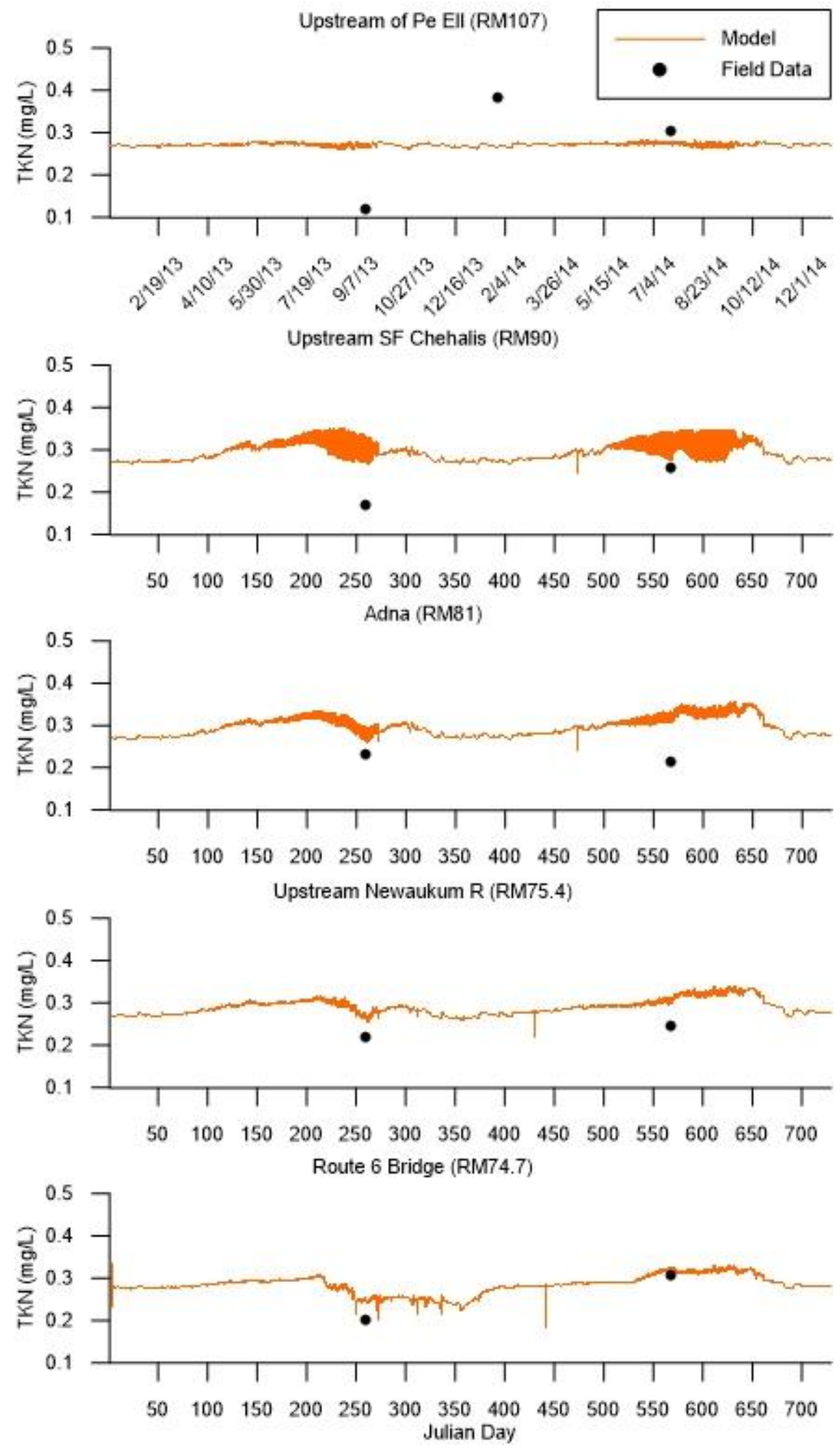

Figure 97. Model total Kjeldahl nitrogen predictions versus field data at upstream of Pe Ell, upstream of South Fork Chehalis River, at Adna, upstream of Newaukum River, and at Route 6 bridge 

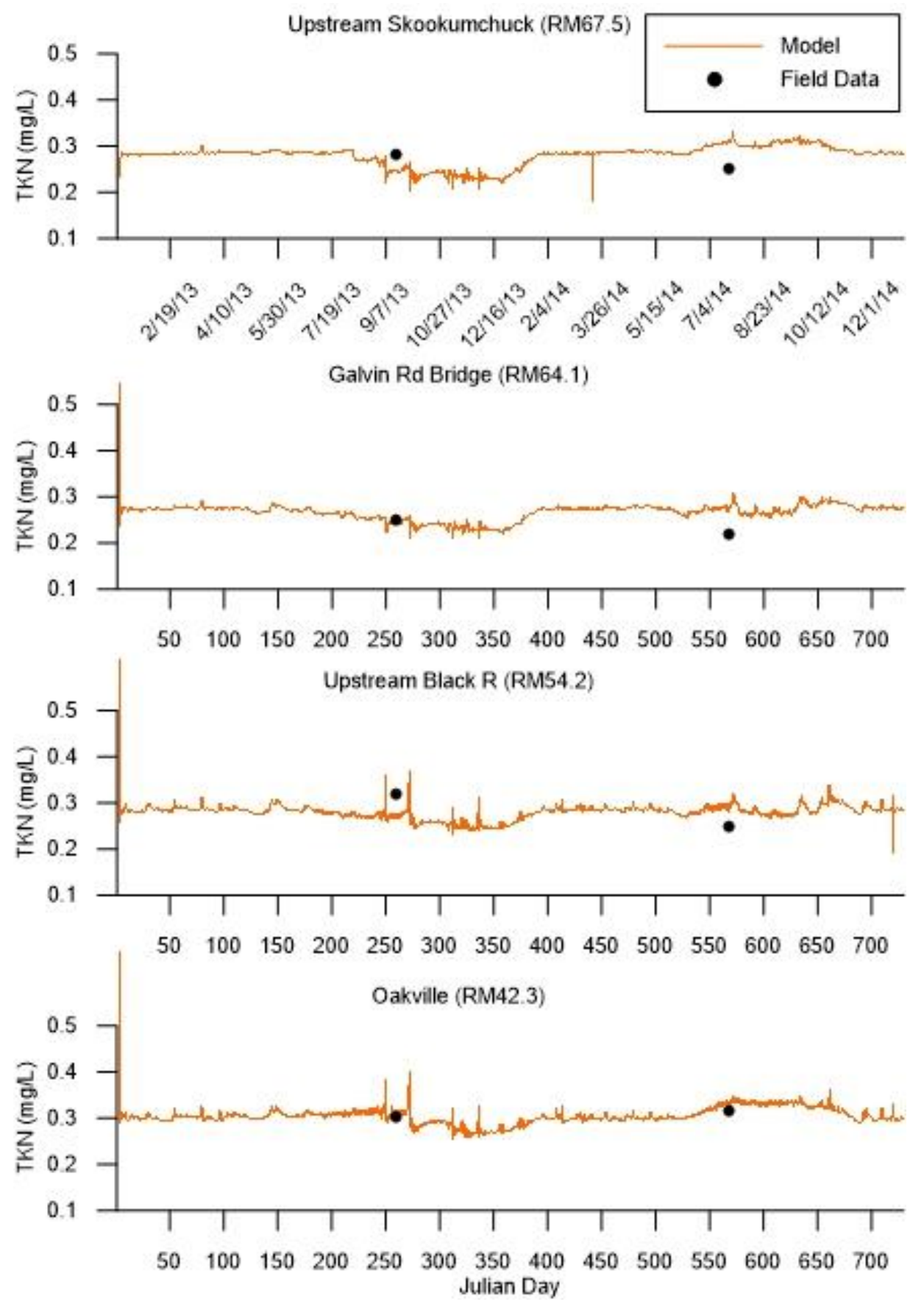

Figure 98. Model total Kjeldahl nitrogen predictions versus field data at upstream of Skookumchuck River, at Galvin Road bridge, upstream of Black River, and at Oakville 

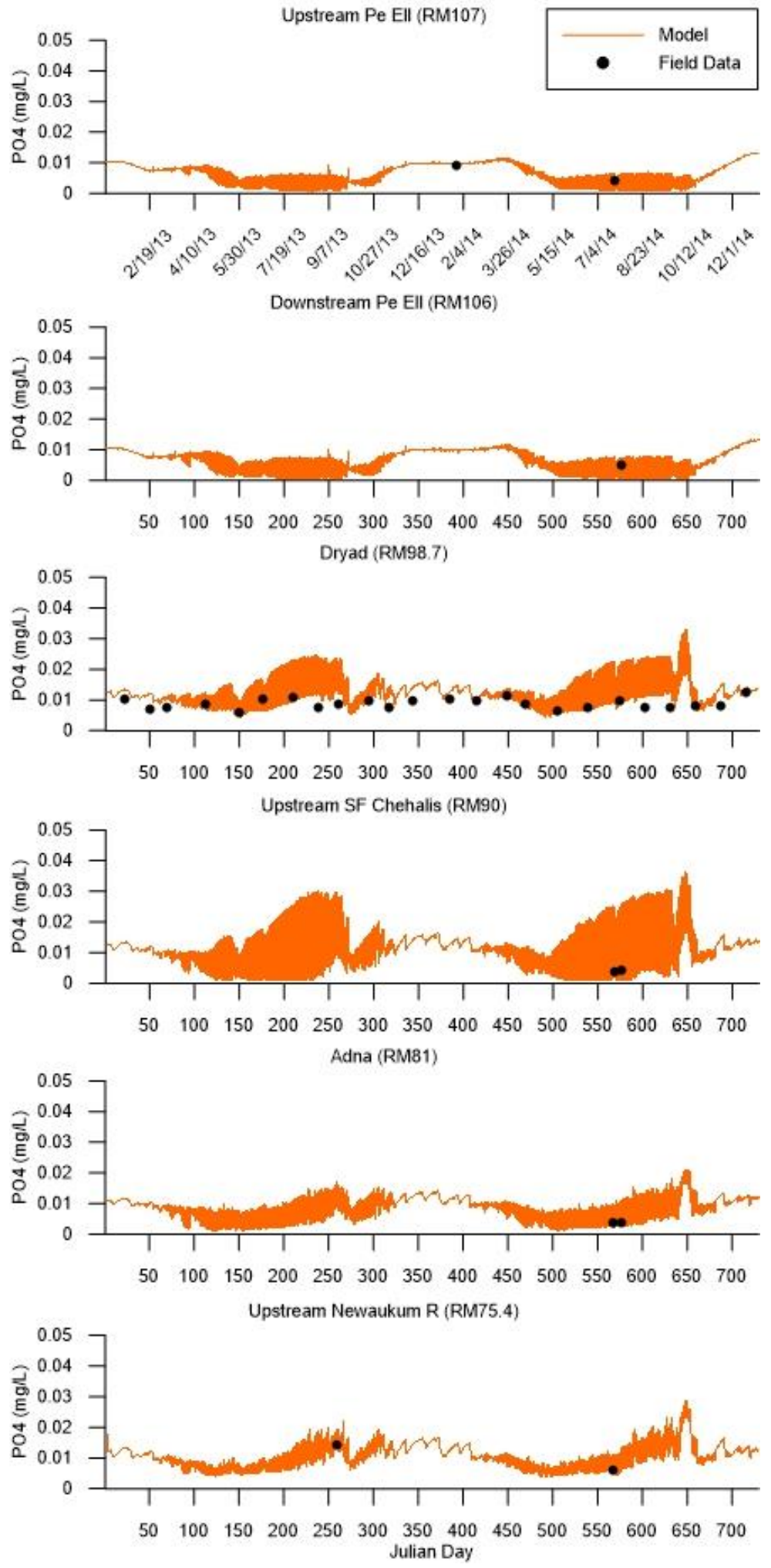

Figure 99. Model phosphate predictions versus field data at upstream of Pe Ell, downstream of Pe EII, at Dryad, upstream of South Fork Chehalis River, at Adna, and upstream of Newaukum River 

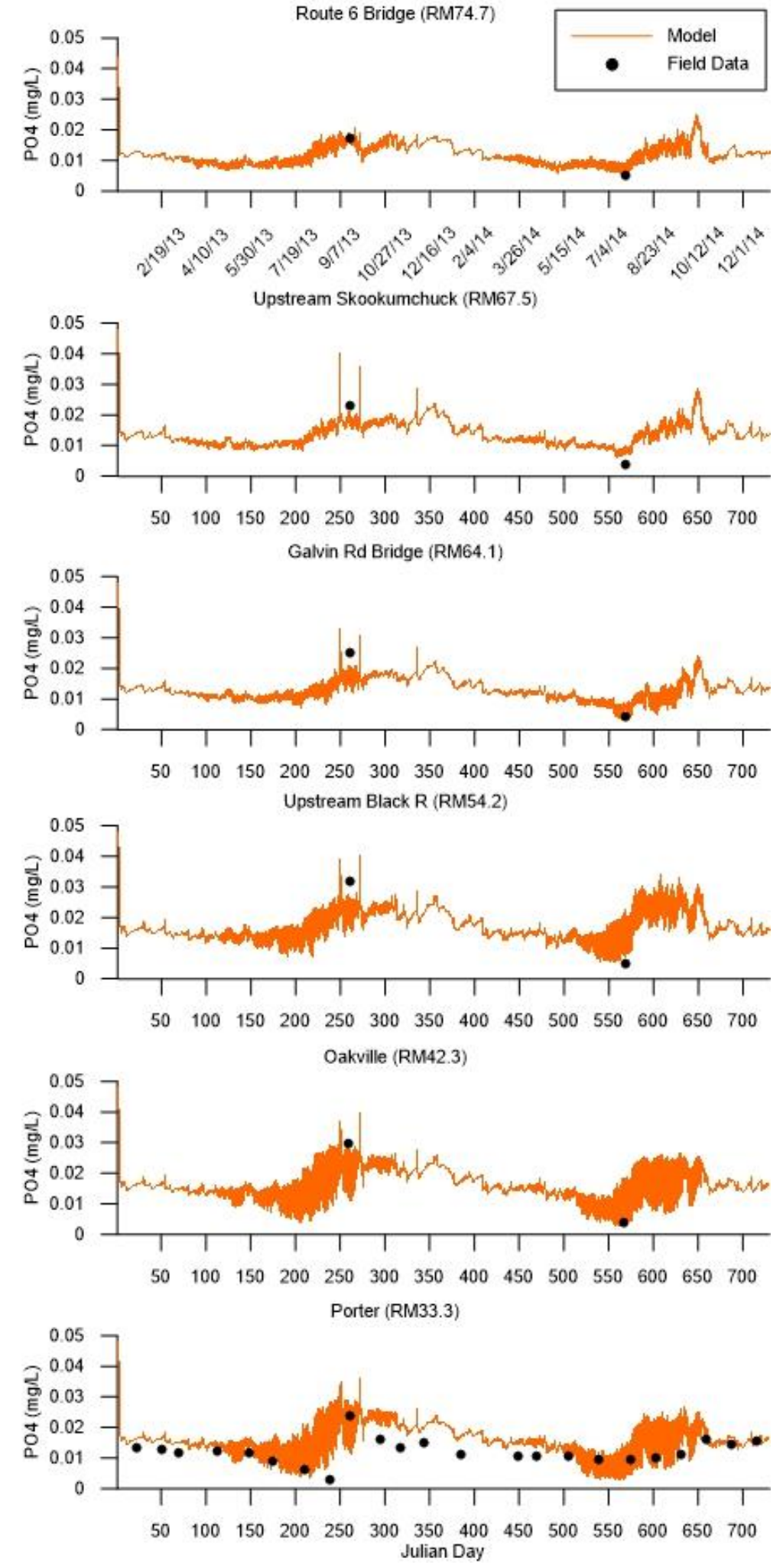

Figure 100. Model phosphate predictions versus field data at Route 6 bridge, upstream of Skookumchuck River, at Galvin Road bridge, upstream of Black River, at Oakville, and at Porter 

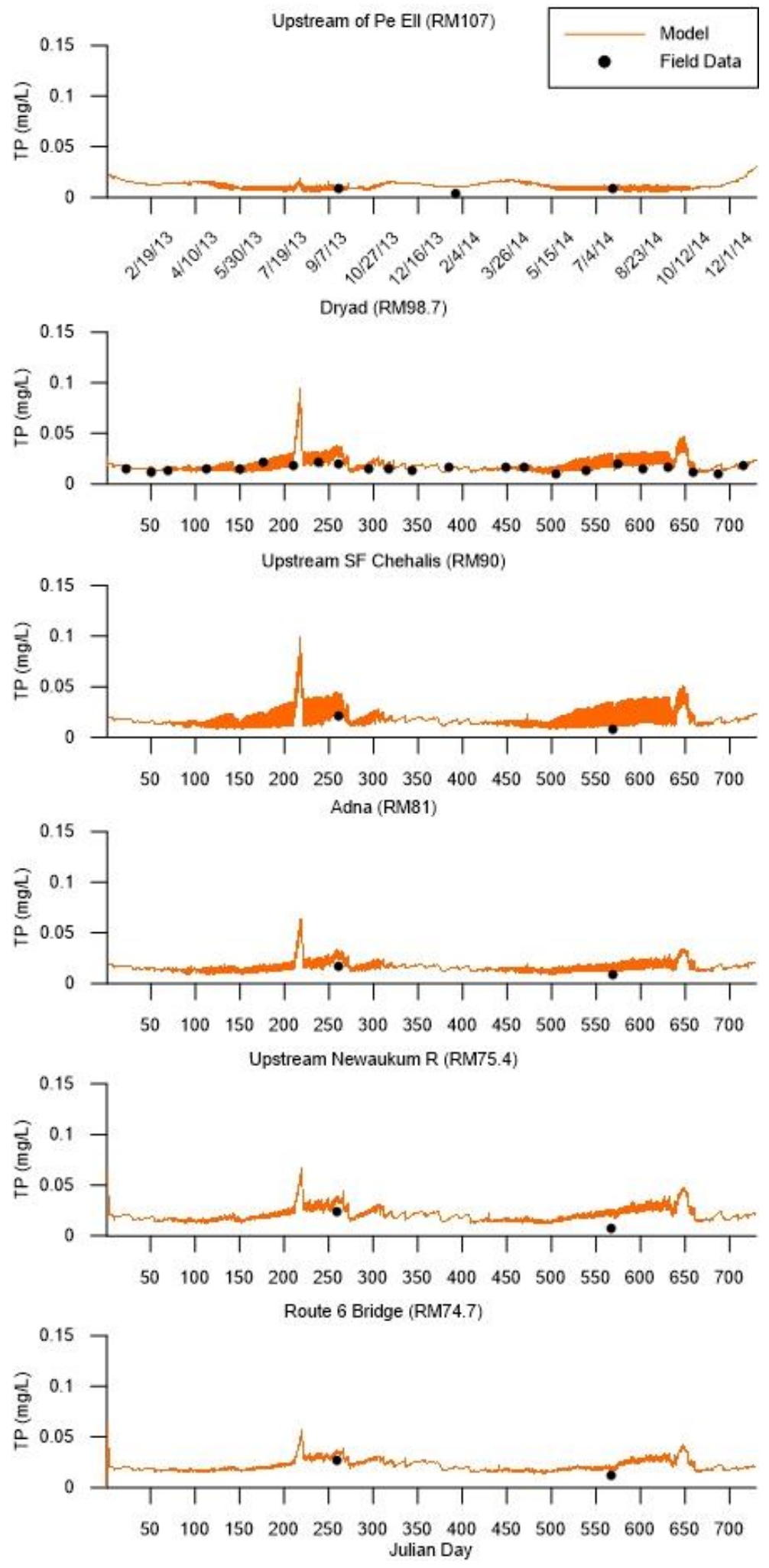

Figure 101. Model total phosphorus predictions versus field data at upstream of Pe Ell, at Dryad, upstream of South Fork Chehalis River, at Adna, upstream of Newaukum River, and at Route 6 bridge 

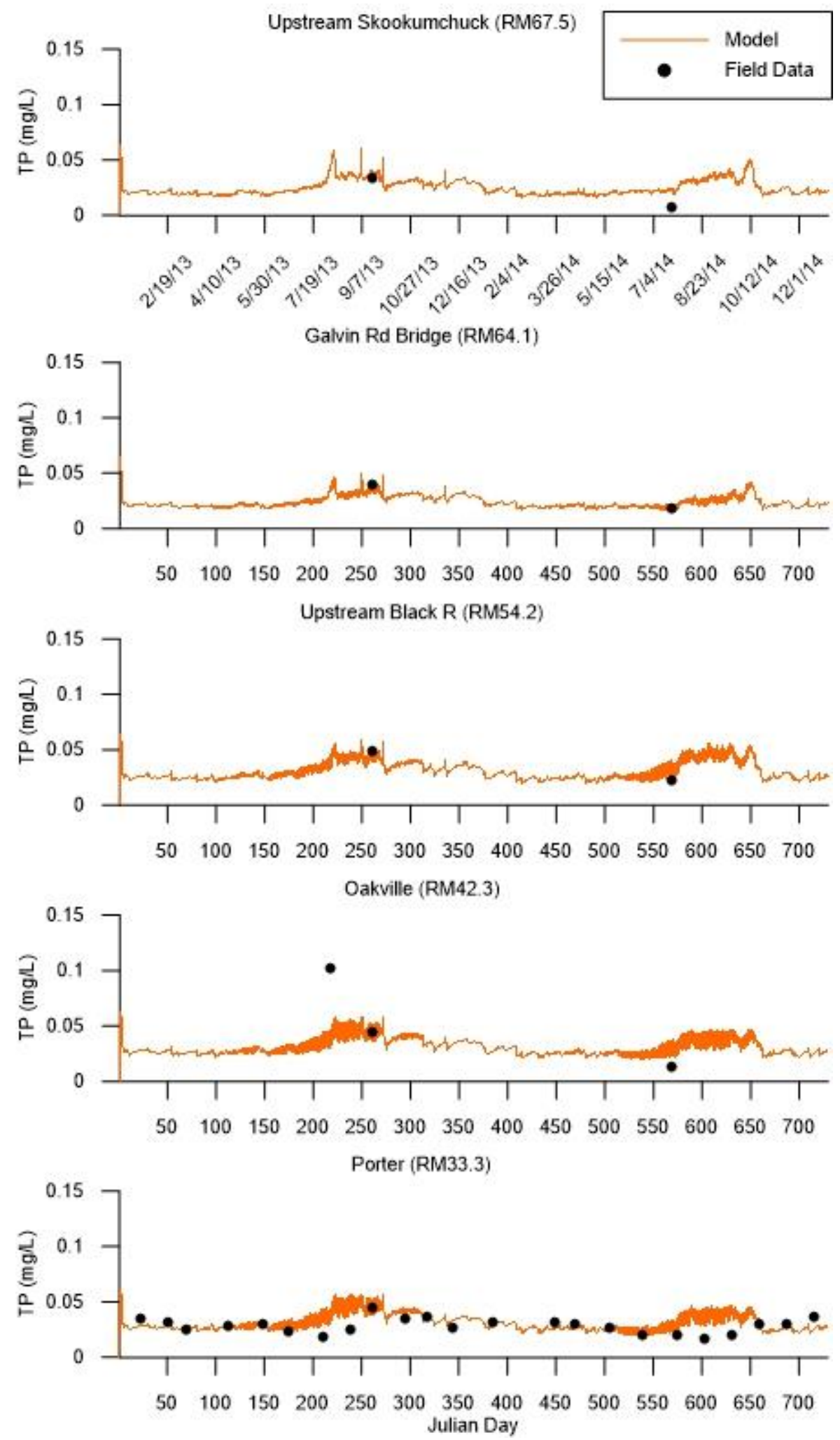

Figure 102. Model total phosphorus predictions versus field data at upstream of Skookumchuck River, at Galvin Road bridge, upstream of Black River, at Oakville, and at Porter 

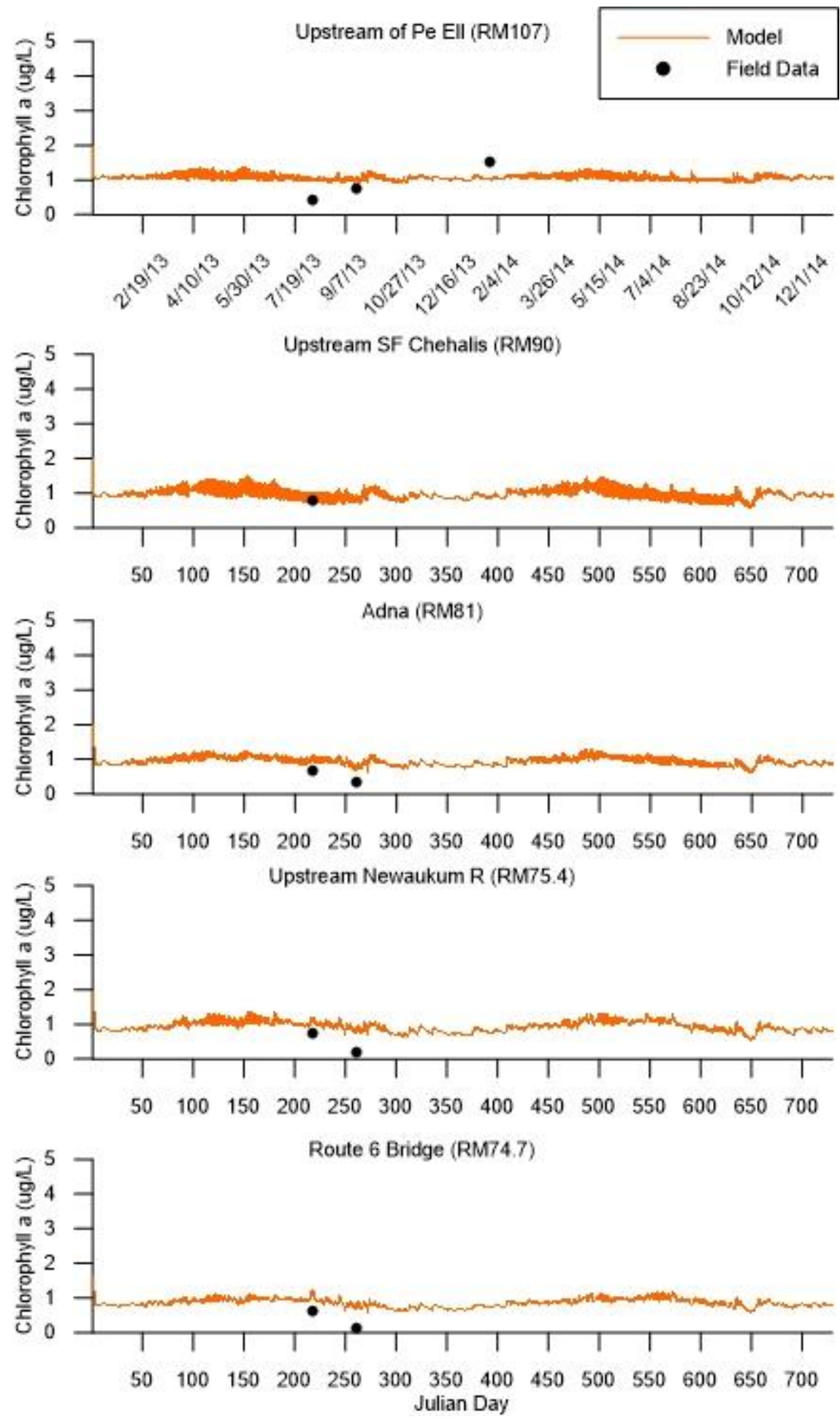

Figure 103. Model chlorophyll a predictions versus field data at upstream of Pe Ell, upstream of South Fork Chehalis River, at Adna, upstream of Newaukum River, and at Route 6 bridge 

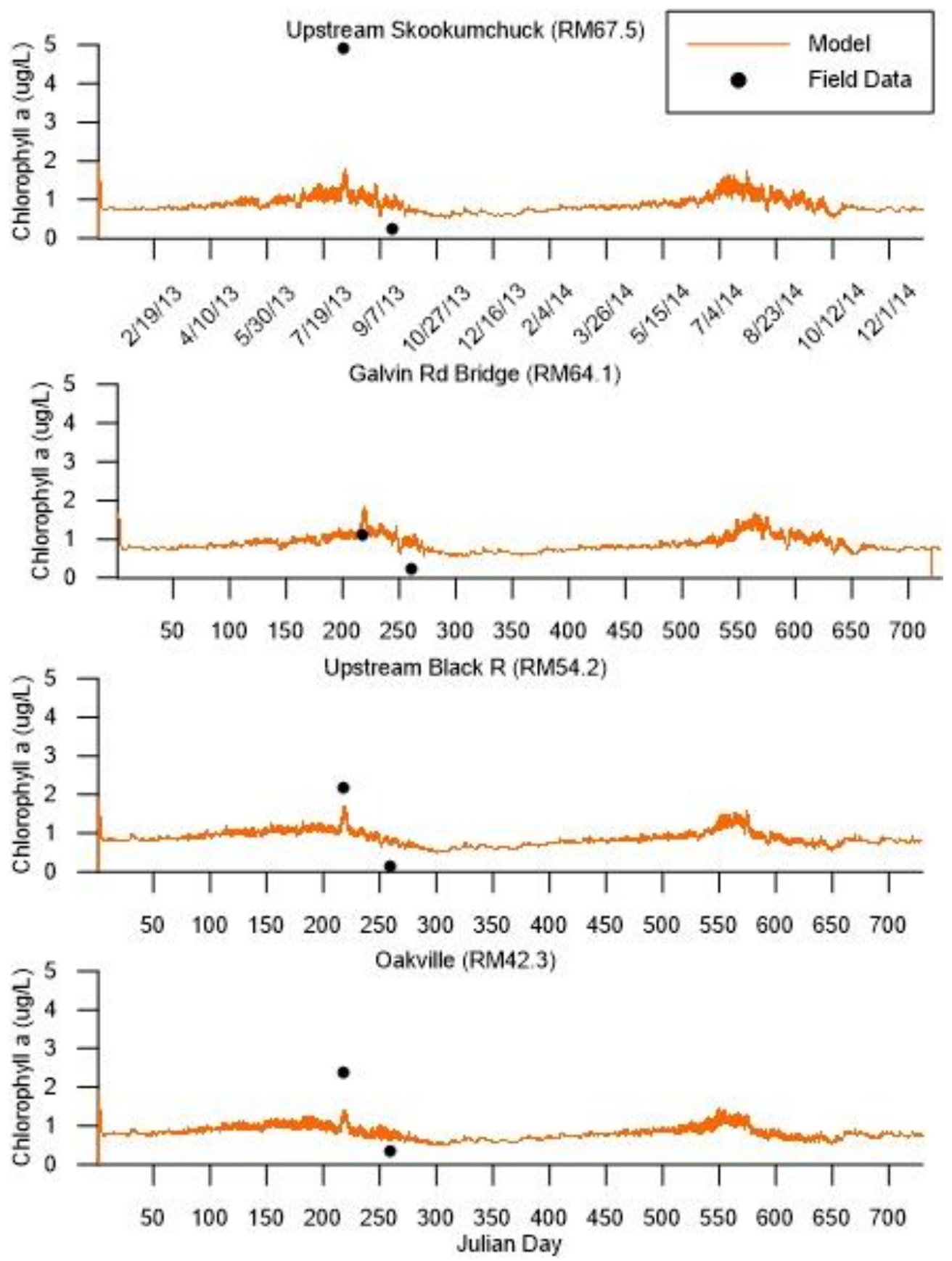

Figure 104. Model chlorophyll a predictions versus field data at upstream of Skookumchuck River, at Galvin Road bridge, upstream of Black River, and at Oakville 

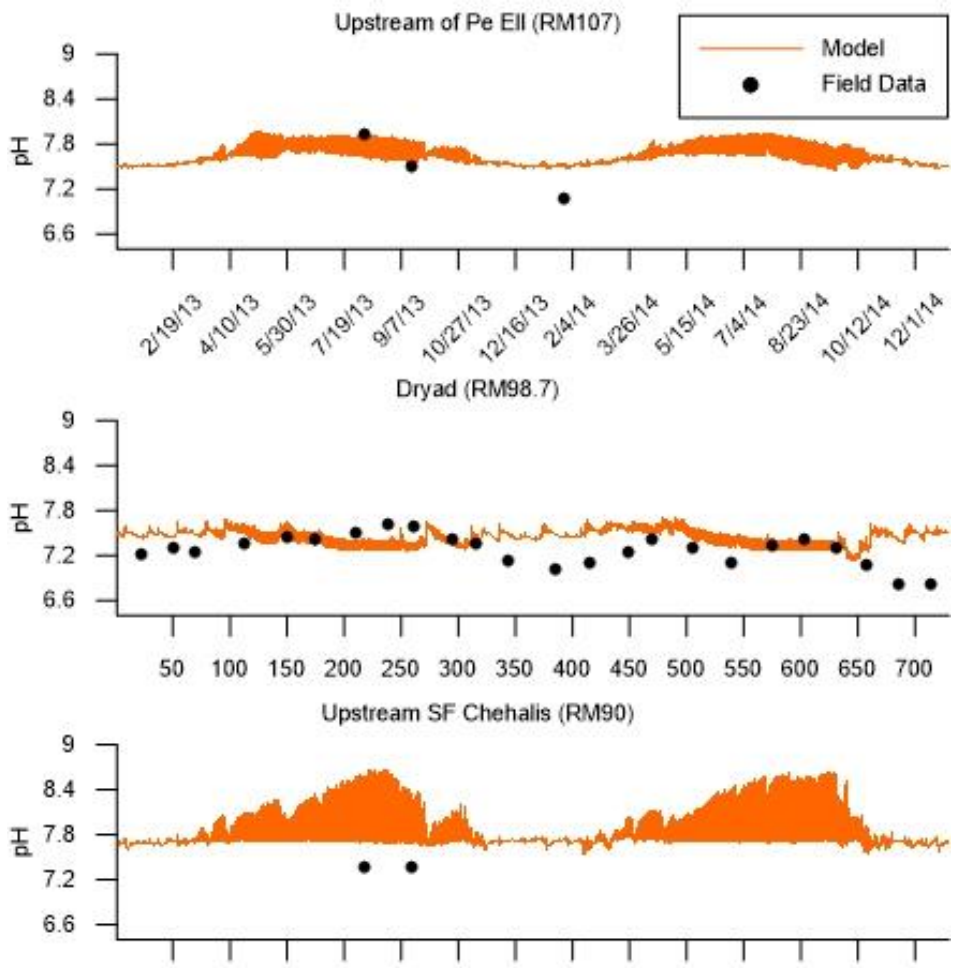

$\begin{array}{llllllllllllll}50 & 100 & 150 & 200 & 250 & 300 & 350 & 400 & 450 & 500 & 550 & 600 & 650 & 700\end{array}$

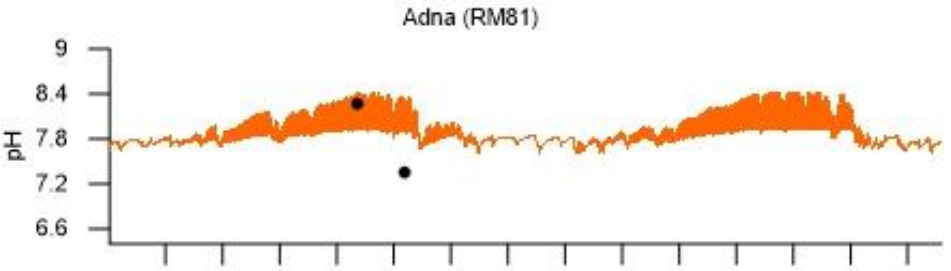

$\begin{array}{llllllllllllll}50 & 100 & 150 & 200 & 250 & 300 & 350 & 400 & 450 & 500 & 550 & 600 & 650 & 700\end{array}$ Upstream Newaukum R (RM75.4)
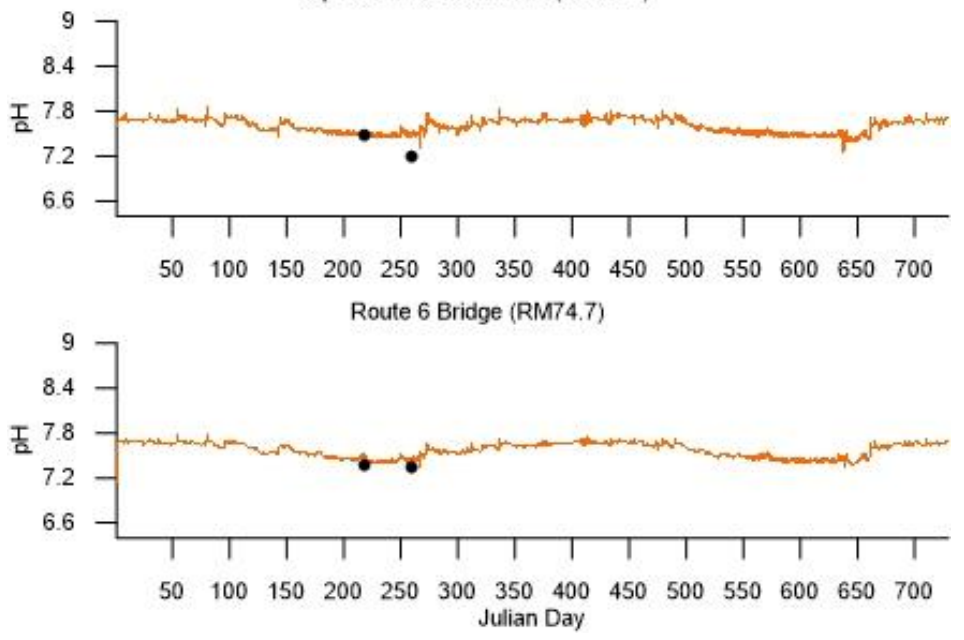

Figure 105. Model pH predictions versus field data at upstream of Pe Ell, at Dryad, upstream of South Fork Chehalis River, at Adna, upstream of Newaukum River, and at Route 6 bridge 

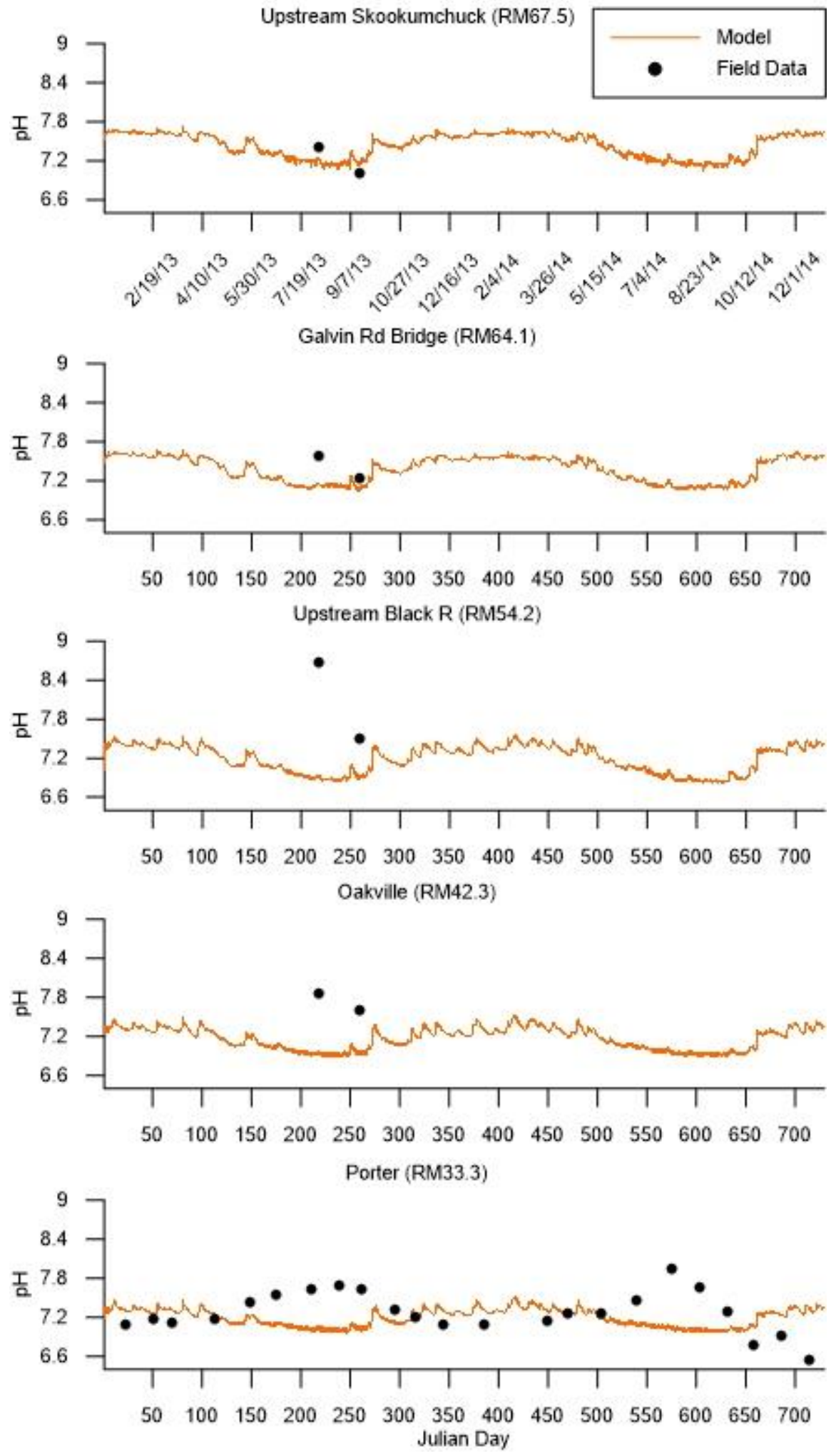

Figure 106. Model pH predictions versus field data at upstream of Skookumchuck River, at Galvin Road bridge, upstream of Black River, at Oakville, and at Porter 

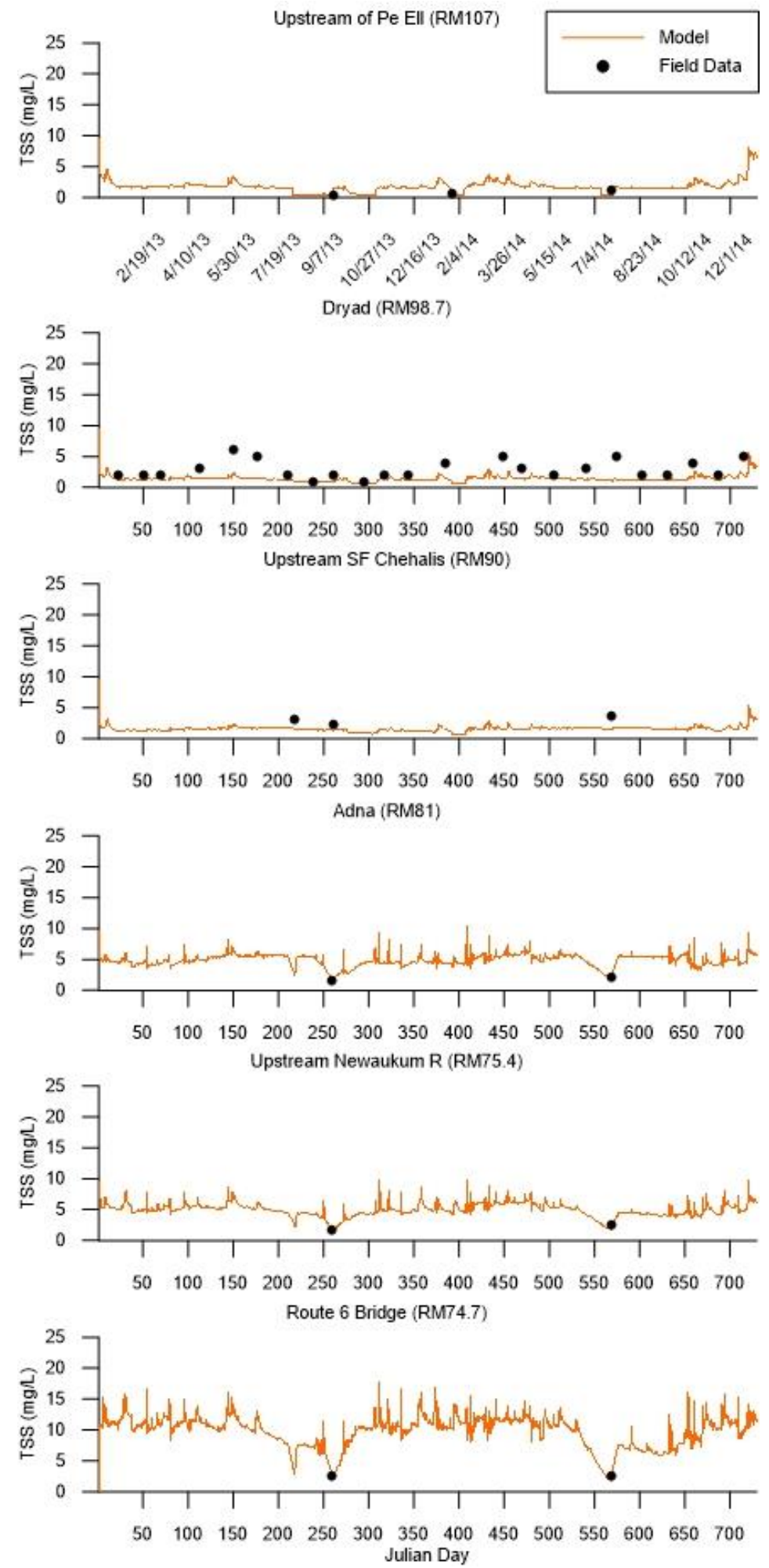

Figure 107. Model TSS predictions versus field data at upstream of Pe Ell, at Dryad, upstream of South Fork Chehalis River, at Adna, upstream of Newaukum River, and at Route 6 bridge 

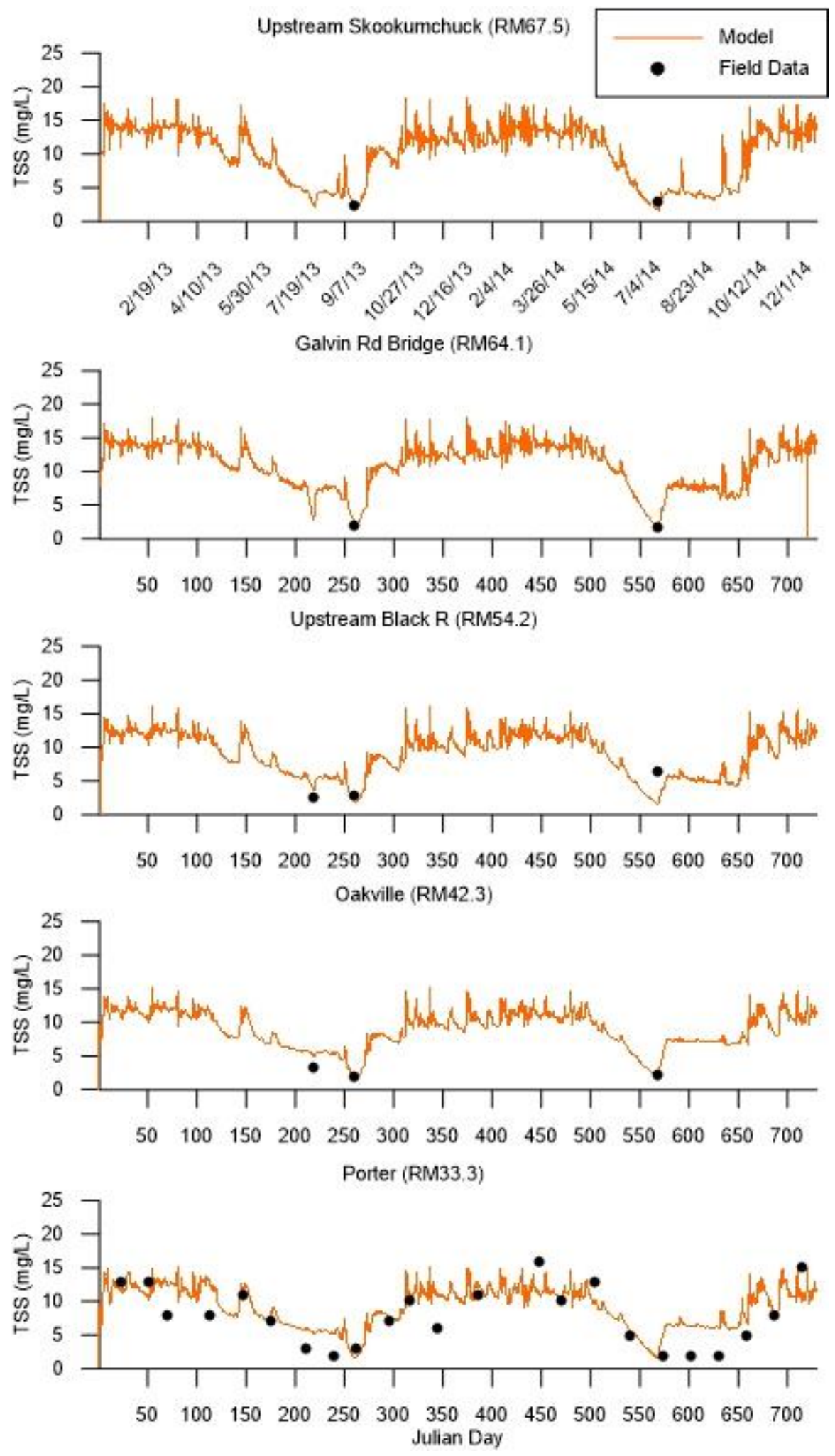

Figure 108. Model TSS predictions versus field data at upstream of Skookumchuck River, at Galvin Road bridge, upstream of Black River, at Oakville, and at Porter 


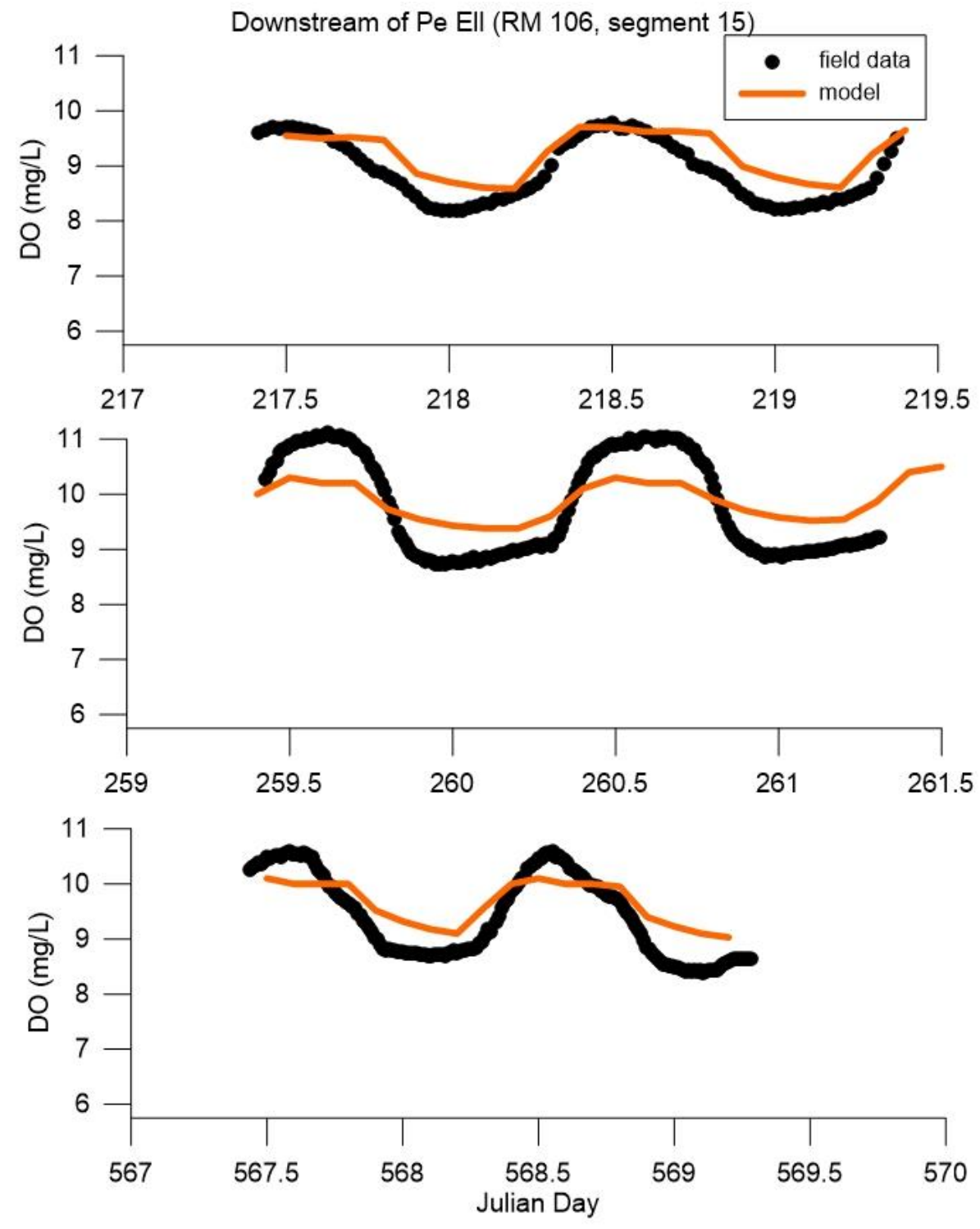

Figure 109. Model dissolved oxygen predictions versus continuous field data at the downstream of Pe Ell monitoring station 

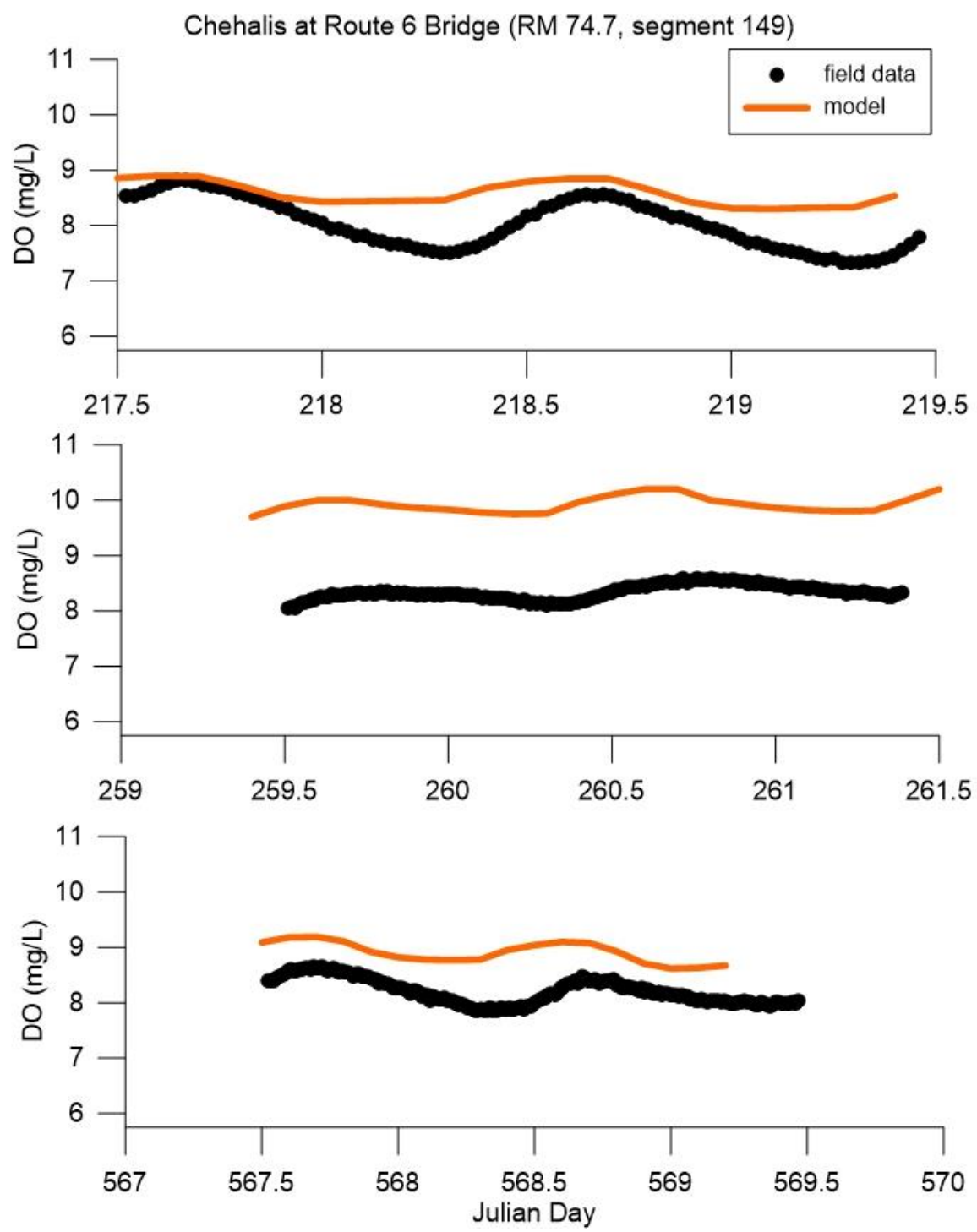

Figure 110. Model dissolved oxygen predictions versus continuous field data at the Route 6 Bridge monitoring station 

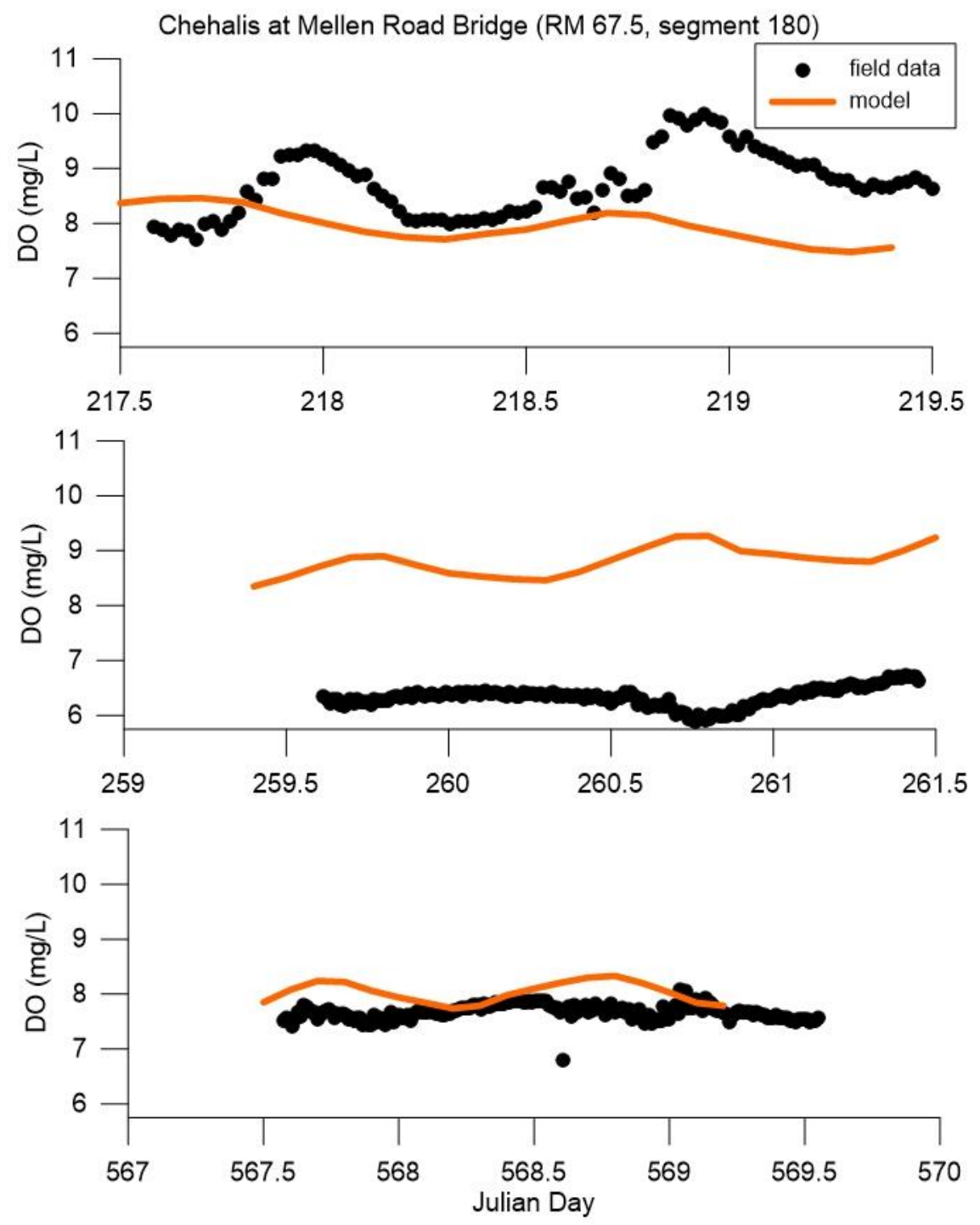

Figure 111. Model dissolved oxygen predictions versus continuous field data at the Mellen Road Bridge monitoring station 

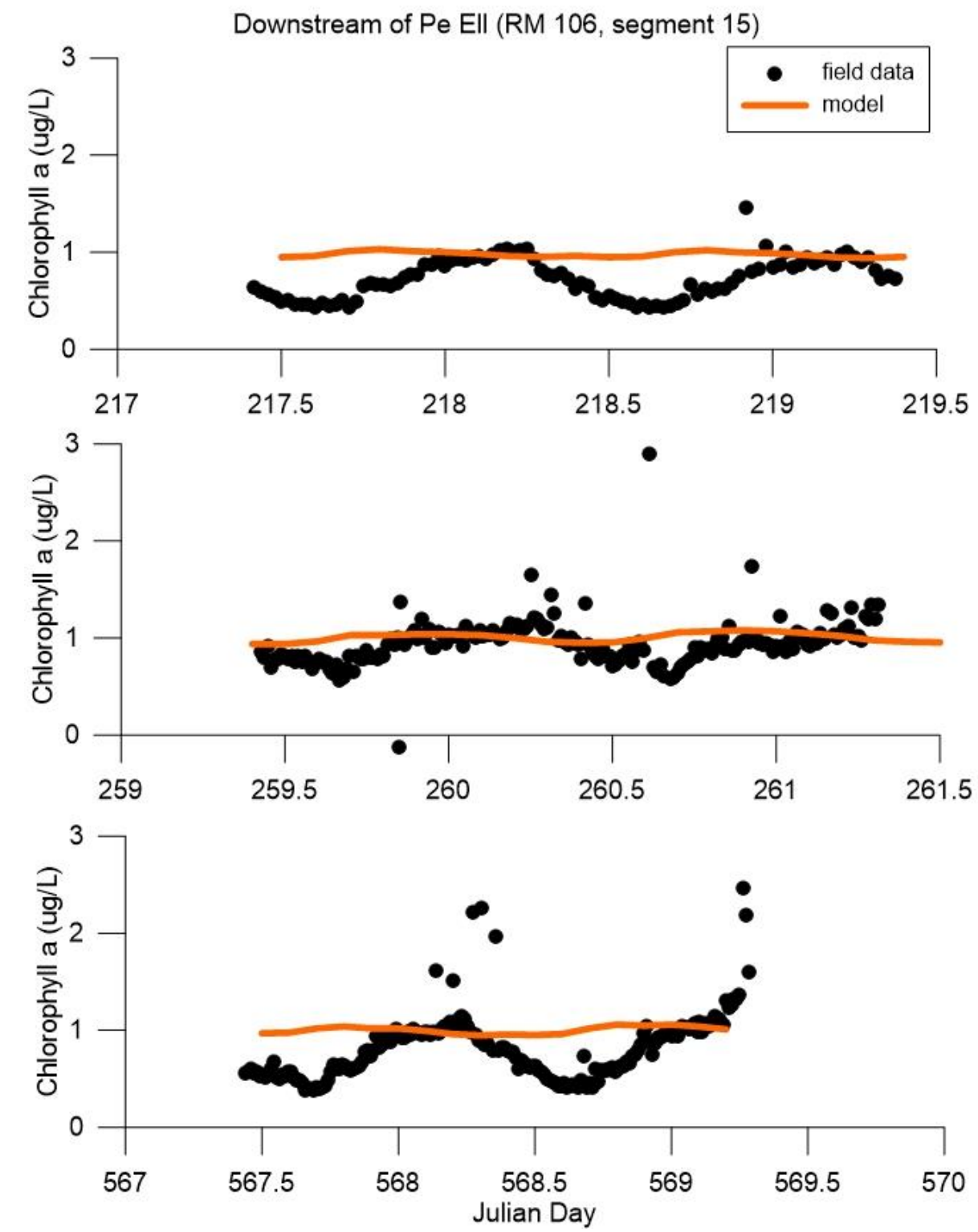

Figure 112. Model chlorophyll a predictions versus continuous field data at the downstream of Pe Ell monitoring station 

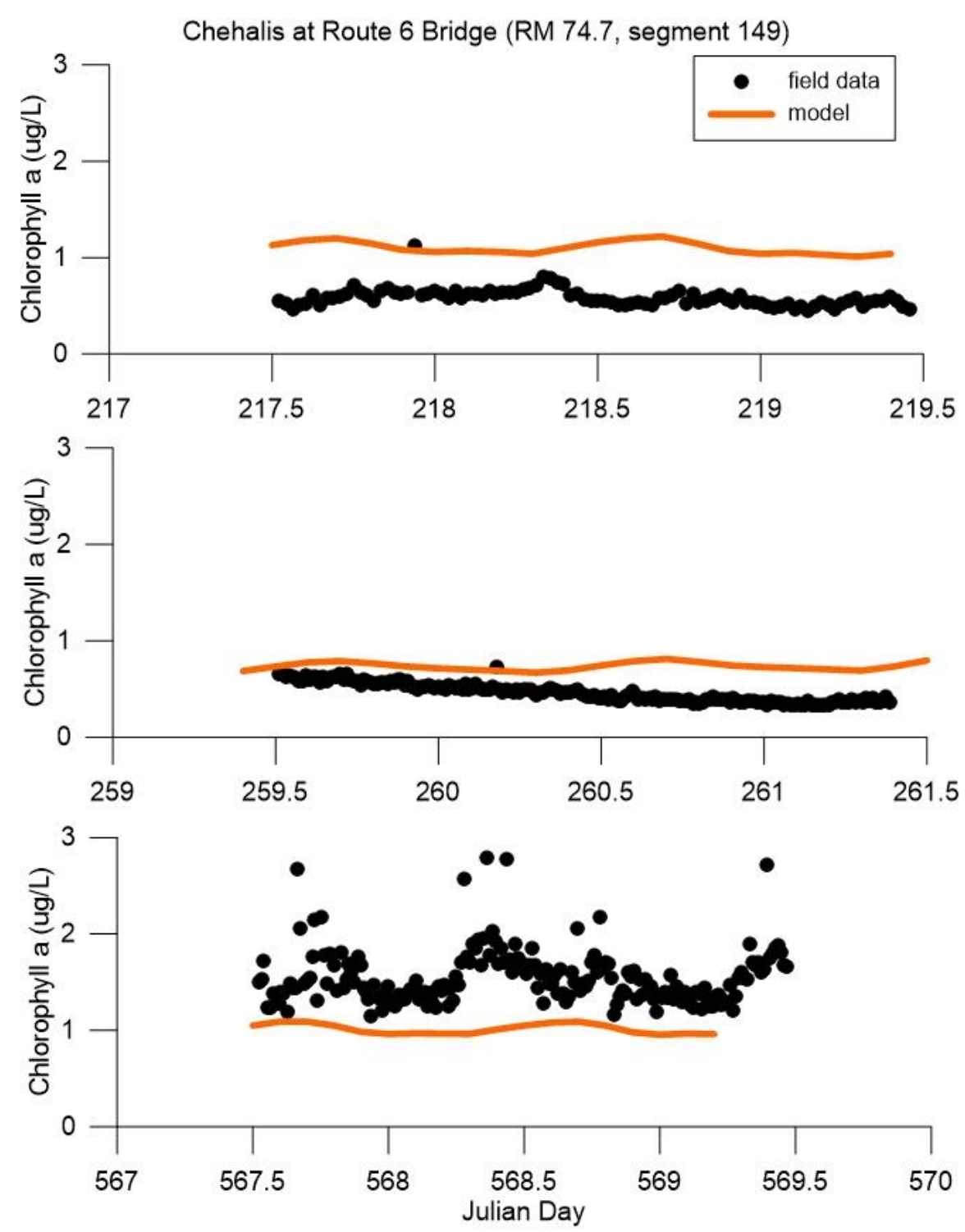

Figure 113. Model chlorophyll a predictions versus continuous field data at the Route 6 Bridge monitoring station 

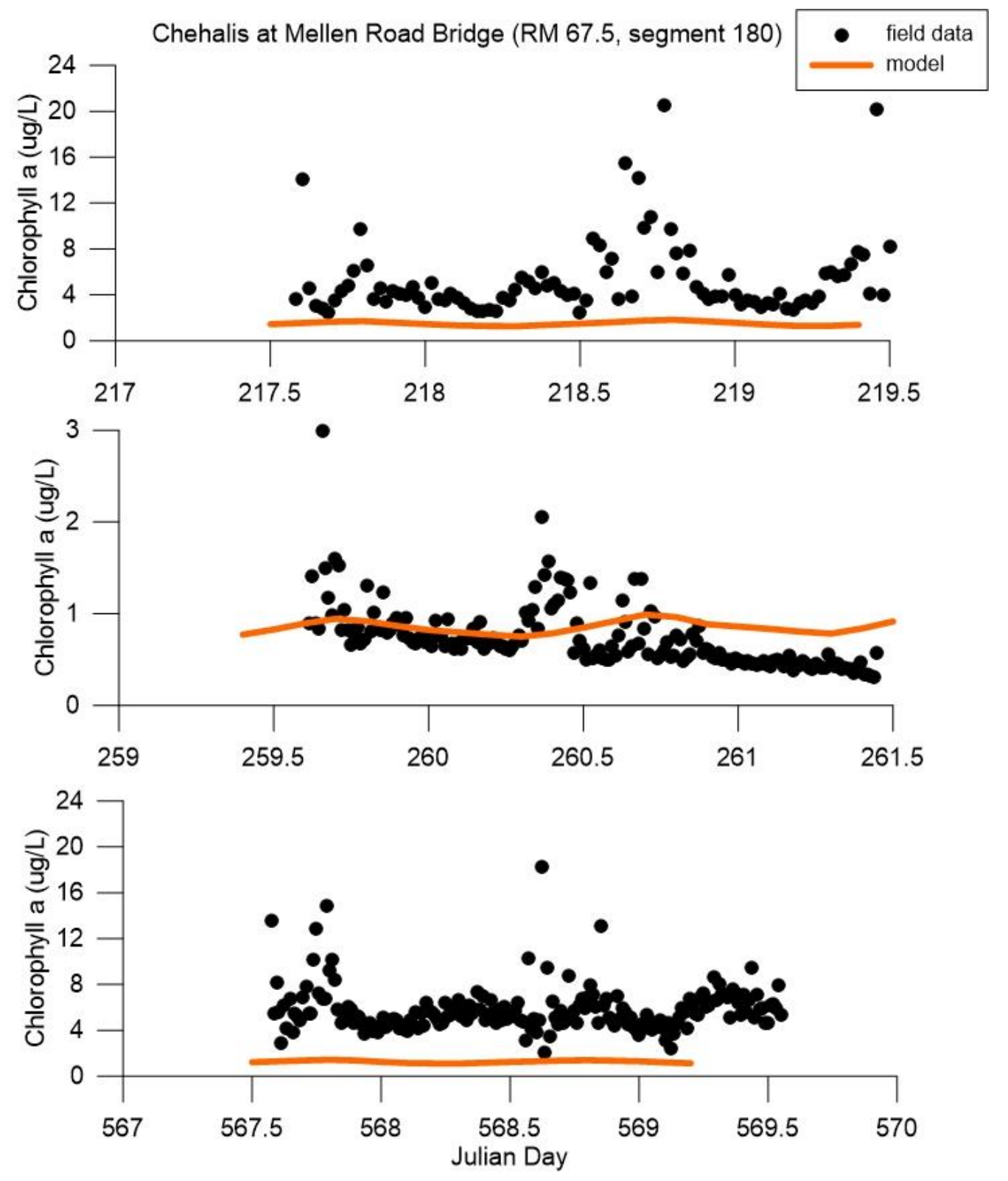

Figure 114. Model chlorophyll a predictions versus continuous field data at the Mellen Road Bridge monitoring station 


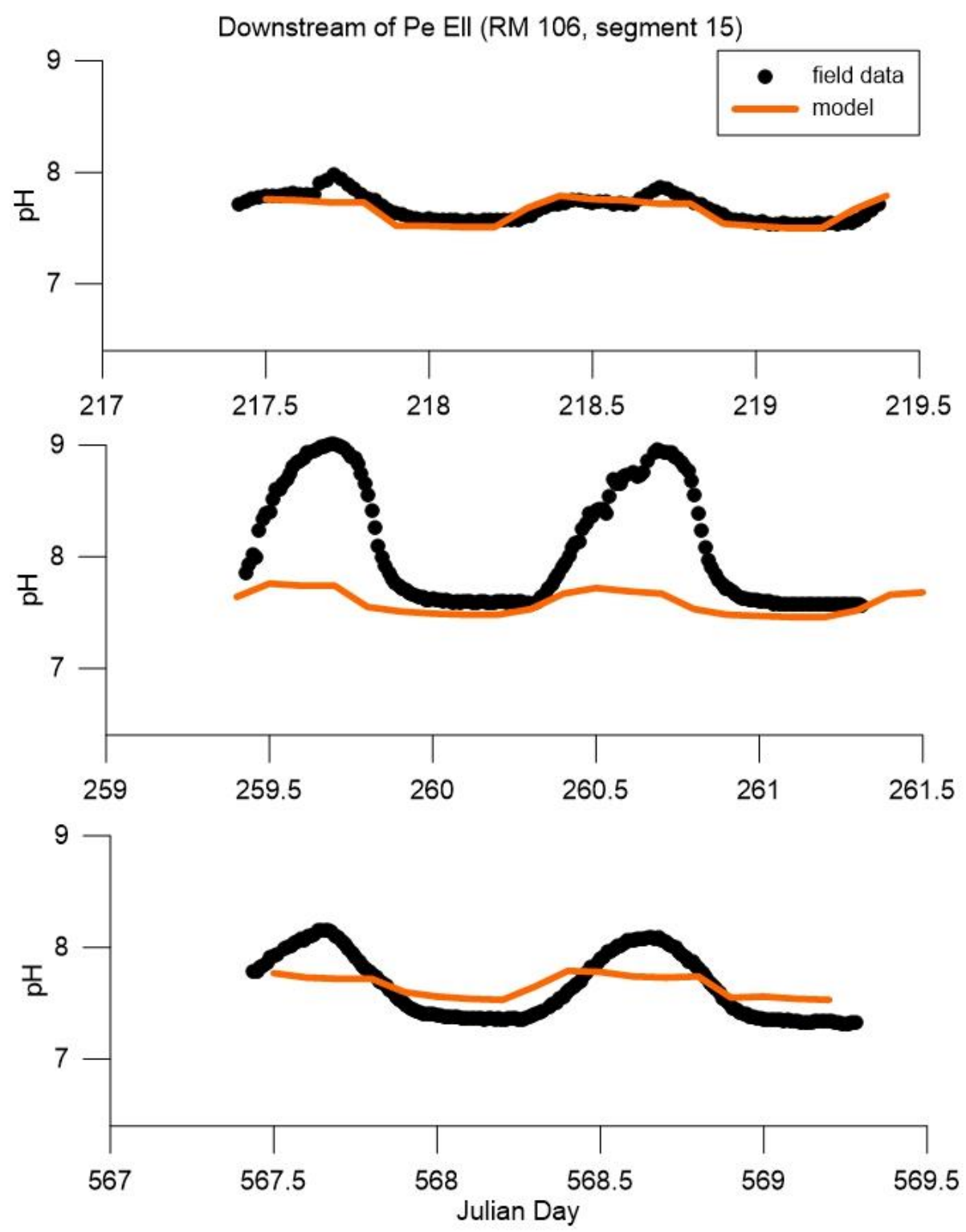

Figure 115. Model pH predictions versus continuous field data at the downstream of Pe Ell monitoring station 


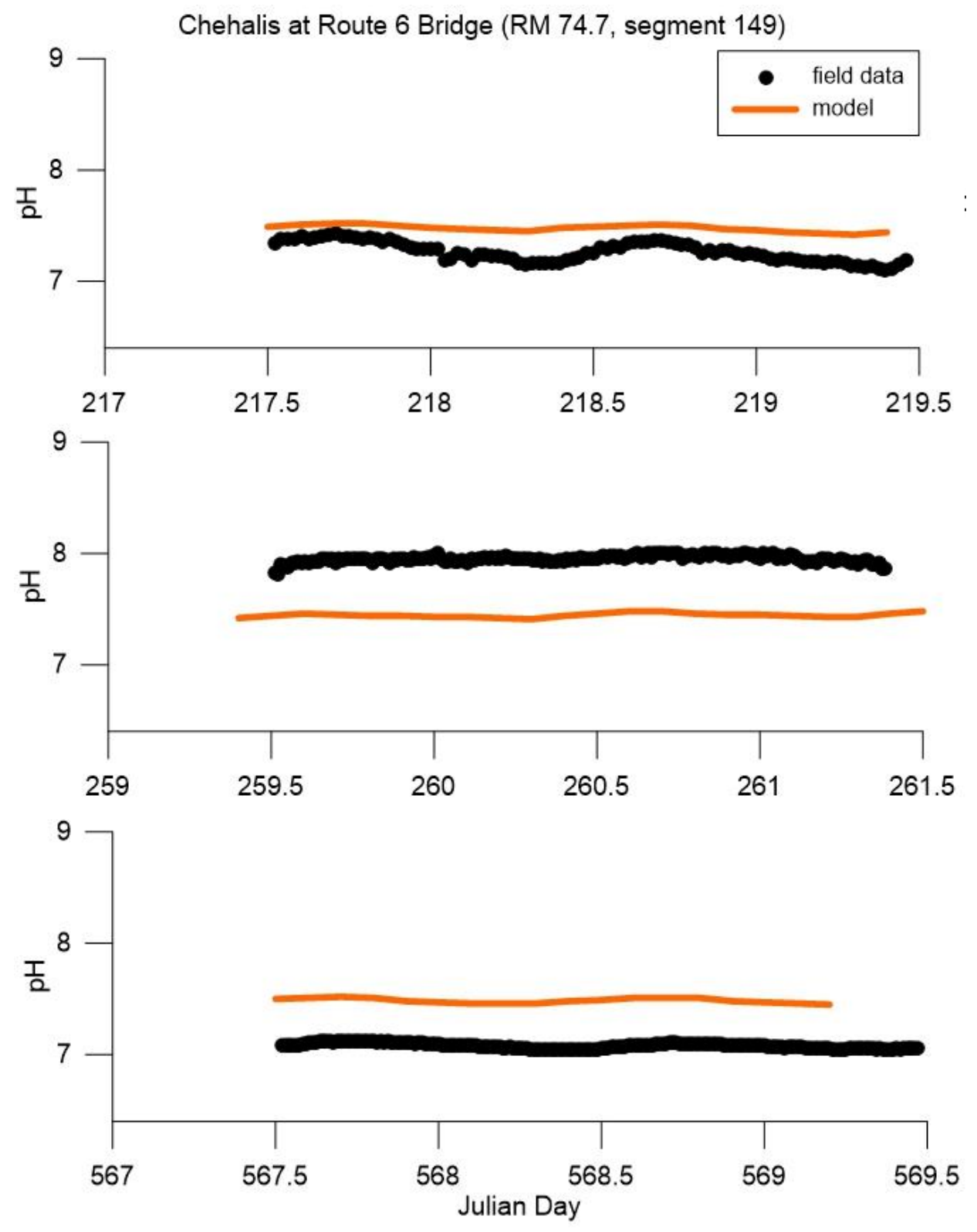

Figure 116. Model pH predictions versus continuous field data at the Route 6 Bridge monitoring station 

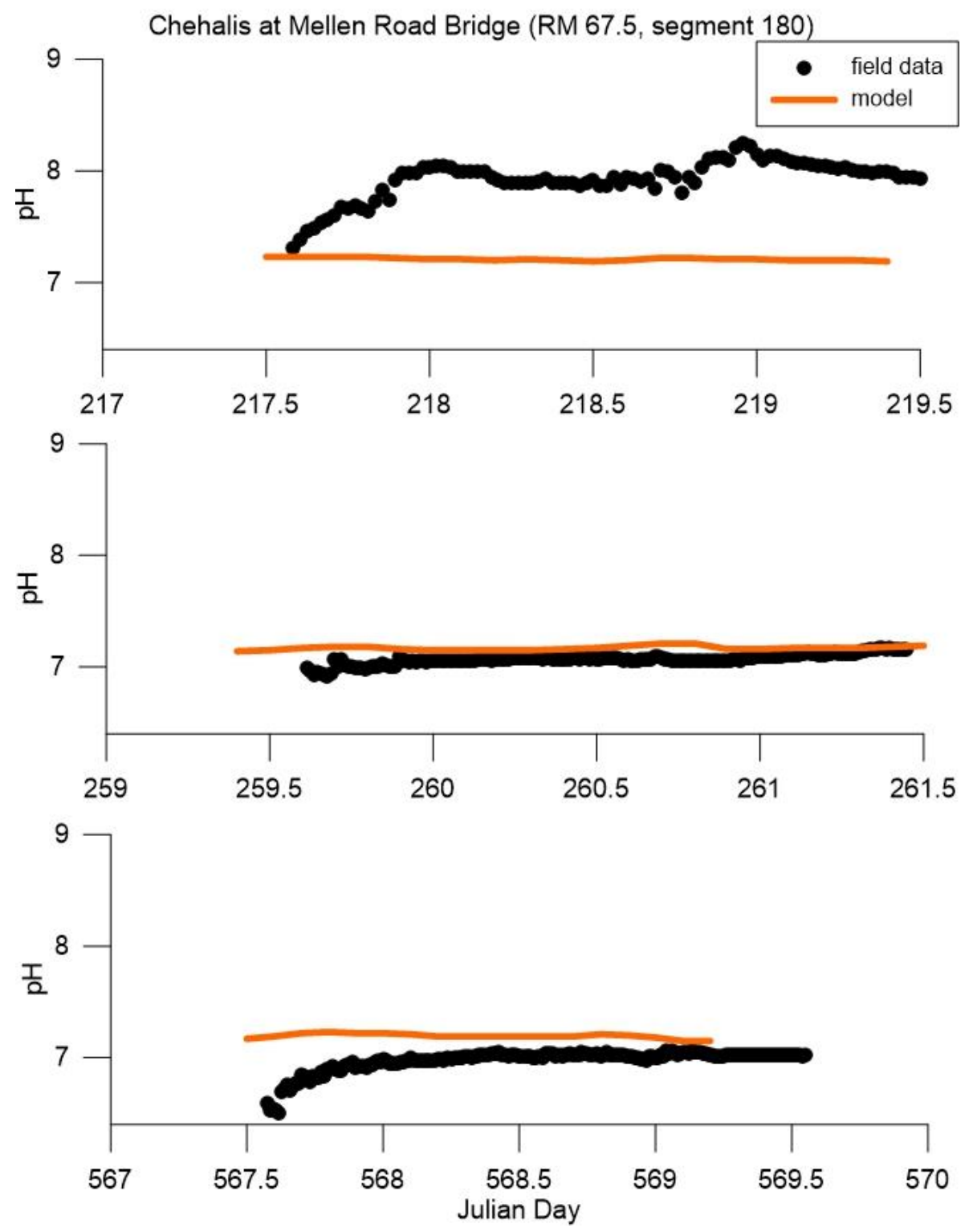

Figure 117. Model pH predictions versus continuous field data at the Mellen Road Bridge monitoring station 


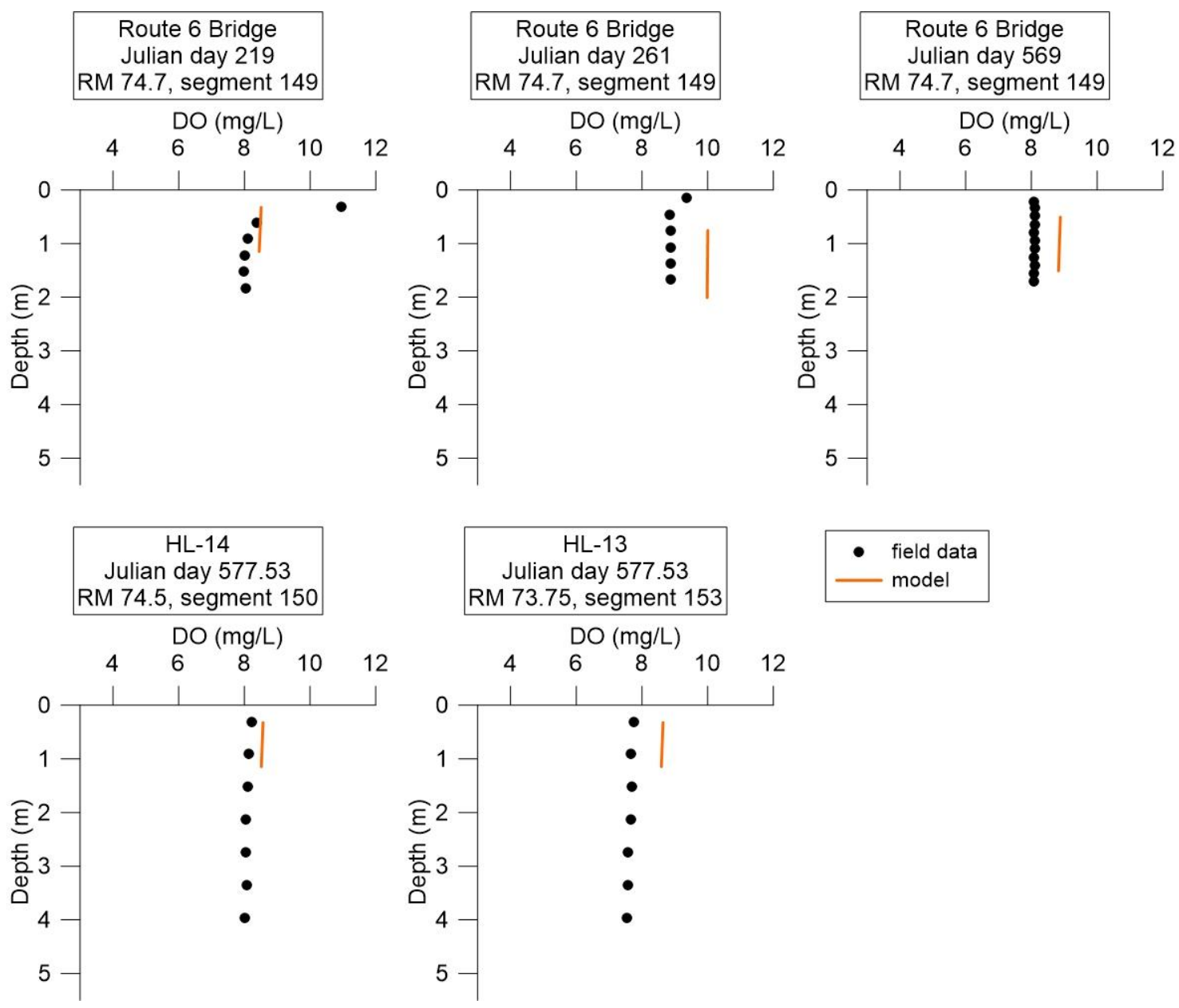

Figure 118. Model-predicted vertical dissolved oxygen profiles compared to field data at the monitoring stations: Route 6 Bridge, HL-14, and HL-13 

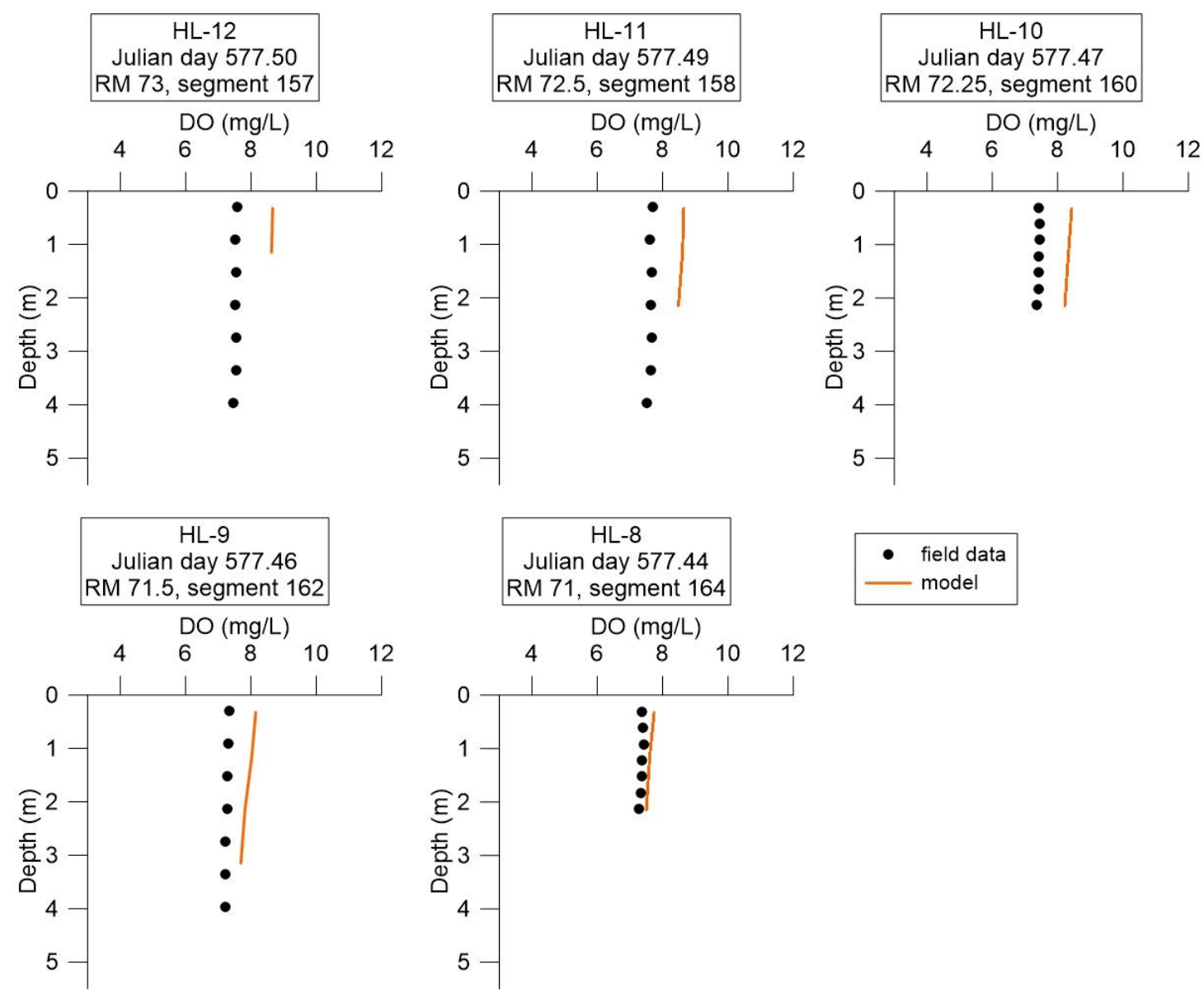

Figure 119. Model-predicted vertical dissolved oxygen profiles compared to field data at the monitoring stations: HL-12, HL-11, HL-10, HL-9 and HL-8 

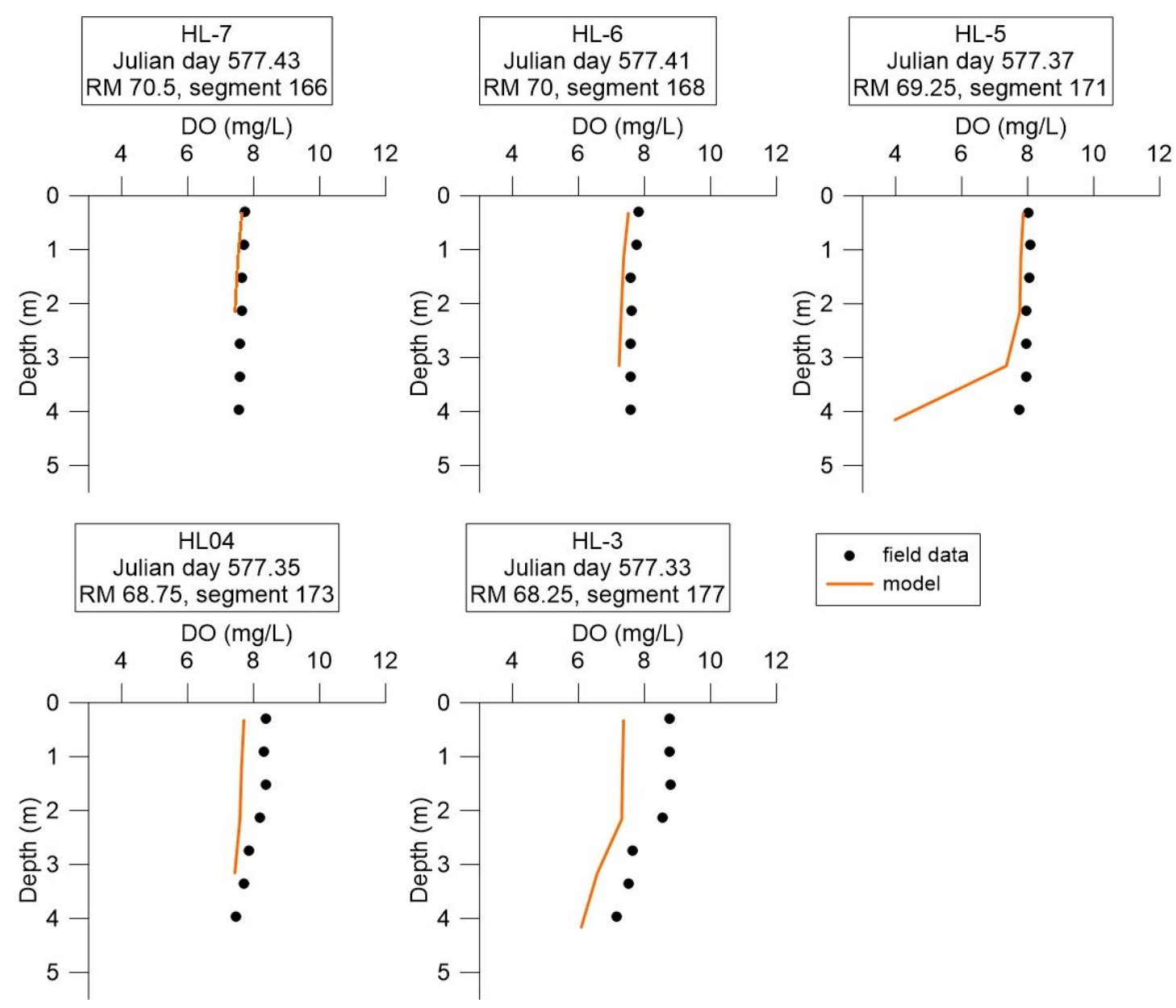

Figure 120. Model-predicted vertical dissolved oxygen profiles compared to field data at the monitoring stations: HL-7, HL-6, HL-5, HL-4 and HL-3 


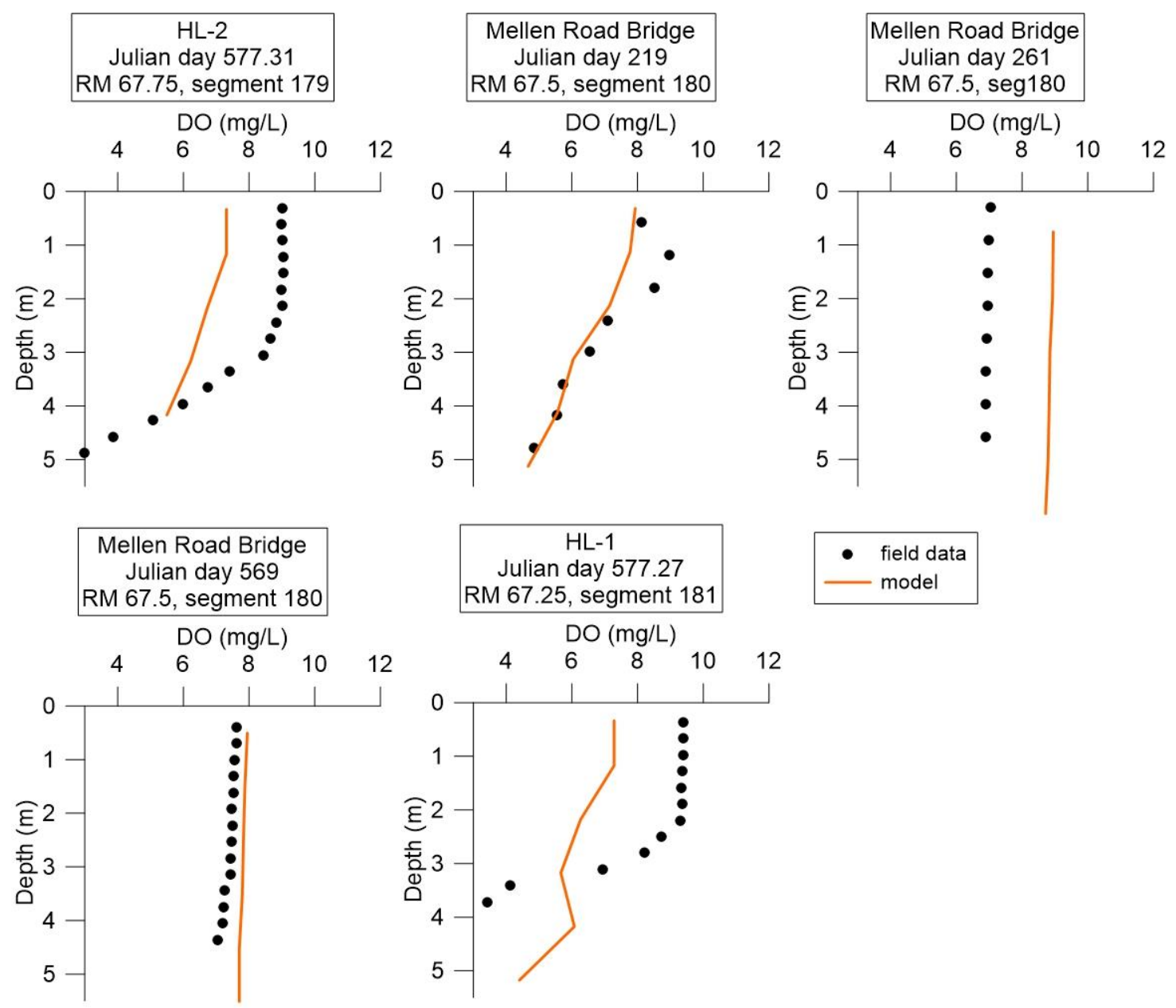

Figure 121. Model-predicted vertical dissolved oxygen profiles compared to field data at the monitoring stations: HL-2, Mellen Road Bridge, and HL-1 
Water quality coefficients used in the model are shown in Table 25. Many of these coefficients were adjusted during the course of water quality calibration.

Table 25. W2 Model Water Quality Parameters in the Chehalis River Model

\begin{tabular}{|c|c|c|c|c|}
\hline Variable & Description & Units & $\begin{array}{l}\text { Typical } \\
\text { values* }\end{array}$ & Values \\
\hline$A X$ & $\begin{array}{l}\text { Longitudinal eddy viscosity (for } \\
\text { momentum dispersion) }\end{array}$ & $\mathrm{m}^{2} / \mathrm{sec}$ & 1 & 1 \\
\hline DX & $\begin{array}{l}\text { Longitudinal eddy diffusivity (for } \\
\text { dispersion of heat and } \\
\text { constituents) }\end{array}$ & $\mathrm{m}^{2} / \mathrm{sec}$ & 1 & 1 \\
\hline $\mathrm{CBHE}$ & $\begin{array}{l}\text { Coefficient of bottom heat } \\
\text { exchange }\end{array}$ & $\mathrm{Wm}^{2} / \mathrm{sec}$ & 0.30 & 0.30 \\
\hline TSED & Sediment (ground) temperature & ${ }^{\circ} \mathrm{C}$ & & 11.5 \\
\hline WSC & Wind sheltering coefficient & & 0.85 & 0.25 \\
\hline BETA & $\begin{array}{l}\text { Fraction of incident solar } \\
\text { radiation absorbed at the water } \\
\text { surface }\end{array}$ & & 0.45 & 0.45 \\
\hline EXH2O & Extinction for water & $/ \mathrm{m}$ & $0.25-0.45$ & 0.25 \\
\hline AG1 & Algal growth rate for group \#1 & /day & $1-3$ & 1.5 \\
\hline AM1 & Algal mortality rate for group \#1 & /day & & 0.1 \\
\hline AE1 & Algal excretion rate for group \#1 & /day & $0.014-0.044$ & 0.04 \\
\hline AR1 & $\begin{array}{l}\text { Algal dark respiration for group } \\
\# 1\end{array}$ & /day & $0.01-0.92$ & 0.04 \\
\hline AS1 & Algal settling rate for group \#1 & /day & $0.02-1.00$ & 0.1 \\
\hline ASAT1 & $\begin{array}{l}\text { Algae Saturation intensity at } \\
\text { maximum photosynthetic rate } \\
\text { for group \#1 }\end{array}$ & $\mathrm{W} / \mathrm{m}^{2}$ & $10-170$ & 150 \\
\hline APOM1 & $\begin{array}{l}\text { Fraction of algal biomass lost by } \\
\text { mortality to detritus for algae for } \\
\text { group \#1 }\end{array}$ & & 0.8 & 0.8 \\
\hline AT1_1 & $\begin{array}{l}\text { Lower temperature for algal } \\
\text { growth for group \#1 }\end{array}$ & ${ }^{\circ} \mathrm{C}$ & & 3 \\
\hline AT2_1 & $\begin{array}{l}\text { Lower temperature for maximum } \\
\text { algal growth for group } \# 1\end{array}$ & ${ }^{\circ} \mathrm{C}$ & & 7 \\
\hline AT3_1 & $\begin{array}{l}\text { Upper temperature for maximum } \\
\text { algal growth for group } \# 1\end{array}$ & ${ }^{\circ} \mathrm{C}$ & & 20 \\
\hline AT4_1 & $\begin{array}{l}\text { Upper temperature for algal } \\
\text { growth for group \#1 }\end{array}$ & ${ }^{\circ} \mathrm{C}$ & & 30 \\
\hline AK1_1 & $\begin{array}{l}\text { Fraction of algal growth rate at } \\
\text { AT1 for group \#1 }\end{array}$ & & 0.1 & 0.1 \\
\hline AK2_1 & $\begin{array}{l}\text { Fraction of maximum algal } \\
\text { growth rate at AT2 for group \#1 }\end{array}$ & & 0.99 & 0.99 \\
\hline AK3_1 & $\begin{array}{l}\text { Fraction of maximum algal } \\
\text { growth rate at AT3 for group \#1 }\end{array}$ & & 0.99 & 0.99 \\
\hline
\end{tabular}




\begin{tabular}{|c|c|c|c|c|}
\hline Variable & Description & Units & $\begin{array}{l}\text { Typical } \\
\text { values* }\end{array}$ & Values \\
\hline AK4_1 & $\begin{array}{l}\text { Fraction of algal growth rate at } \\
\text { AT4 for group \#1 }\end{array}$ & & 0.1 & 0.1 \\
\hline ALGP1 & $\begin{array}{l}\text { Stoichiometric equivalent } \\
\text { between organic matter and } \\
\text { phosphorus for algae group \#1 }\end{array}$ & & 0.005 & 0.01 \\
\hline ALGN1 & $\begin{array}{l}\text { Stoichiometric equivalent } \\
\text { between organic matter and } \\
\text { nitrogen for algae group \#1 }\end{array}$ & & 0.08 & 0.08 \\
\hline ALGC1 & $\begin{array}{l}\text { Stoichiometric equivalent } \\
\text { between organic matter and } \\
\text { carbon for algae group \#1 }\end{array}$ & & $0.4-0.5$ & 0.5 \\
\hline AG2 & Algal growth rate for group \#2 & /day & $1-3$ & 2 \\
\hline AM2 & Algal mortality rate for group \#2 & /day & & 0.1 \\
\hline AE2 & Algal excretion rate for group \#2 & /day & $0.014-0.044$ & 0.04 \\
\hline AR2 & $\begin{array}{l}\text { Algal dark respiration for group } \\
\# 2\end{array}$ & /day & $0.01-0.92$ & 0.04 \\
\hline AS2 & Algal settling rate for group \#2 & /day & $0.02-1.00$ & 0.1 \\
\hline ASAT2 & $\begin{array}{l}\text { Algae Saturation intensity at } \\
\text { maximum photosynthetic rate } \\
\text { for group \#2 }\end{array}$ & $\mathrm{W} / \mathrm{m}^{2}$ & $10-170$ & 150 \\
\hline APOM2 & $\begin{array}{l}\text { Fraction of algal biomass lost by } \\
\text { mortality to detritus for algae for } \\
\text { group \#2 }\end{array}$ & & 0.8 & 0.8 \\
\hline AT1_2 & $\begin{array}{l}\text { Lower temperature for algal } \\
\text { growth for group \#2 }\end{array}$ & ${ }^{\circ} \mathrm{C}$ & & 7 \\
\hline AT2_2 & $\begin{array}{l}\text { Lower temperature for maximum } \\
\text { algal growth for group } \# 2\end{array}$ & ${ }^{\circ} \mathrm{C}$ & & 15 \\
\hline AT3_2 & $\begin{array}{l}\text { Upper temperature for maximum } \\
\text { algal growth for group \#2 }\end{array}$ & ${ }^{\circ} \mathrm{C}$ & & 30 \\
\hline AT4_2 & $\begin{array}{l}\text { Upper temperature for algal } \\
\text { growth for group \#2 }\end{array}$ & ${ }^{\circ} \mathrm{C}$ & & 35 \\
\hline AK1_2 & $\begin{array}{l}\text { Fraction of algal growth rate at } \\
\text { AT1 for group \#2 }\end{array}$ & & 0.1 & 0.1 \\
\hline AK2_2 & $\begin{array}{l}\text { Fraction of maximum algal } \\
\text { growth rate at AT2 for group \#2 }\end{array}$ & & 0.99 & 0.99 \\
\hline AK3_2 & $\begin{array}{l}\text { Fraction of maximum algal } \\
\text { growth rate at AT3 for group \#2 }\end{array}$ & & 0.99 & 0.99 \\
\hline AK4_2 & $\begin{array}{l}\text { Fraction of algal growth rate at } \\
\text { AT4 for group \#2 }\end{array}$ & & 0.1 & 0.1 \\
\hline ALGP2 & $\begin{array}{l}\text { Stoichiometric equivalent } \\
\text { between organic matter and } \\
\text { phosphorus for algae group \#2 }\end{array}$ & & 0.005 & 0.01 \\
\hline ALGN2 & $\begin{array}{l}\text { Stoichiometric equivalent } \\
\text { between organic matter and } \\
\text { nitrogen for algae group } \# 2\end{array}$ & & 0.08 & 0.08 \\
\hline
\end{tabular}




\begin{tabular}{|c|c|c|c|c|}
\hline Variable & Description & Units & $\begin{array}{l}\text { Typical } \\
\text { values* }\end{array}$ & Values \\
\hline ALGC2 & $\begin{array}{l}\text { Stoichiometric equivalent } \\
\text { between organic matter and } \\
\text { carbon for algae group \#2 }\end{array}$ & & $0.4-0.5$ & 0.5 \\
\hline LDOMDK & Labile DOM decay rate & /day & $0.04-0.12$ & 0.08 \\
\hline LRDDK & Labile to refractory decay rate & /day & 0.001 & 0.01 \\
\hline RDOMDK & Maximum refractory decay rate & /day & 0.001 & 0.001 \\
\hline LPOMDK & Labile Detritus decay rate & /day & $0.04-0.1$ & 0.06 \\
\hline POMS & Detritus settling rate & m/day & $0.2-2$ & 0.75 \\
\hline RPOMDK & Refractory detritus decay rate & /day & 0.001 & 0.001 \\
\hline OMT1 & $\begin{array}{l}\text { Lower temperature for organic } \\
\text { matter decay }\end{array}$ & ${ }^{\circ} \mathrm{C}$ & 4 & 4 \\
\hline OMT2 & $\begin{array}{l}\text { Lower temperature for maximum } \\
\text { organic matter decay }\end{array}$ & ${ }^{\circ} \mathrm{C}$ & 30 & 25 \\
\hline OMK1 & $\begin{array}{l}\text { Fraction of organic matter decay } \\
\text { rate at OMT1 }\end{array}$ & & 0.1 & 0.1 \\
\hline ОМК2 & $\begin{array}{l}\text { Fraction of organic matter decay } \\
\text { rate at OMT2 }\end{array}$ & & 0.99 & 0.99 \\
\hline PO4R & $\begin{array}{l}\text { Anaerobic sediment release rate } \\
\text { of phosphorus as fraction of SOD }\end{array}$ & & & 0.001 \\
\hline AHSP1 & $\begin{array}{l}\text { Algal half-saturation constant for } \\
\text { phosphorus for group \#1 }\end{array}$ & $\mathrm{g} / \mathrm{m}^{3}$ & $0.002-0.01$ & 0.003 \\
\hline AHSP2 & $\begin{array}{l}\text { Algal half-saturation constant for } \\
\text { phosphorus for group \#2 }\end{array}$ & $\mathrm{g} / \mathrm{m}^{3}$ & $0.002-0.01$ & 0.003 \\
\hline NH4DK & $\begin{array}{l}\text { Ammonia decay rate } \\
\text { (nitrification rate) }\end{array}$ & /day & $0.001-1.3$ & 0.8 \\
\hline AHSN1 & $\begin{array}{l}\text { Algal half-saturation constant for } \\
\text { nitrogen for group \#1 }\end{array}$ & $\mathrm{g} / \mathrm{m}^{3}$ & 0.014 & 0.014 \\
\hline AHSN2 & $\begin{array}{l}\text { Algal half-saturation constant for } \\
\text { nitrogen for group \#2 }\end{array}$ & $\mathrm{g} / \mathrm{m}^{3}$ & 0.014 & 0.014 \\
\hline NH4T1 & $\begin{array}{l}\text { Lower temperature for ammonia } \\
\text { decay }\end{array}$ & ${ }^{\circ} \mathrm{C}$ & 5 & 5 \\
\hline NH4T2 & $\begin{array}{l}\text { Lower temperature for maximum } \\
\text { ammonia decay }\end{array}$ & ${ }^{\circ} \mathrm{C}$ & 20 & 25 \\
\hline NH4K1 & $\begin{array}{l}\text { Fraction of nitrification rate at } \\
\text { NH4T1 }\end{array}$ & & 0.1 & 0.1 \\
\hline NH4K2 & $\begin{array}{l}\text { Fraction of nitrification rate at } \\
\text { NH4T2 }\end{array}$ & & 0.99 & 0.99 \\
\hline NO3DK & $\begin{array}{l}\text { Nitrate decay rate (denitrification } \\
\text { rate) }\end{array}$ & /day & $0.05-0.15$ & 0.03 \\
\hline NO3T1 & $\begin{array}{l}\text { Lower temperature for nitrate } \\
\text { decay }\end{array}$ & ${ }^{\circ} \mathrm{C}$ & 5 & 5 \\
\hline NO3T2 & $\begin{array}{l}\text { Lower temperature for maximum } \\
\text { nitrate decay }\end{array}$ & ${ }^{\circ} \mathrm{C}$ & 20 & 25 \\
\hline NO3K1 & $\begin{array}{l}\text { Fraction of denitrification rate at } \\
\text { NO3T1 }\end{array}$ & & 0.1 & 0.1 \\
\hline
\end{tabular}




\begin{tabular}{|c|c|c|c|c|}
\hline Variable & Description & Units & $\begin{array}{l}\text { Typical } \\
\text { values* }\end{array}$ & Values \\
\hline NO3K2 & $\begin{array}{l}\text { Fraction of denitrification rate at } \\
\text { NO3T2 }\end{array}$ & & 0.99 & 0.99 \\
\hline $\mathrm{O} 2 \mathrm{NH} 4$ & $\begin{array}{l}\text { Oxygen stoichiometric equivalent } \\
\text { for ammonia decay }\end{array}$ & & 4.57 & 4.57 \\
\hline O2OM & $\begin{array}{l}\text { Oxygen stoichiometric equivalent } \\
\text { for organic matter decay }\end{array}$ & & 1.4 & 1.4 \\
\hline O2AR1 & $\begin{array}{l}\text { Oxygen stoichiometric equivalent } \\
\text { for dark respiration for group \#1 }\end{array}$ & & 1.1 & 1.1 \\
\hline O2AR2 & $\begin{array}{l}\text { Oxygen stoichiometric equivalent } \\
\text { for dark respiration for group \#2 }\end{array}$ & & 1.1 & 1.1 \\
\hline O2AG1 & $\begin{array}{l}\text { Oxygen stoichiometric equivalent } \\
\text { for algal growth for group } \# 1\end{array}$ & & 1.4 & 1.6 \\
\hline O2AG2 & $\begin{array}{l}\text { Oxygen stoichiometric equivalent } \\
\text { for algal growth for group \#2 }\end{array}$ & & 1.4 & 1.6 \\
\hline O2LIM & $\begin{array}{c}\text { Dissolved oxygen concentration } \\
\text { at which anaerobic processes } \\
\text { begin }\end{array}$ & $\mathrm{g} / \mathrm{m}^{3}$ & 0.1 & 0.07 \\
\hline SEDK & $\begin{array}{c}\text { First order sediment } \\
\text { compartment decay rate }\end{array}$ & /day & & 0.03 \\
\hline SOD & $\begin{array}{l}\text { Zeroth order sediment oxygen } \\
\text { demand }\end{array}$ & $\mathrm{g} / \mathrm{m}^{2} /$ day & $0.3-6$ & $0.3-1.9$ \\
\hline SEDBR & Sediment burial rate & /day & & 0.01 \\
\hline
\end{tabular}

\subsection{Boundary Condition Constituents}

The model was very sensitive to boundary inflows for constituents and correctly assessing boundary conditions was perhaps the most important task for water quality calibration. Multiple re-evaluations of estimates used for wastewater treatment plants, tributaries, and groundwater flows were necessary.

\subsubsection{Wastewater Treatment Plants}

Wastewater treatment plants often significantly impacted the resulting conditions in the river, as their constituent concentrations were often much greater than those from the upstream boundary or inputs from tributaries. This was especially important during 
the summer months when flow in the river was low. For this reason, careful analysis of wastewater treatment plant data and filling in missing data was an important step for water quality calibration.

Often, constituent data were missing entirely for some wastewater treatment plants. In this case reasonable values were used as an approximation. For example, NO3 data were completely missing for the Pe Ell, Darigold, and Centralia wastewater treatment plants, so typical values between $0.5 \mathrm{mg} / \mathrm{L}$ and $1 \mathrm{mg} / \mathrm{L}$ were used as estimates. Adjustments were made to concentrations to aid in water quality calibration, as no data were available for confirmation.

Particulate matter settling and decaying in the upper reaches of the model impacted the calibration of dissolved oxygen and nutrient species, particularly ammonia. When the fraction of BOD assumed to be dissolved was low and the fraction assumed particulate was high, large amounts of organic particulates settled to the bottom of the channel and upon degradation in the sediments reseased ammonia back into the water. This raised model concentrations of ammonia above field data values. When BOD was assumed to be equally partitioned between dissolved and particulate, resulting ammonia concentrations more closely matched field data.

\subsubsection{Tributary Winter Estimations}

Generally, tributary water quality data were only available during the summer months. Using summer values as approximations for winter values proved to be inaccurate in many cases. Field data along the mainstem river showed DO, TSS, and 
nitrate levels were higher during winter times, while ammonia concentrations were higher during summer times. Presumably, these trends would also be occurring in the tributaries. These seasonal variations were important to include in order to reproduce field data.

When possible, field data collected during winter from the mainstem Chehalis were used as an estimate for other tributaries. For example, an NO3 value of $0.724 \mathrm{mg} / \mathrm{L}$ was sampled on the mainstem river near the upstream boundary during winter. This value was used also in the major tributaries since no other data were available. This value was higher than summer nitrate concentrations, which generally ranged between $0.01 \mathrm{mg} / \mathrm{L}$ and $0.5 \mathrm{mg} / \mathrm{L}$. Nitrate concentrations were predicted to be too low when summer values were implemented during winter times. Higher winter nitrate concentrations from runoff from surrounding agricultural land during the winter months may not be captured in data sets containing values only collected during summer.

When it was not possible to use data collected during winter times, reasonable winter values were used as an estimate. For example, TSS data were entirely unavailable during the winter months, so $20 \mathrm{mg} / \mathrm{L}$ was used during these times as an approximation. This value was much higher than the summer TSS data, which generally ranged between 1 and $5 \mathrm{mg} / \mathrm{L}$. Higher TSS concentrations are often seen during winter times as rainfall runoff entering the stream often carries additional solids.

Otherwise, TSS values also included the amount of particulate organic matter as some of the BOD was assumed to be particulate. However, one BOD data point collected 
on September 17, 2013 was excluded for Elk Creek. This value equaled $24.3 \mathrm{mg} / \mathrm{L}$, and was much higher than any other BOD value collected for this tributary, or any of the other tributaries. This data value seemed unreasonable to apply for a long period of time when no other field data were available. Including this data point produced high model predictions for TSS and issues with other mainstem measured concentrations around the date it was collected.

DO values were only available for tributaries during the summer months, when water temperatures were warmer. Warmer water generally has lower DO concentrations than cooler water, so using summer DO values as approximations for winter times was unrealistic. DO values were estimated for the tributaries based on temperature and assuming $100 \%$ saturation. This was done using known relationships and assuming zero chloride concentration (Chapra, 1997).

\subsubsection{Groundwater}

While groundwater flows were very small, the impacts on water quality in the river were still necessary to consider for calibration, particularly during the low flow summer season. Some constituents had much different magnitudes in groundwater than seen in the rivers and creeks entering the system.

When gaps in groundwater constituents existed, they were generally filled in using averages or medians of other available groundwater measurements. Often, using median values to estimate missing data rather than averages was important for groundwater since many averages gave constituent concentrations biased towards higher values. 
Sometimes groundwater constituents were estimated using a value within the range of data available. For example, dissolved oxygen for the groundwater reaches ranged between approximately $0.1 \mathrm{mg} / \mathrm{L}$ and $2.6 \mathrm{mg} / \mathrm{L}$, so $2 \mathrm{mg} / \mathrm{L}$ was assumed reasonable and implemented for all groundwater inputs.

Groundwater inputs for nitrates were particularly important for the downstream reaches of the model. When estimates of groundwater nitrate were too high, nitrate built up and steadily increased higher than reflected in mainstem river field data in the downstream reaches. Reducing these concentrations helped to match model predictions to field data. The upstream reaches had a groundwater median nitrate value of $0.01 \mathrm{mg} / \mathrm{L}$ implemented (Pitz, 2005). The groundwater nitrate concentrations generally ranged from $0.01 \mathrm{mg} / \mathrm{L}$ to $1.3 \mathrm{mg} / \mathrm{L}$, so a value of $0.5 \mathrm{mg} / \mathrm{L}$ was assumed reasonable for the downstream reaches for groundwater.

\subsubsection{Locating Tributaries that Affected In-Stream Water Quality}

Since there were a large number of tributary inputs to the model, determining which inputs were affecting in-stream water quality conditions was an important step in water quality calibration.

Figure 122 shows TP values previously predited by the model. Between the locations at river miles 107 and 98.7 a peak in model-predicted TP occured near Julian day 220 that persisted downstream. This peak was not reflected in mainstem Chehalis River field data. Between these two locations the only inputs to the model were the Pe Ell wastewater treatment plant and Elk Creek. Around this time the Pe Ell wastewater 
treatment plant TP concentration was approximately $0.08 \mathrm{mg} / \mathrm{L}$, while the modelpredicted mainstem TP reached approximately $0.1 \mathrm{mg} / \mathrm{L}$. While wastewater treatment plants often had a major influence on water quality in the Chehalis River, in this case the Pe Ell wastewater treatment plant was not the cause for the peak in TP. Elk Creek, however, had TP concentrations exceeding $0.1 \mathrm{mg} / \mathrm{L}$ during this time. This was largely due to its organic matter as phosphorus (OMP) concentration. Elk Creek OMP was initially calculated using an average of its available TP field data, with values of $0.11 \mathrm{mg} / \mathrm{L}, 0.24$ $\mathrm{mg} / \mathrm{L}$, and $0.008 \mathrm{mg} / \mathrm{L}$. In order to reduce the OMP concentration in Elk Creek, OMP was re-estimated using the $0.008 \mathrm{mg} / \mathrm{L}$ value alone. Figure 123 shows TP values predicted by the model after this adjustment was made.

Similar process-of-elimination methods for various constituents and tributaries were conducted in order to determine which inputs to the model were driving water quality in the river. Once the driving influence was located, constituent concentrations were re-evaluated in order to determine whether the original estimation techniques were reasonable or poor. 

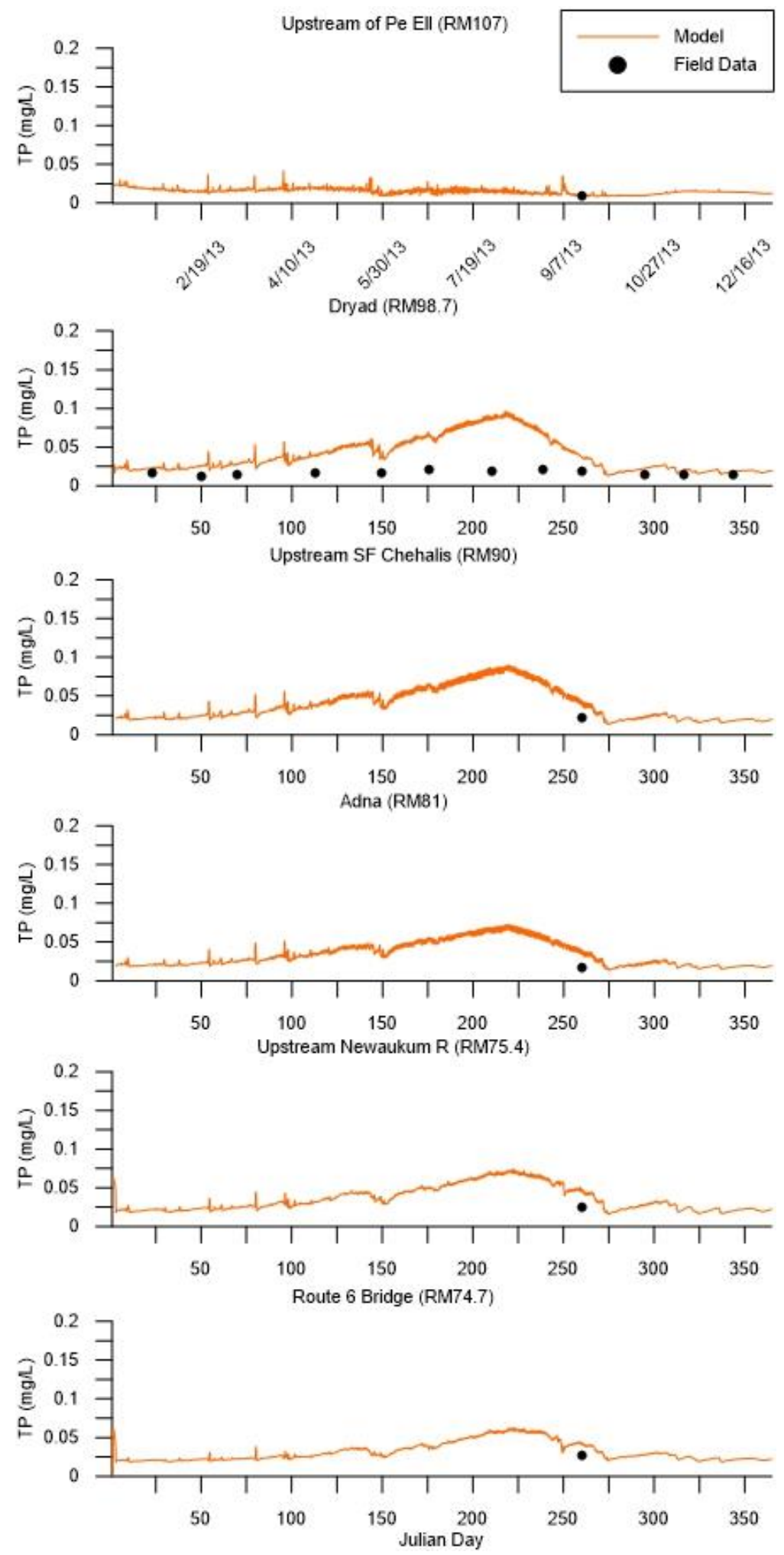

Figure 122. TP model predictions compared to field data when previous technique was used to estimate OMP for Elk Creek 

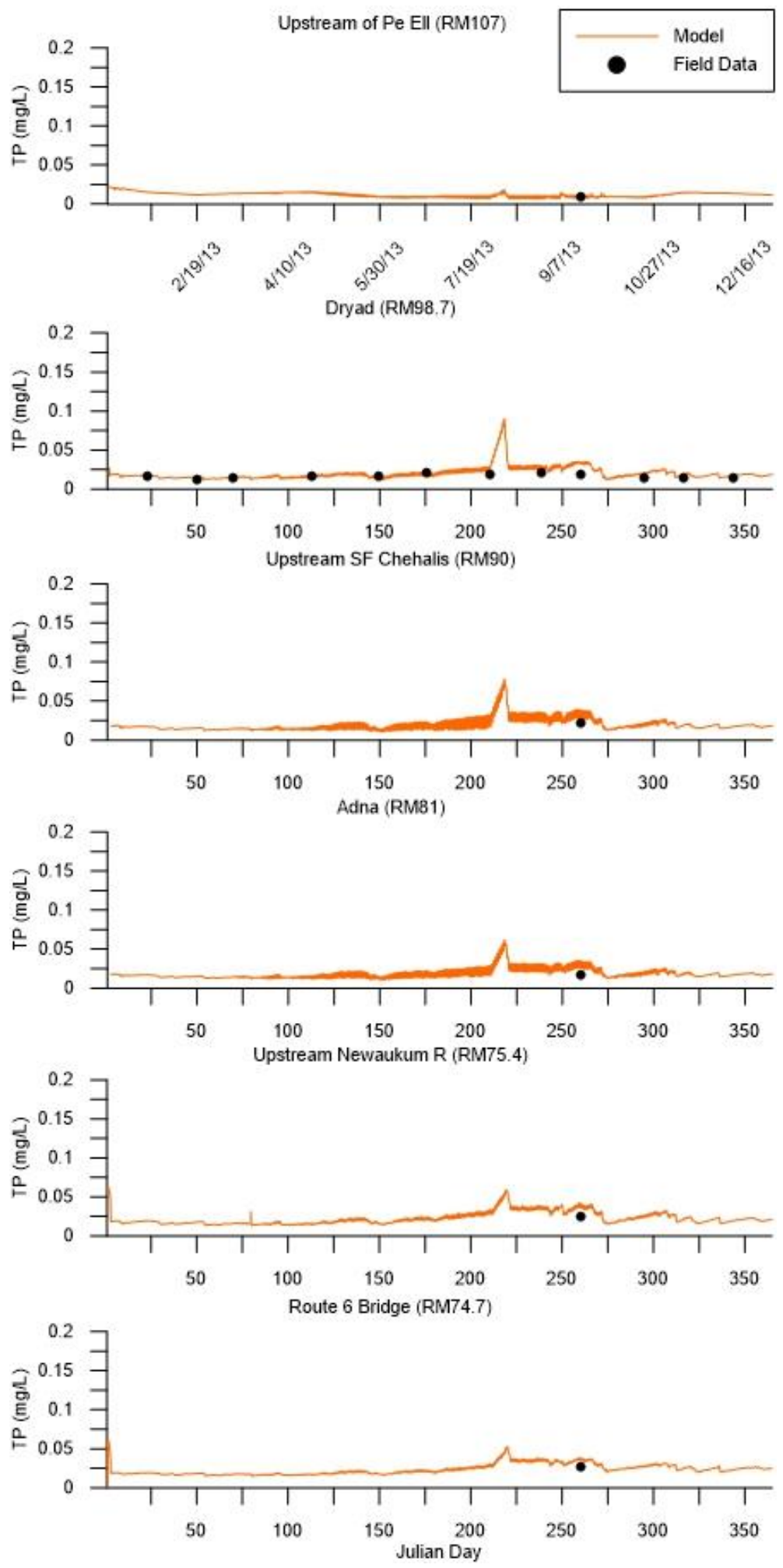

Figure 123. TP model predictions compared to field data when updated technique was used to estimate OMP for Elk Creek 


\subsection{Nitrogen, Phosphorus, \& Oxygen Fluxes}

The ammonia decay rate (NH4DK) and the nitrate decay rate (NO3DK) were important for calibration for ammonia and nitrates. NH4DK specifies the rate at which ammonia is oxidized to nitrate or nitrite. By increasing these decay rates, the concentration of ammonia or nitrates was decreased as the compound decayed more quickly. Conversely, by decreasing these decay rates, concentrations remained higher.

CE-QUAL-W2 allows the user to view outputs of various fluxes thoughout the model simulation, giving a view of what processes are important for various constituents. Viewing these fluxes for nitrogen species, phosphorus species, and dissolved oxygen were used for determining what proceses were the largest drivers for river conditions.

Phosphate fluxes included algal respiration, algal growth, algal production, epiphyton respiration, epiphyton growth, epiphyton production, decay of particulate organic matter, decay of dissolved organic matter, $1^{\text {st }}$ order sediment compartment decay, zeroorder sediment release, and sorbed phosphate from settling.

Ammonia fluxes included algal respiration, algal growth, algal production, epiphyton respiration, epiphyton growth, epiphyton production, ammonia algal uptake, particulate organic matter decay, dissolved organic matter decay, $1^{\text {st }}$ order sediment compartment decay, and zero-order sediment release.

Nitrates fluxes included denitrification, algal growth, epiphyton growth, and $1^{\text {st }}$ order sediment compartment decay. 
Dissolved oxygen fluxes included algal production, algal respiration, epiphyton production, epiphyton respiration, particulate organic matter decay, dissolved organic matter decay, nitrification, carbonaceous BOD decay, reaeration, $1^{\text {st }}$ order sediment compartment decay, and zero-order sediment oxygen demand.

Figure 124, Figure 125, Figure 126, Figure 127, Figure 128, Figure 129, Figure 130, Figure 131, and Figure 132 show the model predictions of NH4, NO3, and DO fluxes in waterbody 1 , waterbody 2 , waterbody 3 , waterbody 4 , waterbody 5 , waterbody 6 , waterbody 7 , waterbody 8 , and waterbody 9 respectively. The largest model-predicted NH4 fluxes were generally attributed to nitrification and periphyton/epiphyton respiration and production. Periphyton/epiphyton growth was generally the dominant model-predicted NO3 flux. The largest model-predicted DO fluxes were generally from algal respiration, periphyton/epiphyton respiration, reaeration, and zero-order sediments. 

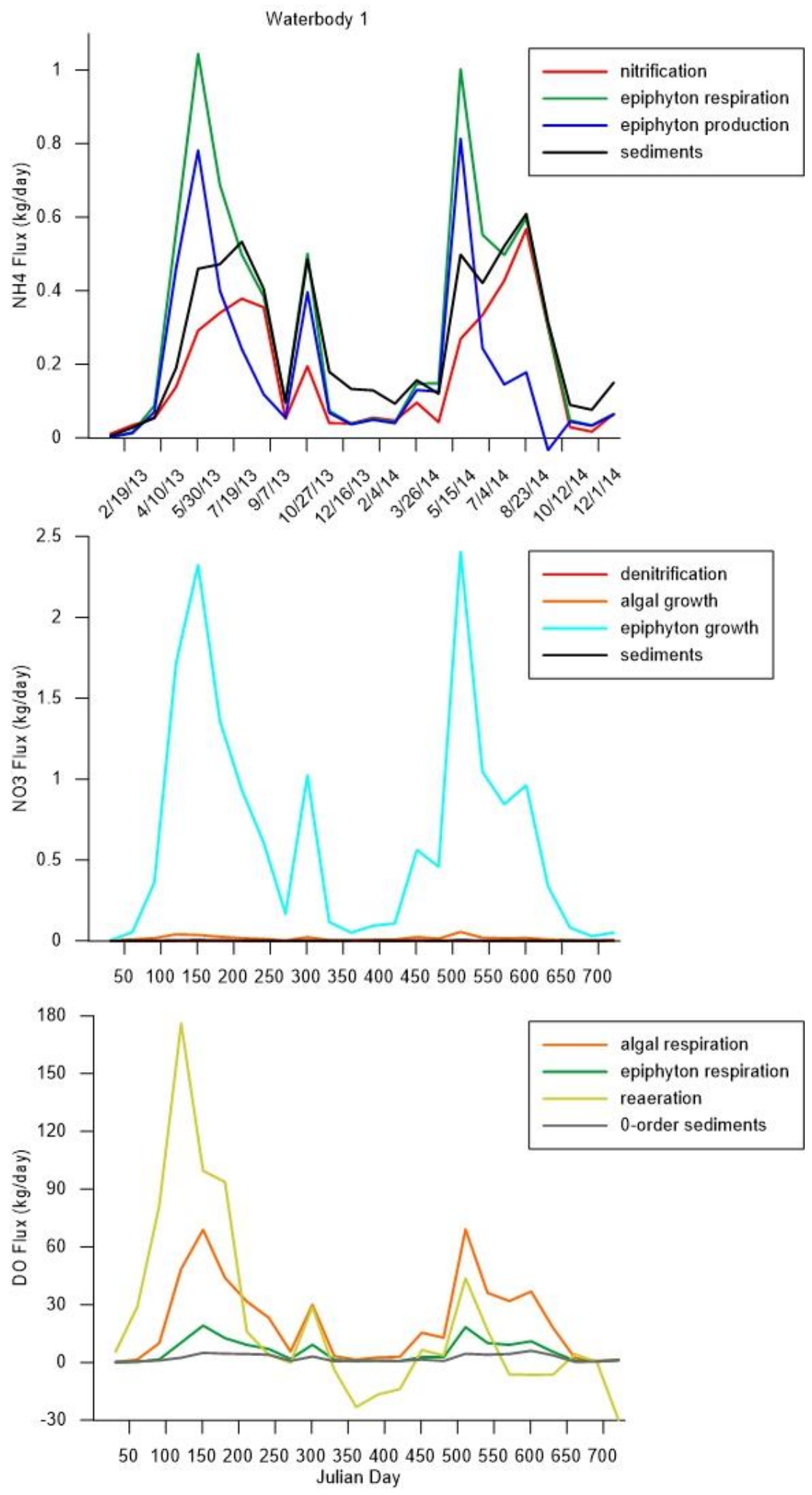

Figure 124. Dominant model-predicted NH4, NO3, and DO fluxes in waterbody 1 

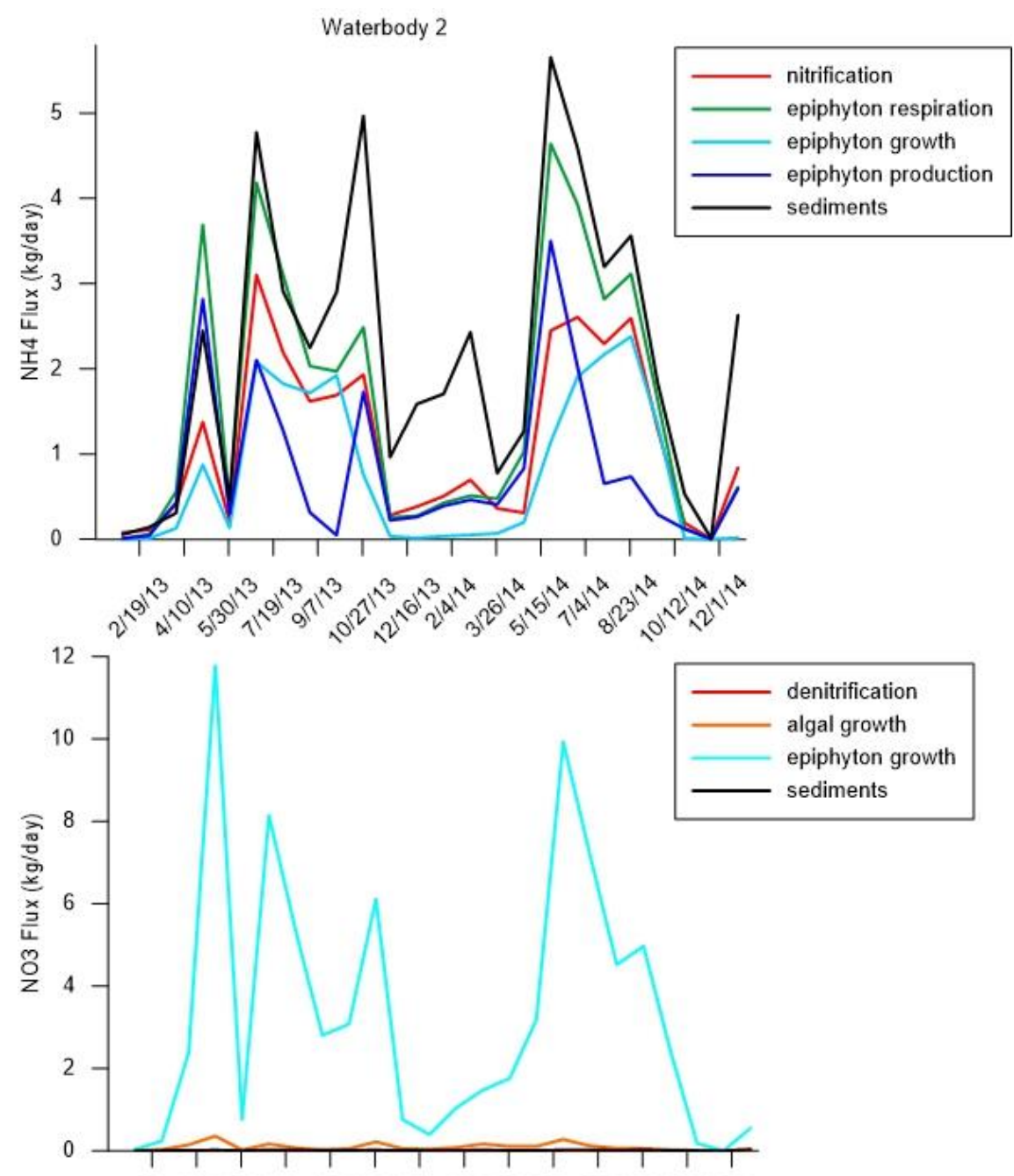

50100150200250300350400450500550600650700

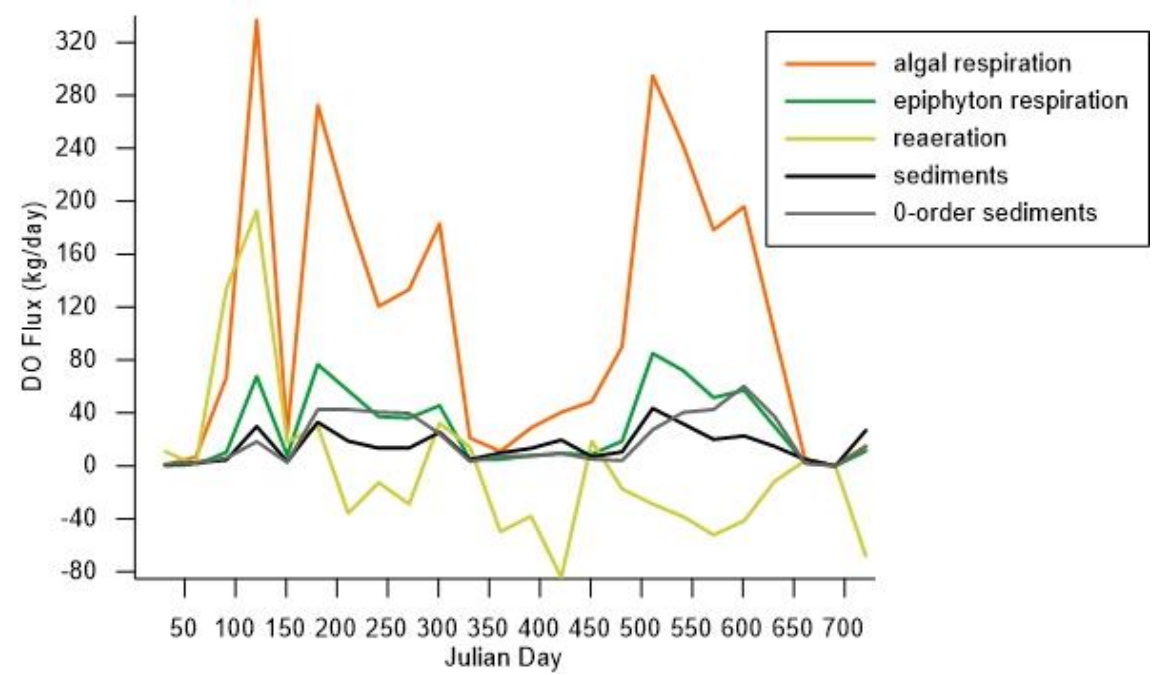

Figure 125. Dominant model-predicted NH4, NO3, and DO fluxes in waterbody 2 

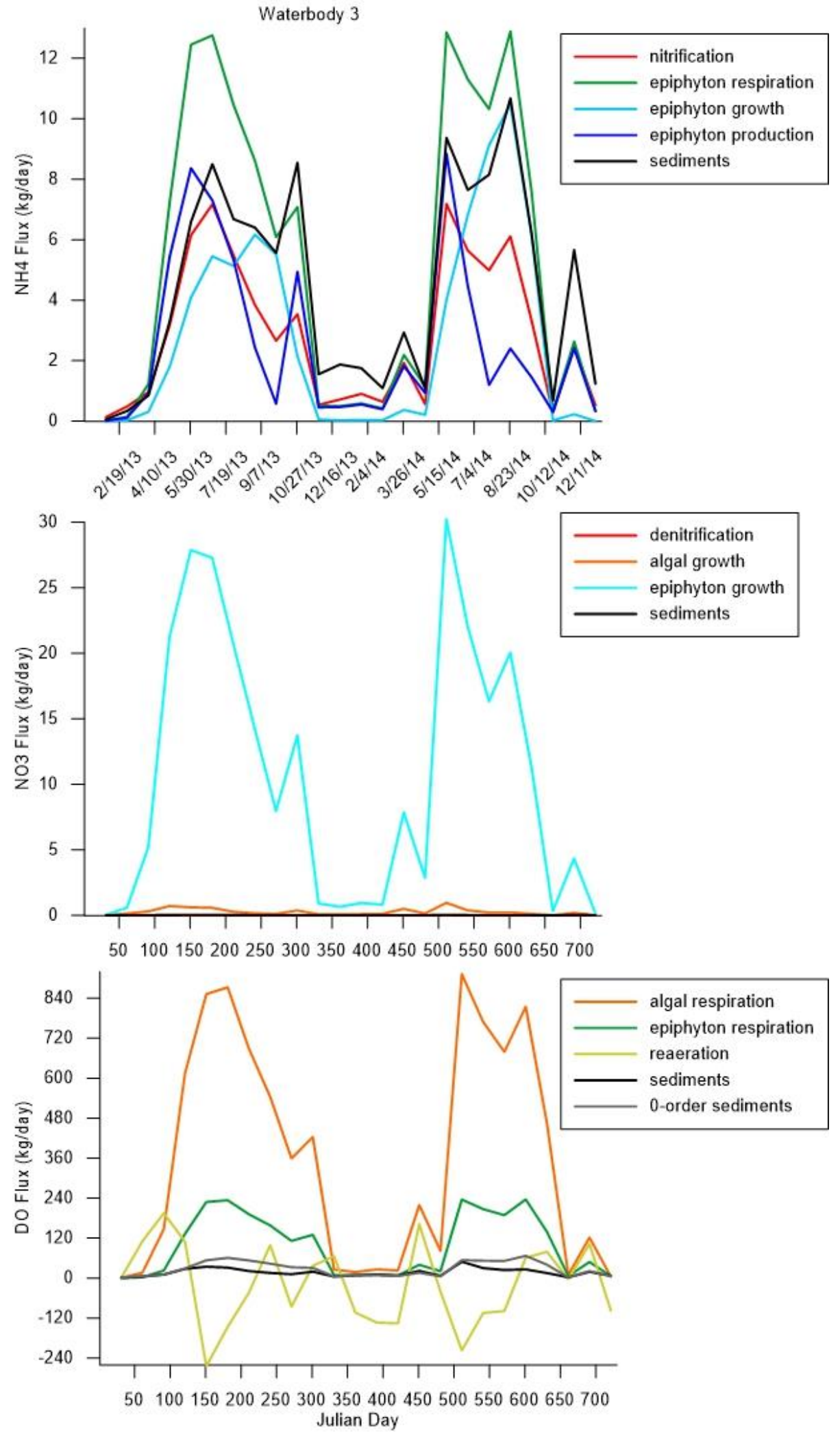

Figure 126. Dominant model-predicted NH4, NO3, and DO fluxes in waterbody 3 

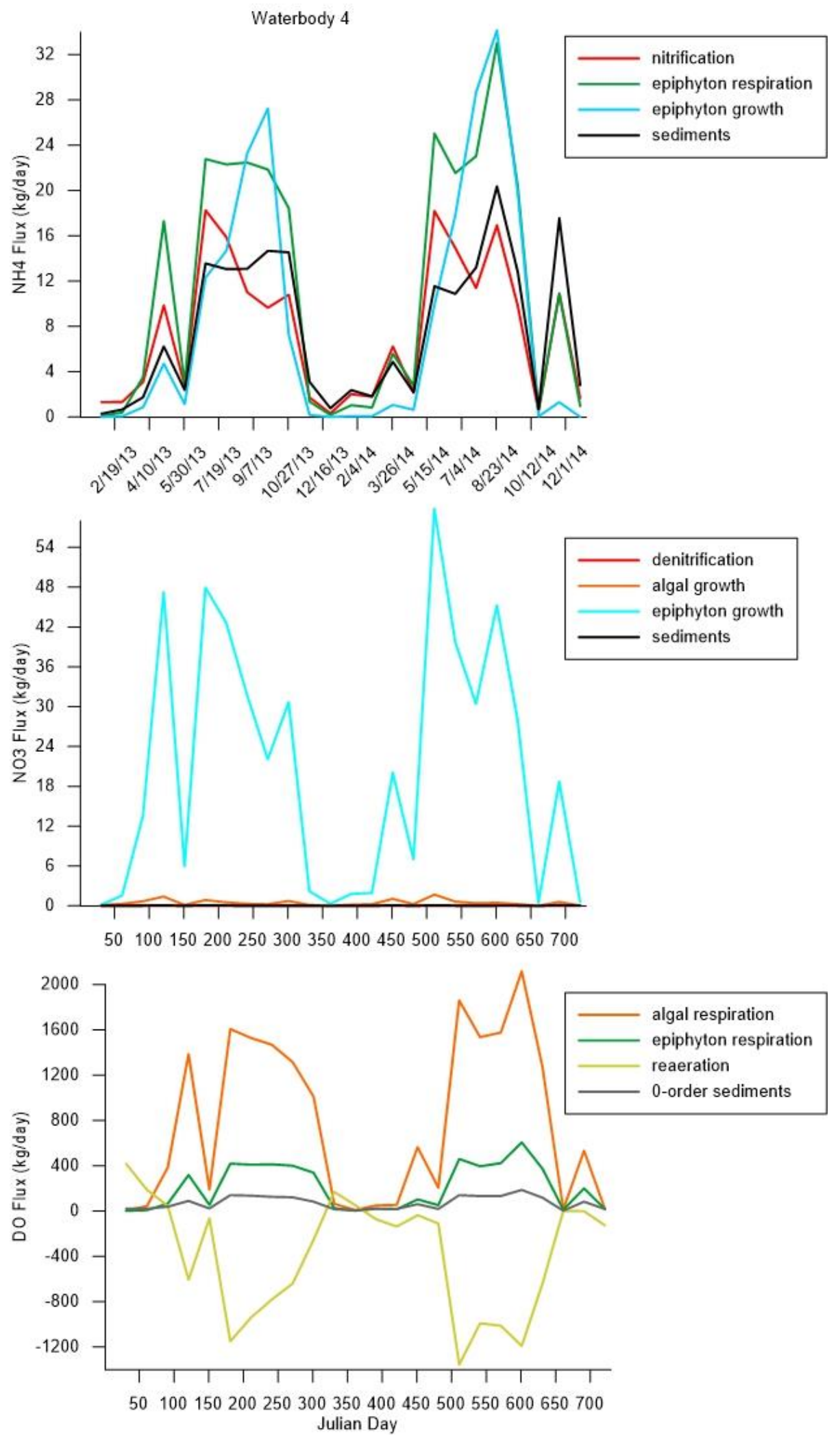

Figure 127. Dominant model-predicted NH4, NO3, and DO fluxes in waterbody 4 

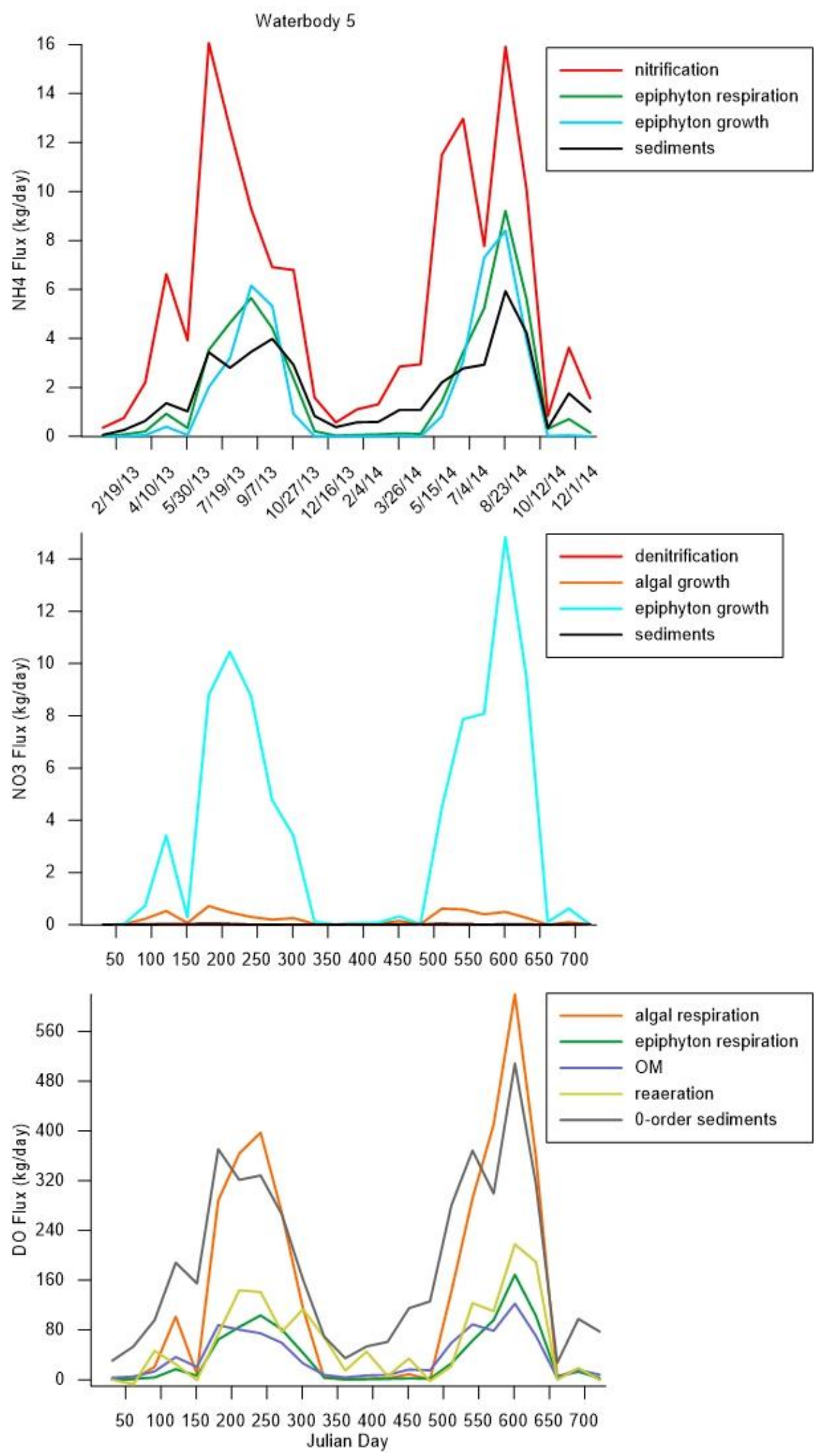

Figure 128. Dominant model-predicted NH4, NO3, and DO fluxes in waterbody 5 

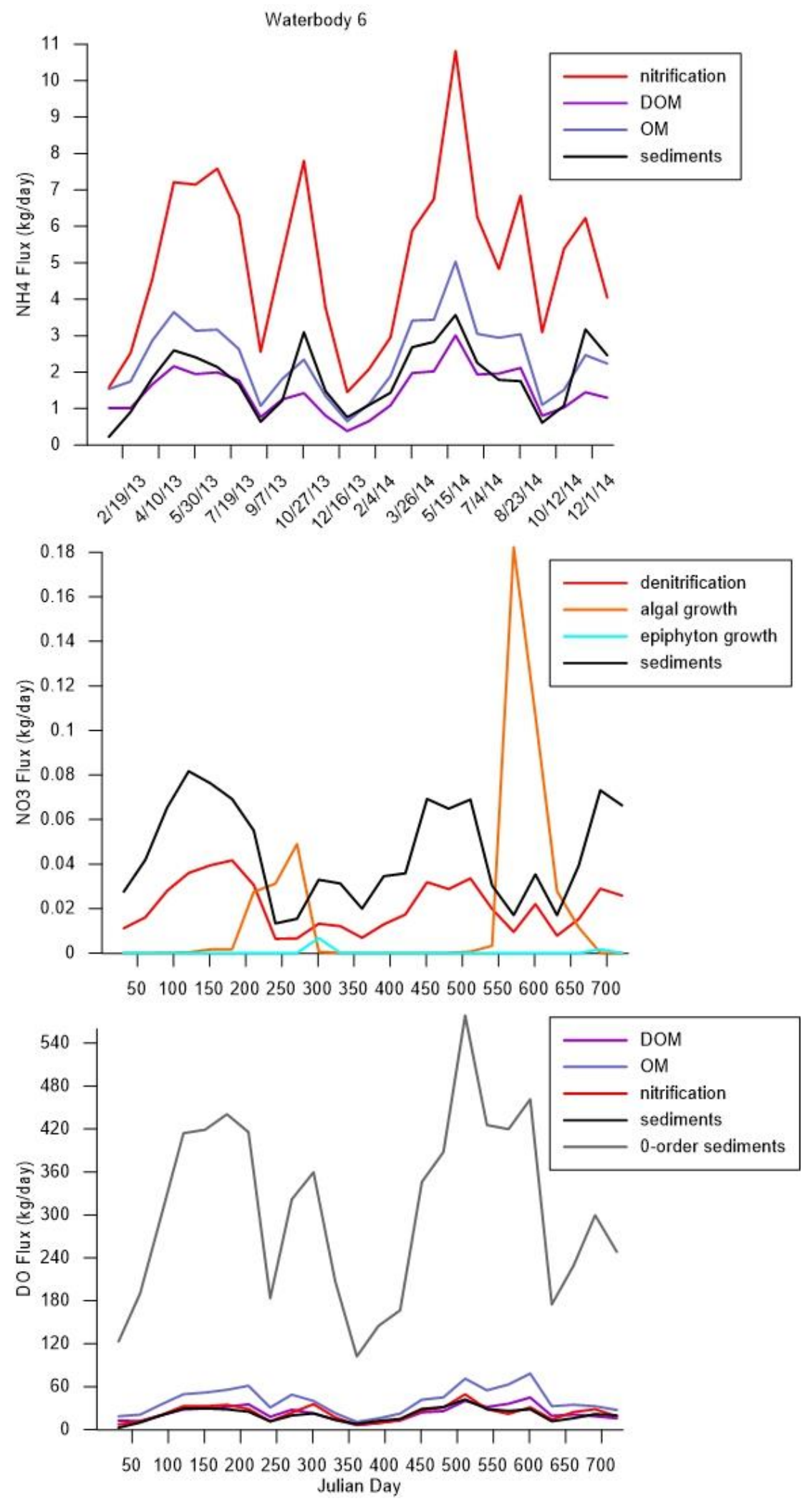

Figure 129. Dominant model-predicted NH4, NO3, and DO fluxes in waterbody 6 

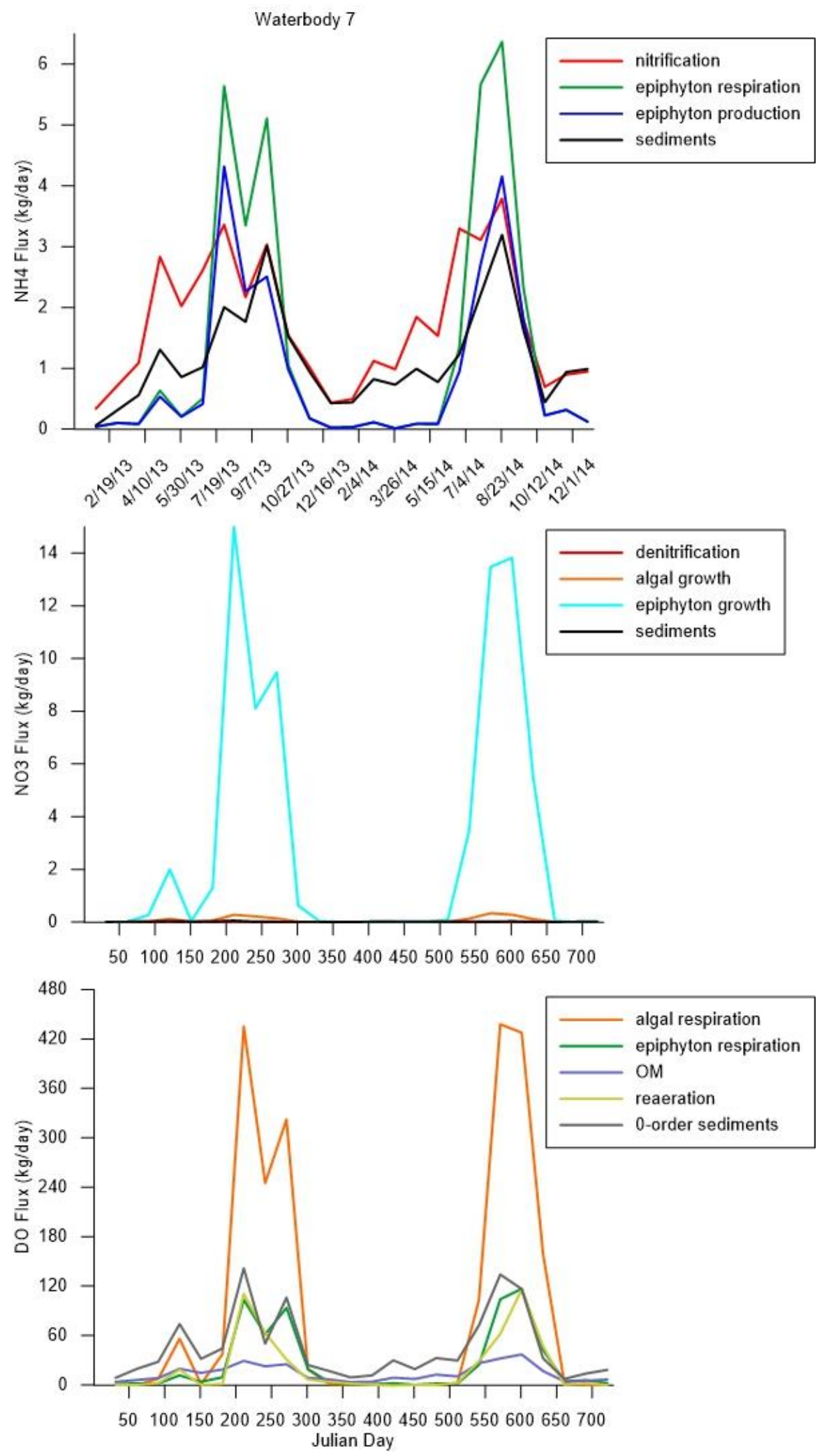

Figure 130. Dominant model-predicted NH4, NO3, and DO fluxes in waterbody 7 

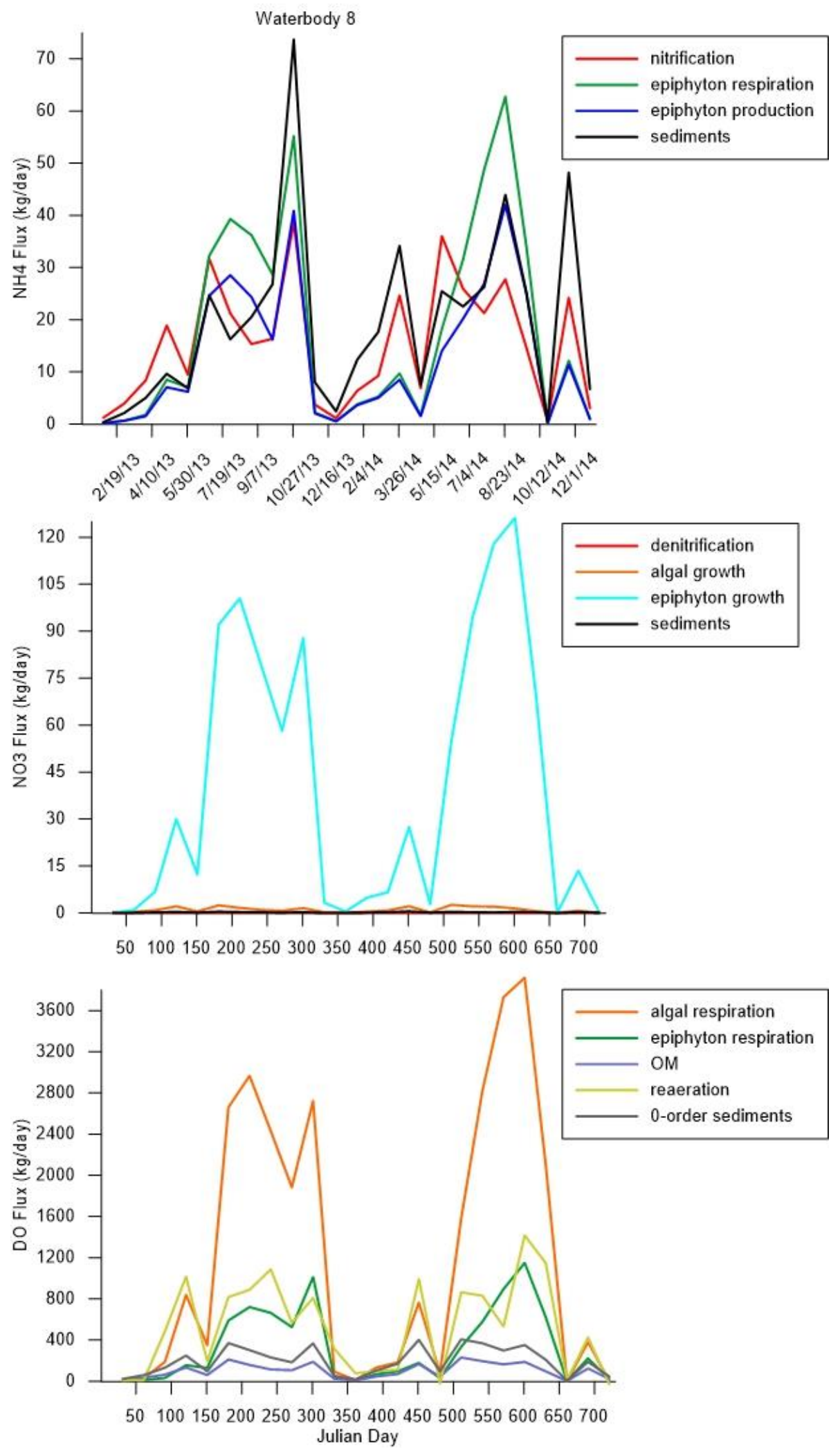

Figure 131. Dominant model-predicted NH4, NO3, and DO fluxes in waterbody 8 

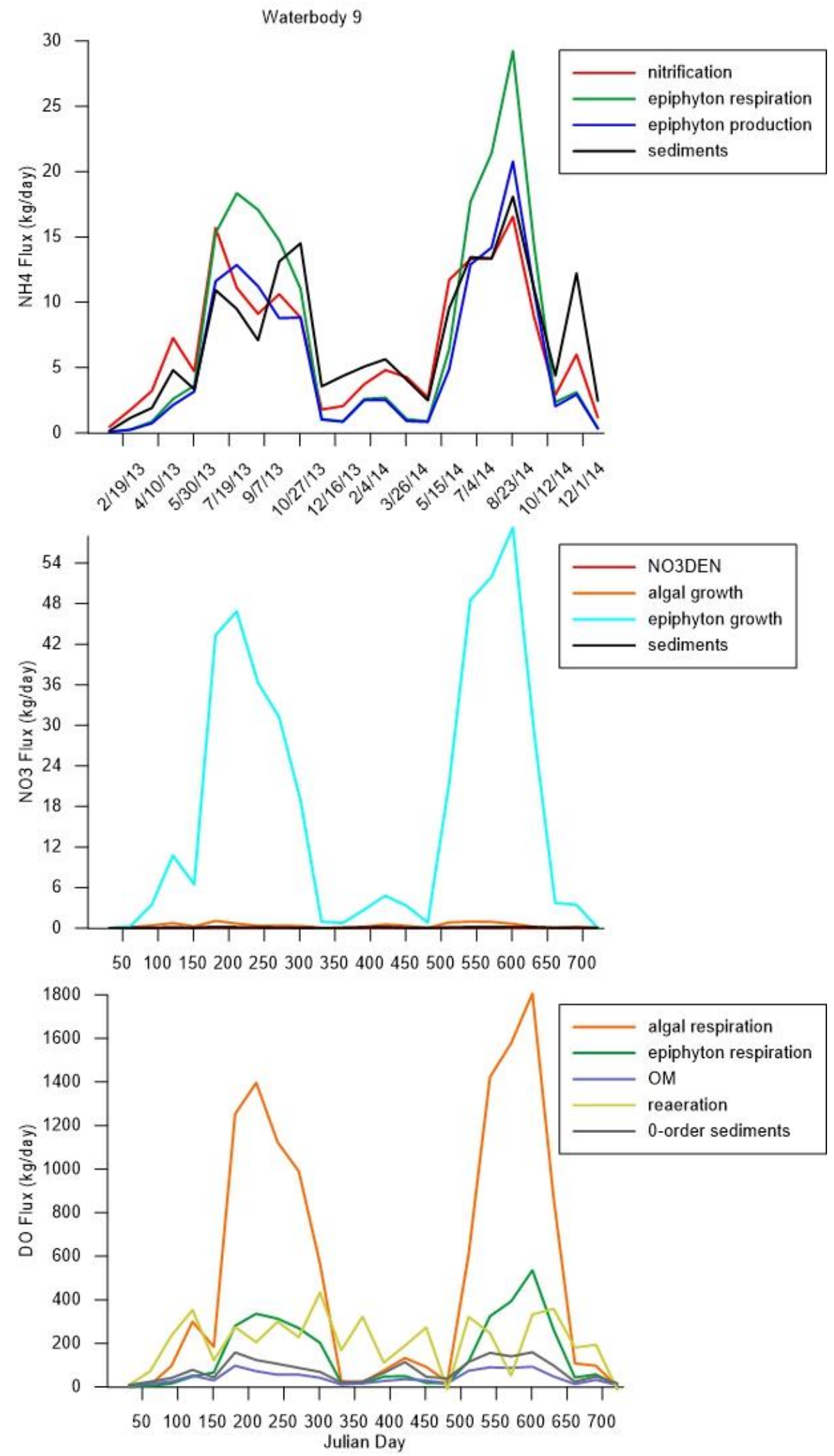

Figure 132. Dominant model-predicted NH4, NO3, and DO fluxes in waterbody 9 


\subsubsection{Algae, Epiphyton, \& Zooplankton Kinetics}

The model required many kinetic coefficients to describe algae, epiphyton, and zooplankton dynamics. Algal kinetics included maximum growth rate, maximum respiration rate, maximum excretion rate, maximum mortality rate, settling rate, halfsaturation for phosphorus limited growth, half-saturation for nitrogen limited growth, half-saturation for silica limited growth, and light saturation intensity at maximum photosynthesis rate (Cole and Wells, 2016). The algal temperature regime included temperature limits for growth and maximum growth and the fraction of algal growth at each temperature limit. Algal stoichiometry and initial condition concentrations were also input to the model. Similar kinetics, temperature regimes, and stoichiometry were also input for epiphyton and zooplankton.

Water quality calibration was sensitive to the dynamics of algae and periphyton/epiphyton because of their direct interactions with nutrients and dissolved oxygen. Nutrients decreased in the water column as a result of algae and epiphyton uptake during growth and increased as a result of algae and epiphyton respiration and mortality. DO increased in the water column during photosynthetic production, and decreased due to algae and epiphyton mortality as bacteria decayed the resulting organic matter. Correctly assessing the characteristics of algae, epiphyton, and zooplankton involved some trial-and-error. When these constituents created too much decaying biomass, the dissolved oxygen fell much lower than field data showed. When growth rates 
were too high and mortality rates were too low, the swings between peak and minimum dissolved oxygen and nutrients were too large.

No data exist for periphyton/epiphyton for the Chehalis River or the tributaries. Periphyton/epiphyton played an important role in model calibration, with uptake of nitrates and ammonia (with a preference for nitrates) during production and release of ammonia during respiration. Confirming the biomass of periphyton/epiphyton would assess whether the current water quality model is realistic.

Algae growth limitation by phosphorus from upstream of Pe Ell to upstream of the Newaukum River can be seen in Figure 133. Algae growth limitation by phosphorus from Route 6 Bridge to Porter can be seen Figure 134. Algae growth imitation by nitrogen from upstream of Pe Ell to upstream of the Newaukum River can be seen in Figure 135. Algae growth limitation by nitrogen from Route 6 Bridge to Porter can be seen in Figure 136. Algae growth limitation by light from upstream of Pe Ell to upstream of the Newaukum River can be seen in Figure 137. Algae growth limitation by light from Route 6 Bridge to Porter can be seen in Figure 138. Lower limitation values indicated more severe limitation.

Algal growth limitation from phosphorus and nitrogen became more important during summer months when light was plentiful. Similarly, algal limitation from light was more important during winter months when solar radiation decreased and cloud cover increased. 

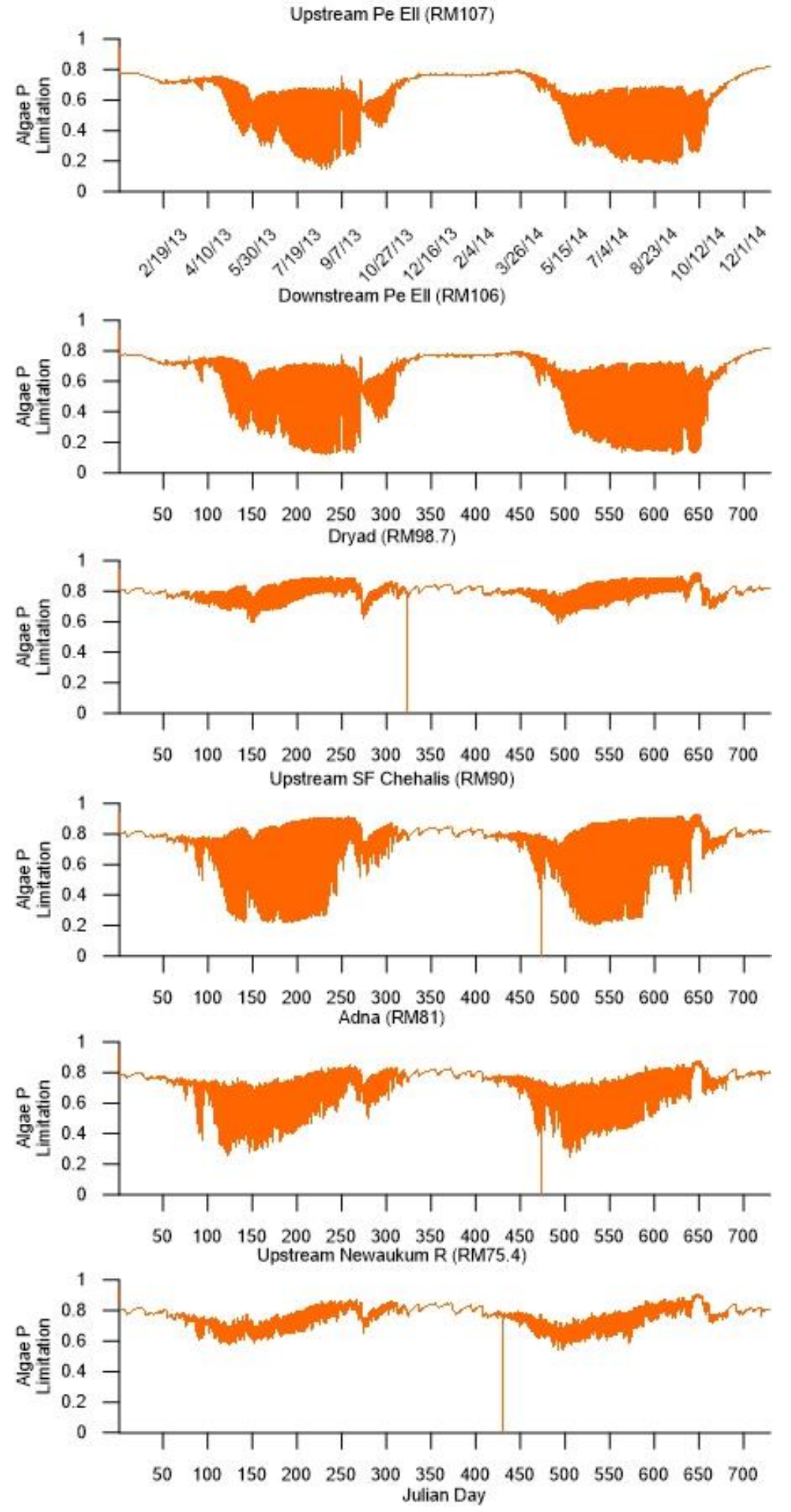

Figure 133. Algae growth limitation by phosphorus predicted by the model at upstream of Pe Ell, downstream of Pe Ell, Dryad, upstream of South Fork Chehalis River, Adna, and upstream of Newaukum River 

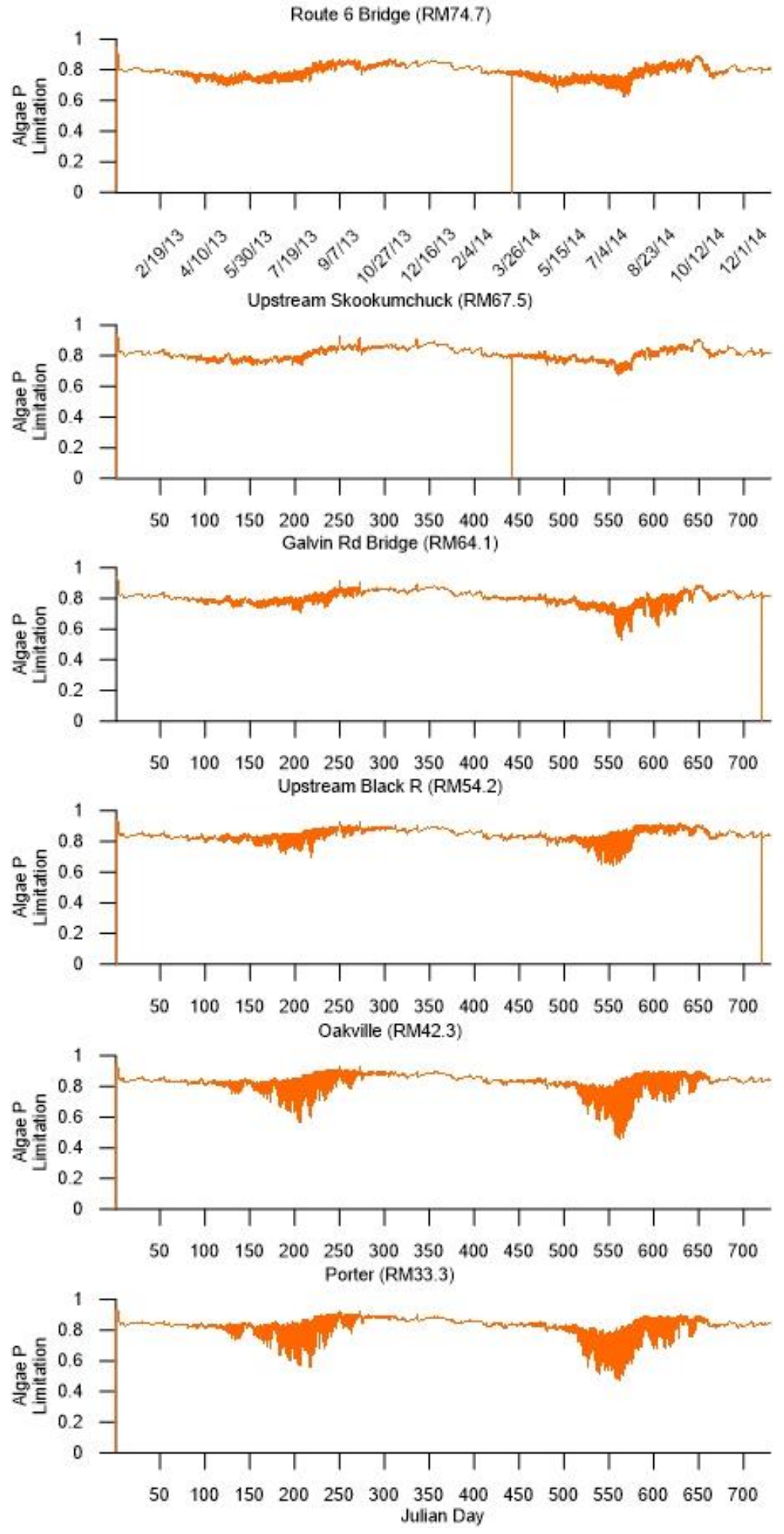

Figure 134. Algae growth limitation by phosphorus predicted by the model at Route 6 Bridge, upstream of Skookumchuck River, Galvin Road Bridge, upstream of Black River, Oakville, and Porter 

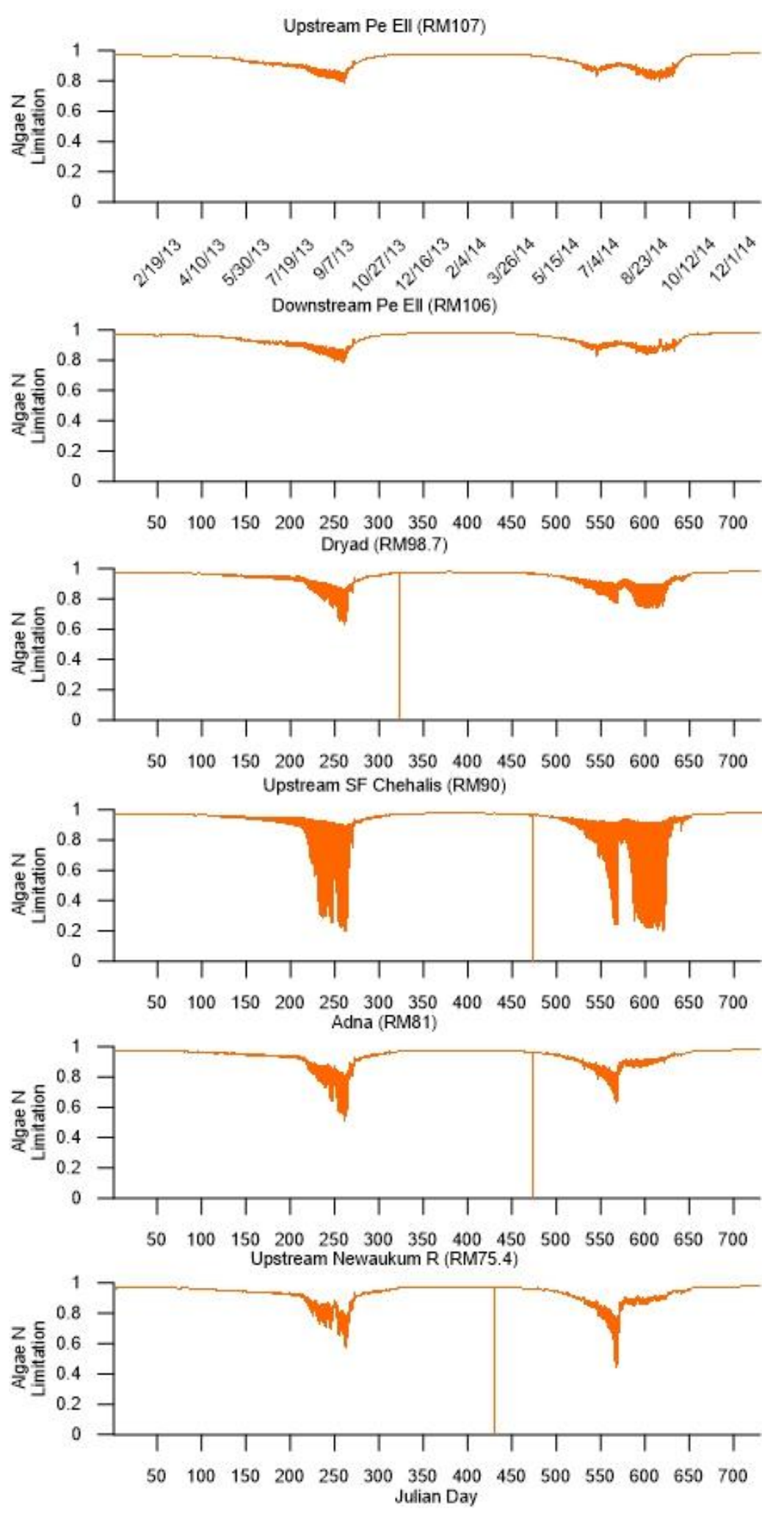

Figure 135. Algae growth limitation by nitrogen predicted by the model at upstream of Pe Ell, downstream of Pe Ell, Dryad, upstream of South Fork Chehalis River, Adna, and upstream of Newaukum River 

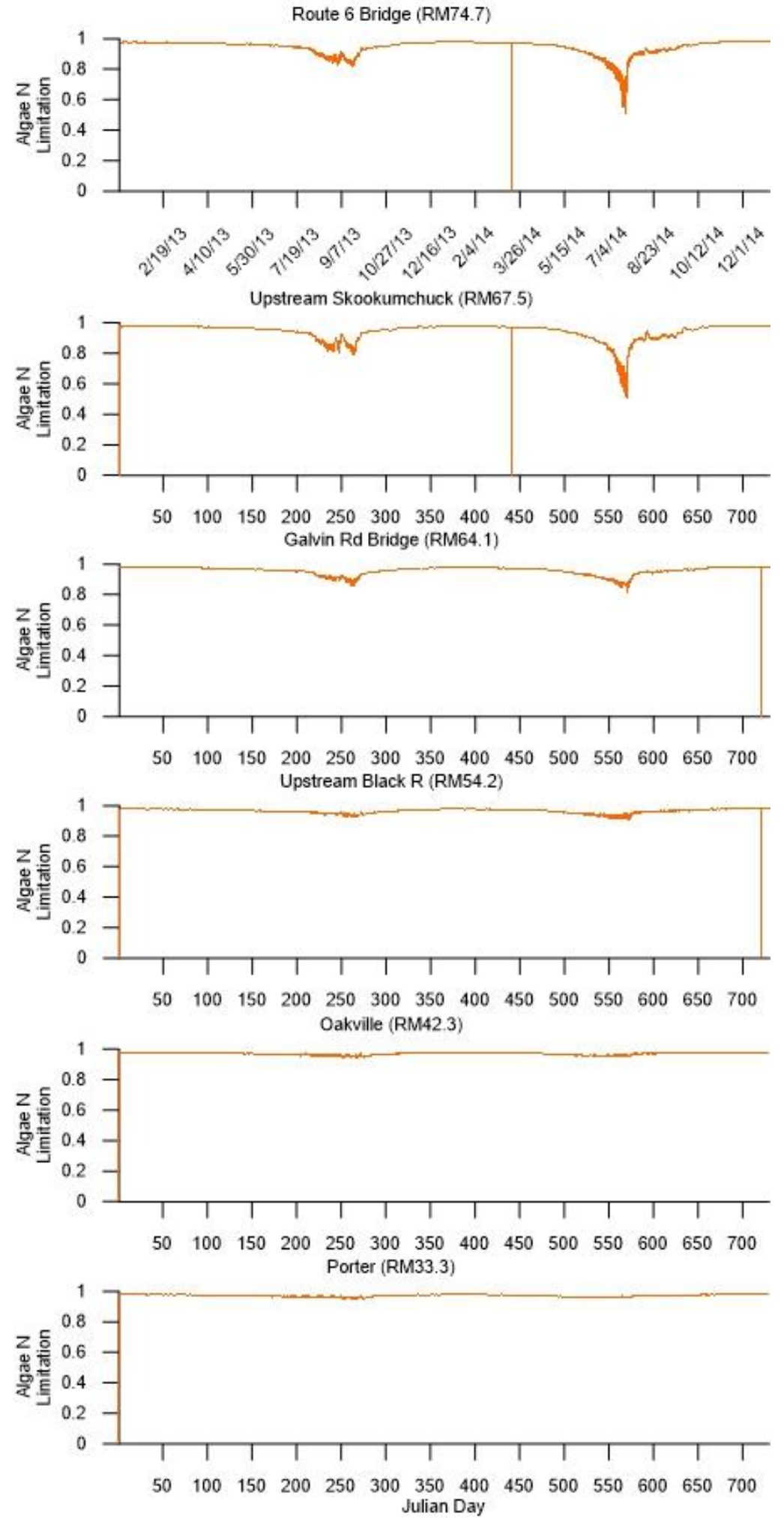

Figure 136. Algae growth limitation by nitrogen predicted by the model at Route 6 Bridge, upstream of Skookumchuck River, Galvin Road Bridge, upstream of Black River, Oakville, and Porter 

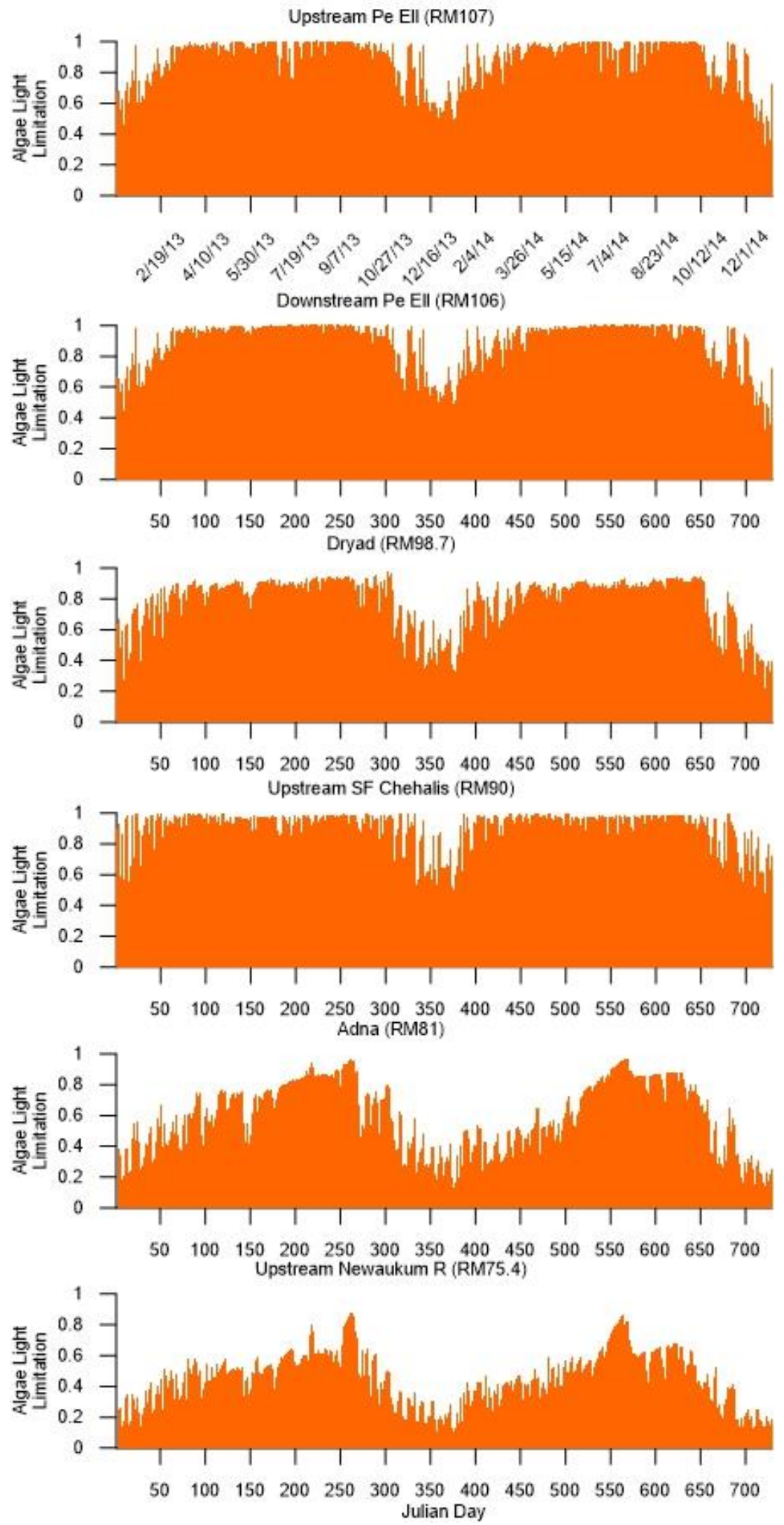

Figure 137. Algae growth limitation by light predicted by the model at upstream of Pe Ell, downstream of Pe Ell, Dryad, upstream of South Fork Chehalis River, Adna, and upstream of Newaukum River 

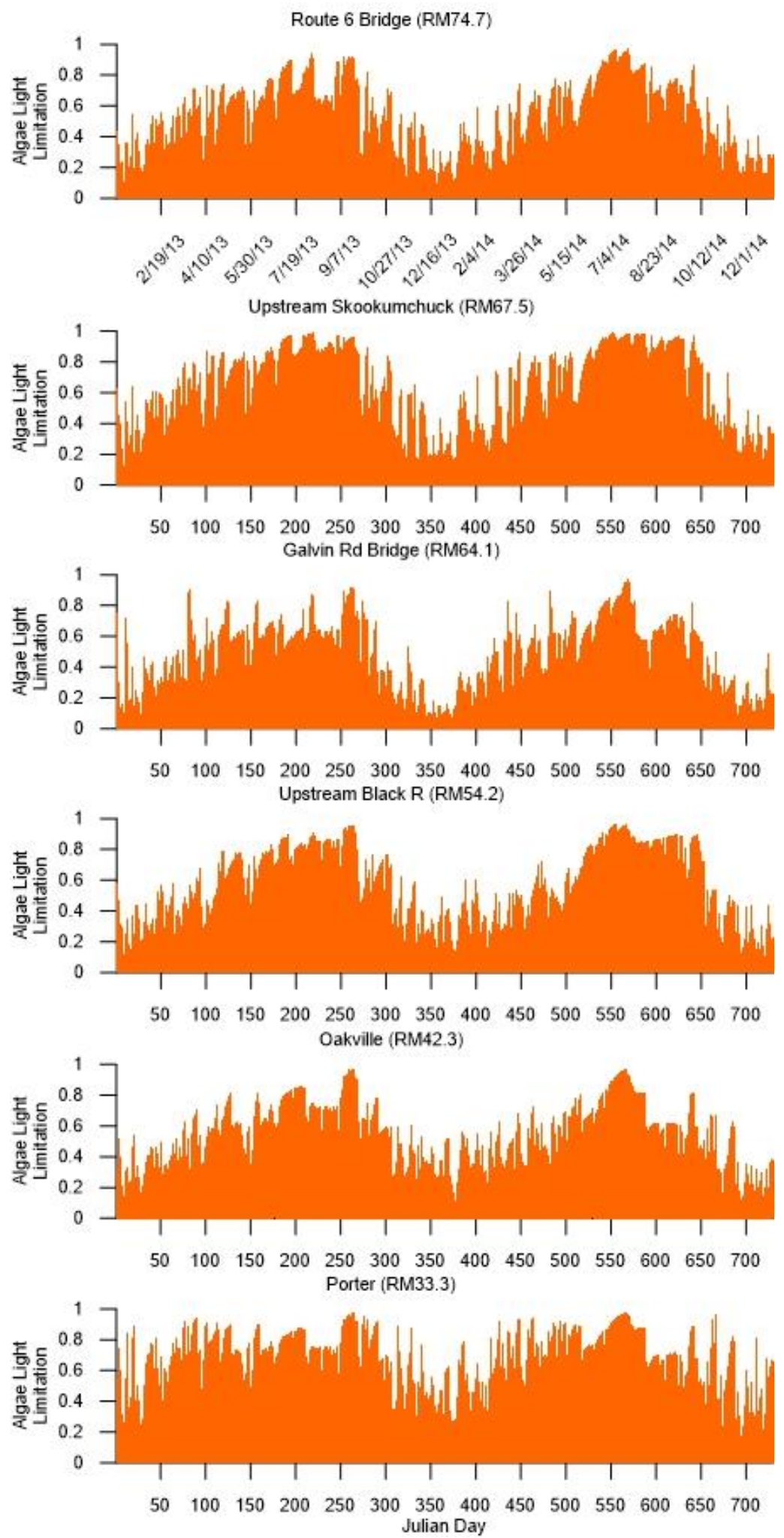

Figure 138. Algae growth limitation by light predicted by the model at Route 6 Bridge, upstream of Skookumchuck River, Galvin Road Bridge, upstream of Black River, Oakville, and Porter 


\subsubsection{Sediments}

Sediment oxygen dynamics were important in the pool area where DO decreased near the channel bottom. Data for oxygen exchanges at the sediments were unavailable, so zero-order sediment oxygen demand (SOD) values were estimated for each segment. While generally SOD values are between 0.1 and $1 \mathrm{O}_{2} \mathrm{~m}^{2}$ day $^{-1}$, they can sometimes be higher (Cole and Wells, 2016). These values vary depending on sediment characteristics and algal production (Cole and Wells, 2016). SOD values in the pool were set to 1.9 $\mathrm{g} / \mathrm{m}^{2} /$ day at $20^{\circ} \mathrm{C}$ and SOD values upstream and downstream of the pool were set to 0.3 $\mathrm{g} / \mathrm{m}^{2} /$ day. These values were important for matching DO values near the bottom of the channel that are seen in vertical profile data from the pool reach.

Large sediment fluxes in the upper waterbodies indicated sediments played a large role in ammonia predictions, due to the settling of particulate organic matter (POM) from wastewater treatment plants. First-order sediment decay was employed in the model. The rate of organic matter settling to the sediments (POMS) and the rate of BOD settling to the sediments (CBODS) were important for DO and nutrient calibration. Increased settling of organic matter to sediments increased oxygen demand as these organics decayed. Settling of organic matter to the sediments was also important for ammonia in the upper reaches. Particulate organic matter and BOD from the Pe Ell wastewater treatment plant settled in the sediments and decayed ammonia back into the water column, resulting in ammonia concentrations greater than seen in field data. By 
reducing POMS and CBODS, the particulates from the treatment plant were able to travel further downstream before settling.

The rate of particulate organic matter decay of the sediments (SEDK) was also available for adjustment, as it is possible that decay of organic matter in sedments may not be the same as in the water column. Decreasing SEDK indicated the sediments are more refractory in nature and decay more slowly. This helped with nutrient calibration. Burial of organics essentially locks the organics in the sediments as they settle and makes them unavailable to decay into the water column or take up oxygen. Increasing the rate of sediment burial of particulate organics (SEDBR) helped to reduce the concentration of nutrients released back into the water column during organic decay. This was especially important for ammonia.

\subsubsection{Reaeration}

The model requires the user to specify a reaeration regime for each waterbody. Each equation corresponds to a set of coefficients that help to describe how DO enters and leaves the water. For the upper waterbodies and lower model waterbodies, river reaeration equations dependent upon stream velocity were used that promoted higher reaeration exchanges. For the middle waterbodies where lake-like conditions exist, and reaeration is controlled by wind speed, lake reaeration equations were used. The lake formulations generally decreased reaeration in the pool area and allowed DO produced by photosynthesis to accumulate. Sometimes, when reaeration was too low, the model 
predicted DO levels that were too high. By reassessing the reaeration regime applied to each waterbody, DO was improved.

\subsection{Comments About Model Predictions}

Some data used for calibration could not be explained from known nutrient sources. For example, mainstem Chehalis River ammonia values were approximately $0.02 \mathrm{mg} / \mathrm{L}$ upstream of the Skookumchuck River and upstream of the Newaukum River. However, between these locations at Adna, the ammonia concentrations increased to approximately $0.15 \mathrm{mg} / \mathrm{L}$. With no other data reflecting this increase in ammonia, it was not possible to calibrate the model to replicate the elevated ammonia values seen at Adna.

TKN is the sum of NH3 and organic matter as nitrogen. Since model predictions reasonably match mainstem NH3 data, the error in TKN predicts may be more closely related to errors in organic matter estimations.

PO4 was sensitive to periphyton/epiphyton characteristics. Further information about periphyton/epiphyton in the system would likely improve PO4 calibration.

Similar to ammonia data, sudden increases or decreases in mainstem constituent data that were not reflected elsewhere in available data were difficult for model predictions reproduce. For example, chlorophyll a increased to approximately $5 \mu \mathrm{g} / \mathrm{L}$ at the upstream of Skookumchuck River station around Julian day 200. The neighboring upstream and downstream monitoring stations, however, had chlorophyll a concentrations of $1 \mu \mathrm{g} / \mathrm{L}$ or less. This chlorophyll a increase was not seen in any other tributary data, so was not 
reflected in the model predictions. A similar increase in TP data was seen at the Oakville monitoring station around Julian day 200 , and similarly was not reflected in model predictions.

Algae and periphyton/epiphyton alter the $\mathrm{pH}$ of the water because of their uptake of carbon dioxide, which produces acidic species in the water column. However, $\mathrm{pH}$ is also a function of alkalinity, temperature, and total inorganic carbon. Single alkalinity data values on the Chehalis River were mentioned in some of the wastewater treatment plant fact sheets. These were not sufficient to provide alkalinity data for all of the tributaries entering the river. Because of the lack of data for alkalinity and total inorganic carbon, $\mathrm{pH}$ was not fully calibrated in this model.

\subsection{Continuous Water Quality}

The timing and magnitudes of model predictions were not always in agreement with field data, as seen in the continuous DO field data comparisons. Model DO diurnal variations were very sensitive to cloud cover. Improvements to meteorological data improved the model DO results. It was useful to view the cloud cover to aid calibration. The cloud cover values during the times continuous DO data were collected can be seen in Figure 139 for the waterbodies data were collected in. Additional cloud cover data would improve model predictions, especially since much of the cloud cover data were estimated based on solar radiation data and calculated theoretical clear sky solar radiation. As model improvements continue, investigations to improvements between model predictions and continuous field data will be explored. 

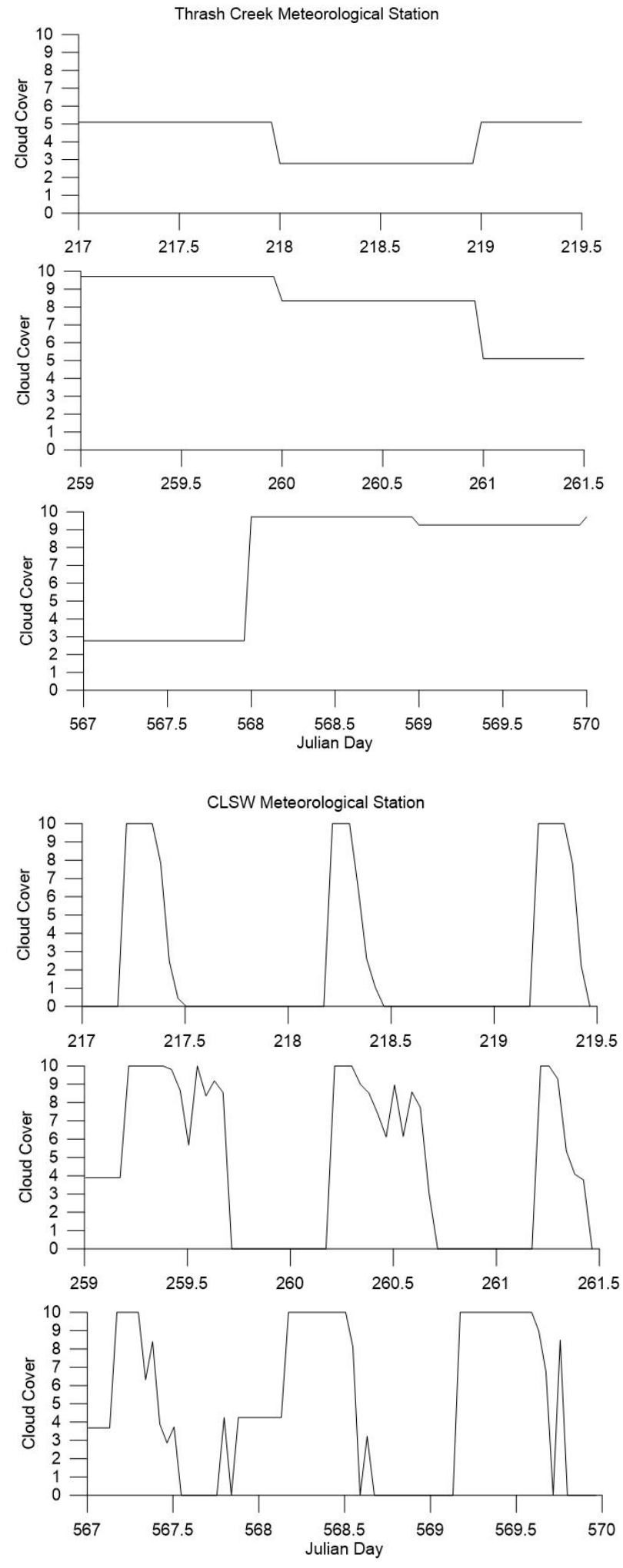

Figure 139. Cloud cover for Thrash Creek and CLSW during the times of continuous DO data collection (10 $=$ fully cloudy and $0=$ clear sky) 


\subsection{Vertical Profiles}

Confirmation of locations of tributaries and monitoring stations in relation to the model grid would generally improve model results. Vertical profiles were especially sensitive to segment location, even when only off by one or two segments. Improvements to temperature vertical profiles is also important for DO profiles, as DO is a direct function of water temperature. Improvements to meteorological data could thus improve DO predictions. 


\section{Model Scenarios}

\subsection{Scenario Descriptions}

Multiple scenarios were applied to the model inputs to simulate dam structure regimes for baseline conditions during 2013-2014 and future conditions. The results of these model simulations will allow for more informed management decisions and strategies in regards to dam implementation. Table 26 gives a list of the scenarios applied to the model.

Table 26. Chehalis River scenarios

\begin{tabular}{|c|c|}
\hline Scenario & Conditions \\
\hline Baseline & Current (2013-2014) and Future \\
\hline FRFA Scenario 1 & Current (2013-2014) and Future \\
\hline FRFA Scenario 2 & Current (2013-2014) and Future \\
\hline FRO - Riparian Shading & Current (2013-2014) and Future \\
\hline FRO - No Shading & Current (2013-2014) and Future \\
\hline
\end{tabular}

\subsubsection{Flood Retention Only (FRO)}

Flood Retention Only (FRO) is one of the dam management regimes. In this case the dam only operates during times when flooding is seen at Grand Mound, with Chehalis River flows greater than 38,800 cfs (Montgomery, 2016). This is approximately a 7-year flood with about $15 \%$ probability of occurrence (Montgomery, 2016). Dam outflow during these times would be reduced to $300 \mathrm{cfs}$. The inundation area for this scenario would have a median value of 187 acres, and could reach a maximum of 778 acres. The pool elevation for this scenario would have a median value of 513 feet, though could reach 520.4 feet at a maximum, which would result in a storage volume of 60,253 acre-feet (Montgomery, 2016). 


\subsubsection{Flood Retention Flow Augmentation (FRFA)}

Flood Retention Flow Augmentation (FRFA) is another dam management regime. Dam operations during flooding follow the same procedure as the FRO scenario. However, the dam would operate during other times as well. Minimum flow releases vary based on season. If the reservoir is not in a flooding operation state, inflows greater than 2,800 would be released. The downstream gage at Doty would be targeted to maintain a minimum flow of 5,000 cfs. Dam releases at a maximum of $15,000 \mathrm{cfs}$ would result in flows at Doty of 23,000 cfs (Montgomery, 2016).

Within the FRFA regime, there are two sub-scenarios. FRFA scenario 1 includes lower dam outflows than FRFA scenario 2 during September and October, has less drawdown, and takes less time for the reservoir to refill during the winter season. Conversely, FRFA scenario 2 has higher dam outflows than FRFA scenario 1 during September and October, has more drawdown, and takes longer for the reservoir to refill during the winter season (Montgomery, 2016). FRFA scenario 1 has an elevation range of 598 to 683 feet; a storage volume range of 44,000 to 59,400 acre-feet, with a mean of 51,386 acre-feet; and an annual drawdown range of 9 to 29 feet. FRFA scenario 2 has an elevation range of 587 to 680 feet; a storage range of 36,800 to 121,700 acre-feet; a minimum storage range of 36,800 to 121,700 acre-feet, with a mean of 46,125 acre-feet; and an annual drawdown range of 8-40 feet (Montgomery, 2016). 


\subsubsection{Future Conditions}

Current and potential future conditions for meteorological, flow, and temperature data were applied to each baseline and dam scenario. Modeling of future scenarios involved simulating one year. Anchor QEA used data made available by the University of Washington (Mauger, 2016) to develop meteorological input files for future climate scenarios. Flow multipliers for future climate scenarios were also provided by Anchor QEA (Hill, 2016), and are shown in Table 27. Tributary flows were multiplied by these values to simulate future flow conditions.

Table 27. Future conditions monthly flow multipliers (Hill, 2016)

\begin{tabular}{|c|c|}
\hline Month & Flow Multiplier \\
\hline January & 1.129 \\
\hline February & 1.085 \\
\hline March & 0.994 \\
\hline April & 0.938 \\
\hline May & 0.889 \\
\hline June & 0.851 \\
\hline July & 0.817 \\
\hline August & 0.785 \\
\hline September & 0.813 \\
\hline October & 1.055 \\
\hline November & 1.058 \\
\hline December & 1.145 \\
\hline
\end{tabular}

As tributary temperatures were not made available for the future climate scenarios, these were assumed to increase by the same magnitude that air temperature increased. The difference in air temperature from baseline conditions to future climate conditions were added to tributary water temperatures from 2014. 
Meteorological, flow, and temperature data were the only inputs to the model that were altered to simulate future conditions. All other model conditions and input data remained the same as for the baseline calibration simulations.

\subsection{Temperature Predictions}

Model predictions of daily maximum temperature of the baseline conditions, FRFA scenarios, and FRO scenarios upstream of Elk Creek are shown in Figure 140 and Figure 141 for current conditions and future conditions respectively. Model predictions of daily maximum temperature of the scenarios at Ceres Hills for current conditions and future conditions are shown in Figure 142 and Figure 143 respectively. Model predictions of daily maximum temperature of the scenarios upstream of the Newaukum River for current conditions and future conditions are shown in Figure 144 and Figure 145 respectively. Model predictions of daily maximum temperature of the scenarios upstream of the Skookumchuck River for current conditions and future conditions are shown in Figure 146 and Figure 147 respectively. Model predictions of daily maximum temperature of the scenarios upstream of the Black River for current conditions and future conditions are shown in Figure 148 and Figure 149 respectively.

The model predicted future climate conditions would increase water temperature for

all scenarios. Temperature predictions were lower for the FRFA scenarios than the baseline and FRO scenarios. However, differences in temperature predictions between the scenarios decreased moving downstream. 


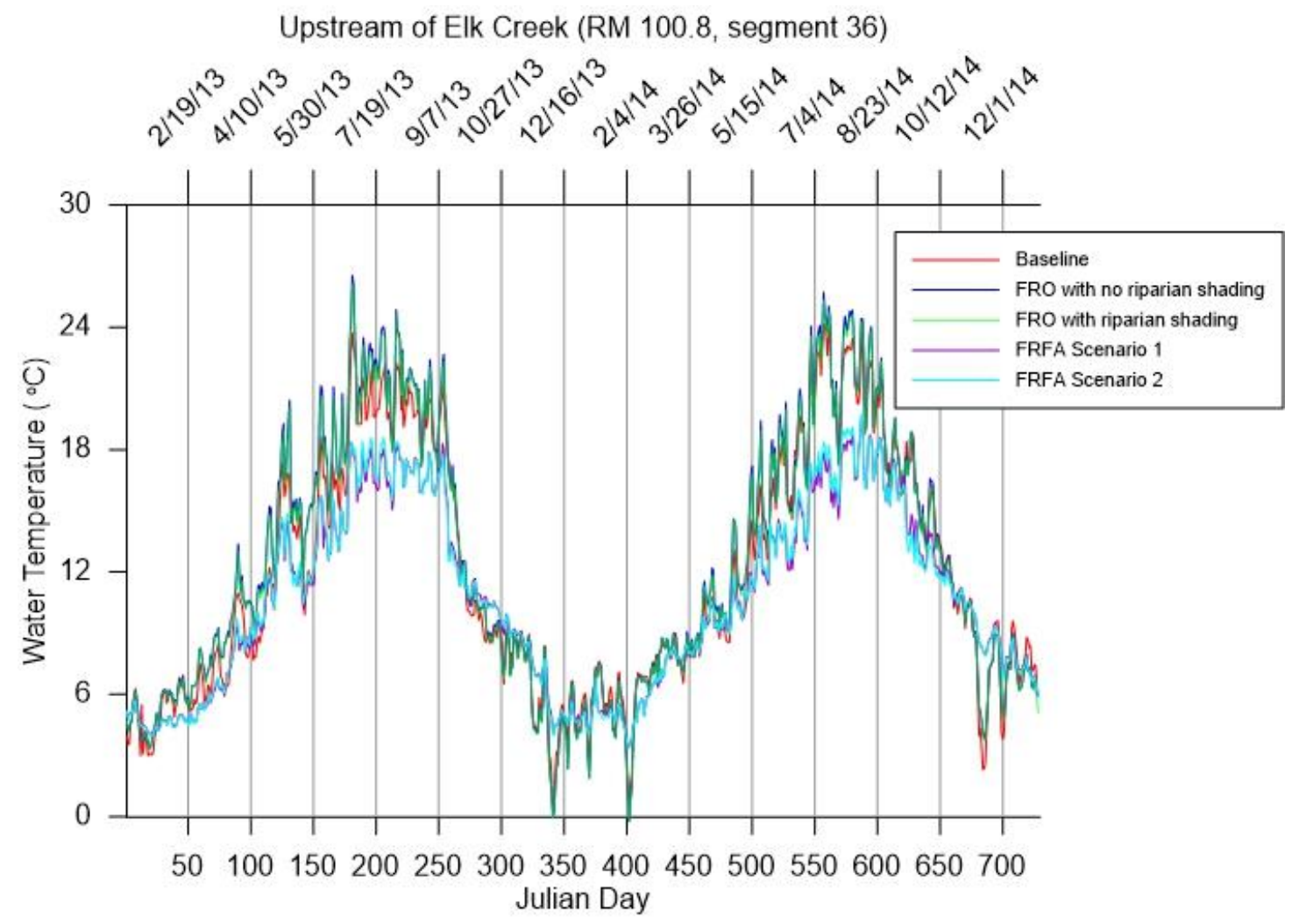

Figure 140. Model daily maximum temperature predictions upstream of Elk Creek for current conditions: baseline, FRO with no vegetative shading, FRO with riparian shading, FRFA scenario 1, and FRFA scenario 2 simulations 


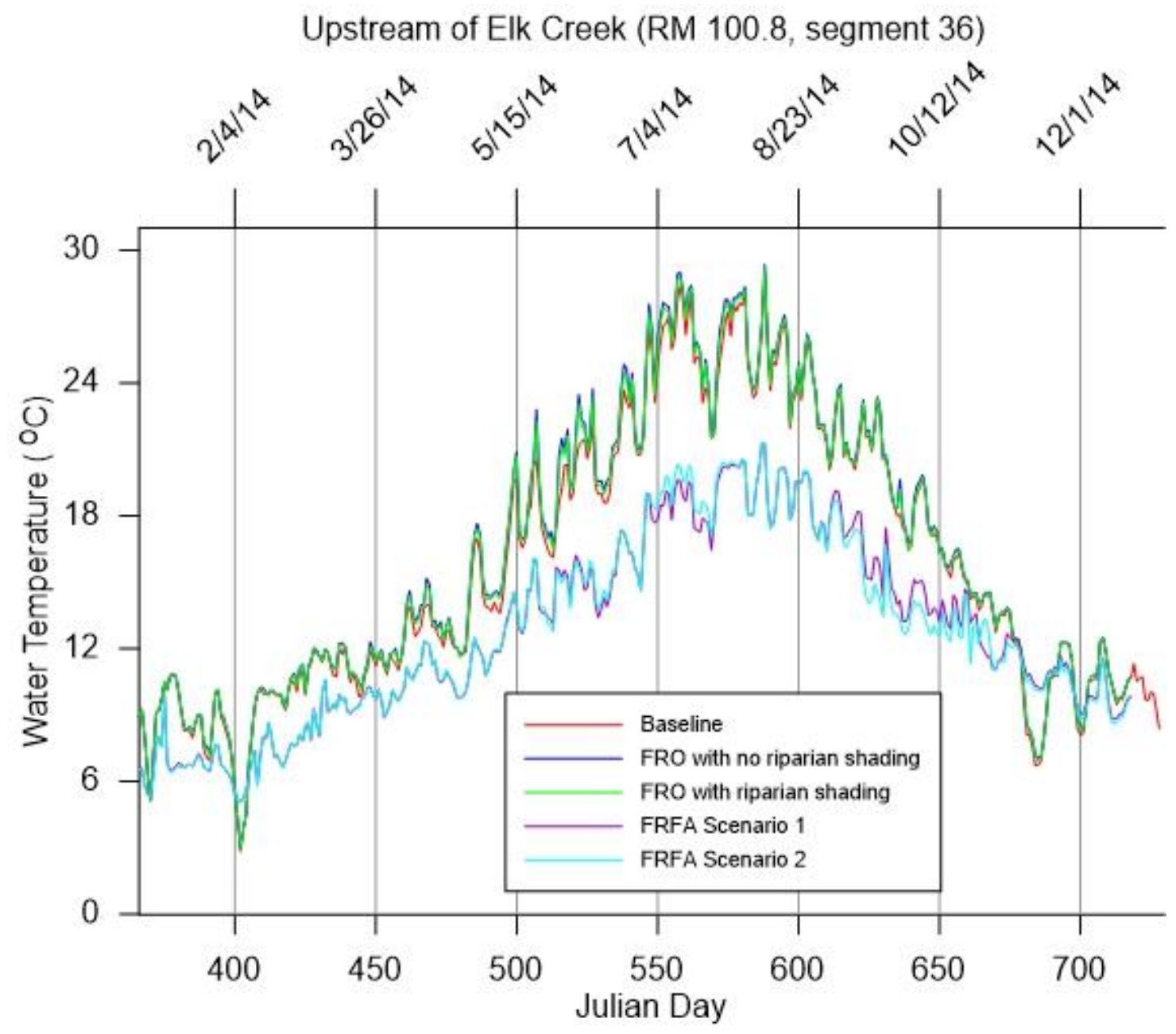

Figure 141. Model daily maximum temperature predictions upstream of Elk Creek for future conditions: baseline, FRO with no vegetative shading, FRO with riparian shading, FRFA scenario 1, and FRFA scenario 2 simulations 


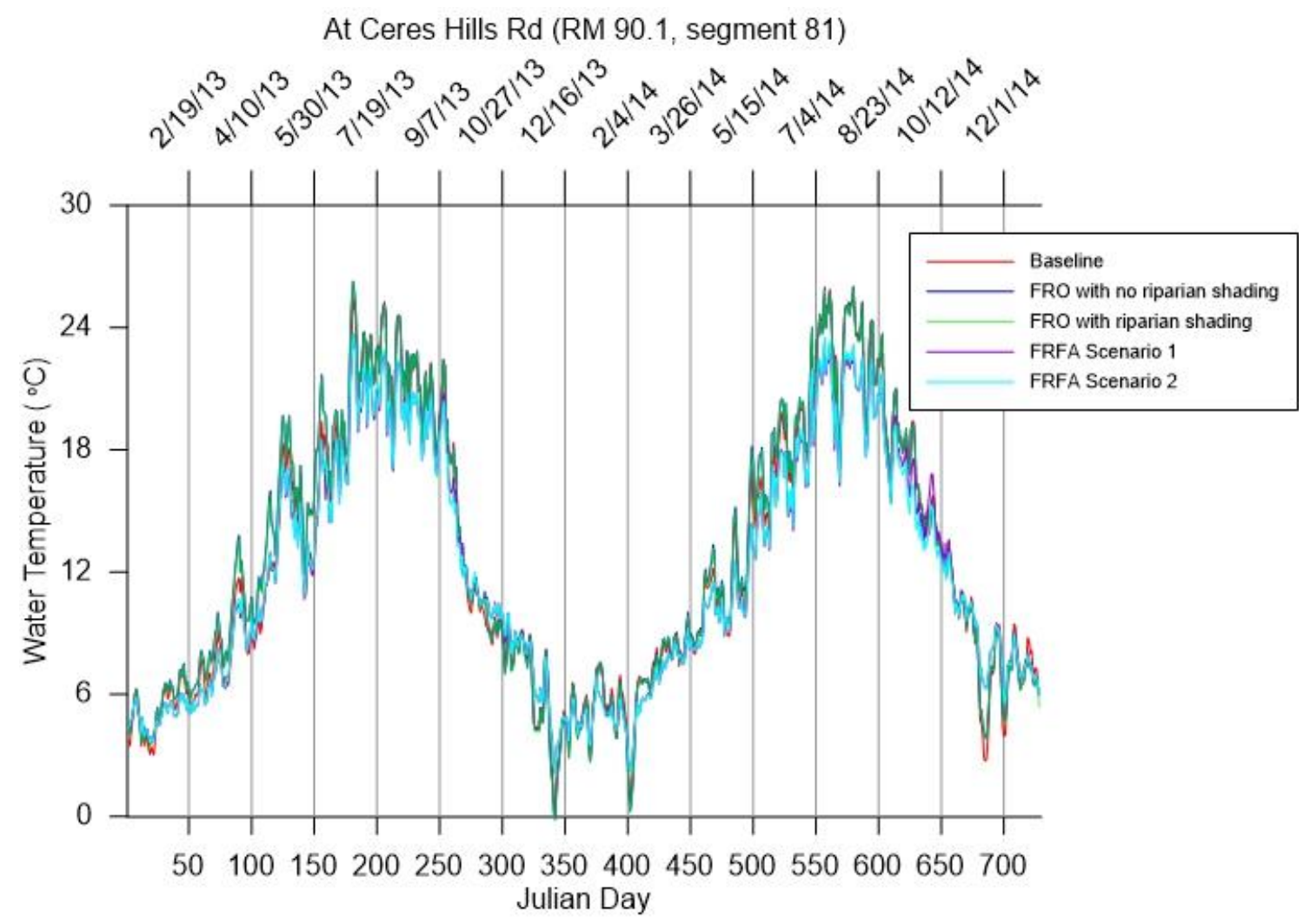

Figure 142. Model daily maximum temperature predictions at Ceres Hills for current conditions: baseline, FRO with no vegetative shading, FRO with riparian shading, FRFA scenario 1, and FRFA scenario 2 simulations 


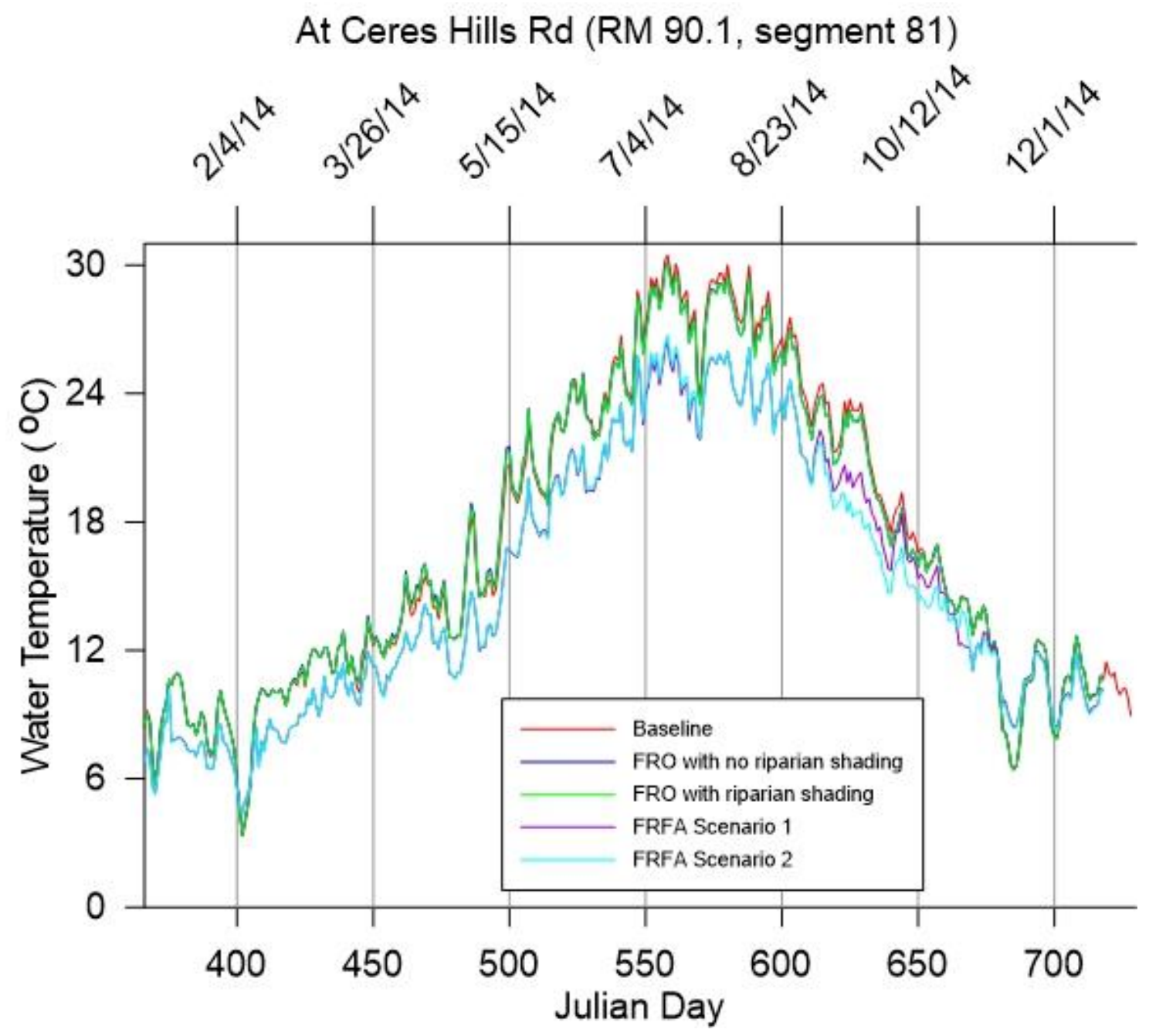

Figure 143. Model daily maximum temperature predictions at Ceres Hills for future conditions: baseline, FRO with no vegetative shading, FRO with riparian shading, FRFA scenario 1, and FRFA scenario 2 simulations 


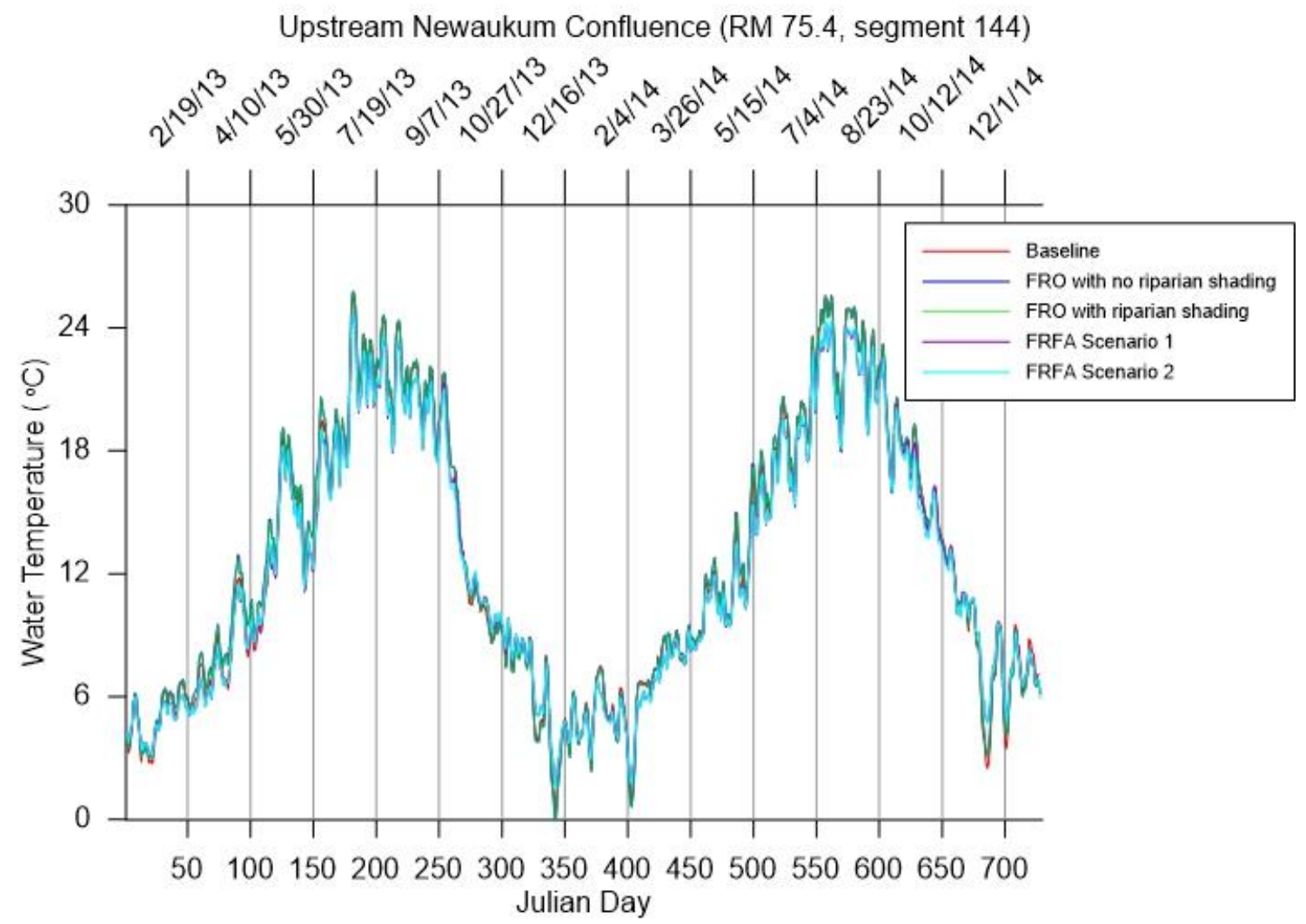

Figure 144. Model daily maximum temperature predictions upstream of the Newaukum River for current conditions: baseline, FRO with no vegetative shading, FRO with riparian shading, FRFA scenario 1, and FRFA scenario 2 simulations 


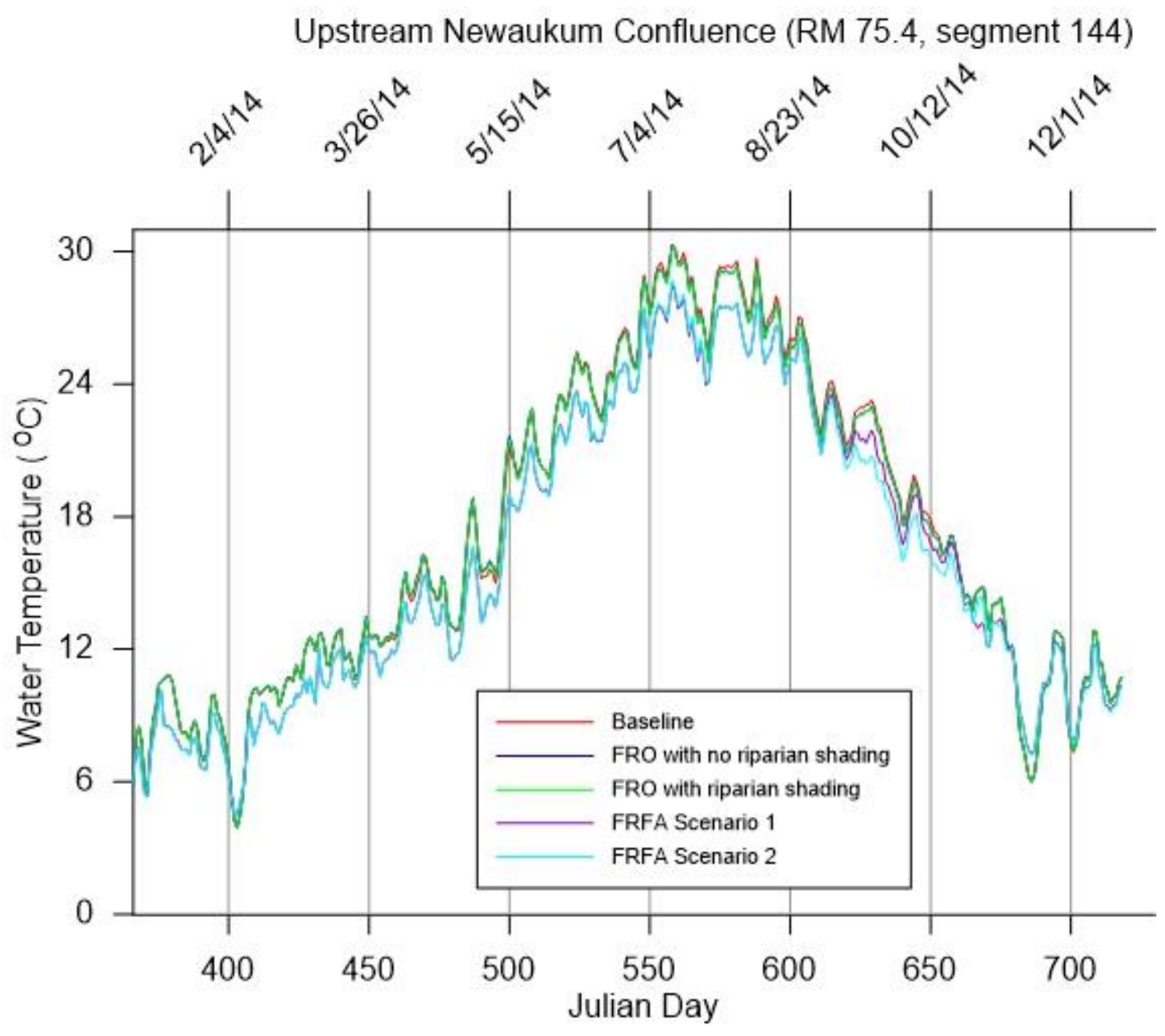

Figure 145. Model daily maximum temperature predictions upstream of the Newaukum River for future conditions: baseline, FRO with no vegetative shading, FRO with riparian shading, FRFA scenario 1 , and FRFA scenario 2 simulations 


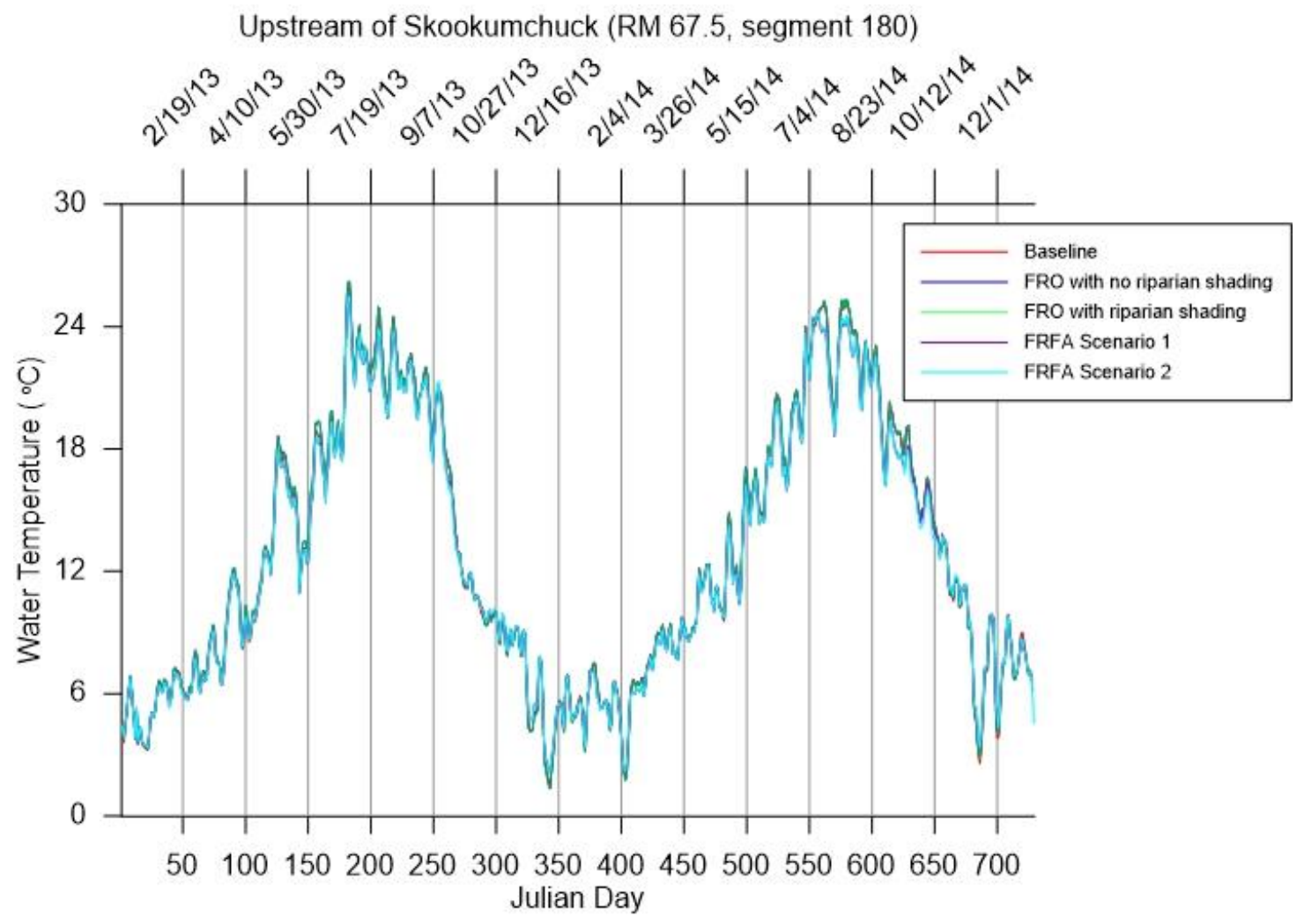

Figure 146. Model daily maximum temperature predictions upstream of the Skookumchuck River for current conditions: baseline, FRO with no vegetative shading, FRO with riparian shading, FRFA scenario 1 , and FRFA scenario 2 simulations 


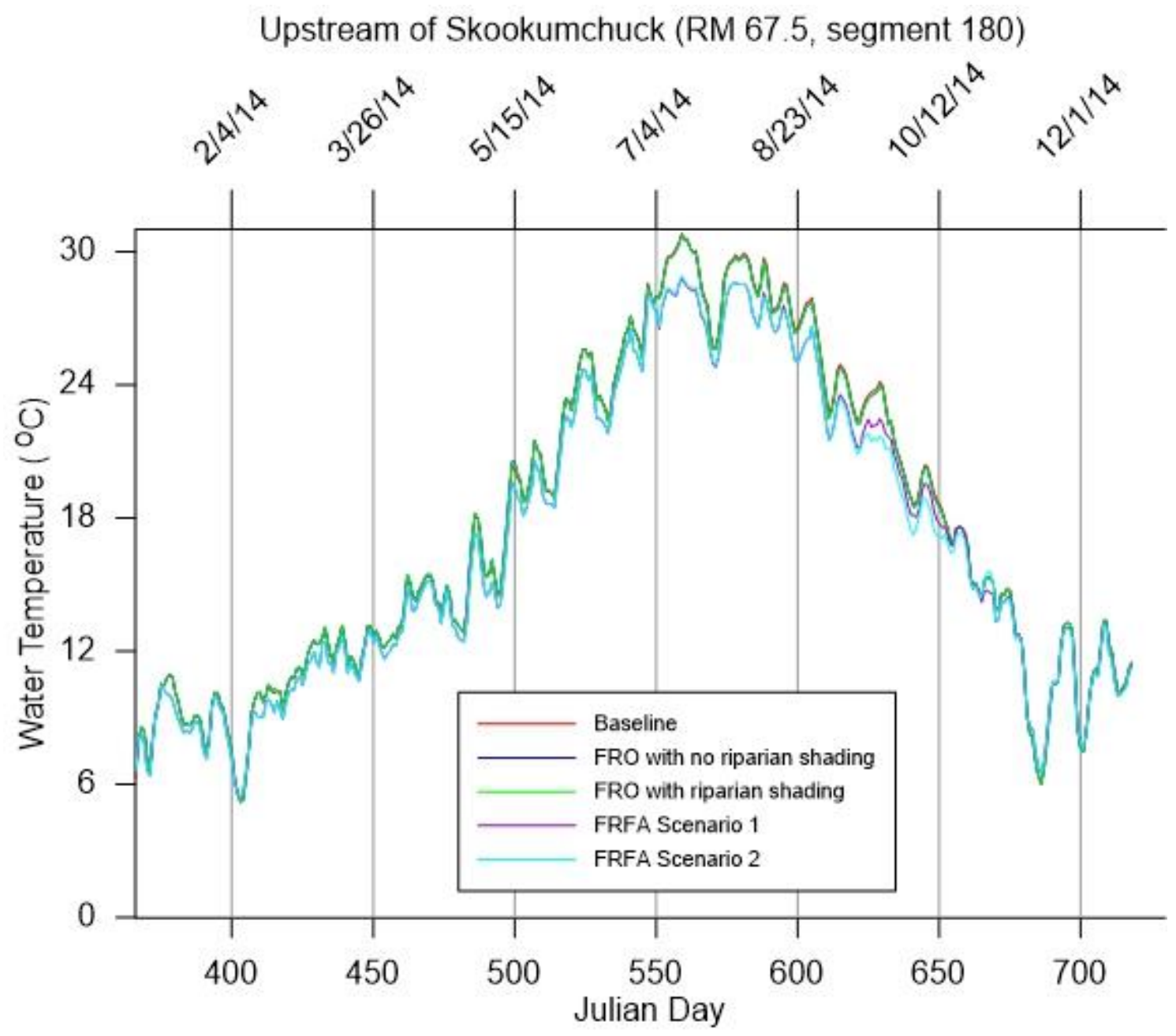

Figure 147. Model daily maximum temperature predictions upstream of the Skookumchuck River for future conditions: baseline, FRO with no vegetative shading, FRO with riparian shading, FRFA scenario 1, and FRFA scenario 2 simulations 


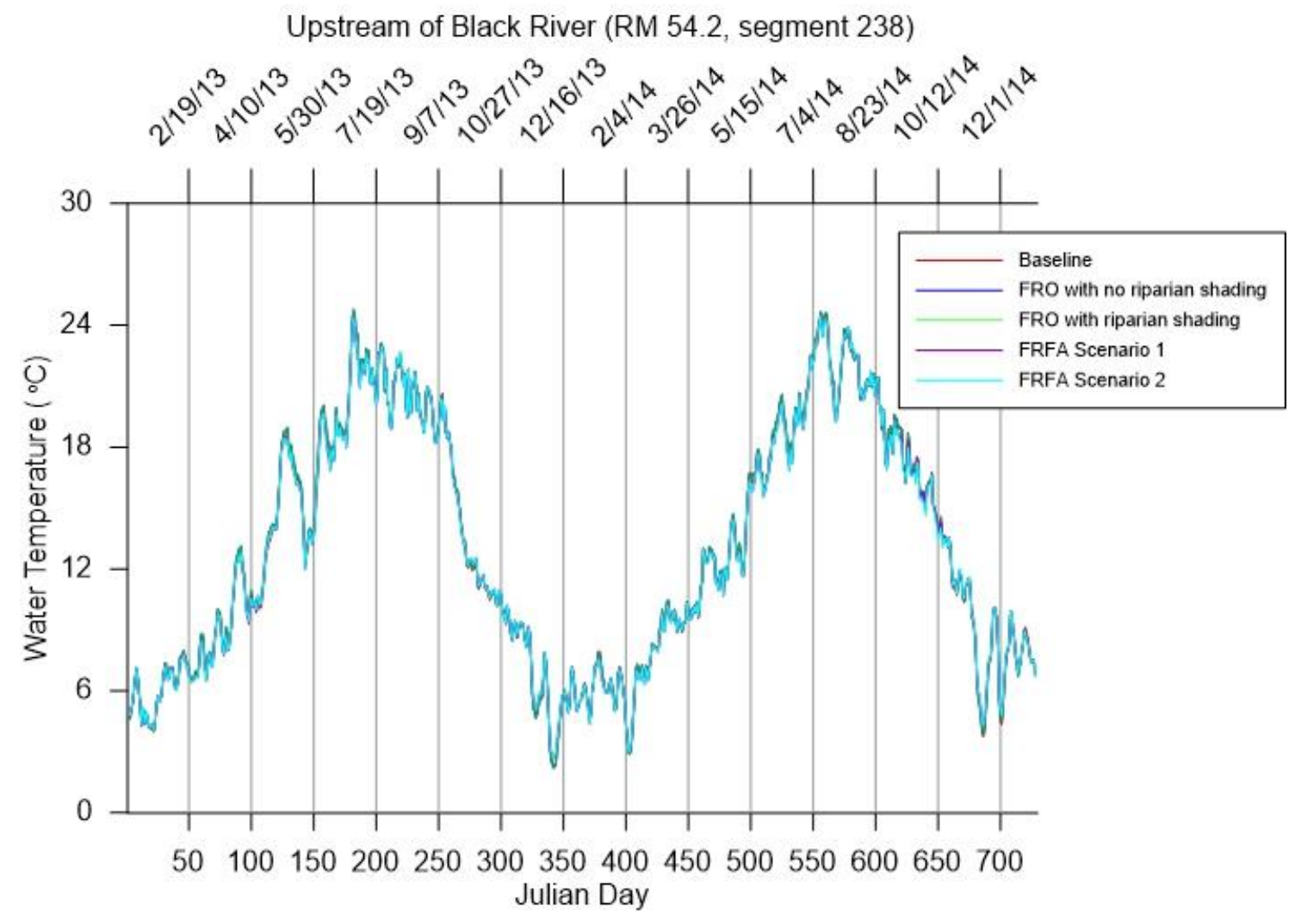

Figure 148. Model daily maximum temperature predictions upstream of the Black River for current conditions: baseline, FRO with no vegetative shading, FRO with riparian shading, FRFA scenario 1, and FRFA scenario 2 simulations 


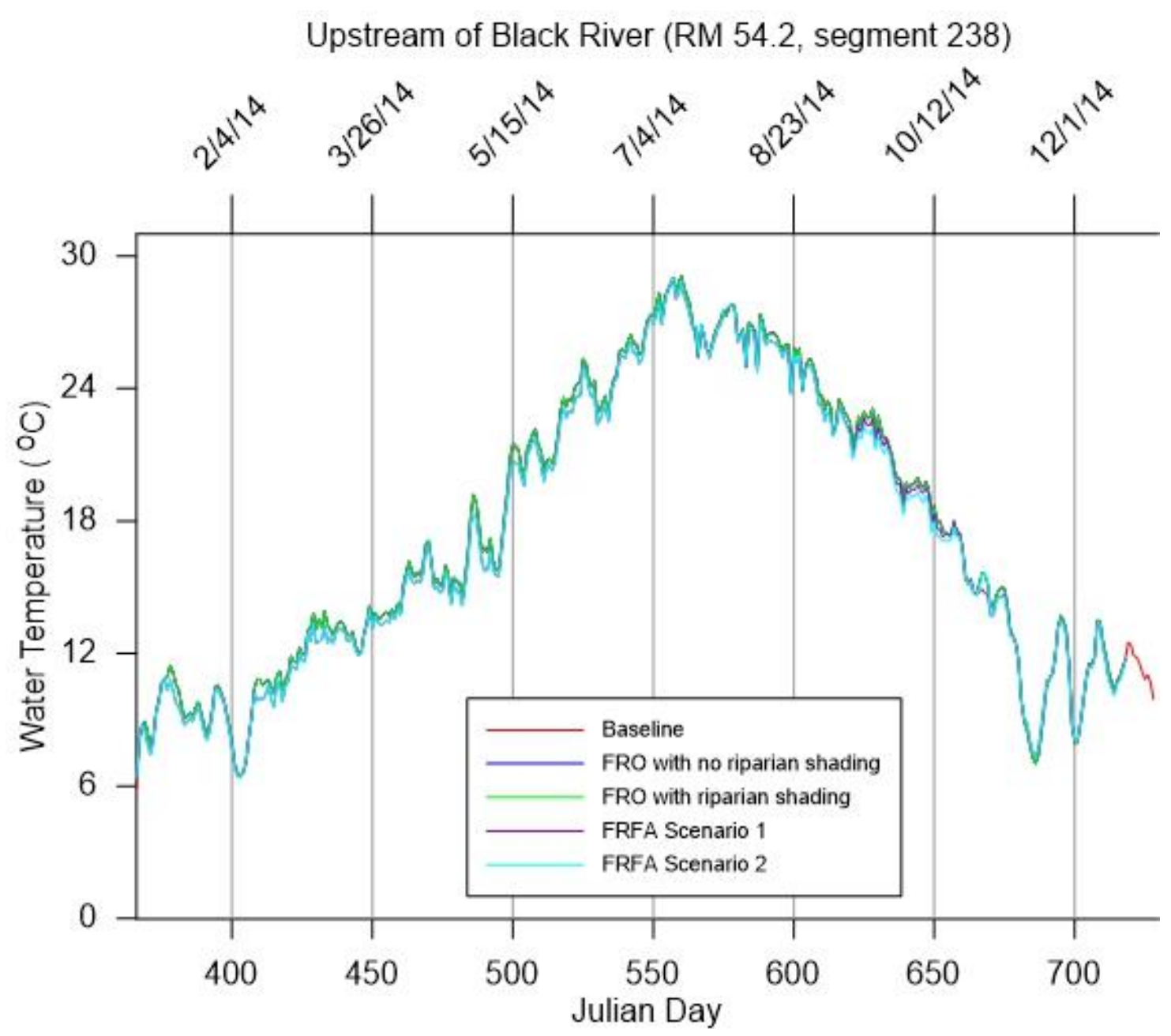

Figure 149. Model daily maximum temperature predictions upstream of the Black River for future conditions: baseline, FRO with no vegetative shading, FRO with riparian shading, FRFA scenario 1, and FRFA scenario 2 simulations 


\subsection{Water Quality Predictions}

DO and nutrients during during summer months are discussed in this section. The warmer summer months are when river water quality and fish health and habitat are of the greatest concern. The upstream boundary input constituents remained the same for all scenario runs. Updating the upstream boundary input constituents specific to each scenario would give more accurate water quality results. This will be implemented and these results will be updated as this project continues.

\subsubsection{Dissolved Oxygen}

Model predictions of DO concentrations were generally higher for the FRFA scenarios than the baseline and FRO scenarios upstream of the Skookumchuck River and upstream of the Newaukum River. The differences between the DO predictions for the scenarios was lowest at the most downstream station upstream of Black River.

The figures in this section contain model-predicted DO concentrations for baseline conditions, FRFA scenario 1, FRFA scenario 2, FRO scenario with riparian shading, and FRO scenario with no riparian shading. DO predictions for the scenarios for current conditions during summer 2013 are shown in Figure 150 for upstream of the South Fork Chehalis River and upstream of the Newaukum River and Figure 151 for upstream of the Skookumchuck River and upstream of the Black River. DO predictions for the scenarios for current conditions during summer 2014 are shown in Figure 152 for upstream of the South Fork Chehalis River and upstream of the Newaukum River and Figure 153 for 
upstream of the Skookumchuck River and upstream of the Black River. DO predictions for the scenarios for future conditions during summer 2014 are shown in Figure 154 for upstream of the South Fork Chehalis River and upstream of the Newaukum River and Figure 155 for upstream of the Skookumchuck River and upstream of the Black River.
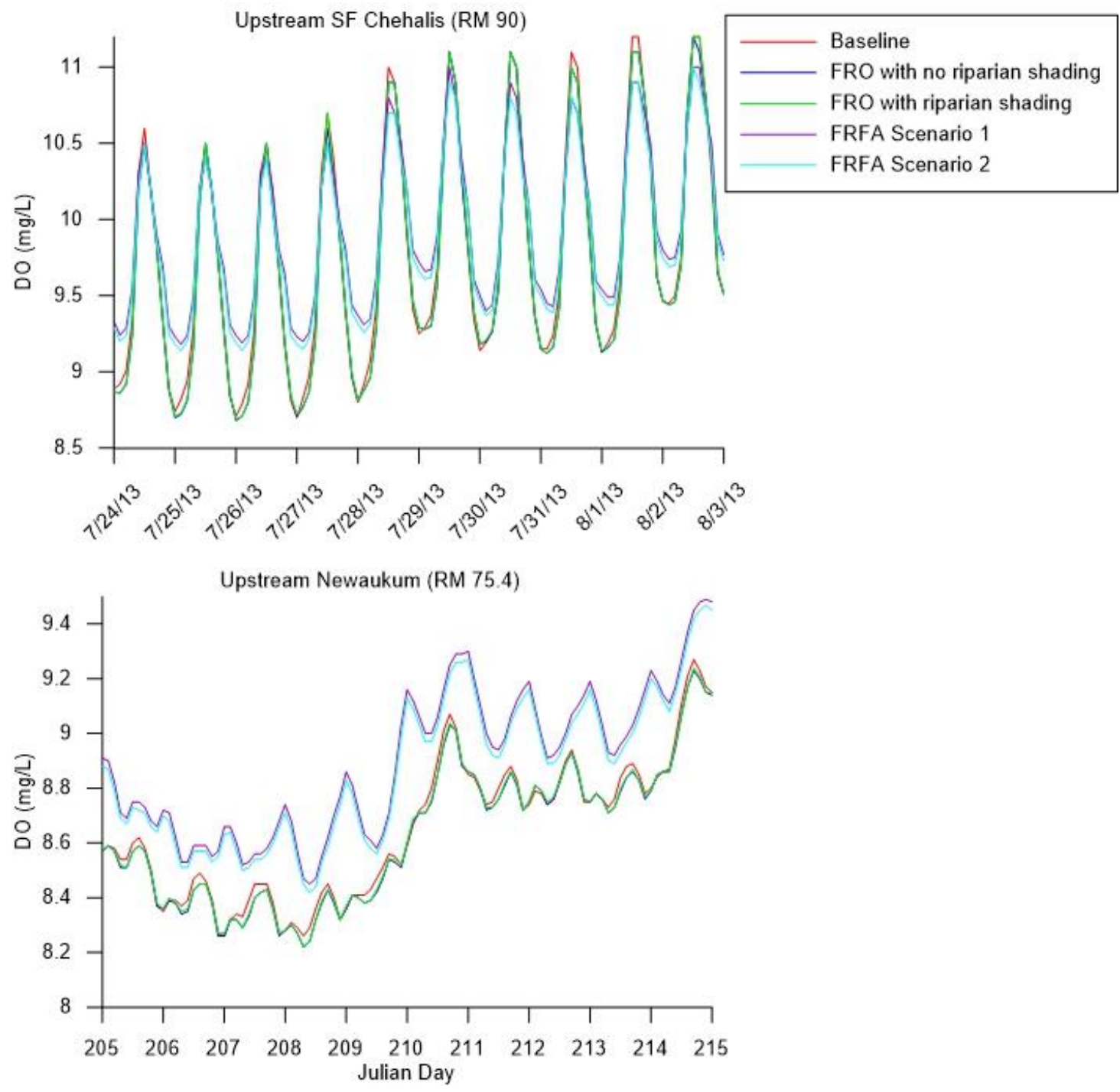

Figure 150. Model DO predictions for current conditions during summer 2013 at upstream of the South Fork Chehalis River and upstream of the Newaukum River for the scenarios: baseline, FRO with riparian shading, FRO with no shading, FRFA scenario 1, and FRFA scenario 2 


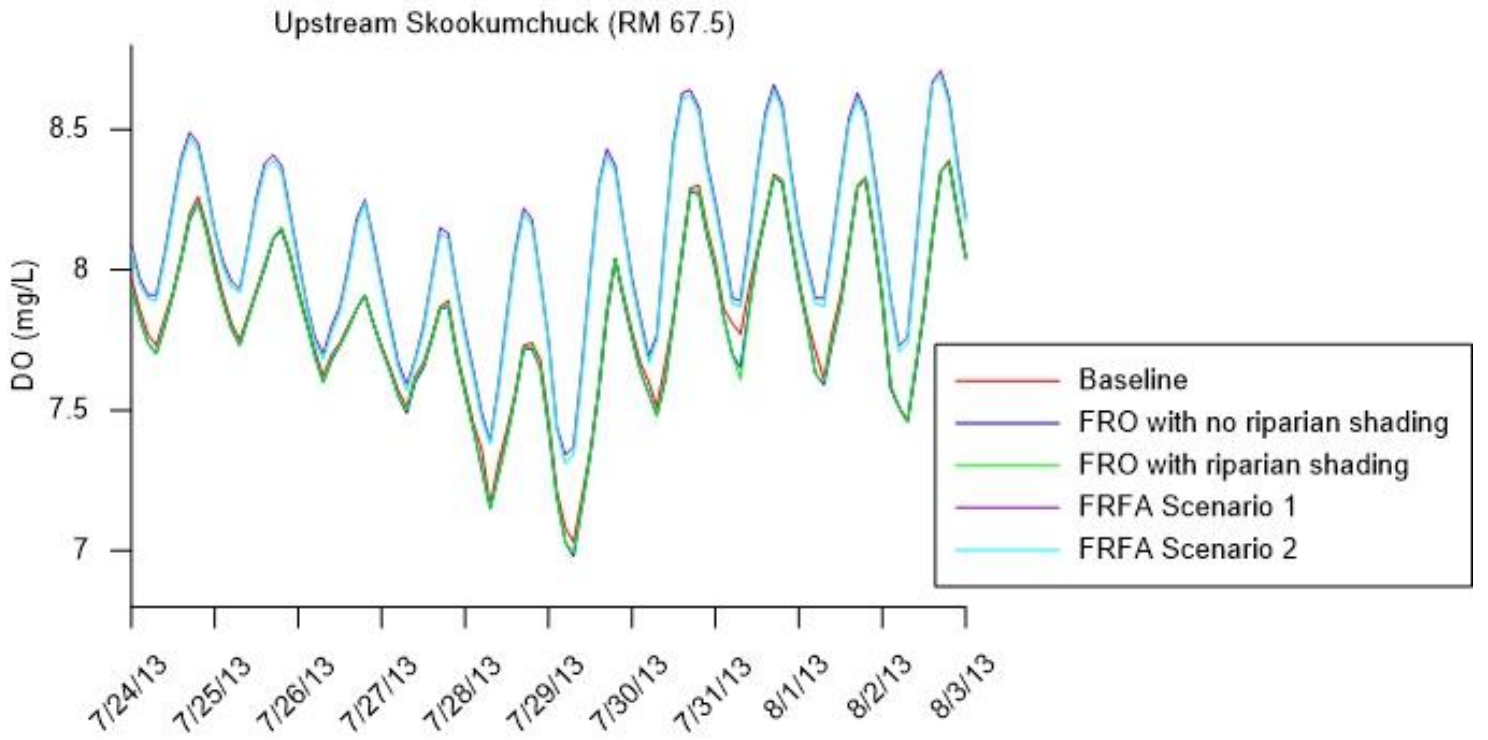

Upstream Black R. (RM 54.2)

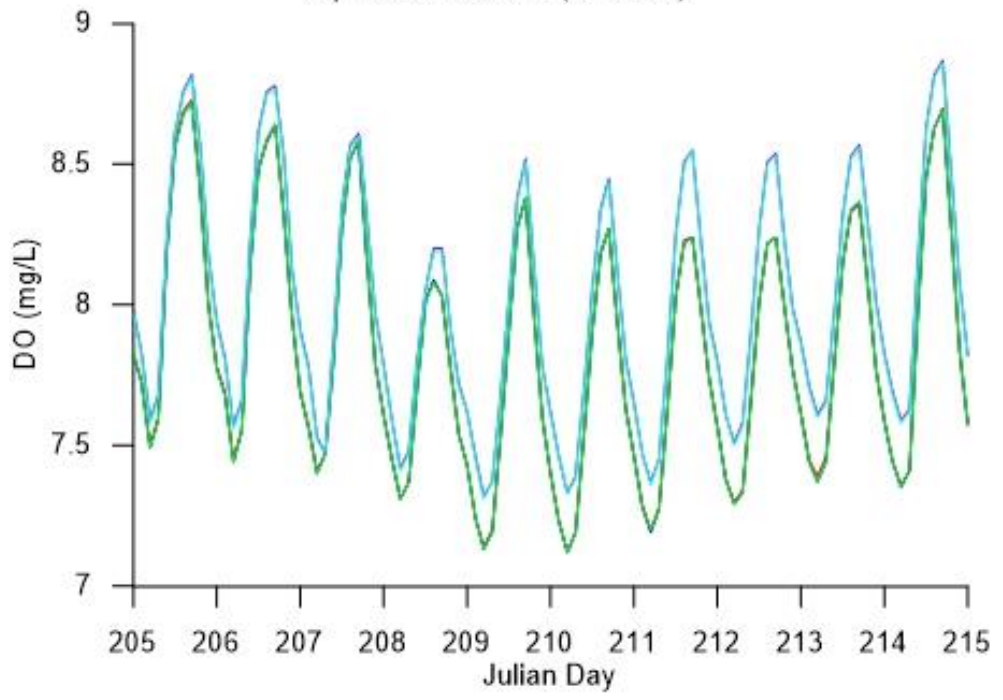

Figure 151. Model DO predictions for current conditions during summer 2013 at upstream of the Skookumchuck River and upstream of the Black River for the scenarios: baseline, FRO with riparian shading, FRO with no shading, FRFA scenario 1, and FRFA scenario 2 

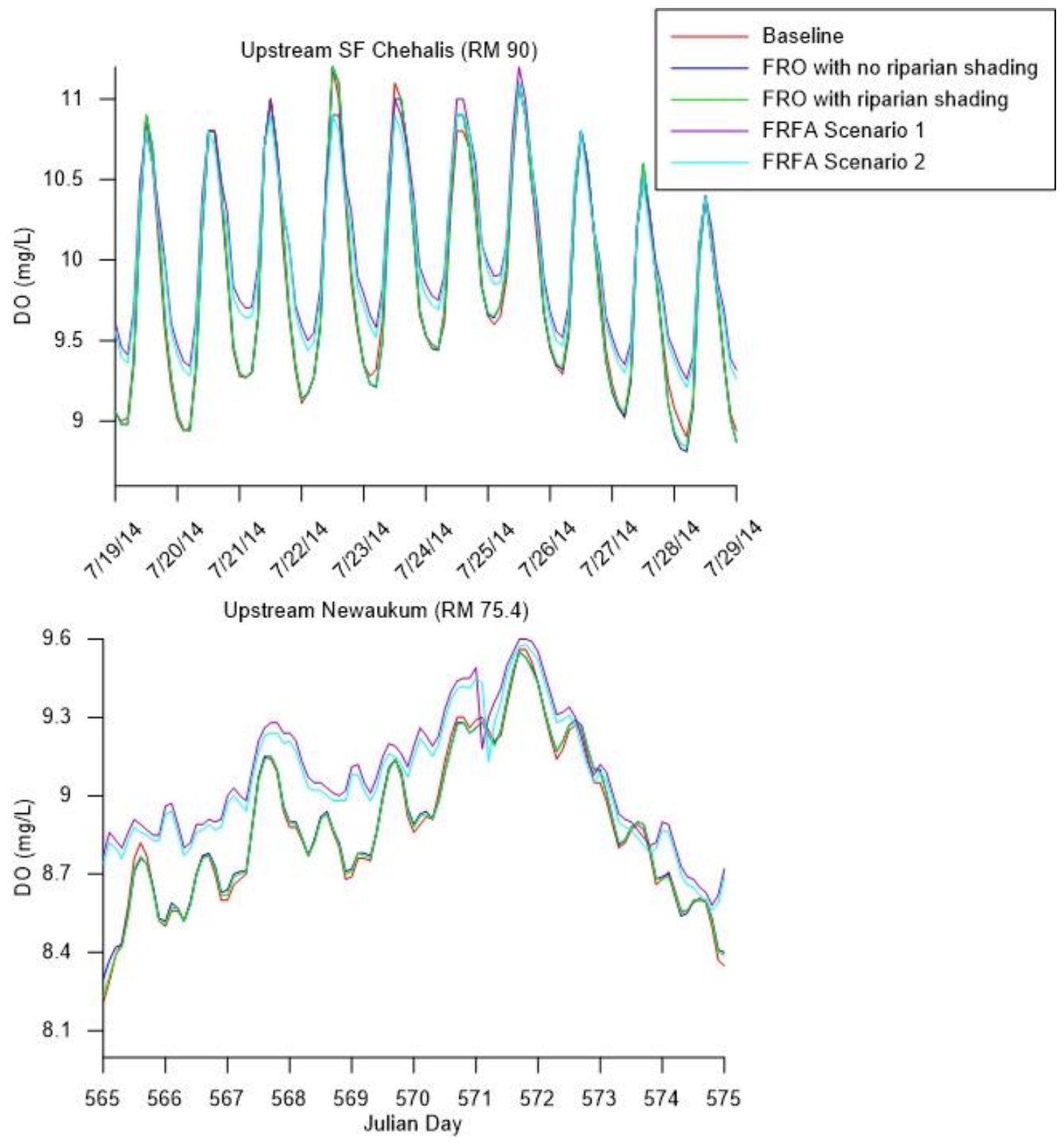

Figure 152. Model DO predictions for current conditions during summer 2014 at upstream of the South Fork Chehalis River and upstream of the Newaukum River for the scenarios: baseline, FRO with riparian shading, FRO with no shading, FRFA scenario 1, and FRFA scenario 2 


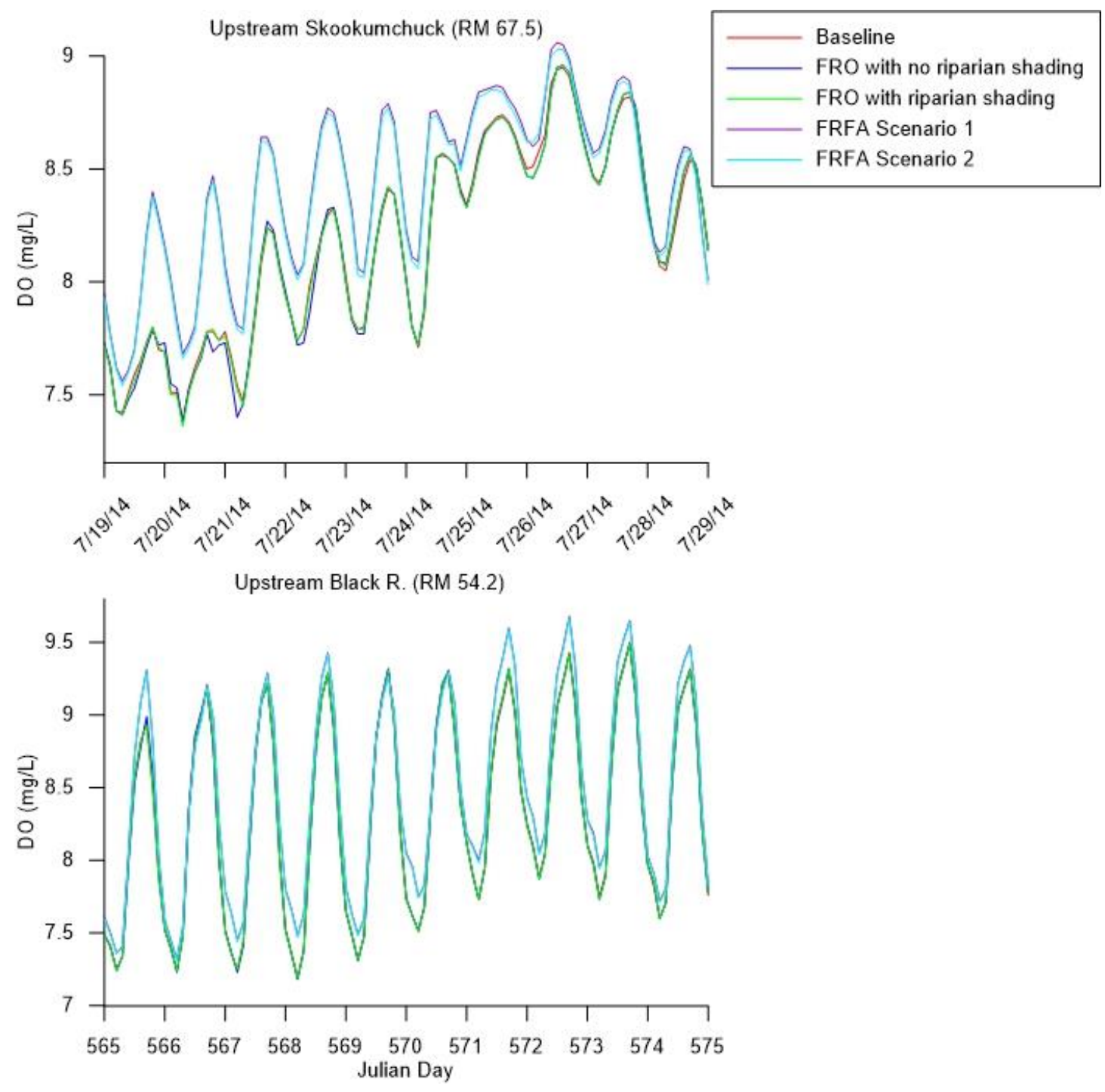

Figure 153. Model DO predictions for current conditions during summer 2014 at upstream of the Skookumchuck River and upstream of the Black River for the scenarios: baseline, FRO with riparian shading, FRO with no shading, FRFA scenario 1, and FRFA scenario 2 


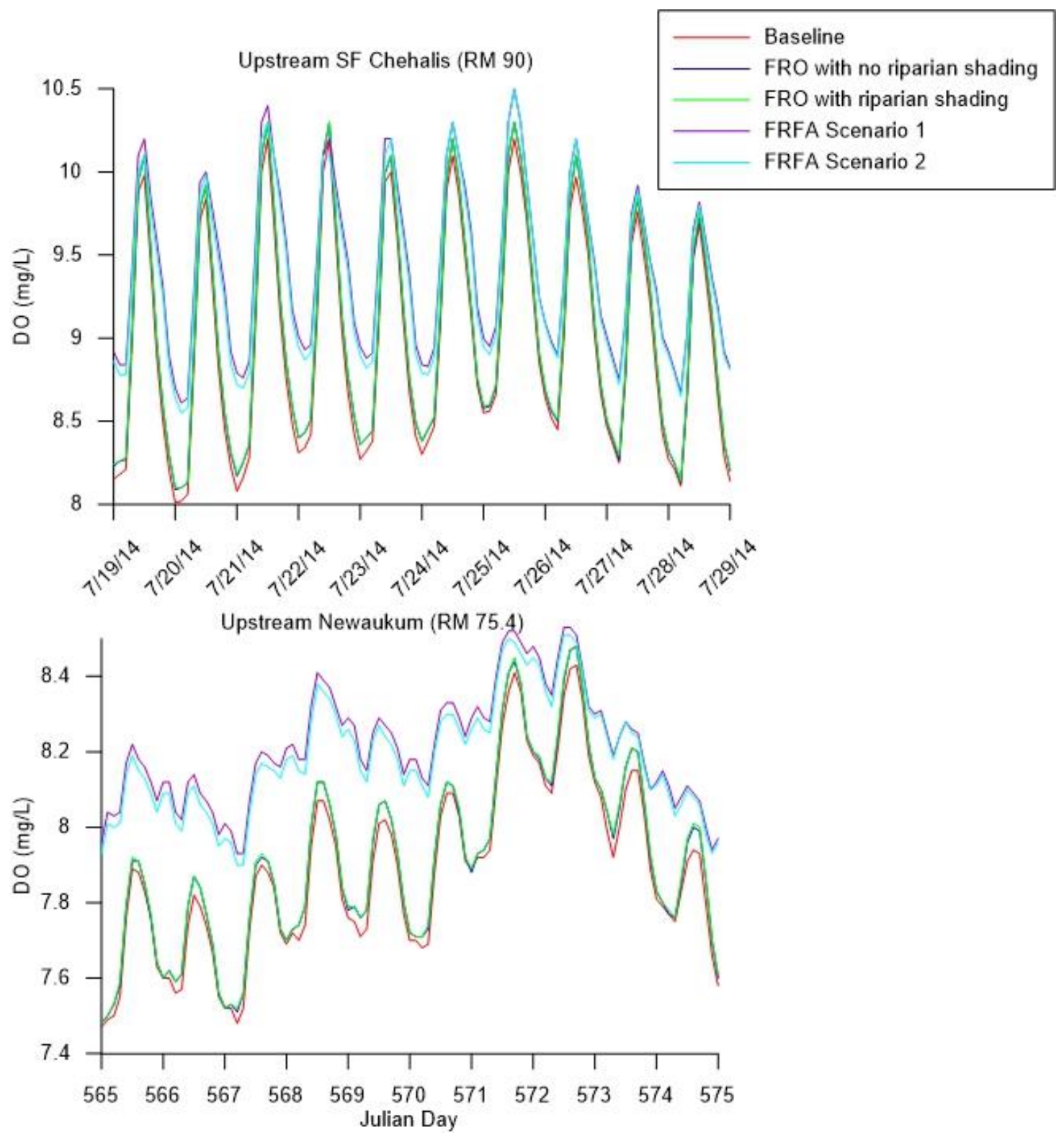

Figure 154. Model DO predictions for future conditions during summer 2014 at upstream of the South Fork Chehalis River and upstream of the Newaukum River for the scenarios: baseline, FRO with riparian shading, FRO with no shading, FRFA scenario 1 , and FRFA scenario 2 


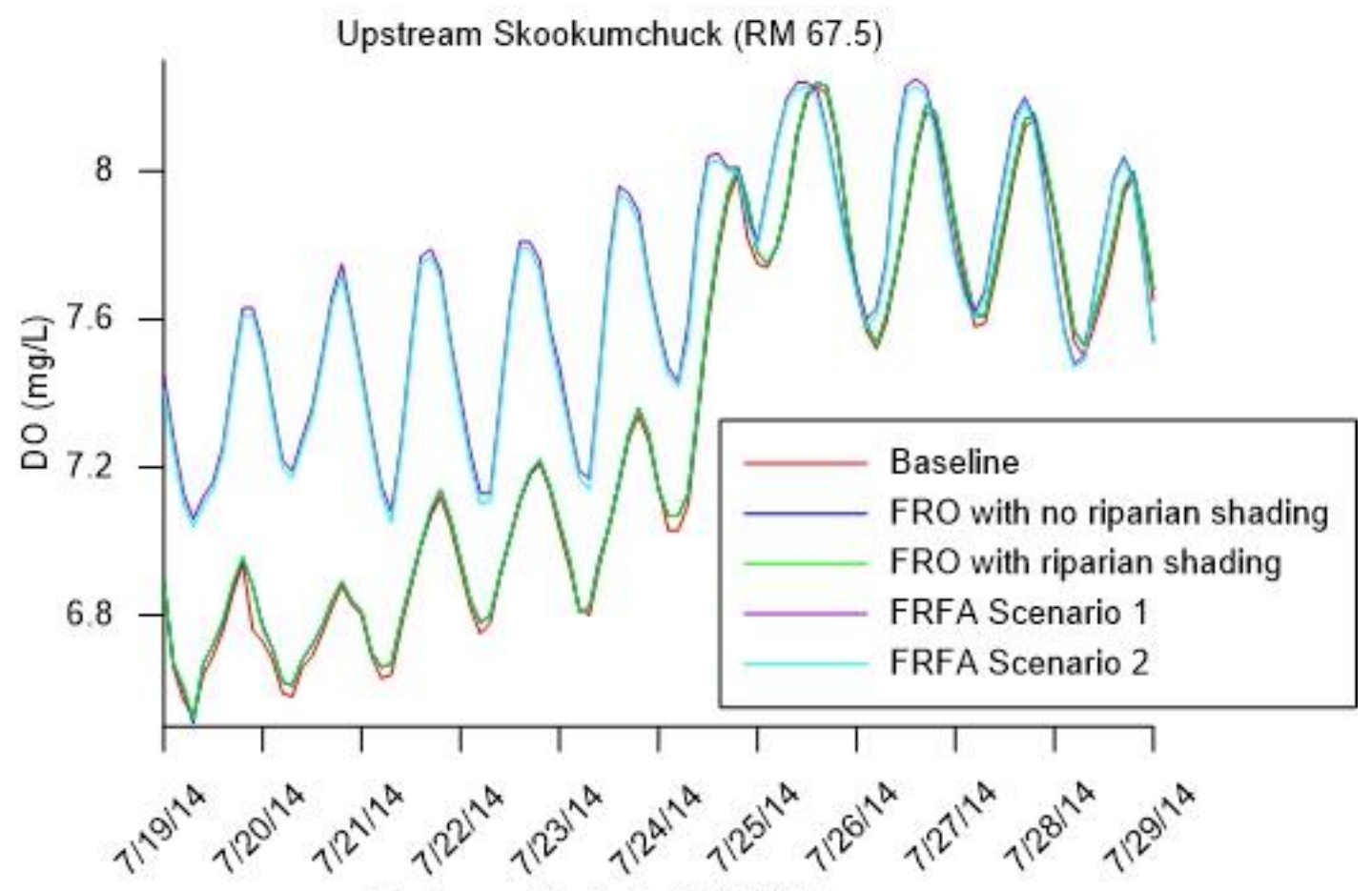

Upstream Black R. (RM 54.2)

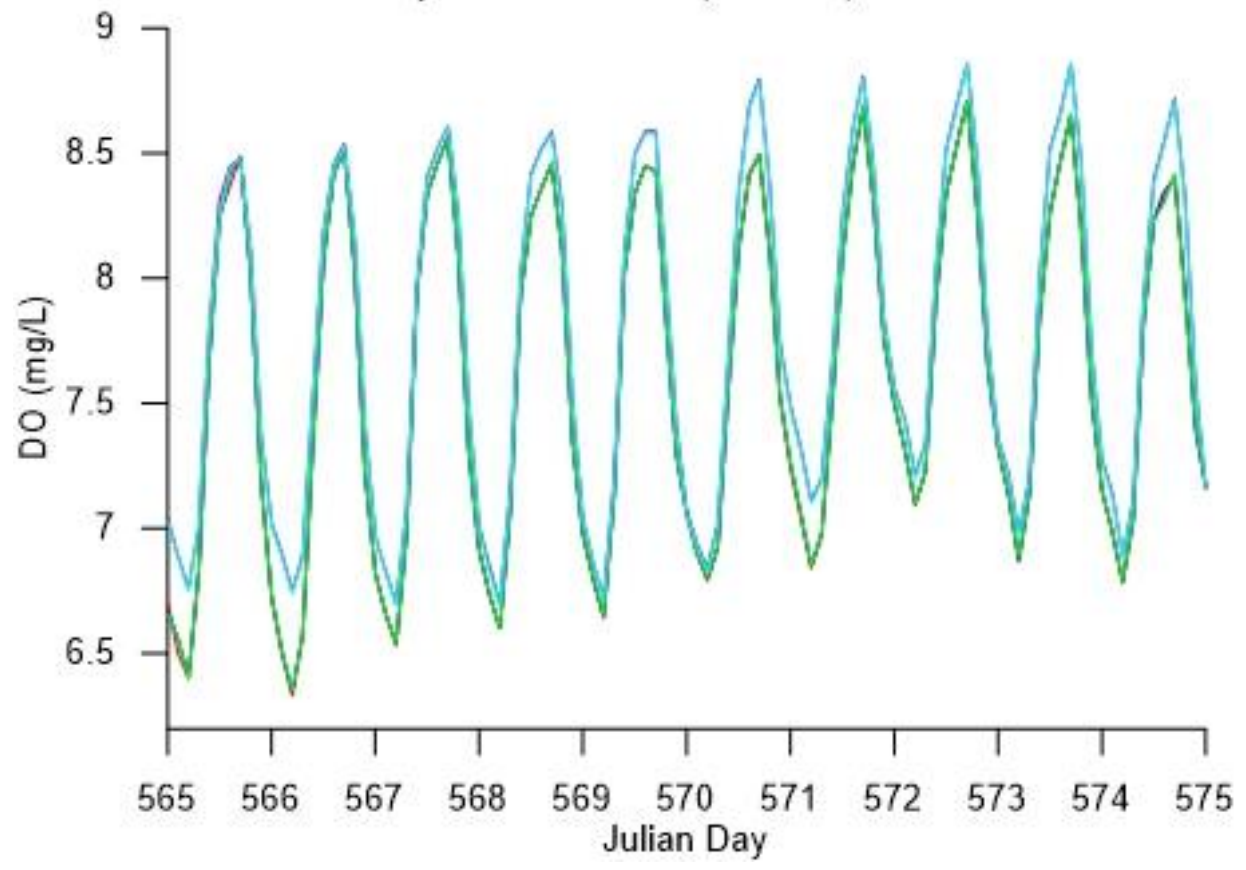

Figure 155. Model DO predictions for future conditions during summer 2014 at upstream of the Skookumchuck River and upstream of the Black River for the scenarios: baseline, FRO with riparian shading, FRO with no shading, FRFA scenario 1, and FRFA scenario 2 


\subsubsection{Ammonia}

Model-predicted NH4 peaks for the baseline and FRO scenarios were generally higher than the FRFA scenarios at upstream of South Fork Chehalis River during baseline summer 2013 and summer 2014, though were lower during summer 2014 for future conditions. NH4 values predicted by the model for upstream of the Newaukum River were slightly higher for the FRFA scenarios than the baseline and FRO scenarios during the baseline and future summer 2014 conditions, though the opposite was true during baseline conditions during summer 2013. The model predicted FRFA scenarios had slightly higher summer NO3 values for baseline and future conditions at upstream of the Skookumchuck River compared to baseline and FRO scenarios.

The figures in this section contain ammonia model predictions for the scenarios: baseline conditions, FRFA scenario 1, FRFA scenario 2, FRO scenario with riparian shading, and FRO scenario with no riparian shading. $\mathrm{NH} 4$ predictions for the scenarios for current conditions during summer 2013 are shown in Figure 156 for upstream of the South Fork Chehalis River and upstream of the Newaukum River and Figure 157 for upstream of the Skookumchuck River and upstream of the Black River. NH4 predictions for the scenarios for current conditions during summer 2014 are shown in Figure 158 for upstream of the South Fork Chehalis River and upstream of the Newaukum River and Figure 159 for upstream of the Skookumchuck River and upstream of the Black River. NH4 predictions for the scenarios for future conditions during summer 2014 are shown in Figure 160 for 
upstream of the South Fork Chehalis River and upstream of the Newaukum River and Figure 161 for upstream of the Skookumchuck River and upstream of the Black River.

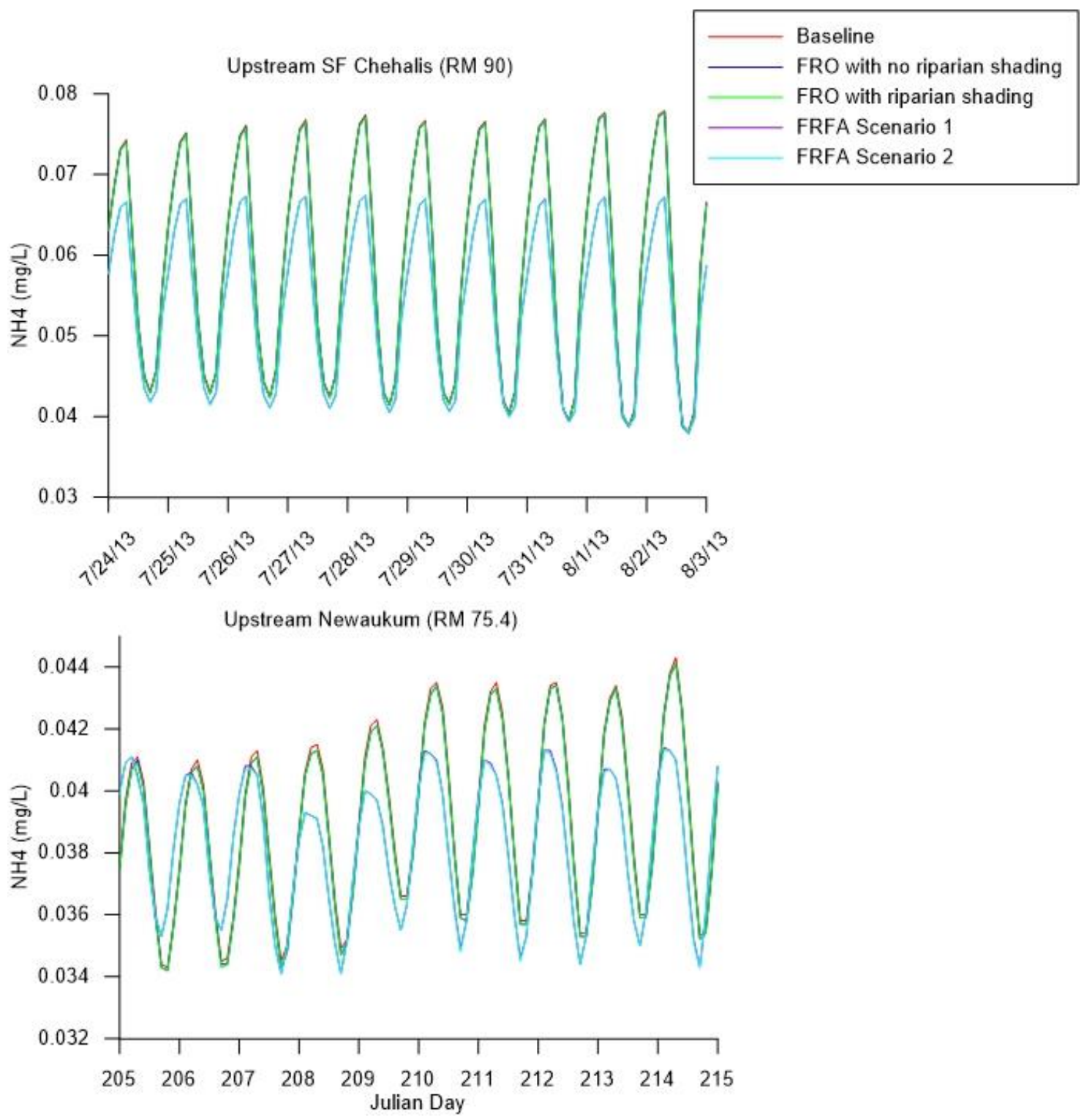

Figure 156. Model NH4 predictions for current conditions during summer 2013 at upstream of the South Fork Chehalis River and upstream of the Newaukum River for the scenarios: baseline, FRO with riparian shading, FRO with no shading, FRFA scenario 1, and FRFA scenario 2 


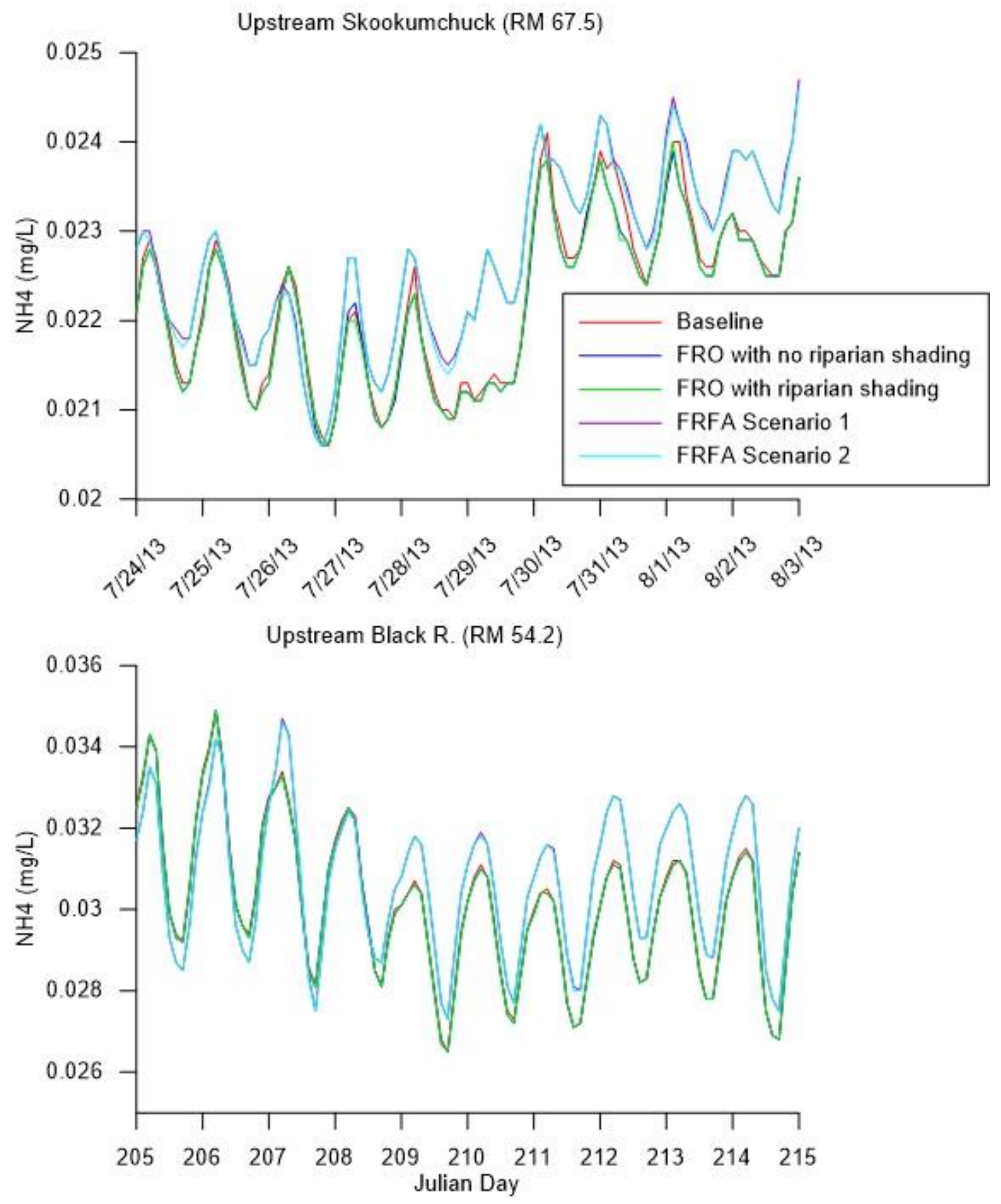

Figure 157. Model NH4 predictions for current conditions during summer 2013 at upstream of the Skookumchuck River and upstream of the Black River for the scenarios: baseline, FRO with riparian shading, FRO with no shading, FRFA scenario 1, and FRFA scenario 2 

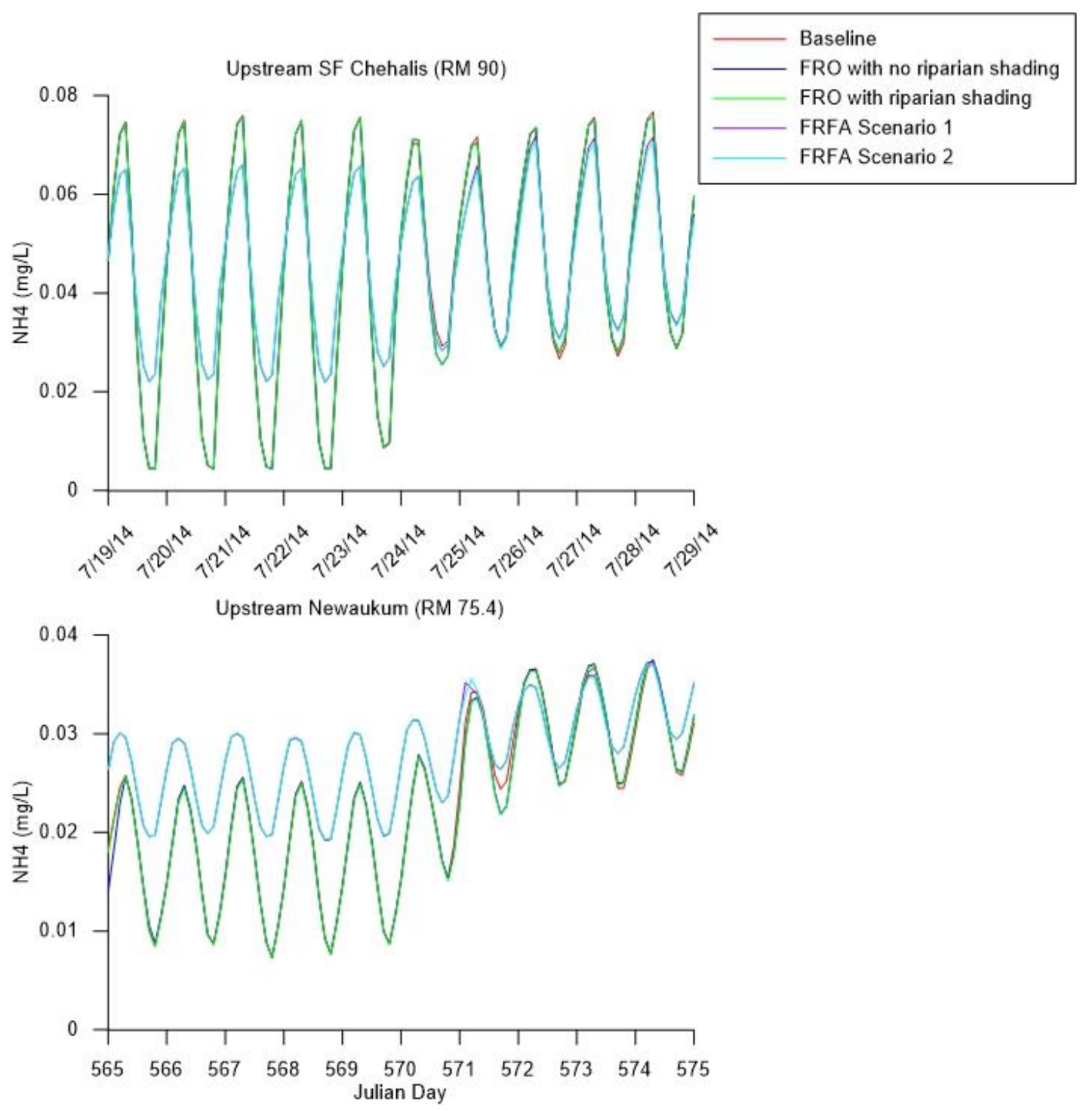

Figure 158. Model NH4 predictions for current conditions during summer 2014 at upstream of the South Fork Chehalis River and upstream of the Newaukum River for the scenarios: baseline, FRO with riparian shading, FRO with no shading, FRFA scenario 1 , and FRFA scenario 2 

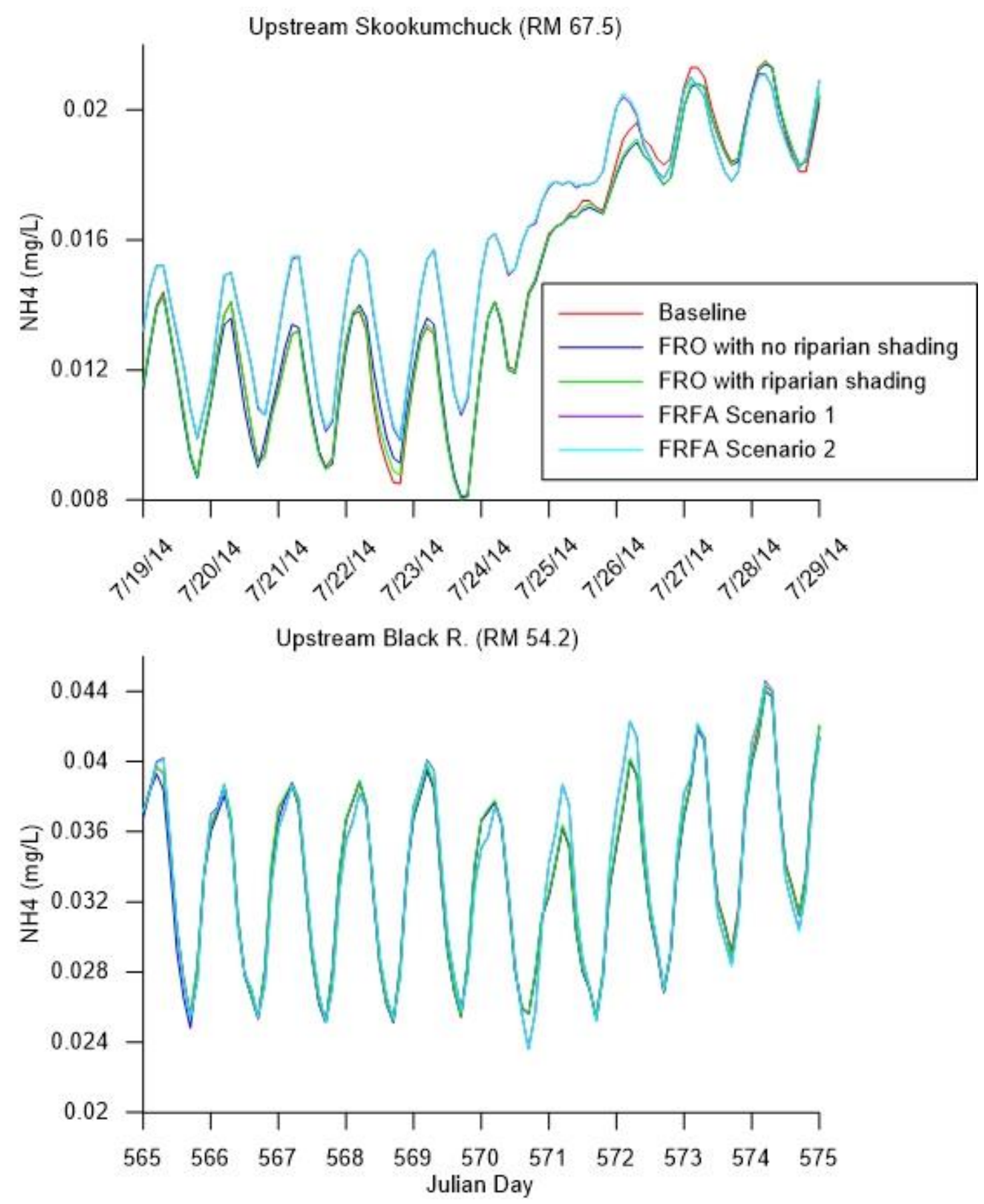

Figure 159. Model NH4 predictions for current conditions during summer 2014 at upstream of the Skookumchuck River and upstream of the Black River for the scenarios: baseline, FRO with riparian shading, FRO with no shading, FRFA scenario 1, and FRFA scenario 2 

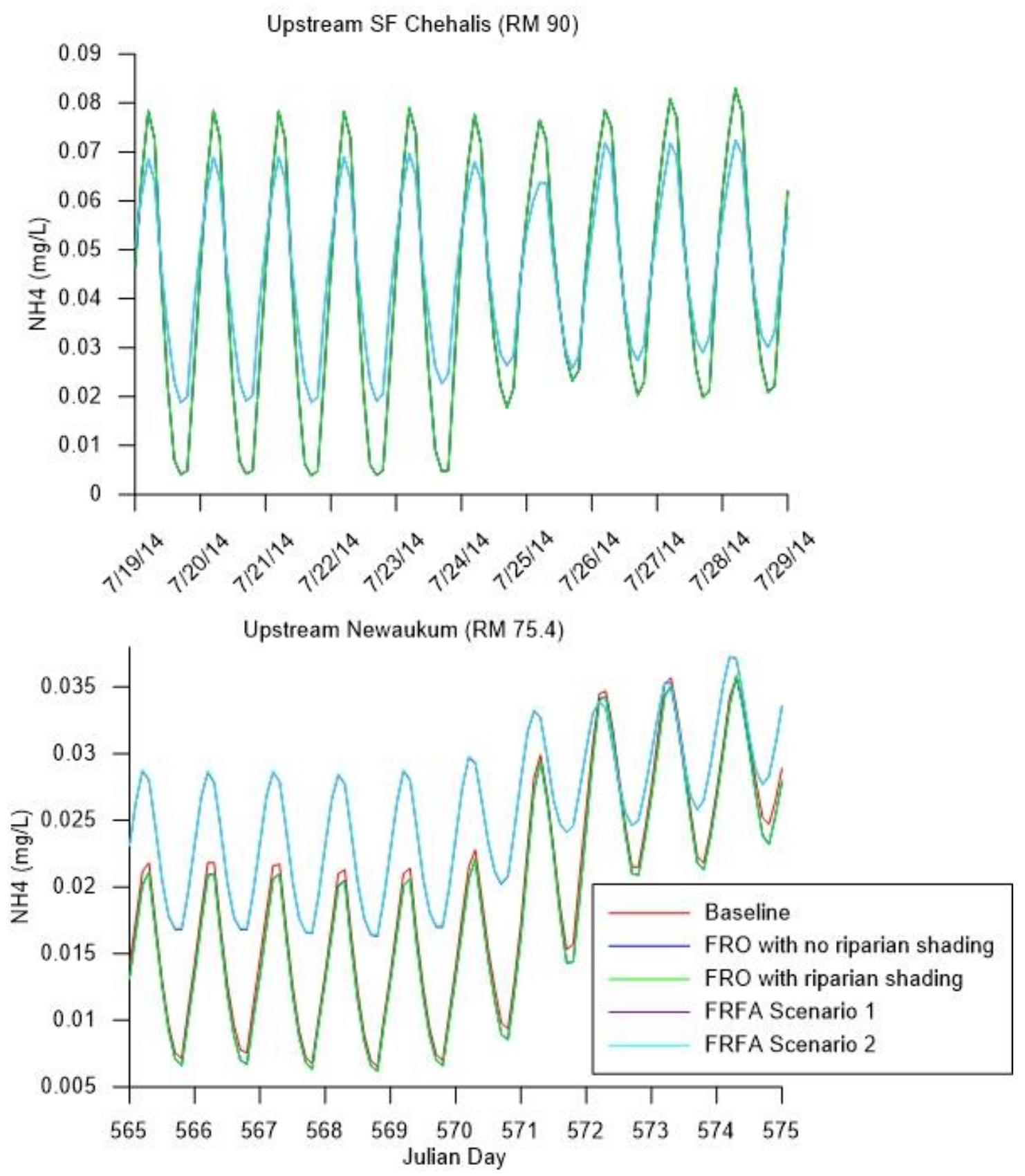

Figure 160. Model NH4 predictions for future conditions during summer 2014 at upstream of the South Fork Chehalis River and upstream of the Newaukum River for the scenarios: baseline, FRO with riparian shading, FRO with no shading, FRFA scenario 1, and FRFA scenario 2 

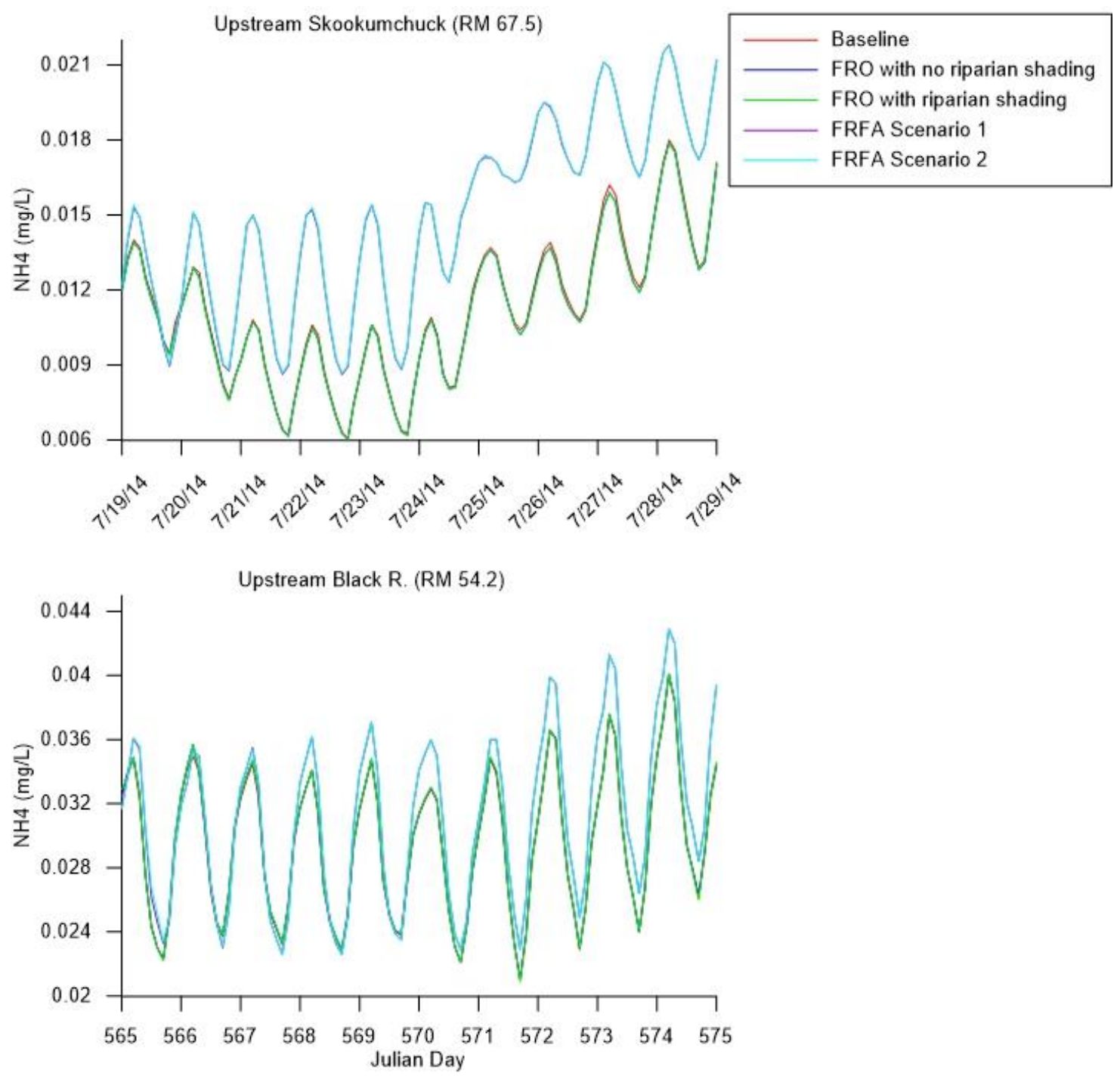

Figure 161. Model NH4 predictions for future conditions during summer 2014 at upstream of the Skookumchuck River and upstream of the Black River for the scenarios: baseline, FRO with riparian shading, FRO with no shading, FRFA scenario 1, and FRFA scenario 2 


\subsubsection{Nitrate}

Summer model predictions of NO3 concentrations were generally higher for the baseline and FRO scenarios than the FRFA scenarios during baseline conditions in summer 2013. The FRFA scenarios had generally higher model predictions of NO3 concentrations at upstream of the Newaukum River and upstream of the Skookumchuck River compared to baseline and FRO scenarios.

The figures in this section contain nitrate model predictions for the scenarios: baseline conditions, FRFA scenario 1, FRFA scenario 2, FRO scenario with riparian shading, and FRO scenario with no riparian shading. NO3 predictions for the scenarios for current conditions during summer 2013 are shown in Figure 162 for upstream of the South Fork Chehalis River and upstream of the Newaukum River and Figure 163 for upstream of the Skookumchuck River and upstream of the Black River. NO3 predictions for the scenarios for current conditions during summer 2014 are shown in Figure 164 for upstream of the South Fork Chehalis River and upstream of the Newaukum River and Figure 165 for upstream of the Skookumchuck River and upstream of the Black River. NO3 predictions for the scenarios for future conditions during summer 2014 are shown in Figure 166 for upstream of the South Fork Chehalis River and upstream of the Newaukum River and Figure 167 for upstream of the Skookumchuck River and upstream of the Black River. 


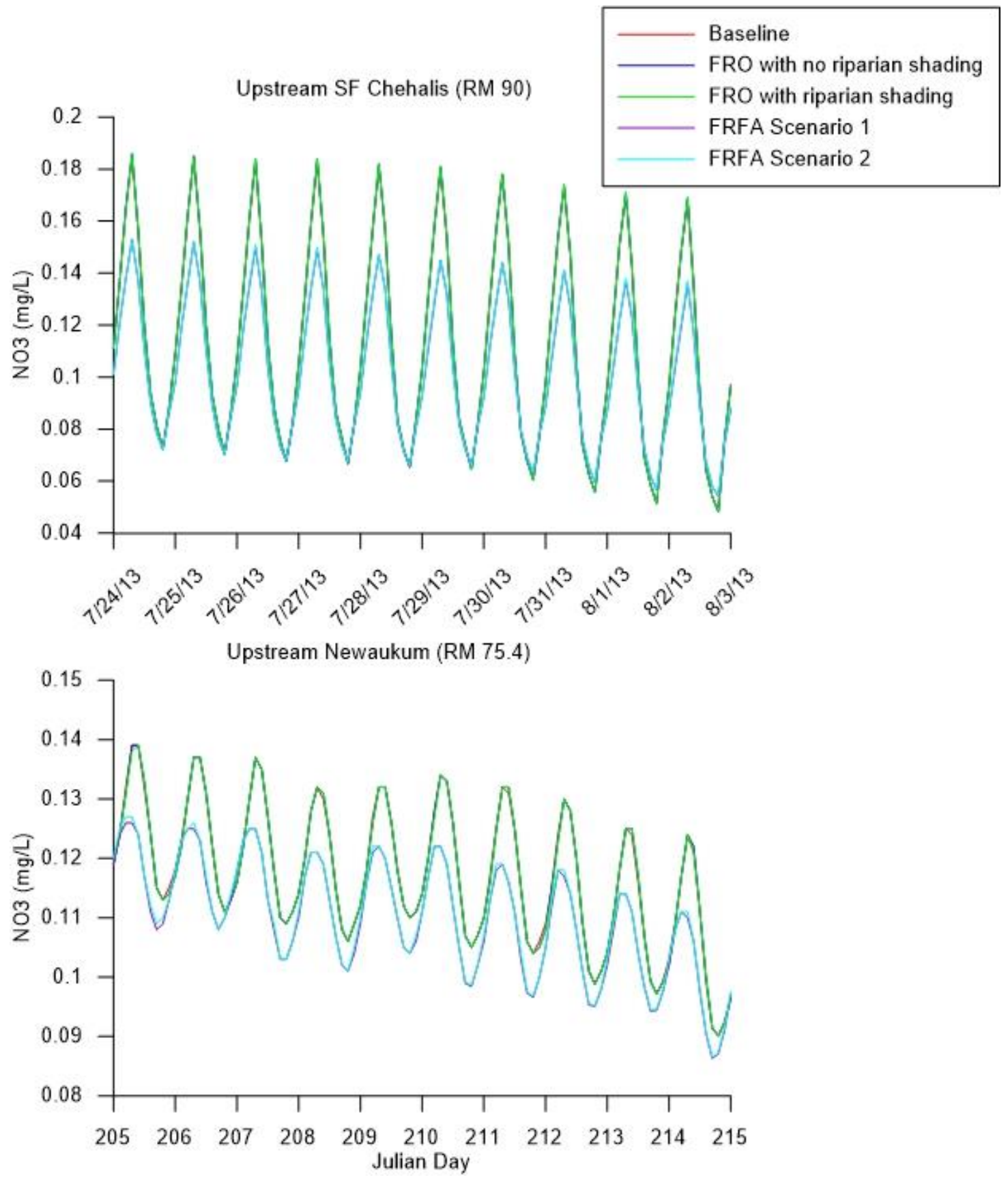

Figure 162. Model NO3 predictions for current conditions during summer 2013 at upstream of the South Fork Chehalis River and upstream of the Newaukum River for the scenarios: baseline, FRO with riparian shading, FRO with no shading, FRFA scenario 1 , and FRFA scenario 2 


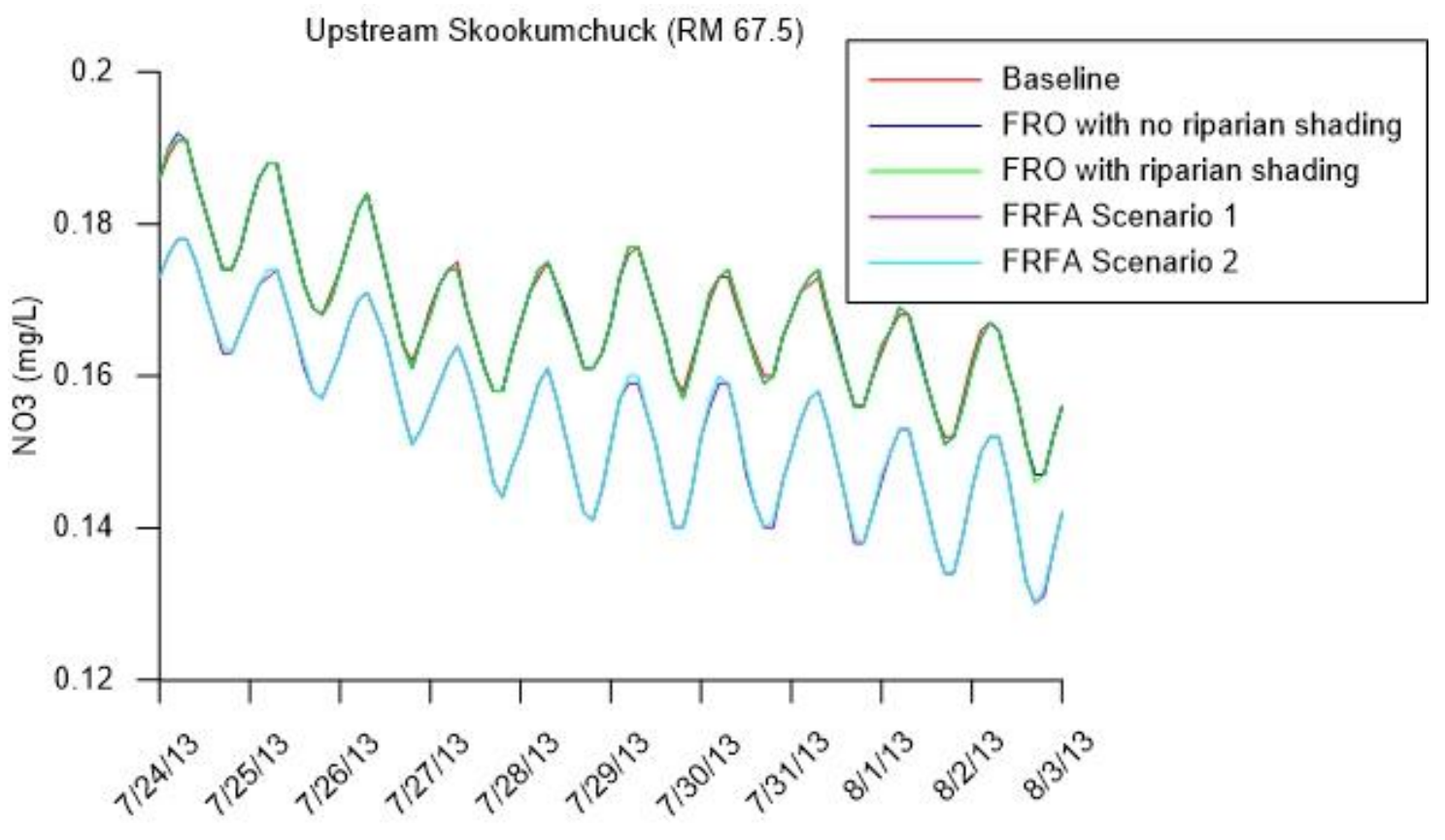

Upstream Black R. (RM 54.2)

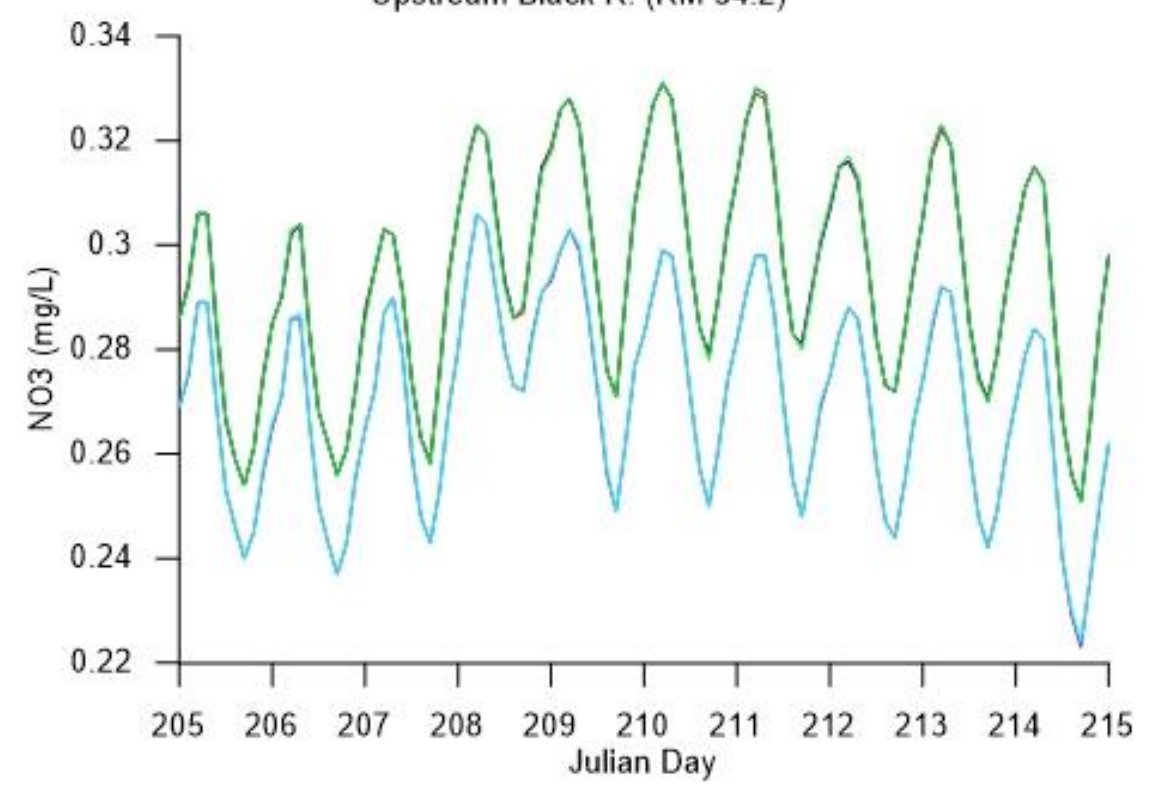

Figure 163. Model NO3 predictions for current conditions during summer 2013 at upstream of the Skookumchuck River and upstream of the Black River for the scenarios: baseline, FRO with riparian shading, FRO with no shading, FRFA scenario 1, and FRFA scenario 2 


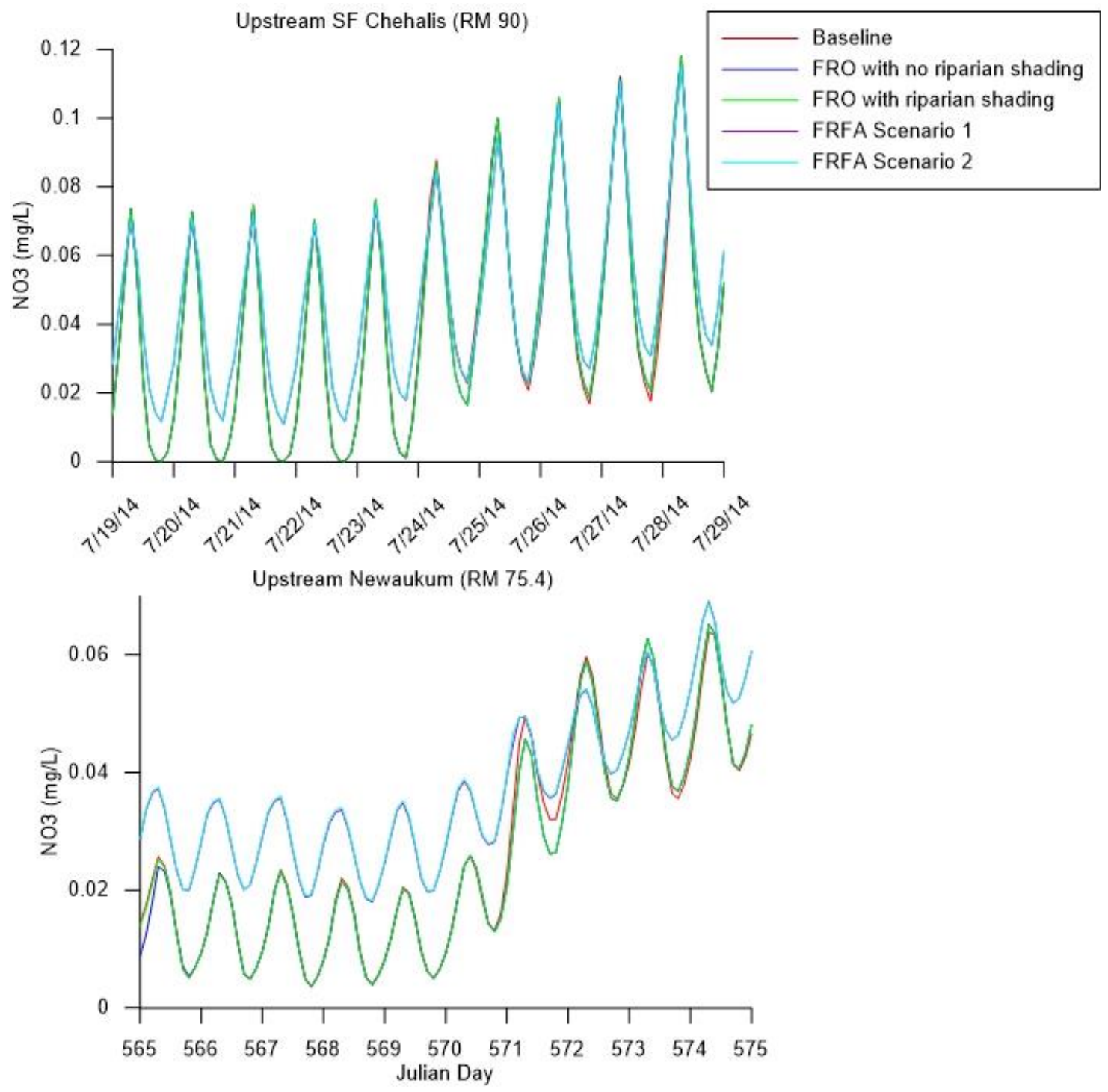

Figure 164. Model NO3 predictions for current conditions during summer 2014 at upstream of the South Fork Chehalis River and upstream of the Newaukum River for the scenarios: baseline, FRO with riparian shading, FRO with no shading, FRFA scenario 1, and FRFA scenario 2 


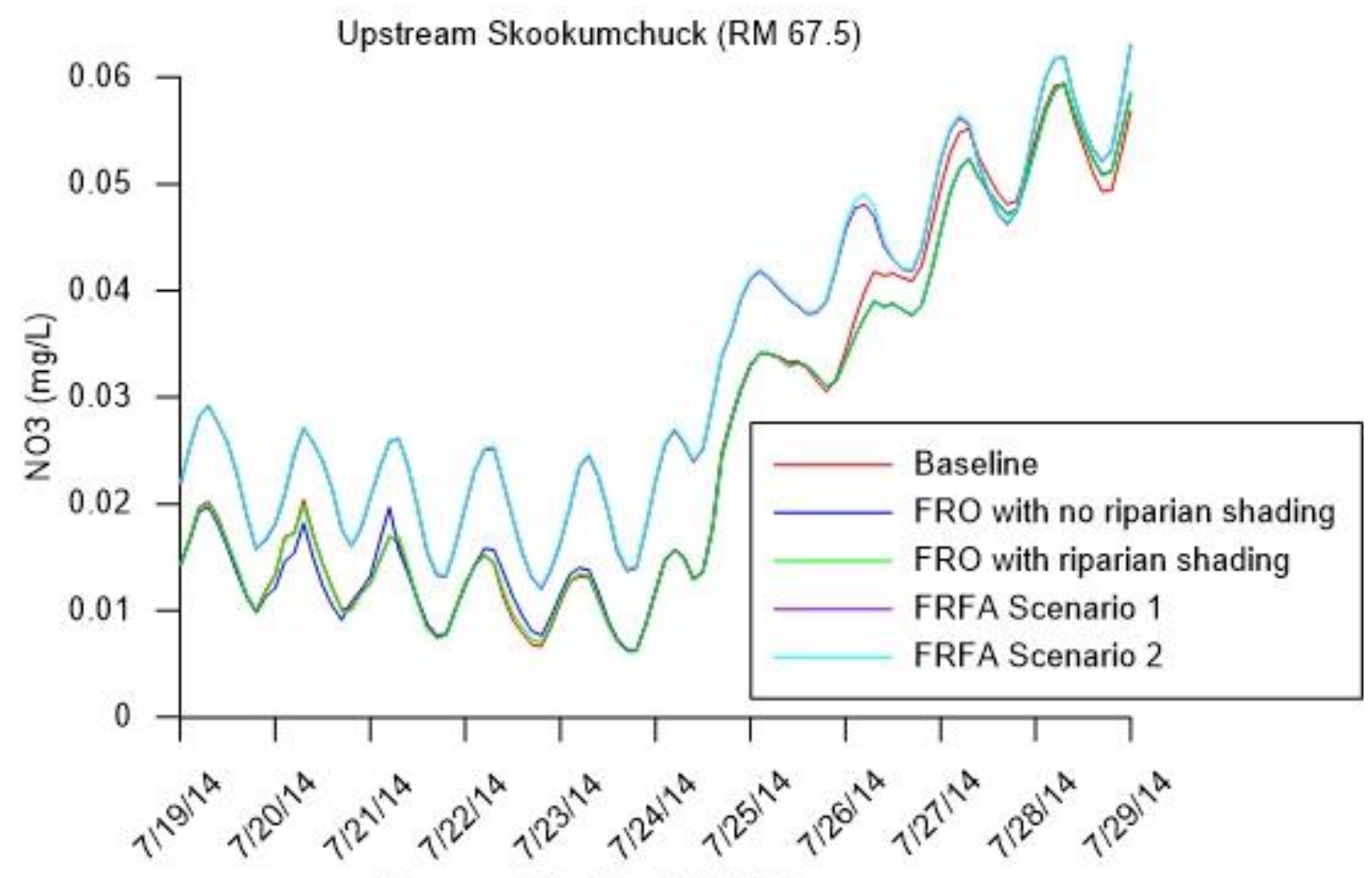

Upstream Black R. (RM 54.2)

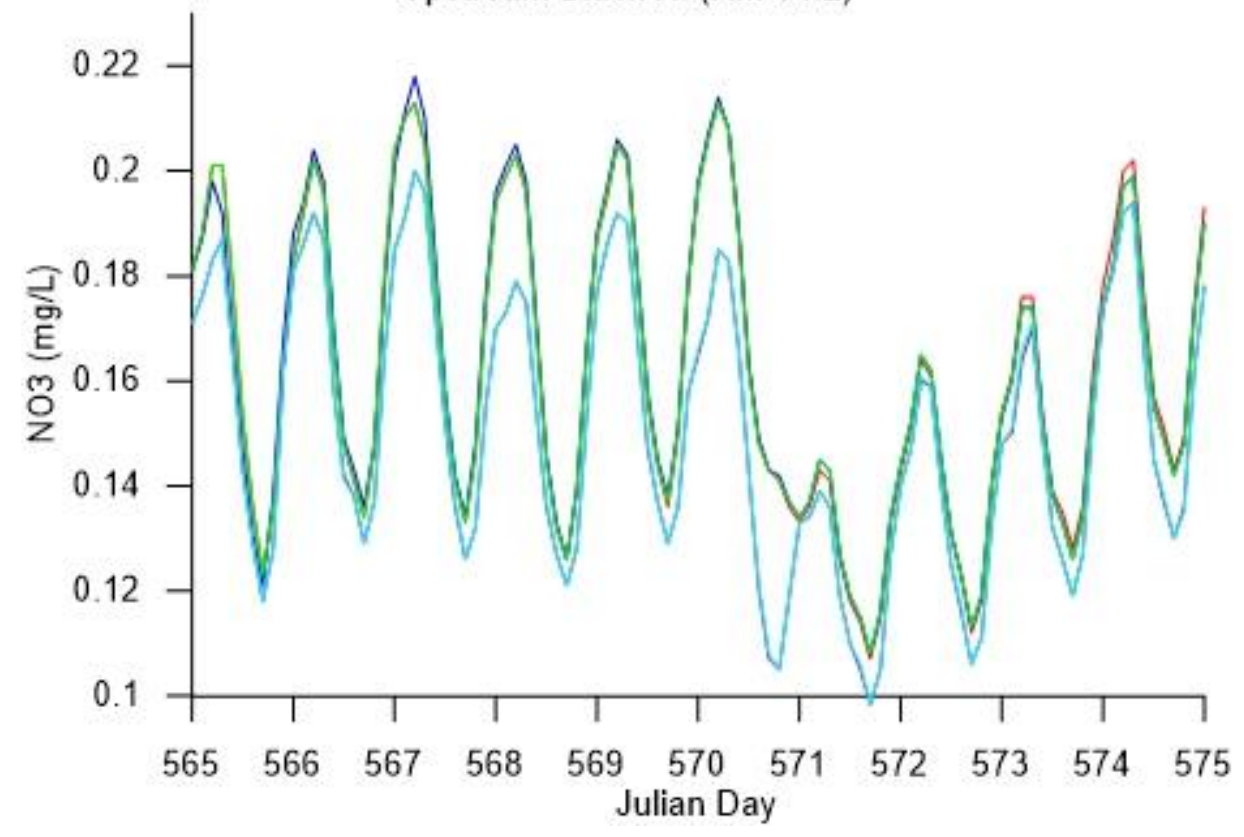

Figure 165. Model NO3 predictions for current conditions during summer 2014 at upstream of the Skookumchuck River and upstream of the Black River for the scenarios: baseline, FRO with riparian shading, FRO with no shading, FRFA scenario 1 , and FRFA scenario 2 


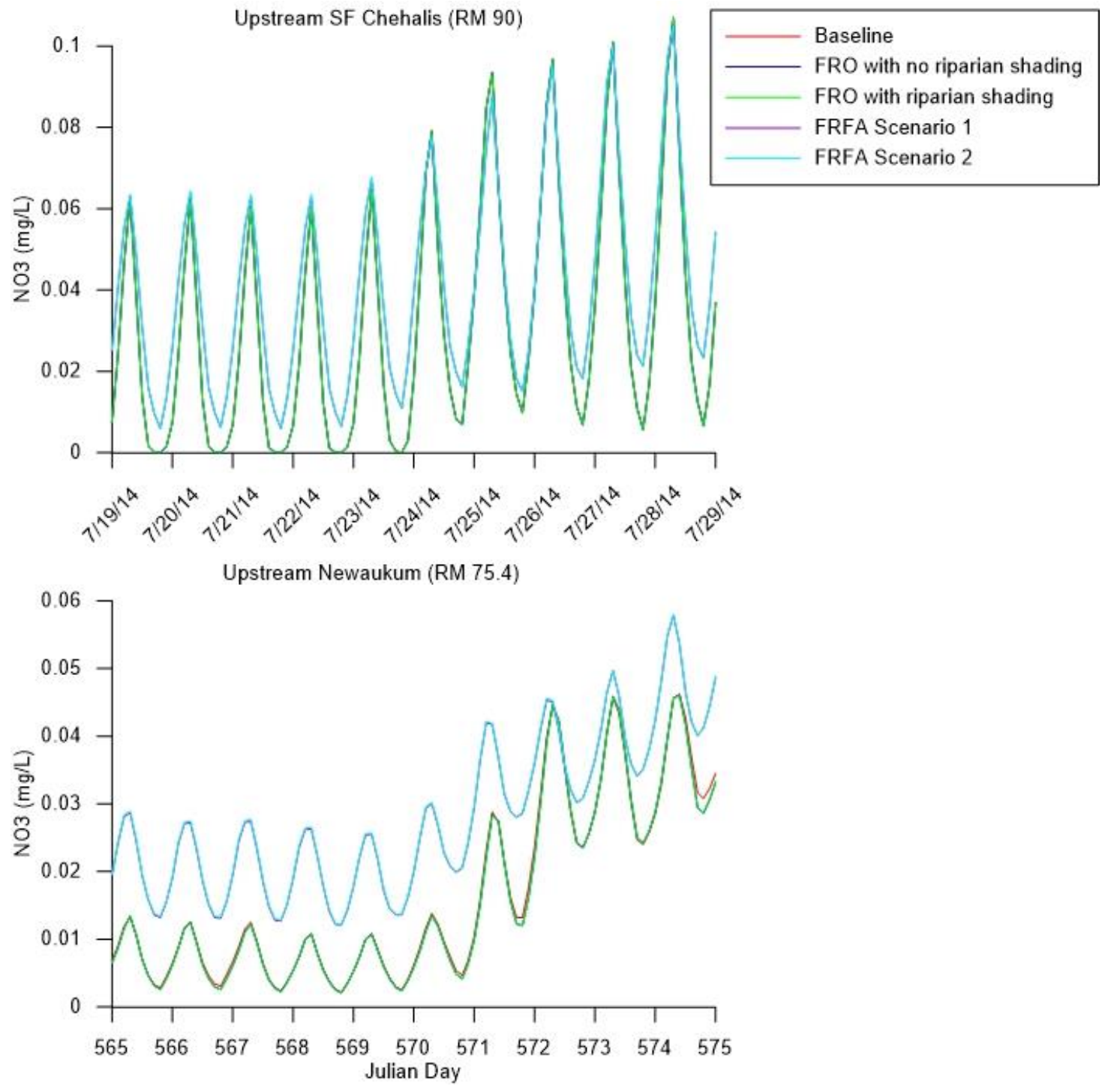

Figure 166. Model NO3 predictions for future conditions during summer 2014 at upstream of the South Fork Chehalis River and upstream of the Newaukum River for the scenarios: baseline, FRO with riparian shading, FRO with no shading, FRFA scenario 1, and FRFA scenario 2 

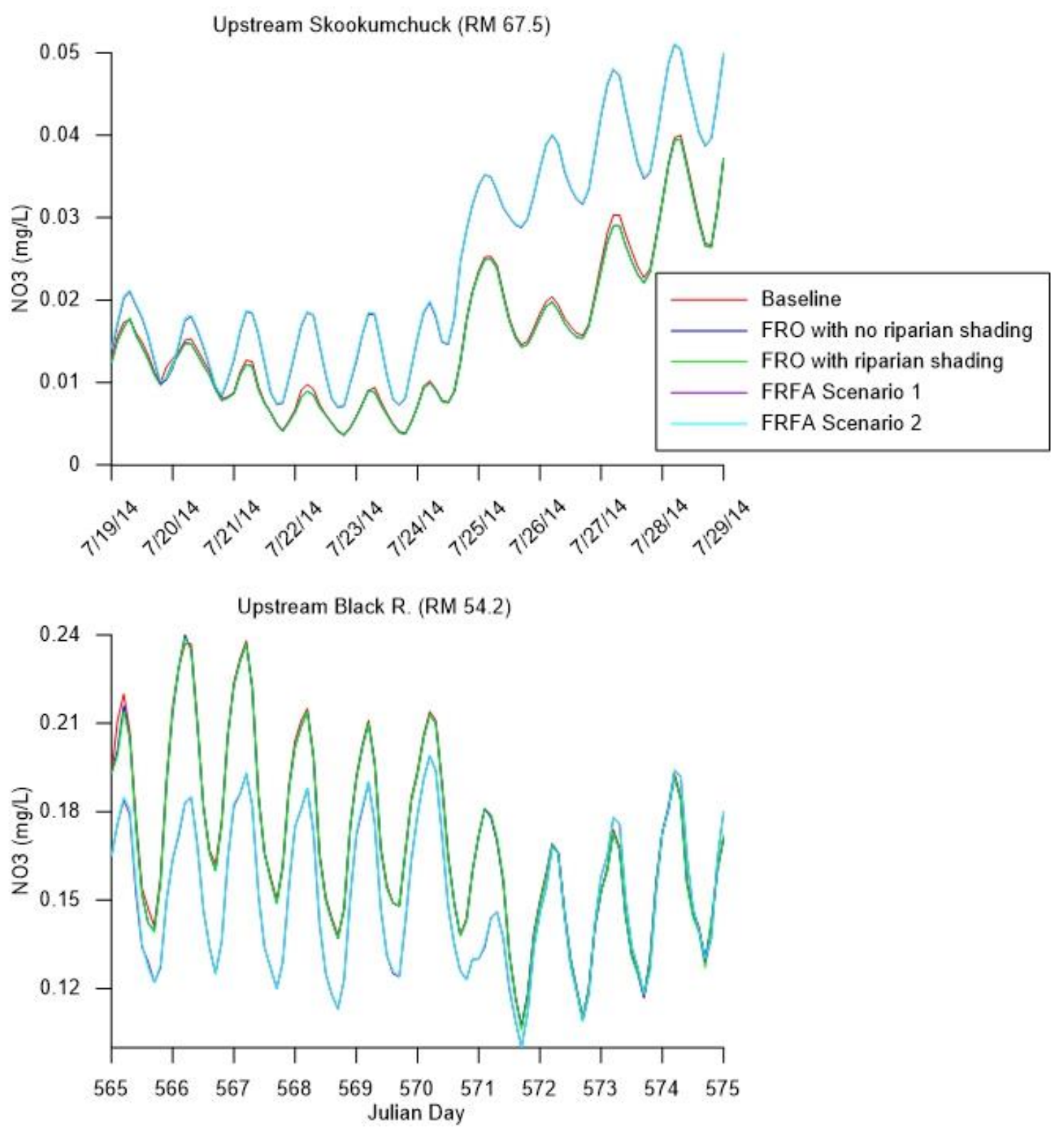

Figure 167. Model NO3 predictions for future conditions during summer 2014 at upstream of the Skookumchuck River and upstream of the Black River for the scenarios: baseline, FRO with riparian shading, FRO with no shading, FRFA scenario 1 , and FRFA scenario 2 


\subsubsection{Phosphate}

Generally, model predictions of PO4 had peaks slightly greater for the baseline and FRO scenarios than the FRFA scenarios for baseline and future conditions.

The figures in this section contain phosphate model predictions for the scenarios: baseline conditions, FRFA scenario 1, FRFA scenario 2, FRO scenario with riparian shading, and FRO scenario with no riparian shading. PO4 predictions for the scenarios for current conditions during summer 2013 are shown in Figure 168 for upstream of the South Fork Chehalis River and upstream of the Newaukum River and Figure 169 for upstream of the Skookumchuck River and upstream of the Black River. PO4 predictions for the scenarios for current conditions during summer 2014 are shown in Figure 170 for upstream of the South Fork Chehalis River and upstream of the Newaukum River and Figure 171 for upstream of the Skookumchuck River and upstream of the Black River. PO4 predictions for the scenarios for future conditions during summer 2014 are shown in Figure 172 for

upstream of the South Fork Chehalis River and upstream of the Newaukum River and Figure 173 for upstream of the Skookumchuck River and upstream of the Black River. 

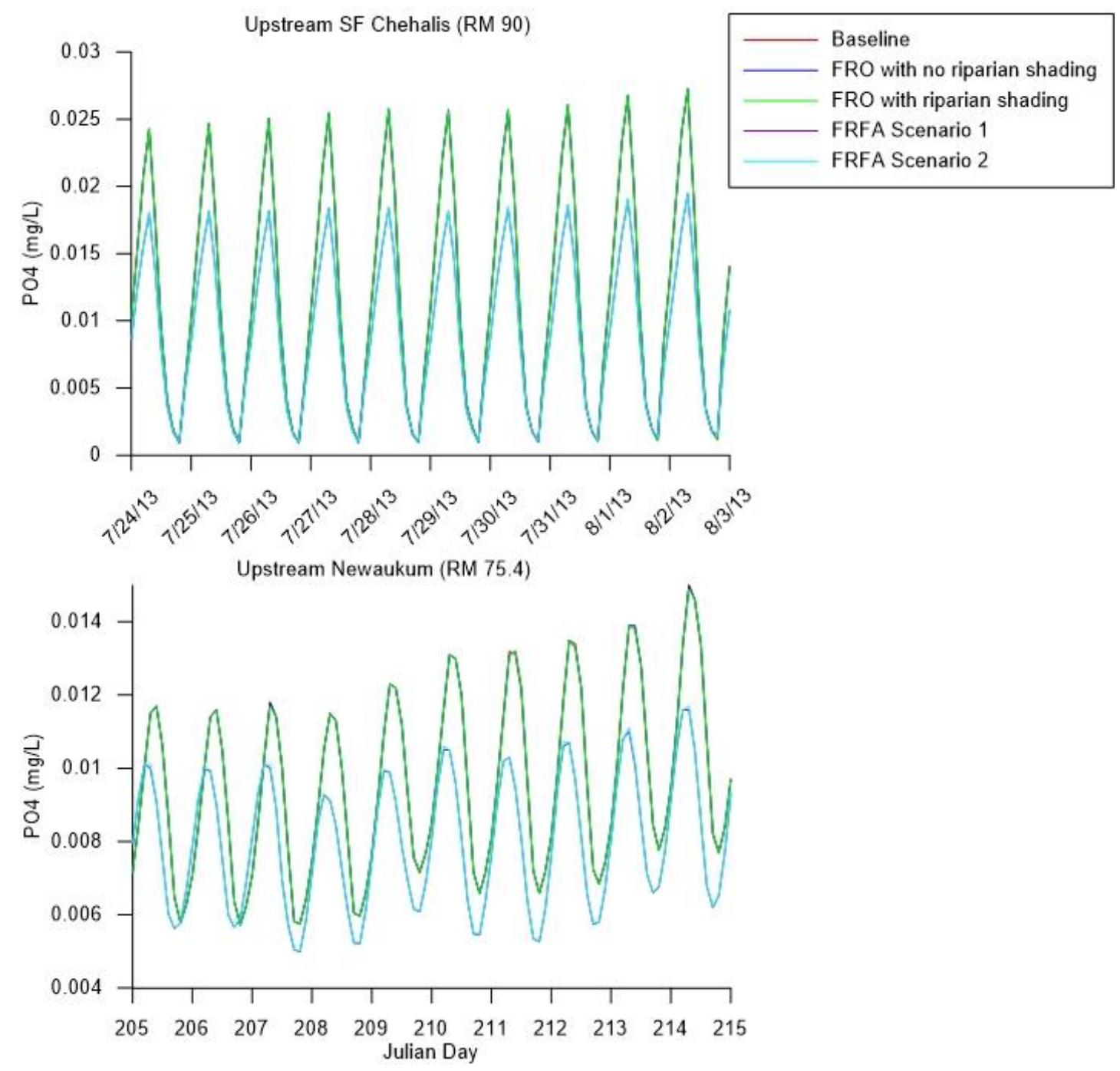

Figure 168. Model PO4 predictions for current conditions during summer 2013 at upstream of the South Fork Chehalis River and upstream of the Newaukum River for the scenarios: baseline, FRO with riparian shading, FRO with no shading, FRFA scenario 1, and FRFA scenario 2 

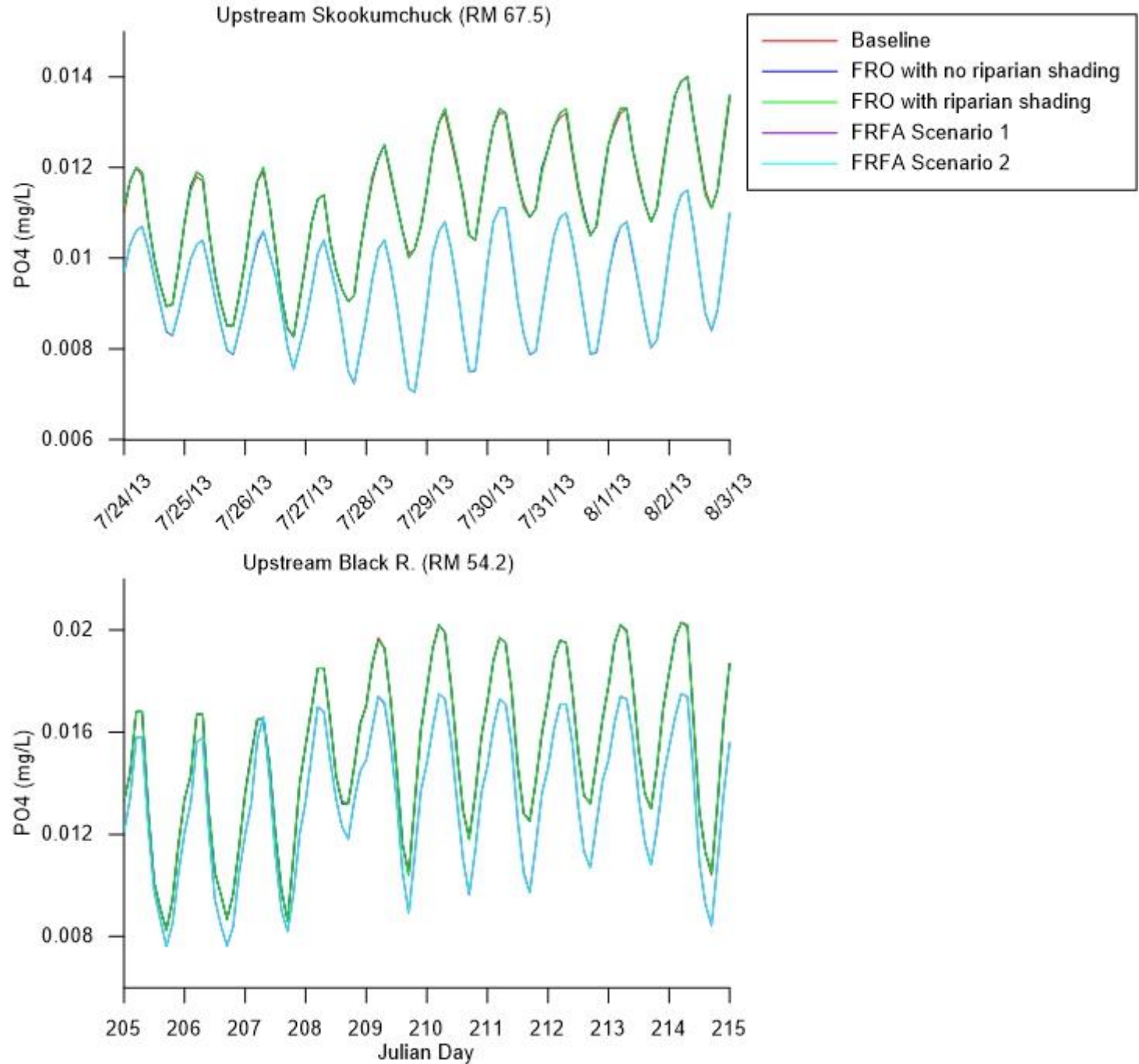

Figure 169. Model PO4 predictions for current conditions during summer 2013 at upstream of the Skookumchuck River and upstream of the Black River for the scenarios: baseline, FRO with riparian shading, FRO with no shading, FRFA scenario 1, and FRFA scenario 2 

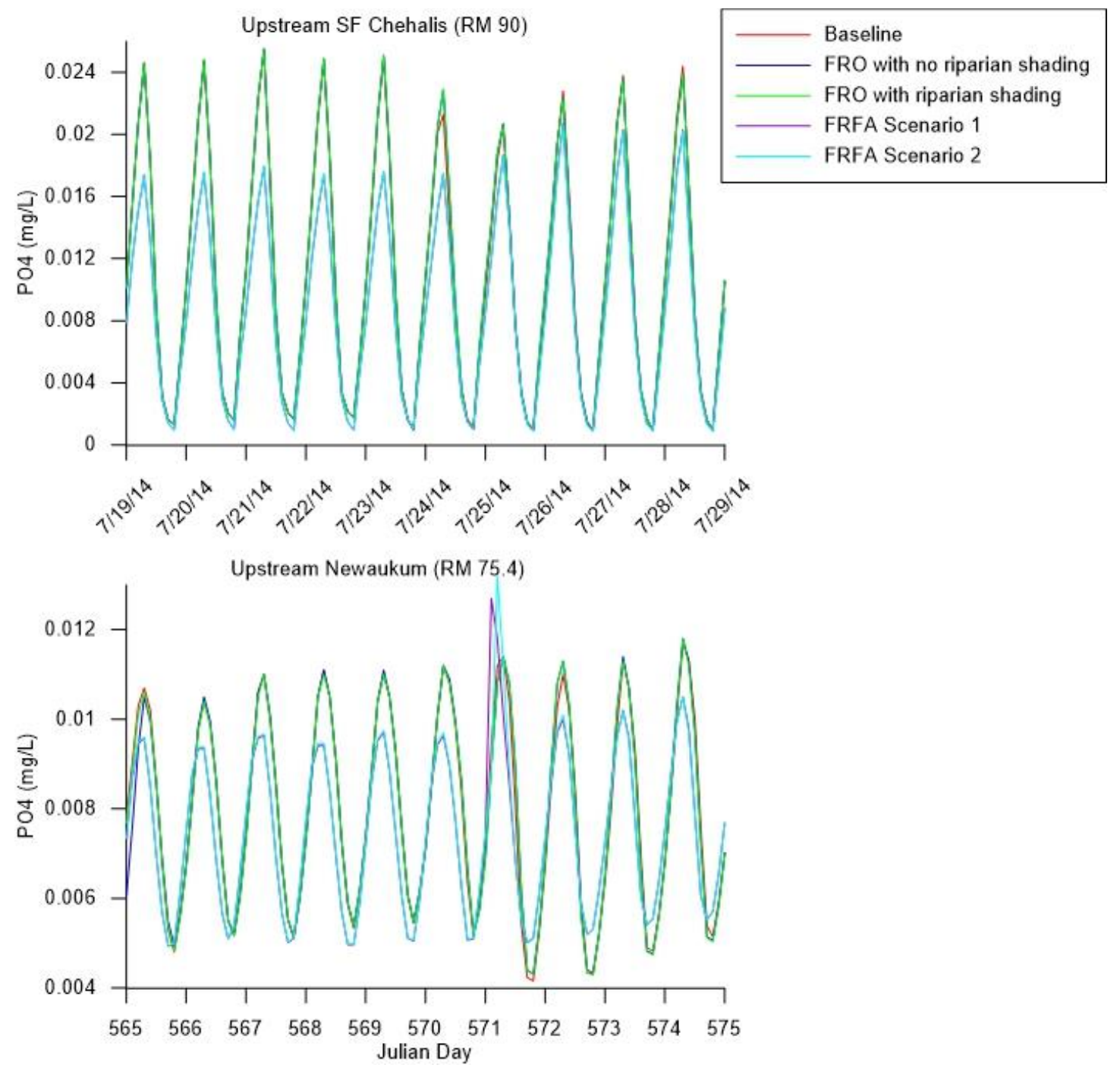

Figure 170. Model PO4 predictions for current conditions during summer 2014 at upstream of the South Fork Chehalis River and upstream of the Newaukum River for the scenarios: baseline, FRO with riparian shading, FRO with no shading, FRFA scenario 1, and FRFA scenario 2 


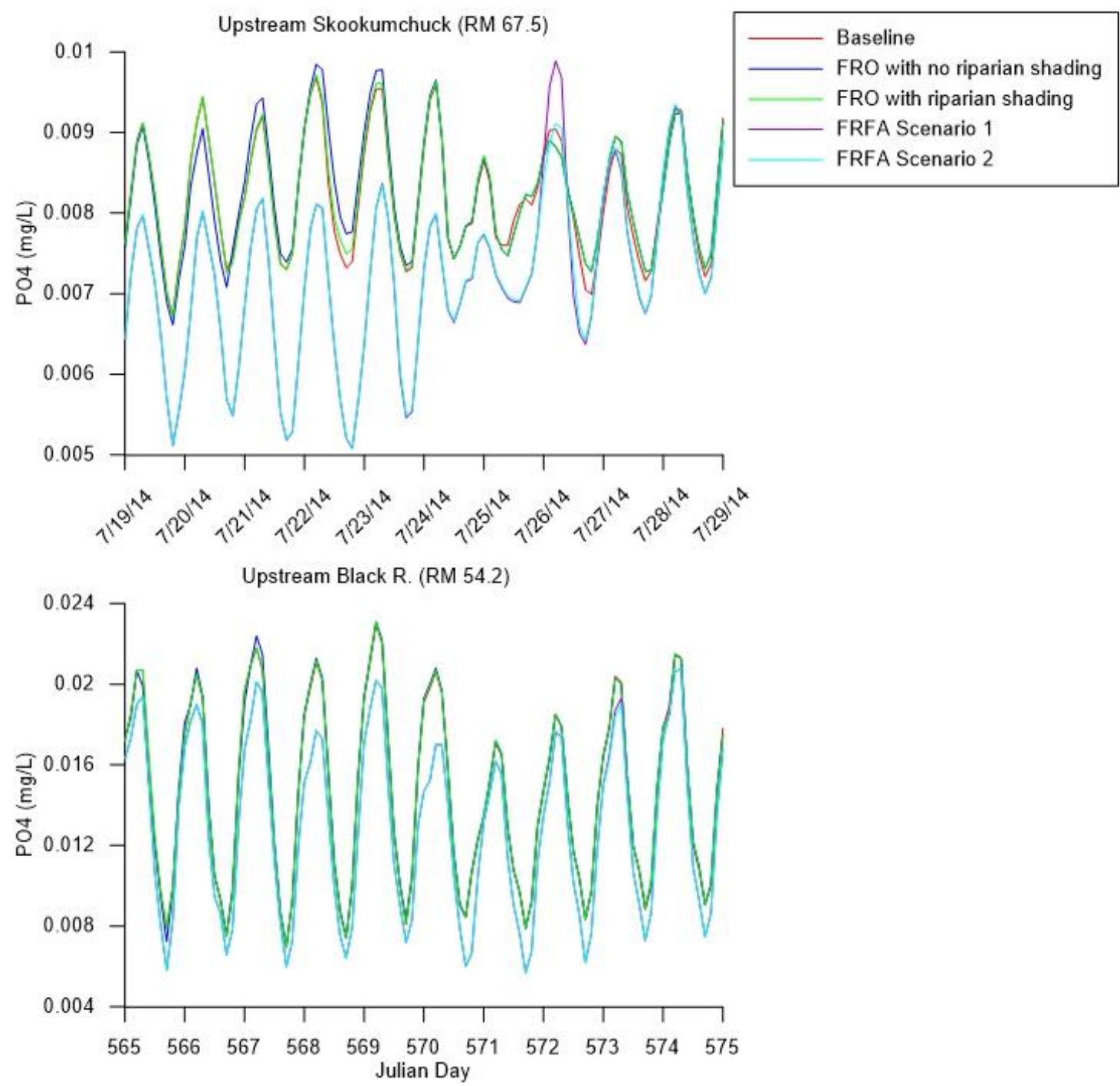

Figure 171. Model PO4 predictions for current conditions during summer 2014 at upstream of the Skookumchuck River and upstream of the Black River for the scenarios: baseline, FRO with riparian shading, FRO with no shading, FRFA scenario 1, and FRFA scenario 2 


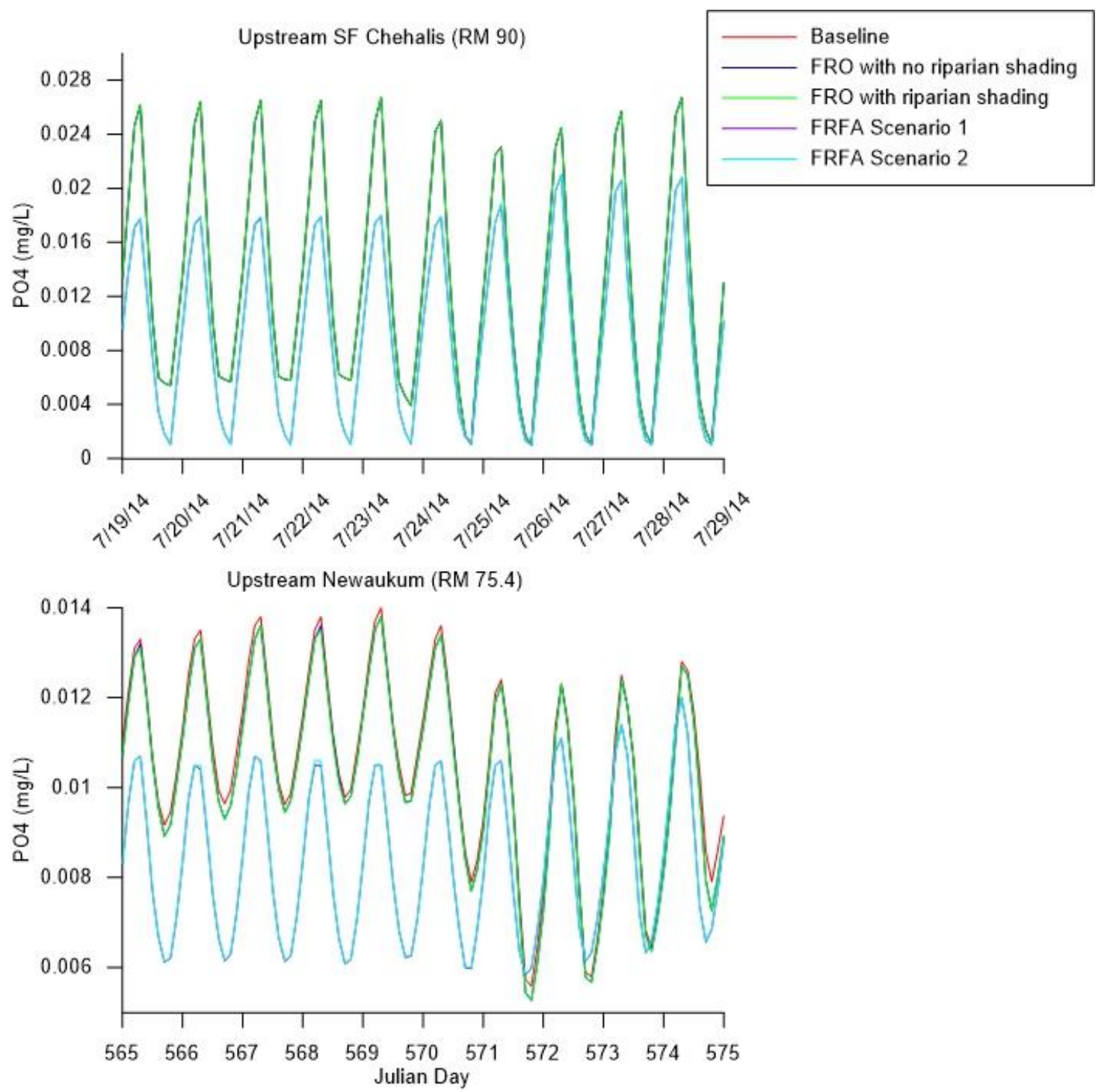

Figure 172. Model PO4 predictions for future conditions during summer 2014 at upstream of the South Fork Chehalis River and upstream of the Newaukum River for the scenarios: baseline, FRO with riparian shading, FRO with no shading, FRFA scenario 1 , and FRFA scenario 2 


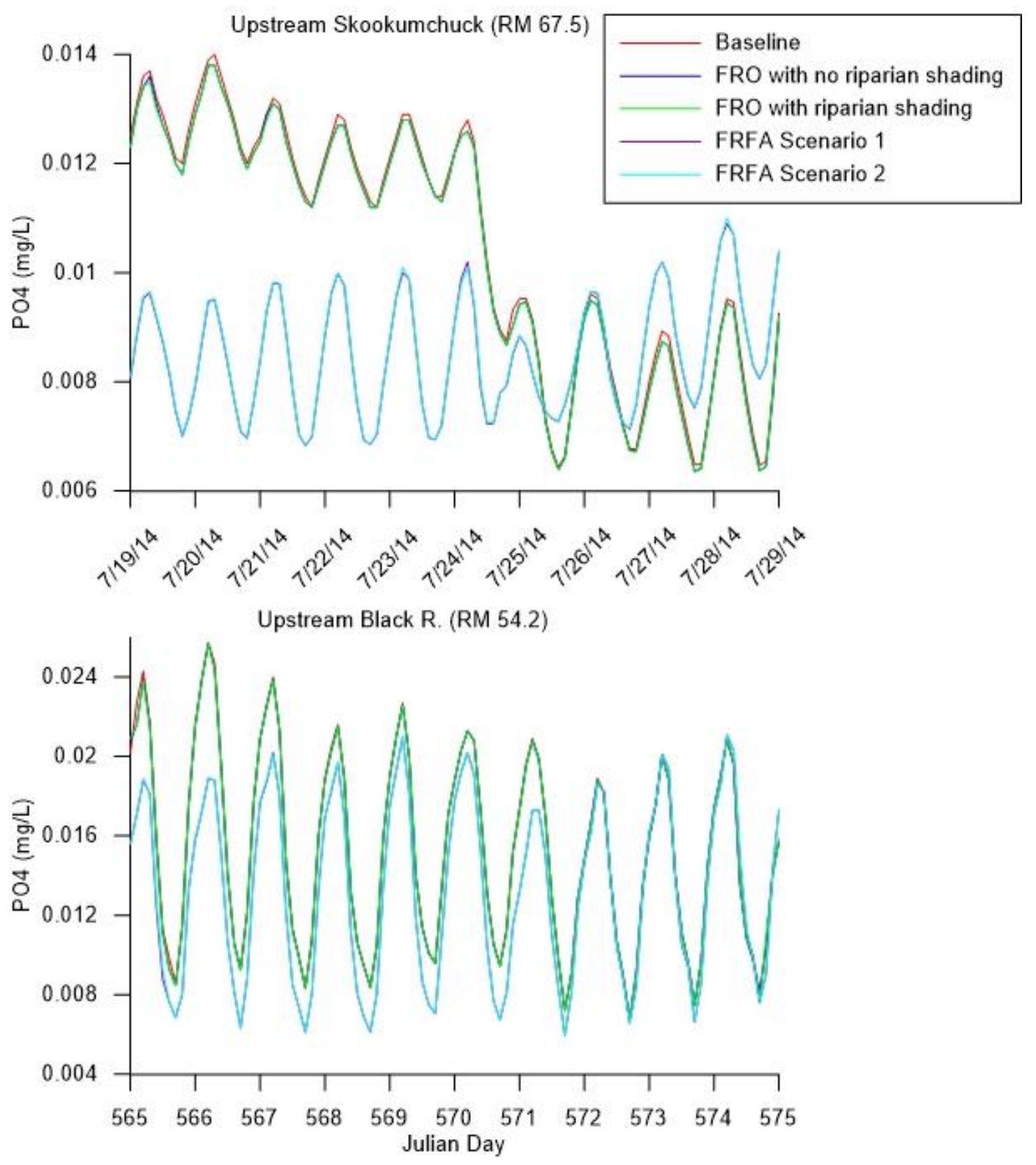

Figure 173. Model PO4 predictions for future conditions during summer 2014 at upstream of the Skookumchuck River and upstream of the Black River for the scenarios: baseline, FRO with riparian shading, FRO with no shading, FRFA scenario 1, and FRFA scenario 2 


\subsubsection{Total Phosphorus}

Similar to phosphate predictions, model predictions of TP were slightly greater for the baseline and FRO scenarios than the FRFA scenarios for baseline and future conditions.

The figures in this section contain total phosphorus model predictions for the scenarios: baseline conditions, FRFA scenario 1, FRFA scenario 2, FRO scenario with riparian shading, and FRO scenario with no riparian shading. TP predictions for the scenarios for current conditions during summer 2013 are shown in Figure 174 for upstream of the South Fork Chehalis River and upstream of the Newaukum River and Figure 175 for upstream of the Skookumchuck River and upstream of the Black River. TP predictions for the scenarios for current conditions during summer 2014 are shown in Figure 176 for upstream of the South Fork Chehalis River and upstream of the Newaukum River and Figure 177 for upstream of the Skookumchuck River and upstream of the Black River. TP predictions for the scenarios for future conditions during summer 2014 are shown in Figure 178 for upstream of the South Fork Chehalis River and upstream of the Newaukum River and Figure 179 for upstream of the Skookumchuck River and upstream of the Black River. 

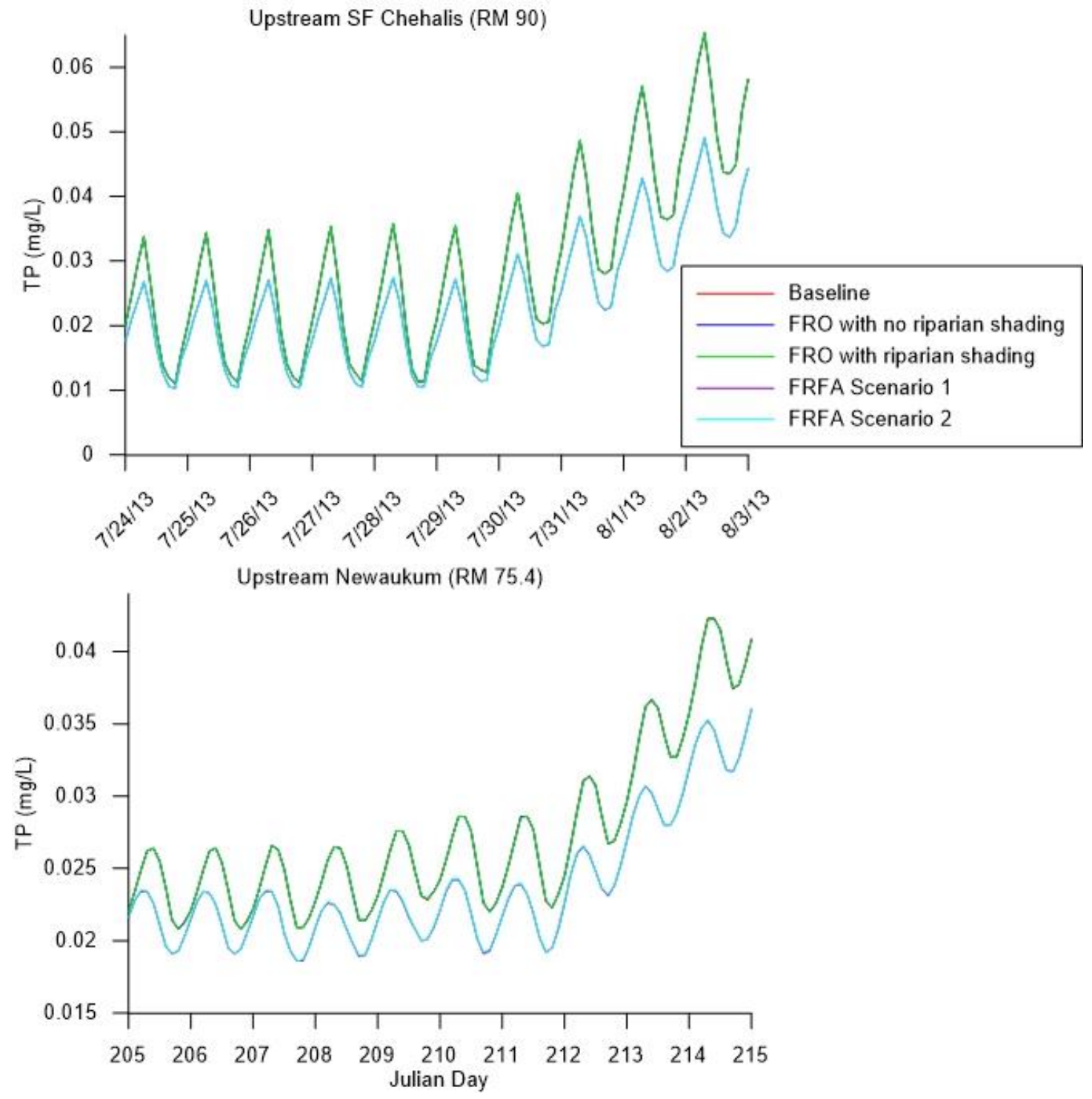

Figure 174. Model TP predictions for current conditions during summer 2013 at upstream of the South Fork Chehalis River and upstream of the Newaukum River for the scenarios: baseline, FRO with riparian shading, FRO with no shading, FRFA scenario 1, and FRFA scenario 2 

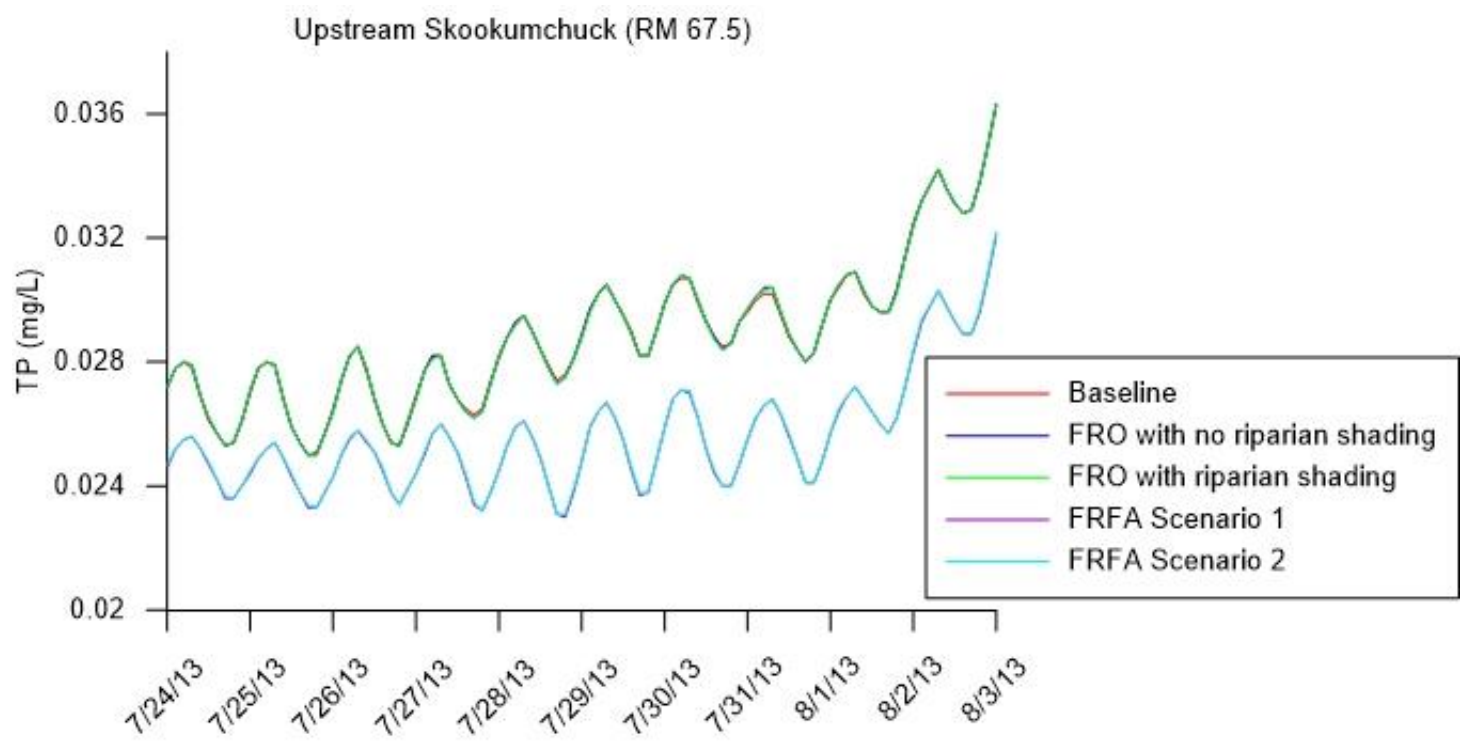

Upstream Black R. (RM 54.2)

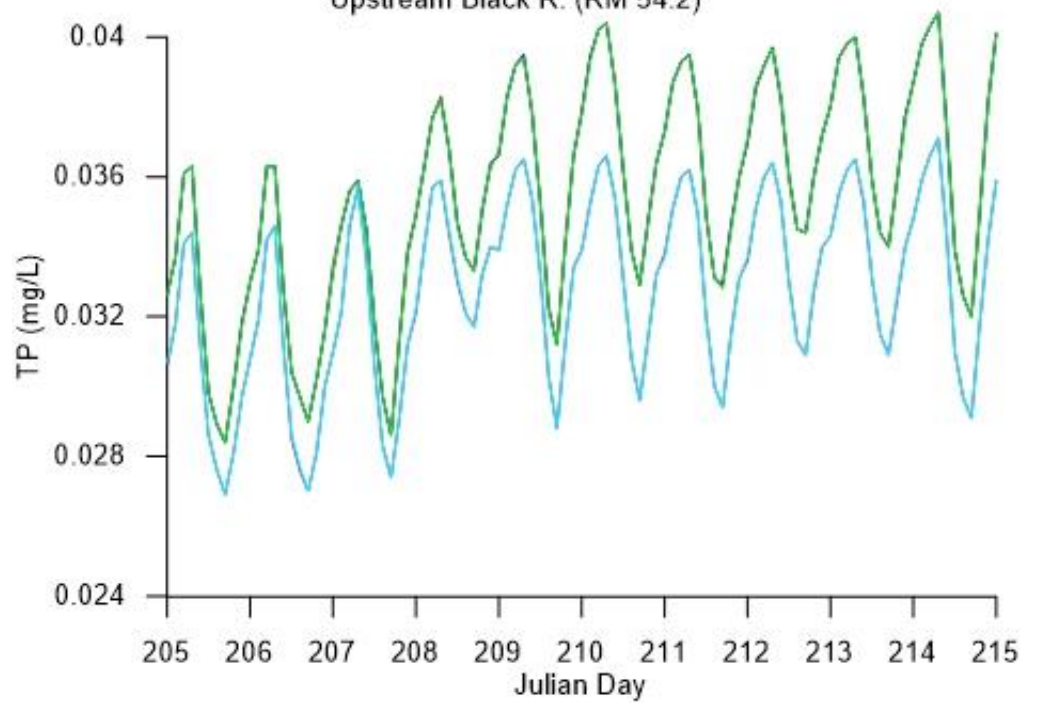

Figure 175. Model TP predictions for current conditions during summer 2013 at upstream of the Skookumchuck River and upstream of the Black River for the scenarios: baseline, FRO with riparian shading, FRO with no shading, FRFA scenario 1, and FRFA scenario 2 


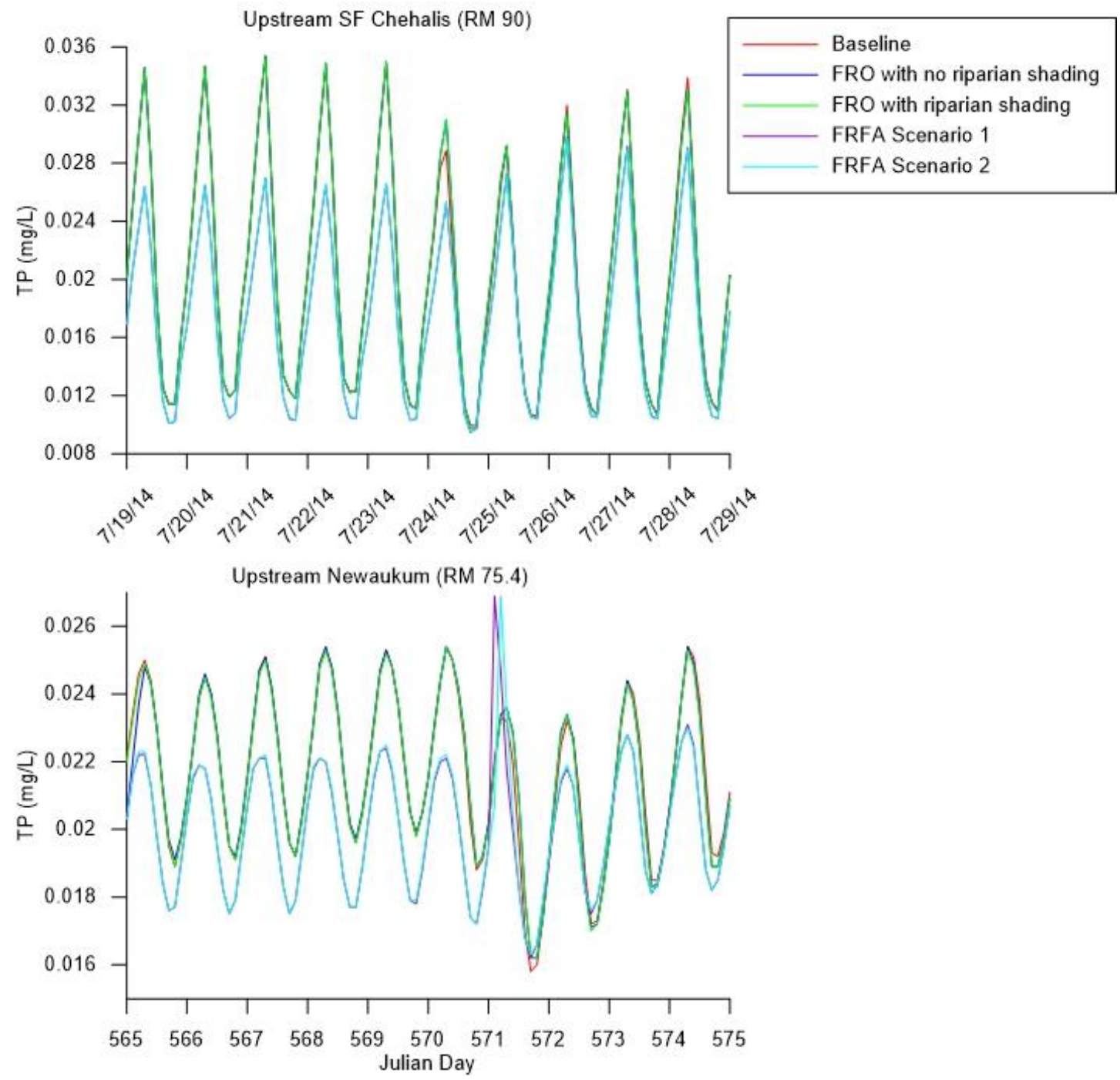

Figure 176. Model TP predictions for current conditions during summer 2014 at upstream of the South Fork Chehalis River and upstream of the Newaukum River for the scenarios: baseline, FRO with riparian shading, FRO with no shading, FRFA scenario 1, and FRFA scenario 2 

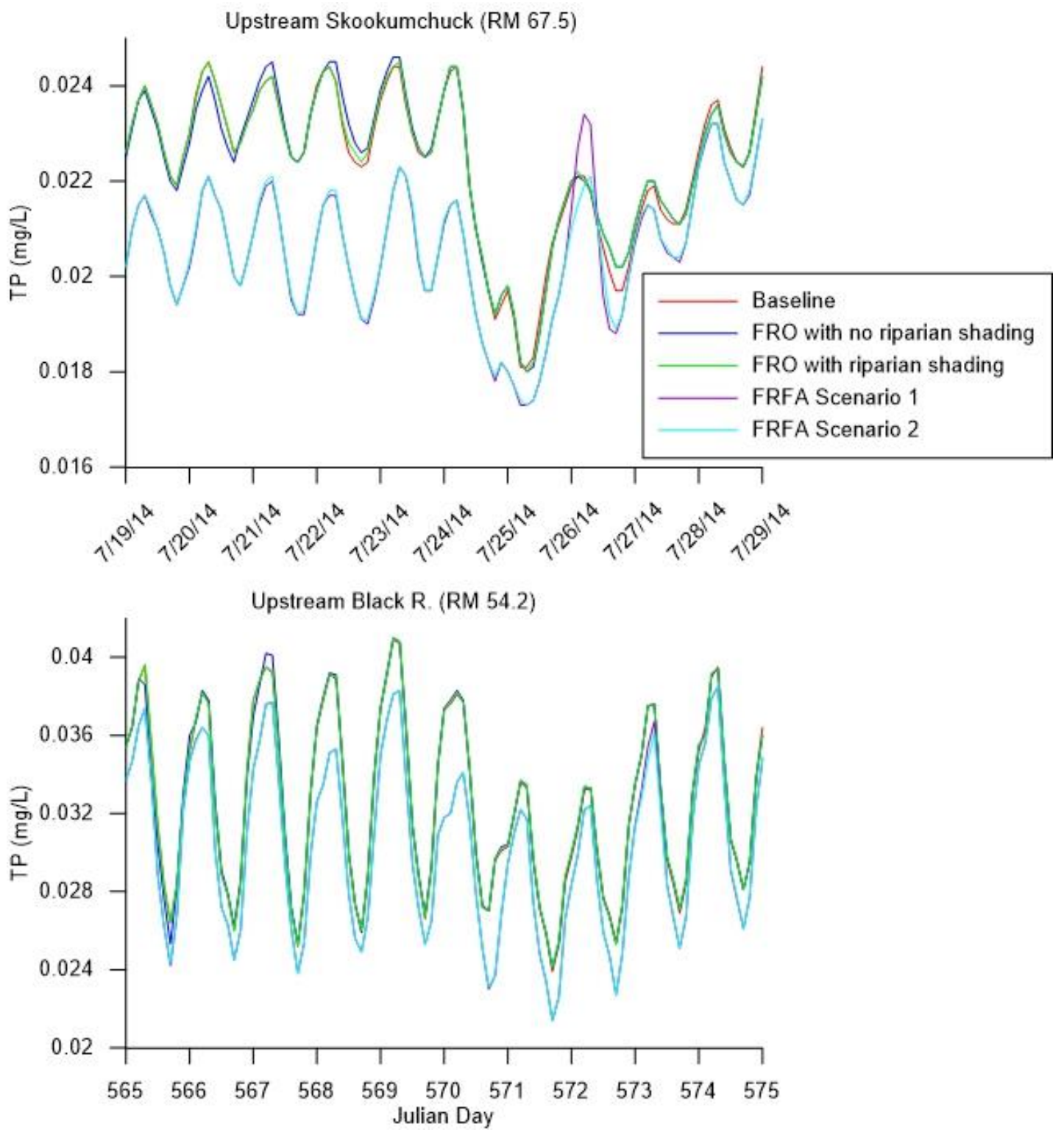

Figure 177. Model TP predictions for current conditions during summer 2014 at upstream of the Skookumchuck River and upstream of the Black River for the scenarios: baseline, FRO with riparian shading, FRO with no shading, FRFA scenario 1, and FRFA scenario 2 

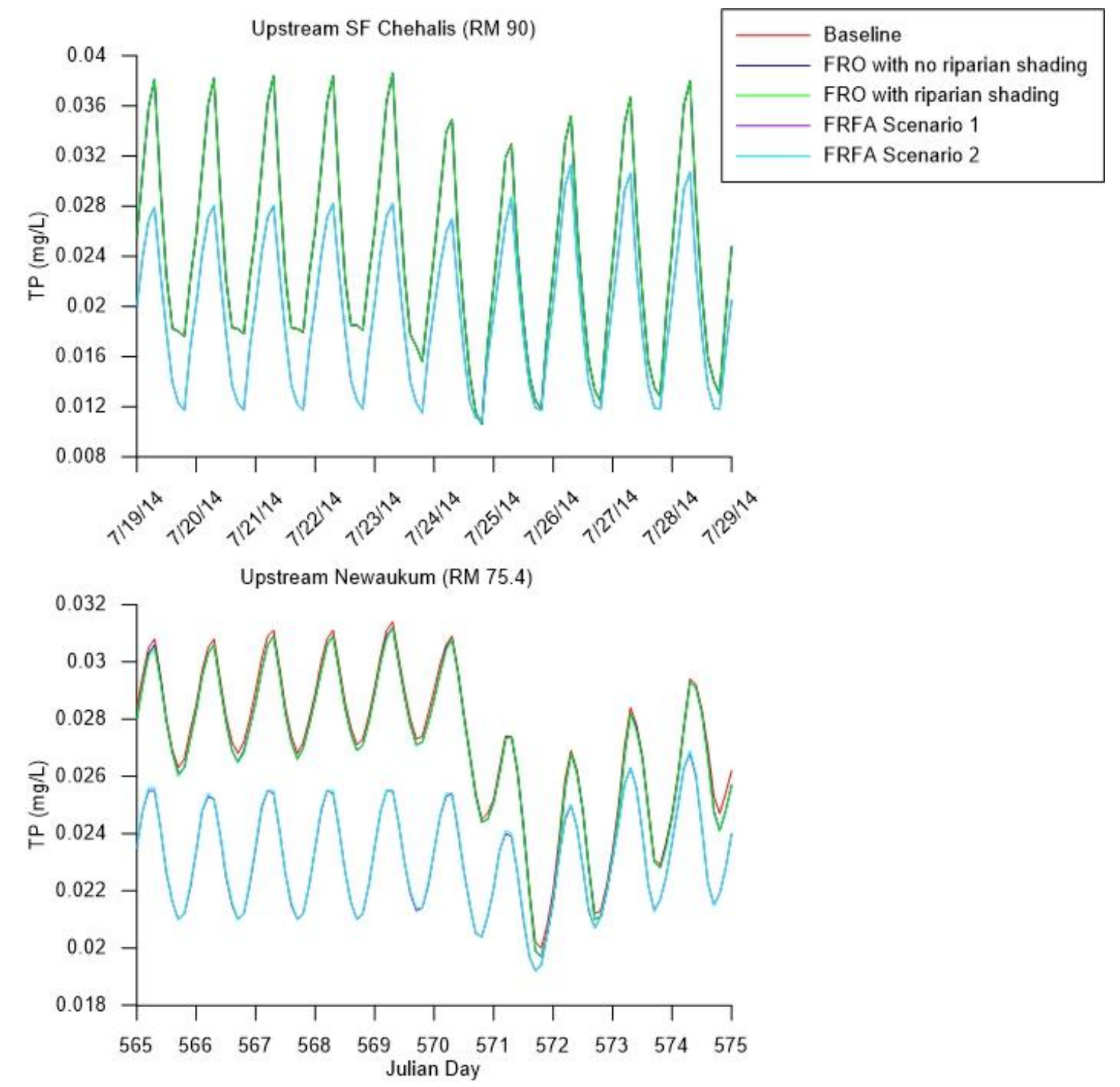

Figure 178. Model TP predictions for future conditions during summer 2014 at upstream of the South Fork Chehalis River and upstream of the Newaukum River for the scenarios: baseline, FRO with riparian shading, FRO with no shading, FRFA scenario 1 , and FRFA scenario 2 

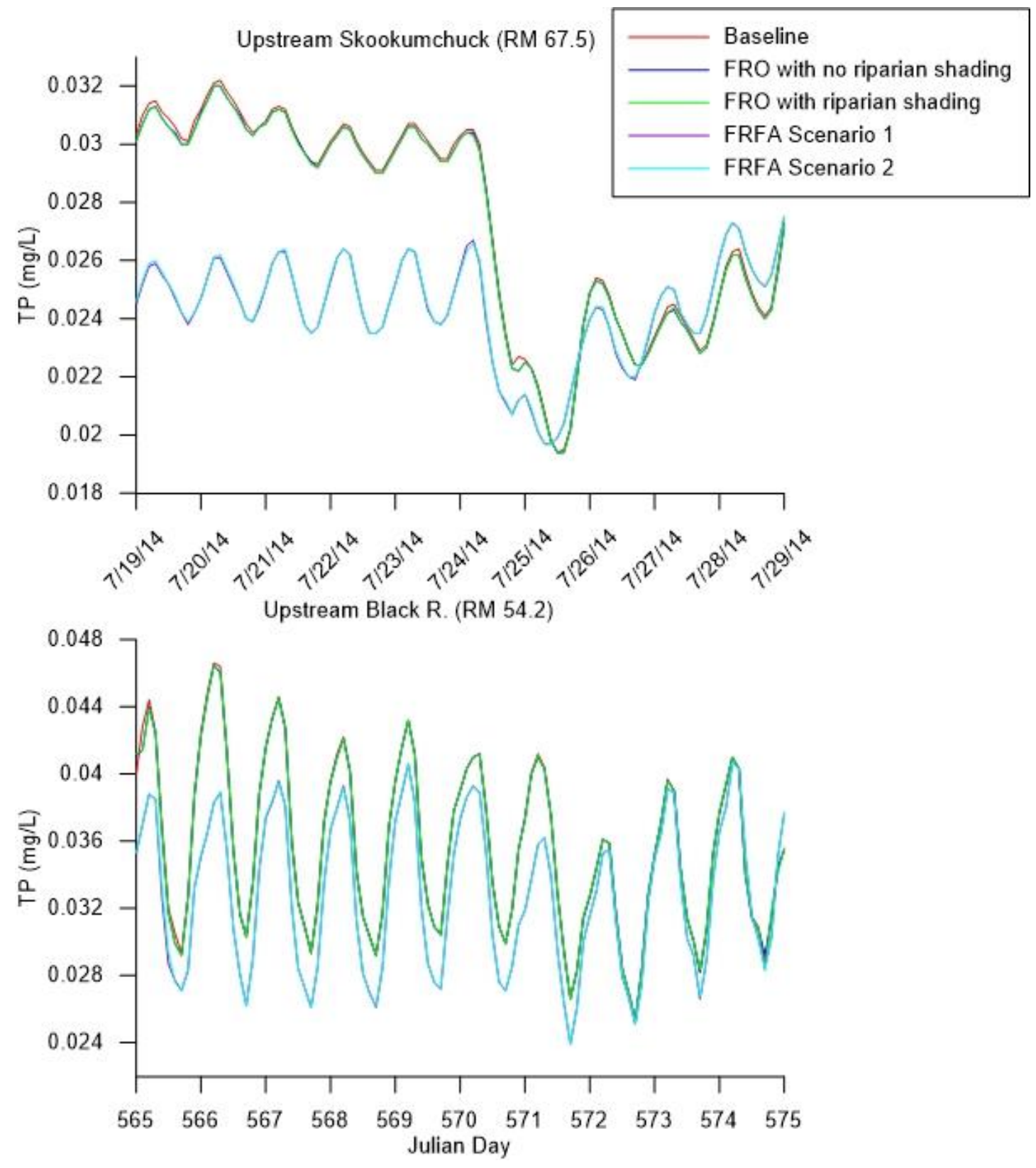

Figure 179. Model TP predictions for future conditions during summer 2014 at upstream of the Skookumchuck River and upstream of the Black River for the scenarios: baseline, FRO with riparian shading, FRO with no shading, FRFA scenario 1, and FRFA scenario 2 


\section{Model Improvements}

This section outlines methods in which the existing model can be improved.

\subsection{Flow Data}

More flow data are needed to reduce model uncertainty. Improved data regarding unmonitored withdrawals, rainfall overland flow, and groundwater interactions would increase understanding of how water is entering and leaving the system. Additional mainstem monitoring locations would allow for additional comparisons between model flow predictions and field data, allowing more certainty in model results. Additional mainstem monitoring would allow for more precise allocation of distributed flows throughout the model system. Many of the tributaries were completely unmonitored for flow. Monitoring these tributaries rather than estimating flows would be helpful for flow calibration.

\subsection{Water Surface Elevation Datums}

Datum verification for water surface elevations are necessary to improve model versus field data water level comparisons. Some of the locations with water surface elevation data had local datums that were not referenced to national standard datums, making it difficult to be sure the elevation data were referenced to the same datum as the model. 


\subsection{Temperature Data}

Even though there were an abundance of temperature data in the Chehalis mainstem for 2013-2014, additional temperature monitoring would also be beneficial. Most of the temperature data sets did not span the entire model time period for the years 2013-2014. Many of the sites only had data for certain times in the year, for example only during the summer seasons. It would give a better understanding of the temperature dynamics if the data sets were more complete. Monitoring tributaries that had no temperature data, rather than estimating these values from another tributary, would also help improve temperature calibration.

\subsection{Water Quality Data}

More continuous water quality data for constituents such a dissolved oxygen, nutrients, algae, zooplankton, organic matter, etc. would be very beneficial. Much of the available water quality data for the mainstem Chehalis River and tributaries were data collected only at a couple times during the 2013-2014 calibration period. This makes it difficult to distinguish specific seasonal and diurnal trends. Without additional data it is impossible to verify that some of these single point values were outliers. Some useful data were missing entirely. For example, periphyton/epiphyton behavior were shown to have important impacts on dissolved oxygen and nutrient results.

The WWTPs have important impacts on many water quality constituents in the river. Many estimations and assumptions were required to fill data gaps for the WWTPs. Sometimes only monthly averages were available for certain constituents. Increased 
frequency of data collection would be useful for improving model predictions since these discharges have an important impact on the river.

$\mathrm{PH}$ is a function of algae and epiphyton characteristics, temperature, total inorganic carbon, and alkalinity. Properly calibrated values of $\mathrm{pH}$ were impossible to achieve because of the lack of alkalinity data. The few mainstem river values available were not sufficient to approximate for all the tributaries entering the system.

A confirmation of quality of data for some constituents would be useful in determining how well the model is calibrated. For example, confirming the abrupt increase and fall of ammonia between the monitoring stations upstream of the Skookumchuck River and upstream of the Newaukum River.

A description of the wastewater involved in land application as an alternative to river discharges during low flow summer months would be useful for characterizing the distributed flows. Currently, the distributed flows use constituent data from a nearby tributary, though the distributed flows may have distinct water quality characteristics.

\subsection{Model Grid Confirmation}

Confirmation of the model grid location, including segments, locations of tributaries and monitoring stations' locations would be useful to model calibration. River mile values and coordinates associated with various tributaries and monitoring stations came from multiple sources. Some monitoring stations did not have any river mile value attached to them and were estimated based on maps. A cohesive set of river mile values and coordinates for the various inputs and monitoring stations would allow for more precise 
calibration, especially for water surface elevation and vertical temperature and DO profile comparisons. These are very sensitive to segment location and can give very different results even when off by only a segment or two.

\subsection{Meteorological Data}

Improved meteorological data would be very useful for temperature and water quality calibration. Large meteorological data gaps often existed, as well as some data values outside a typical range for a given constituent. For example, while it is expected that specific days will have varied solar radiation values, the overall shape and magnitude of solar radiation over an entire year should be nearly the same from year to year. This was not true for any of the meteorological data sets in comparing solar radiation data sets for 2013 and 2014. Additionally, cloud cover data were only available from the Thrash Creek site near the upstream boundary, which is located at a higher elevation than the rest of the modeled system. Since cloud cover was seen to have a large impact on temperature calibration, a more complete view of the cloud cover throughout the basin would be useful. This would improve model vertical profile temperature results, and thus DO vertical profile predictions.

\subsection{Bathymetry}

In some cases, temperature was seen to be very sensitive to the bathymetry of the system, including segment widths and water depths. A more detailed look at specific segments, including comparing the model geometry to field data could improve model 
predictions. Having as accurate a grid as possible that most represents the real river system would allow for more accurate calibration of flow and depths, temperature, and water quality constituents. 


\section{Conclusion}

The Chehalis River was modeled using CE-QUAL-W2 Version 4.0 from the proposed dam site (river mile 108) to Porter, WA (river mile 33.3). The model was implemented from January 1, 2013 to December 31, 2014 for many state variables, including flow velocities, water level, temperature, dissolved oxygen, nutrients, algae, zooplankton, organic matter, and $\mathrm{pH}$. Simulations with dam outflow scenarios and future climate conditions were conducted to aid in management strategies for the river. The river was dicretized into 9 waterbodies, 10 branches, 322 segments of $400 \mathrm{~m}$ length, and 20 vertical layers per segment, each with a height of $1 \mathrm{~m}$.

Data collected for meteorological conditions, bathymetry, shading, flow, water level, groundwater characteristics, temperature, and many water quality constituents were used for input data to the model as well as for calibration by comparing model predictions versus field data. Many agencies provided these data, including Washington State Department of Ecology, Anchor QEA, USGS, Washington Department of Fish and Wildlife, Thurston County, wastewater treatment plant operators, RAWS, CRBFA, and NOAA.

Distributed flows made it possible to take ungaged inflows and withdrawals into account. The model predicted flow agreed well with field data at the three monitoring station locations Doty, Grand Mound, and Porter, with absolute mean errors from 0.67 to $7.54 \mathrm{~m}^{3} / \mathrm{s}$. These values could improve with additional fine tuning of flow calibration.

Water surface elevations from model predictions and field data were compared at Doty, Adna, at Chehalis WWTP, Centralia, Grand Mound, Rochester, and Porter, with 
absolute mean errors from 0.29 to $3.1 \mathrm{~m}$. Resolving uncertainty with the datums of some of the field gages could improve these values.

Temperature results were compared to field data on the river at many locations ranging from near the upstream boundary to the downstream boundary. Absolute mean error values ranged between 0.25 and $1.89{ }^{\circ} \mathrm{C}$. These are expected to improve as this research continues, including as accurately estimating boundary condition temperature values as possible. Vertical profiles of temperatures predicted by the model compared to field data are also expected to improve as cloud cover and bathymetry adjustments are investigated.

Multiple water quality constituents were calibrated for through comparisons of model predictions and field data. This process was made more difficult due to a lack of water quality constituent field data for the mainstem Chehalis River, as well as the many tributaries. Hence, many estimations and approximations were made for model inputs. Due to lack of alkalinity data, $\mathrm{pH}$ could not be fully calibrated in the model. However, many constituents had good agreement between model predictions and field data, such as dissolved oxygen, nitrates, total phosphorus, and total suspended solids. Additional water quality data would allow for better model results. Improved temperature predictions would also improve water quality predictions, for example DO vertical profiles would be improved as vertical temperature profiles improve.

Multiple scenarios were applied to simulate potential dam implementation and operation strategies in order to assess their effects on water quality on the Chehalis river. 
Future climate conditions were also applied to the baseline model and dam scenarios. Future climate conditions had model predicted daily maximum water temperature values greater than current conditions. The FRFA scenarios gave lower temperature predictions than the baseline and FRO scenarios. However, differences between temperature predictions for the various scenarios decreased moving downstream. DO concentrations were generally higher for the FRFA dam scenarios than the baseline and FRO scenarios. Nutrient predictions, such as ammonia, nitrate, phosphate, and total phosphorus, also varied with the scenarios. These results have important implications for fish health and habitat, especially during critical warm summer months when the river is prone to violating water quality standards.

As this project continues, improvements to model predictions are expected. 


\section{References}

Anchor QEA, 2012. Appendix C Water Quality Evaluations, Chehalis Flood Authority Fish Study, prepared for Chehalis River Basin Flood Authority, Chehalis, WA. April, 2012.

Anchor QEA. 2014. "Water Quality Studies - Chehalis Basin Strategy: Reducing Flood Damage and Enhancing Aquatic Species". Prepared for Washington State Office of Financial Management. September, 2014.

Anchor QEA. 2016. "Draft Chehalis River Basin Strategy Technical Memorandum: Proposed Flood Retention Facility Pre-Construction Vegetation Management Plan". May 13, 2016.

Bilhimer, Dustin. 2015. "Chehalis Basin Strategy WQ Technical Tasks". Water Quality Program, Washington Department of Ecology, Olympia, WA. September 22, 2015.

Bilhimer, Dustin. 2016. Personal communication, Washington Department of Ecology, Olympia, WA.

Bowman, Clint. 2016. Personal communication, Washington Department of Ecology, Olympia, WA.

Breckner, Michelle. 2016. Personal communication, Desert Research Institude Western Regional Climate Center, Reno, NV.

Chapra, Steven C. 1997. “Appendix B." Surface Water Quality Modeling. University of Colorado, Boulder, CO.

Chehalis River Basin Flood Authority. 2016. Thrash Creek Station Data 2013-214.

Collyard, Scott and Von Prause, Markus. "Upper Chehals River Watershed MultiParameter Total Maximum Daily Load Water Quality Data Review". Environmental Assessment Program, Washington Department of Ecology, Olympia, WA. November, 2010.

Cole, T. and Wells, S. 2016. "CE-QUAL-W2: A Two-Dimensional, Laterally Averaged, Hydrodynamic and Water Quality Model, Version 4.0 User Manual", Department of Civil and Environmental Engineering, Portland State University, Portland, OR.

Darigold Wastewater Treatment Plant. 2016a. Chehalis River Upstream Darigold WWTP Station Data 2013-2014, Site ID 41. Chehalis, WA.

Darigold Wastewater Treatment Plant. 2016b. Chehalis River Downstream Darigold WWTP Station Data 2013-2014, Site ID 40. Chehalis, WA. 
Ely, D.M., Frasl, K.E., Marshall, C.A., and Reed, F. 2008. "Seepage Investigation for Selected River Reaches in the Chehalis River Basin, Washington". U.S. Geological Survey Scientific Investigation Report 2008-5180, 12 p.

Epp, V. 2016. Personal communication, Washington Department of Ecology, Olympia, WA.

Erickson, Denis. 1993. "Chehalis River TMDL, Ground Water Reconnaissance and Estimated Inflows". Washington Department of Ecology, Olympia, WA. Interdepartmental Correspondence. June 29, 1993.

Garrigues, R. S., Sinclair, K., and Tooley, J. 1998. "Chehalis River Watershed Surficial Aquifer Characterization". Environmental Assessment Program, Watershed Ecology Section, Washington Department of Ecology, Olympia, WA. December, 1998.

Gendaszek, A.S. 2011. "Hydrogeologic Framework and Groundwater/Surface-Water Interactions of the Chehalis River Basin, Southwestern Washington". U.S. Geological Survey Scientific Investigations Report 2011-5160, 42 p.

Hillock, J. 2016. Personal communication, Pe Ell, WA.

Jennings, Kahle and Pickett, Paul. 2000. "Revised Upper Chehalis River Basin Dissolved Oxygen Total Maximum Daily Load". Washington State Department of Ecology. Publication number 00-10-018. March, 2000.

Merrill, A., Stillwater Sciences. 2014. "Riparian Shade along Lower Chehalis River", prepared for Anchor QEA.

Montgomery, Bob. 2016. "Chehalis Basin Strategy Operations Plan”. Water Retention Technical Committee, Anchor QEA. May 13, 2016.

National Oceanic and Atmospheric Administration (NOAA). 2015. Chehalis-Centralia Airport Station, Site ID KCLS. Website: https://www.ncdc.noaa.gov/data-access/quicklinks\#dsi-3505

National Pollutant Discharge Elimination System (NPDES). 2011. "Fact Sheet for NPDES Permit WA0020982 City of Centralia". Environmental Protection Agency.

National Pollutant Discharge Elimination System (NPDES). 2012. "Fact Sheet for NPDES Permit WA0021105 City of Chehalis Water Reclamation Facility". Environmental Protection Agency.

National Pollutant Discharge Elimination System (NPDES). 2010. “Fact Sheet for NPDES Permit WA0037478 Facility Name Darigold, Inc. Chehalis Plant". Environmental Protection Agency. 
National Pollutant Discharge Elimination System (NPDES). 2003a. "Fact Sheet for NPDES Permit WA0042099 Grand Mound Wastewater Treatment Plant". Environmental Protection Agency.

National Pollutant Discharge Elimination System (NPDES). 2003b. "Fact Sheet for NPDES Permit WA0020192 Town of Pe Ell". Environmental Protection Agency.

Patching, K. 2016. Personal communication, Thurston County Public Works, Olympia, WA.

Phelps, J. 2016. Personal communication, Pe Ell, WA.

Pickett, Paul, J. 2015. "Chehalis River Basin Flood Damage Reduction Project - A Historical Summary". Environmental Assessment Program, Washington Department of Ecology, Olympia, WA. January 30, 2015.

Pickett, Paul, J. 1994. "Upper Chehalis River Total Maximum Daily Load Study". Washington State Department of Ecology, Olympia, WA. Publication number 94-126. July, 1994.

Pitz, C.F., Sinclair, K.A., and Oestreich, A.J. 2005. "Hydrology and Quality of Groundwater in the Centralia-Chehalis Area Surficial Aquifer". Groundwater Assessment Program, Washington Department of Ecology, Olympia, WA. December, 2005.

Remote Automated Weather Station (RAWS). 2014. Chehalis Washington Station Data 2013-2014, Site ID CLSW1; Huckleberry Ridge Station Data 2013-2014, Site ID HKFW1; and Minot Peak Station Data 2013-2014, Site ID MIPW1.

Schlenger, Paul and Montgomery, Bob. 2012. "Presentation of the Findings of the Chehalis River Fish Population Impact Study". Anchor QEA. April 19, 2012.

Stumm, W. and Morgan, J. 1981. Aquatic Chemistry, Wiley-Interscience, New York.

Thurston County, Streamflow Monitoring Data. 2014. Scatter Creek Station Data 20132014, Site ID 55a. Website: http://www.co.thurston.wa.us/monitoring/flow/flowscatter.html

U.S. Geological Survey. 2016a. Chehalis River near Adna, WA Station Data 2013-2014, Site ID 12021800. Website: http://waterdata.usgs.gov/wa/nwis/uv?site_no=12021800

U.S. Geological Survey. 2016b. Chehalis River near Doty, WA Station Data 2013-2014, Site ID 12020000. Website: http://waterdata.usgs.gov/nwis/uv?12020000 
U.S. Geological Survey. 2016c. Chehalis River at Chehalis WWTP, WA Station Data 20132014, Site ID 12025100. Website:

http://waterdata.usgs.gov/wa/nwis/uv?site_no=12025100

U.S. Geological Survey. 2016d. Chehalis River at Centralia, WA Station Data 2013-2014, Site ID 12025500. Website: http://waterdata.usgs.gov/wa/nwis/uv?site_no=12025500

U.S. Geological Survey. 2016e. Chehalis River near Grand Mound, WA Station Data 20132014, Site ID 12027500. Website:

http://waterdata.usgs.gov/nwis/uv?site_no=12027500

U.S. Geological Survey. 2016f. Chehalis River above Mahaffey Creek Station Data 20132014, Site ID 12019310. Website:

http://waterdata.usgs.gov/nwis/uv?site_no=12019310

U.S. Geological Survey. 2016g. Chehalis River at Porter, WA Station Data 2013-2014, Site ID 12031000. Website: http://waterdata.usgs.gov/nwis/uv?site_no=12031000

U.S. Geological Survey. 2016h. Chehalis River at Porter, WA Station Data 2013-2014, Site ID 12031000. Website: http://waterdata.usgs.gov/nwis/uv?site_no=12031000

U.S. Geological Survey. 2016i. Chehalis River near Rochester, WA Station Data 20132014, Site ID 12028060. Website:

http://waterdata.usgs.gov/wa/nwis/uv?site_no=12028060

U.S. Geological Survey. 2016j. Newaukum River near Chehalis, WA Station Data 20132014, Site ID 12025000. Website:

http://waterdata.usgs.gov/nwis/uv/?site_no=12025000\&agency_cd=USGS

U.S. Geological Survey. 2016k. Skookumchuck River near Bucoda, WA Station Data 20132014, Site ID 12026400. Website:

http://waterdata.usgs.gov/wa/nwis/uv/?site_no $=12026400 \& P A R A m e t e r \_c d=00060,000$ 65

U.S. Geological Survey. 2016I. South Fork Chehalis River near Wildwood, WA Station Data 2013-2014, Site ID 12020800. Website:

http://waterdata.usgs.gov/wa/nwis/uv/?site_no $=12020800 \& P A R A m e t e r \_c d=00060,000$ 65

U.S. Geological Survey. 2016m. "StreamStats Version 3.0: WA". Website:

http://streamstatsags.cr.usgs.gov/v3_beta/viewer.htm?stabbr=WA

U.S. Geological Survey. 2013. “Chehalis River Basin”. USGS Washington Water Science Center. June 18, 2013. Website: http://wa.water.usgs.gov/projects/chehalis/ 
Van Glubt, Sarah, Berger, Chris, and Wells, Scott. 2016. "Technical Memorandum Chehalis Water Quality and Hydrodynamic Modeling: Model Setup and Preliminary Calibration and Scenario Development". Water Quality Research Group, Department of Civil and Environmental Engineering, Portland State University. Prepared for Washington Department of Ecology. September, 2016.

Washington Department of Ecology (WADOE). 2016a. Centralia STP Data 2013-2014, NPDES Permit No. WA0020982. Water Quality Permitting and Reporting Information System (PARIS).

Washington Department of Ecology (WADOE). 2016b. Chehalis STP Data 2013-2014, NPDES Permit No. WA0021105. Water Quality Permitting and Reporting Information System (PARIS).

Washington Department of Ecology (WADOE). 2016c. Darigold, Inc. STP Data 2013-2014, NPDES Permit No. WA0037478. Water Quality Permitting and Reporting Information System (PARIS).

Washington Department of Ecology (WADOE). 2016d. Pe Ell STP Data 2013-2014, NPDES Permit No. WA0020192. Water Quality Permitting and Reporting Information System (PARIS).

Washington Department of Ecology (WADOE). 2016e. Grand Mound STP Data 20132014, NPDES Permit No. WA0042099. Water Quality Permitting and Reporting Information System (PARIS).

Washington Department of Ecology (WADOE), River and Stream Water Quality Monitoring. 2016f. Black River at Hwy 12 Station Data 2013-2014, Site ID 23E060. Website: https://fortress.wa.gov/ecy/eap/riverwq/station.asp?sta=23E060 Washington Department of Ecology (WADOE), River and Stream Water Quality Monitoring. 2016g. Chehalis River at Dryad Station Data 2013-2014, Site ID 23A160. Website: https://fortress.wa.gov/ecy/eap/riverwq/station.asp?sta=23A160 Washington Department of Ecology (WADOE), River and Stream Water Quality Monitoring. 2016h. Chehalis River at Porter Station Data 2013-2014, Site ID 23A070. Website:

https://fortress.wa.gov/ecy/eap/riverwq/station.asp?tab=continuous_oxy\&sta=23A070 Washington Department of Ecology (WADOE), River and Stream Water Quality Monitoring. 2016i. Salzer Creek at Airport Road Station Data 2013-2014, Site ID 23H060. Website: https://fortress.wa.gov/ecy/eap/flows/station.asp?sta=23H060 
Washington Department of Ecology (WADOE). 2001. “Upper Chehalis River Basin Temperature Total Maximum Daily Load". Publication number 99-52.

Washington Department of Ecology (WADOE). 2016j. “Water Quality Improvement Projects, Chehalis River Area: Multi-parameter".

Washington Department of Fish and Wildlife (WDFW). 2014. Chehalis Mainstem Station Data 2013-2014. Site IDs 3-UCH, 4-UCH, 11-UCH, 13-CH, 15-CH, 16-CH, 17-CH, 18-CH, 19- $\mathrm{CH}, 21-\mathrm{CH}, 22-\mathrm{CH}, 23-\mathrm{CH}, \mathrm{NEW}-1$.

WEST Consultants, Inc. 2011. “Chehalis Basin Ecosystem Restoration General Investigation Study Baseline Hydrology and Hydraulics Modeling". Prepared for the U.S. Army Corps of Engineers, Seattle, WA. November 30, 2011.

Zentner, G. 2016. Personal communication, Washington Department of Ecology, Olympia, WA. 


\section{Appendix-Model Control File}

PSU W2 Model Version 4.0

\begin{tabular}{|c|c|c|c|c|c|c|c|c|c|}
\hline \multirow[t]{2}{*}{ GRID } & NWB & NBR & IMX & KMX & NPROC & CLOSEC & & & \\
\hline & 9 & 10 & 322 & 22 & 1 & $\mathrm{OFF}$ & & & \\
\hline \multirow[t]{2}{*}{ IN/OUTFL } & NTR & NST & NIW & NWD & NGT & NSP & NPI & NPU & \\
\hline & 299 & 0 & 0 & 0 & 0 & 3 & 0 & 0 & \\
\hline \multirow[t]{2}{*}{ CONSTITU } & NGC & NSS & NAL & $\mathrm{NEP}$ & $\mathrm{NBOD}$ & NMC & NZP & & \\
\hline & 11 & 2 & 2 & 1 & 10 & 0 & 1 & & \\
\hline \multirow[t]{2}{*}{ MISCELL } & NDAY & SELECTC & HABTATC & ENVIRPC & AERATEC & INITUWL & & & \\
\hline & 100 & $\mathrm{OFF}$ & OFF & $\mathrm{OFF}$ & $\mathrm{OFF}$ & $\mathrm{OFF}$ & & & \\
\hline \multirow[t]{2}{*}{ TIME CON } & TMSTRT & TMEND & YEAR & & & & & & \\
\hline & 1.00000 & 730.000 & 2013 & & & & & & \\
\hline \multirow[t]{2}{*}{ DLT CON } & $\mathrm{NDT}$ & DLTMIN & DLTINTR & & & & & & \\
\hline & 18 & 0.001 & $\mathrm{ON}$ & & & & & & \\
\hline \multirow[t]{3}{*}{ DLT DATE } & DLTD & DLTD & DLTD & DLTD & DLTD & DLTD & DLTD & DLTD & DLTD \\
\hline & 1.00000 & 6.0 & 45.0 & 150.0 & 165.0 & 245.0 & 265.0 & 315.0 & 320.0 \\
\hline & 410.0 & 425.0 & 445.0 & 510.0 & 550.0 & 605.0 & 630.0 & 645.0 & 655.0 \\
\hline \multirow[t]{3}{*}{ DLT MAX } & DLTMAX & DLTMAX & DLTMAX & DLTMAX & DLTMAX & DLTMAX & DLTMAX & DLTMAX & DLTMAX \\
\hline & 5.0000 & 19.0 & 20.0 & 14.0 & 11.0 & 9.0 & 5.0 & 13.0 & 11.0 \\
\hline & 3.0 & 7.0 & 2.0 & 9.0 & 9.0 & 5.0 & 3.0 & 4.0 & 9.0 \\
\hline \multirow[t]{3}{*}{ DLT FRN } & DLTF & DLTF & DLTF & DLTF & DLTF & DLTF & DLTF & DLTF & DLTE \\
\hline & 0.40000 & 0.6 & 0.6 & 0.6 & 0.6 & 0.6 & 0.6 & 0.6 & 0.6 \\
\hline & 0.6 & 0.6 & 0.6 & 0.6 & 0.6 & 0.6 & 0.6 & 0.6 & 0.6 \\
\hline
\end{tabular}

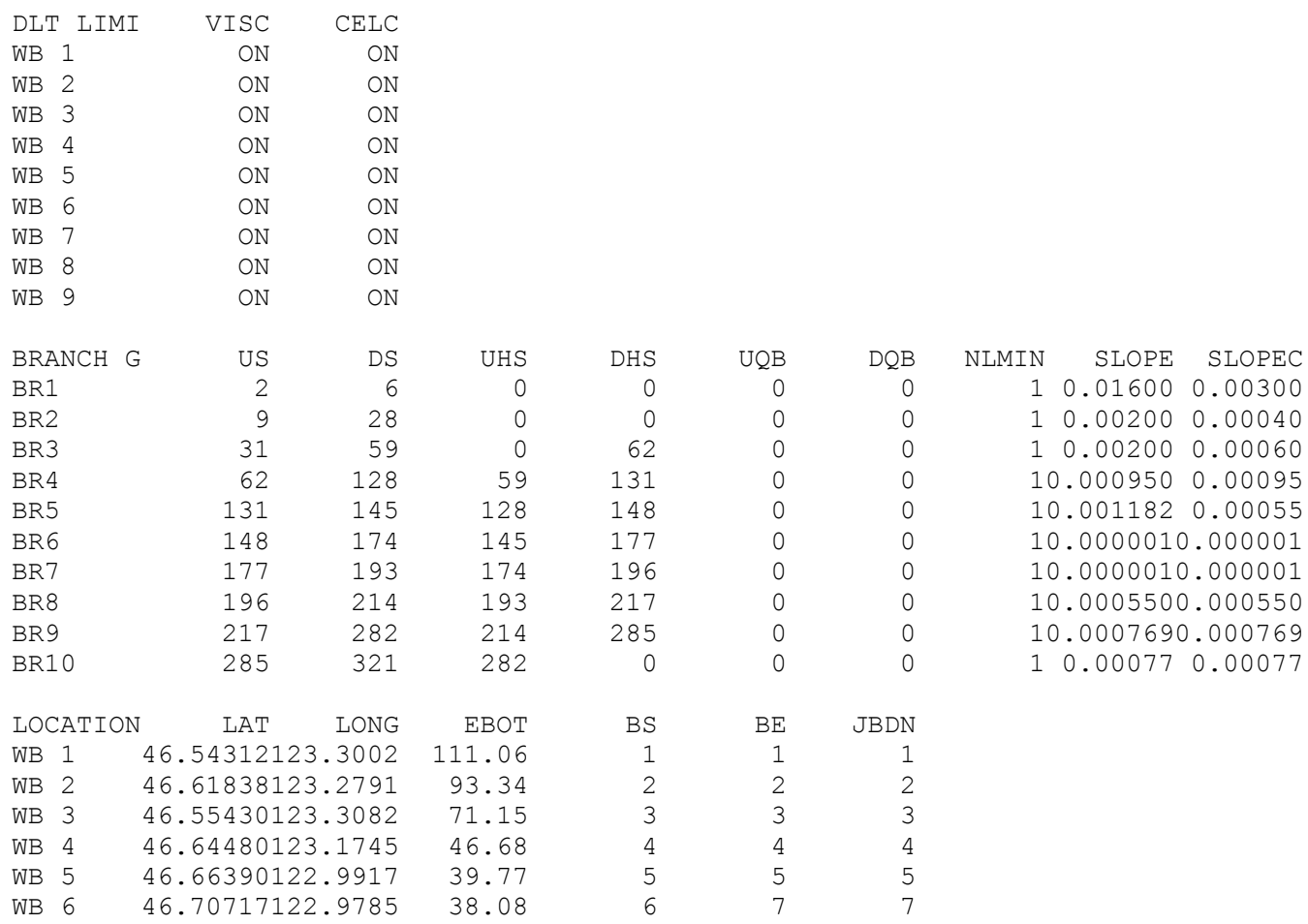




\begin{tabular}{|c|c|c|c|c|c|c|c|c|c|c|}
\hline WB & \multicolumn{3}{|c|}{46.80509123 .1198} & 35.32 & 8 & 8 & 8 & & & \\
\hline WB & \multicolumn{3}{|c|}{$46.8145 \quad 123.243$} & 14.96 & 9 & 9 & 9 & & & \\
\hline WB & \multicolumn{3}{|c|}{46.94020123 .3146} & 3.280 & 10 & 10 & 10 & & & \\
\hline INIT & CND & $\mathrm{T} 2 \mathrm{I}$ & ICEI & WTYPEC & GRIDC & & & & & \\
\hline WB & 1 & 5.00000 & 0.00000 & FRESH & RECT & & & & & \\
\hline WB & 2 & 5.00000 & 0.00000 & FRESH & RECT & & & & & \\
\hline WB & 3 & 5.00000 & 0.00000 & FRESH & RECT & & & & & \\
\hline WB & 4 & 5.00000 & 0.00000 & FRESH & RECT & & & & & \\
\hline WB & 5 & 5.00000 & 0.00000 & FRESH & $\mathrm{RECT}$ & & & & & \\
\hline WB & 6 & 5.00000 & 0.00000 & FRESH & $\mathrm{RECT}$ & & & & & \\
\hline WB & 7 & 5.00000 & 0.00000 & FRESH & $\mathrm{RECT}$ & & & & & \\
\hline WB & 8 & 5.00000 & 0.00000 & FRESH & $\mathrm{RECT}$ & & & & & \\
\hline WB & 9 & 5.00000 & 0.00000 & FRESH & $\mathrm{RECT}$ & & & & & \\
\hline CAL & CULAT & $\mathrm{VBC}$ & $\mathrm{EBC}$ & $\mathrm{MBC}$ & $\mathrm{PQC}$ & EVC & PRC & & & \\
\hline WB & 1 & $\mathrm{ON}$ & ON & $\mathrm{ON}$ & OFF & $\mathrm{ON}$ & OFF & & & \\
\hline WB & 2 & ON & $\mathrm{ON}$ & ON & OFF & $\mathrm{ON}$ & $\mathrm{OFF}$ & & & \\
\hline WB & 3 & ON & $\mathrm{ON}$ & ON & OFF & ON & OFF & & & \\
\hline WB & 4 & ON & $\mathrm{ON}$ & ON & OFF & ON & $\mathrm{OFF}$ & & & \\
\hline WB & 5 & ON & $\mathrm{ON}$ & ON & OFF & ON & OFF & & & \\
\hline WB & 6 & $\mathrm{ON}$ & $\mathrm{ON}$ & ON & OFF & ON & $\mathrm{OFF}$ & & & \\
\hline WB & 7 & ON & $\mathrm{ON}$ & $\mathrm{ON}$ & OFF & ON & $\mathrm{OFF}$ & & & \\
\hline & 8 & ON & $\mathrm{ON}$ & ON & OFF & ON & $\mathrm{OFF}$ & & & \\
\hline WB & 9 & $\mathrm{ON}$ & $\mathrm{ON}$ & ON & OFF & ON & $\mathrm{OFF}$ & & & \\
\hline DEA & D SEA & WINDC & QINC & QOUTC & HEATC & & & & & \\
\hline WB & 1 & $\mathrm{ON}$ & $\mathrm{ON}$ & $\mathrm{ON}$ & $\mathrm{ON}$ & & & & & \\
\hline WB & 2 & $\mathrm{ON}$ & $\mathrm{ON}$ & ON & $\mathrm{ON}$ & & & & & \\
\hline WB & 3 & ON & $\mathrm{ON}$ & ON & $\mathrm{ON}$ & & & & & \\
\hline WB & 4 & ON & $\mathrm{ON}$ & ON & $\mathrm{ON}$ & & & & & \\
\hline WB & 5 & $\mathrm{ON}$ & $\mathrm{ON}$ & ON & $\mathrm{ON}$ & & & & & \\
\hline WB & 6 & ON & $\mathrm{ON}$ & $\mathrm{ON}$ & $\mathrm{ON}$ & & & & & \\
\hline WB & 7 & ON & ON & ON & $\mathrm{ON}$ & & & & & \\
\hline WB & 8 & ON & ON & ON & ON & & & & & \\
\hline WB & 9 & $\mathrm{ON}$ & $\mathrm{ON}$ & ON & $\mathrm{ON}$ & & & & & \\
\hline INT & ERPOL & QINIC & DTRIC & HDIC & & & & & & \\
\hline BR1 & & $\mathrm{ON}$ & ON & ON & & & & & & \\
\hline BR2 & & ON & ON & ON & & & & & & \\
\hline BR3 & & ON & ON & ON & & & & & & \\
\hline BR 4 & & $\mathrm{ON}$ & ON & ON & & & & & & \\
\hline BR5 & & $\mathrm{ON}$ & $\mathrm{ON}$ & ON & & & & & & \\
\hline BR6 & & ON & ON & ON & & & & & & \\
\hline BR7 & & ON & ON & ON & & & & & & \\
\hline BR8 & & ON & ON & ON & & & & & & \\
\hline BR9 & & ON & ON & ON & & & & & & \\
\hline BR1 & & $\mathrm{ON}$ & ON & ON & & & & & & \\
\hline HEA & $\mathrm{T} \mathrm{EXCH}$ & SLHTC & $\mathrm{SROC}$ & RHEVAP & METIC & FETCHC & $\mathrm{AFW}$ & $\mathrm{BFW}$ & $\mathrm{CFW}$ & WINDH \\
\hline & 1 & TERM & OFF & OFF & $\mathrm{ON}$ & $\mathrm{OFF}$ & 4.50000 & 0.46000 & 2.00000 & 3.53600 \\
\hline & 2 & TERM & $\mathrm{OFF}$ & $\mathrm{OFF}$ & $\mathrm{ON}$ & $\mathrm{OFF}$ & 4.50000 & 0.46000 & 2.00000 & 3.53600 \\
\hline & 3 & TERM & OFF & $\mathrm{OFF}$ & ON & OFF & 4.50000 & 0.46000 & 2.00000 & 3.53600 \\
\hline WB & 4 & TERM & OFF & $\mathrm{OFF}$ & $\mathrm{ON}$ & OFF & 4.50000 & 0.46000 & 2.00000 & 6.09600 \\
\hline WB & 5 & TERM & OFF & $\mathrm{OFF}$ & ON & OFF & 4.50000 & 0.46000 & 2.00000 & 6.09600 \\
\hline WB & 6 & TERM & OFF & OFF & $\mathrm{ON}$ & OFF & 4.50000 & 0.46000 & 2.00000 & 6.09600 \\
\hline WB & 7 & TERM & OFF & OFF & $\mathrm{ON}$ & OFF & 4.50000 & 0.46000 & 2.00000 & 6.09600 \\
\hline WB & 8 & TERM & OFF & OFF & $\mathrm{ON}$ & OFF & 4.50000 & 0.46000 & 2.00000 & 6.09600 \\
\hline WB & 9 & TERM & $\mathrm{OFF}$ & $\mathrm{OFF}$ & $\mathrm{ON}$ & $\mathrm{OFF}$ & 4.50000 & 0.46000 & 2.00000 & 6.09600 \\
\hline ICE & COVE & ICEC & SLICEC & ALBEDO & HWICE & BICE & GICE & ICEMIN & ICET2 & \\
\hline WB & 1 & $\mathrm{OFF}$ & DETAIL & 0.25000 & 10.0000 & 0.60000 & 0.07000 & 0.05000 & 3.00000 & \\
\hline WB & 2 & OFF & DETAIL & 0.25000 & 10.0000 & 0.60000 & 0.07000 & 0.05000 & 3.00000 & \\
\hline WB & 3 & OFF & DETAIL & 0.25000 & 10.0000 & 0.60000 & 0.07000 & 0.05000 & 3.00000 & \\
\hline WB & 4 & OFF & DETAIL & 0.25000 & 10.0000 & 0.60000 & 0.07000 & 0.05000 & 3.00000 & \\
\hline WB & 5 & OFF & DETAIL & 0.25000 & 10.0000 & 0.60000 & 0.07000 & 0.05000 & 3.00000 & \\
\hline WB & 6 & OFF & DETAIL & 0.25000 & 10.0000 & 0.60000 & 0.07000 & 0.05000 & 3.00000 & \\
\hline WB & 7 & $\mathrm{OFF}$ & DETAIL & 0.25000 & 10.0000 & 0.60000 & 0.07000 & 0.05000 & 3.00000 & \\
\hline
\end{tabular}




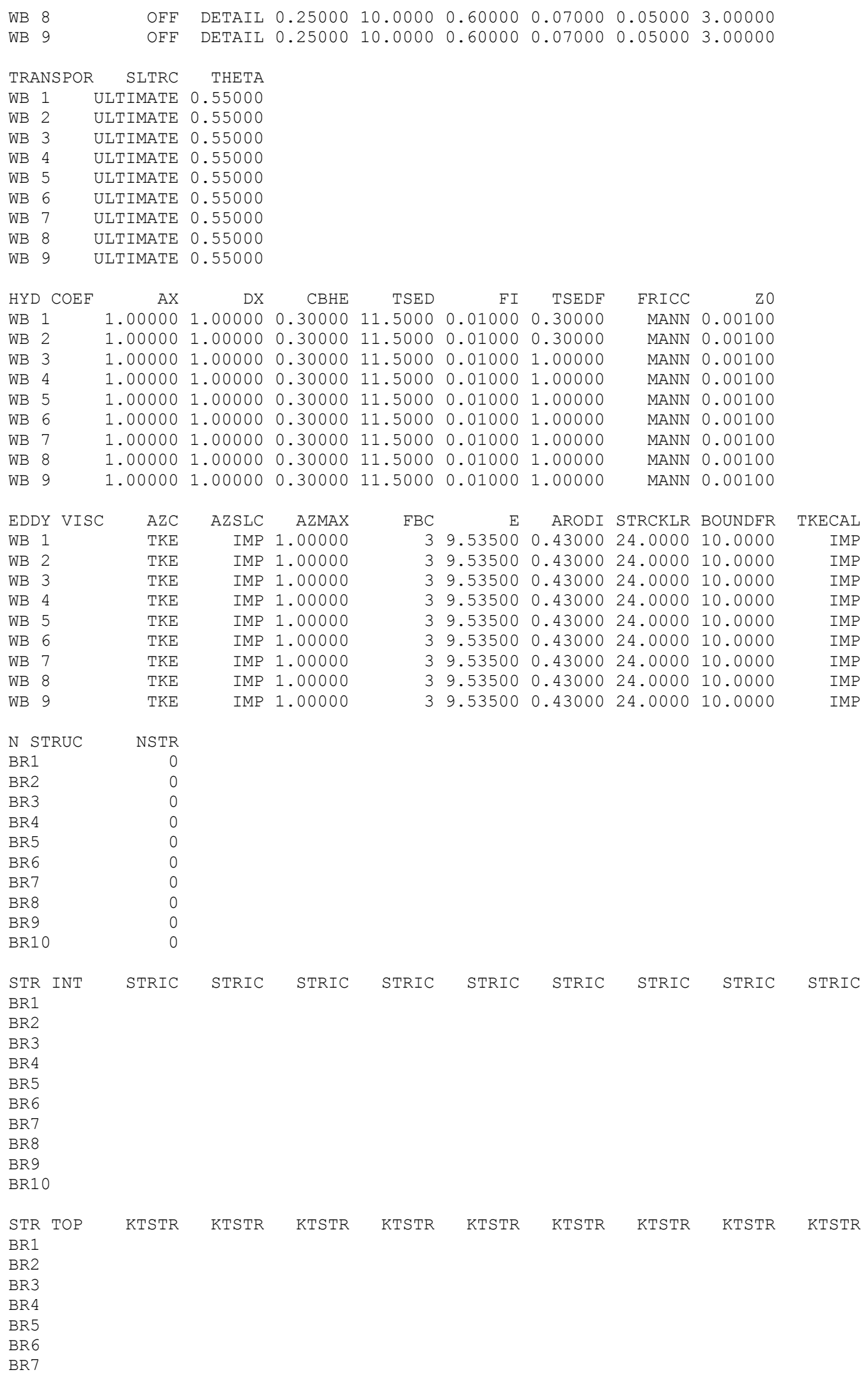




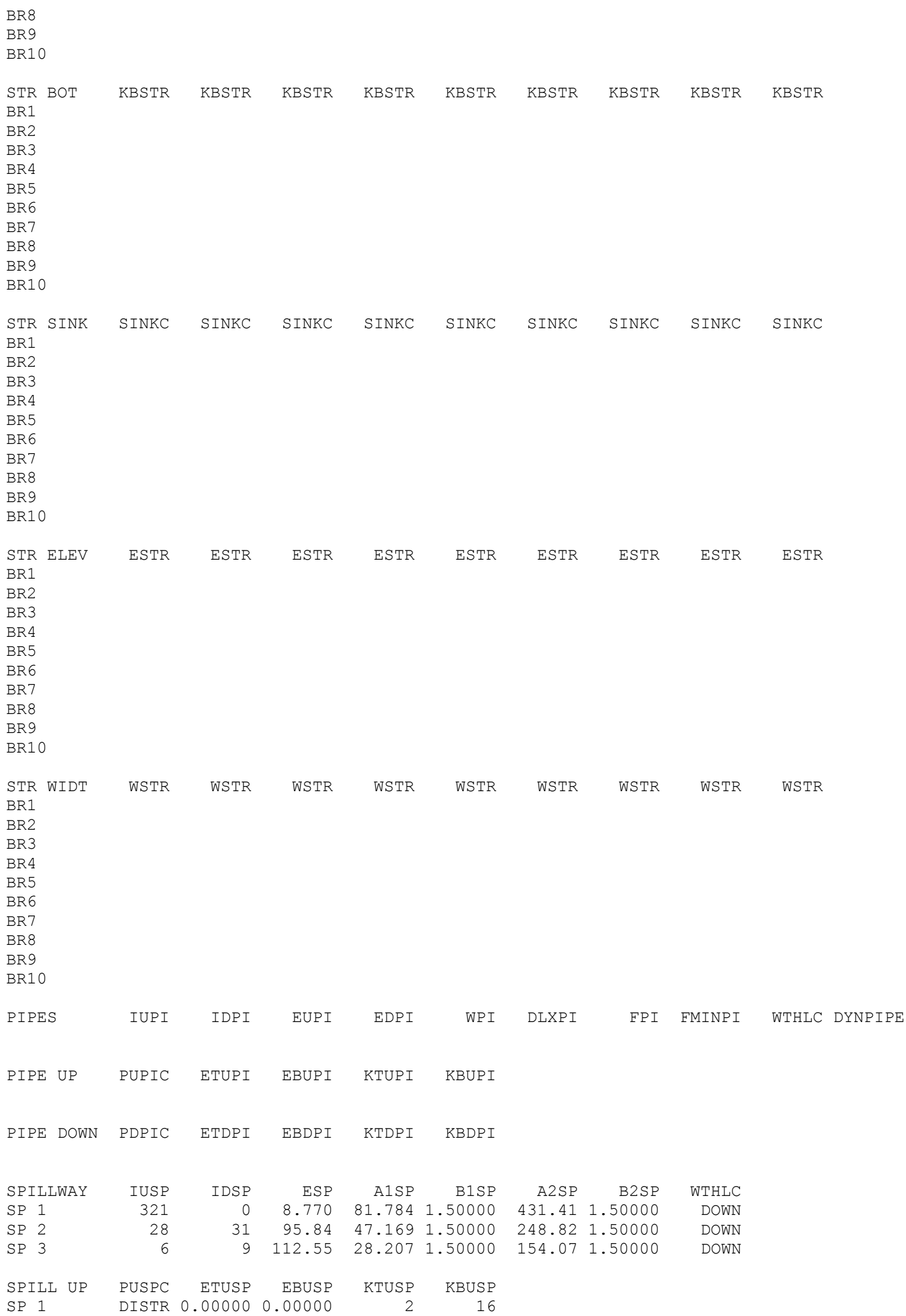




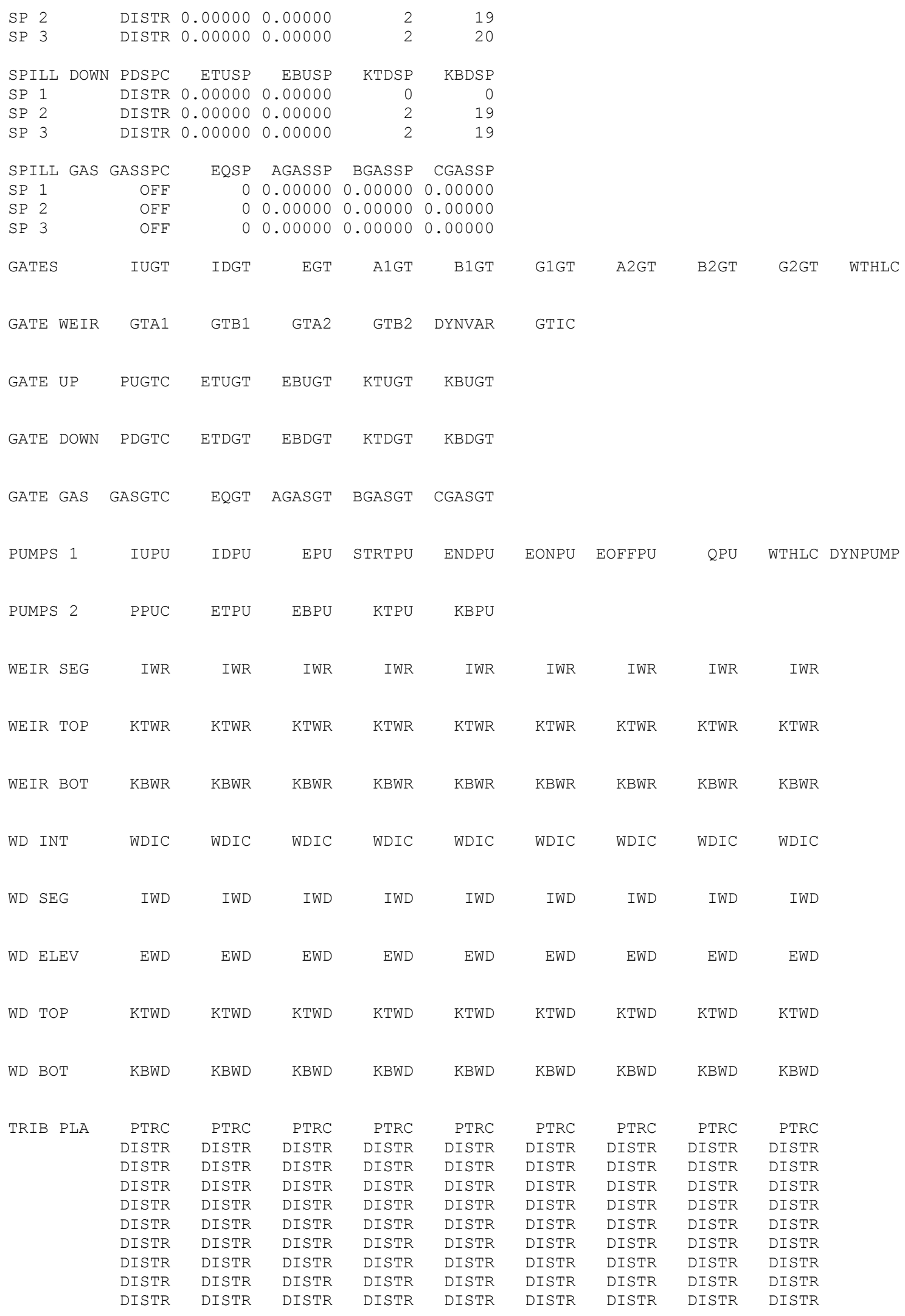




\begin{tabular}{|c|c|c|c|c|c|c|c|c|c|}
\hline & DISTR & DISTR & DISTR & DISTR & DISTR & DISTR & DISTR & DISTR & DISTR \\
\hline & DISTR & DISTR & DISTR & DISTR & DISTR & DISTR & DISTR & DISTR & DISTR \\
\hline & DISTR & DISTR & DISTR & DISTR & DISTR & DISTR & DISTR & DISTR & DISTR \\
\hline & DISTR & DISTR & DISTR & DISTR & DISTR & DISTR & DISTR & DISTR & DISTR \\
\hline & DISTR & DISTR & DISTR & DISTR & DISTR & DISTR & DISTR & DISTR & DISTR \\
\hline & DISTR & DISTR & DISTR & DISTR & DISTR & DISTR & DISTR & DISTR & DISTR \\
\hline & DISTR & DISTR & DISTR & DISTR & DISTR & DISTR & DISTR & DISTR & DISTR \\
\hline & DISTR & DISTR & DISTR & DISTR & DISTR & DISTR & DISTR & DISTR & DISTR \\
\hline & DISTR & DISTR & DISTR & DISTR & DISTR & DISTR & DISTR & DISTR & DISTR \\
\hline & DISTR & DISTR & DISTR & DISTR & DISTR & DISTR & DISTR & DISTR & DISTR \\
\hline & DISTR & DISTR & DISTR & DISTR & DISTR & DISTR & DISTR & DISTR & DISTR \\
\hline & DISTR & DISTR & DISTR & DISTR & DISTR & DISTR & DISTR & DISTR & DISTR \\
\hline & DISTR & DISTR & DISTR & DISTR & DISTR & DISTR & DISTR & DISTR & DISTR \\
\hline & DISTR & DISTR & DISTR & DISTR & DISTR & DISTR & DISTR & DISTR & DISTR \\
\hline & DISTR & DISTR & DISTR & DISTR & DISTR & DISTR & DISTR & DISTR & DISTR \\
\hline & DISTR & DISTR & DISTR & DISTR & DISTR & DISTR & DISTR & DISTR & DISTR \\
\hline & DISTR & DISTR & DISTR & DISTR & DISTR & DISTR & DISTR & DISTR & DISTR \\
\hline & DISTR & DISTR & DISTR & DISTR & DISTR & DISTR & DISTR & DISTR & DISTR \\
\hline & DISTR & DISTR & DISTR & DISTR & DISTR & DISTR & DISTR & DISTR & DISTR \\
\hline & DISTR & DISTR & DISTR & DISTR & DISTR & DISTR & DISTR & DISTR & DISTR \\
\hline & DISTR & DISTR & DISTR & DISTR & DISTR & DISTR & DISTR & DISTR & DISTR \\
\hline & DISTR & DISTR & DISTR & DISTR & DISTR & DISTR & DISTR & DISTR & DISTR \\
\hline & DISTR & DISTR & DISTR & DISTR & DISTR & DISTR & DISTR & DISTR & DISTR \\
\hline & DISTR & DISTR & DISTR & DISTR & DISTR & DISTR & DISTR & DISTR & DISTR \\
\hline & DISTR & DISTR & & & & & & & \\
\hline TRIB INT & TRIC & TRIC & TRIC & TRIC & TRIC & TRIC & TRIC & TRIC & TRIC \\
\hline & ON & ON & ON & $\mathrm{ON}$ & $\mathrm{ON}$ & ON & $\mathrm{ON}$ & ON & $\mathrm{ON}$ \\
\hline & $\mathrm{ON}$ & $\mathrm{ON}$ & ON & $\mathrm{ON}$ & ON & ON & $\mathrm{ON}$ & $\mathrm{ON}$ & $\mathrm{ON}$ \\
\hline & ON & $\mathrm{ON}$ & ON & ON & ON & ON & ON & ON & $\mathrm{ON}$ \\
\hline & ON & $\mathrm{ON}$ & ON & ON & ON & ON & ON & ON & $\mathrm{ON}$ \\
\hline & ON & ON & ON & ON & ON & ON & ON & ON & $\mathrm{ON}$ \\
\hline & ON & $\mathrm{ON}$ & ON & $\mathrm{ON}$ & ON & $\mathrm{ON}$ & $\mathrm{ON}$ & ON & $\mathrm{ON}$ \\
\hline & $\mathrm{ON}$ & $\mathrm{ON}$ & ON & $\mathrm{ON}$ & ON & $\mathrm{ON}$ & ON & ON & $\mathrm{ON}$ \\
\hline & ON & ON & ON & ON & ON & ON & ON & ON & $\mathrm{ON}$ \\
\hline & ON & ON & ON & ON & ON & ON & ON & ON & $\mathrm{ON}$ \\
\hline & ON & $\mathrm{ON}$ & ON & ON & ON & ON & ON & ON & $\mathrm{ON}$ \\
\hline & ON & ON & ON & ON & ON & ON & ON & ON & $\mathrm{ON}$ \\
\hline & $\mathrm{ON}$ & $\mathrm{ON}$ & ON & $\mathrm{ON}$ & ON & ON & $\mathrm{ON}$ & ON & $\mathrm{ON}$ \\
\hline & $\mathrm{ON}$ & ON & ON & ON & ON & ON & ON & ON & $\mathrm{ON}$ \\
\hline & ON & $\mathrm{ON}$ & ON & $\mathrm{ON}$ & ON & $\mathrm{ON}$ & $\mathrm{ON}$ & ON & ON \\
\hline & ON & ON & ON & $\mathrm{ON}$ & ON & ON & $\mathrm{ON}$ & ON & $\mathrm{ON}$ \\
\hline & ON & ON & ON & $\mathrm{ON}$ & ON & ON & $\mathrm{ON}$ & ON & $\mathrm{ON}$ \\
\hline & ON & ON & ON & ON & ON & ON & ON & ON & $\mathrm{ON}$ \\
\hline & ON & ON & ON & ON & ON & ON & ON & ON & $\mathrm{ON}$ \\
\hline & ON & ON & ON & ON & ON & ON & ON & ON & ON \\
\hline & ON & ON & ON & ON & ON & ON & ON & ON & $\mathrm{ON}$ \\
\hline & ON & ON & ON & ON & ON & ON & ON & ON & ON \\
\hline & ON & ON & ON & $\mathrm{ON}$ & ON & ON & ON & ON & ON \\
\hline & ON & ON & ON & ON & ON & ON & ON & ON & $\mathrm{ON}$ \\
\hline & ON & ON & ON & ON & ON & ON & ON & ON & ON \\
\hline & ON & ON & ON & ON & ON & ON & ON & ON & $\mathrm{ON}$ \\
\hline & ON & ON & ON & ON & ON & ON & ON & ON & $\mathrm{ON}$ \\
\hline & ON & ON & ON & ON & ON & ON & ON & ON & ON \\
\hline & ON & ON & ON & ON & ON & ON & ON & ON & ON \\
\hline & ON & ON & ON & ON & ON & ON & ON & ON & $\mathrm{ON}$ \\
\hline & ON & ON & ON & ON & ON & ON & ON & ON & $\mathrm{ON}$ \\
\hline & ON & ON & ON & ON & ON & ON & ON & ON & ON \\
\hline & ON & ON & ON & ON & ON & ON & ON & ON & ON \\
\hline & $\mathrm{ON}$ & ON & ON & ON & $\mathrm{ON}$ & ON & ON & ON & ON \\
\hline & ON & ON & & & & & & & \\
\hline TRIB SEG & ITR & ITR & ITR & ITR & ITR & ITR & ITR & ITR & ITR \\
\hline & 15 & 38 & 89 & 145 & 150 & 150 & 207 & 182 & 218 \\
\hline & 236 & 267 & 300 & 105 & 134 & 150 & 171 & 205 & 250 \\
\hline & 275 & 302 & 321 & 135 & 181 & 187 & 222 & 308 & 35 \\
\hline & 36 & 37 & 38 & 39 & 40 & 41 & 42 & 43 & 44 \\
\hline & 45 & 46 & 47 & 48 & 49 & 50 & 51 & 52 & 53 \\
\hline
\end{tabular}




$\begin{array}{rrrrrrrrr}54 & 55 & 56 & 57 & 58 & 59 & 62 & 63 & 64 \\ 65 & 66 & 67 & 68 & 69 & 70 & 71 & 72 & 73 \\ 74 & 75 & 76 & 77 & 78 & 79 & 80 & 81 & 82 \\ 83 & 84 & 85 & 86 & 87 & 88 & 89 & 90 & 91 \\ 92 & 93 & 94 & 95 & 96 & 97 & 98 & 99 & 100 \\ 101 & 102 & 103 & 104 & 105 & 106 & 107 & 108 & 109 \\ 110 & 111 & 112 & 113 & 114 & 115 & 116 & 117 & 118 \\ 119 & 120 & 121 & 122 & 123 & 124 & 125 & 126 & 127 \\ 128 & 131 & 132 & 133 & 134 & 135 & 136 & 137 & 138 \\ 139 & 140 & 141 & 142 & 143 & 144 & 145 & 148 & 149 \\ 150 & 151 & 152 & 153 & 154 & 155 & 156 & 157 & 158 \\ 159 & 160 & 161 & 162 & 163 & 164 & 165 & 166 & 167 \\ 168 & 169 & 170 & 171 & 172 & 173 & 174 & 177 & 178 \\ 179 & 180 & 181 & 182 & 183 & 184 & 185 & 186 & 187 \\ 188 & 189 & 190 & 191 & 192 & 193 & 196 & 197 & 198 \\ 199 & 200 & 201 & 202 & 203 & 204 & 205 & 206 & 207 \\ 208 & 209 & 210 & 211 & 212 & 213 & 214 & 217 & 218 \\ 219 & 220 & 221 & 222 & 223 & 224 & 225 & 226 & 227 \\ 228 & 229 & 230 & 231 & 232 & 233 & 234 & 235 & 236 \\ 237 & 238 & 239 & 240 & 241 & 242 & 243 & 244 & 245 \\ 246 & 247 & 248 & 249 & 250 & 251 & 252 & 253 & 254 \\ 255 & 256 & 257 & 258 & 259 & 260 & 261 & 262 & 263 \\ 264 & 265 & 266 & 267 & 268 & 269 & 270 & 271 & 272 \\ 273 & 274 & 275 & 276 & 277 & 278 & 279 & 280 & 281 \\ 282 & 285 & 286 & 287 & 288 & 289 & 290 & 291 & 292 \\ 293 & 294 & 295 & 296 & 297 & 298 & 299 & 300 & 301 \\ 302 & 303 & 304 & 305 & 306 & 307 & 308 & 309 & 310 \\ 311 & 312 & 313 & 314 & 315 & 316 & 317 & 318 & 319 \\ 320 & 321 & & & & & & & \end{array}$

TRIB TOP ELTRT ELTRT ELTRT ELTRT ELTRT ELTRT ELTRT ELTRT ELTRT $0.00000 \quad 0.00000 \quad 0.00000 \quad 0.00000 \quad 0.00000 \quad 0.00000 \quad 0.00000 \quad 0.00000 \quad 0.00000$ $0.00000 \quad 0.00000 \quad 0.00000 \quad 0.00000 \quad 0.00000 \quad 0.00000 \quad 0.00000 \quad 0.00000 \quad 0.00000$ $0.00000 \quad 0.00000 \quad 0.00000 \quad 0.000000 .00000 \quad 0.00000 \quad 0.00000 \quad 0.00000 \quad 0.00000$ $0.00000 \quad 0.00000 \quad 0.00000 \quad 0.00000 \quad 0.00000 \quad 0.00000 \quad 0.00000 \quad 0.00000 \quad 0.00000$ $0.00000 \quad 0.00000 \quad 0.00000 \quad 0.00000 \quad 0.00000 \quad 0.00000 \quad 0.00000 \quad 0.00000 \quad 0.00000$ $0.00000 \quad 0.00000 \quad 0.00000 \quad 0.00000 \quad 0.00000 \quad 0.00000 \quad 0.00000 \quad 0.00000 \quad 0.00000$ $0.00000 \quad 0.00000 \quad 0.00000 \quad 0.00000 \quad 0.00000 \quad 0.00000 \quad 0.00000 \quad 0.00000 \quad 0.00000$ $0.00000 \quad 0.00000 \quad 0.00000 \quad 0.00000 \quad 0.00000 \quad 0.00000 \quad 0.00000 \quad 0.00000 \quad 0.00000$ $0.00000 \quad 0.00000 \quad 0.00000 \quad 0.00000 \quad 0.00000 \quad 0.00000 \quad 0.00000 \quad 0.00000 \quad 0.00000$ $0.00000 \quad 0.00000 \quad 0.00000 \quad 0.00000 \quad 0.00000 \quad 0.00000 \quad 0.00000 \quad 0.00000 \quad 0.00000$ $0.00000 \quad 0.00000 \quad 0.00000 \quad 0.00000 \quad 0.00000 \quad 0.00000 \quad 0.00000 \quad 0.00000 \quad 0.00000$ $0.00000 \quad 0.00000 \quad 0.00000 \quad 0.00000 \quad 0.00000 \quad 0.00000 \quad 0.00000 \quad 0.00000 \quad 0.00000$ $0.00000 \quad 0.00000 \quad 0.00000 \quad 0.00000 \quad 0.00000 \quad 0.00000 \quad 0.00000 \quad 0.00000 \quad 0.00000$ $0.00000 \quad 0.00000 \quad 0.00000 \quad 0.00000 \quad 0.00000 \quad 0.00000 \quad 0.00000 \quad 0.00000 \quad 0.00000$ $0.00000 \quad 0.00000 \quad 0.00000 \quad 0.00000 \quad 0.00000 \quad 0.00000 \quad 0.00000 \quad 0.00000 \quad 0.00000$ $0.00000 \quad 0.00000 \quad 0.00000 \quad 0.00000 \quad 0.00000 \quad 0.00000 \quad 0.00000 \quad 0.00000 \quad 0.00000$ $0.00000 \quad 0.00000 \quad 0.00000 \quad 0.00000 \quad 0.00000 \quad 0.00000 \quad 0.00000 \quad 0.00000 \quad 0.00000$ $0.00000 \quad 0.00000 \quad 0.00000 \quad 0.00000 \quad 0.00000 \quad 0.00000 \quad 0.00000 \quad 0.00000 \quad 0.00000$ $0.00000 \quad 0.00000 \quad 0.00000 \quad 0.000000 .00000 \quad 0.00000 \quad 0.00000 \quad 0.00000 \quad 0.00000$ $0.00000 \quad 0.00000 \quad 0.00000 \quad 0.00000 \quad 0.00000 \quad 0.00000 \quad 0.00000 \quad 0.00000 \quad 0.00000$ $0.00000 \quad 0.00000 \quad 0.00000 \quad 0.00000 \quad 0.00000 \quad 0.00000 \quad 0.00000 \quad 0.00000 \quad 0.00000$ $0.00000 \quad 0.00000 \quad 0.00000 \quad 0.00000 \quad 0.00000 \quad 0.00000 \quad 0.00000 \quad 0.00000 \quad 0.00000$ $0.00000 \quad 0.00000 \quad 0.00000 \quad 0.00000 \quad 0.00000 \quad 0.00000 \quad 0.00000 \quad 0.00000 \quad 0.00000$ $0.00000 \quad 0.00000 \quad 0.00000 \quad 0.00000 \quad 0.00000 \quad 0.00000 \quad 0.00000 \quad 0.00000 \quad 0.00000$ $0.00000 \quad 0.00000 \quad 0.00000 \quad 0.00000 \quad 0.00000 \quad 0.00000 \quad 0.00000 \quad 0.00000 \quad 0.00000$ $0.00000 \quad 0.00000 \quad 0.00000 \quad 0.00000 \quad 0.00000 \quad 0.00000 \quad 0.00000 \quad 0.00000 \quad 0.00000$ $0.00000 \quad 0.00000 \quad 0.00000 \quad 0.00000 \quad 0.00000 \quad 0.00000 \quad 0.00000 \quad 0.00000 \quad 0.00000$ $0.00000 \quad 0.00000 \quad 0.00000 \quad 0.00000 \quad 0.00000 \quad 0.00000 \quad 0.00000 \quad 0.00000 \quad 0.00000$ $0.00000 \quad 0.00000 \quad 0.00000 \quad 0.00000 \quad 0.00000 \quad 0.00000 \quad 0.00000 \quad 0.00000 \quad 0.00000$ $0.00000 \quad 0.00000 \quad 0.00000 \quad 0.00000 \quad 0.00000 \quad 0.00000 \quad 0.00000 \quad 0.00000 \quad 0.00000$ $0.00000 \quad 0.00000 \quad 0.00000 \quad 0.00000 \quad 0.00000 \quad 0.00000 \quad 0.00000 \quad 0.00000 \quad 0.00000$ $0.00000 \quad 0.00000 \quad 0.00000 \quad 0.00000 \quad 0.00000 \quad 0.00000 \quad 0.00000 \quad 0.00000 \quad 0.00000$ $0.00000 \quad 0.00000 \quad 0.00000 \quad 0.00000 \quad 0.00000 \quad 0.00000 \quad 0.00000 \quad 0.00000 \quad 0.00000$ $0.00000 \quad 0.00000$

TRIB BOT ELTRB ELTRB ELTRB ELTRB ELTRB ELTRB ELTRB ELTRB ELTRB $0.00000 \quad 0.00000 \quad 0.00000 \quad 0.000000 .00000 \quad 0.00000 \quad 0.000000 .000000 .00000$ 
$0.00000 \quad 0.00000 \quad 0.00000 \quad 0.00000 \quad 0.00000 \quad 0.00000 \quad 0.00000 \quad 0.00000 \quad 0.00000$ $0.00000 \quad 0.00000 \quad 0.00000 \quad 0.00000 \quad 0.00000 \quad 0.00000 \quad 0.00000 \quad 0.00000 \quad 0.00000$ $0.00000 \quad 0.00000 \quad 0.00000 \quad 0.00000 \quad 0.00000 \quad 0.00000 \quad 0.00000 \quad 0.00000 \quad 0.00000$ $0.00000 \quad 0.00000 \quad 0.00000 \quad 0.00000 \quad 0.00000 \quad 0.00000 \quad 0.00000 \quad 0.00000 \quad 0.00000$ $0.00000 \quad 0.00000 \quad 0.00000 \quad 0.00000 \quad 0.00000 \quad 0.00000 \quad 0.00000 \quad 0.00000 \quad 0.00000$ $0.00000 \quad 0.00000 \quad 0.00000 \quad 0.00000 \quad 0.00000 \quad 0.00000 \quad 0.00000 \quad 0.00000 \quad 0.00000$ $0.00000 \quad 0.00000 \quad 0.00000 \quad 0.00000 \quad 0.00000 \quad 0.00000 \quad 0.00000 \quad 0.00000 \quad 0.00000$ $0.00000 \quad 0.00000 \quad 0.00000 \quad 0.00000 \quad 0.00000 \quad 0.00000 \quad 0.00000 \quad 0.00000 \quad 0.00000$ $0.00000 \quad 0.00000 \quad 0.00000 \quad 0.00000 \quad 0.00000 \quad 0.00000 \quad 0.00000 \quad 0.00000 \quad 0.00000$ $0.00000 \quad 0.00000 \quad 0.00000 \quad 0.00000 \quad 0.00000 \quad 0.00000 \quad 0.00000 \quad 0.00000 \quad 0.00000$ $0.00000 \quad 0.00000 \quad 0.00000 \quad 0.00000 \quad 0.00000 \quad 0.00000 \quad 0.00000 \quad 0.00000 \quad 0.00000$ $0.00000 \quad 0.00000 \quad 0.00000 \quad 0.00000 \quad 0.00000 \quad 0.00000 \quad 0.00000 \quad 0.00000 \quad 0.00000$ $0.00000 \quad 0.00000 \quad 0.00000 \quad 0.00000 \quad 0.00000 \quad 0.00000 \quad 0.00000 \quad 0.00000 \quad 0.00000$ $0.00000 \quad 0.00000 \quad 0.00000 \quad 0.00000 \quad 0.00000 \quad 0.00000 \quad 0.00000 \quad 0.00000 \quad 0.00000$ $0.00000 \quad 0.00000 \quad 0.00000 \quad 0.00000 \quad 0.00000 \quad 0.00000 \quad 0.00000 \quad 0.00000 \quad 0.00000$ $0.00000 \quad 0.00000 \quad 0.00000 \quad 0.00000 \quad 0.00000 \quad 0.00000 \quad 0.00000 \quad 0.00000 \quad 0.00000$ $0.00000 \quad 0.00000 \quad 0.00000 \quad 0.00000 \quad 0.00000 \quad 0.00000 \quad 0.00000 \quad 0.00000 \quad 0.00000$ $0.00000 \quad 0.00000 \quad 0.00000 \quad 0.00000 \quad 0.00000 \quad 0.00000 \quad 0.00000 \quad 0.00000 \quad 0.00000$ $\begin{array}{llllllllll}0.00000 & 0.00000 & 0.00000 & 0.00000 & 0.00000 & 0.00000 & 0.00000 & 0.00000 & 0.00000\end{array}$ $0.00000 \quad 0.00000 \quad 0.00000 \quad 0.00000 \quad 0.00000 \quad 0.00000 \quad 0.00000 \quad 0.00000 \quad 0.00000$ $0.00000 \quad 0.00000 \quad 0.00000 \quad 0.00000 \quad 0.00000 \quad 0.00000 \quad 0.00000 \quad 0.00000 \quad 0.00000$ $0.00000 \quad 0.00000 \quad 0.00000 \quad 0.00000 \quad 0.00000 \quad 0.00000 \quad 0.00000 \quad 0.00000 \quad 0.00000$ $0.00000 \quad 0.00000 \quad 0.00000 \quad 0.00000 \quad 0.00000 \quad 0.00000 \quad 0.00000 \quad 0.00000 \quad 0.00000$ $0.00000 \quad 0.00000 \quad 0.00000 \quad 0.00000 \quad 0.00000 \quad 0.00000 \quad 0.00000 \quad 0.00000 \quad 0.00000$ $0.00000 \quad 0.00000 \quad 0.00000 \quad 0.00000 \quad 0.00000 \quad 0.00000 \quad 0.00000 \quad 0.00000 \quad 0.00000$ $0.00000 \quad 0.00000 \quad 0.00000 \quad 0.00000 \quad 0.00000 \quad 0.00000 \quad 0.00000 \quad 0.00000 \quad 0.00000$ $0.00000 \quad 0.00000 \quad 0.00000 \quad 0.00000 \quad 0.00000 \quad 0.00000 \quad 0.00000 \quad 0.00000 \quad 0.00000$ $0.00000 \quad 0.00000 \quad 0.00000 \quad 0.00000 \quad 0.00000 \quad 0.00000 \quad 0.00000 \quad 0.00000 \quad 0.00000$ $0.00000 \quad 0.00000 \quad 0.00000 \quad 0.00000 \quad 0.00000 \quad 0.00000 \quad 0.00000 \quad 0.00000 \quad 0.00000$ $0.00000 \quad 0.00000 \quad 0.00000 \quad 0.00000 \quad 0.00000 \quad 0.00000 \quad 0.00000 \quad 0.00000 \quad 0.00000$ $0.00000 \quad 0.00000 \quad 0.00000 \quad 0.00000 \quad 0.00000 \quad 0.00000 \quad 0.00000 \quad 0.00000 \quad 0.00000$ $0.00000 \quad 0.00000 \quad 0.00000 \quad 0.00000 \quad 0.00000 \quad 0.00000 \quad 0.00000 \quad 0.00000 \quad 0.00000$ $0.00000 \quad 0.00000$

\begin{tabular}{|c|c|c|c|c|c|c|c|c|c|}
\hline DST TRIB & DTRC & DTRC & DTRC & DTRC & DTRC & DTRC & DTRC & DTRC & DTRC \\
\hline $\mathrm{BR} 1$ & ON & & & & & & & & \\
\hline BR 2 & ON & & & & & & & & \\
\hline BR 3 & $\mathrm{OFF}$ & & & & & & & & \\
\hline BR 4 & $\mathrm{OFF}$ & & & & & & & & \\
\hline BR 5 & $\mathrm{OFF}$ & & & & & & & & \\
\hline BR 6 & $\mathrm{ON}$ & & & & & & & & \\
\hline BR 7 & $\mathrm{OFF}$ & & & & & & & & \\
\hline BR 8 & $\mathrm{OFF}$ & & & & & & & & \\
\hline BR 9 & $\mathrm{OFF}$ & & & & & & & & \\
\hline BR 10 & $\mathrm{ON}$ & & & & & & & & \\
\hline HYD PRIN & HPRWBC & HPRWBC & HPRWBC & HPRWBC & HPRWBC & HPRWBC & HPRWBC & HPRWBC & HPRWBC \\
\hline NVIOL & $\mathrm{ON}$ & $\mathrm{ON}$ & $\mathrm{ON}$ & $\mathrm{ON}$ & $\mathrm{ON}$ & $\mathrm{ON}$ & $\mathrm{ON}$ & $\mathrm{ON}$ & $\mathrm{ON}$ \\
\hline $\mathrm{U}$ & $\mathrm{ON}$ & $\mathrm{ON}$ & $\mathrm{ON}$ & $\mathrm{ON}$ & $\mathrm{ON}$ & $\mathrm{ON}$ & $\mathrm{ON}$ & $\mathrm{ON}$ & $\mathrm{ON}$ \\
\hline W & $\mathrm{OFF}$ & $\mathrm{OFF}$ & $\mathrm{OFF}$ & $\mathrm{OFF}$ & $\mathrm{OFF}$ & $\mathrm{OFF}$ & $\mathrm{OFF}$ & $\mathrm{OFF}$ & $\mathrm{OFF}$ \\
\hline $\mathrm{T}$ & $\mathrm{ON}$ & $\mathrm{ON}$ & $\mathrm{ON}$ & $\mathrm{ON}$ & $\mathrm{ON}$ & $\mathrm{ON}$ & $\mathrm{ON}$ & $\mathrm{ON}$ & $\mathrm{ON}$ \\
\hline RHO & $\mathrm{OFF}$ & $\mathrm{OFF}$ & $\mathrm{OFF}$ & $\mathrm{OFF}$ & $\mathrm{OFF}$ & $\mathrm{OFF}$ & $\mathrm{OFF}$ & $\mathrm{OFF}$ & $\mathrm{OFF}$ \\
\hline $\mathrm{AZ}$ & $\mathrm{OFF}$ & $\mathrm{OFF}$ & $\mathrm{OFF}$ & $\mathrm{OFF}$ & $\mathrm{OFF}$ & $\mathrm{OFF}$ & $\mathrm{OFF}$ & $\mathrm{OFF}$ & $\mathrm{OFF}$ \\
\hline SHEAR & $\mathrm{OFF}$ & $\mathrm{OFF}$ & $\mathrm{OFF}$ & $\mathrm{OFF}$ & $\mathrm{OFF}$ & $\mathrm{OFF}$ & $\mathrm{OFF}$ & $\mathrm{OFF}$ & $\mathrm{OFE}$ \\
\hline $\mathrm{ST}$ & $\mathrm{OFF}$ & $\mathrm{OFF}$ & $\mathrm{OFF}$ & $\mathrm{OFF}$ & $\mathrm{OFF}$ & $\mathrm{OFF}$ & $\mathrm{OFF}$ & $\mathrm{OFF}$ & $\mathrm{OFF}$ \\
\hline $\mathrm{SB}$ & $\mathrm{OFF}$ & $\mathrm{OFF}$ & $\mathrm{OFF}$ & $\mathrm{OFF}$ & $\mathrm{OFF}$ & OFF & $\mathrm{OFF}$ & $\mathrm{OFF}$ & $\mathrm{OFE}$ \\
\hline ADMX & $\mathrm{OFF}$ & $\mathrm{OFF}$ & $\mathrm{OFF}$ & $\mathrm{OFF}$ & $\mathrm{OFF}$ & OFF & $\mathrm{OFF}$ & $\mathrm{OFF}$ & $\mathrm{OFF}$ \\
\hline $\mathrm{DM}$ & $\mathrm{OFF}$ & $\mathrm{OFF}$ & $\mathrm{OFF}$ & $\mathrm{OFF}$ & $\mathrm{OFF}$ & OFF & $\mathrm{OFF}$ & $\mathrm{OFF}$ & $\mathrm{OFE}$ \\
\hline HDG & $\mathrm{OFF}$ & $\mathrm{OFF}$ & OFF & OFF & $\mathrm{OFF}$ & OFF & OFF & OFF & $\mathrm{OFF}$ \\
\hline ADMZ & $\mathrm{OFF}$ & $\mathrm{OFF}$ & $\mathrm{OFF}$ & $\mathrm{OFF}$ & $\mathrm{OFF}$ & OFF & $\mathrm{OFF}$ & OFF & $\mathrm{OFE}$ \\
\hline $\mathrm{HPG}$ & $\mathrm{OFF}$ & $\mathrm{OFF}$ & $\mathrm{OFF}$ & OFF & $\mathrm{OFF}$ & OFF & $\mathrm{OFF}$ & OFF & $\mathrm{OFF}$ \\
\hline GRAV & OFF & $\mathrm{OFF}$ & $\mathrm{OFF}$ & $\mathrm{OFF}$ & OFF & OFF & $\mathrm{OFF}$ & OFF & $\mathrm{OFF}$ \\
\hline
\end{tabular}

$\begin{array}{lrrr}\text { SNP PRINT } & \text { SNPC } & \text { NSNP } & \text { NISNP } \\ \text { WB } 1 & \text { ON } & 2 & 5 \\ \text { WB } 2 & \text { ON } & 2 & 9 \\ \text { WB } 3 & \text { ON } & 2 & 14 \\ \text { WB } 4 & \text { ON } & 2 & 14\end{array}$




\begin{tabular}{|c|c|c|c|c|c|c|c|c|c|c|}
\hline WB & 5 & $\mathrm{ON}$ & 2 & 6 & & & & & & \\
\hline WB & 6 & $\mathrm{ON}$ & 2 & 12 & & & & & & \\
\hline WB & 7 & $\mathrm{ON}$ & 2 & 6 & & & & & & \\
\hline WB & 8 & $\mathrm{ON}$ & 2 & 15 & & & & & & \\
\hline WB & 9 & $\mathrm{ON}$ & 2 & 10 & & & & & & \\
\hline SNP & DATE & SNPD & SNPD & SNPD & SNPD & SNPD & SNPD & SNPD & SNPD & SNPD \\
\hline WB & 1 & 1.0 & 2.0 & & & & & & & \\
\hline WB & 2 & 1.0 & 2.0 & & & & & & & \\
\hline WB & 3 & 1.0 & 2.0 & & & & & & & \\
\hline WB & 4 & 1.0 & 2.0 & & & & & & & \\
\hline WB & 5 & 1.0 & 2.0 & & & & & & & \\
\hline WB & 6 & 1.0 & 2.0 & & & & & & & \\
\hline WB & 7 & 1.0 & 2.0 & & & & & & & \\
\hline WB & 8 & 1.0 & 2.0 & & & & & & & \\
\hline WB & 9 & 1.0 & 2.0 & & & & & & & \\
\hline SNP & FREQ & SNPE & SNPE & SNPF & SNPF & SNPF & SNPE & SNPF & SNPF & SNPF \\
\hline WB & 1 & 0.1 & 7.5 & & & & & & & \\
\hline WB & 2 & 0.1 & 7.5 & & & & & & & \\
\hline WB & 3 & 0.1 & 7.5 & & & & & & & \\
\hline WB & 4 & 0.1 & 7.5 & & & & & & & \\
\hline WB & 5 & 0.1 & 7.5 & & & & & & & \\
\hline WB & 6 & 0.1 & 7.5 & & & & & & & \\
\hline WB & 7 & 0.1 & 7.5 & & & & & & & \\
\hline WB & 8 & 0.1 & 7.5 & & & & & & & \\
\hline WB & 9 & 0.1 & 7.5 & & & & & & & \\
\hline SNP & SEG & ISNP & ISNP & ISNP & ISNP & ISNP & ISNP & ISNP & ISNP & ISNP \\
\hline WB & 1 & 2 & 3 & 4 & 5 & 6 & & & & \\
\hline WB & 2 & 9 & 12 & 15 & 18 & 20 & 22 & 24 & 26 & 28 \\
\hline WB & 3 & 32 & 34 & 36 & 38 & 40 & 42 & 44 & 46 & 48 \\
\hline & & 50 & 52 & 54 & 56 & 58 & & & & \\
\hline WB & 4 & 62 & 67 & 72 & 77 & 82 & 87 & 92 & 97 & 102 \\
\hline & & 107 & 112 & 117 & 122 & 127 & & & & \\
\hline WB & 5 & 131 & 134 & 137 & 140 & 143 & 145 & & & \\
\hline WB & 6 & 148 & 155 & 160 & 165 & 170 & 172 & 174 & 177 & 180 \\
\hline & & 185 & 190 & 193 & & & & & & \\
\hline WB & 7 & 196 & 200 & 204 & 208 & 212 & 214 & & & \\
\hline WB & 8 & 217 & 220 & 225 & 230 & 235 & 240 & 245 & 250 & 255 \\
\hline & & 260 & 265 & 270 & 275 & 280 & 282 & & & \\
\hline WB & 9 & 285 & 290 & 295 & 300 & 305 & 310 & 315 & 317 & 319 \\
\hline & & 321 & & & & & & & & \\
\hline $\mathrm{SCR}$ & R PRINT & SCRC & NSCR & & & & & & & \\
\hline WB & 1 & ON & 1 & & & & & & & \\
\hline WB & 2 & $\mathrm{OFF}$ & 1 & & & & & & & \\
\hline WB & 3 & $\mathrm{OFF}$ & 1 & & & & & & & \\
\hline WB & 4 & $\mathrm{OFF}$ & 1 & & & & & & & \\
\hline WB & 5 & $\mathrm{OFF}$ & 1 & & & & & & & \\
\hline WB & 6 & $\mathrm{OFF}$ & 1 & & & & & & & \\
\hline WB & 7 & $\mathrm{OFF}$ & 1 & & & & & & & \\
\hline WB & 8 & $\mathrm{OFF}$ & 1 & & & & & & & \\
\hline WB & 9 & $\mathrm{OFF}$ & 1 & & & & & & & \\
\hline $\mathrm{SCR}$ & RATE & SCRD & SCRD & SCRD & SCRD & SCRD & SCRD & SCRD & SCRD & SCRD \\
\hline WB & 1 & 1.00000 & & & & & & & & \\
\hline WB & 2 & 1.00000 & & & & & & & & \\
\hline WB & 3 & 1.00000 & & & & & & & & \\
\hline WB & 4 & 1.00000 & & & & & & & & \\
\hline WB & 5 & 1.00000 & & & & & & & & \\
\hline WB & 6 & 1.00000 & & & & & & & & \\
\hline WB & 7 & 1.00000 & & & & & & & & \\
\hline WB & 8 & 1.00000 & & & & & & & & \\
\hline WB & 9 & 1.00000 & & & & & & & & \\
\hline $\mathrm{SCR}$ & R FREQ & SCRF & $\mathrm{SCRF}$ & SCRF & SCRF & SCRF & $\mathrm{SCRF}$ & SCRF & $\mathrm{SCRF}$ & $\mathrm{SCRF}$ \\
\hline WB & 1 & 0.05000 & & & & & & & & \\
\hline
\end{tabular}




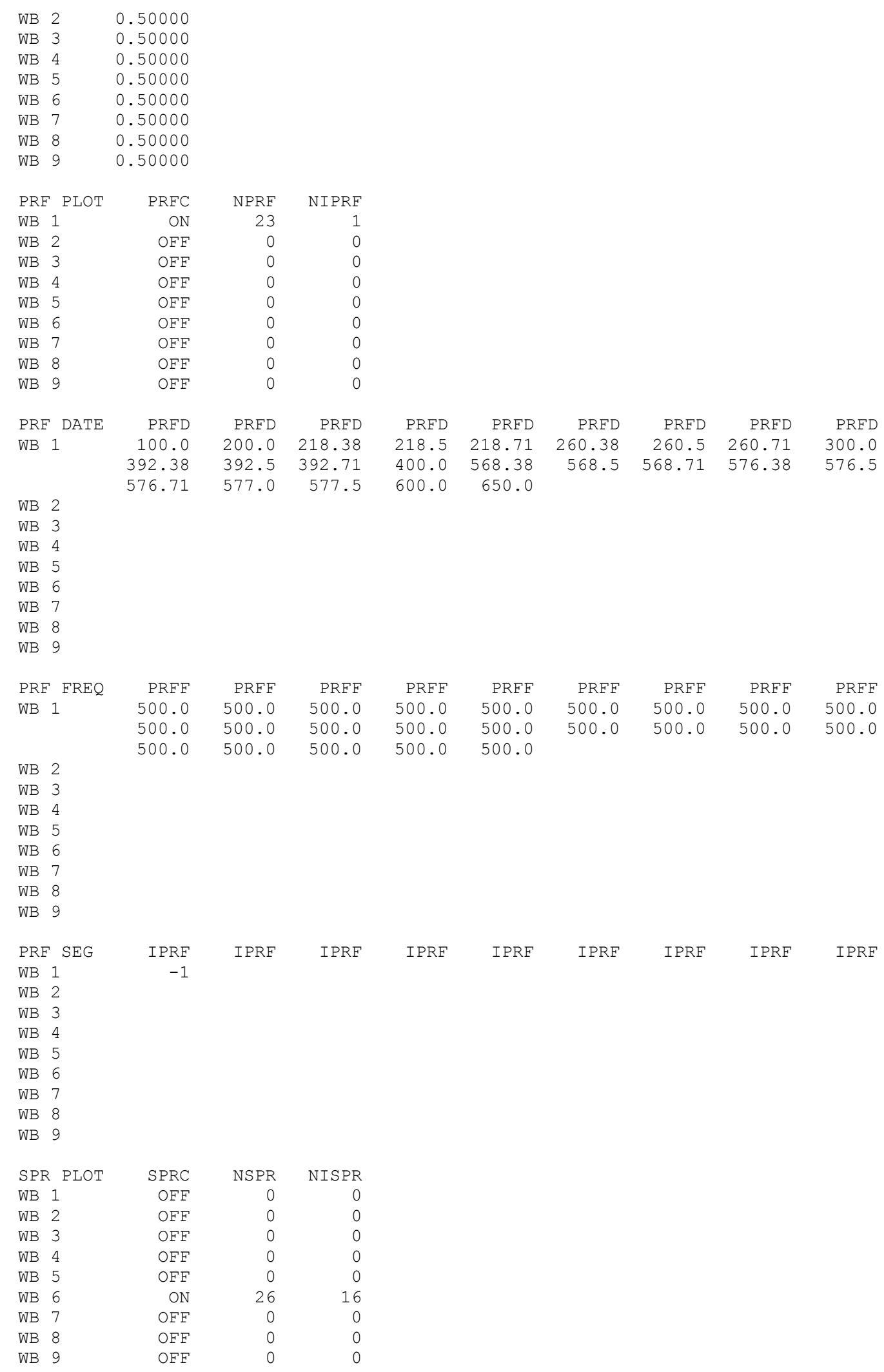




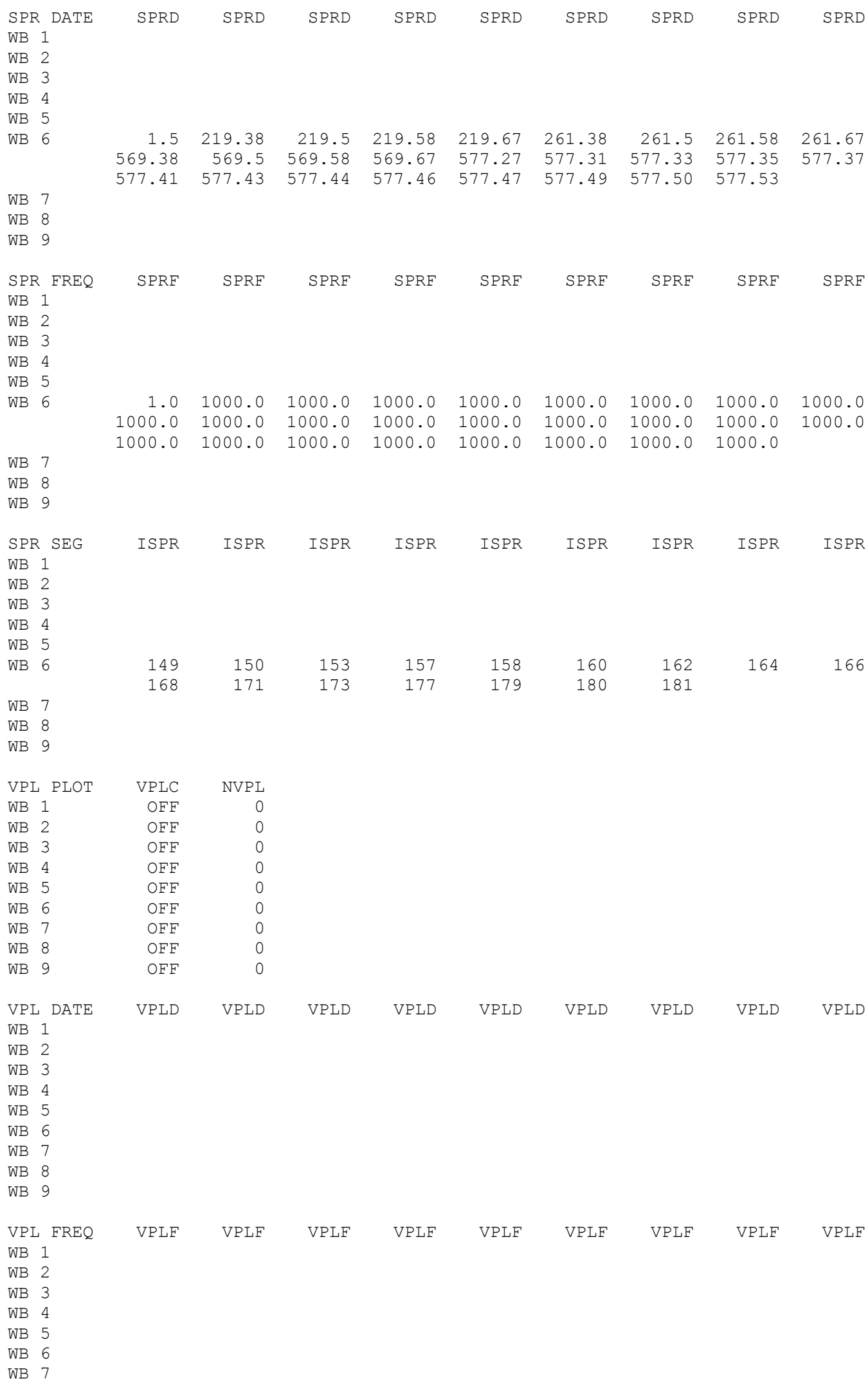




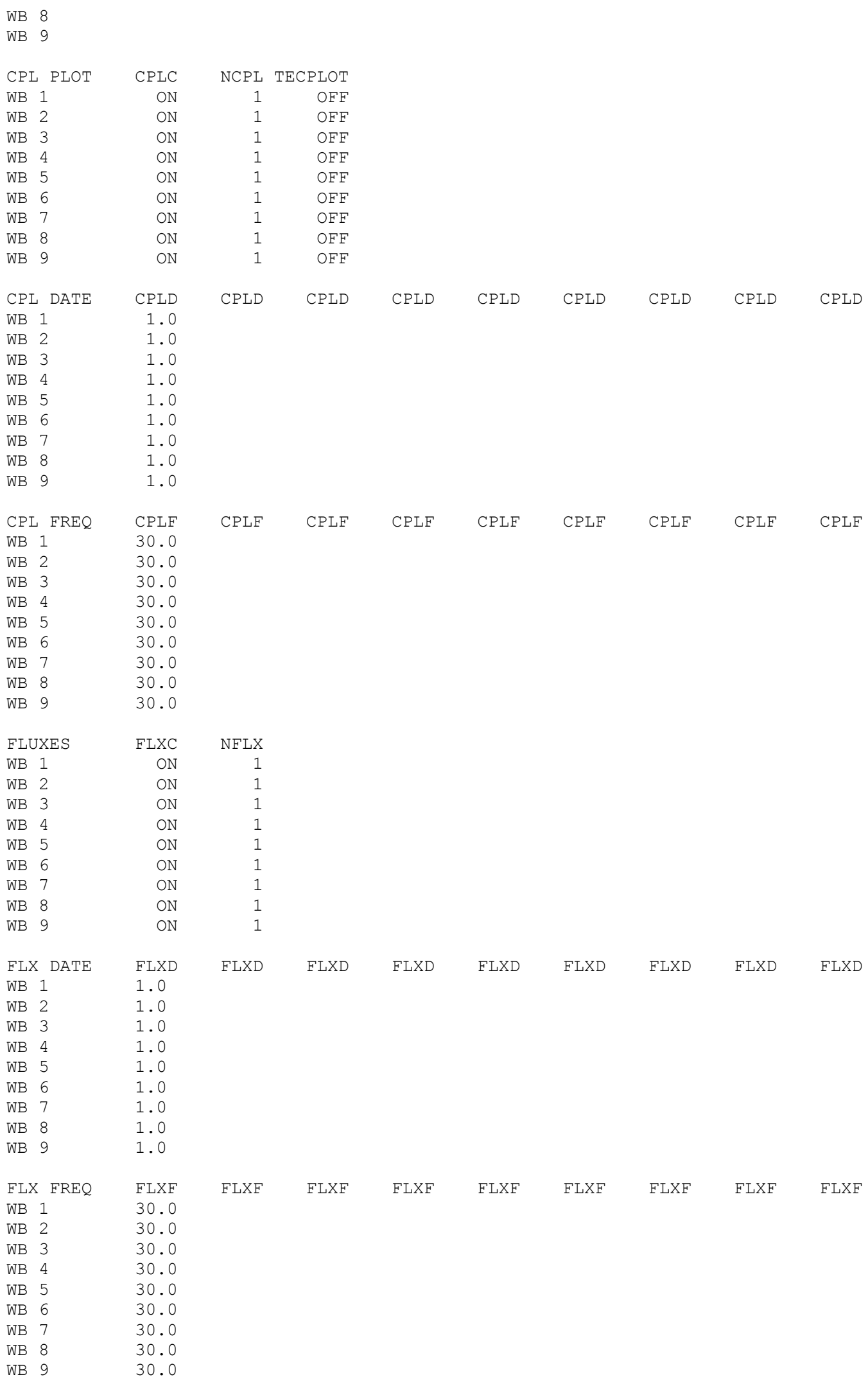




\begin{tabular}{|c|c|c|c|c|c|c|c|c|c|}
\hline TSR PLOT & $\begin{array}{r}\text { TSRC } \\
\text { ON }\end{array}$ & $\begin{array}{r}\text { NTSR } \\
2\end{array}$ & $\begin{array}{r}\text { NITSR } \\
78\end{array}$ & & & & & & \\
\hline TSR DATE & $\begin{array}{r}\text { TSRD } \\
1.0\end{array}$ & $\begin{array}{l}\text { TSRD } \\
2.00\end{array}$ & TSRD & TSRD & TSRD & TSRD & TSRD & TSRD & TSRD \\
\hline TSR FREQ & $\begin{array}{r}\text { TSRF } \\
0.1\end{array}$ & $\begin{array}{r}\text { TSRF } \\
0.1\end{array}$ & $\begin{array}{r}\text { TSRF } \\
0.1\end{array}$ & $\begin{array}{r}\text { TSRF } \\
0.1\end{array}$ & TSRE & TSRF & TSRF & TSRF & TSRF \\
\hline TSR SEG & $\begin{array}{r}\text { ITSR } \\
321 \\
15 \\
80 \\
35 \\
287 \\
19 \\
42 \\
220 \\
267\end{array}$ & $\begin{array}{r}\text { ITSR } \\
57 \\
149 \\
105 \\
78 \\
43 \\
47 \\
74 \\
226 \\
271\end{array}$ & $\begin{array}{r}\text { ITSR } \\
32 \\
150 \\
124 \\
122 \\
81 \\
145 \\
89 \\
233 \\
275\end{array}$ & $\begin{array}{r}\text { ITSR } \\
97 \\
144 \\
156 \\
170 \\
149 \\
213 \\
110 \\
239 \\
281\end{array}$ & $\begin{array}{r}\text { ITSR } \\
150 \\
238 \\
192 \\
12 \\
180 \\
249 \\
133 \\
245 \\
302\end{array}$ & $\begin{array}{r}\text { ITSR } \\
181 \\
84 \\
95 \\
24 \\
36 \\
36 \\
162 \\
249 \\
320\end{array}$ & $\begin{array}{r}\text { ITSR } \\
213 \\
125 \\
103 \\
50 \\
64 \\
119 \\
186 \\
253\end{array}$ & $\begin{array}{r}\text { ITSR } \\
238 \\
198 \\
124 \\
81 \\
155 \\
223 \\
198 \\
258\end{array}$ & $\begin{array}{r}\text { ITSR } \\
321 \\
48 \\
141 \\
196 \\
4 \\
250 \\
208 \\
263\end{array}$ \\
\hline TSR LAYE & $\begin{array}{c}\text { ETSR } \\
0.0 \\
0.0 \\
0.0 \\
0.0 \\
0.0 \\
0.0 \\
0.0 \\
0.0 \\
0.0\end{array}$ & $\begin{array}{r}\text { ETSR } \\
0.0 \\
0.0 \\
0.0 \\
0.0 \\
0.0 \\
0.0 \\
0.0 \\
0.0 \\
0.0\end{array}$ & $\begin{array}{c}\text { ETSR } \\
0.0 \\
0.0 \\
0.0 \\
0.0 \\
0.0 \\
0.0 \\
0.0 \\
0.0 \\
0.0\end{array}$ & $\begin{array}{r}\text { ETSR } \\
0.0 \\
0.0 \\
0.0 \\
0.0 \\
0.0 \\
0.0 \\
0.0 \\
0.0 \\
0.0\end{array}$ & $\begin{array}{r}\text { ETSR } \\
0.0 \\
0.0 \\
0.0 \\
0.0 \\
0.0 \\
0.0 \\
0.0 \\
0.0 \\
0.0\end{array}$ & $\begin{array}{c}\text { ETSR } \\
0.0 \\
0.0 \\
0.0 \\
0.0 \\
0.0 \\
0.0 \\
0.0 \\
0.0 \\
0.0\end{array}$ & $\begin{array}{c}\text { ETSR } \\
0.0 \\
0.0 \\
0.0 \\
0.0 \\
0.0 \\
0.0 \\
0.0 \\
0.0\end{array}$ & $\begin{array}{r}\text { ETSR } \\
0.0 \\
0.0 \\
0.0 \\
0.0 \\
0.0 \\
0.0 \\
0.0 \\
0.0\end{array}$ & $\begin{array}{r}\text { ETSR } \\
0.0 \\
0.0 \\
0.0 \\
0.0 \\
0.0 \\
0.0 \\
0.0 \\
0.0\end{array}$ \\
\hline WITH OUT & $\begin{array}{r}\text { WDOC } \\
\text { ON }\end{array}$ & $\begin{array}{r}\text { NWDO } \\
1\end{array}$ & $\begin{array}{r}\text { NIWDO } \\
9\end{array}$ & & & & & & \\
\hline WITH DAT & $\begin{array}{r}\text { WDOD } \\
1.0\end{array}$ & WDOD & WDOD & WDOD & WDOD & WDOD & WDOD & WDOD & WDOD \\
\hline WITH FRE & $\begin{array}{r}\text { WDOF } \\
0.1\end{array}$ & WDOF & WDOF & WDOF & WDOF & WDOF & WDOF & WDOF & WDOF \\
\hline WITH SEG & $\begin{array}{r}\text { IWDO } \\
321\end{array}$ & $\begin{array}{r}\text { IWDO } \\
28\end{array}$ & $\begin{array}{r}\text { IWDO } \\
174\end{array}$ & $\begin{array}{r}\text { IWDO } \\
282\end{array}$ & $\begin{array}{r}\text { IWDO } \\
193\end{array}$ & $\begin{array}{r}\text { IWDO } \\
59\end{array}$ & $\begin{array}{r}\text { IWDO } \\
145\end{array}$ & $\begin{array}{r}\text { IWDO } \\
128\end{array}$ & $\begin{array}{r}\text { IWDO } \\
6\end{array}$ \\
\hline RESTART & $\begin{array}{r}\text { RSOC } \\
\text { ON }\end{array}$ & $\begin{array}{r}\text { NRSO } \\
1\end{array}$ & $\begin{array}{r}\text { RSIC } \\
\text { ON }\end{array}$ & & & & & & \\
\hline RSO DATE & $\begin{array}{l}\text { RSOD } \\
20.0\end{array}$ & RSOD & RSOD & RSOD & RSOD & RSOD & RSOD & RSOD & RSOD \\
\hline RSO FREQ & $\begin{array}{l}\text { RSOF } \\
20.0\end{array}$ & RSOF & $\mathrm{RSOF}$ & $\mathrm{RSOF}$ & $\mathrm{RSOF}$ & $\mathrm{RSOF}$ & $\mathrm{RSOF}$ & $\mathrm{RSOF}$ & $\mathrm{RSOF}$ \\
\hline CST COMP & $\begin{array}{r}\mathrm{CCC} \\
\mathrm{ON}\end{array}$ & $\begin{array}{r}\text { LIMC } \\
\text { OFF }\end{array}$ & $\begin{array}{r}\text { CUF } \\
20\end{array}$ & & & & & & \\
\hline $\begin{array}{l}\text { CST ACTIVE } \\
\text { TDS } \\
\text { Gen1 } \\
\text { Gen2 } \\
\text { Gen3 } \\
\text { Gen4 } \\
\text { Gen5 } \\
\text { Gen6 } \\
\text { Gen7 } \\
\text { Gen8 } \\
\text { Gen9 } \\
\text { Gen10 }\end{array}$ & $\begin{array}{r}\text { CAC } \\
\text { ON } \\
\text { ON } \\
\text { ON } \\
\text { ON } \\
\text { OFF } \\
\text { OFF } \\
\text { OFF } \\
\text { OFF } \\
\text { OFF } \\
\text { OFF } \\
\text { OFF }\end{array}$ & & & & & & & & \\
\hline
\end{tabular}




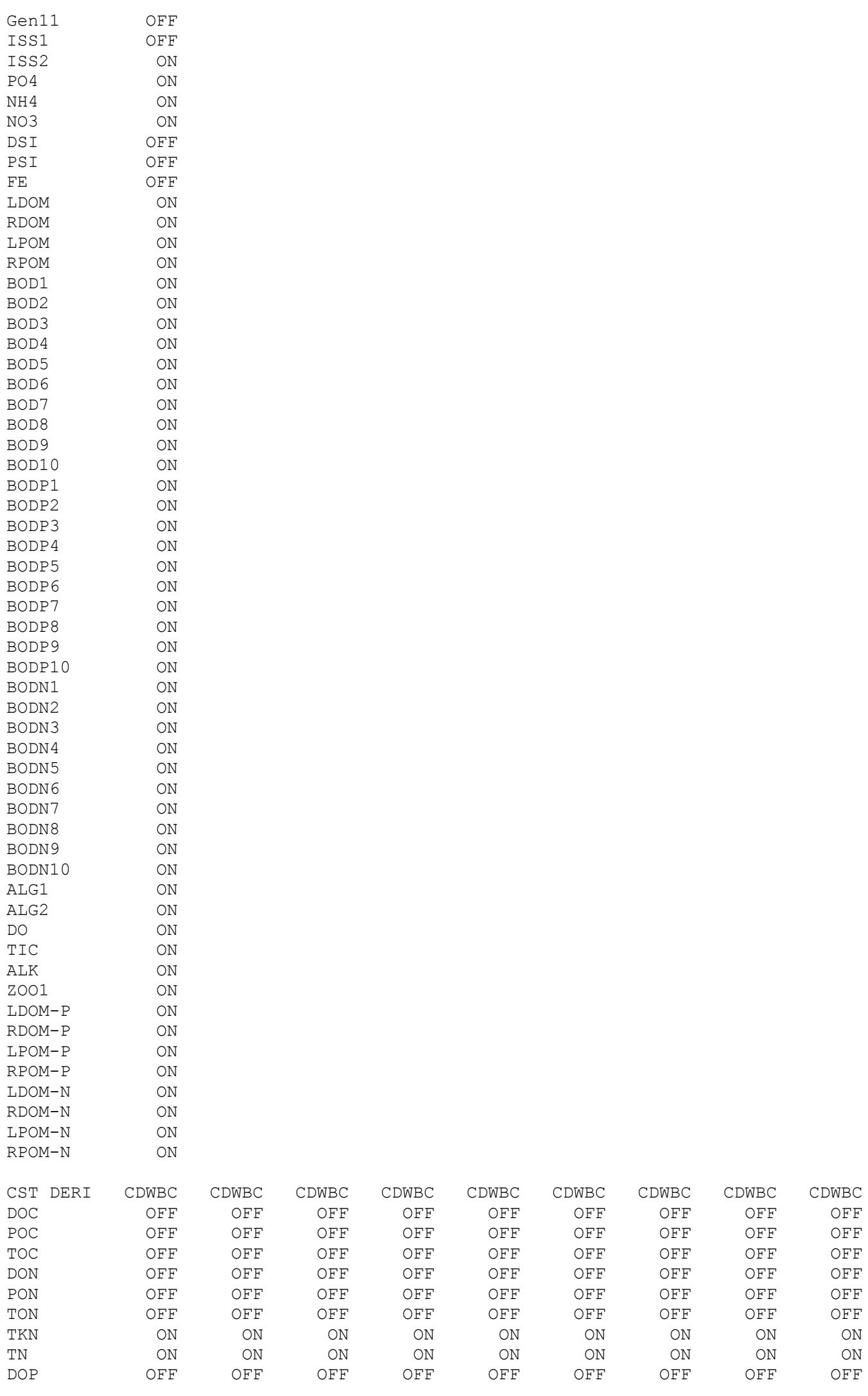




\begin{tabular}{|c|c|c|c|c|c|c|c|c|c|}
\hline $\mathrm{POP}$ & $\mathrm{OFF}$ & $\mathrm{OFF}$ & $\mathrm{OFF}$ & $\mathrm{OFF}$ & $\mathrm{OFF}$ & OFF & $\mathrm{OFF}$ & $\mathrm{OFF}$ & $\mathrm{OFF}$ \\
\hline TOP & $\mathrm{OFF}$ & OFF & $\mathrm{OFF}$ & $\mathrm{OFF}$ & $\mathrm{OFF}$ & OFF & $\mathrm{OFF}$ & $\mathrm{OFF}$ & $\mathrm{OFF}$ \\
\hline $\mathrm{TP}$ & ON & ON & $\mathrm{ON}$ & ON & $\mathrm{ON}$ & ON & ON & $\mathrm{ON}$ & $\mathrm{ON}$ \\
\hline $\mathrm{APR}$ & $\mathrm{OFF}$ & OFF & $\mathrm{OFF}$ & $\mathrm{OFF}$ & $\mathrm{OFF}$ & $\mathrm{OFF}$ & $\mathrm{OFF}$ & $\mathrm{OFF}$ & $\mathrm{OFF}$ \\
\hline CHLA & ON & ON & $\mathrm{ON}$ & $\mathrm{ON}$ & $\mathrm{ON}$ & ON & $\mathrm{ON}$ & $\mathrm{ON}$ & $\mathrm{ON}$ \\
\hline ATOT & $\mathrm{OFF}$ & $\mathrm{OFF}$ & $\mathrm{OFF}$ & $\mathrm{OFF}$ & $\mathrm{OFF}$ & $\mathrm{OFF}$ & $\mathrm{OFF}$ & $\mathrm{OFF}$ & $\mathrm{OFF}$ \\
\hline$\%$ DO & $\mathrm{OFF}$ & $\mathrm{OFF}$ & $\mathrm{OFF}$ & $\mathrm{OFF}$ & $\mathrm{OFF}$ & $\mathrm{OFF}$ & $\mathrm{OFF}$ & $\mathrm{OFF}$ & $\mathrm{OFF}$ \\
\hline TSS & ON & ON & ON & ON & $\mathrm{ON}$ & ON & ON & $\mathrm{ON}$ & $\mathrm{ON}$ \\
\hline TISS & $\mathrm{OFF}$ & OFF & $\mathrm{OFF}$ & OFF & OFF & OFF & OFF & OFF & $\mathrm{OFF}$ \\
\hline CBOD & $\mathrm{OFF}$ & $\mathrm{OFF}$ & $\mathrm{OFF}$ & $\mathrm{OFF}$ & $\mathrm{OFF}$ & $\mathrm{OFF}$ & $\mathrm{OFF}$ & $\mathrm{OFF}$ & $\mathrm{OFF}$ \\
\hline $\mathrm{pH}$ & ON & ON & ON & $\mathrm{ON}$ & $\mathrm{ON}$ & ON & $\mathrm{ON}$ & $\mathrm{ON}$ & $\mathrm{ON}$ \\
\hline $\mathrm{CO} 2$ & $\mathrm{OFF}$ & OFF & $\mathrm{OFF}$ & $\mathrm{OFF}$ & $\mathrm{OFF}$ & OFF & $\mathrm{OFF}$ & $\mathrm{OFF}$ & $\mathrm{OFF}$ \\
\hline $\mathrm{HCO} 3$ & $\mathrm{OFF}$ & OFF & $\mathrm{OFF}$ & $\mathrm{OFF}$ & $\mathrm{OFF}$ & OFF & $\mathrm{OFF}$ & $\mathrm{OFF}$ & $\mathrm{OFF}$ \\
\hline $\mathrm{CO} 3$ & $\mathrm{OFF}$ & OFF & $\mathrm{OFF}$ & $\mathrm{OFF}$ & $\mathrm{OFF}$ & OFF & $\mathrm{OFF}$ & $\mathrm{OFF}$ & $\mathrm{OFF}$ \\
\hline CST FLUX & CFWBC & CEWBC & CEWBC & CFWBC & CEWBC & CFWBC & CFWBC & CEWBC & CEWBC \\
\hline TISSIN & $\mathrm{OFF}$ & OFF & OFF & OFF & OFF & OFF & OFF & OFF & OFF \\
\hline TISSOUT & OFF & OFF & $\mathrm{OFF}$ & OFF & OFF & OFF & OFF & OFF & $\mathrm{OFF}$ \\
\hline PO4AR & ON & $\mathrm{ON}$ & $\mathrm{ON}$ & ON & $\mathrm{ON}$ & ON & ON & $\mathrm{ON}$ & ON \\
\hline PO4AG & ON & ON & ON & ON & ON & $\mathrm{ON}$ & ON & ON & $\mathrm{ON}$ \\
\hline $\mathrm{PO} 4 \mathrm{AP}$ & ON & $\mathrm{ON}$ & ON & ON & ON & $\mathrm{ON}$ & ON & $\mathrm{ON}$ & $\mathrm{ON}$ \\
\hline PO4ER & ON & ON & ON & ON & ON & $\mathrm{ON}$ & ON & ON & $\mathrm{ON}$ \\
\hline PO4EG & ON & $\mathrm{ON}$ & ON & ON & ON & $\mathrm{ON}$ & ON & ON & $\mathrm{ON}$ \\
\hline PO4EP & ON & ON & ON & ON & ON & $\mathrm{ON}$ & ON & ON & $\mathrm{ON}$ \\
\hline PO 4 POM & ON & ON & ON & ON & ON & $\mathrm{ON}$ & ON & ON & $\mathrm{ON}$ \\
\hline PO4DOM & $\mathrm{ON}$ & $\mathrm{ON}$ & ON & ON & ON & $\mathrm{ON}$ & ON & ON & $\mathrm{ON}$ \\
\hline $\mathrm{PO} 4 \mathrm{OM}$ & ON & ON & ON & ON & ON & $\mathrm{ON}$ & ON & ON & $\mathrm{ON}$ \\
\hline PO4SED & $\mathrm{ON}$ & ON & ON & $\mathrm{ON}$ & ON & ON & $\mathrm{ON}$ & ON & $\mathrm{ON}$ \\
\hline PO4SOD & ON & ON & ON & ON & ON & $\mathrm{ON}$ & ON & ON & $\mathrm{ON}$ \\
\hline PO4SET & ON & $\mathrm{ON}$ & ON & ON & ON & $\mathrm{ON}$ & ON & ON & $\mathrm{ON}$ \\
\hline NH4NITR & ON & $\mathrm{ON}$ & ON & $\mathrm{ON}$ & ON & ON & ON & ON & $\mathrm{ON}$ \\
\hline $\mathrm{NH} 4 \mathrm{AR}$ & ON & $\mathrm{ON}$ & ON & ON & ON & $\mathrm{ON}$ & ON & ON & $\mathrm{ON}$ \\
\hline $\mathrm{NH} 4 \mathrm{AG}$ & ON & $\mathrm{ON}$ & ON & ON & ON & $\mathrm{ON}$ & ON & ON & $\mathrm{ON}$ \\
\hline $\mathrm{NH} 4 \mathrm{AP}$ & ON & $\mathrm{ON}$ & ON & $\mathrm{ON}$ & ON & ON & $\mathrm{ON}$ & ON & $\mathrm{ON}$ \\
\hline NH4ER & ON & $\mathrm{ON}$ & ON & ON & ON & $\mathrm{ON}$ & ON & ON & $\mathrm{ON}$ \\
\hline $\mathrm{NH} 4 \mathrm{EG}$ & ON & $\mathrm{ON}$ & ON & ON & ON & $\mathrm{ON}$ & ON & ON & $\mathrm{ON}$ \\
\hline $\mathrm{NH} 4 \mathrm{EP}$ & $\mathrm{ON}$ & $\mathrm{ON}$ & ON & ON & ON & ON & $\mathrm{ON}$ & ON & $\mathrm{ON}$ \\
\hline $\mathrm{NH} 4 \mathrm{POM}$ & ON & $\mathrm{ON}$ & ON & ON & ON & $\mathrm{ON}$ & ON & ON & $\mathrm{ON}$ \\
\hline NH4 DOM & ON & $\mathrm{ON}$ & ON & $\mathrm{ON}$ & ON & $\mathrm{ON}$ & $\mathrm{ON}$ & ON & $\mathrm{ON}$ \\
\hline $\mathrm{NH} 4 \mathrm{OM}$ & ON & ON & ON & ON & ON & $\mathrm{ON}$ & ON & ON & $\mathrm{ON}$ \\
\hline NH4SED & ON & $\mathrm{ON}$ & ON & $\mathrm{ON}$ & ON & $\mathrm{ON}$ & $\mathrm{ON}$ & ON & $\mathrm{ON}$ \\
\hline $\mathrm{NH} 4 \mathrm{SOD}$ & $\mathrm{ON}$ & $\mathrm{ON}$ & ON & ON & ON & $\mathrm{ON}$ & ON & ON & $\mathrm{ON}$ \\
\hline NO3DEN & $\mathrm{ON}$ & $\mathrm{ON}$ & ON & ON & ON & $\mathrm{ON}$ & ON & ON & $\mathrm{ON}$ \\
\hline NO3AG & ON & $\mathrm{ON}$ & ON & ON & ON & $\mathrm{ON}$ & $\mathrm{ON}$ & ON & ON \\
\hline NO3EG & ON & $\mathrm{ON}$ & ON & ON & ON & $\mathrm{ON}$ & ON & ON & $\mathrm{ON}$ \\
\hline NO3SED & ON & ON & ON & ON & ON & ON & ON & ON & $\mathrm{ON}$ \\
\hline DSIAG & $\mathrm{OFF}$ & OFF & $\mathrm{OFF}$ & OFF & $\mathrm{OFF}$ & OFF & OFF & $\mathrm{OFF}$ & $\mathrm{OFF}$ \\
\hline DSIEG & $\mathrm{OFF}$ & $\mathrm{OFF}$ & $\mathrm{OFF}$ & $\mathrm{OFF}$ & $\mathrm{OFF}$ & $\mathrm{OFF}$ & $\mathrm{OFF}$ & $\mathrm{OFF}$ & $\mathrm{OFF}$ \\
\hline DSIPIS & OFF & OFF & $\mathrm{OFF}$ & OFF & OFF & OFF & OFF & OFF & $\mathrm{OFF}$ \\
\hline DSISED & $\mathrm{OFF}$ & OFF & $\mathrm{OFF}$ & $\mathrm{OFF}$ & OFF & $\mathrm{OFF}$ & $\mathrm{OFF}$ & OFF & $\mathrm{OFF}$ \\
\hline DSISOD & OFF & OFF & $\mathrm{OFF}$ & OFF & OFF & OFF & OFF & OFF & OFF \\
\hline DSISET & $\mathrm{OFF}$ & OFF & $\mathrm{OFF}$ & $\mathrm{OFF}$ & $\mathrm{OFF}$ & $\mathrm{OFF}$ & $\mathrm{OFF}$ & $\mathrm{OFF}$ & $\mathrm{OFF}$ \\
\hline PSIAM & OFF & OFF & $\mathrm{OFF}$ & OFF & OFF & OFF & OFF & OFF & OFF \\
\hline PS INET & $\mathrm{OFF}$ & OFF & $\mathrm{OFF}$ & OFF & OFF & $\mathrm{OFF}$ & OFF & OFF & $\mathrm{OFF}$ \\
\hline PSIDK & $\mathrm{OFF}$ & OFF & $\mathrm{OFF}$ & OFF & OFF & OFF & OFF & OFF & OFF \\
\hline FESET & $\mathrm{OFF}$ & $\mathrm{OFF}$ & OFF & OFF & OFF & $\mathrm{OFF}$ & OFF & OFF & $\mathrm{OFF}$ \\
\hline FESED & OFF & OFF & OFF & OFF & OFF & OFF & OFF & OFF & OFF \\
\hline LDOMDK & $\mathrm{OFF}$ & OFF & $\mathrm{OFF}$ & $\mathrm{OFF}$ & $\mathrm{OFF}$ & OFF & $\mathrm{OFF}$ & $\mathrm{OFF}$ & OFF \\
\hline LRDOM & $\mathrm{OFF}$ & OFF & $\mathrm{OFF}$ & $\mathrm{OFF}$ & $\mathrm{OFF}$ & OFF & OFF & OFF & OFF \\
\hline RDOMDK & $\mathrm{OFF}$ & OFF & $\mathrm{OFF}$ & $\mathrm{OFF}$ & $\mathrm{OFF}$ & OFF & $\mathrm{OFF}$ & $\mathrm{OFF}$ & OFF \\
\hline LDOMAP & $\mathrm{OFF}$ & OFF & $\mathrm{OFF}$ & $\mathrm{OFF}$ & $\mathrm{OFF}$ & OFF & $\mathrm{OFF}$ & $\mathrm{OFF}$ & OFF \\
\hline LDOMEP & $\mathrm{OFF}$ & OFF & $\mathrm{OFF}$ & OFF & $\mathrm{OFF}$ & OFF & OFF & $\mathrm{OFF}$ & $\mathrm{OFF}$ \\
\hline LPOMDK & $\mathrm{OFF}$ & $\mathrm{OFF}$ & $\mathrm{OFF}$ & $\mathrm{OFF}$ & $\mathrm{OFF}$ & $\mathrm{OFF}$ & $\mathrm{OFF}$ & $\mathrm{OFF}$ & $\mathrm{OFF}$ \\
\hline LRPOM & $\mathrm{OFF}$ & $\mathrm{OFF}$ & $\mathrm{OFF}$ & $\mathrm{OFF}$ & $\mathrm{OFF}$ & $\mathrm{OFF}$ & $\mathrm{OFF}$ & $\mathrm{OFF}$ & $\mathrm{OFF}$ \\
\hline RPOMDK & $\mathrm{OFF}$ & $\mathrm{OFF}$ & $\mathrm{OFF}$ & $\mathrm{OFF}$ & $\mathrm{OFE}$ & $\mathrm{OFF}$ & $\mathrm{OFF}$ & $\mathrm{OFE}$ & OFF \\
\hline LPOMAP & $\mathrm{OFF}$ & $\mathrm{OFF}$ & $\mathrm{OFF}$ & $\mathrm{OFF}$ & $\mathrm{OFE}$ & $\mathrm{OFF}$ & $\mathrm{OFF}$ & $\mathrm{OFE}$ & $\mathrm{OFF}$ \\
\hline LPOMEP & $\mathrm{OFF}$ & $\mathrm{OFF}$ & $\mathrm{OFF}$ & $\mathrm{OFF}$ & $\mathrm{OFF}$ & $\mathrm{OFF}$ & $\mathrm{OFF}$ & $\mathrm{OFF}$ & $\mathrm{OFF}$ \\
\hline LPOMSET & $\mathrm{OFF}$ & OFF & $\mathrm{OFF}$ & $\mathrm{OFF}$ & $\mathrm{OFF}$ & $\mathrm{OFF}$ & $\mathrm{OFF}$ & OFF & $\mathrm{OFF}$ \\
\hline
\end{tabular}




$\begin{array}{lrrrrrrrrr}\text { RPOMSET } & \text { OFF } & \text { OFF } & \text { OFF } & \text { OFF } & \text { OFF } & \text { OFF } & \text { OFF } & \text { OFF } & \text { OFF } \\ \text { CBODDK } & \text { OFF } & \text { OFF } & \text { OFF } & \text { OFF } & \text { OFF } & \text { OFF } & \text { OFF } & \text { OFF } & \text { OFF } \\ \text { DOAP } & \text { ON } & \text { ON } & \text { ON } & \text { ON } & \text { ON } & \text { ON } & \text { ON } & \text { ON } & \text { ON } \\ \text { DOAR } & \text { ON } & \text { ON } & \text { ON } & \text { ON } & \text { ON } & \text { ON } & \text { ON } & \text { ON } & \text { ON } \\ \text { DOEP } & \text { ON } & \text { ON } & \text { ON } & \text { ON } & \text { ON } & \text { ON } & \text { ON } & \text { ON } & \text { ON } \\ \text { DOER } & \text { ON } & \text { ON } & \text { ON } & \text { ON } & \text { ON } & \text { ON } & \text { ON } & \text { ON } & \text { ON } \\ \text { DOPOM } & \text { ON } & \text { ON } & \text { ON } & \text { ON } & \text { ON } & \text { ON } & \text { ON } & \text { ON } & \text { ON } \\ \text { DODOM } & \text { ON } & \text { ON } & \text { ON } & \text { ON } & \text { ON } & \text { ON } & \text { ON } & \text { ON } & \text { ON } \\ \text { DOOM } & \text { ON } & \text { ON } & \text { ON } & \text { ON } & \text { ON } & \text { ON } & \text { ON } & \text { ON } & \text { ON } \\ \text { DONITR } & \text { ON } & \text { ON } & \text { ON } & \text { ON } & \text { ON } & \text { ON } & \text { ON } & \text { ON } & \text { ON } \\ \text { DOCBOD } & \text { ON } & \text { ON } & \text { ON } & \text { ON } & \text { ON } & \text { ON } & \text { ON } & \text { ON } & \text { ON } \\ \text { DOREAR } & \text { ON } & \text { ON } & \text { ON } & \text { ON } & \text { ON } & \text { ON } & \text { ON } & \text { ON } & \text { ON } \\ \text { DOSED } & \text { ON } & \text { ON } & \text { ON } & \text { ON } & \text { ON } & \text { ON } & \text { ON } & \text { ON } & \text { ON } \\ \text { DOSOD } & \text { ON } & \text { ON } & \text { ON } & \text { ON } & \text { ON } & \text { ON } & \text { ON } & \text { ON } & \text { ON } \\ \text { TICAG } & \text { ON } & \text { ON } & \text { ON } & \text { ON } & \text { ON } & \text { ON } & \text { ON } & \text { ON } & \text { ON } \\ \text { TICEG } & \text { ON } & \text { ON } & \text { ON } & \text { ON } & \text { ON } & \text { ON } & \text { ON } & \text { ON } & \text { ON } \\ \text { SEDDK } & \text { OFF } & \text { OFF } & \text { OFF } & \text { OFF } & \text { OFF } & \text { OFF } & \text { OFF } & \text { OFF } & \text { OFF } \\ \text { SEDAS } & \text { OFF } & \text { OFF } & \text { OFF } & \text { OFF } & \text { OFF } & \text { OFF } & \text { OFF } & \text { OFF } & \text { OFF } \\ \text { SEDLPOM } & \text { OFF } & \text { OFF } & \text { OFF } & \text { OFF } & \text { OFF } & \text { OFF } & \text { OFF } & \text { OFF } & \text { OFF } \\ \text { SEDSET } & \text { OFF } & \text { OFF } & \text { OFF } & \text { OFF } & \text { OFF } & \text { OFF } & \text { OFF } & \text { OFF } & \text { OFF } \\ \text { SODDK } & \text { OFF } & \text { OFF } & \text { OFF } & \text { OFF } & \text { OFF } & \text { OFF } & \text { OFF } & \text { OFF } & O F F \\ & & & & & & & & & \end{array}$

CST ICON C2IWB C2IWB C2IWB C2IWB C2IWB C2IWB C2IWB C2IWB C2IWB

TDS $\quad 57.000057 .0000 \quad 57.000057 .000057 .000057 .000057 .000057 .000057 .0000$

Gen1 $\quad 0.00000 \quad 0.00000 \quad 0.00000 \quad 0.00000 \quad 0.00000 \quad 0.00000 \quad 0.00000 \quad 0.00000 \quad 0.00000$

Gen2 $\quad 0.00000 \quad 0.00000 \quad 0.00000 \quad 0.00000 \quad 0.00000 \quad 0.00000 \quad 0.00000 \quad 0.00000 \quad 0.00000$

Gen3 $\quad 0.00000 \quad 0.00000 \quad 0.00000 \quad 0.00000 \quad 0.00000 \quad 0.00000 \quad 0.00000 \quad 0.00000 \quad 0.00000$

Gen4 $\quad 6.06000 \quad 6.06000 \quad 6.06000 \quad 6.06000 \quad 6.06000 \quad 6.06000 \quad 6.06000 \quad 6.06000 \quad 6.06000$

Gen5 $\quad 0.00000 \quad 0.00000 \quad 0.00000 \quad 0.00000 \quad 0.00000 \quad 0.00000 \quad 0.00000 \quad 0.00000 \quad 0.00000$

Gen6 $\quad 0.00000 \quad 0.00000 \quad 0.00000 \quad 0.00000 \quad 0.00000 \quad 0.00000 \quad 0.00000 \quad 0.00000 \quad 0.00000$

Gen7 $\quad 0.00000 \quad 0.00000 \quad 0.00000 \quad 0.00000 \quad 0.00000 \quad 0.00000 \quad 0.00000 \quad 0.00000 \quad 0.00000$

Gen8 $\quad 0.00000 \quad 0.00000 \quad 0.00000 \quad 0.00000 \quad 0.00000 \quad 0.00000 \quad 0.00000 \quad 0.00000 \quad 0.00000$

Gen9 $\quad 0.00000 \quad 0.00000 \quad 0.00000 \quad 0.00000 \quad 0.00000 \quad 0.00000 \quad 0.00000 \quad 0.00000 \quad 0.00000$

$\begin{array}{lllllllllll}\text { Gen10 } & 0.00000 & 0.00000 & 0.00000 & 0.00000 & 0.00000 & 0.00000 & 0.00000 & 0.00000 & 0.00000\end{array}$

$\begin{array}{llllllllll}\text { Gen11 } & 28.4250 & 28.4250 & 28.4250 & 28.4250 & 28.4250 & 28.4250 & 28.4250 & 28.4250 & 28.4250\end{array}$

ISS1 $\quad 0.00000 \quad 0.00000 \quad 0.000000 .00000 \quad 0.000000 .00000 \quad 0.00000 \quad 0.00000 \quad 0.00000$

ISS2 $\quad 7.70000 \quad 7.70000 \quad 7.70000 \quad 7.70000 \quad 7.70000 \quad 7.70000 \quad 7.70000 \quad 7.700007 .70000$

PO4 $\quad \begin{array}{llllllllll}0.04800 & 0.04800 & 0.04800 & 0.04800 & 0.04800 & 0.04800 & 0.04800 & 0.04800 & 0.04800\end{array}$

$\begin{array}{lllllllllll}\mathrm{NH} 4 & 0.01000 & 0.01000 & 0.01000 & 0.01000 & 0.01000 & 0.01000 & 0.01000 & 0.01000 & 0.01000\end{array}$

NO3 $\quad 0.50000 \quad 0.50000 \quad 0.50000 \quad 0.50000 \quad 0.50000 \quad 0.50000 \quad 0.50000 \quad 0.50000 \quad 0.50000$

DSI $\quad 0.00000 \quad 0.00000 \quad 0.00000 \quad 0.00000 \quad 0.00000 \quad 0.00000 \quad 0.00000 \quad 0.00000 \quad 0.00000$

PSI $\quad 0.00000 \quad 0.00000 \quad 0.00000 \quad 0.00000 \quad 0.00000 \quad 0.00000 \quad 0.00000 \quad 0.00000 \quad 0.00000$

$\begin{array}{llllllllll}\text { FE } & 0.10000 & 0.10000 & 0.10000 & 0.10000 & 0.10000 & 0.10000 & 0.10000 & 0.10000 & 0.10000\end{array}$

LDOM $\quad \begin{array}{lllllllll}2.88900 & 2.88900 & 2.88900 & 2.88900 & 2.88900 & 2.88900 & 2.88900 & 2.88900 & 2.88900\end{array}$

RDOM $\quad \begin{array}{lllllllll}2.88900 & 2.88900 & 2.88900 & 2.88900 & 2.88900 & 2.88900 & 2.88900 & 2.88900 & 2.88900\end{array}$

LPOM $\quad \begin{array}{lllllllllll}0.86900 & 0.86900 & 0.86900 & 0.86900 & 0.86900 & 0.86900 & 0.86900 & 0.86900 & 0.86900\end{array}$

RPOM $\quad \begin{array}{lllllllllll}0.86900 & 0.86900 & 0.86900 & 0.86900 & 0.86900 & 0.86900 & 0.86900 & 0.86900 & 0.86900\end{array}$

$\begin{array}{lllllllllll}\text { BOD1 } & 0.00000 & 0.00000 & 0.00000 & 0.00000 & 0.00000 & 0.00000 & 0.00000 & 0.00000 & 0.00000\end{array}$

$\begin{array}{llllllllll}\text { BOD2 } & 0.00000 & 0.00000 & 0.00000 & 0.00000 & 0.00000 & 0.00000 & 0.00000 & 0.00000 & 0.00000\end{array}$

$\begin{array}{lllllllllll}\text { BOD3 } & 0.00000 & 0.00000 & 0.00000 & 0.00000 & 0.00000 & 0.00000 & 0.00000 & 0.00000 & 0.00000\end{array}$

$\begin{array}{lllllllllll}\text { BOD4 } & 0.00000 & 0.00000 & 0.00000 & 0.00000 & 0.00000 & 0.00000 & 0.00000 & 0.00000 & 0.00000\end{array}$

BOD5 $\quad 0.00000 \quad 0.00000 \quad 0.00000 \quad 0.00000 \quad 0.00000 \quad 0.00000 \quad 0.00000 \quad 0.00000 \quad 0.00000$

$\begin{array}{lllllllllll}\text { BOD6 } & 0.00000 & 0.00000 & 0.00000 & 0.00000 & 0.00000 & 0.00000 & 0.00000 & 0.00000 & 0.00000\end{array}$

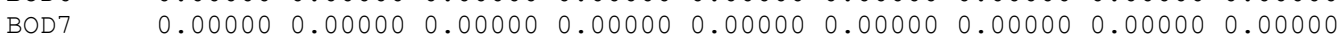

BOD8 $\quad 0.00000 \quad 0.00000 \quad 0.00000 \quad 0.00000 \quad 0.00000 \quad 0.00000 \quad 0.00000 \quad 0.00000 \quad 0.00000$

BOD9 $\quad 0.00000 \quad 0.00000 \quad 0.00000 \quad 0.00000 \quad 0.00000 \quad 0.00000 \quad 0.00000 \quad 0.00000 \quad 0.00000$

$\begin{array}{lllllllllll}\text { BOD10 } & 0.00000 & 0.00000 & 0.00000 & 0.00000 & 0.00000 & 0.00000 & 0.00000 & 0.00000 & 0.00000\end{array}$

$\begin{array}{lllllllllll}\text { BODP1 } & 0.00000 & 0.00000 & 0.00000 & 0.00000 & 0.00000 & 0.00000 & 0.00000 & 0.00000 & 0.00000\end{array}$

$\begin{array}{llllllllllll}\text { BODP2 } & 0.00000 & 0.00000 & 0.00000 & 0.00000 & 0.00000 & 0.00000 & 0.00000 & 0.00000 & 0.00000\end{array}$

$\begin{array}{lllllllllll}\text { BODP3 } & 0.00000 & 0.00000 & 0.00000 & 0.00000 & 0.00000 & 0.00000 & 0.00000 & 0.00000 & 0.00000\end{array}$

$\begin{array}{lllllllllll}\text { BODP4 } & 0.00000 & 0.00000 & 0.00000 & 0.00000 & 0.00000 & 0.00000 & 0.00000 & 0.00000 & 0.00000\end{array}$

$\begin{array}{lllllllllll}\text { BODP5 } & 0.00000 & 0.00000 & 0.00000 & 0.00000 & 0.00000 & 0.00000 & 0.00000 & 0.00000 & 0.00000\end{array}$

$\begin{array}{llllllllll}\text { BODP6 } & 0.00000 & 0.00000 & 0.00000 & 0.00000 & 0.00000 & 0.00000 & 0.00000 & 0.00000 & 0.00000\end{array}$

$\begin{array}{lllllllllll}\text { BODP7 } & 0.00000 & 0.00000 & 0.00000 & 0.00000 & 0.00000 & 0.00000 & 0.00000 & 0.00000 & 0.00000\end{array}$

BODP8 $\quad 0.00000 \quad 0.00000 \quad 0.00000 \quad 0.00000 \quad 0.00000 \quad 0.00000 \quad 0.00000 \quad 0.00000 \quad 0.00000$

$\begin{array}{llllllllllll}\text { BODP9 } & 0.00000 & 0.00000 & 0.00000 & 0.00000 & 0.00000 & 0.00000 & 0.00000 & 0.00000 & 0.00000\end{array}$

BODP10 $0.00000 \quad 0.00000 \quad 0.00000 \quad 0.00000 \quad 0.00000 \quad 0.00000 \quad 0.00000 \quad 0.00000 \quad 0.00000$

BODN1 $\quad 0.00000 \quad 0.00000 \quad 0.00000 \quad 0.00000 \quad 0.00000 \quad 0.00000 \quad 0.00000 \quad 0.00000 \quad 0.00000$ 


\begin{tabular}{|c|c|c|c|c|c|c|c|c|c|}
\hline BODN2 & 0.00000 & 0.00000 & 0.00000 & 0.00000 & 0.00000 & 0.00000 & 0.00000 & 0.00000 & 0.00000 \\
\hline BODN3 & 0.00000 & 0.00000 & 0.00000 & 0.00000 & 0.00000 & 0.00000 & 0.00000 & 0.00000 & 0.00000 \\
\hline BODN4 & 0.00000 & 0.00000 & 0.00000 & 0.00000 & 0.00000 & 0.00000 & 0.00000 & 0.00000 & 0.00000 \\
\hline 3ODN5 & 0.00000 & 0.00000 & 0.00000 & 0.00000 & 0.00000 & 0.00000 & 0.00000 & 0.00000 & 0.00000 \\
\hline 3ODN6 & 0.00000 & 0.00000 & 0.00000 & 0.00000 & 0.00000 & 0.00000 & 0.00000 & 0.00000 & 0.00000 \\
\hline BODN7 & 0.00000 & 0.00000 & 0.00000 & 0.00000 & 0.00000 & 0.00000 & 0.00000 & 0.00000 & 0.00000 \\
\hline BODN8 & 0.00000 & 0.00000 & 0.00000 & 0.00000 & 0.00000 & 0.00000 & 0.00000 & 0.00000 & 0.00000 \\
\hline ODN9 & 0.00000 & 0.00000 & 0.00000 & 0.00000 & 0.00000 & 0.00000 & 0.00000 & 0.00000 & 0.00000 \\
\hline ODN10 & 0.00000 & 0.00000 & 0.00000 & 0.00000 & 0.00000 & 0.00000 & 0.00000 & 0.00000 & 0.00000 \\
\hline ALG1 & 0.10000 & 0.10000 & 0.10000 & 0.10000 & 0.10000 & 0.10000 & 0.10000 & 0.10000 & 0.10000 \\
\hline ALG2 & 0.00000 & 0.00000 & 0.00000 & 0.00000 & 0.00000 & 0.00000 & 0.00000 & 0.00000 & 0.00000 \\
\hline DO & 6.14000 & 6.14000 & 6.14000 & 6.14000 & 6.14000 & 6.14000 & 6.14000 & 6.14000 & 6.14000 \\
\hline TIC & 5.13000 & 5.13000 & 5.13000 & 5.13000 & 5.13000 & 5.13000 & 5.13000 & 5.13000 & 5.13000 \\
\hline ALK & 16.5050 & 16.5050 & 16.5050 & 16.5050 & 16.5050 & 16.5050 & 16.5050 & 16.5050 & 16.5050 \\
\hline 2001 & 0.01000 & 0.01000 & 0.01000 & 0.01000 & 0.01000 & 0.01000 & 0.01000 & 0.01000 & 0.01000 \\
\hline LDOM-P & 0.00589 & 0.00589 & 0.00589 & 0.00589 & 0.00589 & 0.00589 & 0.00589 & 0.00589 & 0.00589 \\
\hline $\mathrm{RDOM}-\mathrm{P}$ & 0.00589 & 0.00589 & 0.00589 & 0.00589 & 0.00589 & 0.00589 & 0.00589 & 0.00589 & 0.00589 \\
\hline LPOM-P & 0.00169 & 0.00169 & 0.00169 & 0.00169 & 0.00169 & 0.00169 & 0.00169 & 0.00169 & 0.00169 \\
\hline RPOM-P & 0.00169 & 0.00169 & 0.00169 & 0.00169 & 0.00169 & 0.00169 & 0.00169 & 0.00169 & 0.00169 \\
\hline LDOM-N & 0.32450 & 0.32450 & 0.32450 & 0.32450 & 0.32450 & 0.32450 & 0.32450 & 0.32450 & 0.32450 \\
\hline RDOM-N & 0.32450 & 0.32450 & 0.32450 & 0.32450 & 0.32450 & 0.32450 & 0.32450 & 0.32450 & 0.32450 \\
\hline LPOM-N & 0.07350 & 0.07350 & 0.07350 & 0.07350 & 0.07350 & 0.07350 & 0.07350 & 0.07350 & 0.07350 \\
\hline $\mathrm{RPOM}-\mathrm{N}$ & 0.07350 & 0.07350 & 0.07350 & 0.07350 & 0.07350 & 0.07350 & 0.07350 & 0.07350 & 0.07350 \\
\hline CST PRIN & CPRWBC & CPRWBC & CPRWBC & CPRWBC & CPRWBC & CPRWBC & CPRWBC & CPRWBC & CPRWBC \\
\hline TDS & $\mathrm{ON}$ & $\mathrm{ON}$ & $\mathrm{ON}$ & $\mathrm{ON}$ & ON & $\mathrm{ON}$ & $\mathrm{ON}$ & ON & $\mathrm{ON}$ \\
\hline Gen1 & ON & ON & ON & ON & ON & ON & ON & ON & ON \\
\hline Gen2 & ON & ON & $\mathrm{ON}$ & ON & ON & ON & ON & ON & ON \\
\hline Gen3 & ON & ON & ON & $\mathrm{ON}$ & ON & ON & ON & ON & $\mathrm{ON}$ \\
\hline Gen 4 & $\mathrm{OFF}$ & $\mathrm{OFF}$ & $\mathrm{OFF}$ & $\mathrm{OFF}$ & $\mathrm{OFF}$ & $\mathrm{OFF}$ & $\mathrm{OFF}$ & $\mathrm{OFF}$ & OFF \\
\hline Gen5 & $\mathrm{OFF}$ & $\mathrm{OFF}$ & $\mathrm{OFF}$ & $\mathrm{OFF}$ & $\mathrm{OFF}$ & $\mathrm{OFF}$ & $\mathrm{OFF}$ & $\mathrm{OFF}$ & OFF \\
\hline Gen 6 & $\mathrm{OFF}$ & $\mathrm{OFF}$ & $\mathrm{OFF}$ & $\mathrm{OFF}$ & $\mathrm{OFF}$ & $\mathrm{OFF}$ & $\mathrm{OFF}$ & $\mathrm{OFF}$ & $\mathrm{OFF}$ \\
\hline Gen7 & $\mathrm{OFF}$ & $\mathrm{OFF}$ & $\mathrm{OFF}$ & $\mathrm{OFF}$ & $\mathrm{OFF}$ & $\mathrm{OFF}$ & $\mathrm{OFF}$ & $\mathrm{OFF}$ & $\mathrm{OFF}$ \\
\hline Gen 8 & $\mathrm{OFF}$ & $\mathrm{OFF}$ & $\mathrm{OFF}$ & $\mathrm{OFF}$ & $\mathrm{OFF}$ & $\mathrm{OFF}$ & $\mathrm{OFF}$ & $\mathrm{OFF}$ & $\mathrm{OFF}$ \\
\hline Gen9 & $\mathrm{OFF}$ & $\mathrm{OFF}$ & $\mathrm{OFF}$ & $\mathrm{OFF}$ & $\mathrm{OFF}$ & $\mathrm{OFF}$ & $\mathrm{OFF}$ & $\mathrm{OFF}$ & $\mathrm{OFF}$ \\
\hline Gen10 & $\mathrm{OFF}$ & $\mathrm{OFF}$ & $\mathrm{OFF}$ & $\mathrm{OFF}$ & $\mathrm{OFF}$ & $\mathrm{OFF}$ & $\mathrm{OFF}$ & $\mathrm{OFF}$ & $\mathrm{OFF}$ \\
\hline Gen11 & $\mathrm{OFF}$ & $\mathrm{OFF}$ & $\mathrm{OFF}$ & $\mathrm{OFF}$ & $\mathrm{OFF}$ & $\mathrm{OFF}$ & $\mathrm{OFF}$ & $\mathrm{OFF}$ & OFF \\
\hline ISS1 & $\mathrm{ON}$ & ON & ON & $\mathrm{ON}$ & ON & $\mathrm{ON}$ & ON & ON & ON \\
\hline ISS2 & $\mathrm{OFF}$ & $\mathrm{OFF}$ & $\mathrm{OFF}$ & $\mathrm{OFF}$ & $\mathrm{OFF}$ & $\mathrm{OFF}$ & $\mathrm{OFF}$ & $\mathrm{OFF}$ & $\mathrm{OFF}$ \\
\hline $\mathrm{PO} 4$ & $\mathrm{ON}$ & ON & ON & ON & ON & $\mathrm{ON}$ & ON & $\mathrm{ON}$ & $\mathrm{ON}$ \\
\hline NH 4 & ON & ON & ON & ON & ON & ON & ON & ON & ON \\
\hline NO3 & ON & $\mathrm{ON}$ & ON & $\mathrm{ON}$ & ON & $\mathrm{ON}$ & $\mathrm{ON}$ & $\mathrm{ON}$ & $\mathrm{ON}$ \\
\hline DSI & $\mathrm{OFF}$ & $\mathrm{OFF}$ & $\mathrm{OFF}$ & $\mathrm{OFF}$ & $\mathrm{OFF}$ & $\mathrm{OFF}$ & $\mathrm{OFF}$ & $\mathrm{OFF}$ & $\mathrm{OFF}$ \\
\hline PSI & $\mathrm{OFF}$ & $\mathrm{OFF}$ & $\mathrm{OFF}$ & $\mathrm{OFF}$ & $\mathrm{OFF}$ & $\mathrm{OFF}$ & $\mathrm{OFF}$ & $\mathrm{OFF}$ & $\mathrm{OFF}$ \\
\hline $\mathrm{FE}$ & $\mathrm{OFF}$ & $\mathrm{OFF}$ & $\mathrm{OFF}$ & $\mathrm{OFF}$ & $\mathrm{OFF}$ & $\mathrm{OFF}$ & $\mathrm{OFF}$ & $\mathrm{OFF}$ & OFF \\
\hline LDOM & ON & ON & ON & ON & ON & $\mathrm{ON}$ & ON & $\mathrm{ON}$ & $\mathrm{ON}$ \\
\hline RDOM & ON & ON & ON & ON & ON & ON & ON & ON & ON \\
\hline LPOM & ON & $\mathrm{ON}$ & ON & ON & ON & ON & ON & ON & ON \\
\hline RPOM & ON & ON & ON & ON & ON & ON & ON & ON & ON \\
\hline BOD1 & ON & ON & ON & ON & ON & ON & ON & ON & ON \\
\hline BOD2 & ON & $\mathrm{ON}$ & ON & ON & ON & ON & $\mathrm{ON}$ & ON & ON \\
\hline BOD3 & ON & ON & ON & ON & ON & ON & ON & ON & ON \\
\hline BOD 4 & ON & ON & ON & ON & ON & ON & ON & ON & ON \\
\hline BOD5 & ON & ON & ON & ON & ON & ON & ON & ON & ON \\
\hline BOD 6 & ON & $\mathrm{ON}$ & ON & ON & ON & ON & ON & ON & ON \\
\hline BOD 7 & ON & ON & ON & ON & ON & ON & ON & ON & ON \\
\hline BOD8 & ON & ON & ON & ON & ON & ON & ON & ON & ON \\
\hline BOD9 & ON & ON & ON & ON & ON & ON & ON & ON & ON \\
\hline BOD10 & ON & ON & $\mathrm{ON}$ & ON & ON & ON & ON & ON & ON \\
\hline BODP1 & ON & ON & ON & ON & ON & ON & ON & ON & ON \\
\hline BODP2 & ON & ON & ON & ON & ON & ON & ON & ON & ON \\
\hline BODP3 & ON & ON & ON & ON & ON & ON & ON & ON & ON \\
\hline BODP 4 & ON & ON & ON & ON & ON & ON & ON & ON & ON \\
\hline BODP5 & ON & ON & $\mathrm{ON}$ & ON & ON & ON & ON & ON & ON \\
\hline BODP 6 & ON & ON & $\mathrm{ON}$ & ON & ON & ON & ON & $\mathrm{ON}$ & ON \\
\hline BODP7 & ON & ON & ON & ON & ON & ON & ON & ON & ON \\
\hline BODP8 & ON & ON & ON & ON & ON & ON & ON & ON & ON \\
\hline DP 9 & ON & ON & ON & ON & ON & ON & ON & ON & ON \\
\hline
\end{tabular}




\begin{tabular}{|c|c|c|c|c|c|c|c|c|c|}
\hline BODP10 & ON & ON & ON & $\mathrm{ON}$ & ON & ON & ON & ON & $\mathrm{ON}$ \\
\hline BODN1 & ON & ON & ON & ON & ON & ON & ON & ON & ON \\
\hline BODN2 & ON & ON & ON & ON & ON & $\mathrm{ON}$ & ON & $\mathrm{ON}$ & ON \\
\hline BODN3 & ON & ON & ON & ON & ON & ON & ON & $\mathrm{ON}$ & $\mathrm{ON}$ \\
\hline BODN4 & ON & ON & ON & ON & ON & $\mathrm{ON}$ & ON & $\mathrm{ON}$ & $\mathrm{ON}$ \\
\hline BODN5 & ON & ON & ON & ON & ON & $\mathrm{ON}$ & $\mathrm{ON}$ & $\mathrm{ON}$ & ON \\
\hline BODN 6 & ON & ON & ON & $\mathrm{ON}$ & ON & $\mathrm{ON}$ & ON & $\mathrm{ON}$ & $\mathrm{ON}$ \\
\hline BODN7 & ON & ON & ON & $\mathrm{ON}$ & ON & $\mathrm{ON}$ & ON & $\mathrm{ON}$ & $\mathrm{ON}$ \\
\hline BODN8 & ON & ON & ON & $\mathrm{ON}$ & ON & $\mathrm{ON}$ & ON & $\mathrm{ON}$ & $\mathrm{ON}$ \\
\hline BODN9 & $\mathrm{ON}$ & ON & ON & $\mathrm{ON}$ & ON & $\mathrm{ON}$ & $\mathrm{ON}$ & $\mathrm{ON}$ & $\mathrm{ON}$ \\
\hline BODN1 0 & ON & ON & ON & $\mathrm{ON}$ & ON & $\mathrm{ON}$ & ON & $\mathrm{ON}$ & $\mathrm{ON}$ \\
\hline ALG1 & ON & ON & ON & ON & ON & $\mathrm{ON}$ & ON & $\mathrm{ON}$ & $\mathrm{ON}$ \\
\hline ALG2 & $\mathrm{ON}$ & ON & ON & $\mathrm{ON}$ & ON & $\mathrm{ON}$ & $\mathrm{ON}$ & $\mathrm{ON}$ & $\mathrm{ON}$ \\
\hline DO & ON & ON & ON & $\mathrm{ON}$ & $\mathrm{ON}$ & $\mathrm{ON}$ & ON & $\mathrm{ON}$ & $\mathrm{ON}$ \\
\hline TIC & ON & ON & ON & $\mathrm{ON}$ & $\mathrm{ON}$ & ON & ON & ON & $\mathrm{ON}$ \\
\hline ALK & ON & ON & ON & $\mathrm{ON}$ & ON & $\mathrm{ON}$ & ON & $\mathrm{ON}$ & $\mathrm{ON}$ \\
\hline Z001 & ON & ON & ON & $\mathrm{ON}$ & $\mathrm{ON}$ & $\mathrm{ON}$ & ON & $\mathrm{ON}$ & $\mathrm{ON}$ \\
\hline LDOM-P & ON & ON & ON & $\mathrm{ON}$ & ON & $\mathrm{ON}$ & ON & $\mathrm{ON}$ & ON \\
\hline RDOM-P & ON & ON & ON & $\mathrm{ON}$ & ON & $\mathrm{ON}$ & ON & $\mathrm{ON}$ & $\mathrm{ON}$ \\
\hline $\mathrm{LPOM}-\mathrm{P}$ & ON & ON & ON & ON & ON & $\mathrm{ON}$ & ON & $\mathrm{ON}$ & $\mathrm{ON}$ \\
\hline RPOM-P & ON & ON & ON & $\mathrm{ON}$ & ON & $\mathrm{ON}$ & ON & $\mathrm{ON}$ & $\mathrm{ON}$ \\
\hline LDOM-N & ON & ON & ON & ON & ON & $\mathrm{ON}$ & ON & ON & $\mathrm{ON}$ \\
\hline RDOM-N & ON & ON & ON & $\mathrm{ON}$ & ON & $\mathrm{ON}$ & ON & $\mathrm{ON}$ & $\mathrm{ON}$ \\
\hline LPOM-N & ON & ON & ON & $\mathrm{ON}$ & ON & $\mathrm{ON}$ & ON & $\mathrm{ON}$ & $\mathrm{ON}$ \\
\hline RPOM-N & ON & ON & ON & $\mathrm{ON}$ & ON & $\mathrm{ON}$ & ON & $\mathrm{ON}$ & $\mathrm{ON}$ \\
\hline CIN CON & CINBRC & CINBRC & CINBRC & CINBRC & CINBRC & CINBRC & CINBRC & CINBRC & CINBRC \\
\hline \multirow[t]{2}{*}{$\mathrm{TDS}$} & $\mathrm{ON}$ & OFF & $\mathrm{OFF}$ & OFF & OFF & OFF & OFF & OFF & $\mathrm{OFF}$ \\
\hline & $\mathrm{OFF}$ & & & & & & & & \\
\hline \multirow[t]{2}{*}{ Gen1 } & ON & OFF & $\mathrm{OFF}$ & $\mathrm{OFF}$ & OFF & OFF & $\mathrm{OFF}$ & $\mathrm{OFF}$ & OFF \\
\hline & OFF & & & & & & & & \\
\hline \multirow[t]{2}{*}{ Gen2 } & ON & $\mathrm{OFF}$ & $\mathrm{OFF}$ & $\mathrm{OFF}$ & OFF & $\mathrm{OFF}$ & $\mathrm{OFF}$ & $\mathrm{OFF}$ & $\mathrm{OFF}$ \\
\hline & OFF & & & & & & & & \\
\hline \multirow[t]{2}{*}{ Gen3 } & ON & $\mathrm{OFF}$ & $\mathrm{OFF}$ & $\mathrm{OFF}$ & $\mathrm{OFF}$ & $\mathrm{OFF}$ & $\mathrm{OFF}$ & $\mathrm{OFF}$ & $\mathrm{OFF}$ \\
\hline & OFF & & & & & & & & \\
\hline \multirow[t]{2}{*}{ Gen 4} & OFF & $\mathrm{OFF}$ & $\mathrm{OFF}$ & OFF & $\mathrm{OFE}$ & $\mathrm{OFF}$ & $\mathrm{OFF}$ & $\mathrm{OFE}$ & $\mathrm{OFF}$ \\
\hline & $\mathrm{OFF}$ & & & & & & & & \\
\hline \multirow[t]{2}{*}{ Gen5 } & OFF & $\mathrm{OFF}$ & $\mathrm{OFF}$ & $\mathrm{OFF}$ & OFF & OFF & $\mathrm{OFF}$ & $\mathrm{OFE}$ & $\mathrm{OFE}$ \\
\hline & $\mathrm{OFF}$ & & & & & & & & \\
\hline \multirow[t]{2}{*}{ Gen 6} & $\mathrm{OFF}$ & OFF & $\mathrm{OFF}$ & $\mathrm{OFE}$ & OFF & OFF & $\mathrm{OFE}$ & OFF & $\mathrm{OFF}$ \\
\hline & $\mathrm{OFF}$ & & & & & & & & \\
\hline \multirow[t]{2}{*}{ Gen7 } & $\mathrm{OFF}$ & $\mathrm{OFF}$ & OFF & OFF & $\mathrm{OFF}$ & OFF & $\mathrm{OFF}$ & OFF & OFF \\
\hline & $\mathrm{OFF}$ & & & & & & & & \\
\hline \multirow[t]{2}{*}{ Gen 8} & $\mathrm{OFF}$ & $\mathrm{OFF}$ & OFF & OFF & $\mathrm{OFF}$ & $\mathrm{OFF}$ & $\mathrm{OFF}$ & OFF & OFF \\
\hline & $\mathrm{OFF}$ & & & & & & & & \\
\hline \multirow[t]{2}{*}{ Gen 9} & OFF & $\mathrm{OFF}$ & OFF & OFF & $\mathrm{OFF}$ & $\mathrm{OFF}$ & OFF & OFF & OFF \\
\hline & OFF & & & & & & & & \\
\hline \multirow[t]{2}{*}{ Gen10 } & $\mathrm{OFF}$ & $\mathrm{OFF}$ & $\mathrm{OFF}$ & $\mathrm{OFF}$ & $\mathrm{OFF}$ & $\mathrm{OFF}$ & $\mathrm{OFF}$ & $\mathrm{OFF}$ & $\mathrm{OFF}$ \\
\hline & $\mathrm{OFF}$ & & & & & & & & \\
\hline Gen11 & $\mathrm{OFF}$ & $\mathrm{OFF}$ & $\mathrm{OFF}$ & $\mathrm{OFF}$ & $\mathrm{OFF}$ & $\mathrm{OFF}$ & $\mathrm{OFF}$ & OFF & $\mathrm{OFF}$ \\
\hline & $\mathrm{OFF}$ & & & & & & & & \\
\hline ISS1 & $\mathrm{OFF}$ & $\mathrm{OFF}$ & $\mathrm{OFF}$ & OFF & $\mathrm{OFF}$ & OFF & $\mathrm{OFF}$ & OFF & OFF \\
\hline & OFF & & & & & & & & \\
\hline ISS2 & ON & $\mathrm{OFF}$ & $\mathrm{OFF}$ & $\mathrm{OFF}$ & $\mathrm{OFF}$ & OFF & $\mathrm{OFF}$ & $\mathrm{OFF}$ & $\mathrm{OFE}$ \\
\hline & OFF & & & & & & & & \\
\hline $\mathrm{PO} 4$ & ON & $\mathrm{OFF}$ & $\mathrm{OFF}$ & $\mathrm{OFF}$ & $\mathrm{OFF}$ & OFF & $\mathrm{OFF}$ & OFF & $\mathrm{OFF}$ \\
\hline & OFF & & & & & & & & \\
\hline NH4 & $\mathrm{ON}$ & $\mathrm{OFF}$ & $\mathrm{OFF}$ & $\mathrm{OFF}$ & $\mathrm{OFF}$ & OFF & $\mathrm{OFF}$ & OFF & OFF \\
\hline & OFF & & & & & & & & \\
\hline NO3 & ON & $\mathrm{OFF}$ & $\mathrm{OFF}$ & $\mathrm{OFF}$ & $\mathrm{OFF}$ & OFF & $\mathrm{OFF}$ & OFF & $\mathrm{OFF}$ \\
\hline & $\mathrm{OFF}$ & & & & & & & & \\
\hline DSI & $\mathrm{OFF}$ & $\mathrm{OFF}$ & OFF & $\mathrm{OFF}$ & $\mathrm{OFF}$ & $\mathrm{OFF}$ & OFF & OFF & OFF \\
\hline & OFF & & & & & & & & \\
\hline PSI & $\mathrm{OFF}$ & $\mathrm{OFF}$ & $\mathrm{OFF}$ & $\mathrm{OFF}$ & $\mathrm{OFF}$ & $\mathrm{OFF}$ & $\mathrm{OFF}$ & $\mathrm{OFF}$ & $\mathrm{OFF}$ \\
\hline & OFF & & & & & & & & \\
\hline $\mathrm{FE}$ & OFF & $\mathrm{OFF}$ & $\mathrm{OFF}$ & $\mathrm{OFF}$ & $\mathrm{OFF}$ & $\mathrm{OFF}$ & $\mathrm{OFF}$ & OFF & $\mathrm{OFF}$ \\
\hline & $\mathrm{OFF}$ & & & & & & & & \\
\hline LDOM & ON & $\mathrm{OFE}$ & $\mathrm{OFF}$ & $\mathrm{OFF}$ & $\mathrm{OFE}$ & $\mathrm{OFE}$ & OFF & $\mathrm{OFE}$ & $\mathrm{OFE}$ \\
\hline
\end{tabular}




\begin{tabular}{|c|c|c|c|c|c|c|c|c|c|}
\hline RDOM & $\begin{array}{r}\mathrm{OFF} \\
\text { ON } \\
\text { OFF }\end{array}$ & $\mathrm{OFF}$ & $\mathrm{OFF}$ & $\mathrm{OFF}$ & $\mathrm{OFF}$ & $\mathrm{OFF}$ & $\mathrm{OFF}$ & $\mathrm{OFF}$ & $\mathrm{OFF}$ \\
\hline LPOM & $\begin{array}{r}\text { ON } \\
\text { OFF }\end{array}$ & $\mathrm{OFF}$ & $\mathrm{OFF}$ & $\mathrm{OFF}$ & $\mathrm{OFF}$ & $\mathrm{OFF}$ & $\mathrm{OFF}$ & $\mathrm{OFF}$ & $\mathrm{OFF}$ \\
\hline $\mathrm{RPOM}$ & $\begin{array}{r}\text { ON } \\
\text { OFF }\end{array}$ & $\mathrm{OFF}$ & $\mathrm{OFF}$ & $\mathrm{OFF}$ & $\mathrm{OFF}$ & $\mathrm{OFF}$ & $\mathrm{OFF}$ & $\mathrm{OFF}$ & OFF \\
\hline BOD1 & $\begin{array}{l}O F F \\
\text { OFF }\end{array}$ & $\mathrm{OFF}$ & $\mathrm{OFF}$ & $\mathrm{OFF}$ & $\mathrm{OFF}$ & $\mathrm{OFF}$ & $\mathrm{OFF}$ & $\mathrm{OFF}$ & $\mathrm{OFF}$ \\
\hline BOD2 & $\begin{array}{l}\text { OFF } \\
\text { OFF }\end{array}$ & $\mathrm{OFF}$ & $\mathrm{OFF}$ & $\mathrm{OFF}$ & $\mathrm{OFF}$ & $\mathrm{OFF}$ & $\mathrm{OFF}$ & $\mathrm{OFF}$ & $\mathrm{OFF}$ \\
\hline BOD3 & $\begin{array}{l}\text { OFF } \\
\text { OFF }\end{array}$ & $\mathrm{OFF}$ & $\mathrm{OFF}$ & $\mathrm{OFF}$ & $\mathrm{OFF}$ & $\mathrm{OFF}$ & $\mathrm{OFF}$ & $\mathrm{OFF}$ & $\mathrm{OFF}$ \\
\hline BOD 4 & $\begin{array}{l}\text { OFF } \\
\text { OFF }\end{array}$ & $\mathrm{OFF}$ & $\mathrm{OFF}$ & $\mathrm{OFF}$ & $\mathrm{OFF}$ & $\mathrm{OFF}$ & $\mathrm{OFF}$ & $\mathrm{OFF}$ & $\mathrm{OFF}$ \\
\hline BOD5 & $\begin{array}{l}\text { OFF } \\
\text { OFF }\end{array}$ & $\mathrm{OFF}$ & $\mathrm{OFF}$ & $\mathrm{OFF}$ & $\mathrm{OFF}$ & $\mathrm{OFF}$ & $\mathrm{OFF}$ & $\mathrm{OFF}$ & $\mathrm{OFF}$ \\
\hline BOD 6 & $\begin{array}{l}\text { OFF } \\
\text { OFF }\end{array}$ & $\mathrm{OFF}$ & $\mathrm{OFF}$ & $\mathrm{OFF}$ & $\mathrm{OFF}$ & $\mathrm{OFF}$ & $\mathrm{OFF}$ & $\mathrm{OFF}$ & $\mathrm{OFF}$ \\
\hline BOD7 & $\begin{array}{l}\text { OFF } \\
\text { OFF }\end{array}$ & $\mathrm{OFF}$ & $\mathrm{OFF}$ & $\mathrm{OFF}$ & $\mathrm{OFF}$ & $\mathrm{OFF}$ & $\mathrm{OFF}$ & $\mathrm{OFF}$ & $\mathrm{OFF}$ \\
\hline BOD8 & $\begin{array}{l}\text { OFF } \\
\text { OFF }\end{array}$ & $\mathrm{OFF}$ & $\mathrm{OFF}$ & $\mathrm{OFF}$ & $\mathrm{OFF}$ & $\mathrm{OFF}$ & $\mathrm{OFF}$ & $\mathrm{OFF}$ & $\mathrm{OFF}$ \\
\hline BOD 9 & $\begin{array}{l}O F F \\
\text { OFF }\end{array}$ & $\mathrm{OFF}$ & $\mathrm{OFF}$ & $\mathrm{OFF}$ & $\mathrm{OFF}$ & $\mathrm{OFF}$ & $\mathrm{OFF}$ & $\mathrm{OFF}$ & $\mathrm{OFF}$ \\
\hline BOD10 & $\begin{array}{l}\text { OFF } \\
\text { OFF }\end{array}$ & $\mathrm{OFF}$ & $\mathrm{OFF}$ & $\mathrm{OFF}$ & $\mathrm{OFF}$ & $\mathrm{OFF}$ & $\mathrm{OFF}$ & $\mathrm{OFF}$ & $\mathrm{OFF}$ \\
\hline BODP1 & $\begin{array}{l}\text { OFF } \\
\text { OFF }\end{array}$ & $\mathrm{OFF}$ & OFF & $\mathrm{OFF}$ & $\mathrm{OFF}$ & $\mathrm{OFF}$ & $\mathrm{OFF}$ & $\mathrm{OFF}$ & $\mathrm{OFF}$ \\
\hline BODP2 & $\begin{array}{l}\text { OFF } \\
\text { OFF }\end{array}$ & $\mathrm{OFF}$ & $\mathrm{OFF}$ & $\mathrm{OFF}$ & $\mathrm{OFF}$ & $\mathrm{OFF}$ & $\mathrm{OFF}$ & $\mathrm{OFF}$ & $\mathrm{OFF}$ \\
\hline BODP3 & $\begin{array}{l}\text { OFF } \\
\text { OFF }\end{array}$ & $\mathrm{OFF}$ & $\mathrm{OFF}$ & $\mathrm{OFF}$ & $\mathrm{OFF}$ & $\mathrm{OFF}$ & $\mathrm{OFF}$ & $\mathrm{OFF}$ & $\mathrm{OFF}$ \\
\hline BODP 4 & $\begin{array}{l}\text { OFF } \\
\text { OFF }\end{array}$ & $\mathrm{OFF}$ & $\mathrm{OFF}$ & $\mathrm{OFF}$ & $\mathrm{OFF}$ & $\mathrm{OFF}$ & $\mathrm{OFF}$ & $\mathrm{OFF}$ & $\mathrm{OFF}$ \\
\hline BODP 5 & $\begin{array}{l}\text { OFF } \\
\text { OFF }\end{array}$ & OFF & $\mathrm{OFF}$ & $\mathrm{OFF}$ & $\mathrm{OFF}$ & $\mathrm{OFF}$ & $\mathrm{OFF}$ & $\mathrm{OFF}$ & $\mathrm{OFF}$ \\
\hline BODP 6 & $\begin{array}{l}\text { OFF } \\
\text { OFF }\end{array}$ & $\mathrm{OFF}$ & $\mathrm{OFF}$ & $\mathrm{OFF}$ & $\mathrm{OFF}$ & $\mathrm{OFF}$ & $\mathrm{OFF}$ & $\mathrm{OFF}$ & $\mathrm{OFF}$ \\
\hline BODP 7 & $\begin{array}{l}\text { OFF } \\
\text { OFF }\end{array}$ & OFF & $\mathrm{OFF}$ & $\mathrm{OFF}$ & $\mathrm{OFF}$ & $\mathrm{OFF}$ & $\mathrm{OFF}$ & $\mathrm{OFF}$ & $\mathrm{OFF}$ \\
\hline BODP 8 & $\begin{array}{l}\text { OFF } \\
\text { OFF }\end{array}$ & $\mathrm{OFF}$ & OFF & $\mathrm{OFF}$ & $\mathrm{OFF}$ & $\mathrm{OFF}$ & $\mathrm{OFF}$ & $\mathrm{OFF}$ & $\mathrm{OFF}$ \\
\hline BODP9 & $\begin{array}{l}O F F \\
O F F\end{array}$ & $\mathrm{OFF}$ & $\mathrm{OFF}$ & $\mathrm{OFF}$ & $\mathrm{OFF}$ & $\mathrm{OFF}$ & $\mathrm{OFF}$ & $\mathrm{OFF}$ & $\mathrm{OFF}$ \\
\hline BODP10 & $\begin{array}{l}\text { OFF } \\
\text { OFF }\end{array}$ & $\mathrm{OFF}$ & $\mathrm{OFF}$ & $\mathrm{OFF}$ & $\mathrm{OFF}$ & $\mathrm{OFF}$ & $\mathrm{OFF}$ & $\mathrm{OFF}$ & $\mathrm{OFF}$ \\
\hline BODN1 & $\begin{array}{l}\text { OFF } \\
\text { OFF }\end{array}$ & $\mathrm{OFF}$ & $\mathrm{OFF}$ & $\mathrm{OFF}$ & $\mathrm{OFF}$ & $\mathrm{OFF}$ & $\mathrm{OFF}$ & $\mathrm{OFF}$ & OFF \\
\hline BODN2 & $\begin{array}{l}\text { OFF } \\
\text { OFF }\end{array}$ & OFF & $\mathrm{OFF}$ & $\mathrm{OFF}$ & $\mathrm{OFF}$ & $\mathrm{OFF}$ & $\mathrm{OFF}$ & $\mathrm{OFF}$ & $\mathrm{OFF}$ \\
\hline BODN3 & $\begin{array}{l}\text { OFF } \\
\text { OFF }\end{array}$ & $O F F$ & $\mathrm{OFF}$ & $\mathrm{OFF}$ & $\mathrm{OFF}$ & $\mathrm{OFF}$ & $\mathrm{OFF}$ & $\mathrm{OFF}$ & OFF \\
\hline BODN4 & $\begin{array}{l}\text { OFF } \\
\text { OFF }\end{array}$ & OFF & $\mathrm{OFF}$ & $\mathrm{OFF}$ & $\mathrm{OFF}$ & OFF & $\mathrm{OFF}$ & $\mathrm{OFF}$ & $\mathrm{OFF}$ \\
\hline BODN5 & $\begin{array}{l}\text { OFF } \\
\text { OFF }\end{array}$ & $\mathrm{OFF}$ & $\mathrm{OFF}$ & $\mathrm{OFF}$ & $\mathrm{OFF}$ & $\mathrm{OFF}$ & $\mathrm{OFF}$ & $\mathrm{OFF}$ & $\mathrm{OFF}$ \\
\hline BODN 6 & $\begin{array}{l}O F F \\
O F F\end{array}$ & $\mathrm{OFF}$ & $\mathrm{OFF}$ & $\mathrm{OFF}$ & $\mathrm{OFF}$ & $\mathrm{OFF}$ & $\mathrm{OFF}$ & $\mathrm{OFF}$ & $\mathrm{OFF}$ \\
\hline BODN7 & $\begin{array}{l}\text { OFF } \\
\text { OFF }\end{array}$ & $\mathrm{OFF}$ & $\mathrm{OFF}$ & $\mathrm{OFF}$ & $\mathrm{OFF}$ & $\mathrm{OFF}$ & $\mathrm{OFF}$ & $\mathrm{OFF}$ & $\mathrm{OFF}$ \\
\hline BODN8 & $\begin{array}{l}\text { OFF } \\
\text { OFF }\end{array}$ & OFF & $\mathrm{OFF}$ & $\mathrm{OFF}$ & $\mathrm{OFF}$ & $\mathrm{OFF}$ & $\mathrm{OFF}$ & $\mathrm{OFF}$ & $\mathrm{OFF}$ \\
\hline BODN9 & $\begin{array}{l}\text { OFF } \\
\text { OFF }\end{array}$ & $\mathrm{OFF}$ & $\mathrm{OFF}$ & $\mathrm{OFF}$ & $\mathrm{OFF}$ & $\mathrm{OFF}$ & $\mathrm{OFF}$ & $\mathrm{OFF}$ & $\mathrm{OFF}$ \\
\hline BODN10 & $\begin{array}{l}\text { OFF } \\
\text { OFF }\end{array}$ & $\mathrm{OFF}$ & $\mathrm{OFF}$ & $\mathrm{OFF}$ & $\mathrm{OFF}$ & $\mathrm{OFF}$ & $\mathrm{OFF}$ & $\mathrm{OFF}$ & $\mathrm{OFF}$ \\
\hline ALG1 & ON & $\mathrm{OFF}$ & $\mathrm{OFF}$ & $\mathrm{OFF}$ & $\mathrm{OFF}$ & $\mathrm{OFF}$ & $\mathrm{OFF}$ & $\mathrm{OFF}$ & $\mathrm{OFF}$ \\
\hline
\end{tabular}




\begin{tabular}{|c|c|c|c|c|c|c|c|c|c|}
\hline & $\mathrm{OFF}$ & & & & & & & & \\
\hline ALG2 & $\begin{array}{r}\text { ON } \\
\text { OFF }\end{array}$ & $\mathrm{OFF}$ & OFF & OFF & OFF & OFF & $\mathrm{OFF}$ & $\mathrm{OFF}$ & $\mathrm{OFF}$ \\
\hline DO & $\begin{array}{r}\text { ON } \\
O F F\end{array}$ & $\mathrm{OFF}$ & $\mathrm{OFF}$ & $\mathrm{OFF}$ & $\mathrm{OFF}$ & $\mathrm{OFF}$ & $\mathrm{OFF}$ & $\mathrm{OFF}$ & $\mathrm{OFF}$ \\
\hline TIC & $\begin{array}{r}\text { ON } \\
\text { OFF }\end{array}$ & $\mathrm{OFE}$ & $\mathrm{OFF}$ & $\mathrm{OFF}$ & $\mathrm{OFF}$ & OFF & $\mathrm{OFF}$ & $\mathrm{OFF}$ & $\mathrm{OFF}$ \\
\hline ALK & $\begin{array}{r}\mathrm{ON} \\
\mathrm{OFF}\end{array}$ & $\mathrm{OFF}$ & $\mathrm{OFF}$ & $\mathrm{OFF}$ & $\mathrm{OFE}$ & $\mathrm{OFF}$ & $\mathrm{OFF}$ & $\mathrm{OFF}$ & $\mathrm{OFF}$ \\
\hline Z001 & $\begin{array}{r}\mathrm{ON} \\
\mathrm{OFF}\end{array}$ & $\mathrm{OFF}$ & $\mathrm{OFF}$ & $\mathrm{OFF}$ & $\mathrm{OFF}$ & $\mathrm{OFF}$ & $\mathrm{OFF}$ & $\mathrm{OFF}$ & $\mathrm{OFF}$ \\
\hline LDOM-P & $\begin{array}{r}\text { ON } \\
O F F\end{array}$ & OFF & OFF & OFF & OFF & OFF & $\mathrm{OFF}$ & $\mathrm{OFF}$ & OFF \\
\hline RDOM-P & $\begin{array}{r}\text { ON } \\
O F F\end{array}$ & $\mathrm{OFF}$ & OFF & OFF & $\mathrm{OFF}$ & $\mathrm{OFF}$ & OFF & $\mathrm{OFF}$ & $\mathrm{OFF}$ \\
\hline LPOM-P & $\begin{array}{r}\mathrm{ON} \\
\mathrm{OFF}\end{array}$ & $\mathrm{OFF}$ & OFF & OFF & $\mathrm{OFF}$ & OFF & OFF & $\mathrm{OFF}$ & $\mathrm{OFF}$ \\
\hline $\mathrm{RPOM}-\mathrm{P}$ & $\begin{array}{r}\text { ON } \\
O F E\end{array}$ & $\mathrm{OFF}$ & $\mathrm{OFF}$ & $\mathrm{OFF}$ & $\mathrm{OFF}$ & $\mathrm{OFF}$ & $\mathrm{OFF}$ & $\mathrm{OFF}$ & $\mathrm{OFF}$ \\
\hline $\mathrm{LDOM}-\mathrm{N}$ & $\begin{array}{r}\text { ON } \\
\text { OFF }\end{array}$ & $\mathrm{OFF}$ & $\mathrm{OFF}$ & $\mathrm{OFF}$ & $\mathrm{OFE}$ & $\mathrm{OFF}$ & $\mathrm{OFF}$ & $\mathrm{OFE}$ & $\mathrm{OFF}$ \\
\hline $\mathrm{RDOM}-\mathrm{N}$ & $\begin{array}{r}\text { ON } \\
\text { OFE }\end{array}$ & $\mathrm{OFF}$ & $\mathrm{OFF}$ & $\mathrm{OFF}$ & $\mathrm{OFF}$ & $\mathrm{OFF}$ & $\mathrm{OFF}$ & $\mathrm{OFF}$ & $\mathrm{OFF}$ \\
\hline LPOM-N & $\begin{array}{r}\mathrm{ON} \\
\mathrm{OFE}\end{array}$ & OFF & $\mathrm{OFF}$ & OFF & OFF & $\mathrm{OFF}$ & OFF & OFF & $\mathrm{OFF}$ \\
\hline $\mathrm{RPOM}-\mathrm{N}$ & $\begin{array}{r}\mathrm{ON} \\
\mathrm{OFF}\end{array}$ & OFF & OFF & OFF & OFF & $\mathrm{OFF}$ & $\mathrm{OFF}$ & OFF & $\mathrm{OFF}$ \\
\hline CTR CON & CTRTRC & CTRTRC & CTRTRC & CTRTRC & CTRTRC & CTRTRC & CTRTRC & CTRTRC & CTRTRC \\
\hline TDS & $\mathrm{ON}$ & $\mathrm{ON}$ & $\mathrm{ON}$ & $\mathrm{ON}$ & $\mathrm{ON}$ & $\mathrm{ON}$ & $\mathrm{ON}$ & $\mathrm{ON}$ & ON \\
\hline & ON & $\mathrm{ON}$ & ON & $\mathrm{ON}$ & $\mathrm{ON}$ & $\mathrm{ON}$ & $\mathrm{ON}$ & $\mathrm{ON}$ & $\mathrm{ON}$ \\
\hline & ON & ON & ON & $\mathrm{ON}$ & ON & ON & $\mathrm{ON}$ & ON & $\mathrm{ON}$ \\
\hline & ON & ON & ON & ON & ON & ON & ON & ON & $\mathrm{ON}$ \\
\hline & ON & ON & ON & ON & ON & ON & ON & ON & ON \\
\hline & ON & ON & ON & ON & ON & ON & ON & ON & ON \\
\hline & ON & ON & ON & ON & ON & ON & ON & ON & $\mathrm{ON}$ \\
\hline & ON & ON & ON & ON & ON & ON & ON & ON & ON \\
\hline & ON & ON & ON & ON & ON & ON & ON & ON & ON \\
\hline & $\mathrm{ON}$ & ON & ON & ON & ON & ON & ON & ON & ON \\
\hline & ON & ON & ON & ON & ON & ON & ON & ON & ON \\
\hline & $\mathrm{ON}$ & ON & ON & ON & ON & ON & ON & ON & $\mathrm{ON}$ \\
\hline & ON & ON & ON & $\mathrm{ON}$ & ON & ON & $\mathrm{ON}$ & ON & ON \\
\hline & ON & ON & ON & ON & ON & ON & ON & ON & ON \\
\hline & ON & ON & ON & ON & ON & ON & ON & ON & $\mathrm{ON}$ \\
\hline & ON & ON & ON & ON & ON & ON & $\mathrm{ON}$ & ON & ON \\
\hline & ON & ON & ON & ON & ON & ON & ON & ON & $\mathrm{ON}$ \\
\hline & ON & ON & ON & ON & ON & ON & ON & ON & $\mathrm{ON}$ \\
\hline & ON & ON & ON & ON & ON & ON & $\mathrm{ON}$ & ON & ON \\
\hline & ON & ON & ON & ON & ON & ON & $\mathrm{ON}$ & ON & ON \\
\hline & ON & ON & ON & ON & ON & ON & $\mathrm{ON}$ & ON & ON \\
\hline & ON & ON & ON & ON & ON & ON & ON & ON & $\mathrm{ON}$ \\
\hline & ON & ON & ON & $\mathrm{ON}$ & ON & ON & ON & ON & ON \\
\hline & ON & ON & ON & ON & ON & ON & ON & ON & $\mathrm{ON}$ \\
\hline & ON & ON & ON & $\mathrm{ON}$ & ON & ON & ON & ON & ON \\
\hline & ON & ON & ON & ON & ON & ON & ON & ON & ON \\
\hline & $\mathrm{ON}$ & ON & ON & ON & ON & ON & ON & ON & ON \\
\hline & $\mathrm{ON}$ & ON & ON & ON & ON & ON & ON & ON & ON \\
\hline & ON & ON & ON & ON & ON & ON & ON & ON & ON \\
\hline & ON & ON & ON & ON & ON & ON & ON & ON & $\mathrm{ON}$ \\
\hline & ON & ON & ON & ON & ON & ON & $\mathrm{ON}$ & ON & ON \\
\hline & ON & ON & ON & ON & ON & ON & ON & ON & ON \\
\hline & ON & ON & ON & ON & ON & ON & ON & ON & $\mathrm{ON}$ \\
\hline & ON & ON & & & & & & & \\
\hline Gen1 & ON & ON & ON & ON & ON & ON & ON & ON & $\mathrm{ON}$ \\
\hline & ON & ON & ON & ON & ON & ON & ON & ON & $\mathrm{ON}$ \\
\hline & ON & ON & ON & ON & ON & ON & ON & ON & $\mathrm{ON}$ \\
\hline & ON & ON & ON & ON & ON & ON & ON & ON & $\mathrm{ON}$ \\
\hline & ON & ON & ON & ON & ON & ON & ON & ON & $\mathrm{ON}$ \\
\hline
\end{tabular}




\begin{tabular}{|c|c|c|c|c|c|c|c|c|c|}
\hline & ON & ON & ON & ON & ON & ON & ON & ON & $\mathrm{ON}$ \\
\hline & ON & ON & ON & ON & ON & ON & ON & ON & ON \\
\hline & ON & ON & ON & ON & ON & ON & ON & ON & ON \\
\hline & ON & ON & ON & ON & $\mathrm{ON}$ & ON & ON & ON & ON \\
\hline & ON & ON & ON & ON & ON & ON & ON & ON & ON \\
\hline & ON & ON & ON & ON & ON & ON & ON & ON & ON \\
\hline & ON & ON & ON & ON & ON & ON & ON & ON & ON \\
\hline & ON & ON & ON & ON & ON & ON & ON & ON & ON \\
\hline & ON & ON & ON & ON & ON & ON & ON & ON & ON \\
\hline & ON & ON & ON & ON & ON & ON & ON & ON & ON \\
\hline & ON & ON & ON & ON & ON & ON & $\mathrm{ON}$ & ON & ON \\
\hline & ON & ON & ON & ON & ON & ON & ON & ON & ON \\
\hline & ON & ON & ON & ON & ON & ON & ON & ON & ON \\
\hline & ON & ON & ON & ON & ON & ON & ON & ON & ON \\
\hline & ON & $\mathrm{ON}$ & ON & ON & ON & ON & ON & ON & ON \\
\hline & ON & ON & ON & ON & ON & ON & ON & ON & ON \\
\hline & ON & ON & ON & ON & ON & ON & ON & ON & ON \\
\hline & ON & ON & ON & ON & ON & ON & ON & ON & ON \\
\hline & ON & ON & $\mathrm{ON}$ & ON & ON & ON & ON & ON & ON \\
\hline & ON & ON & ON & ON & ON & ON & ON & ON & ON \\
\hline & ON & ON & ON & ON & ON & ON & ON & ON & ON \\
\hline & ON & ON & ON & ON & ON & ON & ON & ON & ON \\
\hline & ON & ON & ON & ON & ON & ON & ON & ON & ON \\
\hline & ON & ON & $\mathrm{ON}$ & ON & ON & ON & $\mathrm{ON}$ & ON & ON \\
\hline & ON & ON & ON & ON & ON & ON & $\mathrm{ON}$ & ON & ON \\
\hline & ON & ON & ON & ON & ON & ON & ON & ON & ON \\
\hline & ON & $\mathrm{ON}$ & $\mathrm{ON}$ & ON & ON & ON & ON & ON & ON \\
\hline & ON & ON & ON & ON & ON & ON & ON & ON & ON \\
\hline & ON & ON & & & & & & & \\
\hline Gen2 & ON & ON & ON & ON & ON & ON & $\mathrm{ON}$ & ON & ON \\
\hline & ON & $\mathrm{ON}$ & ON & ON & ON & ON & ON & ON & ON \\
\hline & ON & ON & $\mathrm{ON}$ & ON & ON & ON & ON & ON & ON \\
\hline & ON & ON & ON & ON & ON & ON & ON & ON & ON \\
\hline & ON & ON & ON & ON & ON & ON & ON & ON & ON \\
\hline & ON & ON & ON & ON & ON & ON & $\mathrm{ON}$ & ON & ON \\
\hline & ON & ON & ON & ON & ON & ON & ON & ON & ON \\
\hline & ON & ON & ON & ON & ON & ON & ON & ON & ON \\
\hline & ON & ON & ON & ON & ON & ON & ON & ON & ON \\
\hline & ON & ON & ON & ON & ON & ON & ON & ON & $\mathrm{ON}$ \\
\hline & ON & ON & ON & ON & ON & ON & ON & ON & $\mathrm{ON}$ \\
\hline & ON & ON & ON & ON & ON & ON & ON & ON & ON \\
\hline & ON & ON & ON & ON & ON & ON & ON & ON & ON \\
\hline & ON & ON & ON & ON & ON & ON & ON & ON & ON \\
\hline & ON & ON & ON & ON & ON & ON & ON & ON & $\mathrm{ON}$ \\
\hline & ON & ON & ON & ON & ON & ON & ON & ON & $\mathrm{ON}$ \\
\hline & ON & ON & ON & ON & ON & ON & ON & ON & $\mathrm{ON}$ \\
\hline & ON & ON & ON & ON & ON & ON & ON & ON & $\mathrm{ON}$ \\
\hline & ON & ON & ON & ON & ON & ON & ON & ON & ON \\
\hline & ON & ON & ON & ON & ON & ON & ON & ON & ON \\
\hline & ON & ON & ON & ON & ON & ON & ON & ON & ON \\
\hline & ON & ON & $\mathrm{ON}$ & ON & $\mathrm{ON}$ & ON & ON & ON & $\mathrm{ON}$ \\
\hline & ON & ON & ON & ON & ON & ON & ON & ON & $\mathrm{ON}$ \\
\hline & ON & ON & ON & ON & ON & ON & ON & ON & ON \\
\hline & ON & ON & ON & ON & ON & ON & ON & ON & ON \\
\hline & ON & ON & ON & ON & ON & ON & ON & ON & ON \\
\hline & ON & ON & ON & $\mathrm{ON}$ & ON & ON & $\mathrm{ON}$ & ON & $\mathrm{ON}$ \\
\hline & ON & ON & ON & ON & ON & ON & ON & ON & ON \\
\hline & ON & ON & ON & ON & ON & ON & ON & ON & ON \\
\hline & ON & ON & ON & ON & ON & ON & ON & ON & $\mathrm{ON}$ \\
\hline & ON & ON & ON & ON & ON & ON & ON & ON & ON \\
\hline & ON & ON & ON & ON & ON & ON & ON & ON & ON \\
\hline & ON & ON & ON & ON & ON & ON & ON & ON & ON \\
\hline & ON & $\mathrm{ON}$ & & & & & & & \\
\hline Gen3 & ON & ON & $\mathrm{ON}$ & ON & ON & ON & ON & ON & ON \\
\hline & ON & ON & ON & $\mathrm{ON}$ & ON & ON & ON & ON & ON \\
\hline & ON & $\mathrm{ON}$ & ON & ON & $\mathrm{ON}$ & ON & ON & ON & ON \\
\hline & ON & ON & ON & ON & ON & ON & ON & ON & ON \\
\hline & ON & ON & ON & ON & ON & ON & ON & ON & ON \\
\hline
\end{tabular}




\begin{tabular}{|c|c|c|c|c|c|c|c|c|c|}
\hline & $\mathrm{ON}$ & ON & ON & $\mathrm{ON}$ & ON & ON & ON & $\mathrm{ON}$ & ON \\
\hline & ON & ON & ON & ON & ON & ON & $\mathrm{ON}$ & ON & ON \\
\hline & ON & ON & ON & ON & ON & ON & ON & ON & ON \\
\hline & ON & ON & ON & $\mathrm{ON}$ & ON & $\mathrm{ON}$ & ON & ON & ON \\
\hline & $\mathrm{ON}$ & $\mathrm{ON}$ & ON & ON & $\mathrm{ON}$ & ON & $\mathrm{ON}$ & $\mathrm{ON}$ & $\mathrm{ON}$ \\
\hline & ON & ON & ON & ON & ON & ON & ON & ON & ON \\
\hline & ON & ON & ON & ON & $\mathrm{ON}$ & ON & $\mathrm{ON}$ & ON & ON \\
\hline & ON & ON & ON & ON & ON & ON & $\mathrm{ON}$ & ON & ON \\
\hline & ON & ON & ON & ON & ON & ON & $\mathrm{ON}$ & ON & ON \\
\hline & ON & ON & ON & ON & $\mathrm{ON}$ & ON & ON & ON & ON \\
\hline & ON & ON & ON & ON & ON & ON & ON & ON & ON \\
\hline & ON & ON & ON & $\mathrm{ON}$ & $\mathrm{ON}$ & $\mathrm{ON}$ & $\mathrm{ON}$ & ON & ON \\
\hline & ON & ON & ON & $\mathrm{ON}$ & $\mathrm{ON}$ & ON & $\mathrm{ON}$ & ON & ON \\
\hline & ON & ON & ON & ON & ON & ON & ON & ON & ON \\
\hline & ON & ON & ON & ON & $\mathrm{ON}$ & ON & ON & ON & $\mathrm{ON}$ \\
\hline & ON & ON & ON & ON & ON & ON & ON & ON & ON \\
\hline & ON & ON & ON & ON & ON & ON & ON & ON & ON \\
\hline & ON & ON & ON & $\mathrm{ON}$ & $\mathrm{ON}$ & $\mathrm{ON}$ & $\mathrm{ON}$ & ON & ON \\
\hline & ON & ON & ON & $\mathrm{ON}$ & $\mathrm{ON}$ & ON & ON & ON & ON \\
\hline & ON & ON & ON & ON & $\mathrm{ON}$ & ON & ON & ON & $\mathrm{ON}$ \\
\hline & ON & ON & ON & ON & ON & ON & ON & ON & ON \\
\hline & ON & ON & ON & $\mathrm{ON}$ & ON & $\mathrm{ON}$ & ON & ON & ON \\
\hline & ON & ON & ON & ON & ON & ON & ON & ON & ON \\
\hline & ON & ON & ON & $\mathrm{ON}$ & $\mathrm{ON}$ & ON & ON & ON & ON \\
\hline & $\mathrm{ON}$ & ON & ON & $\mathrm{ON}$ & ON & ON & ON & ON & ON \\
\hline & $\mathrm{ON}$ & $\mathrm{ON}$ & $\mathrm{ON}$ & ON & $\mathrm{ON}$ & ON & $\mathrm{ON}$ & $\mathrm{ON}$ & $\mathrm{ON}$ \\
\hline & ON & ON & ON & $\mathrm{ON}$ & $\mathrm{ON}$ & ON & $\mathrm{ON}$ & ON & ON \\
\hline & ON & ON & ON & $\mathrm{ON}$ & ON & ON & $\mathrm{ON}$ & ON & ON \\
\hline & $\mathrm{ON}$ & ON & & & & & & & \\
\hline Gen 4 & $\mathrm{OFF}$ & $\mathrm{OFF}$ & $\mathrm{OFF}$ & $\mathrm{OFF}$ & OFF & $\mathrm{OFF}$ & OFF & $\mathrm{OFF}$ & $\mathrm{OFF}$ \\
\hline & $\mathrm{OFF}$ & $\mathrm{OFF}$ & $\mathrm{OFF}$ & $\mathrm{OFF}$ & $\mathrm{OFF}$ & $\mathrm{OFF}$ & $\mathrm{OFF}$ & $\mathrm{OFF}$ & $O F F$ \\
\hline & $\mathrm{OFF}$ & $\mathrm{OFF}$ & $\mathrm{OFF}$ & OFF & $\mathrm{OFF}$ & $\mathrm{OFF}$ & OFF & $\mathrm{OFF}$ & OFF \\
\hline & $\mathrm{OFF}$ & $\mathrm{OFF}$ & $\mathrm{OFF}$ & $\mathrm{OFF}$ & $\mathrm{OFF}$ & $\mathrm{OFF}$ & $\mathrm{OFF}$ & $\mathrm{OFF}$ & $\mathrm{OFF}$ \\
\hline & $\mathrm{OFF}$ & $\mathrm{OFF}$ & $\mathrm{OFF}$ & $\mathrm{OFF}$ & $\mathrm{OFF}$ & $\mathrm{OFF}$ & $\mathrm{OFF}$ & $\mathrm{OFF}$ & $\mathrm{OFF}$ \\
\hline & $\mathrm{OFF}$ & $\mathrm{OFF}$ & $\mathrm{OFF}$ & OFF & OFF & $\mathrm{OFF}$ & OFF & $\mathrm{OFF}$ & $\mathrm{OFF}$ \\
\hline & $\mathrm{OFF}$ & $\mathrm{OFF}$ & $\mathrm{OFF}$ & $\mathrm{OFF}$ & $\mathrm{OFF}$ & $\mathrm{OFF}$ & OFF & $\mathrm{OFF}$ & OFF \\
\hline & $\mathrm{OFF}$ & $\mathrm{OFF}$ & $\mathrm{OFF}$ & OFF & $O F F$ & $\mathrm{OFF}$ & $\mathrm{OFF}$ & $O F F$ & $\mathrm{OFF}$ \\
\hline & $\mathrm{OFF}$ & $\mathrm{OFF}$ & $\mathrm{OFF}$ & $\mathrm{OFF}$ & OFF & $\mathrm{OFF}$ & $\mathrm{OFF}$ & $\mathrm{OFF}$ & $\mathrm{OFF}$ \\
\hline & $\mathrm{OFF}$ & $\mathrm{OFF}$ & $\mathrm{OFF}$ & $\mathrm{OFF}$ & OFF & OFF & $\mathrm{OFF}$ & $\mathrm{OFF}$ & $\mathrm{OFF}$ \\
\hline & $\mathrm{OFF}$ & $\mathrm{OFF}$ & $\mathrm{OFF}$ & $\mathrm{OFF}$ & $\mathrm{OFF}$ & $\mathrm{OFF}$ & $\mathrm{OFF}$ & $\mathrm{OFF}$ & $\mathrm{OFF}$ \\
\hline & $\mathrm{OFF}$ & $\mathrm{OFF}$ & $\mathrm{OFF}$ & OFF & $\mathrm{OFF}$ & $\mathrm{OFF}$ & OFF & $\mathrm{OFF}$ & $\mathrm{OFF}$ \\
\hline & $\mathrm{OFF}$ & $O F F$ & $O F F$ & $\mathrm{OFF}$ & $\mathrm{OFF}$ & $\mathrm{OFF}$ & $\mathrm{OFF}$ & $O F F$ & OFF \\
\hline & $\mathrm{OFF}$ & $\mathrm{OFF}$ & $\mathrm{OFF}$ & $\mathrm{OFF}$ & OFF & $\mathrm{OFF}$ & $\mathrm{OFF}$ & $\mathrm{OFF}$ & $\mathrm{OFF}$ \\
\hline & $\mathrm{OFF}$ & $\mathrm{OFF}$ & $\mathrm{OFF}$ & $\mathrm{OFF}$ & $\mathrm{OFF}$ & $\mathrm{OFF}$ & $\mathrm{OFF}$ & $\mathrm{OFF}$ & $\mathrm{OFF}$ \\
\hline & $\mathrm{OFF}$ & $\mathrm{OFF}$ & $\mathrm{OFF}$ & $\mathrm{OFF}$ & $\mathrm{OFF}$ & $\mathrm{OFF}$ & $\mathrm{OFF}$ & $\mathrm{OFF}$ & $\mathrm{OFF}$ \\
\hline & $\mathrm{OFF}$ & $\mathrm{OFF}$ & $\mathrm{OFF}$ & OFF & $\mathrm{OFF}$ & $\mathrm{OFF}$ & OFF & $\mathrm{OFF}$ & $\mathrm{OFF}$ \\
\hline & $\mathrm{OFF}$ & $\mathrm{OFF}$ & $\mathrm{OFF}$ & $\mathrm{OFF}$ & $\mathrm{OFF}$ & $\mathrm{OFF}$ & OFF & $\mathrm{OFF}$ & $\mathrm{OFF}$ \\
\hline & $\mathrm{OFF}$ & $\mathrm{OFF}$ & $\mathrm{OFF}$ & $\mathrm{OFF}$ & $\mathrm{OFF}$ & $\mathrm{OFF}$ & $\mathrm{OFF}$ & $\mathrm{OFF}$ & $\mathrm{OFF}$ \\
\hline & $\mathrm{OFF}$ & $\mathrm{OFF}$ & $\mathrm{OFF}$ & OFF & OFF & $\mathrm{OFF}$ & OFF & $\mathrm{OFF}$ & $\mathrm{OFF}$ \\
\hline & $\mathrm{OFF}$ & $\mathrm{OFF}$ & $\mathrm{OFF}$ & $\mathrm{OFF}$ & $\mathrm{OFF}$ & $\mathrm{OFF}$ & OFF & $\mathrm{OFF}$ & $\mathrm{OFF}$ \\
\hline & $\mathrm{OFF}$ & $\mathrm{OFF}$ & $\mathrm{OFF}$ & $\mathrm{OFF}$ & $\mathrm{OFF}$ & $\mathrm{OFF}$ & OFF & $\mathrm{OFF}$ & $\mathrm{OFF}$ \\
\hline & $\mathrm{OFF}$ & $\mathrm{OFF}$ & $\mathrm{OFF}$ & $\mathrm{OFF}$ & $\mathrm{OFF}$ & $\mathrm{OFF}$ & OFF & $\mathrm{OFF}$ & $\mathrm{OFF}$ \\
\hline & $\mathrm{OFF}$ & $\mathrm{OFF}$ & $\mathrm{OFF}$ & $\mathrm{OFF}$ & $\mathrm{OFF}$ & $\mathrm{OFF}$ & OFF & $\mathrm{OFF}$ & $\mathrm{OFF}$ \\
\hline & $\mathrm{OFF}$ & $\mathrm{OFF}$ & $\mathrm{OFF}$ & OFF & $\mathrm{OFF}$ & OFF & OFF & $\mathrm{OFF}$ & OFF \\
\hline & $\mathrm{OFF}$ & $\mathrm{OFF}$ & $\mathrm{OFF}$ & $\mathrm{OFF}$ & $\mathrm{OFF}$ & $\mathrm{OFF}$ & OFF & $\mathrm{OFF}$ & $\mathrm{OFF}$ \\
\hline & $\mathrm{OFF}$ & $\mathrm{OFF}$ & $\mathrm{OFF}$ & $\mathrm{OFF}$ & OFF & $\mathrm{OFF}$ & OFF & $\mathrm{OFF}$ & $\mathrm{OFF}$ \\
\hline & $\mathrm{OFF}$ & $\mathrm{OFF}$ & $\mathrm{OFF}$ & OFF & $\mathrm{OFF}$ & OFF & OFF & $\mathrm{OFF}$ & $\mathrm{OFF}$ \\
\hline & $\mathrm{OFF}$ & $\mathrm{OFF}$ & $\mathrm{OFF}$ & $\mathrm{OFF}$ & $\mathrm{OFF}$ & $\mathrm{OFF}$ & $\mathrm{OFF}$ & $\mathrm{OFF}$ & $\mathrm{OFF}$ \\
\hline & $\mathrm{OFF}$ & $\mathrm{OFF}$ & $\mathrm{OFF}$ & $\mathrm{OFF}$ & OFF & $\mathrm{OFF}$ & $\mathrm{OFF}$ & $\mathrm{OFF}$ & $\mathrm{OFF}$ \\
\hline & $\mathrm{OFF}$ & $O F F$ & $\mathrm{OFF}$ & $\mathrm{OFF}$ & $\mathrm{OFF}$ & $\mathrm{OFF}$ & $\mathrm{OFF}$ & $\mathrm{OFF}$ & $\mathrm{OFF}$ \\
\hline & $\mathrm{OFF}$ & $\mathrm{OFF}$ & $\mathrm{OFF}$ & OFF & $\mathrm{OFF}$ & $\mathrm{OFF}$ & $\mathrm{OFF}$ & OFF & $\mathrm{OFF}$ \\
\hline & $\mathrm{OFF}$ & $\mathrm{OFF}$ & $\mathrm{OFF}$ & $\mathrm{OFF}$ & $\mathrm{OFF}$ & $\mathrm{OFF}$ & $\mathrm{OFF}$ & $\mathrm{OFF}$ & $\mathrm{OFF}$ \\
\hline & $\mathrm{OFF}$ & $\mathrm{OFF}$ & & & & & & & \\
\hline Gen5 & $\mathrm{OFF}$ & $\mathrm{OFF}$ & $\mathrm{OFF}$ & $\mathrm{OFF}$ & $\mathrm{OFF}$ & $\mathrm{OFF}$ & $\mathrm{OFF}$ & $\mathrm{OFF}$ & $\mathrm{OFF}$ \\
\hline & OFF & $\mathrm{OFF}$ & $\mathrm{OFF}$ & $\mathrm{OFF}$ & $\mathrm{OFF}$ & $\mathrm{OFF}$ & OFF & OFF & $\mathrm{OFF}$ \\
\hline & $\mathrm{OFF}$ & $\mathrm{OFF}$ & $\mathrm{OFF}$ & $\mathrm{OFF}$ & $\mathrm{OFF}$ & $\mathrm{OFF}$ & $\mathrm{OFF}$ & $O F F$ & $\mathrm{OFF}$ \\
\hline & $\mathrm{OFF}$ & $\mathrm{OFF}$ & $\mathrm{OFF}$ & OFF & $\mathrm{OFF}$ & OFF & OFF & $\mathrm{OFF}$ & $\mathrm{OFF}$ \\
\hline & $\mathrm{OFF}$ & $\mathrm{OFF}$ & $\mathrm{OFF}$ & OFF & OFF & $\mathrm{OFF}$ & OFF & $\mathrm{OFF}$ & $\mathrm{OFF}$ \\
\hline
\end{tabular}




\begin{tabular}{|c|c|c|c|c|c|c|c|c|c|}
\hline & OFF & OFF & $\mathrm{OFF}$ & $\mathrm{OFF}$ & $\mathrm{OFF}$ & OFF & $\mathrm{OFF}$ & OFF & OFF \\
\hline & OFF & $\mathrm{OFF}$ & $\mathrm{OFF}$ & OFF & $\mathrm{OFF}$ & OFF & OFF & OFF & OFF \\
\hline & OFF & $\mathrm{OFF}$ & $\mathrm{OFF}$ & $\mathrm{OFF}$ & OFF & $\mathrm{OFF}$ & $\mathrm{OFF}$ & $\mathrm{OFF}$ & $\mathrm{OFE}$ \\
\hline & OFF & $\mathrm{OFF}$ & $\mathrm{OFF}$ & $\mathrm{OFF}$ & OFF & $\mathrm{OFF}$ & $\mathrm{OFF}$ & OFF & OFF \\
\hline & OFF & $\mathrm{OFF}$ & $\mathrm{OFF}$ & $\mathrm{OFF}$ & OFF & OFF & $\mathrm{OFF}$ & $\mathrm{OFF}$ & OFF \\
\hline & OFF & $\mathrm{OFF}$ & $\mathrm{OFF}$ & $\mathrm{OFF}$ & $\mathrm{OFF}$ & OFF & $\mathrm{OFF}$ & OFF & $\mathrm{OFF}$ \\
\hline & OFF & $\mathrm{OFF}$ & $\mathrm{OFF}$ & $\mathrm{OFF}$ & OFF & $\mathrm{OFF}$ & $\mathrm{OFF}$ & $\mathrm{OFF}$ & OFF \\
\hline & OFF & OFF & $\mathrm{OFF}$ & OFF & OFF & OFF & OFF & OFF & OFF \\
\hline & OFF & $\mathrm{OFF}$ & $\mathrm{OFF}$ & $\mathrm{OFF}$ & OFF & $\mathrm{OFF}$ & $\mathrm{OFF}$ & $\mathrm{OFF}$ & $\mathrm{OFE}$ \\
\hline & OFF & OFF & $\mathrm{OFF}$ & $\mathrm{OFF}$ & OFF & OFF & $\mathrm{OFF}$ & OFF & OFF \\
\hline & OFF & $\mathrm{OFF}$ & $\mathrm{OFF}$ & OFF & $\mathrm{OFF}$ & OFF & OFF & $\mathrm{OFF}$ & $\mathrm{OFF}$ \\
\hline & OFF & $\mathrm{OFF}$ & $\mathrm{OFF}$ & OFF & OFF & OFF & OFF & OFF & OFF \\
\hline & OFF & OFF & $\mathrm{OFF}$ & OFF & $\mathrm{OFF}$ & OFF & $\mathrm{OFF}$ & OFF & OFF \\
\hline & OFF & $\mathrm{OFF}$ & $\mathrm{OFF}$ & $\mathrm{OFF}$ & OFF & $\mathrm{OFF}$ & $\mathrm{OFF}$ & OFF & OFF \\
\hline & OFF & OFF & $\mathrm{OFF}$ & $\mathrm{OFF}$ & $\mathrm{OFF}$ & OFF & OFF & $\mathrm{OFF}$ & OFF \\
\hline & OFF & $\mathrm{OFF}$ & $\mathrm{OFF}$ & $\mathrm{OFF}$ & $\mathrm{OFF}$ & $\mathrm{OFF}$ & $\mathrm{OFF}$ & OFF & OFF \\
\hline & OFF & OFF & $\mathrm{OFF}$ & OFF & $\mathrm{OFF}$ & OFF & OFF & OFF & OFF \\
\hline & OFF & $\mathrm{OFF}$ & $\mathrm{OFF}$ & $\mathrm{OFF}$ & OFF & $\mathrm{OFF}$ & $\mathrm{OFF}$ & $\mathrm{OFF}$ & OFF \\
\hline & OFF & OFF & $\mathrm{OFF}$ & $\mathrm{OFF}$ & $\mathrm{OFF}$ & OFF & $\mathrm{OFF}$ & $\mathrm{OFF}$ & $\mathrm{OFF}$ \\
\hline & OFF & $\mathrm{OFF}$ & $\mathrm{OFF}$ & $\mathrm{OFF}$ & OFF & OFF & $\mathrm{OFF}$ & $\mathrm{OFF}$ & OFF \\
\hline & OFF & $\mathrm{OFF}$ & $\mathrm{OFF}$ & $\mathrm{OFF}$ & $\mathrm{OFF}$ & OFF & OFF & OFF & OFF \\
\hline & OFF & $\mathrm{OFF}$ & $\mathrm{OFF}$ & $\mathrm{OFF}$ & OFF & $\mathrm{OFF}$ & $\mathrm{OFF}$ & $\mathrm{OFF}$ & $\mathrm{OFF}$ \\
\hline & $\mathrm{OFF}$ & OFF & $\mathrm{OFF}$ & OFF & OFF & OFF & OFF & $\mathrm{OFF}$ & OFF \\
\hline & OFF & $\mathrm{OFF}$ & $\mathrm{OFF}$ & $\mathrm{OFF}$ & OFF & $\mathrm{OFF}$ & $\mathrm{OFF}$ & $\mathrm{OFF}$ & OFF \\
\hline & $\mathrm{OFF}$ & OFF & $\mathrm{OFF}$ & $\mathrm{OFF}$ & OFF & $\mathrm{OFF}$ & OFF & OFF & OFF \\
\hline & OFF & $\mathrm{OFF}$ & $\mathrm{OFF}$ & OFF & $\mathrm{OFF}$ & OFF & OFF & $\mathrm{OFF}$ & $\mathrm{OFF}$ \\
\hline & $\mathrm{OFF}$ & $\mathrm{OFF}$ & $\mathrm{OFF}$ & $\mathrm{OFF}$ & OFF & OFF & $\mathrm{OFF}$ & $\mathrm{OFF}$ & OFF \\
\hline & OFF & OFF & $\mathrm{OFF}$ & OFF & $\mathrm{OFF}$ & OFF & $\mathrm{OFF}$ & $\mathrm{OFF}$ & $\mathrm{OFF}$ \\
\hline & $\mathrm{OFF}$ & $\mathrm{OFF}$ & & & & & & & \\
\hline Gen 6 & OFF & OFF & $\mathrm{OFF}$ & $\mathrm{OFF}$ & $\mathrm{OFF}$ & $\mathrm{OFF}$ & $\mathrm{OFF}$ & $\mathrm{OFF}$ & OFF \\
\hline & OFF & OFF & $\mathrm{OFF}$ & $\mathrm{OFF}$ & $\mathrm{OFF}$ & OFF & $\mathrm{OFF}$ & $\mathrm{OFF}$ & OFF \\
\hline & OFF & OFF & $\mathrm{OFF}$ & OFF & $\mathrm{OFF}$ & OFF & OFF & $\mathrm{OFF}$ & OFF \\
\hline & OFF & OFF & $\mathrm{OFF}$ & OFF & $\mathrm{OFF}$ & OFF & OFF & OFF & OFF \\
\hline & $\mathrm{OFF}$ & $\mathrm{OFF}$ & $\mathrm{OFF}$ & $\mathrm{OFF}$ & OFF & $\mathrm{OFF}$ & $\mathrm{OFF}$ & OFF & OFF \\
\hline & $\mathrm{OFF}$ & OFF & $\mathrm{OFF}$ & $\mathrm{OFF}$ & $\mathrm{OFF}$ & OFF & OFF & $\mathrm{OFF}$ & $\mathrm{OFF}$ \\
\hline & $\mathrm{OFF}$ & $\mathrm{OFF}$ & $\mathrm{OFF}$ & $\mathrm{OFF}$ & $\mathrm{OFF}$ & OFF & OFF & OFF & OFF \\
\hline & $\mathrm{OFF}$ & OFF & $\mathrm{OFF}$ & OFF & OFF & OFF & OFF & OFF & OFF \\
\hline & $\mathrm{OFF}$ & OFF & $\mathrm{OFF}$ & OFF & OFF & OFF & OFF & $\mathrm{OFF}$ & OFF \\
\hline & $\mathrm{OFF}$ & OFF & $\mathrm{OFF}$ & $\mathrm{OFF}$ & OFF & OFF & $\mathrm{OFF}$ & OFF & OFF \\
\hline & $\mathrm{OFF}$ & OFF & $\mathrm{OFF}$ & OFF & OFF & OFF & OFF & OFF & OFF \\
\hline & $\mathrm{OFF}$ & OFF & $\mathrm{OFF}$ & $\mathrm{OFF}$ & OFF & OFF & $\mathrm{OFF}$ & $\mathrm{OFF}$ & OFF \\
\hline & OFF & OFF & $\mathrm{OFF}$ & OFF & $\mathrm{OFF}$ & OFF & $\mathrm{OFF}$ & OFF & OFF \\
\hline & OFF & OFF & $\mathrm{OFF}$ & OFF & $\mathrm{OFF}$ & OFF & $\mathrm{OFF}$ & OFF & OFF \\
\hline & $\mathrm{OFF}$ & OFF & $\mathrm{OFF}$ & $\mathrm{OFF}$ & OFF & OFF & $\mathrm{OFF}$ & OFF & OFF \\
\hline & OFF & OFF & $\mathrm{OFF}$ & OFF & $\mathrm{OFF}$ & OFF & OFF & $\mathrm{OFF}$ & $\mathrm{OFF}$ \\
\hline & $\mathrm{OFF}$ & OFF & $\mathrm{OFF}$ & OFF & OFF & OFF & OFF & OFF & OFF \\
\hline & $\mathrm{OFF}$ & OFF & OFF & OFF & $\mathrm{OFF}$ & OFF & $\mathrm{OFF}$ & OFF & $\mathrm{OFF}$ \\
\hline & $\mathrm{OFF}$ & $\mathrm{OFF}$ & $\mathrm{OFF}$ & OFF & $\mathrm{OFF}$ & $\mathrm{OFF}$ & $\mathrm{OFF}$ & OFF & $\mathrm{OFF}$ \\
\hline & OFF & $\mathrm{OFF}$ & $\mathrm{OFF}$ & OFF & $\mathrm{OFF}$ & $\mathrm{OFF}$ & $\mathrm{OFF}$ & OFF & OFF \\
\hline & $\mathrm{OFF}$ & $\mathrm{OFF}$ & $\mathrm{OFF}$ & $\mathrm{OFF}$ & $\mathrm{OFF}$ & $\mathrm{OFF}$ & $\mathrm{OFF}$ & OFF & OFF \\
\hline & OFF & $\mathrm{OFF}$ & $\mathrm{OFF}$ & $\mathrm{OFF}$ & $\mathrm{OFF}$ & OFF & OFF & OFF & OFF \\
\hline & $\mathrm{OFF}$ & OFF & $\mathrm{OFF}$ & OFF & OFF & OFF & OFF & OFF & OFF \\
\hline & OFF & $\mathrm{OFF}$ & $\mathrm{OFF}$ & $\mathrm{OFF}$ & OFF & $\mathrm{OFF}$ & $\mathrm{OFF}$ & $\mathrm{OFF}$ & OFF \\
\hline & $\mathrm{OFF}$ & OFF & $\mathrm{OFF}$ & $\mathrm{OFF}$ & OFF & OFF & $\mathrm{OFF}$ & $\mathrm{OFF}$ & $\mathrm{OFF}$ \\
\hline & OFF & $\mathrm{OFF}$ & $\mathrm{OFF}$ & $\mathrm{OFF}$ & OFF & $\mathrm{OFF}$ & $\mathrm{OFF}$ & $\mathrm{OFF}$ & OFF \\
\hline & $\mathrm{OFF}$ & OFF & $\mathrm{OFF}$ & $\mathrm{OFF}$ & OFF & OFF & $\mathrm{OFF}$ & $\mathrm{OFF}$ & OFF \\
\hline & $\mathrm{OFF}$ & $\mathrm{OFF}$ & $\mathrm{OFF}$ & $\mathrm{OFF}$ & OFF & OFF & $\mathrm{OFF}$ & $\mathrm{OFF}$ & OFE \\
\hline & $\mathrm{OFF}$ & OFF & $\mathrm{OFF}$ & $\mathrm{OFF}$ & OFF & OFF & $\mathrm{OFF}$ & $\mathrm{OFF}$ & OFF \\
\hline & OFF & OFF & $\mathrm{OFF}$ & OFF & $\mathrm{OFF}$ & OFF & OFF & OFF & OFF \\
\hline & $\mathrm{OFF}$ & OFF & $\mathrm{OFF}$ & $\mathrm{OFF}$ & OFF & $\mathrm{OFF}$ & $\mathrm{OFF}$ & OFF & $\mathrm{OFF}$ \\
\hline & OFF & OFF & $\mathrm{OFF}$ & $\mathrm{OFF}$ & $\mathrm{OFF}$ & OFF & $\mathrm{OFF}$ & $\mathrm{OFF}$ & OFF \\
\hline & $\mathrm{OFF}$ & OFF & $\mathrm{OFF}$ & $\mathrm{OFF}$ & OFF & OFF & $\mathrm{OFF}$ & OFF & OFF \\
\hline & $\mathrm{OFF}$ & $\mathrm{OFF}$ & & & & & & & \\
\hline Gen 7 & $\mathrm{OFF}$ & OFF & $\mathrm{OFF}$ & $\mathrm{OFF}$ & OFF & OFF & $\mathrm{OFF}$ & OFF & $\mathrm{OFF}$ \\
\hline & OFF & OFF & $\mathrm{OFF}$ & $\mathrm{OFF}$ & $\mathrm{OFF}$ & OFF & $\mathrm{OFF}$ & OFF & OFF \\
\hline & OFF & $\mathrm{OFF}$ & $\mathrm{OFF}$ & $\mathrm{OFF}$ & $\mathrm{OFF}$ & OFF & $\mathrm{OFF}$ & OFF & OFF \\
\hline & OFF & OFF & $\mathrm{OFF}$ & $\mathrm{OFF}$ & OFF & OFF & OFF & $\mathrm{OFF}$ & OFF \\
\hline & OFF & $\mathrm{OFF}$ & $\mathrm{OFF}$ & OFF & OFF & OFF & OFF & $\mathrm{OFF}$ & OFF \\
\hline
\end{tabular}




\begin{tabular}{|c|c|c|c|c|c|c|c|c|c|}
\hline & OFF & OFF & $\mathrm{OFF}$ & $\mathrm{OFF}$ & $\mathrm{OFF}$ & OFF & $\mathrm{OFF}$ & OFF & OFF \\
\hline & OFF & $\mathrm{OFF}$ & $\mathrm{OFF}$ & OFF & $\mathrm{OFF}$ & OFF & OFF & OFF & OFF \\
\hline & OFF & $\mathrm{OFF}$ & $\mathrm{OFF}$ & $\mathrm{OFF}$ & OFF & $\mathrm{OFF}$ & $\mathrm{OFF}$ & $\mathrm{OFF}$ & $\mathrm{OFE}$ \\
\hline & OFF & $\mathrm{OFF}$ & $\mathrm{OFF}$ & $\mathrm{OFF}$ & OFF & $\mathrm{OFF}$ & $\mathrm{OFF}$ & OFF & OFF \\
\hline & OFF & $\mathrm{OFF}$ & $\mathrm{OFF}$ & $\mathrm{OFF}$ & OFF & OFF & $\mathrm{OFF}$ & $\mathrm{OFF}$ & OFF \\
\hline & OFF & $\mathrm{OFF}$ & $\mathrm{OFF}$ & $\mathrm{OFF}$ & $\mathrm{OFF}$ & $\mathrm{OFF}$ & $\mathrm{OFF}$ & OFF & $\mathrm{OFF}$ \\
\hline & OFF & $\mathrm{OFF}$ & $\mathrm{OFF}$ & $\mathrm{OFF}$ & OFF & $\mathrm{OFF}$ & $\mathrm{OFF}$ & $\mathrm{OFF}$ & OFF \\
\hline & OFF & OFF & $\mathrm{OFF}$ & OFF & OFF & OFF & OFF & OFF & OFF \\
\hline & OFF & $\mathrm{OFF}$ & $\mathrm{OFF}$ & $\mathrm{OFF}$ & OFF & OFF & $\mathrm{OFF}$ & OFF & OFF \\
\hline & OFF & OFF & $\mathrm{OFF}$ & $\mathrm{OFF}$ & OFF & OFF & $\mathrm{OFF}$ & OFF & OFF \\
\hline & OFF & $\mathrm{OFF}$ & $\mathrm{OFF}$ & OFF & $\mathrm{OFF}$ & OFF & OFF & $\mathrm{OFF}$ & $\mathrm{OFF}$ \\
\hline & OFF & $\mathrm{OFF}$ & $\mathrm{OFF}$ & OFF & OFF & OFF & OFF & OFF & OFF \\
\hline & OFF & OFF & $\mathrm{OFF}$ & OFF & $\mathrm{OFF}$ & OFF & $\mathrm{OFF}$ & OFF & OFF \\
\hline & OFF & $\mathrm{OFF}$ & $\mathrm{OFF}$ & $\mathrm{OFF}$ & OFF & $\mathrm{OFF}$ & $\mathrm{OFF}$ & OFF & OFF \\
\hline & OFF & OFF & $\mathrm{OFF}$ & $\mathrm{OFF}$ & $\mathrm{OFF}$ & OFF & OFF & $\mathrm{OFF}$ & $\mathrm{OFF}$ \\
\hline & OFF & $\mathrm{OFF}$ & $\mathrm{OFF}$ & $\mathrm{OFF}$ & $\mathrm{OFF}$ & $\mathrm{OFF}$ & $\mathrm{OFF}$ & OFF & OFF \\
\hline & OFF & OFF & $\mathrm{OFF}$ & OFF & $\mathrm{OFF}$ & OFF & OFF & OFF & OFF \\
\hline & OFF & $\mathrm{OFF}$ & $\mathrm{OFF}$ & $\mathrm{OFF}$ & OFF & $\mathrm{OFF}$ & $\mathrm{OFF}$ & $\mathrm{OFF}$ & OFF \\
\hline & OFF & OFF & $\mathrm{OFF}$ & OFF & OFF & OFF & $\mathrm{OFF}$ & $\mathrm{OFF}$ & $\mathrm{OFF}$ \\
\hline & OFF & $\mathrm{OFF}$ & $\mathrm{OFF}$ & $\mathrm{OFF}$ & OFF & OFF & $\mathrm{OFF}$ & $\mathrm{OFF}$ & OFF \\
\hline & OFF & OFF & $\mathrm{OFF}$ & $\mathrm{OFF}$ & $\mathrm{OFF}$ & OFF & OFF & OFF & OFF \\
\hline & OFF & $\mathrm{OFF}$ & $\mathrm{OFF}$ & $\mathrm{OFF}$ & OFF & $\mathrm{OFF}$ & $\mathrm{OFF}$ & $\mathrm{OFF}$ & $\mathrm{OFF}$ \\
\hline & $\mathrm{OFF}$ & OFF & $\mathrm{OFF}$ & OFF & OFF & OFF & OFF & $\mathrm{OFF}$ & OFF \\
\hline & OFF & $\mathrm{OFF}$ & $\mathrm{OFF}$ & $\mathrm{OFF}$ & OFF & $\mathrm{OFF}$ & $\mathrm{OFF}$ & $\mathrm{OFF}$ & OFF \\
\hline & $\mathrm{OFF}$ & OFF & $\mathrm{OFF}$ & OFF & OFF & $\mathrm{OFF}$ & OFF & OFF & $\mathrm{OFF}$ \\
\hline & OFF & $\mathrm{OFF}$ & $\mathrm{OFF}$ & OFF & $\mathrm{OFF}$ & OFF & OFF & $\mathrm{OFF}$ & $\mathrm{OFF}$ \\
\hline & $\mathrm{OFF}$ & $\mathrm{OFF}$ & $\mathrm{OFF}$ & $\mathrm{OFF}$ & OFF & OFF & $\mathrm{OFF}$ & $\mathrm{OFF}$ & OFF \\
\hline & OFF & OFF & $\mathrm{OFF}$ & OFF & $\mathrm{OFF}$ & OFF & $\mathrm{OFF}$ & $\mathrm{OFF}$ & OFF \\
\hline & $\mathrm{OFF}$ & $\mathrm{OFF}$ & & & & & & & \\
\hline Gen 8 & OFF & OFF & $\mathrm{OFF}$ & $\mathrm{OFF}$ & $\mathrm{OFF}$ & $\mathrm{OFF}$ & $\mathrm{OFF}$ & $\mathrm{OFF}$ & OFF \\
\hline & OFF & OFF & $\mathrm{OFF}$ & $\mathrm{OFF}$ & $\mathrm{OFF}$ & OFF & $\mathrm{OFF}$ & $\mathrm{OFF}$ & OFF \\
\hline & OFF & OFF & $\mathrm{OFF}$ & OFF & $\mathrm{OFF}$ & OFF & OFF & $\mathrm{OFF}$ & OFF \\
\hline & OFF & OFF & $\mathrm{OFF}$ & OFF & $\mathrm{OFF}$ & OFF & OFF & OFF & OFF \\
\hline & $\mathrm{OFF}$ & $\mathrm{OFF}$ & $\mathrm{OFF}$ & $\mathrm{OFF}$ & OFF & $\mathrm{OFF}$ & $\mathrm{OFF}$ & OFF & OFF \\
\hline & $\mathrm{OFF}$ & OFF & $\mathrm{OFF}$ & $\mathrm{OFF}$ & $\mathrm{OFF}$ & OFF & $\mathrm{OFF}$ & OFF & OFF \\
\hline & $\mathrm{OFF}$ & $\mathrm{OFF}$ & $\mathrm{OFF}$ & $\mathrm{OFF}$ & $\mathrm{OFF}$ & OFF & OFF & OFF & OFF \\
\hline & $\mathrm{OFF}$ & OFF & $\mathrm{OFF}$ & OFF & OFF & OFF & OFF & OFF & OFF \\
\hline & $\mathrm{OFF}$ & OFF & $\mathrm{OFF}$ & OFF & OFF & OFF & OFF & $\mathrm{OFF}$ & OFF \\
\hline & $\mathrm{OFF}$ & OFF & $\mathrm{OFF}$ & $\mathrm{OFF}$ & OFF & OFF & $\mathrm{OFF}$ & OFF & OFF \\
\hline & $\mathrm{OFF}$ & OFF & $\mathrm{OFF}$ & OFF & OFF & OFF & OFF & OFF & OFF \\
\hline & $\mathrm{OFF}$ & OFF & $\mathrm{OFF}$ & $\mathrm{OFF}$ & OFF & OFF & $\mathrm{OFF}$ & $\mathrm{OFF}$ & $\mathrm{OFF}$ \\
\hline & OFF & OFF & $\mathrm{OFF}$ & OFF & $\mathrm{OFF}$ & OFF & OFF & OFF & OFF \\
\hline & OFF & OFF & $\mathrm{OFF}$ & OFF & $\mathrm{OFF}$ & OFF & OFF & OFF & OFF \\
\hline & $\mathrm{OFF}$ & OFF & $\mathrm{OFF}$ & $\mathrm{OFF}$ & OFF & OFF & $\mathrm{OFF}$ & OFF & OFF \\
\hline & OFF & OFF & $\mathrm{OFF}$ & $\mathrm{OFF}$ & $\mathrm{OFF}$ & OFF & $\mathrm{OFF}$ & $\mathrm{OFF}$ & OFF \\
\hline & $\mathrm{OFF}$ & OFF & $\mathrm{OFF}$ & OFF & OFF & OFF & OFF & OFF & OFF \\
\hline & $\mathrm{OFF}$ & OFF & OFF & OFF & $\mathrm{OFF}$ & OFF & $\mathrm{OFF}$ & OFF & $\mathrm{OFF}$ \\
\hline & $\mathrm{OFF}$ & OFF & $\mathrm{OFF}$ & OFF & $\mathrm{OFF}$ & $\mathrm{OFF}$ & $\mathrm{OFF}$ & OFF & $\mathrm{OFF}$ \\
\hline & OFF & $\mathrm{OFF}$ & $\mathrm{OFF}$ & OFF & $\mathrm{OFF}$ & $\mathrm{OFF}$ & $\mathrm{OFF}$ & OFF & OFF \\
\hline & $\mathrm{OFF}$ & $\mathrm{OFF}$ & $\mathrm{OFF}$ & $\mathrm{OFF}$ & $\mathrm{OFF}$ & $\mathrm{OFF}$ & $\mathrm{OFF}$ & OFF & OFF \\
\hline & OFF & $\mathrm{OFF}$ & $\mathrm{OFF}$ & OFF & $\mathrm{OFF}$ & OFF & OFF & OFF & OFF \\
\hline & $\mathrm{OFF}$ & OFF & $\mathrm{OFF}$ & OFF & OFF & OFF & OFF & OFF & OFF \\
\hline & OFF & $\mathrm{OFF}$ & $\mathrm{OFF}$ & $\mathrm{OFF}$ & OFF & $\mathrm{OFF}$ & $\mathrm{OFF}$ & $\mathrm{OFF}$ & OFF \\
\hline & $\mathrm{OFF}$ & OFF & $\mathrm{OFF}$ & $\mathrm{OFF}$ & OFF & OFF & $\mathrm{OFF}$ & $\mathrm{OFF}$ & OFF \\
\hline & OFF & $\mathrm{OFF}$ & $\mathrm{OFF}$ & $\mathrm{OFF}$ & OFF & $\mathrm{OFF}$ & $\mathrm{OFF}$ & $\mathrm{OFF}$ & OFF \\
\hline & $\mathrm{OFF}$ & OFF & $\mathrm{OFF}$ & $\mathrm{OFF}$ & OFF & OFF & $\mathrm{OFF}$ & $\mathrm{OFF}$ & OFF \\
\hline & $\mathrm{OFF}$ & $\mathrm{OFF}$ & $\mathrm{OFF}$ & $\mathrm{OFF}$ & OFF & OFF & $\mathrm{OFF}$ & $\mathrm{OFF}$ & OFF \\
\hline & $\mathrm{OFF}$ & OFF & $\mathrm{OFF}$ & $\mathrm{OFF}$ & OFF & OFF & $\mathrm{OFF}$ & $\mathrm{OFF}$ & OFF \\
\hline & OFF & OFF & $\mathrm{OFF}$ & OFF & $\mathrm{OFF}$ & OFF & OFF & OFF & OFF \\
\hline & $\mathrm{OFF}$ & OFF & $\mathrm{OFF}$ & $\mathrm{OFF}$ & OFF & $\mathrm{OFF}$ & $\mathrm{OFF}$ & OFF & $\mathrm{OFF}$ \\
\hline & OFF & OFF & $\mathrm{OFF}$ & $\mathrm{OFF}$ & $\mathrm{OFF}$ & OFF & $\mathrm{OFF}$ & $\mathrm{OFF}$ & OFF \\
\hline & $\mathrm{OFF}$ & OFF & $\mathrm{OFF}$ & $\mathrm{OFF}$ & OFF & OFF & $\mathrm{OFF}$ & OFF & OFF \\
\hline & $\mathrm{OFF}$ & $\mathrm{OFF}$ & & & & & & & \\
\hline Gen 9 & $\mathrm{OFF}$ & OFF & $\mathrm{OFF}$ & $\mathrm{OFF}$ & OFF & OFF & $\mathrm{OFF}$ & OFF & $\mathrm{OFF}$ \\
\hline & OFF & OFF & $\mathrm{OFF}$ & $\mathrm{OFF}$ & $\mathrm{OFF}$ & OFF & $\mathrm{OFF}$ & OFF & OFF \\
\hline & OFF & $\mathrm{OFF}$ & $\mathrm{OFF}$ & $\mathrm{OFF}$ & $\mathrm{OFF}$ & OFF & $\mathrm{OFF}$ & OFF & OFF \\
\hline & OFF & OFF & $\mathrm{OFF}$ & $\mathrm{OFF}$ & OFF & OFF & OFF & $\mathrm{OFF}$ & OFF \\
\hline & OFF & $\mathrm{OFF}$ & $\mathrm{OFF}$ & OFF & OFF & OFF & OFF & $\mathrm{OFF}$ & OFF \\
\hline
\end{tabular}




\begin{tabular}{|c|c|c|c|c|c|c|c|c|c|}
\hline & OFF & OFF & $\mathrm{OFF}$ & $\mathrm{OFF}$ & $\mathrm{OFF}$ & OFF & $\mathrm{OFF}$ & OFF & OFF \\
\hline & OFF & $\mathrm{OFF}$ & $\mathrm{OFF}$ & OFF & $\mathrm{OFF}$ & OFF & OFF & OFF & OFF \\
\hline & OFF & $\mathrm{OFF}$ & $\mathrm{OFF}$ & $\mathrm{OFF}$ & OFF & $\mathrm{OFF}$ & $\mathrm{OFF}$ & $\mathrm{OFF}$ & OFF \\
\hline & OFF & $\mathrm{OFF}$ & $\mathrm{OFF}$ & $\mathrm{OFF}$ & OFF & $\mathrm{OFF}$ & $\mathrm{OFF}$ & OFF & OFF \\
\hline & OFF & $\mathrm{OFF}$ & $\mathrm{OFF}$ & $\mathrm{OFF}$ & OFF & OFF & $\mathrm{OFF}$ & $\mathrm{OFF}$ & OFF \\
\hline & OFF & $\mathrm{OFF}$ & $\mathrm{OFF}$ & $\mathrm{OFF}$ & $\mathrm{OFF}$ & $\mathrm{OFF}$ & $\mathrm{OFF}$ & OFF & $\mathrm{OFF}$ \\
\hline & OFF & $\mathrm{OFF}$ & $\mathrm{OFF}$ & $\mathrm{OFF}$ & OFF & $\mathrm{OFF}$ & $\mathrm{OFF}$ & $\mathrm{OFF}$ & OFF \\
\hline & OFF & OFF & $\mathrm{OFF}$ & OFF & OFF & OFF & OFF & OFF & OFF \\
\hline & OFF & $\mathrm{OFF}$ & $\mathrm{OFF}$ & $\mathrm{OFF}$ & OFF & OFF & $\mathrm{OFF}$ & OFF & OFF \\
\hline & OFF & OFF & $\mathrm{OFF}$ & $\mathrm{OFF}$ & OFF & OFF & $\mathrm{OFF}$ & OFF & OFF \\
\hline & OFF & $\mathrm{OFF}$ & $\mathrm{OFF}$ & OFF & $\mathrm{OFF}$ & OFF & OFF & $\mathrm{OFF}$ & $\mathrm{OFF}$ \\
\hline & OFF & $\mathrm{OFF}$ & $\mathrm{OFF}$ & OFF & OFF & OFF & OFF & OFF & OFF \\
\hline & OFF & OFF & $\mathrm{OFF}$ & OFF & $\mathrm{OFF}$ & OFF & $\mathrm{OFF}$ & OFF & OFF \\
\hline & OFF & $\mathrm{OFF}$ & $\mathrm{OFF}$ & $\mathrm{OFF}$ & OFF & $\mathrm{OFF}$ & $\mathrm{OFF}$ & OFF & OFF \\
\hline & OFF & OFF & $\mathrm{OFF}$ & $\mathrm{OFF}$ & $\mathrm{OFF}$ & OFF & OFF & $\mathrm{OFF}$ & $\mathrm{OFF}$ \\
\hline & OFF & $\mathrm{OFF}$ & $\mathrm{OFF}$ & $\mathrm{OFF}$ & $\mathrm{OFF}$ & $\mathrm{OFF}$ & $\mathrm{OFF}$ & OFF & OFF \\
\hline & OFF & OFF & $\mathrm{OFF}$ & OFF & $\mathrm{OFF}$ & OFF & OFF & OFF & OFF \\
\hline & OFF & $\mathrm{OFF}$ & $\mathrm{OFF}$ & $\mathrm{OFF}$ & OFF & $\mathrm{OFF}$ & $\mathrm{OFF}$ & $\mathrm{OFF}$ & $\mathrm{OFE}$ \\
\hline & OFF & OFF & $\mathrm{OFF}$ & OFF & OFF & OFF & $\mathrm{OFF}$ & $\mathrm{OFF}$ & $\mathrm{OFF}$ \\
\hline & OFF & $\mathrm{OFF}$ & $\mathrm{OFF}$ & $\mathrm{OFF}$ & OFF & OFF & $\mathrm{OFF}$ & $\mathrm{OFF}$ & OFF \\
\hline & $\mathrm{OFF}$ & $\mathrm{OFF}$ & $\mathrm{OFF}$ & $\mathrm{OFF}$ & $\mathrm{OFF}$ & OFF & OFF & OFF & OFF \\
\hline & OFF & $\mathrm{OFF}$ & $\mathrm{OFF}$ & $\mathrm{OFF}$ & OFF & $\mathrm{OFF}$ & $\mathrm{OFF}$ & $\mathrm{OFF}$ & OFF \\
\hline & $\mathrm{OFF}$ & OFF & $\mathrm{OFF}$ & OFF & OFF & OFF & OFF & $\mathrm{OFF}$ & OFF \\
\hline & OFF & $\mathrm{OFF}$ & $\mathrm{OFF}$ & $\mathrm{OFF}$ & OFF & $\mathrm{OFF}$ & $\mathrm{OFF}$ & $\mathrm{OFF}$ & OFF \\
\hline & $\mathrm{OFF}$ & OFF & $\mathrm{OFF}$ & OFF & OFF & OFF & OFF & OFF & OFF \\
\hline & $\mathrm{OFF}$ & $\mathrm{OFF}$ & $\mathrm{OFF}$ & OFF & $\mathrm{OFF}$ & OFF & OFF & $\mathrm{OFF}$ & $\mathrm{OFF}$ \\
\hline & $\mathrm{OFF}$ & $\mathrm{OFF}$ & $\mathrm{OFF}$ & $\mathrm{OFF}$ & OFF & OFF & $\mathrm{OFF}$ & $\mathrm{OFF}$ & OFF \\
\hline & OFF & OFF & $\mathrm{OFF}$ & OFF & $\mathrm{OFF}$ & OFF & $\mathrm{OFF}$ & $\mathrm{OFF}$ & OFF \\
\hline & OFF & OFF & & & & & & & \\
\hline Gen10 & OFF & OFF & $\mathrm{OFF}$ & $\mathrm{OFF}$ & $\mathrm{OFF}$ & $\mathrm{OFF}$ & $\mathrm{OFF}$ & $\mathrm{OFF}$ & OFF \\
\hline & OFF & OFF & $\mathrm{OFF}$ & OFF & $\mathrm{OFF}$ & OFF & OFF & $\mathrm{OFF}$ & OFF \\
\hline & OFF & OFF & $\mathrm{OFF}$ & OFF & $\mathrm{OFF}$ & OFF & OFF & OFF & OFF \\
\hline & OFF & OFF & $\mathrm{OFF}$ & OFF & $\mathrm{OFF}$ & OFF & OFF & OFF & OFF \\
\hline & $\mathrm{OFF}$ & OFF & $\mathrm{OFF}$ & $\mathrm{OFF}$ & OFF & OFF & $\mathrm{OFF}$ & OFF & OFF \\
\hline & $\mathrm{OFF}$ & OFF & $\mathrm{OFF}$ & $\mathrm{OFF}$ & $\mathrm{OFF}$ & OFF & $\mathrm{OFF}$ & OFF & OFF \\
\hline & $\mathrm{OFF}$ & OFF & $\mathrm{OFF}$ & $\mathrm{OFF}$ & $\mathrm{OFF}$ & OFF & $\mathrm{OFF}$ & OFF & OFF \\
\hline & $\mathrm{OFF}$ & OFF & $\mathrm{OFF}$ & OFF & OFF & OFF & $\mathrm{OFF}$ & OFF & OFF \\
\hline & $\mathrm{OFF}$ & OFF & $\mathrm{OFF}$ & OFF & $\mathrm{OFF}$ & OFF & $\mathrm{OFF}$ & $\mathrm{OFF}$ & $\mathrm{OFF}$ \\
\hline & $\mathrm{OFF}$ & OFF & $\mathrm{OFF}$ & $\mathrm{OFF}$ & OFF & OFF & $\mathrm{OFF}$ & OFF & OFF \\
\hline & $\mathrm{OFF}$ & OFF & $\mathrm{OFF}$ & $\mathrm{OFF}$ & OFF & OFF & $\mathrm{OFF}$ & OFF & OFF \\
\hline & $\mathrm{OFF}$ & OFF & $\mathrm{OFF}$ & $\mathrm{OFF}$ & OFF & OFF & $\mathrm{OFF}$ & $\mathrm{OFF}$ & OFF \\
\hline & OFF & OFF & $\mathrm{OFF}$ & $\mathrm{OFF}$ & OFF & OFF & $\mathrm{OFF}$ & OFF & OFF \\
\hline & OFF & OFF & $\mathrm{OFF}$ & $\mathrm{OFF}$ & OFF & OFF & $\mathrm{OFF}$ & OFF & OFF \\
\hline & $\mathrm{OFF}$ & OFF & $\mathrm{OFF}$ & $\mathrm{OFF}$ & OFF & OFF & $\mathrm{OFF}$ & $\mathrm{OFF}$ & $\mathrm{OFF}$ \\
\hline & OFF & OFF & $\mathrm{OFF}$ & OFF & $\mathrm{OFF}$ & OFF & OFF & $\mathrm{OFF}$ & OFF \\
\hline & $\mathrm{OFF}$ & OFF & $\mathrm{OFF}$ & OFF & OFF & OFF & OFF & OFF & OFF \\
\hline & $\mathrm{OFF}$ & OFF & OFF & OFF & $\mathrm{OFF}$ & OFF & $\mathrm{OFF}$ & OFF & $\mathrm{OFF}$ \\
\hline & $\mathrm{OFF}$ & OFF & $\mathrm{OFF}$ & $\mathrm{OFF}$ & OFF & OFF & $\mathrm{OFF}$ & OFF & OFF \\
\hline & OFF & OFF & $\mathrm{OFF}$ & $\mathrm{OFF}$ & OFF & OFF & $\mathrm{OFF}$ & OFF & OFF \\
\hline & OFF & $\mathrm{OFF}$ & $\mathrm{OFF}$ & $\mathrm{OFF}$ & $\mathrm{OFF}$ & OFF & $\mathrm{OFF}$ & $\mathrm{OFF}$ & $\mathrm{OFF}$ \\
\hline & OFF & OFF & $\mathrm{OFF}$ & $\mathrm{OFF}$ & $\mathrm{OFF}$ & OFF & $\mathrm{OFF}$ & OFF & OFF \\
\hline & $\mathrm{OFF}$ & OFF & $\mathrm{OFF}$ & OFF & OFF & OFF & $\mathrm{OFF}$ & OFF & OFF \\
\hline & OFF & $\mathrm{OFF}$ & $\mathrm{OFF}$ & $\mathrm{OFF}$ & OFF & $\mathrm{OFF}$ & $\mathrm{OFF}$ & $\mathrm{OFF}$ & OFF \\
\hline & $\mathrm{OFF}$ & OFF & $\mathrm{OFF}$ & $\mathrm{OFF}$ & OFF & OFF & $\mathrm{OFF}$ & $\mathrm{OFF}$ & OFF \\
\hline & OFF & OFF & $\mathrm{OFF}$ & $\mathrm{OFF}$ & OFF & OFF & $\mathrm{OFF}$ & $\mathrm{OFF}$ & OFF \\
\hline & $\mathrm{OFF}$ & OFF & $\mathrm{OFF}$ & $\mathrm{OFF}$ & OFF & OFF & $\mathrm{OFF}$ & $\mathrm{OFF}$ & OFF \\
\hline & $\mathrm{OFF}$ & $\mathrm{OFF}$ & $\mathrm{OFF}$ & $\mathrm{OFF}$ & OFF & OFF & $\mathrm{OFF}$ & OFF & OFF \\
\hline & $\mathrm{OFF}$ & OFF & $\mathrm{OFF}$ & $\mathrm{OFF}$ & OFF & OFF & $\mathrm{OFF}$ & $\mathrm{OFF}$ & OFF \\
\hline & OFF & OFF & $\mathrm{OFF}$ & $\mathrm{OFF}$ & OFF & OFF & $\mathrm{OFF}$ & OFF & OFF \\
\hline & $\mathrm{OFF}$ & OFF & $\mathrm{OFF}$ & $\mathrm{OFF}$ & OFF & OFF & $\mathrm{OFF}$ & OFF & $\mathrm{OFF}$ \\
\hline & OFF & OFF & $\mathrm{OFF}$ & OFF & $\mathrm{OFF}$ & OFF & OFF & $\mathrm{OFF}$ & OFF \\
\hline & $\mathrm{OFF}$ & OFF & $\mathrm{OFF}$ & $\mathrm{OFF}$ & OFF & OFF & $\mathrm{OFF}$ & $\mathrm{OFF}$ & OFF \\
\hline & $\mathrm{OFF}$ & OFF & & & & & & & \\
\hline Gen11 & $\mathrm{OFF}$ & OFF & $\mathrm{OFF}$ & $\mathrm{OFF}$ & OFF & OFF & $\mathrm{OFF}$ & OFF & $\mathrm{OFF}$ \\
\hline & OFF & OFF & $\mathrm{OFF}$ & $\mathrm{OFF}$ & $\mathrm{OFF}$ & OFF & $\mathrm{OFF}$ & OFF & OFF \\
\hline & OFF & $\mathrm{OFF}$ & $\mathrm{OFF}$ & $\mathrm{OFF}$ & $\mathrm{OFF}$ & OFF & $\mathrm{OFF}$ & OFF & OFF \\
\hline & OFF & OFF & $\mathrm{OFF}$ & $\mathrm{OFF}$ & OFF & OFF & OFF & $\mathrm{OFF}$ & OFF \\
\hline & OFF & $\mathrm{OFF}$ & $\mathrm{OFF}$ & OFF & OFF & OFF & OFF & $\mathrm{OFF}$ & OFF \\
\hline
\end{tabular}

304 


\begin{tabular}{|c|c|c|c|c|c|c|c|c|c|}
\hline & $\mathrm{OFF}$ & $\mathrm{OFF}$ & $\mathrm{OFF}$ & $\mathrm{OFF}$ & $\mathrm{OFF}$ & $\mathrm{OFF}$ & $\mathrm{OFF}$ & OFF & $\mathrm{OFF}$ \\
\hline & OFF & $\mathrm{OFF}$ & OFF & OFF & OFF & OFF & OFF & OFF & $\mathrm{OFF}$ \\
\hline & OFF & $\mathrm{OFF}$ & $\mathrm{OFF}$ & $\mathrm{OFF}$ & $\mathrm{OFF}$ & OFF & OFF & OFF & $\mathrm{OFF}$ \\
\hline & OFF & $\mathrm{OFF}$ & $\mathrm{OFF}$ & OFF & $\mathrm{OFF}$ & $\mathrm{OFF}$ & OFF & OFF & $\mathrm{OFF}$ \\
\hline & OFF & $\mathrm{OFF}$ & $\mathrm{OFF}$ & $\mathrm{OFF}$ & $\mathrm{OFF}$ & $\mathrm{OFF}$ & OFF & OFF & $\mathrm{OFF}$ \\
\hline & OFF & $\mathrm{OFF}$ & OFF & OFF & $\mathrm{OFF}$ & OFF & OFF & OFF & $\mathrm{OFF}$ \\
\hline & OFF & $\mathrm{OFF}$ & $\mathrm{OFF}$ & OFF & $\mathrm{OFF}$ & $\mathrm{OFF}$ & OFF & OFF & $\mathrm{OFF}$ \\
\hline & OFF & $\mathrm{OFF}$ & $\mathrm{OFF}$ & OFF & $\mathrm{OFF}$ & $\mathrm{OFF}$ & OFF & OFF & $\mathrm{OFF}$ \\
\hline & OFF & $\mathrm{OFF}$ & OFF & $\mathrm{OFF}$ & $\mathrm{OFF}$ & $\mathrm{OFF}$ & OFF & OFF & $\mathrm{OFF}$ \\
\hline & OFF & $\mathrm{OFF}$ & OFF & $\mathrm{OFF}$ & $\mathrm{OFF}$ & $\mathrm{OFF}$ & OFF & OFF & $\mathrm{OFF}$ \\
\hline & $\mathrm{OFF}$ & $\mathrm{OFF}$ & $\mathrm{OFF}$ & OFF & $\mathrm{OFF}$ & OFF & $\mathrm{OFF}$ & OFF & $\mathrm{OFF}$ \\
\hline & OFF & $\mathrm{OFF}$ & $\mathrm{OFF}$ & OFF & $\mathrm{OFF}$ & $\mathrm{OFF}$ & OFF & OFF & $\mathrm{OFF}$ \\
\hline & $\mathrm{OFF}$ & $\mathrm{OFF}$ & OFF & $\mathrm{OFF}$ & $\mathrm{OFF}$ & OFF & OFF & $\mathrm{OFF}$ & $\mathrm{OFF}$ \\
\hline & $\mathrm{OFF}$ & $\mathrm{OFF}$ & $\mathrm{OFF}$ & $\mathrm{OFF}$ & $\mathrm{OFF}$ & $\mathrm{OFF}$ & $\mathrm{OFF}$ & $\mathrm{OFF}$ & $\mathrm{OFF}$ \\
\hline & $\mathrm{OFF}$ & $\mathrm{OFF}$ & $\mathrm{OFF}$ & $\mathrm{OFF}$ & $\mathrm{OFF}$ & $\mathrm{OFF}$ & $\mathrm{OFF}$ & $\mathrm{OFF}$ & $\mathrm{OFF}$ \\
\hline & $\mathrm{OFF}$ & $\mathrm{OFF}$ & $\mathrm{OFF}$ & $\mathrm{OFF}$ & $\mathrm{OFF}$ & $\mathrm{OFF}$ & $\mathrm{OFF}$ & $\mathrm{OFF}$ & $\mathrm{OFF}$ \\
\hline & $\mathrm{OFF}$ & $\mathrm{OFF}$ & $\mathrm{OFF}$ & $\mathrm{OFF}$ & $\mathrm{OFF}$ & $\mathrm{OFF}$ & $\mathrm{OFF}$ & $\mathrm{OFF}$ & $\mathrm{OFF}$ \\
\hline & $\mathrm{OFF}$ & $\mathrm{OFF}$ & $\mathrm{OFF}$ & $\mathrm{OFF}$ & $\mathrm{OFF}$ & $\mathrm{OFF}$ & $\mathrm{OFF}$ & $\mathrm{OFF}$ & $\mathrm{OFF}$ \\
\hline & $\mathrm{OFF}$ & $\mathrm{OFF}$ & $\mathrm{OFF}$ & $\mathrm{OFF}$ & $\mathrm{OFF}$ & $\mathrm{OFF}$ & $\mathrm{OFF}$ & $\mathrm{OFF}$ & $\mathrm{OFF}$ \\
\hline & OFF & $\mathrm{OFF}$ & $\mathrm{OFF}$ & $\mathrm{OFF}$ & $\mathrm{OFF}$ & $\mathrm{OFF}$ & OFF & OFF & $\mathrm{OFF}$ \\
\hline & $\mathrm{OFF}$ & $\mathrm{OFF}$ & $\mathrm{OFF}$ & $\mathrm{OFF}$ & $\mathrm{OFF}$ & $\mathrm{OFF}$ & $\mathrm{OFF}$ & $\mathrm{OFF}$ & $\mathrm{OFF}$ \\
\hline & OFF & $\mathrm{OFF}$ & $\mathrm{OFF}$ & OFF & $\mathrm{OFF}$ & $\mathrm{OFF}$ & OFF & OFF & $\mathrm{OFF}$ \\
\hline & $\mathrm{OFF}$ & $\mathrm{OFF}$ & $\mathrm{OFF}$ & $\mathrm{OFF}$ & $\mathrm{OFF}$ & $\mathrm{OFF}$ & $\mathrm{OFF}$ & $\mathrm{OFF}$ & $\mathrm{OFF}$ \\
\hline & OFF & $\mathrm{OFF}$ & OFF & $\mathrm{OFF}$ & $\mathrm{OFF}$ & $\mathrm{OFF}$ & OFF & OFF & $\mathrm{OFF}$ \\
\hline & OFF & $\mathrm{OFF}$ & OFF & $\mathrm{OFF}$ & $\mathrm{OFF}$ & $\mathrm{OFF}$ & OFF & OFF & $\mathrm{OFF}$ \\
\hline & OFF & $\mathrm{OFF}$ & OFF & OFF & $\mathrm{OFF}$ & $\mathrm{OFF}$ & OFF & OFF & $\mathrm{OFF}$ \\
\hline & OFF & $\mathrm{OFF}$ & OFF & OFF & $\mathrm{OFF}$ & $\mathrm{OFF}$ & OFF & OFF & $\mathrm{OFF}$ \\
\hline & $\mathrm{OFF}$ & $\mathrm{OFF}$ & OFF & $\mathrm{OFF}$ & $\mathrm{OFF}$ & $\mathrm{OFF}$ & $\mathrm{OFF}$ & $\mathrm{OFF}$ & $\mathrm{OFF}$ \\
\hline & OFF & $\mathrm{OFF}$ & & & & & & & \\
\hline ISS1 & $\mathrm{OFF}$ & $\mathrm{OFF}$ & $\mathrm{OFF}$ & $\mathrm{OFF}$ & $\mathrm{OFF}$ & $\mathrm{OFF}$ & $\mathrm{OFF}$ & $\mathrm{OFF}$ & $\mathrm{OFF}$ \\
\hline & OFF & $\mathrm{OFF}$ & $\mathrm{OFF}$ & $\mathrm{OFF}$ & $\mathrm{OFF}$ & $\mathrm{OFF}$ & OFF & OFF & $\mathrm{OFF}$ \\
\hline & $\mathrm{OFF}$ & $\mathrm{OFF}$ & OFF & $\mathrm{OFF}$ & $\mathrm{OFF}$ & $\mathrm{OFF}$ & $\mathrm{OFF}$ & $\mathrm{OFF}$ & $\mathrm{OFF}$ \\
\hline & OFF & OFF & OFF & OFF & OFF & OFF & OFF & OFF & $\mathrm{OFF}$ \\
\hline & $\mathrm{OFF}$ & $\mathrm{OFF}$ & $\mathrm{OFF}$ & $\mathrm{OFF}$ & $\mathrm{OFF}$ & $\mathrm{OFF}$ & $\mathrm{OFF}$ & $\mathrm{OFF}$ & $\mathrm{OFF}$ \\
\hline & OFF & $\mathrm{OFF}$ & $\mathrm{OFF}$ & OFF & $\mathrm{OFF}$ & $\mathrm{OFF}$ & OFF & OFF & $\mathrm{OFF}$ \\
\hline & $\mathrm{OFF}$ & $\mathrm{OFF}$ & $\mathrm{OFF}$ & $\mathrm{OFF}$ & $\mathrm{OFF}$ & $\mathrm{OFF}$ & $\mathrm{OFF}$ & OFF & $\mathrm{OFF}$ \\
\hline & OFF & $\mathrm{OFF}$ & $\mathrm{OFF}$ & OFF & $\mathrm{OFF}$ & $\mathrm{OFF}$ & OFF & OFF & $\mathrm{OFF}$ \\
\hline & $\mathrm{OFF}$ & $\mathrm{OFF}$ & $\mathrm{OFF}$ & $\mathrm{OFF}$ & $\mathrm{OFF}$ & $\mathrm{OFF}$ & $\mathrm{OFF}$ & $\mathrm{OFF}$ & $\mathrm{OFF}$ \\
\hline & OFF & $\mathrm{OFF}$ & OFF & $\mathrm{OFF}$ & $\mathrm{OFF}$ & $\mathrm{OFF}$ & OFF & OFF & $\mathrm{OFF}$ \\
\hline & $\mathrm{OFF}$ & $\mathrm{OFF}$ & $\mathrm{OFF}$ & $\mathrm{OFF}$ & $\mathrm{OFF}$ & $\mathrm{OFF}$ & $\mathrm{OFF}$ & OFF & $\mathrm{OFF}$ \\
\hline & OFF & $\mathrm{OFF}$ & OFF & $\mathrm{OFF}$ & $\mathrm{OFF}$ & $\mathrm{OFF}$ & OFF & $\mathrm{OFF}$ & $\mathrm{OFF}$ \\
\hline & OFF & $\mathrm{OFF}$ & OFF & OFF & $\mathrm{OFF}$ & $\mathrm{OFF}$ & OFF & $\mathrm{OFF}$ & $\mathrm{OFF}$ \\
\hline & $\mathrm{OFF}$ & $\mathrm{OFF}$ & OFF & $\mathrm{OFF}$ & $\mathrm{OFF}$ & $\mathrm{OFF}$ & $\mathrm{OFF}$ & $\mathrm{OFF}$ & $\mathrm{OFF}$ \\
\hline & OFF & $\mathrm{OFF}$ & OFF & $\mathrm{OFF}$ & $\mathrm{OFF}$ & OFF & OFF & $\mathrm{OFF}$ & $\mathrm{OFF}$ \\
\hline & $\mathrm{OFF}$ & $\mathrm{OFF}$ & $\mathrm{OFF}$ & $\mathrm{OFF}$ & $\mathrm{OFF}$ & $\mathrm{OFF}$ & $\mathrm{OFF}$ & $\mathrm{OFF}$ & $\mathrm{OFF}$ \\
\hline & $\mathrm{OFF}$ & $\mathrm{OFF}$ & OFF & $\mathrm{OFF}$ & $\mathrm{OFF}$ & $\mathrm{OFF}$ & $\mathrm{OFF}$ & OFF & $\mathrm{OFF}$ \\
\hline & $\mathrm{OFF}$ & $\mathrm{OFF}$ & OFF & $\mathrm{OFF}$ & $\mathrm{OFF}$ & $\mathrm{OFF}$ & OFF & OFF & $\mathrm{OFF}$ \\
\hline & $\mathrm{OFF}$ & $\mathrm{OFF}$ & $\mathrm{OFF}$ & $\mathrm{OFF}$ & $\mathrm{OFF}$ & $\mathrm{OFF}$ & $\mathrm{OFF}$ & $\mathrm{OFF}$ & $\mathrm{OFF}$ \\
\hline & OFF & $\mathrm{OFF}$ & $\mathrm{OFF}$ & $\mathrm{OFF}$ & $\mathrm{OFF}$ & $\mathrm{OFF}$ & $\mathrm{OFF}$ & $\mathrm{OFF}$ & $\mathrm{OFF}$ \\
\hline & $\mathrm{OFF}$ & $\mathrm{OFF}$ & $\mathrm{OFF}$ & $\mathrm{OFF}$ & $\mathrm{OFF}$ & $\mathrm{OFF}$ & $\mathrm{OFF}$ & OFF & $\mathrm{OFF}$ \\
\hline & $\mathrm{OFF}$ & $\mathrm{OFF}$ & $\mathrm{OFF}$ & $\mathrm{OFF}$ & $\mathrm{OFF}$ & $\mathrm{OFF}$ & $\mathrm{OFF}$ & OFF & $\mathrm{OFF}$ \\
\hline & $\mathrm{OFF}$ & $\mathrm{OFF}$ & $\mathrm{OFF}$ & $\mathrm{OFF}$ & $\mathrm{OFF}$ & $\mathrm{OFF}$ & $\mathrm{OFF}$ & OFF & $\mathrm{OFF}$ \\
\hline & $\mathrm{OFF}$ & $\mathrm{OFF}$ & $\mathrm{OFF}$ & $\mathrm{OFF}$ & $\mathrm{OFF}$ & $\mathrm{OFF}$ & $\mathrm{OFF}$ & $\mathrm{OFF}$ & $\mathrm{OFF}$ \\
\hline & $\mathrm{OFF}$ & $\mathrm{OFF}$ & $\mathrm{OFF}$ & $\mathrm{OFF}$ & OFF & $\mathrm{OFF}$ & $\mathrm{OFF}$ & OFF & $\mathrm{OFF}$ \\
\hline & $\mathrm{OFF}$ & $\mathrm{OFF}$ & $\mathrm{OFF}$ & $\mathrm{OFF}$ & $\mathrm{OFF}$ & $\mathrm{OFF}$ & $\mathrm{OFF}$ & OFF & $\mathrm{OFF}$ \\
\hline & OFF & $\mathrm{OFF}$ & $\mathrm{OFF}$ & $\mathrm{OFF}$ & $\mathrm{OFF}$ & $\mathrm{OFF}$ & OFF & OFF & $\mathrm{OFF}$ \\
\hline & OFF & $\mathrm{OFF}$ & OFF & OFF & $\mathrm{OFF}$ & $\mathrm{OFF}$ & OFF & OFF & $\mathrm{OFF}$ \\
\hline & $\mathrm{OFF}$ & $\mathrm{OFF}$ & OFF & $\mathrm{OFF}$ & $\mathrm{OFF}$ & $\mathrm{OFF}$ & $\mathrm{OFF}$ & $\mathrm{OFF}$ & $\mathrm{OFF}$ \\
\hline & OFF & $\mathrm{OFF}$ & OFF & OFF & $\mathrm{OFF}$ & $\mathrm{OFF}$ & OFF & OFF & $\mathrm{OFF}$ \\
\hline & $\mathrm{OFF}$ & $\mathrm{OFF}$ & $\mathrm{OFF}$ & $\mathrm{OFF}$ & $\mathrm{OFF}$ & $\mathrm{OFF}$ & $\mathrm{OFF}$ & $\mathrm{OFF}$ & $\mathrm{OFF}$ \\
\hline & $\mathrm{OFF}$ & $\mathrm{OFF}$ & $\mathrm{OFF}$ & $\mathrm{OFF}$ & $\mathrm{OFF}$ & $\mathrm{OFF}$ & $\mathrm{OFF}$ & $\mathrm{OFF}$ & $\mathrm{OFF}$ \\
\hline & OFF & $\mathrm{OFF}$ & OFF & OFF & OFF & OFF & OFF & OFF & $\mathrm{OFF}$ \\
\hline & $\mathrm{OFF}$ & $\mathrm{OFF}$ & & & & & & & \\
\hline ISS2 & ON & $\mathrm{ON}$ & ON & ON & ON & ON & ON & $\mathrm{ON}$ & ON \\
\hline & ON & ON & ON & ON & ON & ON & ON & $\mathrm{ON}$ & $\mathrm{ON}$ \\
\hline & ON & ON & ON & ON & ON & ON & ON & $\mathrm{ON}$ & ON \\
\hline & ON & ON & ON & ON & ON & ON & ON & ON & ON \\
\hline & ON & $\mathrm{ON}$ & ON & ON & ON & ON & ON & ON & ON \\
\hline
\end{tabular}




\begin{tabular}{|c|c|c|c|c|c|c|c|c|c|}
\hline & $\mathrm{ON}$ & ON & ON & $\mathrm{ON}$ & $\mathrm{ON}$ & $\mathrm{ON}$ & $\mathrm{ON}$ & ON & ON \\
\hline & $\mathrm{ON}$ & ON & ON & $\mathrm{ON}$ & $\mathrm{ON}$ & $\mathrm{ON}$ & ON & ON & ON \\
\hline & $\mathrm{ON}$ & $\mathrm{ON}$ & $\mathrm{ON}$ & $\mathrm{ON}$ & ON & $\mathrm{ON}$ & ON & ON & ON \\
\hline & $\mathrm{ON}$ & ON & $\mathrm{ON}$ & $\mathrm{ON}$ & ON & ON & ON & $\mathrm{ON}$ & ON \\
\hline & $\mathrm{ON}$ & $\mathrm{ON}$ & $\mathrm{ON}$ & $\mathrm{ON}$ & ON & $\mathrm{ON}$ & ON & ON & ON \\
\hline & $\mathrm{ON}$ & $\mathrm{ON}$ & $\mathrm{ON}$ & $\mathrm{ON}$ & $\mathrm{ON}$ & $\mathrm{ON}$ & ON & ON & ON \\
\hline & $\mathrm{ON}$ & $\mathrm{ON}$ & $\mathrm{ON}$ & $\mathrm{ON}$ & $\mathrm{ON}$ & $\mathrm{ON}$ & ON & ON & ON \\
\hline & ON & ON & ON & ON & ON & ON & ON & ON & ON \\
\hline & $\mathrm{ON}$ & $\mathrm{ON}$ & $\mathrm{ON}$ & $\mathrm{ON}$ & $\mathrm{ON}$ & $\mathrm{ON}$ & $\mathrm{ON}$ & ON & ON \\
\hline & $\mathrm{ON}$ & $\mathrm{ON}$ & ON & $\mathrm{ON}$ & ON & $\mathrm{ON}$ & ON & $\mathrm{ON}$ & ON \\
\hline & $\mathrm{ON}$ & $\mathrm{ON}$ & $\mathrm{ON}$ & $\mathrm{ON}$ & $\mathrm{ON}$ & $\mathrm{ON}$ & ON & $\mathrm{ON}$ & ON \\
\hline & $\mathrm{ON}$ & $\mathrm{ON}$ & ON & $\mathrm{ON}$ & ON & ON & ON & ON & ON \\
\hline & $\mathrm{ON}$ & $\mathrm{ON}$ & ON & $\mathrm{ON}$ & ON & $\mathrm{ON}$ & $\mathrm{ON}$ & ON & ON \\
\hline & $\mathrm{ON}$ & $\mathrm{ON}$ & $\mathrm{ON}$ & $\mathrm{ON}$ & $\mathrm{ON}$ & $\mathrm{ON}$ & $\mathrm{ON}$ & ON & ON \\
\hline & $\mathrm{ON}$ & $\mathrm{ON}$ & $\mathrm{ON}$ & $\mathrm{ON}$ & ON & $\mathrm{ON}$ & ON & $\mathrm{ON}$ & $\mathrm{ON}$ \\
\hline & ON & ON & ON & $\mathrm{ON}$ & ON & $\mathrm{ON}$ & $\mathrm{ON}$ & ON & ON \\
\hline & $\mathrm{ON}$ & $\mathrm{ON}$ & $\mathrm{ON}$ & $\mathrm{ON}$ & ON & $\mathrm{ON}$ & $\mathrm{ON}$ & ON & ON \\
\hline & ON & $\mathrm{ON}$ & $\mathrm{ON}$ & $\mathrm{ON}$ & ON & $\mathrm{ON}$ & ON & ON & ON \\
\hline & $\mathrm{ON}$ & $\mathrm{ON}$ & $\mathrm{ON}$ & $\mathrm{ON}$ & $\mathrm{ON}$ & $\mathrm{ON}$ & $\mathrm{ON}$ & $\mathrm{ON}$ & ON \\
\hline & $\mathrm{ON}$ & ON & $\mathrm{ON}$ & ON & ON & ON & ON & ON & ON \\
\hline & $\mathrm{ON}$ & ON & $\mathrm{ON}$ & $\mathrm{ON}$ & ON & ON & ON & ON & ON \\
\hline & $\mathrm{ON}$ & $\mathrm{ON}$ & $\mathrm{ON}$ & $\mathrm{ON}$ & $\mathrm{ON}$ & $\mathrm{ON}$ & $\mathrm{ON}$ & ON & ON \\
\hline & ON & $\mathrm{ON}$ & ON & $\mathrm{ON}$ & ON & $\mathrm{ON}$ & ON & ON & ON \\
\hline & $\mathrm{ON}$ & $\mathrm{ON}$ & $\mathrm{ON}$ & $\mathrm{ON}$ & $\mathrm{ON}$ & $\mathrm{ON}$ & $\mathrm{ON}$ & $\mathrm{ON}$ & ON \\
\hline & ON & ON & $\mathrm{ON}$ & ON & ON & ON & ON & $\mathrm{ON}$ & ON \\
\hline & $\mathrm{ON}$ & ON & ON & $\mathrm{ON}$ & ON & ON & ON & ON & ON \\
\hline & ON & ON & $\mathrm{ON}$ & $\mathrm{ON}$ & ON & ON & ON & ON & $\mathrm{ON}$ \\
\hline & $\mathrm{ON}$ & $\mathrm{ON}$ & ON & $\mathrm{ON}$ & ON & $\mathrm{ON}$ & $\mathrm{ON}$ & $\mathrm{ON}$ & ON \\
\hline & $\mathrm{ON}$ & $\mathrm{ON}$ & & & & & & & \\
\hline $\mathrm{PO} 4$ & ON & $\mathrm{ON}$ & $\mathrm{ON}$ & $\mathrm{ON}$ & ON & ON & ON & ON & ON \\
\hline & $\mathrm{ON}$ & $\mathrm{ON}$ & $\mathrm{ON}$ & $\mathrm{ON}$ & ON & $\mathrm{ON}$ & $\mathrm{ON}$ & ON & ON \\
\hline & $\mathrm{ON}$ & ON & ON & $\mathrm{ON}$ & ON & ON & ON & ON & ON \\
\hline & $\mathrm{ON}$ & ON & ON & $\mathrm{ON}$ & ON & $\mathrm{ON}$ & ON & ON & ON \\
\hline & ON & ON & ON & $\mathrm{ON}$ & ON & ON & ON & ON & ON \\
\hline & $\mathrm{ON}$ & ON & $\mathrm{ON}$ & $\mathrm{ON}$ & ON & $\mathrm{ON}$ & $\mathrm{ON}$ & ON & ON \\
\hline & $\mathrm{ON}$ & $\mathrm{ON}$ & $\mathrm{ON}$ & $\mathrm{ON}$ & ON & $\mathrm{ON}$ & $\mathrm{ON}$ & ON & ON \\
\hline & $\mathrm{ON}$ & $\mathrm{ON}$ & ON & $\mathrm{ON}$ & ON & $\mathrm{ON}$ & $\mathrm{ON}$ & ON & ON \\
\hline & $\mathrm{ON}$ & $\mathrm{ON}$ & ON & $\mathrm{ON}$ & ON & $\mathrm{ON}$ & ON & ON & ON \\
\hline & ON & ON & $\mathrm{ON}$ & ON & ON & $\mathrm{ON}$ & ON & $\mathrm{ON}$ & ON \\
\hline & $\mathrm{ON}$ & $\mathrm{ON}$ & ON & $\mathrm{ON}$ & ON & $\mathrm{ON}$ & $\mathrm{ON}$ & ON & ON \\
\hline & $\mathrm{ON}$ & $\mathrm{ON}$ & ON & $\mathrm{ON}$ & ON & $\mathrm{ON}$ & $\mathrm{ON}$ & ON & ON \\
\hline & $\mathrm{ON}$ & $\mathrm{ON}$ & ON & $\mathrm{ON}$ & ON & $\mathrm{ON}$ & $\mathrm{ON}$ & $\mathrm{ON}$ & ON \\
\hline & $\mathrm{ON}$ & $\mathrm{ON}$ & ON & $\mathrm{ON}$ & ON & $\mathrm{ON}$ & ON & ON & ON \\
\hline & $\mathrm{ON}$ & $\mathrm{ON}$ & $\mathrm{ON}$ & $\mathrm{ON}$ & ON & $\mathrm{ON}$ & ON & ON & ON \\
\hline & $\mathrm{ON}$ & ON & ON & $\mathrm{ON}$ & ON & $\mathrm{ON}$ & $\mathrm{ON}$ & ON & ON \\
\hline & ON & ON & ON & $\mathrm{ON}$ & ON & $\mathrm{ON}$ & ON & ON & $\mathrm{ON}$ \\
\hline & $\mathrm{ON}$ & ON & ON & $\mathrm{ON}$ & ON & $\mathrm{ON}$ & ON & ON & ON \\
\hline & $\mathrm{ON}$ & ON & ON & $\mathrm{ON}$ & ON & ON & ON & ON & ON \\
\hline & $\mathrm{ON}$ & ON & ON & $\mathrm{ON}$ & ON & ON & ON & $\mathrm{ON}$ & ON \\
\hline & ON & $\mathrm{ON}$ & ON & $\mathrm{ON}$ & ON & ON & ON & ON & ON \\
\hline & $\mathrm{ON}$ & ON & $\mathrm{ON}$ & $\mathrm{ON}$ & ON & $\mathrm{ON}$ & ON & ON & ON \\
\hline & $\mathrm{ON}$ & $\mathrm{ON}$ & ON & $\mathrm{ON}$ & ON & $\mathrm{ON}$ & ON & ON & ON \\
\hline & $\mathrm{ON}$ & $\mathrm{ON}$ & $\mathrm{ON}$ & $\mathrm{ON}$ & $\mathrm{ON}$ & $\mathrm{ON}$ & $\mathrm{ON}$ & ON & ON \\
\hline & $\mathrm{ON}$ & $\mathrm{ON}$ & $\mathrm{ON}$ & $\mathrm{ON}$ & $\mathrm{ON}$ & $\mathrm{ON}$ & $\mathrm{ON}$ & ON & ON \\
\hline & $\mathrm{ON}$ & ON & $\mathrm{ON}$ & $\mathrm{ON}$ & ON & $\mathrm{ON}$ & ON & $\mathrm{ON}$ & ON \\
\hline & ON & ON & $\mathrm{ON}$ & ON & ON & ON & ON & ON & ON \\
\hline & ON & $\mathrm{ON}$ & $\mathrm{ON}$ & $\mathrm{ON}$ & ON & ON & ON & ON & ON \\
\hline & $\mathrm{ON}$ & $\mathrm{ON}$ & ON & $\mathrm{ON}$ & ON & $\mathrm{ON}$ & $\mathrm{ON}$ & ON & ON \\
\hline & $\mathrm{ON}$ & $\mathrm{ON}$ & ON & $\mathrm{ON}$ & $\mathrm{ON}$ & $\mathrm{ON}$ & $\mathrm{ON}$ & ON & ON \\
\hline & $\mathrm{ON}$ & $\mathrm{ON}$ & $\mathrm{ON}$ & $\mathrm{ON}$ & ON & ON & ON & $\mathrm{ON}$ & ON \\
\hline & $\mathrm{ON}$ & $\mathrm{ON}$ & $\mathrm{ON}$ & $\mathrm{ON}$ & $\mathrm{ON}$ & $\mathrm{ON}$ & $\mathrm{ON}$ & ON & ON \\
\hline & ON & ON & $\mathrm{ON}$ & $\mathrm{ON}$ & $\mathrm{ON}$ & ON & ON & ON & ON \\
\hline & $\mathrm{ON}$ & $\mathrm{ON}$ & & & & & & & \\
\hline NH 4 & $\mathrm{ON}$ & $\mathrm{ON}$ & $\mathrm{ON}$ & $\mathrm{ON}$ & ON & $\mathrm{ON}$ & $\mathrm{ON}$ & $\mathrm{ON}$ & ON \\
\hline & $\mathrm{ON}$ & $\mathrm{ON}$ & $\mathrm{ON}$ & $\mathrm{ON}$ & ON & ON & ON & ON & ON \\
\hline & $\mathrm{ON}$ & $\mathrm{ON}$ & ON & $\mathrm{ON}$ & $\mathrm{ON}$ & ON & $\mathrm{ON}$ & ON & ON \\
\hline & $\mathrm{ON}$ & ON & ON & $\mathrm{ON}$ & $\mathrm{ON}$ & ON & ON & $\mathrm{ON}$ & ON \\
\hline & $\mathrm{ON}$ & ON & ON & $\mathrm{ON}$ & ON & ON & ON & ON & \\
\hline
\end{tabular}




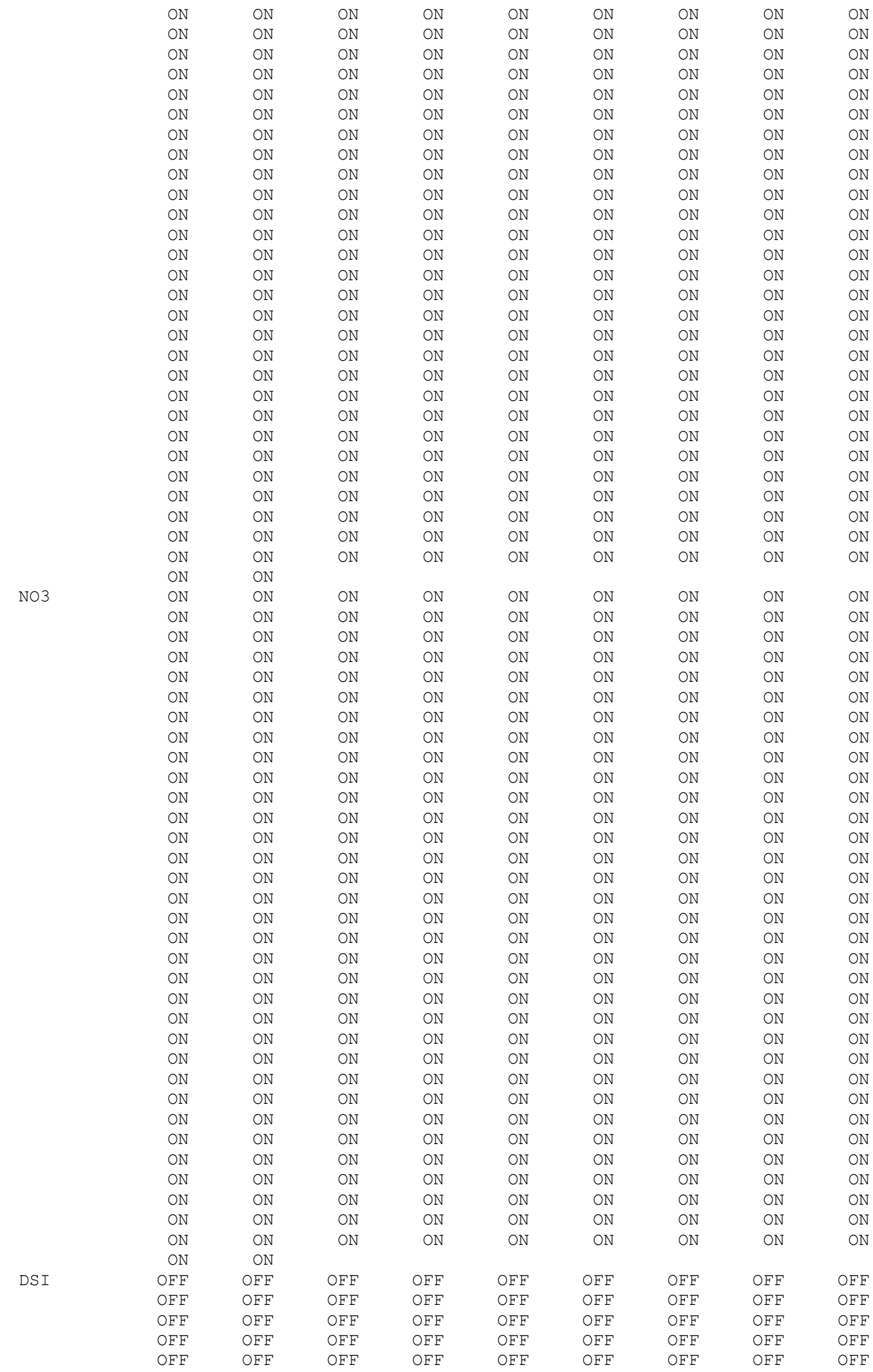




\begin{tabular}{|c|c|c|c|c|c|c|c|c|c|}
\hline & OFF & OFF & $\mathrm{OFF}$ & $\mathrm{OFF}$ & $\mathrm{OFF}$ & $\mathrm{OFF}$ & $\mathrm{OFE}$ & OFF & OFF \\
\hline & OFF & OFF & $\mathrm{OFF}$ & OFF & $\mathrm{OFF}$ & OFF & OFF & OFF & OFF \\
\hline & OFF & $\mathrm{OFF}$ & $\mathrm{OFF}$ & $\mathrm{OFF}$ & OFF & $\mathrm{OFF}$ & $\mathrm{OFF}$ & $\mathrm{OFF}$ & OFF \\
\hline & OFF & OFF & $\mathrm{OFF}$ & $\mathrm{OFF}$ & OFF & $\mathrm{OFF}$ & $\mathrm{OFF}$ & OFF & $\mathrm{OFF}$ \\
\hline & OFF & $\mathrm{OFF}$ & $\mathrm{OFF}$ & $\mathrm{OFF}$ & OFF & $\mathrm{OFF}$ & $\mathrm{OFF}$ & $\mathrm{OFF}$ & OFF \\
\hline & OFF & OFF & $\mathrm{OFF}$ & OFF & OFF & OFF & OFF & OFF & OFF \\
\hline & OFF & $\mathrm{OFF}$ & $\mathrm{OFF}$ & $\mathrm{OFF}$ & OFF & $\mathrm{OFF}$ & $\mathrm{OFF}$ & $\mathrm{OFF}$ & OFF \\
\hline & OFF & OFF & $\mathrm{OFF}$ & $\mathrm{OFF}$ & OFF & $\mathrm{OFF}$ & $\mathrm{OFF}$ & OFF & OFF \\
\hline & OFF & $\mathrm{OFF}$ & $\mathrm{OFF}$ & $\mathrm{OFF}$ & OFF & $\mathrm{OFF}$ & $\mathrm{OFF}$ & $\mathrm{OFF}$ & OFF \\
\hline & OFF & OFF & $\mathrm{OFF}$ & $\mathrm{OFF}$ & OFF & $\mathrm{OFF}$ & $\mathrm{OFF}$ & OFF & OFF \\
\hline & OFF & $\mathrm{OFF}$ & $\mathrm{OFF}$ & OFF & $\mathrm{OFF}$ & $\mathrm{OFF}$ & $\mathrm{OFF}$ & $\mathrm{OFF}$ & $\mathrm{OFF}$ \\
\hline & OFF & $\mathrm{OFF}$ & $\mathrm{OFF}$ & OFF & OFF & $\mathrm{OFF}$ & OFF & OFF & OFF \\
\hline & OFF & OFF & $\mathrm{OFF}$ & OFF & $\mathrm{OFF}$ & $\mathrm{OFF}$ & $\mathrm{OFF}$ & OFF & OFF \\
\hline & OFF & $\mathrm{OFF}$ & $\mathrm{OFF}$ & $\mathrm{OFF}$ & OFF & $\mathrm{OFF}$ & OFF & OFF & OFF \\
\hline & OFF & OFF & $\mathrm{OFF}$ & $\mathrm{OFF}$ & $\mathrm{OFF}$ & OFF & OFF & $\mathrm{OFF}$ & OFF \\
\hline & OFF & $\mathrm{OFF}$ & $\mathrm{OFF}$ & $\mathrm{OFF}$ & $\mathrm{OFF}$ & $\mathrm{OFF}$ & $\mathrm{OFF}$ & OFF & OFF \\
\hline & OFF & OFF & $\mathrm{OFF}$ & OFF & $\mathrm{OFF}$ & OFF & OFF & $\mathrm{OFF}$ & $\mathrm{OFF}$ \\
\hline & OFF & $\mathrm{OFF}$ & $\mathrm{OFF}$ & $\mathrm{OFF}$ & OFF & $\mathrm{OFF}$ & $\mathrm{OFF}$ & $\mathrm{OFF}$ & OFF \\
\hline & OFF & OFF & $\mathrm{OFF}$ & OFF & OFF & $\mathrm{OFF}$ & $\mathrm{OFF}$ & $\mathrm{OFF}$ & $\mathrm{OFF}$ \\
\hline & OFF & $\mathrm{OFF}$ & $\mathrm{OFF}$ & $\mathrm{OFF}$ & OFF & $\mathrm{OFF}$ & $\mathrm{OFF}$ & $\mathrm{OFF}$ & OFF \\
\hline & OFF & $\mathrm{OFF}$ & $\mathrm{OFF}$ & $\mathrm{OFF}$ & $\mathrm{OFF}$ & $\mathrm{OFF}$ & OFF & OFF & OFF \\
\hline & OFF & $\mathrm{OFF}$ & $\mathrm{OFF}$ & $\mathrm{OFF}$ & OFF & $\mathrm{OFF}$ & $\mathrm{OFF}$ & $\mathrm{OFF}$ & OFF \\
\hline & OFF & OFF & $\mathrm{OFF}$ & $\mathrm{OFF}$ & OFF & OFF & OFF & $\mathrm{OFF}$ & OFF \\
\hline & OFF & $\mathrm{OFF}$ & $\mathrm{OFF}$ & $\mathrm{OFF}$ & OFF & $\mathrm{OFF}$ & $\mathrm{OFF}$ & $\mathrm{OFF}$ & OFF \\
\hline & OFF & OFF & $\mathrm{OFF}$ & $\mathrm{OFF}$ & OFF & $\mathrm{OFF}$ & OFF & OFF & OFF \\
\hline & OFF & $\mathrm{OFF}$ & $\mathrm{OFF}$ & OFF & $\mathrm{OFF}$ & OFF & OFF & $\mathrm{OFF}$ & $\mathrm{OFF}$ \\
\hline & OFF & $\mathrm{OFF}$ & $\mathrm{OFF}$ & $\mathrm{OFF}$ & OFF & $\mathrm{OFF}$ & $\mathrm{OFF}$ & $\mathrm{OFF}$ & OFF \\
\hline & OFF & OFF & $\mathrm{OFF}$ & OFF & $\mathrm{OFF}$ & $\mathrm{OFF}$ & $\mathrm{OFF}$ & OFF & OFF \\
\hline & $\mathrm{OFF}$ & $\mathrm{OFF}$ & & & & & & & \\
\hline PS I & OFF & $\mathrm{OFF}$ & $\mathrm{OFF}$ & $\mathrm{OFF}$ & $\mathrm{OFF}$ & $\mathrm{OFF}$ & $\mathrm{OFF}$ & $\mathrm{OFF}$ & OFF \\
\hline & $\mathrm{OFF}$ & OFF & $\mathrm{OFF}$ & OFF & $\mathrm{OFF}$ & OFF & OFF & $\mathrm{OFF}$ & $\mathrm{OFF}$ \\
\hline & OFF & OFF & $\mathrm{OFF}$ & OFF & $\mathrm{OFF}$ & OFF & OFF & OFF & OFF \\
\hline & OFF & OFF & $\mathrm{OFF}$ & OFF & $\mathrm{OFF}$ & OFF & OFF & OFF & OFF \\
\hline & $\mathrm{OFF}$ & $\mathrm{OFF}$ & $\mathrm{OFF}$ & OFF & $\mathrm{OFF}$ & $\mathrm{OFF}$ & $\mathrm{OFF}$ & OFF & OFF \\
\hline & $\mathrm{OFF}$ & OFF & $\mathrm{OFF}$ & $\mathrm{OFF}$ & $\mathrm{OFF}$ & $\mathrm{OFF}$ & OFF & OFF & OFF \\
\hline & $\mathrm{OFF}$ & $\mathrm{OFF}$ & $\mathrm{OFF}$ & $\mathrm{OFF}$ & $\mathrm{OFF}$ & $\mathrm{OFF}$ & OFF & OFF & OFF \\
\hline & $\mathrm{OFF}$ & OFF & $\mathrm{OFF}$ & OFF & OFF & $\mathrm{OFF}$ & OFF & OFF & OFF \\
\hline & $\mathrm{OFF}$ & OFF & $\mathrm{OFF}$ & OFF & OFF & OFF & OFF & $\mathrm{OFF}$ & OFF \\
\hline & $\mathrm{OFF}$ & OFF & $\mathrm{OFF}$ & $\mathrm{OFF}$ & OFF & $\mathrm{OFF}$ & $\mathrm{OFF}$ & OFF & OFF \\
\hline & $\mathrm{OFF}$ & OFF & $\mathrm{OFF}$ & OFF & OFF & $\mathrm{OFF}$ & $\mathrm{OFF}$ & OFF & $\mathrm{OFF}$ \\
\hline & $\mathrm{OFF}$ & OFF & $\mathrm{OFF}$ & $\mathrm{OFF}$ & OFF & $\mathrm{OFF}$ & $\mathrm{OFF}$ & $\mathrm{OFF}$ & OFF \\
\hline & OFF & OFF & $\mathrm{OFF}$ & OFF & $\mathrm{OFF}$ & $\mathrm{OFF}$ & $\mathrm{OFF}$ & OFF & OFF \\
\hline & OFF & OFF & $\mathrm{OFF}$ & OFF & $\mathrm{OFF}$ & $\mathrm{OFF}$ & $\mathrm{OFF}$ & $\mathrm{OFF}$ & $\mathrm{OFF}$ \\
\hline & $\mathrm{OFF}$ & OFF & $\mathrm{OFF}$ & $\mathrm{OFF}$ & OFF & OFF & OFF & OFF & OFF \\
\hline & OFF & OFF & $\mathrm{OFF}$ & $\mathrm{OFF}$ & $\mathrm{OFF}$ & OFF & OFF & $\mathrm{OFF}$ & OFF \\
\hline & $\mathrm{OFF}$ & $\mathrm{OFF}$ & $\mathrm{OFF}$ & OFF & OFF & OFF & OFF & OFF & OFF \\
\hline & $\mathrm{OFF}$ & OFF & OFF & OFF & $\mathrm{OFF}$ & OFF & $\mathrm{OFF}$ & OFF & $\mathrm{OFF}$ \\
\hline & $\mathrm{OFF}$ & $\mathrm{OFF}$ & $\mathrm{OFF}$ & OFF & $\mathrm{OFF}$ & $\mathrm{OFF}$ & $\mathrm{OFF}$ & OFF & OFF \\
\hline & $\mathrm{OFF}$ & $\mathrm{OFF}$ & $\mathrm{OFF}$ & OFF & $\mathrm{OFF}$ & $\mathrm{OFF}$ & $\mathrm{OFF}$ & OFF & OFF \\
\hline & $\mathrm{OFF}$ & $\mathrm{OFF}$ & $\mathrm{OFF}$ & $\mathrm{OFF}$ & $\mathrm{OFF}$ & $\mathrm{OFF}$ & $\mathrm{OFF}$ & OFF & OFF \\
\hline & $\mathrm{OFF}$ & $\mathrm{OFF}$ & $\mathrm{OFF}$ & $\mathrm{OFF}$ & $\mathrm{OFF}$ & $\mathrm{OFF}$ & $\mathrm{OFF}$ & OFF & OFF \\
\hline & $\mathrm{OFF}$ & OFF & $\mathrm{OFF}$ & OFF & OFF & $\mathrm{OFF}$ & OFF & OFF & OFF \\
\hline & $\mathrm{OFF}$ & $\mathrm{OFF}$ & $\mathrm{OFF}$ & $\mathrm{OFF}$ & OFF & $\mathrm{OFF}$ & $\mathrm{OFF}$ & $\mathrm{OFF}$ & $\mathrm{OFF}$ \\
\hline & $\mathrm{OFF}$ & OFF & $\mathrm{OFF}$ & $\mathrm{OFF}$ & OFF & $\mathrm{OFF}$ & $\mathrm{OFF}$ & OFF & OFF \\
\hline & $\mathrm{OFF}$ & $\mathrm{OFF}$ & $\mathrm{OFF}$ & $\mathrm{OFF}$ & OFF & $\mathrm{OFF}$ & $\mathrm{OFF}$ & $\mathrm{OFF}$ & OFF \\
\hline & $\mathrm{OFF}$ & $\mathrm{OFF}$ & $\mathrm{OFF}$ & $\mathrm{OFF}$ & OFF & $\mathrm{OFF}$ & $\mathrm{OFF}$ & $\mathrm{OFF}$ & OFF \\
\hline & $\mathrm{OFF}$ & $\mathrm{OFF}$ & $\mathrm{OFF}$ & $\mathrm{OFF}$ & OFF & $\mathrm{OFF}$ & $\mathrm{OFF}$ & $\mathrm{OFF}$ & OFF \\
\hline & $\mathrm{OFF}$ & OFF & $\mathrm{OFF}$ & $\mathrm{OFF}$ & OFF & $\mathrm{OFF}$ & OFF & $\mathrm{OFF}$ & OFF \\
\hline & OFF & OFF & $\mathrm{OFF}$ & OFF & $\mathrm{OFF}$ & $\mathrm{OFF}$ & $\mathrm{OFF}$ & $\mathrm{OFF}$ & OFF \\
\hline & $\mathrm{OFF}$ & OFF & $\mathrm{OFF}$ & $\mathrm{OFF}$ & OFF & $\mathrm{OFF}$ & $\mathrm{OFF}$ & OFF & $\mathrm{OFF}$ \\
\hline & OFF & OFF & $\mathrm{OFF}$ & $\mathrm{OFF}$ & $\mathrm{OFF}$ & OFF & $\mathrm{OFF}$ & $\mathrm{OFF}$ & OFF \\
\hline & $\mathrm{OFF}$ & OFF & $\mathrm{OFF}$ & $\mathrm{OFF}$ & OFF & $\mathrm{OFF}$ & $\mathrm{OFF}$ & OFF & $\mathrm{OFF}$ \\
\hline & $\mathrm{OFF}$ & $\mathrm{OFF}$ & & & & & & & \\
\hline $\mathrm{FE}$ & OFF & OFF & $\mathrm{OFF}$ & OFF & OFF & $\mathrm{OFF}$ & $\mathrm{OFF}$ & $\mathrm{OFF}$ & OFF \\
\hline & OFF & OFF & $\mathrm{OFF}$ & $\mathrm{OFF}$ & $\mathrm{OFF}$ & $\mathrm{OFF}$ & $\mathrm{OFF}$ & OFF & OFF \\
\hline & OFF & $\mathrm{OFF}$ & $\mathrm{OFF}$ & $\mathrm{OFF}$ & $\mathrm{OFF}$ & $\mathrm{OFF}$ & OFF & OFF & OFF \\
\hline & OFF & OFF & $\mathrm{OFF}$ & $\mathrm{OFF}$ & OFF & $\mathrm{OFF}$ & OFF & $\mathrm{OFF}$ & OFF \\
\hline & OFF & $\mathrm{OFF}$ & $\mathrm{OFF}$ & OFF & OFF & $\mathrm{OFF}$ & OFF & $\mathrm{OFF}$ & OFF \\
\hline
\end{tabular}




\begin{tabular}{|c|c|c|c|c|c|c|c|c|c|}
\hline & $\mathrm{OFF}$ & OFF & $\mathrm{OFF}$ & $\mathrm{OFF}$ & $\mathrm{OFF}$ & OFF & OFF & OFF & OFF \\
\hline & $\mathrm{OFF}$ & OFF & $\mathrm{OFF}$ & OFF & OFF & OFF & OFF & OFF & $\mathrm{OFF}$ \\
\hline & OFF & $\mathrm{OFF}$ & $\mathrm{OFF}$ & $\mathrm{OFF}$ & $\mathrm{OFF}$ & $\mathrm{OFF}$ & OFF & $\mathrm{OFF}$ & $\mathrm{OFF}$ \\
\hline & $\mathrm{OFF}$ & $\mathrm{OFF}$ & $\mathrm{OFF}$ & OFF & $\mathrm{OFF}$ & $\mathrm{OFF}$ & OFF & OFF & OFF \\
\hline & $\mathrm{OFF}$ & $\mathrm{OFF}$ & $\mathrm{OFF}$ & $\mathrm{OFF}$ & $\mathrm{OFF}$ & $\mathrm{OFF}$ & $\mathrm{OFF}$ & $\mathrm{OFF}$ & OFF \\
\hline & $\mathrm{OFF}$ & $\mathrm{OFF}$ & $\mathrm{OFF}$ & $\mathrm{OFF}$ & $\mathrm{OFF}$ & OFF & OFF & OFF & OFF \\
\hline & $\mathrm{OFF}$ & $\mathrm{OFF}$ & $\mathrm{OFF}$ & $\mathrm{OFF}$ & $\mathrm{OFF}$ & $\mathrm{OFF}$ & $\mathrm{OFF}$ & $\mathrm{OFF}$ & OFF \\
\hline & $\mathrm{OFF}$ & $\mathrm{OFF}$ & $\mathrm{OFF}$ & $\mathrm{OFF}$ & $\mathrm{OFF}$ & OFF & OFF & OFF & OFF \\
\hline & $\mathrm{OFF}$ & $\mathrm{OFF}$ & $\mathrm{OFF}$ & $\mathrm{OFF}$ & $\mathrm{OFF}$ & $\mathrm{OFF}$ & OFF & $\mathrm{OFF}$ & OFF \\
\hline & $\mathrm{OFF}$ & OFF & $\mathrm{OFF}$ & $\mathrm{OFF}$ & $\mathrm{OFF}$ & OFF & OFF & OFF & $\mathrm{OFF}$ \\
\hline & $\mathrm{OFF}$ & OFF & $\mathrm{OFF}$ & $\mathrm{OFF}$ & OFF & $\mathrm{OFF}$ & OFF & OFF & OFF \\
\hline & $\mathrm{OFF}$ & $\mathrm{OFF}$ & $\mathrm{OFF}$ & $\mathrm{OFF}$ & $\mathrm{OFF}$ & OFF & OFF & OFF & OFF \\
\hline & $\mathrm{OFF}$ & $\mathrm{OFF}$ & $\mathrm{OFF}$ & $\mathrm{OFF}$ & $\mathrm{OFF}$ & OFF & OFF & OFF & OFF \\
\hline & $\mathrm{OFF}$ & $\mathrm{OFF}$ & $\mathrm{OFF}$ & $\mathrm{OFF}$ & $\mathrm{OFF}$ & OFF & OFF & OFF & OFF \\
\hline & $\mathrm{OFF}$ & $\mathrm{OFF}$ & $\mathrm{OFF}$ & $\mathrm{OFF}$ & $\mathrm{OFF}$ & OFF & OFF & OFF & OFF \\
\hline & OFF & $\mathrm{OFF}$ & $\mathrm{OFF}$ & OFF & $\mathrm{OFF}$ & OFF & OFF & OFF & OFF \\
\hline & $\mathrm{OFF}$ & $\mathrm{OFF}$ & $\mathrm{OFF}$ & $\mathrm{OFF}$ & $\mathrm{OFF}$ & OFF & OFF & OFF & OFF \\
\hline & $\mathrm{OFF}$ & $\mathrm{OFF}$ & $\mathrm{OFF}$ & OFF & $\mathrm{OFF}$ & OFF & OFF & OFF & $\mathrm{OFF}$ \\
\hline & $\mathrm{OFF}$ & $\mathrm{OFF}$ & $\mathrm{OFF}$ & OFF & $\mathrm{OFF}$ & $\mathrm{OFF}$ & OFF & OFF & $\mathrm{OFF}$ \\
\hline & $\mathrm{OFF}$ & $\mathrm{OFF}$ & $\mathrm{OFF}$ & $\mathrm{OFF}$ & $\mathrm{OFF}$ & OFF & OFF & OFF & $\mathrm{OFF}$ \\
\hline & $\mathrm{OFF}$ & OFF & $\mathrm{OFF}$ & $\mathrm{OFF}$ & $\mathrm{OFF}$ & OFF & OFF & OFF & OFF \\
\hline & $\mathrm{OFF}$ & $\mathrm{OFF}$ & $\mathrm{OFF}$ & $\mathrm{OFF}$ & $\mathrm{OFF}$ & OFF & OFF & OFF & OFF \\
\hline & $\mathrm{OFF}$ & OFF & $\mathrm{OFF}$ & $\mathrm{OFF}$ & $\mathrm{OFF}$ & OFF & OFF & OFF & OFF \\
\hline & $\mathrm{OFF}$ & $\mathrm{OFF}$ & $\mathrm{OFF}$ & $\mathrm{OFF}$ & $\mathrm{OFF}$ & OFF & OFF & OFF & $\mathrm{OFF}$ \\
\hline & $\mathrm{OFF}$ & OFF & $\mathrm{OFF}$ & $\mathrm{OFF}$ & $\mathrm{OFF}$ & OFF & OFF & OFF & $\mathrm{OFF}$ \\
\hline & $\mathrm{OFF}$ & OFF & $\mathrm{OFF}$ & $\mathrm{OFF}$ & $\mathrm{OFF}$ & OFF & OFF & OFF & $\mathrm{OFF}$ \\
\hline & $\mathrm{OFF}$ & OFF & $\mathrm{OFF}$ & $\mathrm{OFF}$ & $\mathrm{OFF}$ & OFF & OFF & OFF & OFF \\
\hline & $\mathrm{OFF}$ & OFF & $\mathrm{OFF}$ & $\mathrm{OFF}$ & $\mathrm{OFF}$ & $\mathrm{OFF}$ & $\mathrm{OFF}$ & $\mathrm{OFF}$ & OFF \\
\hline & $\mathrm{OFF}$ & OFF & & & & & & & \\
\hline LDOM & $\mathrm{ON}$ & $\mathrm{ON}$ & ON & ON & ON & $\mathrm{ON}$ & ON & ON & $\mathrm{ON}$ \\
\hline & $\mathrm{ON}$ & ON & ON & ON & ON & ON & ON & $\mathrm{ON}$ & $\mathrm{ON}$ \\
\hline & $\mathrm{ON}$ & ON & ON & $\mathrm{ON}$ & ON & ON & $\mathrm{ON}$ & $\mathrm{ON}$ & $\mathrm{ON}$ \\
\hline & $\mathrm{ON}$ & ON & ON & ON & ON & ON & ON & $\mathrm{ON}$ & $\mathrm{ON}$ \\
\hline & $\mathrm{ON}$ & $\mathrm{ON}$ & ON & ON & ON & ON & ON & $\mathrm{ON}$ & $\mathrm{ON}$ \\
\hline & $\mathrm{ON}$ & ON & ON & $\mathrm{ON}$ & ON & ON & $\mathrm{ON}$ & ON & $\mathrm{ON}$ \\
\hline & $\mathrm{ON}$ & $\mathrm{ON}$ & ON & ON & ON & ON & ON & ON & ON \\
\hline & $\mathrm{ON}$ & ON & ON & ON & ON & ON & ON & ON & $\mathrm{ON}$ \\
\hline & $\mathrm{ON}$ & $\mathrm{ON}$ & ON & ON & ON & ON & ON & ON & $\mathrm{ON}$ \\
\hline & $\mathrm{ON}$ & ON & ON & ON & ON & ON & ON & ON & $\mathrm{ON}$ \\
\hline & $\mathrm{ON}$ & ON & ON & $\mathrm{ON}$ & ON & ON & $\mathrm{ON}$ & ON & ON \\
\hline & $\mathrm{ON}$ & $\mathrm{ON}$ & ON & ON & ON & ON & $\mathrm{ON}$ & ON & $\mathrm{ON}$ \\
\hline & $\mathrm{ON}$ & $\mathrm{ON}$ & ON & ON & ON & ON & ON & ON & ON \\
\hline & $\mathrm{ON}$ & ON & ON & ON & ON & ON & ON & ON & $\mathrm{ON}$ \\
\hline & $\mathrm{ON}$ & $\mathrm{ON}$ & ON & ON & ON & ON & ON & ON & ON \\
\hline & $\mathrm{ON}$ & ON & ON & $\mathrm{ON}$ & ON & ON & ON & ON & $\mathrm{ON}$ \\
\hline & $\mathrm{ON}$ & $\mathrm{ON}$ & ON & ON & ON & ON & ON & ON & ON \\
\hline & $\mathrm{ON}$ & $\mathrm{ON}$ & ON & ON & ON & ON & ON & ON & $\mathrm{ON}$ \\
\hline & $\mathrm{ON}$ & $\mathrm{ON}$ & ON & ON & ON & ON & ON & ON & ON \\
\hline & $\mathrm{ON}$ & $\mathrm{ON}$ & ON & ON & ON & ON & ON & ON & $\mathrm{ON}$ \\
\hline & $\mathrm{ON}$ & $\mathrm{ON}$ & ON & $\mathrm{ON}$ & ON & ON & $\mathrm{ON}$ & ON & $\mathrm{ON}$ \\
\hline & $\mathrm{ON}$ & $\mathrm{ON}$ & ON & ON & ON & ON & ON & ON & ON \\
\hline & $\mathrm{ON}$ & ON & ON & ON & ON & ON & ON & ON & $\mathrm{ON}$ \\
\hline & $\mathrm{ON}$ & $\mathrm{ON}$ & ON & ON & ON & ON & ON & ON & ON \\
\hline & $\mathrm{ON}$ & $\mathrm{ON}$ & ON & ON & ON & ON & ON & ON & $\mathrm{ON}$ \\
\hline & $\mathrm{ON}$ & $\mathrm{ON}$ & ON & ON & ON & ON & ON & ON & $\mathrm{ON}$ \\
\hline & $\mathrm{ON}$ & $\mathrm{ON}$ & ON & ON & ON & ON & ON & ON & $\mathrm{ON}$ \\
\hline & $\mathrm{ON}$ & $\mathrm{ON}$ & ON & ON & ON & ON & ON & ON & $\mathrm{ON}$ \\
\hline & $\mathrm{ON}$ & ON & ON & ON & ON & ON & ON & ON & $\mathrm{ON}$ \\
\hline & $\mathrm{ON}$ & ON & ON & ON & ON & ON & ON & ON & ON \\
\hline & $\mathrm{ON}$ & ON & ON & $\mathrm{ON}$ & ON & ON & ON & ON & $\mathrm{ON}$ \\
\hline & $\mathrm{ON}$ & ON & ON & ON & ON & ON & ON & ON & $\mathrm{ON}$ \\
\hline & $\mathrm{ON}$ & $\mathrm{ON}$ & ON & ON & ON & ON & ON & ON & $\mathrm{ON}$ \\
\hline & $\mathrm{ON}$ & ON & & & & & & & \\
\hline $\mathrm{RDOM}$ & $\mathrm{ON}$ & $\mathrm{ON}$ & ON & ON & ON & ON & ON & ON & $\mathrm{ON}$ \\
\hline & $\mathrm{ON}$ & $\mathrm{ON}$ & ON & ON & ON & ON & ON & ON & $\mathrm{ON}$ \\
\hline & $\mathrm{ON}$ & ON & ON & $\mathrm{ON}$ & ON & ON & ON & ON & $\mathrm{ON}$ \\
\hline & $\mathrm{ON}$ & ON & ON & ON & ON & ON & ON & ON & $\mathrm{ON}$ \\
\hline & $\mathrm{ON}$ & ON & ON & ON & ON & ON & ON & ON & $\mathrm{ON}$ \\
\hline
\end{tabular}




\begin{tabular}{|c|c|c|c|c|c|c|c|c|c|}
\hline & ON & ON & $\mathrm{ON}$ & ON & ON & ON & ON & ON & ON \\
\hline & ON & ON & $\mathrm{ON}$ & $\mathrm{ON}$ & $\mathrm{ON}$ & ON & $\mathrm{ON}$ & ON & $\mathrm{ON}$ \\
\hline & ON & ON & ON & ON & ON & ON & $\mathrm{ON}$ & ON & $\mathrm{ON}$ \\
\hline & $\mathrm{ON}$ & ON & ON & $\mathrm{ON}$ & ON & ON & ON & ON & $\mathrm{ON}$ \\
\hline & ON & ON & $\mathrm{ON}$ & $\mathrm{ON}$ & ON & $\mathrm{ON}$ & ON & ON & $\mathrm{ON}$ \\
\hline & $\mathrm{ON}$ & ON & ON & ON & $\mathrm{ON}$ & $\mathrm{ON}$ & $\mathrm{ON}$ & ON & $\mathrm{ON}$ \\
\hline & ON & ON & ON & ON & ON & ON & ON & ON & $\mathrm{ON}$ \\
\hline & ON & ON & ON & ON & ON & ON & ON & $\mathrm{ON}$ & $\mathrm{ON}$ \\
\hline & $\mathrm{ON}$ & ON & $\mathrm{ON}$ & $\mathrm{ON}$ & ON & $\mathrm{ON}$ & ON & ON & $\mathrm{ON}$ \\
\hline & $\mathrm{ON}$ & ON & $\mathrm{ON}$ & $\mathrm{ON}$ & ON & $\mathrm{ON}$ & $\mathrm{ON}$ & ON & $\mathrm{ON}$ \\
\hline & $\mathrm{ON}$ & ON & ON & ON & ON & ON & ON & ON & ON \\
\hline & $\mathrm{ON}$ & $\mathrm{ON}$ & ON & $\mathrm{ON}$ & ON & $\mathrm{ON}$ & ON & ON & $\mathrm{ON}$ \\
\hline & ON & ON & ON & $\mathrm{ON}$ & ON & ON & ON & ON & $\mathrm{ON}$ \\
\hline & $\mathrm{ON}$ & ON & $\mathrm{ON}$ & $\mathrm{ON}$ & $\mathrm{ON}$ & $\mathrm{ON}$ & ON & ON & $\mathrm{ON}$ \\
\hline & ON & ON & ON & ON & ON & ON & ON & ON & $\mathrm{ON}$ \\
\hline & $\mathrm{ON}$ & ON & ON & ON & ON & ON & $\mathrm{ON}$ & ON & ON \\
\hline & ON & ON & ON & ON & ON & ON & $\mathrm{ON}$ & ON & $\mathrm{ON}$ \\
\hline & ON & ON & ON & $\mathrm{ON}$ & ON & $\mathrm{ON}$ & ON & ON & $\mathrm{ON}$ \\
\hline & $\mathrm{ON}$ & ON & $\mathrm{ON}$ & ON & ON & ON & ON & ON & $\mathrm{ON}$ \\
\hline & ON & ON & ON & ON & ON & ON & ON & $\mathrm{ON}$ & $\mathrm{ON}$ \\
\hline & ON & ON & $\mathrm{ON}$ & ON & ON & ON & ON & ON & $\mathrm{ON}$ \\
\hline & $\mathrm{ON}$ & ON & $\mathrm{ON}$ & $\mathrm{ON}$ & ON & $\mathrm{ON}$ & $\mathrm{ON}$ & ON & $\mathrm{ON}$ \\
\hline & $\mathrm{ON}$ & ON & ON & ON & ON & ON & $\mathrm{ON}$ & $\mathrm{ON}$ & $\mathrm{ON}$ \\
\hline & ON & ON & ON & ON & ON & ON & $\mathrm{ON}$ & $\mathrm{ON}$ & $\mathrm{ON}$ \\
\hline & ON & $\mathrm{ON}$ & ON & ON & ON & ON & $\mathrm{ON}$ & ON & $\mathrm{ON}$ \\
\hline & ON & ON & ON & ON & ON & ON & $\mathrm{ON}$ & ON & $\mathrm{ON}$ \\
\hline & $\mathrm{ON}$ & ON & ON & $\mathrm{ON}$ & ON & ON & ON & ON & $\mathrm{ON}$ \\
\hline & $\mathrm{ON}$ & ON & ON & $\mathrm{ON}$ & ON & ON & $\mathrm{ON}$ & ON & $\mathrm{ON}$ \\
\hline & ON & ON & & & & & & & \\
\hline LPOM & ON & ON & $\mathrm{ON}$ & ON & $\mathrm{ON}$ & ON & $\mathrm{ON}$ & ON & ON \\
\hline & ON & ON & $\mathrm{ON}$ & ON & ON & ON & $\mathrm{ON}$ & ON & $\mathrm{ON}$ \\
\hline & $\mathrm{ON}$ & ON & $\mathrm{ON}$ & ON & ON & ON & $\mathrm{ON}$ & ON & $\mathrm{ON}$ \\
\hline & ON & ON & ON & ON & ON & ON & $\mathrm{ON}$ & ON & $\mathrm{ON}$ \\
\hline & ON & ON & ON & ON & $\mathrm{ON}$ & ON & $\mathrm{ON}$ & ON & $\mathrm{ON}$ \\
\hline & ON & ON & ON & ON & ON & ON & ON & ON & $\mathrm{ON}$ \\
\hline & ON & ON & $\mathrm{ON}$ & ON & ON & ON & $\mathrm{ON}$ & ON & $\mathrm{ON}$ \\
\hline & $\mathrm{ON}$ & ON & $\mathrm{ON}$ & ON & ON & ON & $\mathrm{ON}$ & ON & $\mathrm{ON}$ \\
\hline & ON & ON & ON & ON & ON & ON & $\mathrm{ON}$ & ON & $\mathrm{ON}$ \\
\hline & ON & ON & ON & ON & $\mathrm{ON}$ & $\mathrm{ON}$ & $\mathrm{ON}$ & ON & $\mathrm{ON}$ \\
\hline & $\mathrm{ON}$ & ON & $\mathrm{ON}$ & $\mathrm{ON}$ & ON & ON & $\mathrm{ON}$ & ON & ON \\
\hline & $\mathrm{ON}$ & ON & ON & ON & $\mathrm{ON}$ & ON & $\mathrm{ON}$ & ON & $\mathrm{ON}$ \\
\hline & $\mathrm{ON}$ & ON & $\mathrm{ON}$ & $\mathrm{ON}$ & ON & ON & $\mathrm{ON}$ & ON & $\mathrm{ON}$ \\
\hline & ON & ON & ON & ON & ON & ON & $\mathrm{ON}$ & ON & $\mathrm{ON}$ \\
\hline & ON & ON & ON & ON & $\mathrm{ON}$ & ON & $\mathrm{ON}$ & ON & $\mathrm{ON}$ \\
\hline & $\mathrm{ON}$ & ON & $\mathrm{ON}$ & ON & ON & ON & $\mathrm{ON}$ & ON & $\mathrm{ON}$ \\
\hline & ON & ON & ON & ON & ON & ON & ON & $\mathrm{ON}$ & $\mathrm{ON}$ \\
\hline & ON & ON & ON & ON & ON & ON & $\mathrm{ON}$ & ON & $\mathrm{ON}$ \\
\hline & ON & ON & ON & ON & $\mathrm{ON}$ & ON & $\mathrm{ON}$ & ON & $\mathrm{ON}$ \\
\hline & ON & ON & ON & $\mathrm{ON}$ & $\mathrm{ON}$ & $\mathrm{ON}$ & $\mathrm{ON}$ & ON & $\mathrm{ON}$ \\
\hline & ON & ON & ON & $\mathrm{ON}$ & $\mathrm{ON}$ & ON & $\mathrm{ON}$ & ON & $\mathrm{ON}$ \\
\hline & $\mathrm{ON}$ & ON & ON & $\mathrm{ON}$ & ON & ON & ON & ON & $\mathrm{ON}$ \\
\hline & ON & ON & ON & ON & $\mathrm{ON}$ & ON & $\mathrm{ON}$ & ON & $\mathrm{ON}$ \\
\hline & $\mathrm{ON}$ & ON & $\mathrm{ON}$ & $\mathrm{ON}$ & $\mathrm{ON}$ & $\mathrm{ON}$ & $\mathrm{ON}$ & ON & $\mathrm{ON}$ \\
\hline & ON & ON & ON & ON & $\mathrm{ON}$ & ON & $\mathrm{ON}$ & ON & $\mathrm{ON}$ \\
\hline & ON & ON & ON & ON & ON & ON & $\mathrm{ON}$ & ON & $\mathrm{ON}$ \\
\hline & ON & ON & ON & ON & ON & ON & ON & ON & $\mathrm{ON}$ \\
\hline & ON & ON & ON & $\mathrm{ON}$ & ON & ON & $\mathrm{ON}$ & ON & ON \\
\hline & ON & ON & ON & $\mathrm{ON}$ & ON & ON & ON & ON & $\mathrm{ON}$ \\
\hline & $\mathrm{ON}$ & ON & $\mathrm{ON}$ & $\mathrm{ON}$ & $\mathrm{ON}$ & ON & $\mathrm{ON}$ & ON & $\mathrm{ON}$ \\
\hline & ON & ON & ON & ON & ON & ON & $\mathrm{ON}$ & ON & $\mathrm{ON}$ \\
\hline & ON & ON & ON & ON & ON & ON & ON & ON & $\mathrm{ON}$ \\
\hline & $\mathrm{ON}$ & ON & $\mathrm{ON}$ & $\mathrm{ON}$ & $\mathrm{ON}$ & ON & ON & $\mathrm{ON}$ & $\mathrm{ON}$ \\
\hline & ON & ON & & & & & & & \\
\hline RPOM & $\mathrm{ON}$ & ON & $\mathrm{ON}$ & ON & $\mathrm{ON}$ & $\mathrm{ON}$ & $\mathrm{ON}$ & ON & $\mathrm{ON}$ \\
\hline & $\mathrm{ON}$ & ON & ON & $\mathrm{ON}$ & ON & ON & $\mathrm{ON}$ & ON & $\mathrm{ON}$ \\
\hline & ON & ON & ON & ON & ON & ON & ON & ON & $\mathrm{ON}$ \\
\hline & ON & ON & ON & ON & ON & ON & $\mathrm{ON}$ & ON & $\mathrm{ON}$ \\
\hline & $\mathrm{ON}$ & ON & ON & ON & $\mathrm{ON}$ & $\mathrm{ON}$ & $\mathrm{ON}$ & ON & ON \\
\hline
\end{tabular}




\begin{tabular}{|c|c|c|c|c|c|c|c|c|c|}
\hline & ON & ON & ON & ON & ON & ON & ON & ON & ON \\
\hline & $\mathrm{ON}$ & ON & ON & $\mathrm{ON}$ & $\mathrm{ON}$ & $\mathrm{ON}$ & ON & ON & ON \\
\hline & $\mathrm{ON}$ & ON & $\mathrm{ON}$ & $\mathrm{ON}$ & ON & ON & ON & ON & ON \\
\hline & $\mathrm{ON}$ & ON & $\mathrm{ON}$ & $\mathrm{ON}$ & ON & ON & ON & $\mathrm{ON}$ & ON \\
\hline & $\mathrm{ON}$ & ON & $\mathrm{ON}$ & $\mathrm{ON}$ & ON & $\mathrm{ON}$ & ON & ON & ON \\
\hline & $\mathrm{ON}$ & ON & $\mathrm{ON}$ & $\mathrm{ON}$ & $\mathrm{ON}$ & ON & ON & $\mathrm{ON}$ & ON \\
\hline & $\mathrm{ON}$ & $\mathrm{ON}$ & $\mathrm{ON}$ & $\mathrm{ON}$ & $\mathrm{ON}$ & $\mathrm{ON}$ & ON & $\mathrm{ON}$ & ON \\
\hline & $\mathrm{ON}$ & $\mathrm{ON}$ & $\mathrm{ON}$ & $\mathrm{ON}$ & $\mathrm{ON}$ & $\mathrm{ON}$ & ON & ON & $\mathrm{ON}$ \\
\hline & ON & ON & ON & ON & ON & ON & ON & ON & ON \\
\hline & $\mathrm{ON}$ & $\mathrm{ON}$ & $\mathrm{ON}$ & $\mathrm{ON}$ & ON & $\mathrm{ON}$ & $\mathrm{ON}$ & $\mathrm{ON}$ & ON \\
\hline & $\mathrm{ON}$ & ON & $\mathrm{ON}$ & $\mathrm{ON}$ & $\mathrm{ON}$ & ON & ON & $\mathrm{ON}$ & ON \\
\hline & $\mathrm{ON}$ & ON & $\mathrm{ON}$ & $\mathrm{ON}$ & ON & $\mathrm{ON}$ & ON & ON & ON \\
\hline & $\mathrm{ON}$ & ON & $\mathrm{ON}$ & $\mathrm{ON}$ & $\mathrm{ON}$ & $\mathrm{ON}$ & ON & ON & ON \\
\hline & $\mathrm{ON}$ & $\mathrm{ON}$ & $\mathrm{ON}$ & $\mathrm{ON}$ & $\mathrm{ON}$ & $\mathrm{ON}$ & $\mathrm{ON}$ & ON & ON \\
\hline & $\mathrm{ON}$ & ON & $\mathrm{ON}$ & $\mathrm{ON}$ & ON & ON & ON & ON & ON \\
\hline & $\mathrm{ON}$ & ON & $\mathrm{ON}$ & $\mathrm{ON}$ & ON & ON & ON & $\mathrm{ON}$ & ON \\
\hline & $\mathrm{ON}$ & $\mathrm{ON}$ & $\mathrm{ON}$ & $\mathrm{ON}$ & $\mathrm{ON}$ & $\mathrm{ON}$ & $\mathrm{ON}$ & $\mathrm{ON}$ & ON \\
\hline & $\mathrm{ON}$ & $\mathrm{ON}$ & $\mathrm{ON}$ & $\mathrm{ON}$ & ON & ON & ON & $\mathrm{ON}$ & ON \\
\hline & $\mathrm{ON}$ & $\mathrm{ON}$ & $\mathrm{ON}$ & $\mathrm{ON}$ & $\mathrm{ON}$ & $\mathrm{ON}$ & $\mathrm{ON}$ & $\mathrm{ON}$ & ON \\
\hline & $\mathrm{ON}$ & ON & $\mathrm{ON}$ & ON & ON & ON & ON & ON & ON \\
\hline & $\mathrm{ON}$ & ON & $\mathrm{ON}$ & ON & ON & ON & ON & ON & ON \\
\hline & $\mathrm{ON}$ & $\mathrm{ON}$ & $\mathrm{ON}$ & $\mathrm{ON}$ & $\mathrm{ON}$ & $\mathrm{ON}$ & $\mathrm{ON}$ & ON & ON \\
\hline & ON & $\mathrm{ON}$ & ON & $\mathrm{ON}$ & ON & $\mathrm{ON}$ & ON & $\mathrm{ON}$ & ON \\
\hline & $\mathrm{ON}$ & $\mathrm{ON}$ & $\mathrm{ON}$ & $\mathrm{ON}$ & $\mathrm{ON}$ & $\mathrm{ON}$ & $\mathrm{ON}$ & $\mathrm{ON}$ & ON \\
\hline & ON & ON & $\mathrm{ON}$ & ON & ON & ON & ON & $\mathrm{ON}$ & ON \\
\hline & $\mathrm{ON}$ & ON & $\mathrm{ON}$ & $\mathrm{ON}$ & ON & ON & ON & ON & ON \\
\hline & $\mathrm{ON}$ & ON & ON & $\mathrm{ON}$ & ON & ON & ON & $\mathrm{ON}$ & ON \\
\hline & $\mathrm{ON}$ & $\mathrm{ON}$ & ON & $\mathrm{ON}$ & ON & $\mathrm{ON}$ & $\mathrm{ON}$ & $\mathrm{ON}$ & ON \\
\hline & $\mathrm{ON}$ & $\mathrm{ON}$ & & & & & & & \\
\hline BOD1 & ON & $\mathrm{ON}$ & $\mathrm{ON}$ & $\mathrm{ON}$ & ON & $\mathrm{ON}$ & ON & $\mathrm{ON}$ & ON \\
\hline & ON & ON & $\mathrm{ON}$ & $\mathrm{ON}$ & ON & ON & ON & ON & ON \\
\hline & $\mathrm{ON}$ & ON & ON & $\mathrm{ON}$ & ON & $\mathrm{ON}$ & $\mathrm{ON}$ & $\mathrm{ON}$ & ON \\
\hline & $\mathrm{ON}$ & ON & ON & $\mathrm{ON}$ & ON & $\mathrm{ON}$ & ON & $\mathrm{ON}$ & ON \\
\hline & ON & ON & ON & $\mathrm{ON}$ & ON & ON & ON & ON & ON \\
\hline & ON & ON & $\mathrm{ON}$ & ON & ON & ON & ON & $\mathrm{ON}$ & ON \\
\hline & $\mathrm{ON}$ & ON & $\mathrm{ON}$ & $\mathrm{ON}$ & ON & $\mathrm{ON}$ & $\mathrm{ON}$ & ON & ON \\
\hline & $\mathrm{ON}$ & $\mathrm{ON}$ & ON & $\mathrm{ON}$ & ON & $\mathrm{ON}$ & $\mathrm{ON}$ & $\mathrm{ON}$ & ON \\
\hline & $\mathrm{ON}$ & $\mathrm{ON}$ & ON & $\mathrm{ON}$ & ON & $\mathrm{ON}$ & ON & $\mathrm{ON}$ & ON \\
\hline & ON & ON & $\mathrm{ON}$ & ON & ON & $\mathrm{ON}$ & ON & $\mathrm{ON}$ & ON \\
\hline & $\mathrm{ON}$ & ON & $\mathrm{ON}$ & $\mathrm{ON}$ & ON & ON & $\mathrm{ON}$ & $\mathrm{ON}$ & ON \\
\hline & $\mathrm{ON}$ & $\mathrm{ON}$ & ON & $\mathrm{ON}$ & ON & ON & $\mathrm{ON}$ & ON & ON \\
\hline & $\mathrm{ON}$ & $\mathrm{ON}$ & ON & $\mathrm{ON}$ & ON & $\mathrm{ON}$ & $\mathrm{ON}$ & $\mathrm{ON}$ & ON \\
\hline & $\mathrm{ON}$ & $\mathrm{ON}$ & ON & $\mathrm{ON}$ & ON & $\mathrm{ON}$ & ON & $\mathrm{ON}$ & ON \\
\hline & $\mathrm{ON}$ & $\mathrm{ON}$ & $\mathrm{ON}$ & $\mathrm{ON}$ & ON & $\mathrm{ON}$ & ON & $\mathrm{ON}$ & ON \\
\hline & $\mathrm{ON}$ & ON & ON & $\mathrm{ON}$ & ON & $\mathrm{ON}$ & ON & $\mathrm{ON}$ & ON \\
\hline & ON & ON & ON & $\mathrm{ON}$ & ON & $\mathrm{ON}$ & ON & ON & $\mathrm{ON}$ \\
\hline & $\mathrm{ON}$ & ON & $\mathrm{ON}$ & $\mathrm{ON}$ & ON & $\mathrm{ON}$ & ON & $\mathrm{ON}$ & ON \\
\hline & $\mathrm{ON}$ & ON & ON & $\mathrm{ON}$ & ON & ON & ON & $\mathrm{ON}$ & ON \\
\hline & $\mathrm{ON}$ & $\mathrm{ON}$ & ON & $\mathrm{ON}$ & ON & ON & ON & $\mathrm{ON}$ & ON \\
\hline & ON & $\mathrm{ON}$ & ON & $\mathrm{ON}$ & ON & ON & ON & ON & ON \\
\hline & $\mathrm{ON}$ & ON & $\mathrm{ON}$ & $\mathrm{ON}$ & ON & $\mathrm{ON}$ & ON & $\mathrm{ON}$ & ON \\
\hline & $\mathrm{ON}$ & $\mathrm{ON}$ & $\mathrm{ON}$ & $\mathrm{ON}$ & ON & $\mathrm{ON}$ & ON & $\mathrm{ON}$ & ON \\
\hline & $\mathrm{ON}$ & $\mathrm{ON}$ & ON & $\mathrm{ON}$ & $\mathrm{ON}$ & $\mathrm{ON}$ & $\mathrm{ON}$ & ON & ON \\
\hline & $\mathrm{ON}$ & $\mathrm{ON}$ & $\mathrm{ON}$ & $\mathrm{ON}$ & $\mathrm{ON}$ & $\mathrm{ON}$ & $\mathrm{ON}$ & ON & ON \\
\hline & $\mathrm{ON}$ & ON & ON & $\mathrm{ON}$ & ON & $\mathrm{ON}$ & ON & $\mathrm{ON}$ & ON \\
\hline & $\mathrm{ON}$ & ON & ON & $\mathrm{ON}$ & ON & ON & ON & $\mathrm{ON}$ & ON \\
\hline & $\mathrm{ON}$ & $\mathrm{ON}$ & $\mathrm{ON}$ & $\mathrm{ON}$ & ON & ON & ON & $\mathrm{ON}$ & ON \\
\hline & $\mathrm{ON}$ & ON & ON & $\mathrm{ON}$ & ON & ON & ON & ON & ON \\
\hline & $\mathrm{ON}$ & $\mathrm{ON}$ & ON & $\mathrm{ON}$ & ON & $\mathrm{ON}$ & $\mathrm{ON}$ & $\mathrm{ON}$ & ON \\
\hline & $\mathrm{ON}$ & ON & $\mathrm{ON}$ & $\mathrm{ON}$ & ON & $\mathrm{ON}$ & $\mathrm{ON}$ & ON & ON \\
\hline & $\mathrm{ON}$ & $\mathrm{ON}$ & ON & $\mathrm{ON}$ & $\mathrm{ON}$ & $\mathrm{ON}$ & $\mathrm{ON}$ & ON & ON \\
\hline & ON & ON & $\mathrm{ON}$ & $\mathrm{ON}$ & $\mathrm{ON}$ & ON & ON & ON & ON \\
\hline & $\mathrm{ON}$ & $\mathrm{ON}$ & & & & & & & \\
\hline BOD2 & $\mathrm{ON}$ & ON & $\mathrm{ON}$ & $\mathrm{ON}$ & ON & ON & $\mathrm{ON}$ & $\mathrm{ON}$ & ON \\
\hline & $\mathrm{ON}$ & $\mathrm{ON}$ & $\mathrm{ON}$ & $\mathrm{ON}$ & ON & ON & ON & ON & ON \\
\hline & ON & ON & ON & ON & ON & ON & ON & ON & ON \\
\hline & $\mathrm{ON}$ & ON & ON & $\mathrm{ON}$ & $\mathrm{ON}$ & ON & ON & $\mathrm{ON}$ & ON \\
\hline & $\mathrm{ON}$ & $\mathrm{ON}$ & ON & $\mathrm{ON}$ & ON & ON & ON & ON & \\
\hline
\end{tabular}




\begin{tabular}{|c|c|c|c|c|c|c|c|c|c|}
\hline & ON & ON & ON & ON & ON & ON & ON & ON & ON \\
\hline & $\mathrm{ON}$ & ON & ON & $\mathrm{ON}$ & $\mathrm{ON}$ & $\mathrm{ON}$ & ON & ON & ON \\
\hline & $\mathrm{ON}$ & ON & $\mathrm{ON}$ & $\mathrm{ON}$ & ON & ON & ON & ON & ON \\
\hline & $\mathrm{ON}$ & ON & $\mathrm{ON}$ & $\mathrm{ON}$ & ON & ON & ON & $\mathrm{ON}$ & ON \\
\hline & $\mathrm{ON}$ & ON & $\mathrm{ON}$ & $\mathrm{ON}$ & ON & $\mathrm{ON}$ & ON & ON & ON \\
\hline & $\mathrm{ON}$ & ON & $\mathrm{ON}$ & $\mathrm{ON}$ & $\mathrm{ON}$ & ON & ON & $\mathrm{ON}$ & ON \\
\hline & $\mathrm{ON}$ & $\mathrm{ON}$ & $\mathrm{ON}$ & $\mathrm{ON}$ & $\mathrm{ON}$ & $\mathrm{ON}$ & ON & $\mathrm{ON}$ & ON \\
\hline & $\mathrm{ON}$ & $\mathrm{ON}$ & $\mathrm{ON}$ & $\mathrm{ON}$ & $\mathrm{ON}$ & $\mathrm{ON}$ & ON & ON & $\mathrm{ON}$ \\
\hline & ON & ON & ON & ON & ON & ON & ON & ON & ON \\
\hline & $\mathrm{ON}$ & $\mathrm{ON}$ & $\mathrm{ON}$ & $\mathrm{ON}$ & ON & $\mathrm{ON}$ & $\mathrm{ON}$ & $\mathrm{ON}$ & ON \\
\hline & $\mathrm{ON}$ & ON & $\mathrm{ON}$ & $\mathrm{ON}$ & $\mathrm{ON}$ & ON & ON & $\mathrm{ON}$ & ON \\
\hline & $\mathrm{ON}$ & ON & $\mathrm{ON}$ & $\mathrm{ON}$ & ON & $\mathrm{ON}$ & ON & ON & ON \\
\hline & $\mathrm{ON}$ & ON & $\mathrm{ON}$ & $\mathrm{ON}$ & $\mathrm{ON}$ & $\mathrm{ON}$ & ON & ON & ON \\
\hline & $\mathrm{ON}$ & $\mathrm{ON}$ & $\mathrm{ON}$ & $\mathrm{ON}$ & $\mathrm{ON}$ & $\mathrm{ON}$ & $\mathrm{ON}$ & ON & ON \\
\hline & $\mathrm{ON}$ & ON & $\mathrm{ON}$ & $\mathrm{ON}$ & ON & ON & ON & ON & ON \\
\hline & $\mathrm{ON}$ & ON & $\mathrm{ON}$ & $\mathrm{ON}$ & ON & ON & ON & ON & ON \\
\hline & $\mathrm{ON}$ & $\mathrm{ON}$ & $\mathrm{ON}$ & $\mathrm{ON}$ & $\mathrm{ON}$ & $\mathrm{ON}$ & $\mathrm{ON}$ & $\mathrm{ON}$ & ON \\
\hline & $\mathrm{ON}$ & $\mathrm{ON}$ & $\mathrm{ON}$ & $\mathrm{ON}$ & ON & ON & ON & $\mathrm{ON}$ & ON \\
\hline & $\mathrm{ON}$ & $\mathrm{ON}$ & $\mathrm{ON}$ & $\mathrm{ON}$ & $\mathrm{ON}$ & $\mathrm{ON}$ & $\mathrm{ON}$ & $\mathrm{ON}$ & ON \\
\hline & $\mathrm{ON}$ & ON & $\mathrm{ON}$ & ON & ON & ON & ON & ON & ON \\
\hline & $\mathrm{ON}$ & ON & $\mathrm{ON}$ & ON & ON & ON & ON & ON & ON \\
\hline & $\mathrm{ON}$ & $\mathrm{ON}$ & $\mathrm{ON}$ & $\mathrm{ON}$ & $\mathrm{ON}$ & $\mathrm{ON}$ & $\mathrm{ON}$ & ON & ON \\
\hline & ON & $\mathrm{ON}$ & ON & $\mathrm{ON}$ & ON & $\mathrm{ON}$ & ON & $\mathrm{ON}$ & ON \\
\hline & $\mathrm{ON}$ & $\mathrm{ON}$ & $\mathrm{ON}$ & $\mathrm{ON}$ & $\mathrm{ON}$ & $\mathrm{ON}$ & $\mathrm{ON}$ & $\mathrm{ON}$ & ON \\
\hline & ON & ON & $\mathrm{ON}$ & ON & ON & ON & ON & $\mathrm{ON}$ & ON \\
\hline & $\mathrm{ON}$ & ON & $\mathrm{ON}$ & $\mathrm{ON}$ & ON & ON & ON & ON & ON \\
\hline & $\mathrm{ON}$ & ON & ON & $\mathrm{ON}$ & ON & ON & ON & $\mathrm{ON}$ & ON \\
\hline & $\mathrm{ON}$ & $\mathrm{ON}$ & ON & $\mathrm{ON}$ & ON & $\mathrm{ON}$ & $\mathrm{ON}$ & $\mathrm{ON}$ & ON \\
\hline & $\mathrm{ON}$ & $\mathrm{ON}$ & & & & & & & \\
\hline BOD3 & ON & ON & $\mathrm{ON}$ & $\mathrm{ON}$ & ON & $\mathrm{ON}$ & ON & $\mathrm{ON}$ & ON \\
\hline & ON & ON & $\mathrm{ON}$ & $\mathrm{ON}$ & ON & ON & ON & ON & ON \\
\hline & $\mathrm{ON}$ & ON & ON & $\mathrm{ON}$ & ON & $\mathrm{ON}$ & $\mathrm{ON}$ & $\mathrm{ON}$ & ON \\
\hline & $\mathrm{ON}$ & ON & ON & $\mathrm{ON}$ & ON & $\mathrm{ON}$ & ON & $\mathrm{ON}$ & ON \\
\hline & ON & ON & ON & $\mathrm{ON}$ & ON & ON & ON & ON & ON \\
\hline & ON & ON & $\mathrm{ON}$ & ON & ON & ON & ON & $\mathrm{ON}$ & ON \\
\hline & $\mathrm{ON}$ & ON & $\mathrm{ON}$ & $\mathrm{ON}$ & ON & $\mathrm{ON}$ & $\mathrm{ON}$ & ON & ON \\
\hline & $\mathrm{ON}$ & $\mathrm{ON}$ & ON & $\mathrm{ON}$ & ON & $\mathrm{ON}$ & $\mathrm{ON}$ & $\mathrm{ON}$ & ON \\
\hline & $\mathrm{ON}$ & $\mathrm{ON}$ & ON & $\mathrm{ON}$ & ON & $\mathrm{ON}$ & ON & $\mathrm{ON}$ & ON \\
\hline & ON & ON & $\mathrm{ON}$ & ON & ON & $\mathrm{ON}$ & ON & $\mathrm{ON}$ & ON \\
\hline & $\mathrm{ON}$ & ON & $\mathrm{ON}$ & $\mathrm{ON}$ & ON & ON & $\mathrm{ON}$ & $\mathrm{ON}$ & ON \\
\hline & $\mathrm{ON}$ & $\mathrm{ON}$ & ON & $\mathrm{ON}$ & ON & ON & $\mathrm{ON}$ & ON & ON \\
\hline & $\mathrm{ON}$ & $\mathrm{ON}$ & ON & $\mathrm{ON}$ & ON & $\mathrm{ON}$ & $\mathrm{ON}$ & $\mathrm{ON}$ & ON \\
\hline & $\mathrm{ON}$ & $\mathrm{ON}$ & ON & $\mathrm{ON}$ & ON & $\mathrm{ON}$ & ON & $\mathrm{ON}$ & ON \\
\hline & $\mathrm{ON}$ & $\mathrm{ON}$ & $\mathrm{ON}$ & $\mathrm{ON}$ & ON & $\mathrm{ON}$ & ON & $\mathrm{ON}$ & ON \\
\hline & $\mathrm{ON}$ & ON & ON & $\mathrm{ON}$ & ON & $\mathrm{ON}$ & ON & $\mathrm{ON}$ & ON \\
\hline & ON & ON & ON & $\mathrm{ON}$ & ON & $\mathrm{ON}$ & ON & ON & $\mathrm{ON}$ \\
\hline & $\mathrm{ON}$ & ON & $\mathrm{ON}$ & $\mathrm{ON}$ & ON & $\mathrm{ON}$ & ON & $\mathrm{ON}$ & ON \\
\hline & $\mathrm{ON}$ & ON & ON & $\mathrm{ON}$ & ON & ON & ON & $\mathrm{ON}$ & ON \\
\hline & $\mathrm{ON}$ & $\mathrm{ON}$ & ON & $\mathrm{ON}$ & ON & ON & ON & $\mathrm{ON}$ & ON \\
\hline & ON & $\mathrm{ON}$ & ON & $\mathrm{ON}$ & ON & ON & ON & ON & ON \\
\hline & $\mathrm{ON}$ & ON & $\mathrm{ON}$ & $\mathrm{ON}$ & ON & $\mathrm{ON}$ & ON & $\mathrm{ON}$ & ON \\
\hline & $\mathrm{ON}$ & $\mathrm{ON}$ & $\mathrm{ON}$ & $\mathrm{ON}$ & ON & $\mathrm{ON}$ & ON & $\mathrm{ON}$ & ON \\
\hline & $\mathrm{ON}$ & $\mathrm{ON}$ & $\mathrm{ON}$ & $\mathrm{ON}$ & $\mathrm{ON}$ & $\mathrm{ON}$ & $\mathrm{ON}$ & ON & ON \\
\hline & $\mathrm{ON}$ & $\mathrm{ON}$ & $\mathrm{ON}$ & $\mathrm{ON}$ & $\mathrm{ON}$ & $\mathrm{ON}$ & $\mathrm{ON}$ & $\mathrm{ON}$ & ON \\
\hline & $\mathrm{ON}$ & ON & ON & $\mathrm{ON}$ & ON & $\mathrm{ON}$ & ON & $\mathrm{ON}$ & ON \\
\hline & $\mathrm{ON}$ & ON & ON & $\mathrm{ON}$ & ON & ON & ON & $\mathrm{ON}$ & ON \\
\hline & $\mathrm{ON}$ & $\mathrm{ON}$ & $\mathrm{ON}$ & $\mathrm{ON}$ & ON & ON & ON & $\mathrm{ON}$ & ON \\
\hline & $\mathrm{ON}$ & ON & ON & $\mathrm{ON}$ & ON & ON & ON & ON & ON \\
\hline & $\mathrm{ON}$ & $\mathrm{ON}$ & ON & $\mathrm{ON}$ & ON & $\mathrm{ON}$ & $\mathrm{ON}$ & $\mathrm{ON}$ & ON \\
\hline & $\mathrm{ON}$ & ON & $\mathrm{ON}$ & $\mathrm{ON}$ & ON & $\mathrm{ON}$ & $\mathrm{ON}$ & ON & ON \\
\hline & $\mathrm{ON}$ & $\mathrm{ON}$ & ON & $\mathrm{ON}$ & $\mathrm{ON}$ & $\mathrm{ON}$ & $\mathrm{ON}$ & ON & ON \\
\hline & ON & ON & $\mathrm{ON}$ & $\mathrm{ON}$ & $\mathrm{ON}$ & ON & ON & ON & ON \\
\hline & $\mathrm{ON}$ & $\mathrm{ON}$ & & & & & & & \\
\hline BOD 4 & $\mathrm{ON}$ & ON & $\mathrm{ON}$ & $\mathrm{ON}$ & ON & ON & $\mathrm{ON}$ & $\mathrm{ON}$ & ON \\
\hline & $\mathrm{ON}$ & $\mathrm{ON}$ & $\mathrm{ON}$ & $\mathrm{ON}$ & ON & ON & ON & ON & ON \\
\hline & ON & ON & ON & ON & ON & ON & ON & ON & ON \\
\hline & $\mathrm{ON}$ & ON & ON & $\mathrm{ON}$ & $\mathrm{ON}$ & ON & ON & $\mathrm{ON}$ & ON \\
\hline & $\mathrm{ON}$ & $\mathrm{ON}$ & ON & $\mathrm{ON}$ & ON & ON & ON & ON & \\
\hline
\end{tabular}




\begin{tabular}{|c|c|c|c|c|c|c|c|c|c|}
\hline & ON & ON & ON & ON & ON & ON & ON & ON & ON \\
\hline & $\mathrm{ON}$ & ON & ON & $\mathrm{ON}$ & $\mathrm{ON}$ & $\mathrm{ON}$ & ON & ON & ON \\
\hline & $\mathrm{ON}$ & ON & $\mathrm{ON}$ & $\mathrm{ON}$ & ON & ON & ON & ON & ON \\
\hline & $\mathrm{ON}$ & ON & $\mathrm{ON}$ & $\mathrm{ON}$ & ON & ON & ON & $\mathrm{ON}$ & ON \\
\hline & $\mathrm{ON}$ & ON & $\mathrm{ON}$ & $\mathrm{ON}$ & ON & $\mathrm{ON}$ & ON & ON & ON \\
\hline & $\mathrm{ON}$ & ON & $\mathrm{ON}$ & $\mathrm{ON}$ & $\mathrm{ON}$ & ON & ON & $\mathrm{ON}$ & ON \\
\hline & $\mathrm{ON}$ & $\mathrm{ON}$ & $\mathrm{ON}$ & $\mathrm{ON}$ & $\mathrm{ON}$ & $\mathrm{ON}$ & ON & $\mathrm{ON}$ & ON \\
\hline & $\mathrm{ON}$ & $\mathrm{ON}$ & $\mathrm{ON}$ & $\mathrm{ON}$ & $\mathrm{ON}$ & $\mathrm{ON}$ & ON & ON & $\mathrm{ON}$ \\
\hline & ON & ON & ON & ON & ON & ON & ON & ON & ON \\
\hline & $\mathrm{ON}$ & $\mathrm{ON}$ & $\mathrm{ON}$ & $\mathrm{ON}$ & ON & $\mathrm{ON}$ & $\mathrm{ON}$ & $\mathrm{ON}$ & ON \\
\hline & $\mathrm{ON}$ & ON & $\mathrm{ON}$ & $\mathrm{ON}$ & $\mathrm{ON}$ & ON & ON & $\mathrm{ON}$ & ON \\
\hline & $\mathrm{ON}$ & ON & $\mathrm{ON}$ & $\mathrm{ON}$ & ON & $\mathrm{ON}$ & ON & ON & ON \\
\hline & $\mathrm{ON}$ & ON & $\mathrm{ON}$ & $\mathrm{ON}$ & $\mathrm{ON}$ & $\mathrm{ON}$ & ON & ON & ON \\
\hline & $\mathrm{ON}$ & $\mathrm{ON}$ & $\mathrm{ON}$ & $\mathrm{ON}$ & $\mathrm{ON}$ & $\mathrm{ON}$ & $\mathrm{ON}$ & ON & ON \\
\hline & ON & $\mathrm{ON}$ & $\mathrm{ON}$ & $\mathrm{ON}$ & ON & $\mathrm{ON}$ & ON & $\mathrm{ON}$ & ON \\
\hline & $\mathrm{ON}$ & ON & $\mathrm{ON}$ & $\mathrm{ON}$ & ON & ON & ON & $\mathrm{ON}$ & ON \\
\hline & $\mathrm{ON}$ & $\mathrm{ON}$ & $\mathrm{ON}$ & $\mathrm{ON}$ & $\mathrm{ON}$ & $\mathrm{ON}$ & $\mathrm{ON}$ & $\mathrm{ON}$ & ON \\
\hline & $\mathrm{ON}$ & $\mathrm{ON}$ & $\mathrm{ON}$ & $\mathrm{ON}$ & ON & ON & ON & $\mathrm{ON}$ & ON \\
\hline & $\mathrm{ON}$ & $\mathrm{ON}$ & $\mathrm{ON}$ & $\mathrm{ON}$ & $\mathrm{ON}$ & $\mathrm{ON}$ & $\mathrm{ON}$ & $\mathrm{ON}$ & $\mathrm{ON}$ \\
\hline & $\mathrm{ON}$ & ON & $\mathrm{ON}$ & ON & ON & ON & ON & ON & ON \\
\hline & $\mathrm{ON}$ & ON & $\mathrm{ON}$ & ON & ON & ON & ON & ON & ON \\
\hline & $\mathrm{ON}$ & $\mathrm{ON}$ & $\mathrm{ON}$ & $\mathrm{ON}$ & $\mathrm{ON}$ & $\mathrm{ON}$ & $\mathrm{ON}$ & ON & ON \\
\hline & ON & $\mathrm{ON}$ & ON & $\mathrm{ON}$ & ON & $\mathrm{ON}$ & ON & $\mathrm{ON}$ & ON \\
\hline & $\mathrm{ON}$ & $\mathrm{ON}$ & $\mathrm{ON}$ & $\mathrm{ON}$ & $\mathrm{ON}$ & $\mathrm{ON}$ & $\mathrm{ON}$ & $\mathrm{ON}$ & ON \\
\hline & ON & ON & $\mathrm{ON}$ & ON & ON & ON & ON & $\mathrm{ON}$ & ON \\
\hline & $\mathrm{ON}$ & ON & $\mathrm{ON}$ & $\mathrm{ON}$ & ON & ON & ON & ON & ON \\
\hline & $\mathrm{ON}$ & ON & ON & $\mathrm{ON}$ & ON & ON & ON & $\mathrm{ON}$ & ON \\
\hline & $\mathrm{ON}$ & $\mathrm{ON}$ & ON & $\mathrm{ON}$ & ON & $\mathrm{ON}$ & $\mathrm{ON}$ & $\mathrm{ON}$ & ON \\
\hline & $\mathrm{ON}$ & $\mathrm{ON}$ & & & & & & & \\
\hline BOD5 & ON & $\mathrm{ON}$ & $\mathrm{ON}$ & ON & ON & ON & ON & ON & ON \\
\hline & ON & ON & $\mathrm{ON}$ & $\mathrm{ON}$ & ON & ON & ON & $\mathrm{ON}$ & ON \\
\hline & $\mathrm{ON}$ & ON & ON & $\mathrm{ON}$ & ON & $\mathrm{ON}$ & $\mathrm{ON}$ & $\mathrm{ON}$ & ON \\
\hline & $\mathrm{ON}$ & ON & ON & $\mathrm{ON}$ & ON & $\mathrm{ON}$ & ON & $\mathrm{ON}$ & ON \\
\hline & ON & ON & ON & $\mathrm{ON}$ & ON & ON & ON & ON & ON \\
\hline & ON & ON & $\mathrm{ON}$ & ON & ON & ON & ON & $\mathrm{ON}$ & ON \\
\hline & $\mathrm{ON}$ & ON & $\mathrm{ON}$ & $\mathrm{ON}$ & ON & $\mathrm{ON}$ & $\mathrm{ON}$ & ON & ON \\
\hline & $\mathrm{ON}$ & $\mathrm{ON}$ & ON & $\mathrm{ON}$ & ON & $\mathrm{ON}$ & $\mathrm{ON}$ & $\mathrm{ON}$ & ON \\
\hline & $\mathrm{ON}$ & $\mathrm{ON}$ & ON & $\mathrm{ON}$ & ON & $\mathrm{ON}$ & ON & $\mathrm{ON}$ & ON \\
\hline & ON & ON & $\mathrm{ON}$ & ON & ON & $\mathrm{ON}$ & ON & $\mathrm{ON}$ & ON \\
\hline & $\mathrm{ON}$ & ON & $\mathrm{ON}$ & $\mathrm{ON}$ & ON & ON & $\mathrm{ON}$ & $\mathrm{ON}$ & ON \\
\hline & $\mathrm{ON}$ & $\mathrm{ON}$ & ON & $\mathrm{ON}$ & ON & ON & $\mathrm{ON}$ & ON & ON \\
\hline & $\mathrm{ON}$ & $\mathrm{ON}$ & ON & $\mathrm{ON}$ & ON & $\mathrm{ON}$ & $\mathrm{ON}$ & $\mathrm{ON}$ & ON \\
\hline & $\mathrm{ON}$ & $\mathrm{ON}$ & ON & $\mathrm{ON}$ & ON & $\mathrm{ON}$ & ON & $\mathrm{ON}$ & ON \\
\hline & $\mathrm{ON}$ & $\mathrm{ON}$ & $\mathrm{ON}$ & $\mathrm{ON}$ & ON & $\mathrm{ON}$ & ON & $\mathrm{ON}$ & ON \\
\hline & $\mathrm{ON}$ & ON & ON & $\mathrm{ON}$ & ON & $\mathrm{ON}$ & ON & $\mathrm{ON}$ & ON \\
\hline & ON & ON & ON & $\mathrm{ON}$ & ON & $\mathrm{ON}$ & ON & ON & $\mathrm{ON}$ \\
\hline & $\mathrm{ON}$ & ON & $\mathrm{ON}$ & $\mathrm{ON}$ & ON & $\mathrm{ON}$ & ON & $\mathrm{ON}$ & ON \\
\hline & $\mathrm{ON}$ & ON & ON & $\mathrm{ON}$ & ON & ON & ON & $\mathrm{ON}$ & ON \\
\hline & $\mathrm{ON}$ & $\mathrm{ON}$ & ON & $\mathrm{ON}$ & ON & ON & ON & $\mathrm{ON}$ & ON \\
\hline & ON & $\mathrm{ON}$ & ON & $\mathrm{ON}$ & ON & ON & ON & ON & ON \\
\hline & $\mathrm{ON}$ & ON & $\mathrm{ON}$ & $\mathrm{ON}$ & ON & $\mathrm{ON}$ & ON & $\mathrm{ON}$ & ON \\
\hline & $\mathrm{ON}$ & $\mathrm{ON}$ & $\mathrm{ON}$ & $\mathrm{ON}$ & ON & $\mathrm{ON}$ & ON & $\mathrm{ON}$ & ON \\
\hline & $\mathrm{ON}$ & $\mathrm{ON}$ & $\mathrm{ON}$ & $\mathrm{ON}$ & $\mathrm{ON}$ & $\mathrm{ON}$ & $\mathrm{ON}$ & ON & ON \\
\hline & $\mathrm{ON}$ & $\mathrm{ON}$ & $\mathrm{ON}$ & $\mathrm{ON}$ & $\mathrm{ON}$ & $\mathrm{ON}$ & $\mathrm{ON}$ & $\mathrm{ON}$ & ON \\
\hline & $\mathrm{ON}$ & ON & ON & $\mathrm{ON}$ & ON & $\mathrm{ON}$ & ON & $\mathrm{ON}$ & ON \\
\hline & ON & ON & ON & ON & ON & ON & ON & ON & ON \\
\hline & $\mathrm{ON}$ & $\mathrm{ON}$ & $\mathrm{ON}$ & $\mathrm{ON}$ & ON & ON & ON & $\mathrm{ON}$ & ON \\
\hline & $\mathrm{ON}$ & ON & ON & $\mathrm{ON}$ & ON & ON & ON & ON & ON \\
\hline & $\mathrm{ON}$ & $\mathrm{ON}$ & ON & $\mathrm{ON}$ & ON & $\mathrm{ON}$ & $\mathrm{ON}$ & $\mathrm{ON}$ & ON \\
\hline & $\mathrm{ON}$ & ON & $\mathrm{ON}$ & $\mathrm{ON}$ & ON & $\mathrm{ON}$ & $\mathrm{ON}$ & ON & ON \\
\hline & $\mathrm{ON}$ & $\mathrm{ON}$ & ON & $\mathrm{ON}$ & $\mathrm{ON}$ & $\mathrm{ON}$ & $\mathrm{ON}$ & ON & ON \\
\hline & ON & ON & $\mathrm{ON}$ & $\mathrm{ON}$ & $\mathrm{ON}$ & ON & ON & ON & ON \\
\hline & $\mathrm{ON}$ & $\mathrm{ON}$ & & & & & & & \\
\hline BOD 6 & $\mathrm{ON}$ & ON & $\mathrm{ON}$ & $\mathrm{ON}$ & ON & ON & $\mathrm{ON}$ & $\mathrm{ON}$ & ON \\
\hline & $\mathrm{ON}$ & $\mathrm{ON}$ & $\mathrm{ON}$ & $\mathrm{ON}$ & ON & ON & ON & ON & ON \\
\hline & ON & ON & ON & ON & ON & ON & ON & ON & ON \\
\hline & $\mathrm{ON}$ & ON & ON & $\mathrm{ON}$ & $\mathrm{ON}$ & ON & ON & $\mathrm{ON}$ & ON \\
\hline & $\mathrm{ON}$ & $\mathrm{ON}$ & ON & $\mathrm{ON}$ & ON & ON & ON & ON & \\
\hline
\end{tabular}

313 


\begin{tabular}{|c|c|c|c|c|c|c|c|c|c|}
\hline & ON & ON & ON & $\mathrm{ON}$ & ON & $\mathrm{ON}$ & $\mathrm{ON}$ & $\mathrm{ON}$ & ON \\
\hline & ON & ON & ON & $\mathrm{ON}$ & ON & ON & ON & $\mathrm{ON}$ & ON \\
\hline & ON & ON & ON & $\mathrm{ON}$ & ON & ON & ON & ON & ON \\
\hline & ON & $\mathrm{ON}$ & ON & $\mathrm{ON}$ & ON & ON & ON & $\mathrm{ON}$ & $\mathrm{ON}$ \\
\hline & $\mathrm{ON}$ & ON & ON & $\mathrm{ON}$ & ON & $\mathrm{ON}$ & ON & $\mathrm{ON}$ & ON \\
\hline & ON & ON & $\mathrm{ON}$ & $\mathrm{ON}$ & ON & ON & ON & $\mathrm{ON}$ & ON \\
\hline & ON & ON & $\mathrm{ON}$ & $\mathrm{ON}$ & ON & $\mathrm{ON}$ & ON & ON & ON \\
\hline & ON & ON & ON & ON & ON & ON & ON & ON & ON \\
\hline & ON & $\mathrm{ON}$ & $\mathrm{ON}$ & $\mathrm{ON}$ & $\mathrm{ON}$ & $\mathrm{ON}$ & $\mathrm{ON}$ & $\mathrm{ON}$ & ON \\
\hline & ON & ON & $\mathrm{ON}$ & $\mathrm{ON}$ & ON & ON & ON & $\mathrm{ON}$ & ON \\
\hline & $\mathrm{ON}$ & $\mathrm{ON}$ & $\mathrm{ON}$ & $\mathrm{ON}$ & ON & ON & ON & $\mathrm{ON}$ & ON \\
\hline & ON & $\mathrm{ON}$ & $\mathrm{ON}$ & $\mathrm{ON}$ & $\mathrm{ON}$ & $\mathrm{ON}$ & $\mathrm{ON}$ & ON & ON \\
\hline & ON & ON & ON & ON & ON & ON & ON & ON & ON \\
\hline & ON & $\mathrm{ON}$ & $\mathrm{ON}$ & $\mathrm{ON}$ & $\mathrm{ON}$ & $\mathrm{ON}$ & $\mathrm{ON}$ & ON & ON \\
\hline & ON & ON & $\mathrm{ON}$ & $\mathrm{ON}$ & ON & $\mathrm{ON}$ & ON & ON & ON \\
\hline & $\mathrm{ON}$ & ON & $\mathrm{ON}$ & $\mathrm{ON}$ & ON & $\mathrm{ON}$ & ON & $\mathrm{ON}$ & $\mathrm{ON}$ \\
\hline & ON & $\mathrm{ON}$ & $\mathrm{ON}$ & $\mathrm{ON}$ & $\mathrm{ON}$ & $\mathrm{ON}$ & $\mathrm{ON}$ & $\mathrm{ON}$ & ON \\
\hline & ON & ON & ON & $\mathrm{ON}$ & ON & ON & ON & $\mathrm{ON}$ & ON \\
\hline & ON & ON & $\mathrm{ON}$ & $\mathrm{ON}$ & ON & ON & ON & $\mathrm{ON}$ & ON \\
\hline & ON & ON & $\mathrm{ON}$ & $\mathrm{ON}$ & ON & $\mathrm{ON}$ & ON & ON & ON \\
\hline & ON & $\mathrm{ON}$ & $\mathrm{ON}$ & $\mathrm{ON}$ & ON & ON & ON & $\mathrm{ON}$ & ON \\
\hline & ON & $\mathrm{ON}$ & $\mathrm{ON}$ & $\mathrm{ON}$ & $\mathrm{ON}$ & $\mathrm{ON}$ & $\mathrm{ON}$ & ON & ON \\
\hline & ON & ON & ON & $\mathrm{ON}$ & ON & $\mathrm{ON}$ & ON & ON & ON \\
\hline & ON & ON & $\mathrm{ON}$ & $\mathrm{ON}$ & ON & ON & ON & $\mathrm{ON}$ & ON \\
\hline & ON & $\mathrm{ON}$ & $\mathrm{ON}$ & $\mathrm{ON}$ & ON & $\mathrm{ON}$ & $\mathrm{ON}$ & ON & ON \\
\hline & ON & ON & ON & ON & ON & $\mathrm{ON}$ & ON & ON & ON \\
\hline & ON & $\mathrm{ON}$ & ON & ON & ON & $\mathrm{ON}$ & ON & ON & ON \\
\hline & ON & ON & ON & $\mathrm{ON}$ & ON & ON & $\mathrm{ON}$ & $\mathrm{ON}$ & $\mathrm{ON}$ \\
\hline & ON & ON & & & & & & & \\
\hline BOD 7 & ON & $\mathrm{ON}$ & $\mathrm{ON}$ & ON & ON & ON & ON & $\mathrm{ON}$ & ON \\
\hline & ON & ON & ON & $\mathrm{ON}$ & ON & $\mathrm{ON}$ & ON & $\mathrm{ON}$ & ON \\
\hline & ON & ON & $\mathrm{ON}$ & $\mathrm{ON}$ & ON & $\mathrm{ON}$ & $\mathrm{ON}$ & $\mathrm{ON}$ & $\mathrm{ON}$ \\
\hline & ON & ON & ON & $\mathrm{ON}$ & ON & ON & ON & $\mathrm{ON}$ & ON \\
\hline & ON & ON & $\mathrm{ON}$ & $\mathrm{ON}$ & ON & ON & ON & $\mathrm{ON}$ & ON \\
\hline & ON & $\mathrm{ON}$ & $\mathrm{ON}$ & $\mathrm{ON}$ & ON & $\mathrm{ON}$ & ON & $\mathrm{ON}$ & $\mathrm{ON}$ \\
\hline & ON & ON & ON & $\mathrm{ON}$ & ON & $\mathrm{ON}$ & ON & $\mathrm{ON}$ & ON \\
\hline & ON & ON & ON & ON & ON & $\mathrm{ON}$ & ON & $\mathrm{ON}$ & ON \\
\hline & ON & ON & ON & $\mathrm{ON}$ & ON & $\mathrm{ON}$ & ON & ON & ON \\
\hline & ON & ON & ON & ON & ON & ON & ON & ON & ON \\
\hline & ON & ON & ON & $\mathrm{ON}$ & ON & ON & $\mathrm{ON}$ & $\mathrm{ON}$ & ON \\
\hline & ON & ON & ON & $\mathrm{ON}$ & ON & $\mathrm{ON}$ & ON & $\mathrm{ON}$ & ON \\
\hline & ON & $\mathrm{ON}$ & ON & $\mathrm{ON}$ & ON & ON & ON & $\mathrm{ON}$ & ON \\
\hline & ON & ON & ON & $\mathrm{ON}$ & ON & $\mathrm{ON}$ & ON & $\mathrm{ON}$ & ON \\
\hline & ON & ON & ON & ON & ON & ON & ON & ON & ON \\
\hline & ON & ON & ON & $\mathrm{ON}$ & ON & $\mathrm{ON}$ & ON & $\mathrm{ON}$ & ON \\
\hline & ON & ON & ON & $\mathrm{ON}$ & ON & $\mathrm{ON}$ & ON & $\mathrm{ON}$ & ON \\
\hline & ON & ON & ON & $\mathrm{ON}$ & ON & ON & ON & $\mathrm{ON}$ & ON \\
\hline & ON & ON & ON & $\mathrm{ON}$ & ON & ON & ON & $\mathrm{ON}$ & ON \\
\hline & ON & ON & ON & $\mathrm{ON}$ & ON & ON & ON & $\mathrm{ON}$ & ON \\
\hline & ON & ON & ON & $\mathrm{ON}$ & ON & ON & ON & $\mathrm{ON}$ & ON \\
\hline & ON & ON & ON & $\mathrm{ON}$ & ON & $\mathrm{ON}$ & ON & ON & ON \\
\hline & ON & ON & ON & $\mathrm{ON}$ & ON & ON & ON & $\mathrm{ON}$ & $\mathrm{ON}$ \\
\hline & ON & $\mathrm{ON}$ & $\mathrm{ON}$ & $\mathrm{ON}$ & $\mathrm{ON}$ & $\mathrm{ON}$ & $\mathrm{ON}$ & ON & ON \\
\hline & ON & ON & ON & $\mathrm{ON}$ & ON & ON & ON & ON & ON \\
\hline & ON & ON & ON & $\mathrm{ON}$ & ON & ON & ON & $\mathrm{ON}$ & ON \\
\hline & ON & ON & ON & $\mathrm{ON}$ & ON & $\mathrm{ON}$ & ON & $\mathrm{ON}$ & ON \\
\hline & ON & ON & ON & ON & ON & ON & ON & ON & ON \\
\hline & ON & ON & ON & ON & ON & ON & ON & ON & ON \\
\hline & ON & ON & ON & $\mathrm{ON}$ & ON & ON & ON & ON & ON \\
\hline & ON & ON & ON & $\mathrm{ON}$ & ON & $\mathrm{ON}$ & ON & ON & ON \\
\hline & $\mathrm{ON}$ & ON & $\mathrm{ON}$ & ON & ON & ON & ON & $\mathrm{ON}$ & $\mathrm{ON}$ \\
\hline & ON & ON & ON & ON & ON & ON & ON & ON & ON \\
\hline & ON & $\mathrm{ON}$ & & & & & & & \\
\hline BOD8 & ON & ON & ON & $\mathrm{ON}$ & ON & ON & ON & $\mathrm{ON}$ & ON \\
\hline & ON & ON & ON & $\mathrm{ON}$ & ON & $\mathrm{ON}$ & ON & ON & ON \\
\hline & ON & $\mathrm{ON}$ & $\mathrm{ON}$ & $\mathrm{ON}$ & ON & ON & ON & $\mathrm{ON}$ & ON \\
\hline & ON & $\mathrm{ON}$ & ON & $\mathrm{ON}$ & $\mathrm{ON}$ & $\mathrm{ON}$ & $\mathrm{ON}$ & ON & ON \\
\hline & ON & ON & ON & ON & ON & ON & ON & ON & \\
\hline
\end{tabular}




\begin{tabular}{|c|c|c|c|c|c|c|c|c|c|}
\hline & ON & ON & $\mathrm{ON}$ & ON & ON & ON & ON & ON & ON \\
\hline & ON & ON & $\mathrm{ON}$ & $\mathrm{ON}$ & $\mathrm{ON}$ & ON & $\mathrm{ON}$ & ON & $\mathrm{ON}$ \\
\hline & ON & ON & ON & ON & ON & ON & $\mathrm{ON}$ & ON & $\mathrm{ON}$ \\
\hline & $\mathrm{ON}$ & ON & ON & $\mathrm{ON}$ & ON & ON & ON & $\mathrm{ON}$ & $\mathrm{ON}$ \\
\hline & ON & ON & $\mathrm{ON}$ & $\mathrm{ON}$ & ON & $\mathrm{ON}$ & ON & ON & $\mathrm{ON}$ \\
\hline & $\mathrm{ON}$ & ON & ON & ON & $\mathrm{ON}$ & $\mathrm{ON}$ & $\mathrm{ON}$ & ON & $\mathrm{ON}$ \\
\hline & ON & ON & ON & $\mathrm{ON}$ & ON & ON & ON & ON & $\mathrm{ON}$ \\
\hline & ON & ON & ON & ON & ON & ON & ON & $\mathrm{ON}$ & $\mathrm{ON}$ \\
\hline & $\mathrm{ON}$ & ON & $\mathrm{ON}$ & $\mathrm{ON}$ & ON & $\mathrm{ON}$ & ON & ON & $\mathrm{ON}$ \\
\hline & $\mathrm{ON}$ & ON & $\mathrm{ON}$ & $\mathrm{ON}$ & ON & $\mathrm{ON}$ & $\mathrm{ON}$ & ON & $\mathrm{ON}$ \\
\hline & $\mathrm{ON}$ & ON & ON & ON & ON & ON & ON & ON & ON \\
\hline & $\mathrm{ON}$ & $\mathrm{ON}$ & ON & $\mathrm{ON}$ & ON & $\mathrm{ON}$ & ON & ON & $\mathrm{ON}$ \\
\hline & ON & ON & ON & $\mathrm{ON}$ & ON & ON & ON & ON & $\mathrm{ON}$ \\
\hline & $\mathrm{ON}$ & ON & $\mathrm{ON}$ & $\mathrm{ON}$ & $\mathrm{ON}$ & $\mathrm{ON}$ & ON & ON & $\mathrm{ON}$ \\
\hline & ON & ON & ON & ON & ON & ON & ON & ON & $\mathrm{ON}$ \\
\hline & $\mathrm{ON}$ & ON & ON & ON & ON & ON & $\mathrm{ON}$ & ON & ON \\
\hline & ON & ON & ON & ON & ON & ON & $\mathrm{ON}$ & ON & $\mathrm{ON}$ \\
\hline & ON & ON & ON & $\mathrm{ON}$ & ON & $\mathrm{ON}$ & ON & ON & $\mathrm{ON}$ \\
\hline & $\mathrm{ON}$ & ON & $\mathrm{ON}$ & ON & ON & ON & ON & ON & $\mathrm{ON}$ \\
\hline & ON & ON & ON & ON & ON & ON & ON & $\mathrm{ON}$ & $\mathrm{ON}$ \\
\hline & ON & ON & $\mathrm{ON}$ & ON & ON & ON & ON & ON & $\mathrm{ON}$ \\
\hline & $\mathrm{ON}$ & ON & $\mathrm{ON}$ & $\mathrm{ON}$ & ON & $\mathrm{ON}$ & $\mathrm{ON}$ & ON & $\mathrm{ON}$ \\
\hline & $\mathrm{ON}$ & ON & ON & ON & ON & ON & $\mathrm{ON}$ & $\mathrm{ON}$ & $\mathrm{ON}$ \\
\hline & ON & ON & ON & ON & ON & ON & $\mathrm{ON}$ & $\mathrm{ON}$ & $\mathrm{ON}$ \\
\hline & ON & $\mathrm{ON}$ & ON & ON & ON & ON & $\mathrm{ON}$ & ON & $\mathrm{ON}$ \\
\hline & ON & ON & ON & ON & ON & ON & $\mathrm{ON}$ & ON & ON \\
\hline & $\mathrm{ON}$ & ON & $\mathrm{ON}$ & $\mathrm{ON}$ & ON & ON & $\mathrm{ON}$ & ON & $\mathrm{ON}$ \\
\hline & $\mathrm{ON}$ & ON & ON & $\mathrm{ON}$ & ON & ON & $\mathrm{ON}$ & ON & $\mathrm{ON}$ \\
\hline & ON & ON & & & & & & & \\
\hline BOD9 & ON & ON & $\mathrm{ON}$ & $\mathrm{ON}$ & $\mathrm{ON}$ & ON & $\mathrm{ON}$ & ON & $\mathrm{ON}$ \\
\hline & ON & ON & $\mathrm{ON}$ & ON & ON & ON & $\mathrm{ON}$ & $\mathrm{ON}$ & $\mathrm{ON}$ \\
\hline & $\mathrm{ON}$ & ON & $\mathrm{ON}$ & ON & ON & ON & $\mathrm{ON}$ & ON & $\mathrm{ON}$ \\
\hline & ON & ON & ON & ON & ON & ON & $\mathrm{ON}$ & ON & $\mathrm{ON}$ \\
\hline & ON & ON & ON & ON & $\mathrm{ON}$ & ON & $\mathrm{ON}$ & ON & $\mathrm{ON}$ \\
\hline & ON & ON & ON & ON & ON & ON & ON & ON & $\mathrm{ON}$ \\
\hline & $\mathrm{ON}$ & ON & $\mathrm{ON}$ & $\mathrm{ON}$ & $\mathrm{ON}$ & ON & ON & $\mathrm{ON}$ & $\mathrm{ON}$ \\
\hline & $\mathrm{ON}$ & ON & $\mathrm{ON}$ & ON & ON & ON & $\mathrm{ON}$ & ON & $\mathrm{ON}$ \\
\hline & ON & ON & ON & ON & ON & ON & $\mathrm{ON}$ & ON & $\mathrm{ON}$ \\
\hline & ON & ON & ON & ON & $\mathrm{ON}$ & $\mathrm{ON}$ & $\mathrm{ON}$ & ON & $\mathrm{ON}$ \\
\hline & $\mathrm{ON}$ & ON & $\mathrm{ON}$ & $\mathrm{ON}$ & ON & ON & $\mathrm{ON}$ & ON & ON \\
\hline & $\mathrm{ON}$ & ON & ON & ON & $\mathrm{ON}$ & ON & $\mathrm{ON}$ & ON & $\mathrm{ON}$ \\
\hline & $\mathrm{ON}$ & ON & $\mathrm{ON}$ & $\mathrm{ON}$ & ON & ON & $\mathrm{ON}$ & ON & $\mathrm{ON}$ \\
\hline & ON & ON & ON & ON & ON & ON & $\mathrm{ON}$ & ON & $\mathrm{ON}$ \\
\hline & ON & ON & ON & ON & $\mathrm{ON}$ & ON & $\mathrm{ON}$ & ON & $\mathrm{ON}$ \\
\hline & $\mathrm{ON}$ & ON & $\mathrm{ON}$ & ON & ON & ON & $\mathrm{ON}$ & ON & $\mathrm{ON}$ \\
\hline & $\mathrm{ON}$ & ON & ON & ON & ON & ON & ON & $\mathrm{ON}$ & $\mathrm{ON}$ \\
\hline & ON & ON & ON & ON & ON & ON & $\mathrm{ON}$ & ON & $\mathrm{ON}$ \\
\hline & ON & ON & ON & ON & $\mathrm{ON}$ & ON & $\mathrm{ON}$ & ON & $\mathrm{ON}$ \\
\hline & ON & ON & ON & $\mathrm{ON}$ & $\mathrm{ON}$ & $\mathrm{ON}$ & $\mathrm{ON}$ & ON & $\mathrm{ON}$ \\
\hline & $\mathrm{ON}$ & ON & ON & ON & ON & ON & $\mathrm{ON}$ & ON & ON \\
\hline & $\mathrm{ON}$ & ON & $\mathrm{ON}$ & $\mathrm{ON}$ & ON & ON & ON & ON & $\mathrm{ON}$ \\
\hline & ON & ON & ON & ON & $\mathrm{ON}$ & ON & $\mathrm{ON}$ & ON & $\mathrm{ON}$ \\
\hline & $\mathrm{ON}$ & ON & $\mathrm{ON}$ & $\mathrm{ON}$ & $\mathrm{ON}$ & $\mathrm{ON}$ & $\mathrm{ON}$ & ON & $\mathrm{ON}$ \\
\hline & ON & ON & ON & ON & $\mathrm{ON}$ & ON & $\mathrm{ON}$ & ON & $\mathrm{ON}$ \\
\hline & ON & ON & ON & ON & ON & ON & $\mathrm{ON}$ & ON & $\mathrm{ON}$ \\
\hline & ON & ON & ON & $\mathrm{ON}$ & ON & ON & $\mathrm{ON}$ & ON & ON \\
\hline & $\mathrm{ON}$ & ON & ON & $\mathrm{ON}$ & $\mathrm{ON}$ & ON & ON & $\mathrm{ON}$ & $\mathrm{ON}$ \\
\hline & $\mathrm{ON}$ & ON & ON & $\mathrm{ON}$ & $\mathrm{ON}$ & $\mathrm{ON}$ & $\mathrm{ON}$ & ON & $\mathrm{ON}$ \\
\hline & $\mathrm{ON}$ & ON & $\mathrm{ON}$ & $\mathrm{ON}$ & $\mathrm{ON}$ & ON & $\mathrm{ON}$ & ON & $\mathrm{ON}$ \\
\hline & ON & ON & ON & ON & ON & ON & ON & ON & $\mathrm{ON}$ \\
\hline & ON & ON & ON & ON & ON & ON & ON & ON & $\mathrm{ON}$ \\
\hline & $\mathrm{ON}$ & ON & $\mathrm{ON}$ & $\mathrm{ON}$ & $\mathrm{ON}$ & ON & ON & $\mathrm{ON}$ & $\mathrm{ON}$ \\
\hline & ON & ON & & & & & & & \\
\hline BOD10 & $\mathrm{ON}$ & ON & $\mathrm{ON}$ & ON & $\mathrm{ON}$ & $\mathrm{ON}$ & $\mathrm{ON}$ & ON & $\mathrm{ON}$ \\
\hline & $\mathrm{ON}$ & ON & ON & ON & ON & ON & $\mathrm{ON}$ & ON & $\mathrm{ON}$ \\
\hline & ON & ON & ON & ON & ON & ON & ON & ON & $\mathrm{ON}$ \\
\hline & ON & ON & ON & ON & ON & ON & $\mathrm{ON}$ & ON & $\mathrm{ON}$ \\
\hline & $\mathrm{ON}$ & ON & ON & ON & ON & $\mathrm{ON}$ & $\mathrm{ON}$ & ON & ON \\
\hline
\end{tabular}




\begin{tabular}{|c|c|c|c|c|c|c|c|c|c|}
\hline & ON & ON & $\mathrm{ON}$ & ON & ON & ON & ON & ON & ON \\
\hline & ON & ON & $\mathrm{ON}$ & $\mathrm{ON}$ & $\mathrm{ON}$ & ON & $\mathrm{ON}$ & ON & $\mathrm{ON}$ \\
\hline & ON & ON & ON & ON & ON & ON & $\mathrm{ON}$ & ON & $\mathrm{ON}$ \\
\hline & $\mathrm{ON}$ & ON & ON & $\mathrm{ON}$ & ON & ON & ON & $\mathrm{ON}$ & $\mathrm{ON}$ \\
\hline & ON & ON & $\mathrm{ON}$ & $\mathrm{ON}$ & ON & $\mathrm{ON}$ & ON & ON & $\mathrm{ON}$ \\
\hline & $\mathrm{ON}$ & ON & ON & ON & $\mathrm{ON}$ & $\mathrm{ON}$ & $\mathrm{ON}$ & ON & $\mathrm{ON}$ \\
\hline & ON & ON & ON & ON & ON & ON & ON & ON & $\mathrm{ON}$ \\
\hline & ON & ON & ON & ON & ON & ON & ON & $\mathrm{ON}$ & $\mathrm{ON}$ \\
\hline & $\mathrm{ON}$ & ON & $\mathrm{ON}$ & $\mathrm{ON}$ & ON & $\mathrm{ON}$ & ON & ON & $\mathrm{ON}$ \\
\hline & $\mathrm{ON}$ & ON & $\mathrm{ON}$ & $\mathrm{ON}$ & ON & $\mathrm{ON}$ & $\mathrm{ON}$ & ON & $\mathrm{ON}$ \\
\hline & $\mathrm{ON}$ & ON & ON & ON & ON & ON & ON & ON & ON \\
\hline & $\mathrm{ON}$ & $\mathrm{ON}$ & ON & $\mathrm{ON}$ & ON & $\mathrm{ON}$ & ON & ON & $\mathrm{ON}$ \\
\hline & ON & ON & ON & $\mathrm{ON}$ & ON & ON & ON & ON & $\mathrm{ON}$ \\
\hline & $\mathrm{ON}$ & ON & $\mathrm{ON}$ & $\mathrm{ON}$ & $\mathrm{ON}$ & $\mathrm{ON}$ & ON & ON & $\mathrm{ON}$ \\
\hline & ON & ON & ON & ON & ON & ON & ON & ON & $\mathrm{ON}$ \\
\hline & $\mathrm{ON}$ & ON & ON & ON & ON & ON & $\mathrm{ON}$ & ON & ON \\
\hline & ON & ON & ON & ON & ON & ON & $\mathrm{ON}$ & ON & $\mathrm{ON}$ \\
\hline & ON & ON & ON & $\mathrm{ON}$ & ON & $\mathrm{ON}$ & ON & ON & $\mathrm{ON}$ \\
\hline & $\mathrm{ON}$ & ON & $\mathrm{ON}$ & ON & ON & ON & ON & ON & $\mathrm{ON}$ \\
\hline & ON & ON & ON & ON & ON & ON & ON & $\mathrm{ON}$ & $\mathrm{ON}$ \\
\hline & ON & ON & $\mathrm{ON}$ & ON & ON & ON & ON & ON & $\mathrm{ON}$ \\
\hline & ON & ON & ON & ON & ON & ON & $\mathrm{ON}$ & ON & $\mathrm{ON}$ \\
\hline & $\mathrm{ON}$ & ON & ON & ON & ON & ON & $\mathrm{ON}$ & $\mathrm{ON}$ & $\mathrm{ON}$ \\
\hline & ON & ON & ON & ON & ON & ON & $\mathrm{ON}$ & $\mathrm{ON}$ & $\mathrm{ON}$ \\
\hline & ON & $\mathrm{ON}$ & ON & ON & ON & ON & $\mathrm{ON}$ & ON & $\mathrm{ON}$ \\
\hline & ON & ON & ON & ON & ON & ON & $\mathrm{ON}$ & ON & ON \\
\hline & ON & ON & ON & $\mathrm{ON}$ & ON & ON & $\mathrm{ON}$ & $\mathrm{ON}$ & $\mathrm{ON}$ \\
\hline & $\mathrm{ON}$ & ON & ON & $\mathrm{ON}$ & ON & ON & $\mathrm{ON}$ & ON & $\mathrm{ON}$ \\
\hline & ON & ON & & & & & & & \\
\hline BODP1 & ON & ON & $\mathrm{ON}$ & $\mathrm{ON}$ & $\mathrm{ON}$ & ON & $\mathrm{ON}$ & ON & $\mathrm{ON}$ \\
\hline & ON & ON & $\mathrm{ON}$ & ON & ON & ON & $\mathrm{ON}$ & $\mathrm{ON}$ & $\mathrm{ON}$ \\
\hline & $\mathrm{ON}$ & ON & $\mathrm{ON}$ & ON & ON & ON & $\mathrm{ON}$ & ON & $\mathrm{ON}$ \\
\hline & ON & ON & ON & ON & ON & ON & $\mathrm{ON}$ & ON & $\mathrm{ON}$ \\
\hline & ON & ON & ON & ON & $\mathrm{ON}$ & ON & $\mathrm{ON}$ & ON & $\mathrm{ON}$ \\
\hline & ON & ON & ON & ON & ON & ON & ON & ON & $\mathrm{ON}$ \\
\hline & ON & ON & $\mathrm{ON}$ & ON & ON & ON & $\mathrm{ON}$ & ON & $\mathrm{ON}$ \\
\hline & $\mathrm{ON}$ & ON & $\mathrm{ON}$ & ON & ON & ON & $\mathrm{ON}$ & ON & $\mathrm{ON}$ \\
\hline & ON & ON & ON & ON & ON & ON & $\mathrm{ON}$ & ON & $\mathrm{ON}$ \\
\hline & ON & ON & ON & ON & $\mathrm{ON}$ & $\mathrm{ON}$ & $\mathrm{ON}$ & ON & $\mathrm{ON}$ \\
\hline & $\mathrm{ON}$ & ON & $\mathrm{ON}$ & $\mathrm{ON}$ & ON & ON & $\mathrm{ON}$ & ON & ON \\
\hline & $\mathrm{ON}$ & ON & ON & ON & $\mathrm{ON}$ & ON & $\mathrm{ON}$ & ON & $\mathrm{ON}$ \\
\hline & $\mathrm{ON}$ & ON & $\mathrm{ON}$ & $\mathrm{ON}$ & ON & ON & $\mathrm{ON}$ & ON & $\mathrm{ON}$ \\
\hline & ON & ON & ON & ON & ON & ON & $\mathrm{ON}$ & ON & $\mathrm{ON}$ \\
\hline & ON & ON & ON & ON & $\mathrm{ON}$ & ON & $\mathrm{ON}$ & ON & $\mathrm{ON}$ \\
\hline & $\mathrm{ON}$ & ON & $\mathrm{ON}$ & ON & ON & ON & $\mathrm{ON}$ & ON & $\mathrm{ON}$ \\
\hline & $\mathrm{ON}$ & ON & ON & ON & ON & ON & ON & $\mathrm{ON}$ & $\mathrm{ON}$ \\
\hline & ON & ON & ON & ON & ON & ON & $\mathrm{ON}$ & ON & $\mathrm{ON}$ \\
\hline & ON & ON & ON & ON & $\mathrm{ON}$ & ON & $\mathrm{ON}$ & ON & $\mathrm{ON}$ \\
\hline & ON & ON & ON & $\mathrm{ON}$ & $\mathrm{ON}$ & $\mathrm{ON}$ & $\mathrm{ON}$ & ON & $\mathrm{ON}$ \\
\hline & $\mathrm{ON}$ & ON & ON & ON & ON & ON & $\mathrm{ON}$ & ON & ON \\
\hline & $\mathrm{ON}$ & ON & ON & $\mathrm{ON}$ & ON & ON & ON & ON & $\mathrm{ON}$ \\
\hline & ON & ON & ON & ON & $\mathrm{ON}$ & ON & $\mathrm{ON}$ & ON & $\mathrm{ON}$ \\
\hline & $\mathrm{ON}$ & ON & $\mathrm{ON}$ & $\mathrm{ON}$ & $\mathrm{ON}$ & $\mathrm{ON}$ & $\mathrm{ON}$ & ON & $\mathrm{ON}$ \\
\hline & ON & ON & ON & ON & $\mathrm{ON}$ & ON & $\mathrm{ON}$ & ON & $\mathrm{ON}$ \\
\hline & ON & ON & ON & ON & ON & ON & $\mathrm{ON}$ & ON & $\mathrm{ON}$ \\
\hline & ON & ON & ON & ON & ON & ON & ON & ON & $\mathrm{ON}$ \\
\hline & ON & ON & ON & $\mathrm{ON}$ & ON & ON & $\mathrm{ON}$ & ON & ON \\
\hline & $\mathrm{ON}$ & ON & ON & $\mathrm{ON}$ & $\mathrm{ON}$ & $\mathrm{ON}$ & $\mathrm{ON}$ & ON & $\mathrm{ON}$ \\
\hline & $\mathrm{ON}$ & ON & $\mathrm{ON}$ & $\mathrm{ON}$ & $\mathrm{ON}$ & ON & $\mathrm{ON}$ & ON & $\mathrm{ON}$ \\
\hline & ON & ON & ON & ON & ON & ON & $\mathrm{ON}$ & ON & $\mathrm{ON}$ \\
\hline & $\mathrm{ON}$ & ON & $\mathrm{ON}$ & $\mathrm{ON}$ & $\mathrm{ON}$ & $\mathrm{ON}$ & $\mathrm{ON}$ & ON & $\mathrm{ON}$ \\
\hline & $\mathrm{ON}$ & ON & $\mathrm{ON}$ & $\mathrm{ON}$ & $\mathrm{ON}$ & ON & ON & $\mathrm{ON}$ & $\mathrm{ON}$ \\
\hline & ON & ON & & & & & & & \\
\hline BODP2 & $\mathrm{ON}$ & ON & $\mathrm{ON}$ & ON & $\mathrm{ON}$ & ON & $\mathrm{ON}$ & ON & $\mathrm{ON}$ \\
\hline & $\mathrm{ON}$ & ON & ON & $\mathrm{ON}$ & ON & ON & $\mathrm{ON}$ & ON & $\mathrm{ON}$ \\
\hline & $\mathrm{ON}$ & ON & $\mathrm{ON}$ & $\mathrm{ON}$ & $\mathrm{ON}$ & $\mathrm{ON}$ & $\mathrm{ON}$ & ON & $\mathrm{ON}$ \\
\hline & ON & ON & ON & ON & ON & ON & $\mathrm{ON}$ & ON & $\mathrm{ON}$ \\
\hline & $\mathrm{ON}$ & ON & ON & ON & $\mathrm{ON}$ & $\mathrm{ON}$ & ON & ON & ON \\
\hline
\end{tabular}




\begin{tabular}{|c|c|c|c|c|c|c|c|c|c|}
\hline & ON & ON & ON & ON & ON & ON & ON & ON & ON \\
\hline & ON & ON & ON & $\mathrm{ON}$ & $\mathrm{ON}$ & $\mathrm{ON}$ & ON & ON & ON \\
\hline & ON & $\mathrm{ON}$ & $\mathrm{ON}$ & $\mathrm{ON}$ & $\mathrm{ON}$ & $\mathrm{ON}$ & ON & $\mathrm{ON}$ & ON \\
\hline & $\mathrm{ON}$ & ON & $\mathrm{ON}$ & $\mathrm{ON}$ & ON & ON & ON & $\mathrm{ON}$ & ON \\
\hline & ON & $\mathrm{ON}$ & $\mathrm{ON}$ & $\mathrm{ON}$ & ON & $\mathrm{ON}$ & ON & $\mathrm{ON}$ & ON \\
\hline & ON & ON & $\mathrm{ON}$ & $\mathrm{ON}$ & $\mathrm{ON}$ & ON & ON & $\mathrm{ON}$ & ON \\
\hline & ON & $\mathrm{ON}$ & $\mathrm{ON}$ & $\mathrm{ON}$ & $\mathrm{ON}$ & $\mathrm{ON}$ & ON & $\mathrm{ON}$ & ON \\
\hline & ON & $\mathrm{ON}$ & $\mathrm{ON}$ & $\mathrm{ON}$ & ON & $\mathrm{ON}$ & ON & $\mathrm{ON}$ & $\mathrm{ON}$ \\
\hline & ON & ON & ON & ON & ON & ON & ON & ON & ON \\
\hline & $\mathrm{ON}$ & $\mathrm{ON}$ & $\mathrm{ON}$ & $\mathrm{ON}$ & ON & $\mathrm{ON}$ & ON & ON & ON \\
\hline & ON & ON & $\mathrm{ON}$ & $\mathrm{ON}$ & $\mathrm{ON}$ & ON & ON & $\mathrm{ON}$ & ON \\
\hline & ON & ON & $\mathrm{ON}$ & $\mathrm{ON}$ & ON & $\mathrm{ON}$ & ON & $\mathrm{ON}$ & ON \\
\hline & ON & $\mathrm{ON}$ & $\mathrm{ON}$ & $\mathrm{ON}$ & ON & $\mathrm{ON}$ & ON & $\mathrm{ON}$ & ON \\
\hline & ON & $\mathrm{ON}$ & $\mathrm{ON}$ & $\mathrm{ON}$ & $\mathrm{ON}$ & $\mathrm{ON}$ & $\mathrm{ON}$ & ON & ON \\
\hline & ON & ON & $\mathrm{ON}$ & $\mathrm{ON}$ & ON & ON & ON & ON & ON \\
\hline & ON & ON & $\mathrm{ON}$ & $\mathrm{ON}$ & ON & ON & ON & $\mathrm{ON}$ & ON \\
\hline & ON & $\mathrm{ON}$ & $\mathrm{ON}$ & $\mathrm{ON}$ & $\mathrm{ON}$ & $\mathrm{ON}$ & $\mathrm{ON}$ & $\mathrm{ON}$ & ON \\
\hline & ON & $\mathrm{ON}$ & $\mathrm{ON}$ & $\mathrm{ON}$ & ON & $\mathrm{ON}$ & ON & ON & ON \\
\hline & ON & $\mathrm{ON}$ & $\mathrm{ON}$ & $\mathrm{ON}$ & $\mathrm{ON}$ & $\mathrm{ON}$ & $\mathrm{ON}$ & $\mathrm{ON}$ & ON \\
\hline & $\mathrm{ON}$ & ON & $\mathrm{ON}$ & ON & ON & ON & ON & ON & ON \\
\hline & ON & ON & $\mathrm{ON}$ & $\mathrm{ON}$ & ON & ON & ON & ON & ON \\
\hline & ON & $\mathrm{ON}$ & $\mathrm{ON}$ & $\mathrm{ON}$ & $\mathrm{ON}$ & $\mathrm{ON}$ & $\mathrm{ON}$ & ON & ON \\
\hline & ON & $\mathrm{ON}$ & ON & $\mathrm{ON}$ & ON & $\mathrm{ON}$ & ON & $\mathrm{ON}$ & ON \\
\hline & ON & $\mathrm{ON}$ & $\mathrm{ON}$ & $\mathrm{ON}$ & $\mathrm{ON}$ & $\mathrm{ON}$ & $\mathrm{ON}$ & $\mathrm{ON}$ & ON \\
\hline & ON & ON & $\mathrm{ON}$ & ON & ON & ON & ON & $\mathrm{ON}$ & ON \\
\hline & ON & ON & $\mathrm{ON}$ & $\mathrm{ON}$ & ON & ON & ON & ON & ON \\
\hline & ON & ON & ON & $\mathrm{ON}$ & ON & ON & ON & $\mathrm{ON}$ & ON \\
\hline & ON & $\mathrm{ON}$ & ON & $\mathrm{ON}$ & ON & $\mathrm{ON}$ & $\mathrm{ON}$ & $\mathrm{ON}$ & ON \\
\hline & ON & $\mathrm{ON}$ & & & & & & & \\
\hline BODP3 & ON & ON & $\mathrm{ON}$ & $\mathrm{ON}$ & ON & $\mathrm{ON}$ & ON & ON & ON \\
\hline & ON & $\mathrm{ON}$ & $\mathrm{ON}$ & $\mathrm{ON}$ & ON & $\mathrm{ON}$ & ON & $\mathrm{ON}$ & ON \\
\hline & ON & $\mathrm{ON}$ & ON & $\mathrm{ON}$ & ON & $\mathrm{ON}$ & $\mathrm{ON}$ & $\mathrm{ON}$ & ON \\
\hline & ON & ON & ON & $\mathrm{ON}$ & ON & $\mathrm{ON}$ & ON & $\mathrm{ON}$ & ON \\
\hline & ON & ON & ON & $\mathrm{ON}$ & ON & ON & ON & ON & ON \\
\hline & ON & ON & $\mathrm{ON}$ & ON & ON & ON & ON & $\mathrm{ON}$ & ON \\
\hline & ON & $\mathrm{ON}$ & $\mathrm{ON}$ & $\mathrm{ON}$ & ON & $\mathrm{ON}$ & ON & ON & ON \\
\hline & ON & $\mathrm{ON}$ & ON & $\mathrm{ON}$ & ON & $\mathrm{ON}$ & $\mathrm{ON}$ & $\mathrm{ON}$ & ON \\
\hline & ON & $\mathrm{ON}$ & ON & $\mathrm{ON}$ & ON & $\mathrm{ON}$ & ON & $\mathrm{ON}$ & ON \\
\hline & ON & ON & $\mathrm{ON}$ & ON & ON & $\mathrm{ON}$ & ON & $\mathrm{ON}$ & ON \\
\hline & ON & ON & $\mathrm{ON}$ & $\mathrm{ON}$ & ON & ON & $\mathrm{ON}$ & $\mathrm{ON}$ & ON \\
\hline & ON & $\mathrm{ON}$ & ON & $\mathrm{ON}$ & ON & $\mathrm{ON}$ & $\mathrm{ON}$ & ON & ON \\
\hline & ON & $\mathrm{ON}$ & ON & $\mathrm{ON}$ & ON & $\mathrm{ON}$ & $\mathrm{ON}$ & $\mathrm{ON}$ & ON \\
\hline & ON & $\mathrm{ON}$ & ON & $\mathrm{ON}$ & ON & $\mathrm{ON}$ & ON & $\mathrm{ON}$ & ON \\
\hline & ON & $\mathrm{ON}$ & $\mathrm{ON}$ & $\mathrm{ON}$ & ON & $\mathrm{ON}$ & ON & ON & ON \\
\hline & ON & ON & ON & $\mathrm{ON}$ & ON & $\mathrm{ON}$ & ON & $\mathrm{ON}$ & ON \\
\hline & ON & ON & ON & $\mathrm{ON}$ & ON & $\mathrm{ON}$ & ON & ON & $\mathrm{ON}$ \\
\hline & ON & ON & $\mathrm{ON}$ & $\mathrm{ON}$ & ON & $\mathrm{ON}$ & ON & $\mathrm{ON}$ & ON \\
\hline & ON & ON & ON & $\mathrm{ON}$ & ON & ON & ON & $\mathrm{ON}$ & ON \\
\hline & ON & $\mathrm{ON}$ & ON & $\mathrm{ON}$ & ON & $\mathrm{ON}$ & ON & $\mathrm{ON}$ & ON \\
\hline & ON & $\mathrm{ON}$ & $\mathrm{ON}$ & $\mathrm{ON}$ & ON & ON & ON & ON & ON \\
\hline & ON & ON & $\mathrm{ON}$ & $\mathrm{ON}$ & ON & $\mathrm{ON}$ & ON & $\mathrm{ON}$ & ON \\
\hline & ON & $\mathrm{ON}$ & $\mathrm{ON}$ & $\mathrm{ON}$ & ON & $\mathrm{ON}$ & ON & $\mathrm{ON}$ & ON \\
\hline & ON & $\mathrm{ON}$ & ON & $\mathrm{ON}$ & $\mathrm{ON}$ & $\mathrm{ON}$ & $\mathrm{ON}$ & ON & ON \\
\hline & $\mathrm{ON}$ & $\mathrm{ON}$ & $\mathrm{ON}$ & $\mathrm{ON}$ & ON & $\mathrm{ON}$ & $\mathrm{ON}$ & $\mathrm{ON}$ & $\mathrm{ON}$ \\
\hline & ON & ON & ON & $\mathrm{ON}$ & ON & $\mathrm{ON}$ & ON & $\mathrm{ON}$ & ON \\
\hline & ON & ON & ON & ON & ON & ON & ON & ON & ON \\
\hline & ON & ON & ON & $\mathrm{ON}$ & ON & $\mathrm{ON}$ & ON & $\mathrm{ON}$ & ON \\
\hline & ON & ON & ON & $\mathrm{ON}$ & ON & ON & ON & ON & ON \\
\hline & ON & $\mathrm{ON}$ & ON & $\mathrm{ON}$ & ON & $\mathrm{ON}$ & $\mathrm{ON}$ & $\mathrm{ON}$ & ON \\
\hline & ON & ON & $\mathrm{ON}$ & $\mathrm{ON}$ & ON & ON & $\mathrm{ON}$ & ON & ON \\
\hline & ON & $\mathrm{ON}$ & $\mathrm{ON}$ & $\mathrm{ON}$ & $\mathrm{ON}$ & $\mathrm{ON}$ & $\mathrm{ON}$ & ON & ON \\
\hline & ON & ON & $\mathrm{ON}$ & $\mathrm{ON}$ & $\mathrm{ON}$ & ON & ON & ON & ON \\
\hline & ON & $\mathrm{ON}$ & & & & & & & \\
\hline BODP 4 & ON & $\mathrm{ON}$ & $\mathrm{ON}$ & $\mathrm{ON}$ & ON & $\mathrm{ON}$ & $\mathrm{ON}$ & $\mathrm{ON}$ & ON \\
\hline & ON & ON & ON & $\mathrm{ON}$ & ON & $\mathrm{ON}$ & ON & $\mathrm{ON}$ & ON \\
\hline & ON & ON & ON & ON & ON & ON & ON & ON & ON \\
\hline & ON & ON & ON & $\mathrm{ON}$ & ON & $\mathrm{ON}$ & ON & ON & ON \\
\hline & ON & ON & ON & $\mathrm{ON}$ & ON & ON & ON & $\mathrm{ON}$ & \\
\hline
\end{tabular}




\begin{tabular}{|c|c|c|c|c|c|c|c|c|c|}
\hline & ON & ON & $\mathrm{ON}$ & ON & ON & ON & ON & ON & ON \\
\hline & ON & ON & $\mathrm{ON}$ & $\mathrm{ON}$ & $\mathrm{ON}$ & ON & $\mathrm{ON}$ & ON & $\mathrm{ON}$ \\
\hline & ON & ON & ON & ON & ON & ON & $\mathrm{ON}$ & ON & $\mathrm{ON}$ \\
\hline & $\mathrm{ON}$ & ON & ON & $\mathrm{ON}$ & ON & ON & ON & $\mathrm{ON}$ & $\mathrm{ON}$ \\
\hline & ON & ON & $\mathrm{ON}$ & $\mathrm{ON}$ & ON & $\mathrm{ON}$ & ON & ON & $\mathrm{ON}$ \\
\hline & $\mathrm{ON}$ & ON & ON & ON & $\mathrm{ON}$ & $\mathrm{ON}$ & $\mathrm{ON}$ & ON & $\mathrm{ON}$ \\
\hline & ON & ON & ON & $\mathrm{ON}$ & ON & ON & ON & ON & $\mathrm{ON}$ \\
\hline & ON & ON & ON & ON & ON & ON & ON & $\mathrm{ON}$ & $\mathrm{ON}$ \\
\hline & $\mathrm{ON}$ & ON & $\mathrm{ON}$ & $\mathrm{ON}$ & ON & $\mathrm{ON}$ & ON & ON & $\mathrm{ON}$ \\
\hline & $\mathrm{ON}$ & ON & $\mathrm{ON}$ & $\mathrm{ON}$ & ON & $\mathrm{ON}$ & $\mathrm{ON}$ & ON & $\mathrm{ON}$ \\
\hline & $\mathrm{ON}$ & ON & ON & ON & ON & ON & ON & ON & ON \\
\hline & $\mathrm{ON}$ & $\mathrm{ON}$ & ON & $\mathrm{ON}$ & ON & $\mathrm{ON}$ & ON & ON & $\mathrm{ON}$ \\
\hline & ON & ON & ON & $\mathrm{ON}$ & ON & ON & ON & ON & $\mathrm{ON}$ \\
\hline & $\mathrm{ON}$ & ON & $\mathrm{ON}$ & $\mathrm{ON}$ & $\mathrm{ON}$ & $\mathrm{ON}$ & ON & ON & $\mathrm{ON}$ \\
\hline & ON & ON & ON & ON & ON & ON & ON & ON & $\mathrm{ON}$ \\
\hline & $\mathrm{ON}$ & ON & ON & ON & ON & ON & $\mathrm{ON}$ & ON & ON \\
\hline & ON & ON & ON & ON & ON & ON & $\mathrm{ON}$ & ON & $\mathrm{ON}$ \\
\hline & ON & ON & ON & $\mathrm{ON}$ & ON & $\mathrm{ON}$ & ON & ON & $\mathrm{ON}$ \\
\hline & $\mathrm{ON}$ & ON & $\mathrm{ON}$ & ON & ON & ON & ON & ON & $\mathrm{ON}$ \\
\hline & ON & ON & ON & ON & ON & ON & ON & $\mathrm{ON}$ & $\mathrm{ON}$ \\
\hline & ON & ON & $\mathrm{ON}$ & ON & ON & ON & ON & ON & $\mathrm{ON}$ \\
\hline & ON & ON & ON & ON & ON & ON & $\mathrm{ON}$ & ON & $\mathrm{ON}$ \\
\hline & $\mathrm{ON}$ & ON & ON & ON & ON & ON & $\mathrm{ON}$ & $\mathrm{ON}$ & $\mathrm{ON}$ \\
\hline & ON & ON & ON & ON & ON & ON & $\mathrm{ON}$ & ON & $\mathrm{ON}$ \\
\hline & ON & $\mathrm{ON}$ & ON & ON & ON & ON & $\mathrm{ON}$ & ON & $\mathrm{ON}$ \\
\hline & ON & ON & ON & ON & ON & ON & $\mathrm{ON}$ & ON & ON \\
\hline & ON & ON & ON & $\mathrm{ON}$ & ON & ON & $\mathrm{ON}$ & $\mathrm{ON}$ & $\mathrm{ON}$ \\
\hline & $\mathrm{ON}$ & ON & ON & $\mathrm{ON}$ & ON & ON & $\mathrm{ON}$ & ON & $\mathrm{ON}$ \\
\hline & ON & ON & & & & & & & \\
\hline BODP5 & ON & ON & $\mathrm{ON}$ & $\mathrm{ON}$ & $\mathrm{ON}$ & ON & $\mathrm{ON}$ & ON & $\mathrm{ON}$ \\
\hline & ON & ON & $\mathrm{ON}$ & ON & ON & ON & $\mathrm{ON}$ & ON & $\mathrm{ON}$ \\
\hline & $\mathrm{ON}$ & ON & $\mathrm{ON}$ & ON & ON & ON & $\mathrm{ON}$ & ON & $\mathrm{ON}$ \\
\hline & ON & ON & ON & ON & ON & ON & $\mathrm{ON}$ & ON & $\mathrm{ON}$ \\
\hline & ON & ON & ON & ON & $\mathrm{ON}$ & ON & $\mathrm{ON}$ & ON & $\mathrm{ON}$ \\
\hline & ON & ON & ON & ON & ON & ON & ON & ON & $\mathrm{ON}$ \\
\hline & ON & ON & $\mathrm{ON}$ & ON & ON & ON & $\mathrm{ON}$ & ON & $\mathrm{ON}$ \\
\hline & $\mathrm{ON}$ & ON & $\mathrm{ON}$ & ON & ON & ON & $\mathrm{ON}$ & ON & $\mathrm{ON}$ \\
\hline & ON & ON & ON & ON & ON & ON & $\mathrm{ON}$ & ON & $\mathrm{ON}$ \\
\hline & ON & ON & ON & ON & $\mathrm{ON}$ & $\mathrm{ON}$ & $\mathrm{ON}$ & ON & $\mathrm{ON}$ \\
\hline & $\mathrm{ON}$ & ON & $\mathrm{ON}$ & $\mathrm{ON}$ & ON & ON & $\mathrm{ON}$ & ON & ON \\
\hline & $\mathrm{ON}$ & ON & ON & ON & $\mathrm{ON}$ & ON & $\mathrm{ON}$ & ON & $\mathrm{ON}$ \\
\hline & $\mathrm{ON}$ & ON & $\mathrm{ON}$ & $\mathrm{ON}$ & ON & ON & $\mathrm{ON}$ & ON & $\mathrm{ON}$ \\
\hline & ON & ON & ON & ON & ON & ON & $\mathrm{ON}$ & ON & $\mathrm{ON}$ \\
\hline & ON & ON & ON & ON & $\mathrm{ON}$ & ON & $\mathrm{ON}$ & ON & $\mathrm{ON}$ \\
\hline & $\mathrm{ON}$ & ON & $\mathrm{ON}$ & ON & ON & ON & $\mathrm{ON}$ & ON & $\mathrm{ON}$ \\
\hline & ON & ON & ON & ON & ON & ON & ON & $\mathrm{ON}$ & $\mathrm{ON}$ \\
\hline & ON & ON & ON & ON & ON & ON & $\mathrm{ON}$ & ON & $\mathrm{ON}$ \\
\hline & ON & ON & ON & ON & $\mathrm{ON}$ & ON & $\mathrm{ON}$ & ON & $\mathrm{ON}$ \\
\hline & ON & ON & ON & $\mathrm{ON}$ & $\mathrm{ON}$ & $\mathrm{ON}$ & $\mathrm{ON}$ & ON & $\mathrm{ON}$ \\
\hline & $\mathrm{ON}$ & ON & ON & ON & ON & ON & $\mathrm{ON}$ & ON & ON \\
\hline & $\mathrm{ON}$ & ON & ON & $\mathrm{ON}$ & ON & ON & ON & ON & $\mathrm{ON}$ \\
\hline & ON & ON & ON & ON & $\mathrm{ON}$ & ON & $\mathrm{ON}$ & ON & $\mathrm{ON}$ \\
\hline & $\mathrm{ON}$ & ON & $\mathrm{ON}$ & $\mathrm{ON}$ & $\mathrm{ON}$ & $\mathrm{ON}$ & $\mathrm{ON}$ & ON & $\mathrm{ON}$ \\
\hline & ON & ON & ON & ON & $\mathrm{ON}$ & ON & $\mathrm{ON}$ & ON & $\mathrm{ON}$ \\
\hline & ON & ON & ON & ON & ON & ON & $\mathrm{ON}$ & ON & $\mathrm{ON}$ \\
\hline & ON & ON & ON & ON & ON & ON & ON & ON & $\mathrm{ON}$ \\
\hline & ON & ON & ON & $\mathrm{ON}$ & ON & ON & $\mathrm{ON}$ & ON & ON \\
\hline & $\mathrm{ON}$ & ON & ON & $\mathrm{ON}$ & $\mathrm{ON}$ & $\mathrm{ON}$ & $\mathrm{ON}$ & ON & $\mathrm{ON}$ \\
\hline & $\mathrm{ON}$ & ON & $\mathrm{ON}$ & $\mathrm{ON}$ & $\mathrm{ON}$ & ON & $\mathrm{ON}$ & ON & $\mathrm{ON}$ \\
\hline & ON & ON & ON & ON & ON & ON & ON & ON & $\mathrm{ON}$ \\
\hline & $\mathrm{ON}$ & ON & $\mathrm{ON}$ & $\mathrm{ON}$ & $\mathrm{ON}$ & $\mathrm{ON}$ & $\mathrm{ON}$ & ON & $\mathrm{ON}$ \\
\hline & $\mathrm{ON}$ & ON & $\mathrm{ON}$ & $\mathrm{ON}$ & $\mathrm{ON}$ & ON & ON & $\mathrm{ON}$ & $\mathrm{ON}$ \\
\hline & ON & ON & & & & & & & \\
\hline BODP 6 & $\mathrm{ON}$ & ON & $\mathrm{ON}$ & ON & $\mathrm{ON}$ & ON & $\mathrm{ON}$ & ON & $\mathrm{ON}$ \\
\hline & $\mathrm{ON}$ & ON & ON & $\mathrm{ON}$ & ON & ON & $\mathrm{ON}$ & ON & $\mathrm{ON}$ \\
\hline & ON & ON & ON & ON & ON & ON & ON & ON & $\mathrm{ON}$ \\
\hline & ON & ON & ON & ON & ON & ON & $\mathrm{ON}$ & ON & $\mathrm{ON}$ \\
\hline & $\mathrm{ON}$ & ON & ON & ON & $\mathrm{ON}$ & $\mathrm{ON}$ & ON & ON & ON \\
\hline
\end{tabular}




\begin{tabular}{|c|c|c|c|c|c|c|c|c|c|}
\hline & ON & ON & $\mathrm{ON}$ & ON & ON & ON & ON & ON & ON \\
\hline & ON & ON & $\mathrm{ON}$ & $\mathrm{ON}$ & $\mathrm{ON}$ & ON & $\mathrm{ON}$ & ON & $\mathrm{ON}$ \\
\hline & ON & ON & ON & ON & ON & ON & $\mathrm{ON}$ & ON & $\mathrm{ON}$ \\
\hline & $\mathrm{ON}$ & ON & ON & $\mathrm{ON}$ & ON & ON & ON & $\mathrm{ON}$ & $\mathrm{ON}$ \\
\hline & ON & ON & $\mathrm{ON}$ & $\mathrm{ON}$ & ON & $\mathrm{ON}$ & ON & ON & $\mathrm{ON}$ \\
\hline & $\mathrm{ON}$ & ON & ON & ON & $\mathrm{ON}$ & $\mathrm{ON}$ & $\mathrm{ON}$ & ON & $\mathrm{ON}$ \\
\hline & ON & ON & ON & $\mathrm{ON}$ & ON & ON & ON & ON & $\mathrm{ON}$ \\
\hline & ON & ON & ON & ON & ON & ON & ON & $\mathrm{ON}$ & $\mathrm{ON}$ \\
\hline & $\mathrm{ON}$ & ON & $\mathrm{ON}$ & $\mathrm{ON}$ & ON & $\mathrm{ON}$ & ON & ON & $\mathrm{ON}$ \\
\hline & $\mathrm{ON}$ & ON & $\mathrm{ON}$ & $\mathrm{ON}$ & ON & $\mathrm{ON}$ & $\mathrm{ON}$ & ON & $\mathrm{ON}$ \\
\hline & $\mathrm{ON}$ & ON & ON & ON & ON & ON & ON & ON & $\mathrm{ON}$ \\
\hline & $\mathrm{ON}$ & $\mathrm{ON}$ & ON & $\mathrm{ON}$ & ON & $\mathrm{ON}$ & ON & ON & $\mathrm{ON}$ \\
\hline & ON & ON & ON & $\mathrm{ON}$ & ON & ON & ON & ON & $\mathrm{ON}$ \\
\hline & $\mathrm{ON}$ & ON & $\mathrm{ON}$ & $\mathrm{ON}$ & $\mathrm{ON}$ & $\mathrm{ON}$ & ON & ON & $\mathrm{ON}$ \\
\hline & ON & ON & ON & ON & ON & ON & ON & ON & $\mathrm{ON}$ \\
\hline & $\mathrm{ON}$ & ON & ON & ON & ON & ON & $\mathrm{ON}$ & ON & ON \\
\hline & ON & ON & ON & ON & ON & ON & $\mathrm{ON}$ & ON & $\mathrm{ON}$ \\
\hline & ON & ON & ON & $\mathrm{ON}$ & ON & $\mathrm{ON}$ & ON & ON & $\mathrm{ON}$ \\
\hline & $\mathrm{ON}$ & ON & $\mathrm{ON}$ & ON & ON & ON & ON & ON & $\mathrm{ON}$ \\
\hline & ON & ON & ON & ON & ON & ON & ON & $\mathrm{ON}$ & $\mathrm{ON}$ \\
\hline & ON & ON & $\mathrm{ON}$ & ON & ON & ON & ON & ON & $\mathrm{ON}$ \\
\hline & $\mathrm{ON}$ & ON & $\mathrm{ON}$ & $\mathrm{ON}$ & ON & $\mathrm{ON}$ & $\mathrm{ON}$ & ON & $\mathrm{ON}$ \\
\hline & $\mathrm{ON}$ & ON & ON & ON & ON & ON & $\mathrm{ON}$ & $\mathrm{ON}$ & $\mathrm{ON}$ \\
\hline & ON & ON & ON & ON & ON & ON & $\mathrm{ON}$ & $\mathrm{ON}$ & $\mathrm{ON}$ \\
\hline & ON & $\mathrm{ON}$ & ON & ON & ON & ON & $\mathrm{ON}$ & ON & $\mathrm{ON}$ \\
\hline & ON & ON & ON & ON & ON & ON & $\mathrm{ON}$ & ON & ON \\
\hline & ON & ON & ON & $\mathrm{ON}$ & ON & ON & ON & $\mathrm{ON}$ & $\mathrm{ON}$ \\
\hline & $\mathrm{ON}$ & ON & ON & $\mathrm{ON}$ & ON & ON & $\mathrm{ON}$ & ON & $\mathrm{ON}$ \\
\hline & ON & ON & & & & & & & \\
\hline BODP7 & ON & ON & $\mathrm{ON}$ & ON & $\mathrm{ON}$ & $\mathrm{ON}$ & $\mathrm{ON}$ & ON & ON \\
\hline & $\mathrm{ON}$ & ON & ON & $\mathrm{ON}$ & ON & ON & ON & ON & $\mathrm{ON}$ \\
\hline & ON & ON & ON & $\mathrm{ON}$ & ON & ON & $\mathrm{ON}$ & $\mathrm{ON}$ & $\mathrm{ON}$ \\
\hline & ON & ON & ON & ON & ON & ON & $\mathrm{ON}$ & ON & $\mathrm{ON}$ \\
\hline & ON & ON & ON & ON & $\mathrm{ON}$ & ON & $\mathrm{ON}$ & ON & $\mathrm{ON}$ \\
\hline & ON & ON & ON & ON & ON & ON & ON & ON & $\mathrm{ON}$ \\
\hline & ON & ON & $\mathrm{ON}$ & ON & ON & ON & $\mathrm{ON}$ & ON & $\mathrm{ON}$ \\
\hline & $\mathrm{ON}$ & ON & $\mathrm{ON}$ & ON & ON & ON & $\mathrm{ON}$ & ON & $\mathrm{ON}$ \\
\hline & ON & ON & ON & ON & ON & ON & $\mathrm{ON}$ & ON & $\mathrm{ON}$ \\
\hline & ON & ON & ON & ON & $\mathrm{ON}$ & $\mathrm{ON}$ & $\mathrm{ON}$ & ON & $\mathrm{ON}$ \\
\hline & $\mathrm{ON}$ & ON & $\mathrm{ON}$ & $\mathrm{ON}$ & ON & ON & $\mathrm{ON}$ & ON & ON \\
\hline & $\mathrm{ON}$ & ON & ON & ON & $\mathrm{ON}$ & ON & $\mathrm{ON}$ & ON & $\mathrm{ON}$ \\
\hline & $\mathrm{ON}$ & ON & $\mathrm{ON}$ & $\mathrm{ON}$ & ON & ON & $\mathrm{ON}$ & ON & $\mathrm{ON}$ \\
\hline & ON & ON & ON & ON & ON & ON & $\mathrm{ON}$ & ON & $\mathrm{ON}$ \\
\hline & ON & ON & ON & ON & $\mathrm{ON}$ & ON & $\mathrm{ON}$ & ON & $\mathrm{ON}$ \\
\hline & $\mathrm{ON}$ & ON & $\mathrm{ON}$ & ON & ON & ON & $\mathrm{ON}$ & ON & $\mathrm{ON}$ \\
\hline & $\mathrm{ON}$ & ON & ON & ON & ON & ON & ON & $\mathrm{ON}$ & $\mathrm{ON}$ \\
\hline & ON & ON & ON & ON & ON & ON & $\mathrm{ON}$ & ON & $\mathrm{ON}$ \\
\hline & ON & ON & ON & ON & $\mathrm{ON}$ & ON & $\mathrm{ON}$ & ON & $\mathrm{ON}$ \\
\hline & ON & ON & ON & $\mathrm{ON}$ & $\mathrm{ON}$ & $\mathrm{ON}$ & $\mathrm{ON}$ & ON & $\mathrm{ON}$ \\
\hline & $\mathrm{ON}$ & ON & ON & ON & ON & ON & $\mathrm{ON}$ & ON & ON \\
\hline & $\mathrm{ON}$ & ON & $\mathrm{ON}$ & $\mathrm{ON}$ & ON & ON & ON & ON & $\mathrm{ON}$ \\
\hline & ON & ON & ON & ON & $\mathrm{ON}$ & ON & $\mathrm{ON}$ & ON & $\mathrm{ON}$ \\
\hline & $\mathrm{ON}$ & ON & $\mathrm{ON}$ & $\mathrm{ON}$ & $\mathrm{ON}$ & $\mathrm{ON}$ & $\mathrm{ON}$ & ON & $\mathrm{ON}$ \\
\hline & ON & ON & ON & ON & $\mathrm{ON}$ & ON & $\mathrm{ON}$ & ON & $\mathrm{ON}$ \\
\hline & ON & ON & ON & ON & ON & ON & $\mathrm{ON}$ & ON & $\mathrm{ON}$ \\
\hline & ON & ON & ON & $\mathrm{ON}$ & ON & ON & $\mathrm{ON}$ & ON & $\mathrm{ON}$ \\
\hline & $\mathrm{ON}$ & ON & ON & $\mathrm{ON}$ & $\mathrm{ON}$ & ON & ON & $\mathrm{ON}$ & $\mathrm{ON}$ \\
\hline & $\mathrm{ON}$ & ON & ON & $\mathrm{ON}$ & $\mathrm{ON}$ & $\mathrm{ON}$ & $\mathrm{ON}$ & ON & $\mathrm{ON}$ \\
\hline & $\mathrm{ON}$ & ON & $\mathrm{ON}$ & $\mathrm{ON}$ & $\mathrm{ON}$ & ON & $\mathrm{ON}$ & ON & $\mathrm{ON}$ \\
\hline & ON & ON & ON & ON & ON & ON & ON & ON & $\mathrm{ON}$ \\
\hline & $\mathrm{ON}$ & ON & $\mathrm{ON}$ & $\mathrm{ON}$ & $\mathrm{ON}$ & $\mathrm{ON}$ & $\mathrm{ON}$ & ON & $\mathrm{ON}$ \\
\hline & $\mathrm{ON}$ & ON & $\mathrm{ON}$ & $\mathrm{ON}$ & $\mathrm{ON}$ & ON & ON & $\mathrm{ON}$ & $\mathrm{ON}$ \\
\hline & ON & ON & & & & & & & \\
\hline BODP 8 & $\mathrm{ON}$ & ON & $\mathrm{ON}$ & ON & $\mathrm{ON}$ & $\mathrm{ON}$ & $\mathrm{ON}$ & ON & $\mathrm{ON}$ \\
\hline & $\mathrm{ON}$ & ON & ON & ON & ON & ON & $\mathrm{ON}$ & ON & $\mathrm{ON}$ \\
\hline & $\mathrm{ON}$ & ON & $\mathrm{ON}$ & $\mathrm{ON}$ & $\mathrm{ON}$ & $\mathrm{ON}$ & $\mathrm{ON}$ & ON & $\mathrm{ON}$ \\
\hline & ON & ON & ON & ON & ON & ON & $\mathrm{ON}$ & ON & $\mathrm{ON}$ \\
\hline & $\mathrm{ON}$ & ON & ON & ON & ON & $\mathrm{ON}$ & $\mathrm{ON}$ & ON & ON \\
\hline
\end{tabular}




\begin{tabular}{|c|c|c|c|c|c|c|c|c|c|}
\hline & ON & ON & ON & ON & ON & ON & ON & ON & ON \\
\hline & $\mathrm{ON}$ & ON & ON & $\mathrm{ON}$ & $\mathrm{ON}$ & $\mathrm{ON}$ & ON & ON & ON \\
\hline & $\mathrm{ON}$ & $\mathrm{ON}$ & $\mathrm{ON}$ & $\mathrm{ON}$ & ON & $\mathrm{ON}$ & ON & $\mathrm{ON}$ & ON \\
\hline & $\mathrm{ON}$ & ON & $\mathrm{ON}$ & $\mathrm{ON}$ & ON & ON & ON & $\mathrm{ON}$ & ON \\
\hline & $\mathrm{ON}$ & $\mathrm{ON}$ & $\mathrm{ON}$ & $\mathrm{ON}$ & ON & $\mathrm{ON}$ & ON & $\mathrm{ON}$ & ON \\
\hline & $\mathrm{ON}$ & ON & $\mathrm{ON}$ & $\mathrm{ON}$ & $\mathrm{ON}$ & ON & ON & $\mathrm{ON}$ & ON \\
\hline & $\mathrm{ON}$ & $\mathrm{ON}$ & $\mathrm{ON}$ & $\mathrm{ON}$ & $\mathrm{ON}$ & $\mathrm{ON}$ & ON & $\mathrm{ON}$ & ON \\
\hline & $\mathrm{ON}$ & $\mathrm{ON}$ & $\mathrm{ON}$ & $\mathrm{ON}$ & ON & $\mathrm{ON}$ & ON & $\mathrm{ON}$ & $\mathrm{ON}$ \\
\hline & ON & ON & ON & ON & ON & ON & ON & ON & ON \\
\hline & $\mathrm{ON}$ & $\mathrm{ON}$ & $\mathrm{ON}$ & $\mathrm{ON}$ & ON & $\mathrm{ON}$ & ON & ON & ON \\
\hline & $\mathrm{ON}$ & ON & $\mathrm{ON}$ & $\mathrm{ON}$ & $\mathrm{ON}$ & ON & ON & $\mathrm{ON}$ & ON \\
\hline & $\mathrm{ON}$ & ON & $\mathrm{ON}$ & $\mathrm{ON}$ & ON & $\mathrm{ON}$ & ON & $\mathrm{ON}$ & ON \\
\hline & $\mathrm{ON}$ & $\mathrm{ON}$ & $\mathrm{ON}$ & $\mathrm{ON}$ & ON & $\mathrm{ON}$ & ON & $\mathrm{ON}$ & ON \\
\hline & $\mathrm{ON}$ & $\mathrm{ON}$ & $\mathrm{ON}$ & $\mathrm{ON}$ & $\mathrm{ON}$ & $\mathrm{ON}$ & $\mathrm{ON}$ & ON & ON \\
\hline & $\mathrm{ON}$ & ON & $\mathrm{ON}$ & $\mathrm{ON}$ & ON & ON & ON & ON & ON \\
\hline & $\mathrm{ON}$ & ON & $\mathrm{ON}$ & $\mathrm{ON}$ & ON & ON & ON & $\mathrm{ON}$ & ON \\
\hline & $\mathrm{ON}$ & $\mathrm{ON}$ & $\mathrm{ON}$ & $\mathrm{ON}$ & $\mathrm{ON}$ & $\mathrm{ON}$ & $\mathrm{ON}$ & $\mathrm{ON}$ & ON \\
\hline & $\mathrm{ON}$ & $\mathrm{ON}$ & $\mathrm{ON}$ & $\mathrm{ON}$ & ON & $\mathrm{ON}$ & ON & $\mathrm{ON}$ & ON \\
\hline & $\mathrm{ON}$ & $\mathrm{ON}$ & $\mathrm{ON}$ & $\mathrm{ON}$ & $\mathrm{ON}$ & $\mathrm{ON}$ & $\mathrm{ON}$ & $\mathrm{ON}$ & ON \\
\hline & $\mathrm{ON}$ & ON & $\mathrm{ON}$ & ON & ON & ON & ON & ON & ON \\
\hline & $\mathrm{ON}$ & ON & $\mathrm{ON}$ & $\mathrm{ON}$ & ON & ON & ON & ON & ON \\
\hline & $\mathrm{ON}$ & $\mathrm{ON}$ & $\mathrm{ON}$ & $\mathrm{ON}$ & $\mathrm{ON}$ & $\mathrm{ON}$ & $\mathrm{ON}$ & ON & ON \\
\hline & ON & $\mathrm{ON}$ & ON & $\mathrm{ON}$ & ON & $\mathrm{ON}$ & ON & $\mathrm{ON}$ & ON \\
\hline & $\mathrm{ON}$ & $\mathrm{ON}$ & $\mathrm{ON}$ & $\mathrm{ON}$ & $\mathrm{ON}$ & $\mathrm{ON}$ & $\mathrm{ON}$ & $\mathrm{ON}$ & ON \\
\hline & ON & ON & $\mathrm{ON}$ & ON & ON & ON & ON & $\mathrm{ON}$ & ON \\
\hline & $\mathrm{ON}$ & ON & $\mathrm{ON}$ & $\mathrm{ON}$ & ON & ON & ON & ON & ON \\
\hline & $\mathrm{ON}$ & ON & ON & $\mathrm{ON}$ & ON & ON & ON & $\mathrm{ON}$ & ON \\
\hline & $\mathrm{ON}$ & $\mathrm{ON}$ & ON & $\mathrm{ON}$ & ON & $\mathrm{ON}$ & $\mathrm{ON}$ & $\mathrm{ON}$ & ON \\
\hline & $\mathrm{ON}$ & $\mathrm{ON}$ & & & & & & & \\
\hline BODP9 & ON & ON & $\mathrm{ON}$ & $\mathrm{ON}$ & ON & $\mathrm{ON}$ & ON & ON & ON \\
\hline & $\mathrm{ON}$ & $\mathrm{ON}$ & $\mathrm{ON}$ & $\mathrm{ON}$ & ON & $\mathrm{ON}$ & ON & $\mathrm{ON}$ & ON \\
\hline & $\mathrm{ON}$ & $\mathrm{ON}$ & ON & $\mathrm{ON}$ & ON & $\mathrm{ON}$ & $\mathrm{ON}$ & $\mathrm{ON}$ & ON \\
\hline & $\mathrm{ON}$ & ON & ON & $\mathrm{ON}$ & ON & $\mathrm{ON}$ & ON & $\mathrm{ON}$ & ON \\
\hline & ON & ON & ON & $\mathrm{ON}$ & ON & ON & ON & ON & ON \\
\hline & $\mathrm{ON}$ & ON & $\mathrm{ON}$ & $\mathrm{ON}$ & ON & $\mathrm{ON}$ & $\mathrm{ON}$ & $\mathrm{ON}$ & ON \\
\hline & ON & ON & $\mathrm{ON}$ & $\mathrm{ON}$ & ON & ON & ON & $\mathrm{ON}$ & ON \\
\hline & $\mathrm{ON}$ & $\mathrm{ON}$ & ON & $\mathrm{ON}$ & ON & $\mathrm{ON}$ & $\mathrm{ON}$ & $\mathrm{ON}$ & $\mathrm{ON}$ \\
\hline & $\mathrm{ON}$ & $\mathrm{ON}$ & ON & $\mathrm{ON}$ & ON & $\mathrm{ON}$ & ON & $\mathrm{ON}$ & ON \\
\hline & ON & ON & $\mathrm{ON}$ & ON & ON & $\mathrm{ON}$ & ON & $\mathrm{ON}$ & ON \\
\hline & $\mathrm{ON}$ & ON & $\mathrm{ON}$ & $\mathrm{ON}$ & ON & ON & $\mathrm{ON}$ & $\mathrm{ON}$ & ON \\
\hline & $\mathrm{ON}$ & $\mathrm{ON}$ & ON & $\mathrm{ON}$ & ON & $\mathrm{ON}$ & $\mathrm{ON}$ & ON & ON \\
\hline & $\mathrm{ON}$ & $\mathrm{ON}$ & ON & $\mathrm{ON}$ & ON & $\mathrm{ON}$ & $\mathrm{ON}$ & $\mathrm{ON}$ & ON \\
\hline & $\mathrm{ON}$ & $\mathrm{ON}$ & ON & $\mathrm{ON}$ & ON & $\mathrm{ON}$ & ON & $\mathrm{ON}$ & ON \\
\hline & $\mathrm{ON}$ & $\mathrm{ON}$ & $\mathrm{ON}$ & $\mathrm{ON}$ & ON & $\mathrm{ON}$ & ON & $\mathrm{ON}$ & ON \\
\hline & $\mathrm{ON}$ & ON & ON & $\mathrm{ON}$ & ON & $\mathrm{ON}$ & ON & $\mathrm{ON}$ & ON \\
\hline & ON & ON & ON & $\mathrm{ON}$ & ON & $\mathrm{ON}$ & ON & ON & $\mathrm{ON}$ \\
\hline & $\mathrm{ON}$ & ON & $\mathrm{ON}$ & $\mathrm{ON}$ & ON & $\mathrm{ON}$ & ON & $\mathrm{ON}$ & ON \\
\hline & $\mathrm{ON}$ & $\mathrm{ON}$ & ON & $\mathrm{ON}$ & ON & $\mathrm{ON}$ & ON & $\mathrm{ON}$ & ON \\
\hline & $\mathrm{ON}$ & $\mathrm{ON}$ & $\mathrm{ON}$ & $\mathrm{ON}$ & ON & $\mathrm{ON}$ & $\mathrm{ON}$ & $\mathrm{ON}$ & ON \\
\hline & ON & $\mathrm{ON}$ & $\mathrm{ON}$ & $\mathrm{ON}$ & ON & ON & ON & ON & ON \\
\hline & ON & ON & $\mathrm{ON}$ & ON & ON & ON & ON & ON & ON \\
\hline & $\mathrm{ON}$ & $\mathrm{ON}$ & $\mathrm{ON}$ & $\mathrm{ON}$ & ON & $\mathrm{ON}$ & $\mathrm{ON}$ & $\mathrm{ON}$ & ON \\
\hline & $\mathrm{ON}$ & $\mathrm{ON}$ & ON & $\mathrm{ON}$ & $\mathrm{ON}$ & $\mathrm{ON}$ & $\mathrm{ON}$ & $\mathrm{ON}$ & ON \\
\hline & ON & $\mathrm{ON}$ & $\mathrm{ON}$ & $\mathrm{ON}$ & ON & $\mathrm{ON}$ & $\mathrm{ON}$ & $\mathrm{ON}$ & $\mathrm{ON}$ \\
\hline & $\mathrm{ON}$ & $\mathrm{ON}$ & ON & $\mathrm{ON}$ & ON & $\mathrm{ON}$ & ON & $\mathrm{ON}$ & ON \\
\hline & ON & ON & ON & ON & ON & ON & ON & ON & ON \\
\hline & ON & $\mathrm{ON}$ & $\mathrm{ON}$ & $\mathrm{ON}$ & ON & ON & ON & $\mathrm{ON}$ & ON \\
\hline & $\mathrm{ON}$ & ON & ON & $\mathrm{ON}$ & ON & ON & ON & ON & ON \\
\hline & $\mathrm{ON}$ & $\mathrm{ON}$ & ON & $\mathrm{ON}$ & $\mathrm{ON}$ & $\mathrm{ON}$ & $\mathrm{ON}$ & $\mathrm{ON}$ & $\mathrm{ON}$ \\
\hline & $\mathrm{ON}$ & $\mathrm{ON}$ & $\mathrm{ON}$ & $\mathrm{ON}$ & $\mathrm{ON}$ & ON & ON & ON & ON \\
\hline & ON & ON & ON & ON & ON & ON & ON & ON & ON \\
\hline & ON & ON & $\mathrm{ON}$ & $\mathrm{ON}$ & $\mathrm{ON}$ & ON & ON & ON & ON \\
\hline & $\mathrm{ON}$ & $\mathrm{ON}$ & & & & & & & \\
\hline BODP10 & $\mathrm{ON}$ & $\mathrm{ON}$ & $\mathrm{ON}$ & $\mathrm{ON}$ & ON & $\mathrm{ON}$ & $\mathrm{ON}$ & $\mathrm{ON}$ & ON \\
\hline & $\mathrm{ON}$ & $\mathrm{ON}$ & $\mathrm{ON}$ & $\mathrm{ON}$ & ON & ON & ON & $\mathrm{ON}$ & ON \\
\hline & ON & ON & ON & ON & ON & ON & ON & ON & ON \\
\hline & $\mathrm{ON}$ & $\mathrm{ON}$ & ON & $\mathrm{ON}$ & $\mathrm{ON}$ & ON & $\mathrm{ON}$ & $\mathrm{ON}$ & ON \\
\hline & $\mathrm{ON}$ & ON & ON & $\mathrm{ON}$ & ON & ON & ON & $\mathrm{ON}$ & \\
\hline
\end{tabular}




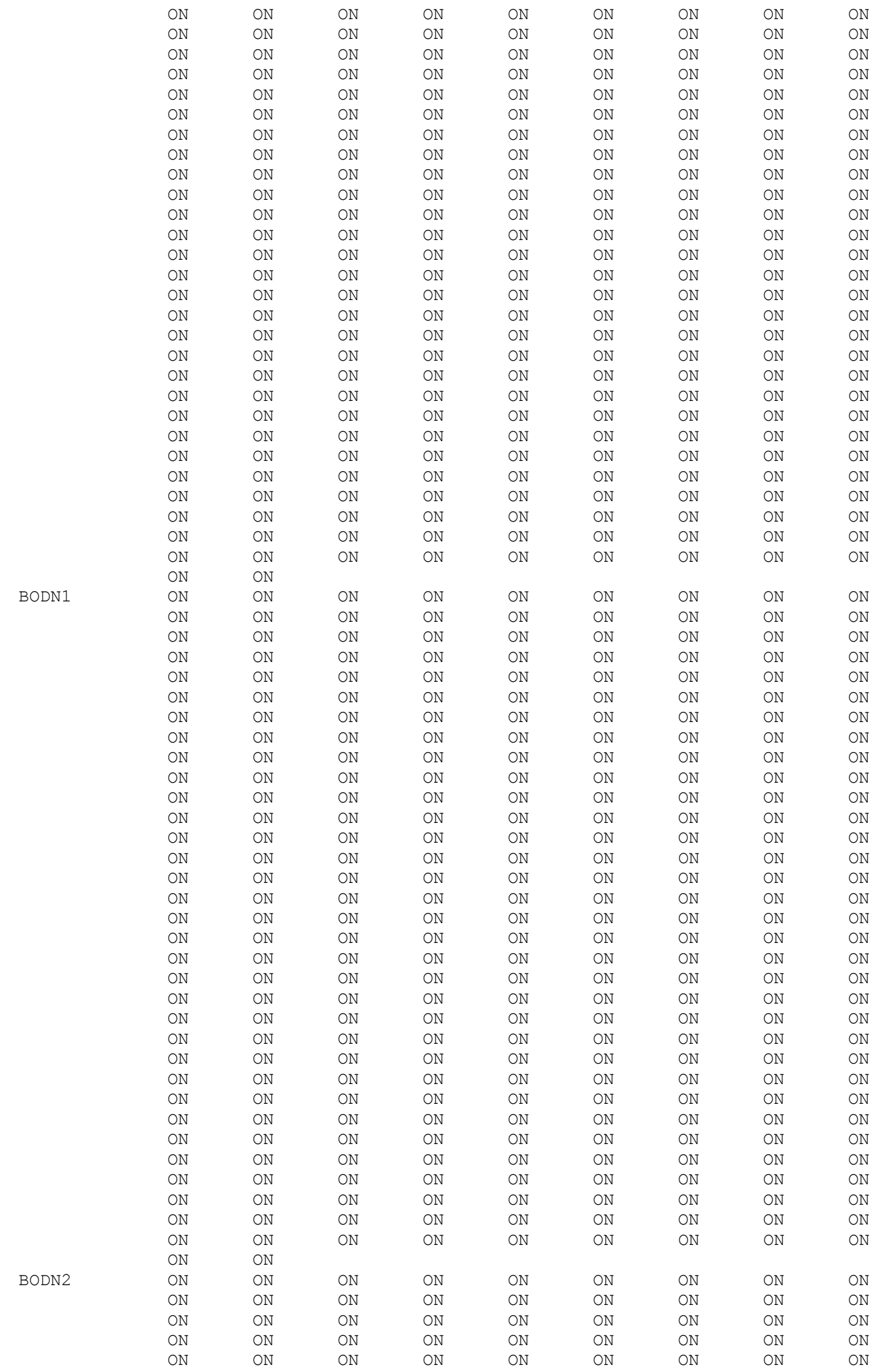




\begin{tabular}{|c|c|c|c|c|c|c|c|c|c|}
\hline & ON & ON & ON & ON & ON & ON & ON & ON & ON \\
\hline & ON & ON & ON & $\mathrm{ON}$ & $\mathrm{ON}$ & $\mathrm{ON}$ & ON & ON & ON \\
\hline & $\mathrm{ON}$ & ON & $\mathrm{ON}$ & $\mathrm{ON}$ & ON & ON & ON & $\mathrm{ON}$ & ON \\
\hline & $\mathrm{ON}$ & ON & $\mathrm{ON}$ & $\mathrm{ON}$ & ON & ON & ON & $\mathrm{ON}$ & ON \\
\hline & ON & $\mathrm{ON}$ & $\mathrm{ON}$ & $\mathrm{ON}$ & ON & $\mathrm{ON}$ & ON & $\mathrm{ON}$ & ON \\
\hline & ON & ON & $\mathrm{ON}$ & $\mathrm{ON}$ & $\mathrm{ON}$ & ON & ON & $\mathrm{ON}$ & ON \\
\hline & ON & $\mathrm{ON}$ & $\mathrm{ON}$ & $\mathrm{ON}$ & $\mathrm{ON}$ & $\mathrm{ON}$ & ON & $\mathrm{ON}$ & ON \\
\hline & ON & $\mathrm{ON}$ & $\mathrm{ON}$ & $\mathrm{ON}$ & ON & $\mathrm{ON}$ & ON & $\mathrm{ON}$ & $\mathrm{ON}$ \\
\hline & ON & ON & ON & ON & ON & ON & ON & ON & ON \\
\hline & $\mathrm{ON}$ & $\mathrm{ON}$ & $\mathrm{ON}$ & $\mathrm{ON}$ & ON & $\mathrm{ON}$ & ON & ON & ON \\
\hline & ON & ON & $\mathrm{ON}$ & $\mathrm{ON}$ & $\mathrm{ON}$ & ON & ON & $\mathrm{ON}$ & ON \\
\hline & ON & ON & $\mathrm{ON}$ & $\mathrm{ON}$ & ON & $\mathrm{ON}$ & ON & $\mathrm{ON}$ & ON \\
\hline & ON & $\mathrm{ON}$ & $\mathrm{ON}$ & $\mathrm{ON}$ & ON & $\mathrm{ON}$ & ON & $\mathrm{ON}$ & ON \\
\hline & ON & $\mathrm{ON}$ & $\mathrm{ON}$ & $\mathrm{ON}$ & $\mathrm{ON}$ & $\mathrm{ON}$ & $\mathrm{ON}$ & ON & ON \\
\hline & ON & ON & $\mathrm{ON}$ & $\mathrm{ON}$ & ON & ON & ON & ON & ON \\
\hline & ON & ON & $\mathrm{ON}$ & $\mathrm{ON}$ & ON & ON & ON & $\mathrm{ON}$ & ON \\
\hline & ON & $\mathrm{ON}$ & $\mathrm{ON}$ & $\mathrm{ON}$ & $\mathrm{ON}$ & $\mathrm{ON}$ & $\mathrm{ON}$ & $\mathrm{ON}$ & ON \\
\hline & ON & $\mathrm{ON}$ & $\mathrm{ON}$ & $\mathrm{ON}$ & ON & $\mathrm{ON}$ & ON & $\mathrm{ON}$ & ON \\
\hline & ON & $\mathrm{ON}$ & $\mathrm{ON}$ & $\mathrm{ON}$ & $\mathrm{ON}$ & $\mathrm{ON}$ & $\mathrm{ON}$ & $\mathrm{ON}$ & ON \\
\hline & $\mathrm{ON}$ & ON & $\mathrm{ON}$ & ON & ON & ON & ON & ON & ON \\
\hline & ON & ON & $\mathrm{ON}$ & $\mathrm{ON}$ & ON & ON & ON & ON & ON \\
\hline & ON & $\mathrm{ON}$ & $\mathrm{ON}$ & $\mathrm{ON}$ & $\mathrm{ON}$ & $\mathrm{ON}$ & $\mathrm{ON}$ & ON & ON \\
\hline & ON & $\mathrm{ON}$ & ON & $\mathrm{ON}$ & ON & $\mathrm{ON}$ & ON & $\mathrm{ON}$ & ON \\
\hline & ON & $\mathrm{ON}$ & $\mathrm{ON}$ & $\mathrm{ON}$ & $\mathrm{ON}$ & $\mathrm{ON}$ & $\mathrm{ON}$ & $\mathrm{ON}$ & ON \\
\hline & ON & ON & $\mathrm{ON}$ & ON & ON & ON & ON & $\mathrm{ON}$ & ON \\
\hline & ON & ON & $\mathrm{ON}$ & $\mathrm{ON}$ & ON & ON & ON & ON & ON \\
\hline & ON & ON & ON & $\mathrm{ON}$ & ON & ON & ON & $\mathrm{ON}$ & ON \\
\hline & ON & $\mathrm{ON}$ & ON & $\mathrm{ON}$ & ON & $\mathrm{ON}$ & $\mathrm{ON}$ & $\mathrm{ON}$ & ON \\
\hline & ON & $\mathrm{ON}$ & & & & & & & \\
\hline BODN3 & ON & ON & $\mathrm{ON}$ & $\mathrm{ON}$ & ON & $\mathrm{ON}$ & ON & ON & ON \\
\hline & ON & $\mathrm{ON}$ & $\mathrm{ON}$ & $\mathrm{ON}$ & ON & $\mathrm{ON}$ & ON & ON & ON \\
\hline & ON & $\mathrm{ON}$ & ON & $\mathrm{ON}$ & ON & $\mathrm{ON}$ & $\mathrm{ON}$ & $\mathrm{ON}$ & ON \\
\hline & ON & ON & ON & $\mathrm{ON}$ & ON & $\mathrm{ON}$ & ON & $\mathrm{ON}$ & ON \\
\hline & ON & ON & ON & $\mathrm{ON}$ & ON & ON & ON & ON & ON \\
\hline & ON & ON & $\mathrm{ON}$ & ON & ON & ON & ON & $\mathrm{ON}$ & ON \\
\hline & ON & $\mathrm{ON}$ & $\mathrm{ON}$ & $\mathrm{ON}$ & ON & $\mathrm{ON}$ & ON & ON & ON \\
\hline & ON & $\mathrm{ON}$ & ON & $\mathrm{ON}$ & ON & $\mathrm{ON}$ & $\mathrm{ON}$ & $\mathrm{ON}$ & ON \\
\hline & ON & $\mathrm{ON}$ & ON & $\mathrm{ON}$ & ON & $\mathrm{ON}$ & ON & $\mathrm{ON}$ & ON \\
\hline & ON & ON & $\mathrm{ON}$ & ON & ON & $\mathrm{ON}$ & ON & $\mathrm{ON}$ & ON \\
\hline & ON & ON & $\mathrm{ON}$ & $\mathrm{ON}$ & ON & ON & $\mathrm{ON}$ & $\mathrm{ON}$ & ON \\
\hline & ON & $\mathrm{ON}$ & ON & $\mathrm{ON}$ & ON & $\mathrm{ON}$ & $\mathrm{ON}$ & ON & ON \\
\hline & ON & $\mathrm{ON}$ & ON & $\mathrm{ON}$ & ON & $\mathrm{ON}$ & $\mathrm{ON}$ & $\mathrm{ON}$ & ON \\
\hline & ON & $\mathrm{ON}$ & ON & $\mathrm{ON}$ & ON & $\mathrm{ON}$ & ON & $\mathrm{ON}$ & ON \\
\hline & ON & $\mathrm{ON}$ & $\mathrm{ON}$ & $\mathrm{ON}$ & ON & $\mathrm{ON}$ & ON & $\mathrm{ON}$ & ON \\
\hline & ON & ON & ON & $\mathrm{ON}$ & ON & $\mathrm{ON}$ & ON & $\mathrm{ON}$ & ON \\
\hline & ON & ON & ON & $\mathrm{ON}$ & ON & $\mathrm{ON}$ & ON & ON & $\mathrm{ON}$ \\
\hline & ON & ON & $\mathrm{ON}$ & $\mathrm{ON}$ & ON & $\mathrm{ON}$ & ON & $\mathrm{ON}$ & ON \\
\hline & ON & ON & ON & $\mathrm{ON}$ & ON & ON & ON & $\mathrm{ON}$ & ON \\
\hline & ON & $\mathrm{ON}$ & ON & $\mathrm{ON}$ & ON & $\mathrm{ON}$ & ON & ON & ON \\
\hline & ON & $\mathrm{ON}$ & $\mathrm{ON}$ & $\mathrm{ON}$ & ON & ON & ON & ON & ON \\
\hline & ON & ON & $\mathrm{ON}$ & $\mathrm{ON}$ & ON & $\mathrm{ON}$ & ON & $\mathrm{ON}$ & ON \\
\hline & ON & $\mathrm{ON}$ & $\mathrm{ON}$ & $\mathrm{ON}$ & ON & $\mathrm{ON}$ & ON & $\mathrm{ON}$ & ON \\
\hline & ON & $\mathrm{ON}$ & ON & $\mathrm{ON}$ & $\mathrm{ON}$ & $\mathrm{ON}$ & $\mathrm{ON}$ & ON & ON \\
\hline & $\mathrm{ON}$ & $\mathrm{ON}$ & $\mathrm{ON}$ & $\mathrm{ON}$ & ON & $\mathrm{ON}$ & $\mathrm{ON}$ & $\mathrm{ON}$ & $\mathrm{ON}$ \\
\hline & ON & ON & ON & $\mathrm{ON}$ & ON & $\mathrm{ON}$ & ON & $\mathrm{ON}$ & ON \\
\hline & ON & ON & ON & ON & ON & ON & ON & ON & ON \\
\hline & ON & ON & $\mathrm{ON}$ & $\mathrm{ON}$ & ON & $\mathrm{ON}$ & ON & $\mathrm{ON}$ & ON \\
\hline & ON & ON & ON & $\mathrm{ON}$ & ON & ON & ON & ON & ON \\
\hline & ON & $\mathrm{ON}$ & ON & $\mathrm{ON}$ & $\mathrm{ON}$ & $\mathrm{ON}$ & $\mathrm{ON}$ & $\mathrm{ON}$ & ON \\
\hline & ON & ON & $\mathrm{ON}$ & $\mathrm{ON}$ & ON & ON & $\mathrm{ON}$ & ON & ON \\
\hline & ON & $\mathrm{ON}$ & $\mathrm{ON}$ & $\mathrm{ON}$ & $\mathrm{ON}$ & $\mathrm{ON}$ & $\mathrm{ON}$ & ON & ON \\
\hline & ON & ON & $\mathrm{ON}$ & $\mathrm{ON}$ & $\mathrm{ON}$ & ON & ON & ON & ON \\
\hline & ON & $\mathrm{ON}$ & & & & & & & \\
\hline BODN4 & ON & $\mathrm{ON}$ & $\mathrm{ON}$ & $\mathrm{ON}$ & ON & $\mathrm{ON}$ & $\mathrm{ON}$ & $\mathrm{ON}$ & ON \\
\hline & ON & ON & ON & $\mathrm{ON}$ & ON & $\mathrm{ON}$ & ON & $\mathrm{ON}$ & ON \\
\hline & ON & ON & ON & ON & ON & ON & ON & ON & ON \\
\hline & ON & ON & ON & $\mathrm{ON}$ & ON & ON & ON & ON & ON \\
\hline & ON & ON & ON & $\mathrm{ON}$ & ON & ON & $\mathrm{ON}$ & $\mathrm{ON}$ & \\
\hline
\end{tabular}




\begin{tabular}{|c|c|c|c|c|c|c|c|c|c|}
\hline & $\mathrm{ON}$ & ON & ON & ON & ON & ON & $\mathrm{ON}$ & ON & $\mathrm{ON}$ \\
\hline & ON & ON & $\mathrm{ON}$ & ON & ON & ON & $\mathrm{ON}$ & ON & $\mathrm{ON}$ \\
\hline & ON & ON & ON & ON & ON & ON & $\mathrm{ON}$ & ON & ON \\
\hline & $\mathrm{ON}$ & ON & ON & $\mathrm{ON}$ & ON & ON & ON & $\mathrm{ON}$ & $\mathrm{ON}$ \\
\hline & $\mathrm{ON}$ & ON & $\mathrm{ON}$ & ON & ON & $\mathrm{ON}$ & $\mathrm{ON}$ & ON & $\mathrm{ON}$ \\
\hline & $\mathrm{ON}$ & ON & ON & ON & ON & ON & $\mathrm{ON}$ & ON & $\mathrm{ON}$ \\
\hline & $\mathrm{ON}$ & ON & $\mathrm{ON}$ & $\mathrm{ON}$ & ON & ON & $\mathrm{ON}$ & ON & $\mathrm{ON}$ \\
\hline & $\mathrm{ON}$ & ON & ON & $\mathrm{ON}$ & ON & $\mathrm{ON}$ & $\mathrm{ON}$ & ON & $\mathrm{ON}$ \\
\hline & $\mathrm{ON}$ & ON & $\mathrm{ON}$ & $\mathrm{ON}$ & ON & $\mathrm{ON}$ & ON & ON & $\mathrm{ON}$ \\
\hline & ON & ON & ON & ON & ON & $\mathrm{ON}$ & ON & ON & $\mathrm{ON}$ \\
\hline & $\mathrm{ON}$ & ON & ON & $\mathrm{ON}$ & ON & ON & $\mathrm{ON}$ & $\mathrm{ON}$ & $\mathrm{ON}$ \\
\hline & $\mathrm{ON}$ & ON & ON & $\mathrm{ON}$ & ON & $\mathrm{ON}$ & $\mathrm{ON}$ & ON & $\mathrm{ON}$ \\
\hline & $\mathrm{ON}$ & ON & ON & $\mathrm{ON}$ & ON & $\mathrm{ON}$ & $\mathrm{ON}$ & ON & $\mathrm{ON}$ \\
\hline & $\mathrm{ON}$ & ON & $\mathrm{ON}$ & $\mathrm{ON}$ & $\mathrm{ON}$ & $\mathrm{ON}$ & $\mathrm{ON}$ & ON & $\mathrm{ON}$ \\
\hline & ON & ON & ON & ON & ON & ON & ON & $\mathrm{ON}$ & $\mathrm{ON}$ \\
\hline & $\mathrm{ON}$ & ON & $\mathrm{ON}$ & ON & ON & ON & $\mathrm{ON}$ & ON & $\mathrm{ON}$ \\
\hline & $\mathrm{ON}$ & ON & $\mathrm{ON}$ & $\mathrm{ON}$ & ON & $\mathrm{ON}$ & $\mathrm{ON}$ & ON & $\mathrm{ON}$ \\
\hline & $\mathrm{ON}$ & ON & $\mathrm{ON}$ & $\mathrm{ON}$ & ON & ON & $\mathrm{ON}$ & ON & $\mathrm{ON}$ \\
\hline & $\mathrm{ON}$ & ON & $\mathrm{ON}$ & ON & ON & ON & $\mathrm{ON}$ & ON & $\mathrm{ON}$ \\
\hline & ON & ON & $\mathrm{ON}$ & ON & ON & $\mathrm{ON}$ & $\mathrm{ON}$ & ON & $\mathrm{ON}$ \\
\hline & $\mathrm{ON}$ & ON & $\mathrm{ON}$ & $\mathrm{ON}$ & $\mathrm{ON}$ & ON & ON & ON & $\mathrm{ON}$ \\
\hline & $\mathrm{ON}$ & ON & $\mathrm{ON}$ & $\mathrm{ON}$ & ON & $\mathrm{ON}$ & $\mathrm{ON}$ & ON & $\mathrm{ON}$ \\
\hline & $\mathrm{ON}$ & ON & $\mathrm{ON}$ & $\mathrm{ON}$ & ON & ON & $\mathrm{ON}$ & ON & $\mathrm{ON}$ \\
\hline & $\mathrm{ON}$ & ON & $\mathrm{ON}$ & $\mathrm{ON}$ & ON & ON & $\mathrm{ON}$ & ON & $\mathrm{ON}$ \\
\hline & ON & $\mathrm{ON}$ & ON & ON & ON & ON & ON & $\mathrm{ON}$ & $\mathrm{ON}$ \\
\hline & $\mathrm{ON}$ & ON & ON & $\mathrm{ON}$ & ON & ON & ON & ON & $\mathrm{ON}$ \\
\hline & ON & ON & ON & ON & ON & ON & $\mathrm{ON}$ & $\mathrm{ON}$ & $\mathrm{ON}$ \\
\hline & $\mathrm{ON}$ & ON & ON & ON & ON & ON & $\mathrm{ON}$ & ON & $\mathrm{ON}$ \\
\hline & $\mathrm{ON}$ & ON & & & & & & & \\
\hline BODN5 & $\mathrm{ON}$ & ON & ON & ON & ON & ON & ON & ON & ON \\
\hline & ON & ON & $\mathrm{ON}$ & $\mathrm{ON}$ & ON & $\mathrm{ON}$ & $\mathrm{ON}$ & ON & $\mathrm{ON}$ \\
\hline & $\mathrm{ON}$ & ON & $\mathrm{ON}$ & ON & ON & ON & $\mathrm{ON}$ & ON & $\mathrm{ON}$ \\
\hline & $\mathrm{ON}$ & ON & $\mathrm{ON}$ & $\mathrm{ON}$ & ON & $\mathrm{ON}$ & $\mathrm{ON}$ & ON & ON \\
\hline & $\mathrm{ON}$ & $\mathrm{ON}$ & $\mathrm{ON}$ & ON & ON & ON & $\mathrm{ON}$ & $\mathrm{ON}$ & ON \\
\hline & $\mathrm{ON}$ & $\mathrm{ON}$ & $\mathrm{ON}$ & $\mathrm{ON}$ & ON & $\mathrm{ON}$ & ON & ON & $\mathrm{ON}$ \\
\hline & $\mathrm{ON}$ & $\mathrm{ON}$ & $\mathrm{ON}$ & $\mathrm{ON}$ & ON & $\mathrm{ON}$ & $\mathrm{ON}$ & ON & $\mathrm{ON}$ \\
\hline & ON & ON & $\mathrm{ON}$ & ON & ON & ON & $\mathrm{ON}$ & ON & $\mathrm{ON}$ \\
\hline & $\mathrm{ON}$ & $\mathrm{ON}$ & $\mathrm{ON}$ & $\mathrm{ON}$ & ON & ON & $\mathrm{ON}$ & ON & ON \\
\hline & ON & $\mathrm{ON}$ & $\mathrm{ON}$ & ON & ON & ON & $\mathrm{ON}$ & ON & $\mathrm{ON}$ \\
\hline & $\mathrm{ON}$ & $\mathrm{ON}$ & $\mathrm{ON}$ & $\mathrm{ON}$ & ON & ON & $\mathrm{ON}$ & ON & ON \\
\hline & ON & ON & $\mathrm{ON}$ & $\mathrm{ON}$ & ON & ON & $\mathrm{ON}$ & ON & $\mathrm{ON}$ \\
\hline & $\mathrm{ON}$ & $\mathrm{ON}$ & $\mathrm{ON}$ & $\mathrm{ON}$ & $\mathrm{ON}$ & ON & $\mathrm{ON}$ & ON & $\mathrm{ON}$ \\
\hline & ON & $\mathrm{ON}$ & $\mathrm{ON}$ & $\mathrm{ON}$ & ON & ON & $\mathrm{ON}$ & ON & ON \\
\hline & ON & ON & $\mathrm{ON}$ & ON & ON & ON & $\mathrm{ON}$ & ON & ON \\
\hline & ON & $\mathrm{ON}$ & $\mathrm{ON}$ & ON & ON & ON & $\mathrm{ON}$ & ON & $\mathrm{ON}$ \\
\hline & ON & $\mathrm{ON}$ & $\mathrm{ON}$ & $\mathrm{ON}$ & ON & ON & $\mathrm{ON}$ & ON & $\mathrm{ON}$ \\
\hline & $\mathrm{ON}$ & ON & $\mathrm{ON}$ & ON & ON & ON & $\mathrm{ON}$ & ON & $\mathrm{ON}$ \\
\hline & $\mathrm{ON}$ & $\mathrm{ON}$ & $\mathrm{ON}$ & $\mathrm{ON}$ & ON & ON & $\mathrm{ON}$ & ON & ON \\
\hline & $\mathrm{ON}$ & $\mathrm{ON}$ & $\mathrm{ON}$ & $\mathrm{ON}$ & ON & ON & $\mathrm{ON}$ & ON & $\mathrm{ON}$ \\
\hline & $\mathrm{ON}$ & $\mathrm{ON}$ & $\mathrm{ON}$ & $\mathrm{ON}$ & ON & ON & $\mathrm{ON}$ & ON & ON \\
\hline & $\mathrm{ON}$ & $\mathrm{ON}$ & $\mathrm{ON}$ & $\mathrm{ON}$ & ON & $\mathrm{ON}$ & $\mathrm{ON}$ & ON & $\mathrm{ON}$ \\
\hline & ON & ON & $\mathrm{ON}$ & ON & ON & ON & ON & ON & $\mathrm{ON}$ \\
\hline & $\mathrm{ON}$ & $\mathrm{ON}$ & $\mathrm{ON}$ & $\mathrm{ON}$ & $\mathrm{ON}$ & $\mathrm{ON}$ & $\mathrm{ON}$ & ON & $\mathrm{ON}$ \\
\hline & $\mathrm{ON}$ & ON & $\mathrm{ON}$ & ON & ON & ON & $\mathrm{ON}$ & ON & $\mathrm{ON}$ \\
\hline & $\mathrm{ON}$ & ON & ON & ON & ON & ON & $\mathrm{ON}$ & ON & ON \\
\hline & ON & $\mathrm{ON}$ & ON & $\mathrm{ON}$ & ON & ON & $\mathrm{ON}$ & ON & ON \\
\hline & $\mathrm{ON}$ & ON & ON & $\mathrm{ON}$ & ON & ON & $\mathrm{ON}$ & ON & $\mathrm{ON}$ \\
\hline & $\mathrm{ON}$ & ON & $\mathrm{ON}$ & ON & ON & ON & ON & ON & $\mathrm{ON}$ \\
\hline & ON & $\mathrm{ON}$ & $\mathrm{ON}$ & $\mathrm{ON}$ & ON & $\mathrm{ON}$ & $\mathrm{ON}$ & ON & $\mathrm{ON}$ \\
\hline & ON & $\mathrm{ON}$ & $\mathrm{ON}$ & ON & ON & $\mathrm{ON}$ & $\mathrm{ON}$ & ON & $\mathrm{ON}$ \\
\hline & $\mathrm{ON}$ & $\mathrm{ON}$ & $\mathrm{ON}$ & $\mathrm{ON}$ & $\mathrm{ON}$ & $\mathrm{ON}$ & $\mathrm{ON}$ & ON & $\mathrm{ON}$ \\
\hline & $\mathrm{ON}$ & ON & ON & $\mathrm{ON}$ & ON & ON & $\mathrm{ON}$ & ON & $\mathrm{ON}$ \\
\hline & $\mathrm{ON}$ & $\mathrm{ON}$ & & & & & & & \\
\hline BODN6 & $\mathrm{ON}$ & $\mathrm{ON}$ & ON & ON & ON & $\mathrm{ON}$ & $\mathrm{ON}$ & ON & ON \\
\hline & ON & $\mathrm{ON}$ & $\mathrm{ON}$ & ON & ON & $\mathrm{ON}$ & $\mathrm{ON}$ & ON & $\mathrm{ON}$ \\
\hline & $\mathrm{ON}$ & $\mathrm{ON}$ & $\mathrm{ON}$ & $\mathrm{ON}$ & $\mathrm{ON}$ & $\mathrm{ON}$ & $\mathrm{ON}$ & $\mathrm{ON}$ & $\mathrm{ON}$ \\
\hline & $\mathrm{ON}$ & ON & $\mathrm{ON}$ & $\mathrm{ON}$ & ON & $\mathrm{ON}$ & $\mathrm{ON}$ & ON & $\mathrm{ON}$ \\
\hline & ON & ON & ON & $\mathrm{ON}$ & ON & ON & ON & ON & \\
\hline
\end{tabular}




\begin{tabular}{|c|c|c|c|c|c|c|c|c|c|}
\hline & ON & ON & ON & ON & ON & ON & ON & ON & ON \\
\hline & ON & ON & ON & ON & ON & ON & ON & ON & ON \\
\hline & ON & ON & ON & ON & ON & ON & ON & ON & ON \\
\hline & ON & ON & ON & ON & $\mathrm{ON}$ & ON & ON & ON & ON \\
\hline & ON & ON & ON & ON & ON & ON & ON & ON & ON \\
\hline & ON & ON & ON & ON & ON & ON & ON & ON & ON \\
\hline & ON & ON & ON & ON & ON & ON & ON & ON & ON \\
\hline & ON & ON & ON & ON & ON & ON & ON & ON & ON \\
\hline & ON & ON & ON & ON & ON & ON & ON & ON & ON \\
\hline & ON & $\mathrm{ON}$ & ON & ON & ON & ON & ON & ON & ON \\
\hline & ON & ON & ON & ON & ON & ON & $\mathrm{ON}$ & ON & ON \\
\hline & ON & ON & ON & ON & ON & ON & ON & ON & ON \\
\hline & ON & ON & ON & ON & ON & ON & ON & ON & ON \\
\hline & ON & ON & ON & ON & ON & ON & ON & ON & ON \\
\hline & ON & $\mathrm{ON}$ & ON & ON & ON & ON & ON & ON & ON \\
\hline & ON & ON & ON & ON & ON & ON & ON & ON & ON \\
\hline & ON & ON & ON & ON & ON & ON & ON & ON & ON \\
\hline & ON & ON & ON & ON & ON & ON & ON & ON & ON \\
\hline & ON & ON & $\mathrm{ON}$ & ON & ON & ON & ON & ON & ON \\
\hline & ON & ON & ON & ON & ON & ON & ON & ON & ON \\
\hline & ON & ON & ON & ON & ON & ON & ON & ON & ON \\
\hline & ON & ON & ON & ON & ON & ON & ON & ON & ON \\
\hline & ON & ON & ON & ON & ON & ON & ON & ON & ON \\
\hline & ON & ON & $\mathrm{ON}$ & ON & ON & ON & $\mathrm{ON}$ & ON & ON \\
\hline & ON & ON & ON & ON & ON & ON & $\mathrm{ON}$ & ON & ON \\
\hline & ON & ON & ON & ON & ON & ON & ON & ON & ON \\
\hline & ON & $\mathrm{ON}$ & $\mathrm{ON}$ & ON & ON & ON & ON & ON & ON \\
\hline & ON & $\mathrm{ON}$ & ON & ON & ON & ON & ON & ON & ON \\
\hline & ON & ON & & & & & & & \\
\hline BODN7 & ON & ON & ON & ON & $\mathrm{ON}$ & ON & $\mathrm{ON}$ & ON & ON \\
\hline & ON & $\mathrm{ON}$ & ON & ON & ON & ON & ON & ON & ON \\
\hline & ON & ON & $\mathrm{ON}$ & ON & ON & ON & ON & ON & ON \\
\hline & ON & ON & ON & ON & ON & ON & ON & ON & ON \\
\hline & ON & $\mathrm{ON}$ & ON & ON & ON & $\mathrm{ON}$ & ON & ON & ON \\
\hline & ON & ON & ON & ON & ON & ON & ON & ON & ON \\
\hline & ON & ON & ON & ON & ON & $\mathrm{ON}$ & ON & ON & ON \\
\hline & ON & ON & ON & ON & ON & ON & ON & ON & ON \\
\hline & ON & ON & ON & ON & ON & $\mathrm{ON}$ & ON & ON & ON \\
\hline & ON & ON & ON & ON & ON & $\mathrm{ON}$ & ON & ON & ON \\
\hline & ON & ON & ON & ON & ON & ON & ON & ON & $\mathrm{ON}$ \\
\hline & ON & ON & ON & ON & ON & ON & ON & ON & ON \\
\hline & ON & ON & ON & ON & ON & ON & ON & ON & ON \\
\hline & ON & ON & ON & ON & ON & ON & ON & ON & ON \\
\hline & ON & ON & ON & ON & ON & $\mathrm{ON}$ & ON & ON & $\mathrm{ON}$ \\
\hline & ON & ON & ON & ON & ON & ON & ON & ON & $\mathrm{ON}$ \\
\hline & ON & ON & ON & $\mathrm{ON}$ & ON & ON & ON & ON & $\mathrm{ON}$ \\
\hline & ON & ON & ON & ON & ON & ON & ON & ON & $\mathrm{ON}$ \\
\hline & ON & $\mathrm{ON}$ & ON & ON & ON & $\mathrm{ON}$ & ON & ON & ON \\
\hline & ON & ON & ON & ON & ON & ON & ON & ON & $\mathrm{ON}$ \\
\hline & ON & $\mathrm{ON}$ & ON & $\mathrm{ON}$ & ON & ON & ON & ON & ON \\
\hline & ON & ON & $\mathrm{ON}$ & $\mathrm{ON}$ & ON & ON & ON & ON & $\mathrm{ON}$ \\
\hline & ON & ON & ON & ON & ON & $\mathrm{ON}$ & ON & ON & $\mathrm{ON}$ \\
\hline & ON & ON & ON & ON & ON & ON & ON & ON & ON \\
\hline & ON & ON & ON & ON & ON & ON & ON & ON & ON \\
\hline & ON & ON & ON & ON & ON & ON & ON & ON & ON \\
\hline & ON & ON & ON & $\mathrm{ON}$ & ON & ON & $\mathrm{ON}$ & ON & $\mathrm{ON}$ \\
\hline & ON & ON & ON & ON & ON & ON & ON & ON & ON \\
\hline & ON & ON & ON & ON & ON & ON & ON & ON & $\mathrm{ON}$ \\
\hline & ON & ON & ON & ON & ON & ON & ON & ON & ON \\
\hline & ON & ON & ON & ON & ON & ON & ON & ON & ON \\
\hline & ON & ON & ON & ON & ON & ON & ON & ON & ON \\
\hline & ON & ON & ON & $\mathrm{ON}$ & ON & ON & ON & ON & ON \\
\hline & ON & $\mathrm{ON}$ & & & & & & & \\
\hline BODN8 & ON & ON & $\mathrm{ON}$ & ON & ON & ON & ON & $\mathrm{ON}$ & ON \\
\hline & ON & ON & ON & $\mathrm{ON}$ & ON & ON & ON & ON & ON \\
\hline & ON & $\mathrm{ON}$ & ON & $\mathrm{ON}$ & ON & $\mathrm{ON}$ & ON & $\mathrm{ON}$ & ON \\
\hline & ON & ON & ON & ON & ON & ON & ON & ON & ON \\
\hline & ON & ON & ON & ON & ON & $\mathrm{ON}$ & ON & ON & ON \\
\hline
\end{tabular}




\begin{tabular}{|c|c|c|c|c|c|c|c|c|c|}
\hline & ON & ON & $\mathrm{ON}$ & ON & ON & ON & ON & ON & ON \\
\hline & ON & ON & $\mathrm{ON}$ & $\mathrm{ON}$ & $\mathrm{ON}$ & ON & $\mathrm{ON}$ & ON & $\mathrm{ON}$ \\
\hline & ON & ON & ON & ON & ON & ON & $\mathrm{ON}$ & ON & $\mathrm{ON}$ \\
\hline & $\mathrm{ON}$ & ON & ON & $\mathrm{ON}$ & ON & ON & ON & $\mathrm{ON}$ & $\mathrm{ON}$ \\
\hline & ON & ON & $\mathrm{ON}$ & $\mathrm{ON}$ & ON & $\mathrm{ON}$ & ON & ON & $\mathrm{ON}$ \\
\hline & $\mathrm{ON}$ & ON & ON & ON & $\mathrm{ON}$ & $\mathrm{ON}$ & $\mathrm{ON}$ & ON & $\mathrm{ON}$ \\
\hline & ON & ON & ON & $\mathrm{ON}$ & ON & ON & ON & ON & $\mathrm{ON}$ \\
\hline & ON & ON & ON & ON & ON & ON & ON & $\mathrm{ON}$ & $\mathrm{ON}$ \\
\hline & $\mathrm{ON}$ & ON & $\mathrm{ON}$ & $\mathrm{ON}$ & ON & $\mathrm{ON}$ & ON & ON & $\mathrm{ON}$ \\
\hline & $\mathrm{ON}$ & ON & $\mathrm{ON}$ & $\mathrm{ON}$ & ON & $\mathrm{ON}$ & $\mathrm{ON}$ & ON & $\mathrm{ON}$ \\
\hline & $\mathrm{ON}$ & ON & ON & ON & ON & ON & ON & ON & ON \\
\hline & $\mathrm{ON}$ & $\mathrm{ON}$ & ON & $\mathrm{ON}$ & ON & $\mathrm{ON}$ & ON & ON & $\mathrm{ON}$ \\
\hline & ON & ON & ON & $\mathrm{ON}$ & ON & ON & ON & ON & $\mathrm{ON}$ \\
\hline & $\mathrm{ON}$ & ON & $\mathrm{ON}$ & $\mathrm{ON}$ & $\mathrm{ON}$ & $\mathrm{ON}$ & ON & ON & $\mathrm{ON}$ \\
\hline & ON & ON & ON & ON & ON & ON & ON & ON & $\mathrm{ON}$ \\
\hline & $\mathrm{ON}$ & ON & ON & ON & ON & ON & $\mathrm{ON}$ & ON & $\mathrm{ON}$ \\
\hline & ON & ON & ON & ON & ON & ON & $\mathrm{ON}$ & ON & $\mathrm{ON}$ \\
\hline & ON & ON & ON & $\mathrm{ON}$ & ON & $\mathrm{ON}$ & ON & ON & $\mathrm{ON}$ \\
\hline & $\mathrm{ON}$ & ON & $\mathrm{ON}$ & ON & ON & ON & ON & ON & $\mathrm{ON}$ \\
\hline & ON & ON & ON & ON & ON & ON & ON & $\mathrm{ON}$ & $\mathrm{ON}$ \\
\hline & ON & ON & $\mathrm{ON}$ & ON & ON & ON & ON & ON & $\mathrm{ON}$ \\
\hline & ON & ON & ON & ON & ON & ON & $\mathrm{ON}$ & ON & $\mathrm{ON}$ \\
\hline & $\mathrm{ON}$ & ON & ON & ON & ON & ON & $\mathrm{ON}$ & $\mathrm{ON}$ & $\mathrm{ON}$ \\
\hline & ON & ON & ON & ON & ON & ON & $\mathrm{ON}$ & $\mathrm{ON}$ & $\mathrm{ON}$ \\
\hline & ON & $\mathrm{ON}$ & ON & ON & ON & ON & ON & ON & $\mathrm{ON}$ \\
\hline & ON & ON & ON & ON & ON & ON & $\mathrm{ON}$ & ON & ON \\
\hline & ON & ON & ON & $\mathrm{ON}$ & ON & ON & $\mathrm{ON}$ & $\mathrm{ON}$ & $\mathrm{ON}$ \\
\hline & $\mathrm{ON}$ & ON & ON & $\mathrm{ON}$ & ON & ON & $\mathrm{ON}$ & ON & $\mathrm{ON}$ \\
\hline & ON & ON & & & & & & & \\
\hline BODN9 & ON & ON & $\mathrm{ON}$ & $\mathrm{ON}$ & $\mathrm{ON}$ & ON & $\mathrm{ON}$ & ON & $\mathrm{ON}$ \\
\hline & ON & ON & $\mathrm{ON}$ & ON & ON & ON & $\mathrm{ON}$ & ON & $\mathrm{ON}$ \\
\hline & ON & ON & ON & $\mathrm{ON}$ & ON & ON & $\mathrm{ON}$ & $\mathrm{ON}$ & $\mathrm{ON}$ \\
\hline & ON & ON & ON & ON & ON & ON & $\mathrm{ON}$ & ON & $\mathrm{ON}$ \\
\hline & ON & ON & ON & ON & ON & ON & $\mathrm{ON}$ & ON & $\mathrm{ON}$ \\
\hline & ON & ON & ON & ON & ON & ON & ON & ON & $\mathrm{ON}$ \\
\hline & $\mathrm{ON}$ & ON & $\mathrm{ON}$ & $\mathrm{ON}$ & $\mathrm{ON}$ & ON & ON & $\mathrm{ON}$ & $\mathrm{ON}$ \\
\hline & $\mathrm{ON}$ & ON & $\mathrm{ON}$ & ON & ON & ON & $\mathrm{ON}$ & ON & $\mathrm{ON}$ \\
\hline & ON & ON & ON & ON & ON & ON & $\mathrm{ON}$ & ON & $\mathrm{ON}$ \\
\hline & ON & ON & ON & ON & $\mathrm{ON}$ & $\mathrm{ON}$ & $\mathrm{ON}$ & ON & $\mathrm{ON}$ \\
\hline & $\mathrm{ON}$ & ON & $\mathrm{ON}$ & $\mathrm{ON}$ & ON & ON & $\mathrm{ON}$ & ON & ON \\
\hline & $\mathrm{ON}$ & ON & ON & ON & $\mathrm{ON}$ & ON & $\mathrm{ON}$ & ON & $\mathrm{ON}$ \\
\hline & $\mathrm{ON}$ & ON & $\mathrm{ON}$ & $\mathrm{ON}$ & ON & ON & $\mathrm{ON}$ & ON & $\mathrm{ON}$ \\
\hline & ON & ON & ON & ON & ON & ON & $\mathrm{ON}$ & ON & $\mathrm{ON}$ \\
\hline & ON & ON & ON & ON & $\mathrm{ON}$ & ON & $\mathrm{ON}$ & ON & $\mathrm{ON}$ \\
\hline & $\mathrm{ON}$ & ON & $\mathrm{ON}$ & ON & ON & ON & $\mathrm{ON}$ & ON & ON \\
\hline & $\mathrm{ON}$ & ON & ON & ON & ON & ON & ON & $\mathrm{ON}$ & $\mathrm{ON}$ \\
\hline & ON & ON & ON & ON & ON & ON & $\mathrm{ON}$ & ON & $\mathrm{ON}$ \\
\hline & ON & ON & ON & ON & $\mathrm{ON}$ & ON & $\mathrm{ON}$ & ON & $\mathrm{ON}$ \\
\hline & ON & ON & ON & $\mathrm{ON}$ & $\mathrm{ON}$ & $\mathrm{ON}$ & $\mathrm{ON}$ & ON & $\mathrm{ON}$ \\
\hline & $\mathrm{ON}$ & ON & ON & ON & ON & ON & $\mathrm{ON}$ & ON & ON \\
\hline & $\mathrm{ON}$ & ON & $\mathrm{ON}$ & $\mathrm{ON}$ & ON & ON & ON & ON & $\mathrm{ON}$ \\
\hline & ON & ON & ON & ON & $\mathrm{ON}$ & ON & $\mathrm{ON}$ & ON & $\mathrm{ON}$ \\
\hline & $\mathrm{ON}$ & ON & $\mathrm{ON}$ & $\mathrm{ON}$ & $\mathrm{ON}$ & $\mathrm{ON}$ & $\mathrm{ON}$ & ON & $\mathrm{ON}$ \\
\hline & $\mathrm{ON}$ & ON & ON & $\mathrm{ON}$ & $\mathrm{ON}$ & ON & $\mathrm{ON}$ & ON & $\mathrm{ON}$ \\
\hline & ON & ON & ON & ON & ON & ON & $\mathrm{ON}$ & ON & $\mathrm{ON}$ \\
\hline & $\mathrm{ON}$ & ON & $\mathrm{ON}$ & $\mathrm{ON}$ & $\mathrm{ON}$ & $\mathrm{ON}$ & $\mathrm{ON}$ & ON & $\mathrm{ON}$ \\
\hline & $\mathrm{ON}$ & ON & ON & $\mathrm{ON}$ & $\mathrm{ON}$ & ON & $\mathrm{ON}$ & ON & $\mathrm{ON}$ \\
\hline & $\mathrm{ON}$ & ON & $\mathrm{ON}$ & $\mathrm{ON}$ & $\mathrm{ON}$ & $\mathrm{ON}$ & $\mathrm{ON}$ & ON & $\mathrm{ON}$ \\
\hline & $\mathrm{ON}$ & ON & $\mathrm{ON}$ & $\mathrm{ON}$ & $\mathrm{ON}$ & ON & $\mathrm{ON}$ & ON & $\mathrm{ON}$ \\
\hline & ON & ON & ON & ON & ON & ON & ON & ON & $\mathrm{ON}$ \\
\hline & ON & ON & ON & ON & ON & ON & ON & ON & $\mathrm{ON}$ \\
\hline & $\mathrm{ON}$ & ON & $\mathrm{ON}$ & $\mathrm{ON}$ & $\mathrm{ON}$ & ON & ON & $\mathrm{ON}$ & $\mathrm{ON}$ \\
\hline & ON & ON & & & & & & & \\
\hline BODN10 & $\mathrm{ON}$ & ON & $\mathrm{ON}$ & $\mathrm{ON}$ & $\mathrm{ON}$ & $\mathrm{ON}$ & $\mathrm{ON}$ & ON & $\mathrm{ON}$ \\
\hline & $\mathrm{ON}$ & ON & ON & ON & $\mathrm{ON}$ & ON & $\mathrm{ON}$ & ON & $\mathrm{ON}$ \\
\hline & ON & ON & ON & ON & ON & ON & ON & ON & $\mathrm{ON}$ \\
\hline & $\mathrm{ON}$ & ON & ON & $\mathrm{ON}$ & $\mathrm{ON}$ & ON & $\mathrm{ON}$ & ON & $\mathrm{ON}$ \\
\hline & $\mathrm{ON}$ & ON & ON & $\mathrm{ON}$ & ON & $\mathrm{ON}$ & $\mathrm{ON}$ & ON & ON \\
\hline
\end{tabular}




\begin{tabular}{|c|c|c|c|c|c|c|c|c|c|}
\hline & ON & ON & ON & ON & ON & ON & ON & ON & ON \\
\hline & ON & ON & $\mathrm{ON}$ & ON & ON & ON & $\mathrm{ON}$ & ON & ON \\
\hline & $\mathrm{ON}$ & ON & ON & ON & $\mathrm{ON}$ & ON & $\mathrm{ON}$ & ON & $\mathrm{ON}$ \\
\hline & ON & ON & $\mathrm{ON}$ & ON & ON & ON & ON & ON & $\mathrm{ON}$ \\
\hline & ON & ON & ON & $\mathrm{ON}$ & ON & ON & ON & ON & $\mathrm{ON}$ \\
\hline & ON & ON & ON & ON & ON & ON & ON & ON & $\mathrm{ON}$ \\
\hline & ON & ON & ON & ON & ON & ON & ON & ON & $\mathrm{ON}$ \\
\hline & ON & ON & ON & ON & ON & ON & ON & ON & $\mathrm{ON}$ \\
\hline & ON & ON & $\mathrm{ON}$ & $\mathrm{ON}$ & ON & $\mathrm{ON}$ & ON & ON & $\mathrm{ON}$ \\
\hline & $\mathrm{ON}$ & ON & $\mathrm{ON}$ & ON & ON & ON & ON & ON & $\mathrm{ON}$ \\
\hline & ON & ON & ON & ON & ON & ON & ON & ON & $\mathrm{ON}$ \\
\hline & ON & ON & ON & ON & ON & ON & ON & ON & ON \\
\hline & ON & ON & ON & $\mathrm{ON}$ & ON & ON & ON & ON & $\mathrm{ON}$ \\
\hline & ON & ON & ON & $\mathrm{ON}$ & ON & ON & $\mathrm{ON}$ & ON & $\mathrm{ON}$ \\
\hline & ON & ON & $\mathrm{ON}$ & ON & ON & ON & ON & ON & $\mathrm{ON}$ \\
\hline & ON & ON & ON & ON & ON & ON & ON & ON & $\mathrm{ON}$ \\
\hline & ON & ON & ON & $\mathrm{ON}$ & ON & ON & ON & ON & $\mathrm{ON}$ \\
\hline & ON & ON & ON & $\mathrm{ON}$ & ON & ON & ON & ON & $\mathrm{ON}$ \\
\hline & ON & ON & $\mathrm{ON}$ & ON & ON & ON & ON & ON & $\mathrm{ON}$ \\
\hline & ON & ON & $\mathrm{ON}$ & ON & ON & ON & ON & ON & $\mathrm{ON}$ \\
\hline & ON & ON & $\mathrm{ON}$ & ON & ON & ON & ON & ON & $\mathrm{ON}$ \\
\hline & ON & ON & ON & ON & ON & ON & ON & ON & $\mathrm{ON}$ \\
\hline & $\mathrm{ON}$ & ON & ON & ON & ON & ON & $\mathrm{ON}$ & ON & $\mathrm{ON}$ \\
\hline & $\mathrm{ON}$ & ON & $\mathrm{ON}$ & ON & ON & ON & $\mathrm{ON}$ & ON & $\mathrm{ON}$ \\
\hline & ON & ON & $\mathrm{ON}$ & ON & ON & $\mathrm{ON}$ & $\mathrm{ON}$ & ON & $\mathrm{ON}$ \\
\hline & ON & ON & ON & ON & ON & ON & $\mathrm{ON}$ & ON & ON \\
\hline & ON & ON & $\mathrm{ON}$ & ON & $\mathrm{ON}$ & ON & $\mathrm{ON}$ & ON & $\mathrm{ON}$ \\
\hline & ON & ON & ON & ON & ON & ON & ON & ON & $\mathrm{ON}$ \\
\hline & ON & ON & & & & & & & \\
\hline ALG1 & ON & ON & ON & ON & ON & ON & ON & ON & ON \\
\hline & ON & ON & $\mathrm{ON}$ & ON & ON & ON & $\mathrm{ON}$ & ON & $\mathrm{ON}$ \\
\hline & ON & ON & $\mathrm{ON}$ & ON & $\mathrm{ON}$ & ON & ON & ON & $\mathrm{ON}$ \\
\hline & ON & ON & ON & ON & ON & ON & ON & ON & $\mathrm{ON}$ \\
\hline & ON & ON & ON & ON & ON & ON & ON & ON & $\mathrm{ON}$ \\
\hline & ON & ON & ON & ON & $\mathrm{ON}$ & ON & ON & ON & ON \\
\hline & ON & ON & $\mathrm{ON}$ & ON & ON & ON & $\mathrm{ON}$ & ON & $\mathrm{ON}$ \\
\hline & ON & ON & $\mathrm{ON}$ & ON & ON & ON & ON & ON & $\mathrm{ON}$ \\
\hline & ON & ON & ON & ON & ON & ON & ON & ON & $\mathrm{ON}$ \\
\hline & ON & ON & ON & ON & ON & ON & $\mathrm{ON}$ & ON & $\mathrm{ON}$ \\
\hline & ON & ON & $\mathrm{ON}$ & ON & ON & ON & $\mathrm{ON}$ & ON & ON \\
\hline & ON & ON & ON & ON & ON & ON & $\mathrm{ON}$ & ON & $\mathrm{ON}$ \\
\hline & ON & ON & $\mathrm{ON}$ & ON & ON & ON & $\mathrm{ON}$ & ON & $\mathrm{ON}$ \\
\hline & ON & ON & ON & ON & ON & ON & $\mathrm{ON}$ & ON & ON \\
\hline & ON & ON & ON & ON & ON & ON & ON & ON & ON \\
\hline & ON & ON & $\mathrm{ON}$ & ON & ON & ON & ON & ON & ON \\
\hline & ON & ON & ON & ON & ON & ON & $\mathrm{ON}$ & ON & $\mathrm{ON}$ \\
\hline & ON & ON & ON & ON & ON & ON & ON & ON & $\mathrm{ON}$ \\
\hline & ON & ON & ON & ON & ON & ON & ON & ON & $\mathrm{ON}$ \\
\hline & ON & ON & ON & $\mathrm{ON}$ & ON & ON & $\mathrm{ON}$ & ON & $\mathrm{ON}$ \\
\hline & ON & ON & ON & ON & ON & ON & ON & ON & $\mathrm{ON}$ \\
\hline & $\mathrm{ON}$ & ON & $\mathrm{ON}$ & ON & ON & ON & ON & $\mathrm{ON}$ & $\mathrm{ON}$ \\
\hline & ON & ON & ON & ON & ON & ON & ON & ON & $\mathrm{ON}$ \\
\hline & ON & ON & ON & ON & ON & ON & $\mathrm{ON}$ & ON & $\mathrm{ON}$ \\
\hline & ON & ON & ON & ON & ON & ON & $\mathrm{ON}$ & ON & $\mathrm{ON}$ \\
\hline & ON & ON & ON & ON & ON & ON & ON & ON & $\mathrm{ON}$ \\
\hline & ON & ON & ON & ON & ON & ON & ON & $\mathrm{ON}$ & ON \\
\hline & ON & ON & ON & ON & ON & ON & $\mathrm{ON}$ & ON & ON \\
\hline & $\mathrm{ON}$ & ON & ON & $\mathrm{ON}$ & $\mathrm{ON}$ & ON & ON & ON & ON \\
\hline & ON & ON & $\mathrm{ON}$ & ON & ON & ON & $\mathrm{ON}$ & ON & $\mathrm{ON}$ \\
\hline & ON & ON & ON & ON & ON & ON & ON & ON & $\mathrm{ON}$ \\
\hline & ON & ON & ON & $\mathrm{ON}$ & ON & ON & ON & ON & $\mathrm{ON}$ \\
\hline & ON & ON & ON & ON & ON & ON & $\mathrm{ON}$ & ON & $\mathrm{ON}$ \\
\hline & ON & ON & & & & & & & \\
\hline ALG2 & $\mathrm{OFF}$ & $O F F$ & $\mathrm{OFF}$ & $\mathrm{OFF}$ & $\mathrm{OFF}$ & $\mathrm{OFF}$ & $\mathrm{OFF}$ & $\mathrm{OFF}$ & $\mathrm{OFF}$ \\
\hline & OFF & $\mathrm{OFF}$ & $\mathrm{OFF}$ & $\mathrm{OFF}$ & $\mathrm{OFF}$ & $\mathrm{OFF}$ & $\mathrm{OFF}$ & $O F F$ & $\mathrm{OFF}$ \\
\hline & $\mathrm{OFF}$ & $\mathrm{OFF}$ & $\mathrm{OFF}$ & $\mathrm{OFF}$ & $\mathrm{OFF}$ & $\mathrm{OFF}$ & OFF & $\mathrm{OFF}$ & $\mathrm{OFF}$ \\
\hline & OFF & $\mathrm{OFF}$ & $\mathrm{OFF}$ & OFF & $\mathrm{OFF}$ & $\mathrm{OFF}$ & OFF & $\mathrm{OFF}$ & $\mathrm{OFF}$ \\
\hline & $\mathrm{OFF}$ & $\mathrm{OFF}$ & $\mathrm{OFF}$ & $\mathrm{OFF}$ & $\mathrm{OFF}$ & $\mathrm{OFF}$ & $\mathrm{OFF}$ & $\mathrm{OFF}$ & $\mathrm{OFF}$ \\
\hline
\end{tabular}




\begin{tabular}{|c|c|c|c|c|c|c|c|c|c|}
\hline & $\mathrm{OFF}$ & $\mathrm{OFF}$ & $\mathrm{OFF}$ & $\mathrm{OFF}$ & $\mathrm{OFF}$ & $\mathrm{OFF}$ & $\mathrm{OFF}$ & $\mathrm{OFF}$ & $\mathrm{OFF}$ \\
\hline & $\mathrm{OFF}$ & $\mathrm{OFF}$ & $\mathrm{OFF}$ & $\mathrm{OFF}$ & $\mathrm{OFF}$ & $\mathrm{OFF}$ & $\mathrm{OFF}$ & $\mathrm{OFF}$ & $\mathrm{OFF}$ \\
\hline & $\mathrm{OFF}$ & $\mathrm{OFF}$ & $\mathrm{OFF}$ & $\mathrm{OFF}$ & $\mathrm{OFF}$ & $\mathrm{OFF}$ & $\mathrm{OFF}$ & $\mathrm{OFF}$ & $\mathrm{OFF}$ \\
\hline & $\mathrm{OFF}$ & $\mathrm{OFF}$ & $\mathrm{OFF}$ & $\mathrm{OFF}$ & $\mathrm{OFF}$ & $\mathrm{OFF}$ & $\mathrm{OFF}$ & $\mathrm{OFF}$ & $\mathrm{OFF}$ \\
\hline & OFF & $\mathrm{OFF}$ & $\mathrm{OFF}$ & $\mathrm{OFF}$ & OFF & OFF & OFF & $\mathrm{OFF}$ & $\mathrm{OFF}$ \\
\hline & $\mathrm{OFF}$ & $\mathrm{OFF}$ & $\mathrm{OFF}$ & $\mathrm{OFF}$ & $\mathrm{OFF}$ & $\mathrm{OFF}$ & $\mathrm{OFF}$ & $\mathrm{OFF}$ & $\mathrm{OFF}$ \\
\hline & OFF & $\mathrm{OFF}$ & $\mathrm{OFF}$ & $\mathrm{OFF}$ & OFF & OFF & OFF & OFF & $\mathrm{OFF}$ \\
\hline & $\mathrm{OFF}$ & $\mathrm{OFE}$ & $\mathrm{OFF}$ & $\mathrm{OFF}$ & $\mathrm{OFF}$ & $\mathrm{OFF}$ & $\mathrm{OFF}$ & $\mathrm{OFF}$ & $\mathrm{OFF}$ \\
\hline & $\mathrm{OFF}$ & OFF & $\mathrm{OFF}$ & $\mathrm{OFF}$ & OFF & OFF & OFF & OFF & $\mathrm{OFF}$ \\
\hline & $\mathrm{OFF}$ & $\mathrm{OFF}$ & $\mathrm{OFF}$ & $\mathrm{OFF}$ & $\mathrm{OFF}$ & $\mathrm{OFF}$ & $\mathrm{OFF}$ & $\mathrm{OFF}$ & $\mathrm{OFF}$ \\
\hline & $\mathrm{OFF}$ & $\mathrm{OFF}$ & $\mathrm{OFF}$ & $\mathrm{OFF}$ & $\mathrm{OFF}$ & $\mathrm{OFF}$ & $\mathrm{OFF}$ & $\mathrm{OFF}$ & $\mathrm{OFF}$ \\
\hline & $\mathrm{OFF}$ & OFF & $\mathrm{OFF}$ & $\mathrm{OFF}$ & $\mathrm{OFF}$ & $\mathrm{OFF}$ & $\mathrm{OFF}$ & $\mathrm{OFF}$ & $\mathrm{OFF}$ \\
\hline & $\mathrm{OFF}$ & $\mathrm{OFF}$ & $\mathrm{OFF}$ & $\mathrm{OFF}$ & $\mathrm{OFF}$ & OFF & $\mathrm{OFF}$ & $\mathrm{OFF}$ & $\mathrm{OFF}$ \\
\hline & $\mathrm{OFF}$ & $\mathrm{OFF}$ & $\mathrm{OFF}$ & $\mathrm{OFF}$ & $\mathrm{OFF}$ & $\mathrm{OFF}$ & $\mathrm{OFF}$ & $\mathrm{OFF}$ & $\mathrm{OFF}$ \\
\hline & $\mathrm{OFF}$ & $\mathrm{OFF}$ & $\mathrm{OFF}$ & $\mathrm{OFF}$ & $\mathrm{OFF}$ & $\mathrm{OFF}$ & $\mathrm{OFF}$ & $\mathrm{OFF}$ & $\mathrm{OFF}$ \\
\hline & $\mathrm{OFF}$ & OFF & $\mathrm{OFF}$ & $\mathrm{OFF}$ & OFF & $\mathrm{OFF}$ & $\mathrm{OFF}$ & $\mathrm{OFF}$ & $\mathrm{OFF}$ \\
\hline & $\mathrm{OFF}$ & $\mathrm{OFF}$ & $\mathrm{OFF}$ & $\mathrm{OFF}$ & $\mathrm{OFF}$ & $\mathrm{OFF}$ & $\mathrm{OFF}$ & $\mathrm{OFF}$ & $\mathrm{OFF}$ \\
\hline & OFF & OFF & $\mathrm{OFF}$ & $\mathrm{OFF}$ & OFF & OFF & OFF & OFF & $\mathrm{OFF}$ \\
\hline & $\mathrm{OFF}$ & $\mathrm{OFF}$ & $\mathrm{OFF}$ & $\mathrm{OFF}$ & $\mathrm{OFF}$ & $\mathrm{OFF}$ & $\mathrm{OFF}$ & $\mathrm{OFF}$ & $\mathrm{OFF}$ \\
\hline & OFF & OFF & $\mathrm{OFF}$ & $\mathrm{OFF}$ & OFF & OFF & OFF & OFF & $\mathrm{OFF}$ \\
\hline & $\mathrm{OFF}$ & $\mathrm{OFF}$ & $\mathrm{OFF}$ & $\mathrm{OFF}$ & $\mathrm{OFF}$ & $\mathrm{OFF}$ & $\mathrm{OFF}$ & $\mathrm{OFF}$ & $\mathrm{OFF}$ \\
\hline & OFF & OFF & $\mathrm{OFF}$ & OFF & OFF & OFF & OFF & OFF & $\mathrm{OFF}$ \\
\hline & $\mathrm{OFF}$ & $\mathrm{OFF}$ & $\mathrm{OFF}$ & $\mathrm{OFF}$ & $\mathrm{OFF}$ & $\mathrm{OFF}$ & $\mathrm{OFF}$ & $\mathrm{OFF}$ & $\mathrm{OFF}$ \\
\hline & $\mathrm{OFF}$ & OFF & $\mathrm{OFF}$ & OFF & OFF & OFF & OFF & OFF & $\mathrm{OFF}$ \\
\hline & $\mathrm{OFF}$ & $\mathrm{OFF}$ & $\mathrm{OFF}$ & $\mathrm{OFF}$ & $\mathrm{OFF}$ & $\mathrm{OFF}$ & $\mathrm{OFF}$ & $\mathrm{OFF}$ & $\mathrm{OFF}$ \\
\hline & $\mathrm{OFF}$ & $\mathrm{OFF}$ & $\mathrm{OFF}$ & $\mathrm{OFF}$ & $\mathrm{OFF}$ & $\mathrm{OFF}$ & $\mathrm{OFF}$ & $\mathrm{OFF}$ & $\mathrm{OFF}$ \\
\hline & $\mathrm{OFF}$ & $\mathrm{OFF}$ & $\mathrm{OFF}$ & $\mathrm{OFF}$ & $\mathrm{OFF}$ & $\mathrm{OFF}$ & $\mathrm{OFF}$ & $\mathrm{OFF}$ & $\mathrm{OFF}$ \\
\hline & $\mathrm{OFF}$ & $\mathrm{OFF}$ & $\mathrm{OFF}$ & $\mathrm{OFF}$ & $\mathrm{OFF}$ & OFF & $\mathrm{OFF}$ & $\mathrm{OFF}$ & $\mathrm{OFF}$ \\
\hline & OFF & $\mathrm{OFF}$ & & & & & & & \\
\hline DO & $\mathrm{ON}$ & ON & ON & $\mathrm{ON}$ & ON & ON & ON & ON & $\mathrm{ON}$ \\
\hline & ON & ON & ON & $\mathrm{ON}$ & $\mathrm{ON}$ & ON & $\mathrm{ON}$ & ON & $\mathrm{ON}$ \\
\hline & ON & ON & ON & ON & ON & ON & ON & ON & $\mathrm{ON}$ \\
\hline & ON & ON & ON & $\mathrm{ON}$ & ON & ON & $\mathrm{ON}$ & ON & $\mathrm{ON}$ \\
\hline & ON & ON & ON & $\mathrm{ON}$ & ON & ON & ON & ON & $\mathrm{ON}$ \\
\hline & ON & ON & ON & $\mathrm{ON}$ & ON & ON & ON & ON & $\mathrm{ON}$ \\
\hline & ON & ON & ON & $\mathrm{ON}$ & ON & ON & $\mathrm{ON}$ & ON & $\mathrm{ON}$ \\
\hline & $\mathrm{ON}$ & ON & ON & ON & ON & ON & ON & ON & ON \\
\hline & ON & ON & ON & ON & ON & ON & ON & ON & $\mathrm{ON}$ \\
\hline & ON & ON & ON & ON & ON & ON & ON & ON & ON \\
\hline & ON & ON & ON & ON & ON & ON & ON & ON & ON \\
\hline & ON & ON & ON & ON & $\mathrm{ON}$ & $\mathrm{ON}$ & ON & ON & $\mathrm{ON}$ \\
\hline & ON & ON & ON & ON & ON & ON & ON & ON & $\mathrm{ON}$ \\
\hline & ON & ON & ON & $\mathrm{ON}$ & ON & ON & $\mathrm{ON}$ & ON & $\mathrm{ON}$ \\
\hline & ON & ON & ON & ON & ON & ON & ON & ON & $\mathrm{ON}$ \\
\hline & ON & ON & ON & $\mathrm{ON}$ & ON & ON & ON & ON & $\mathrm{ON}$ \\
\hline & ON & ON & ON & $\mathrm{ON}$ & ON & ON & $\mathrm{ON}$ & ON & $\mathrm{ON}$ \\
\hline & ON & ON & ON & $\mathrm{ON}$ & ON & ON & ON & ON & ON \\
\hline & ON & ON & ON & $\mathrm{ON}$ & ON & ON & $\mathrm{ON}$ & ON & $\mathrm{ON}$ \\
\hline & ON & ON & ON & ON & ON & ON & $\mathrm{ON}$ & ON & ON \\
\hline & ON & ON & ON & ON & ON & ON & ON & ON & $\mathrm{ON}$ \\
\hline & ON & ON & ON & ON & ON & ON & ON & ON & $\mathrm{ON}$ \\
\hline & $\mathrm{ON}$ & ON & ON & ON & ON & ON & ON & ON & ON \\
\hline & ON & ON & ON & ON & ON & ON & ON & ON & $\mathrm{ON}$ \\
\hline & ON & ON & ON & $\mathrm{ON}$ & ON & $\mathrm{ON}$ & ON & ON & $\mathrm{ON}$ \\
\hline & ON & ON & ON & ON & ON & ON & ON & ON & ON \\
\hline & ON & ON & ON & ON & ON & ON & ON & ON & $\mathrm{ON}$ \\
\hline & ON & ON & ON & ON & ON & ON & ON & ON & $\mathrm{ON}$ \\
\hline & ON & ON & ON & $\mathrm{ON}$ & ON & ON & $\mathrm{ON}$ & ON & $\mathrm{ON}$ \\
\hline & ON & ON & ON & ON & ON & ON & ON & ON & $\mathrm{ON}$ \\
\hline & ON & ON & ON & ON & ON & ON & ON & ON & ON \\
\hline & ON & ON & ON & ON & ON & ON & ON & ON & $\mathrm{ON}$ \\
\hline & ON & ON & ON & ON & ON & ON & ON & ON & ON \\
\hline & ON & ON & & & & & & & \\
\hline TIC & ON & ON & ON & ON & ON & ON & ON & ON & ON \\
\hline & ON & ON & ON & ON & ON & ON & ON & ON & $\mathrm{ON}$ \\
\hline & ON & ON & ON & ON & ON & ON & ON & ON & $\mathrm{ON}$ \\
\hline & ON & ON & ON & ON & ON & ON & ON & ON & ON \\
\hline & ON & ON & $\mathrm{ON}$ & $\mathrm{ON}$ & ON & $\mathrm{ON}$ & $\mathrm{ON}$ & ON & ON \\
\hline
\end{tabular}




\begin{tabular}{|c|c|c|c|c|c|c|c|c|c|}
\hline & $\mathrm{ON}$ & ON & ON & $\mathrm{ON}$ & $\mathrm{ON}$ & $\mathrm{ON}$ & $\mathrm{ON}$ & ON & ON \\
\hline & $\mathrm{ON}$ & ON & ON & $\mathrm{ON}$ & $\mathrm{ON}$ & $\mathrm{ON}$ & ON & ON & ON \\
\hline & $\mathrm{ON}$ & $\mathrm{ON}$ & $\mathrm{ON}$ & $\mathrm{ON}$ & ON & $\mathrm{ON}$ & ON & ON & ON \\
\hline & $\mathrm{ON}$ & ON & $\mathrm{ON}$ & $\mathrm{ON}$ & ON & ON & ON & $\mathrm{ON}$ & ON \\
\hline & $\mathrm{ON}$ & $\mathrm{ON}$ & $\mathrm{ON}$ & $\mathrm{ON}$ & ON & $\mathrm{ON}$ & ON & ON & ON \\
\hline & $\mathrm{ON}$ & $\mathrm{ON}$ & $\mathrm{ON}$ & $\mathrm{ON}$ & $\mathrm{ON}$ & $\mathrm{ON}$ & ON & ON & ON \\
\hline & $\mathrm{ON}$ & $\mathrm{ON}$ & $\mathrm{ON}$ & $\mathrm{ON}$ & $\mathrm{ON}$ & $\mathrm{ON}$ & ON & ON & ON \\
\hline & $\mathrm{ON}$ & ON & ON & $\mathrm{ON}$ & ON & $\mathrm{ON}$ & ON & $\mathrm{ON}$ & $\mathrm{ON}$ \\
\hline & $\mathrm{ON}$ & $\mathrm{ON}$ & $\mathrm{ON}$ & $\mathrm{ON}$ & $\mathrm{ON}$ & $\mathrm{ON}$ & $\mathrm{ON}$ & ON & ON \\
\hline & $\mathrm{ON}$ & $\mathrm{ON}$ & ON & $\mathrm{ON}$ & ON & $\mathrm{ON}$ & ON & $\mathrm{ON}$ & ON \\
\hline & $\mathrm{ON}$ & $\mathrm{ON}$ & $\mathrm{ON}$ & $\mathrm{ON}$ & $\mathrm{ON}$ & $\mathrm{ON}$ & ON & $\mathrm{ON}$ & ON \\
\hline & $\mathrm{ON}$ & $\mathrm{ON}$ & $\mathrm{ON}$ & $\mathrm{ON}$ & $\mathrm{ON}$ & ON & $\mathrm{ON}$ & ON & ON \\
\hline & $\mathrm{ON}$ & $\mathrm{ON}$ & ON & $\mathrm{ON}$ & ON & $\mathrm{ON}$ & $\mathrm{ON}$ & ON & ON \\
\hline & $\mathrm{ON}$ & $\mathrm{ON}$ & $\mathrm{ON}$ & $\mathrm{ON}$ & $\mathrm{ON}$ & $\mathrm{ON}$ & $\mathrm{ON}$ & ON & ON \\
\hline & $\mathrm{ON}$ & $\mathrm{ON}$ & $\mathrm{ON}$ & $\mathrm{ON}$ & ON & $\mathrm{ON}$ & ON & $\mathrm{ON}$ & $\mathrm{ON}$ \\
\hline & $\mathrm{ON}$ & ON & $\mathrm{ON}$ & $\mathrm{ON}$ & ON & $\mathrm{ON}$ & ON & ON & ON \\
\hline & $\mathrm{ON}$ & $\mathrm{ON}$ & $\mathrm{ON}$ & $\mathrm{ON}$ & ON & $\mathrm{ON}$ & $\mathrm{ON}$ & ON & ON \\
\hline & ON & $\mathrm{ON}$ & $\mathrm{ON}$ & $\mathrm{ON}$ & ON & $\mathrm{ON}$ & ON & ON & ON \\
\hline & $\mathrm{ON}$ & $\mathrm{ON}$ & $\mathrm{ON}$ & $\mathrm{ON}$ & $\mathrm{ON}$ & $\mathrm{ON}$ & $\mathrm{ON}$ & $\mathrm{ON}$ & ON \\
\hline & $\mathrm{ON}$ & ON & $\mathrm{ON}$ & ON & ON & ON & ON & ON & ON \\
\hline & $\mathrm{ON}$ & ON & $\mathrm{ON}$ & $\mathrm{ON}$ & ON & ON & ON & ON & ON \\
\hline & $\mathrm{ON}$ & $\mathrm{ON}$ & $\mathrm{ON}$ & $\mathrm{ON}$ & $\mathrm{ON}$ & $\mathrm{ON}$ & $\mathrm{ON}$ & ON & ON \\
\hline & $\mathrm{ON}$ & $\mathrm{ON}$ & $\mathrm{ON}$ & $\mathrm{ON}$ & ON & $\mathrm{ON}$ & $\mathrm{ON}$ & ON & ON \\
\hline & $\mathrm{ON}$ & $\mathrm{ON}$ & $\mathrm{ON}$ & $\mathrm{ON}$ & $\mathrm{ON}$ & $\mathrm{ON}$ & $\mathrm{ON}$ & $\mathrm{ON}$ & ON \\
\hline & ON & ON & $\mathrm{ON}$ & ON & ON & ON & ON & $\mathrm{ON}$ & ON \\
\hline & $\mathrm{ON}$ & ON & ON & $\mathrm{ON}$ & ON & ON & ON & ON & ON \\
\hline & ON & ON & $\mathrm{ON}$ & $\mathrm{ON}$ & ON & ON & ON & $\mathrm{ON}$ & ON \\
\hline & $\mathrm{ON}$ & $\mathrm{ON}$ & ON & $\mathrm{ON}$ & ON & $\mathrm{ON}$ & $\mathrm{ON}$ & ON & ON \\
\hline & $\mathrm{ON}$ & $\mathrm{ON}$ & & & & & & & \\
\hline ALK & ON & ON & $\mathrm{ON}$ & $\mathrm{ON}$ & ON & $\mathrm{ON}$ & ON & ON & ON \\
\hline & $\mathrm{ON}$ & $\mathrm{ON}$ & $\mathrm{ON}$ & $\mathrm{ON}$ & ON & $\mathrm{ON}$ & $\mathrm{ON}$ & ON & ON \\
\hline & $\mathrm{ON}$ & ON & ON & $\mathrm{ON}$ & ON & ON & ON & ON & ON \\
\hline & $\mathrm{ON}$ & ON & ON & $\mathrm{ON}$ & ON & $\mathrm{ON}$ & ON & ON & ON \\
\hline & $\mathrm{ON}$ & $\mathrm{ON}$ & $\mathrm{ON}$ & $\mathrm{ON}$ & ON & $\mathrm{ON}$ & ON & ON & ON \\
\hline & $\mathrm{ON}$ & ON & $\mathrm{ON}$ & $\mathrm{ON}$ & ON & $\mathrm{ON}$ & ON & ON & ON \\
\hline & $\mathrm{ON}$ & $\mathrm{ON}$ & $\mathrm{ON}$ & $\mathrm{ON}$ & ON & $\mathrm{ON}$ & $\mathrm{ON}$ & ON & ON \\
\hline & $\mathrm{ON}$ & $\mathrm{ON}$ & ON & $\mathrm{ON}$ & ON & $\mathrm{ON}$ & $\mathrm{ON}$ & ON & ON \\
\hline & $\mathrm{ON}$ & $\mathrm{ON}$ & ON & $\mathrm{ON}$ & ON & $\mathrm{ON}$ & ON & ON & ON \\
\hline & ON & ON & $\mathrm{ON}$ & ON & ON & $\mathrm{ON}$ & ON & $\mathrm{ON}$ & ON \\
\hline & $\mathrm{ON}$ & $\mathrm{ON}$ & ON & $\mathrm{ON}$ & ON & $\mathrm{ON}$ & $\mathrm{ON}$ & $\mathrm{ON}$ & ON \\
\hline & $\mathrm{ON}$ & $\mathrm{ON}$ & ON & $\mathrm{ON}$ & ON & $\mathrm{ON}$ & $\mathrm{ON}$ & ON & ON \\
\hline & $\mathrm{ON}$ & $\mathrm{ON}$ & ON & $\mathrm{ON}$ & ON & $\mathrm{ON}$ & $\mathrm{ON}$ & $\mathrm{ON}$ & ON \\
\hline & $\mathrm{ON}$ & $\mathrm{ON}$ & ON & $\mathrm{ON}$ & ON & $\mathrm{ON}$ & ON & ON & ON \\
\hline & $\mathrm{ON}$ & $\mathrm{ON}$ & $\mathrm{ON}$ & $\mathrm{ON}$ & ON & $\mathrm{ON}$ & ON & ON & ON \\
\hline & $\mathrm{ON}$ & ON & ON & $\mathrm{ON}$ & ON & $\mathrm{ON}$ & $\mathrm{ON}$ & ON & ON \\
\hline & ON & ON & ON & $\mathrm{ON}$ & ON & $\mathrm{ON}$ & ON & ON & $\mathrm{ON}$ \\
\hline & $\mathrm{ON}$ & ON & ON & $\mathrm{ON}$ & ON & $\mathrm{ON}$ & ON & ON & ON \\
\hline & $\mathrm{ON}$ & ON & ON & $\mathrm{ON}$ & ON & ON & ON & ON & ON \\
\hline & $\mathrm{ON}$ & ON & ON & $\mathrm{ON}$ & ON & ON & ON & $\mathrm{ON}$ & ON \\
\hline & $\mathrm{ON}$ & $\mathrm{ON}$ & ON & $\mathrm{ON}$ & ON & ON & ON & ON & ON \\
\hline & ON & ON & $\mathrm{ON}$ & ON & ON & ON & ON & ON & ON \\
\hline & $\mathrm{ON}$ & $\mathrm{ON}$ & ON & $\mathrm{ON}$ & ON & $\mathrm{ON}$ & ON & ON & ON \\
\hline & $\mathrm{ON}$ & $\mathrm{ON}$ & $\mathrm{ON}$ & $\mathrm{ON}$ & $\mathrm{ON}$ & $\mathrm{ON}$ & $\mathrm{ON}$ & ON & ON \\
\hline & $\mathrm{ON}$ & $\mathrm{ON}$ & $\mathrm{ON}$ & $\mathrm{ON}$ & $\mathrm{ON}$ & $\mathrm{ON}$ & $\mathrm{ON}$ & ON & ON \\
\hline & $\mathrm{ON}$ & ON & $\mathrm{ON}$ & $\mathrm{ON}$ & ON & $\mathrm{ON}$ & ON & $\mathrm{ON}$ & ON \\
\hline & ON & ON & $\mathrm{ON}$ & ON & ON & ON & ON & ON & ON \\
\hline & ON & $\mathrm{ON}$ & $\mathrm{ON}$ & $\mathrm{ON}$ & ON & ON & ON & ON & ON \\
\hline & $\mathrm{ON}$ & ON & ON & $\mathrm{ON}$ & ON & ON & ON & ON & ON \\
\hline & $\mathrm{ON}$ & $\mathrm{ON}$ & ON & $\mathrm{ON}$ & $\mathrm{ON}$ & $\mathrm{ON}$ & $\mathrm{ON}$ & $\mathrm{ON}$ & ON \\
\hline & $\mathrm{ON}$ & ON & $\mathrm{ON}$ & $\mathrm{ON}$ & ON & $\mathrm{ON}$ & $\mathrm{ON}$ & ON & ON \\
\hline & $\mathrm{ON}$ & $\mathrm{ON}$ & $\mathrm{ON}$ & $\mathrm{ON}$ & $\mathrm{ON}$ & $\mathrm{ON}$ & $\mathrm{ON}$ & ON & ON \\
\hline & ON & ON & $\mathrm{ON}$ & $\mathrm{ON}$ & $\mathrm{ON}$ & ON & ON & ON & ON \\
\hline & $\mathrm{ON}$ & $\mathrm{ON}$ & & & & & & & \\
\hline Z0O1 & $\mathrm{ON}$ & ON & $\mathrm{ON}$ & $\mathrm{ON}$ & ON & ON & $\mathrm{ON}$ & $\mathrm{ON}$ & $\mathrm{ON}$ \\
\hline & $\mathrm{ON}$ & ON & ON & $\mathrm{ON}$ & ON & ON & ON & $\mathrm{ON}$ & ON \\
\hline & $\mathrm{ON}$ & $\mathrm{ON}$ & ON & $\mathrm{ON}$ & $\mathrm{ON}$ & ON & $\mathrm{ON}$ & ON & ON \\
\hline & ON & $\mathrm{ON}$ & ON & $\mathrm{ON}$ & $\mathrm{ON}$ & ON & ON & $\mathrm{ON}$ & ON \\
\hline & ON & ON & ON & ON & ON & ON & ON & ON & \\
\hline
\end{tabular}




\begin{tabular}{|c|c|c|c|c|c|c|c|c|c|}
\hline & ON & ON & $\mathrm{ON}$ & ON & ON & ON & $\mathrm{ON}$ & ON & $\mathrm{ON}$ \\
\hline & ON & $\mathrm{ON}$ & $\mathrm{ON}$ & $\mathrm{ON}$ & $\mathrm{ON}$ & $\mathrm{ON}$ & $\mathrm{ON}$ & ON & $\mathrm{ON}$ \\
\hline & ON & ON & ON & ON & ON & ON & $\mathrm{ON}$ & ON & $\mathrm{ON}$ \\
\hline & $\mathrm{ON}$ & ON & ON & $\mathrm{ON}$ & ON & ON & ON & $\mathrm{ON}$ & $\mathrm{ON}$ \\
\hline & ON & ON & $\mathrm{ON}$ & $\mathrm{ON}$ & ON & ON & $\mathrm{ON}$ & ON & $\mathrm{ON}$ \\
\hline & $\mathrm{ON}$ & ON & ON & ON & $\mathrm{ON}$ & $\mathrm{ON}$ & $\mathrm{ON}$ & ON & $\mathrm{ON}$ \\
\hline & ON & ON & ON & ON & ON & ON & ON & ON & $\mathrm{ON}$ \\
\hline & ON & ON & ON & ON & ON & ON & ON & $\mathrm{ON}$ & $\mathrm{ON}$ \\
\hline & $\mathrm{ON}$ & ON & $\mathrm{ON}$ & $\mathrm{ON}$ & $\mathrm{ON}$ & $\mathrm{ON}$ & $\mathrm{ON}$ & ON & $\mathrm{ON}$ \\
\hline & $\mathrm{ON}$ & ON & $\mathrm{ON}$ & $\mathrm{ON}$ & ON & $\mathrm{ON}$ & $\mathrm{ON}$ & $\mathrm{ON}$ & $\mathrm{ON}$ \\
\hline & $\mathrm{ON}$ & ON & ON & ON & ON & ON & $\mathrm{ON}$ & ON & $\mathrm{ON}$ \\
\hline & $\mathrm{ON}$ & $\mathrm{ON}$ & $\mathrm{ON}$ & $\mathrm{ON}$ & $\mathrm{ON}$ & $\mathrm{ON}$ & $\mathrm{ON}$ & ON & $\mathrm{ON}$ \\
\hline & $\mathrm{ON}$ & ON & ON & $\mathrm{ON}$ & ON & ON & $\mathrm{ON}$ & ON & $\mathrm{ON}$ \\
\hline & $\mathrm{ON}$ & ON & $\mathrm{ON}$ & $\mathrm{ON}$ & $\mathrm{ON}$ & $\mathrm{ON}$ & $\mathrm{ON}$ & ON & $\mathrm{ON}$ \\
\hline & ON & ON & ON & ON & ON & ON & ON & ON & $\mathrm{ON}$ \\
\hline & $\mathrm{ON}$ & ON & ON & ON & ON & ON & $\mathrm{ON}$ & ON & $\mathrm{ON}$ \\
\hline & ON & ON & ON & $\mathrm{ON}$ & ON & ON & $\mathrm{ON}$ & ON & $\mathrm{ON}$ \\
\hline & ON & ON & ON & $\mathrm{ON}$ & ON & ON & ON & $\mathrm{ON}$ & $\mathrm{ON}$ \\
\hline & $\mathrm{ON}$ & ON & $\mathrm{ON}$ & $\mathrm{ON}$ & $\mathrm{ON}$ & $\mathrm{ON}$ & ON & $\mathrm{ON}$ & $\mathrm{ON}$ \\
\hline & ON & ON & ON & ON & ON & ON & ON & $\mathrm{ON}$ & $\mathrm{ON}$ \\
\hline & ON & ON & $\mathrm{ON}$ & ON & ON & ON & $\mathrm{ON}$ & ON & $\mathrm{ON}$ \\
\hline & $\mathrm{ON}$ & ON & $\mathrm{ON}$ & $\mathrm{ON}$ & $\mathrm{ON}$ & $\mathrm{ON}$ & $\mathrm{ON}$ & ON & $\mathrm{ON}$ \\
\hline & $\mathrm{ON}$ & ON & ON & $\mathrm{ON}$ & ON & $\mathrm{ON}$ & $\mathrm{ON}$ & $\mathrm{ON}$ & $\mathrm{ON}$ \\
\hline & $\mathrm{ON}$ & ON & $\mathrm{ON}$ & $\mathrm{ON}$ & $\mathrm{ON}$ & $\mathrm{ON}$ & $\mathrm{ON}$ & ON & $\mathrm{ON}$ \\
\hline & ON & $\mathrm{ON}$ & ON & ON & ON & ON & $\mathrm{ON}$ & ON & $\mathrm{ON}$ \\
\hline & $\mathrm{ON}$ & ON & ON & ON & ON & ON & $\mathrm{ON}$ & ON & $\mathrm{ON}$ \\
\hline & ON & ON & ON & $\mathrm{ON}$ & ON & ON & $\mathrm{ON}$ & $\mathrm{ON}$ & $\mathrm{ON}$ \\
\hline & $\mathrm{ON}$ & ON & ON & $\mathrm{ON}$ & ON & ON & $\mathrm{ON}$ & $\mathrm{ON}$ & $\mathrm{ON}$ \\
\hline & ON & ON & & & & & & & \\
\hline LDOM-P & $\mathrm{ON}$ & ON & $\mathrm{ON}$ & ON & $\mathrm{ON}$ & $\mathrm{ON}$ & $\mathrm{ON}$ & ON & ON \\
\hline & ON & ON & $\mathrm{ON}$ & ON & ON & ON & $\mathrm{ON}$ & $\mathrm{ON}$ & $\mathrm{ON}$ \\
\hline & $\mathrm{ON}$ & ON & $\mathrm{ON}$ & ON & ON & $\mathrm{ON}$ & $\mathrm{ON}$ & ON & $\mathrm{ON}$ \\
\hline & ON & ON & ON & ON & ON & ON & $\mathrm{ON}$ & ON & $\mathrm{ON}$ \\
\hline & ON & ON & ON & ON & ON & ON & $\mathrm{ON}$ & ON & $\mathrm{ON}$ \\
\hline & ON & ON & ON & ON & ON & ON & ON & ON & $\mathrm{ON}$ \\
\hline & ON & ON & $\mathrm{ON}$ & ON & $\mathrm{ON}$ & ON & $\mathrm{ON}$ & ON & $\mathrm{ON}$ \\
\hline & $\mathrm{ON}$ & ON & $\mathrm{ON}$ & $\mathrm{ON}$ & ON & ON & $\mathrm{ON}$ & ON & $\mathrm{ON}$ \\
\hline & ON & ON & ON & ON & ON & ON & $\mathrm{ON}$ & ON & $\mathrm{ON}$ \\
\hline & ON & ON & ON & ON & $\mathrm{ON}$ & $\mathrm{ON}$ & $\mathrm{ON}$ & ON & $\mathrm{ON}$ \\
\hline & $\mathrm{ON}$ & ON & $\mathrm{ON}$ & $\mathrm{ON}$ & $\mathrm{ON}$ & ON & $\mathrm{ON}$ & ON & $\mathrm{ON}$ \\
\hline & $\mathrm{ON}$ & ON & ON & ON & $\mathrm{ON}$ & ON & $\mathrm{ON}$ & ON & $\mathrm{ON}$ \\
\hline & $\mathrm{ON}$ & ON & $\mathrm{ON}$ & $\mathrm{ON}$ & ON & ON & $\mathrm{ON}$ & ON & $\mathrm{ON}$ \\
\hline & ON & ON & ON & ON & ON & ON & $\mathrm{ON}$ & ON & $\mathrm{ON}$ \\
\hline & ON & ON & ON & ON & $\mathrm{ON}$ & ON & $\mathrm{ON}$ & ON & $\mathrm{ON}$ \\
\hline & $\mathrm{ON}$ & ON & $\mathrm{ON}$ & ON & $\mathrm{ON}$ & ON & $\mathrm{ON}$ & ON & $\mathrm{ON}$ \\
\hline & $\mathrm{ON}$ & ON & ON & ON & ON & ON & ON & $\mathrm{ON}$ & $\mathrm{ON}$ \\
\hline & ON & ON & ON & ON & ON & ON & $\mathrm{ON}$ & ON & $\mathrm{ON}$ \\
\hline & ON & ON & ON & ON & $\mathrm{ON}$ & ON & $\mathrm{ON}$ & ON & $\mathrm{ON}$ \\
\hline & ON & ON & ON & $\mathrm{ON}$ & $\mathrm{ON}$ & ON & $\mathrm{ON}$ & ON & $\mathrm{ON}$ \\
\hline & ON & ON & ON & $\mathrm{ON}$ & $\mathrm{ON}$ & ON & $\mathrm{ON}$ & ON & $\mathrm{ON}$ \\
\hline & $\mathrm{ON}$ & ON & ON & $\mathrm{ON}$ & ON & ON & ON & ON & $\mathrm{ON}$ \\
\hline & ON & ON & ON & ON & $\mathrm{ON}$ & ON & $\mathrm{ON}$ & ON & $\mathrm{ON}$ \\
\hline & $\mathrm{ON}$ & ON & $\mathrm{ON}$ & $\mathrm{ON}$ & $\mathrm{ON}$ & $\mathrm{ON}$ & $\mathrm{ON}$ & ON & $\mathrm{ON}$ \\
\hline & $\mathrm{ON}$ & ON & ON & $\mathrm{ON}$ & $\mathrm{ON}$ & ON & $\mathrm{ON}$ & ON & $\mathrm{ON}$ \\
\hline & $\mathrm{ON}$ & ON & ON & ON & $\mathrm{ON}$ & ON & $\mathrm{ON}$ & ON & $\mathrm{ON}$ \\
\hline & ON & ON & ON & ON & ON & ON & ON & ON & $\mathrm{ON}$ \\
\hline & $\mathrm{ON}$ & ON & ON & $\mathrm{ON}$ & $\mathrm{ON}$ & ON & ON & $\mathrm{ON}$ & $\mathrm{ON}$ \\
\hline & $\mathrm{ON}$ & ON & $\mathrm{ON}$ & $\mathrm{ON}$ & $\mathrm{ON}$ & $\mathrm{ON}$ & $\mathrm{ON}$ & ON & $\mathrm{ON}$ \\
\hline & $\mathrm{ON}$ & ON & $\mathrm{ON}$ & $\mathrm{ON}$ & $\mathrm{ON}$ & ON & $\mathrm{ON}$ & ON & $\mathrm{ON}$ \\
\hline & ON & ON & ON & ON & ON & ON & ON & ON & $\mathrm{ON}$ \\
\hline & ON & ON & ON & ON & ON & ON & ON & ON & $\mathrm{ON}$ \\
\hline & $\mathrm{ON}$ & ON & $\mathrm{ON}$ & $\mathrm{ON}$ & $\mathrm{ON}$ & ON & ON & $\mathrm{ON}$ & $\mathrm{ON}$ \\
\hline & ON & ON & & & & & & & \\
\hline RDOM-P & $\mathrm{ON}$ & ON & $\mathrm{ON}$ & $\mathrm{ON}$ & $\mathrm{ON}$ & $\mathrm{ON}$ & $\mathrm{ON}$ & ON & $\mathrm{ON}$ \\
\hline & ON & ON & $\mathrm{ON}$ & $\mathrm{ON}$ & ON & ON & $\mathrm{ON}$ & ON & $\mathrm{ON}$ \\
\hline & ON & ON & ON & ON & ON & ON & ON & ON & $\mathrm{ON}$ \\
\hline & $\mathrm{ON}$ & ON & ON & $\mathrm{ON}$ & $\mathrm{ON}$ & ON & $\mathrm{ON}$ & ON & $\mathrm{ON}$ \\
\hline & $\mathrm{ON}$ & ON & ON & $\mathrm{ON}$ & $\mathrm{ON}$ & $\mathrm{ON}$ & $\mathrm{ON}$ & ON & ON \\
\hline
\end{tabular}




\begin{tabular}{|c|c|c|c|c|c|c|c|c|c|}
\hline & ON & ON & $\mathrm{ON}$ & ON & ON & ON & $\mathrm{ON}$ & ON & $\mathrm{ON}$ \\
\hline & ON & $\mathrm{ON}$ & $\mathrm{ON}$ & $\mathrm{ON}$ & $\mathrm{ON}$ & $\mathrm{ON}$ & $\mathrm{ON}$ & ON & $\mathrm{ON}$ \\
\hline & ON & ON & ON & ON & ON & ON & $\mathrm{ON}$ & ON & $\mathrm{ON}$ \\
\hline & $\mathrm{ON}$ & ON & ON & $\mathrm{ON}$ & ON & ON & ON & $\mathrm{ON}$ & $\mathrm{ON}$ \\
\hline & ON & ON & $\mathrm{ON}$ & $\mathrm{ON}$ & ON & ON & $\mathrm{ON}$ & ON & $\mathrm{ON}$ \\
\hline & $\mathrm{ON}$ & ON & ON & ON & $\mathrm{ON}$ & $\mathrm{ON}$ & $\mathrm{ON}$ & ON & $\mathrm{ON}$ \\
\hline & ON & ON & ON & ON & ON & ON & ON & ON & $\mathrm{ON}$ \\
\hline & ON & ON & ON & ON & ON & ON & ON & $\mathrm{ON}$ & $\mathrm{ON}$ \\
\hline & $\mathrm{ON}$ & ON & $\mathrm{ON}$ & $\mathrm{ON}$ & $\mathrm{ON}$ & $\mathrm{ON}$ & $\mathrm{ON}$ & ON & $\mathrm{ON}$ \\
\hline & $\mathrm{ON}$ & ON & $\mathrm{ON}$ & $\mathrm{ON}$ & ON & $\mathrm{ON}$ & $\mathrm{ON}$ & $\mathrm{ON}$ & $\mathrm{ON}$ \\
\hline & $\mathrm{ON}$ & ON & ON & ON & ON & ON & $\mathrm{ON}$ & ON & $\mathrm{ON}$ \\
\hline & $\mathrm{ON}$ & $\mathrm{ON}$ & $\mathrm{ON}$ & $\mathrm{ON}$ & $\mathrm{ON}$ & $\mathrm{ON}$ & $\mathrm{ON}$ & ON & $\mathrm{ON}$ \\
\hline & $\mathrm{ON}$ & ON & ON & $\mathrm{ON}$ & ON & ON & $\mathrm{ON}$ & ON & $\mathrm{ON}$ \\
\hline & $\mathrm{ON}$ & ON & $\mathrm{ON}$ & $\mathrm{ON}$ & $\mathrm{ON}$ & $\mathrm{ON}$ & $\mathrm{ON}$ & ON & $\mathrm{ON}$ \\
\hline & ON & ON & ON & ON & ON & ON & ON & ON & $\mathrm{ON}$ \\
\hline & $\mathrm{ON}$ & ON & ON & ON & ON & ON & $\mathrm{ON}$ & ON & $\mathrm{ON}$ \\
\hline & ON & ON & ON & $\mathrm{ON}$ & ON & ON & $\mathrm{ON}$ & ON & $\mathrm{ON}$ \\
\hline & ON & ON & ON & $\mathrm{ON}$ & ON & ON & ON & ON & $\mathrm{ON}$ \\
\hline & $\mathrm{ON}$ & ON & $\mathrm{ON}$ & $\mathrm{ON}$ & $\mathrm{ON}$ & $\mathrm{ON}$ & ON & $\mathrm{ON}$ & $\mathrm{ON}$ \\
\hline & ON & ON & ON & ON & ON & ON & ON & $\mathrm{ON}$ & $\mathrm{ON}$ \\
\hline & ON & ON & $\mathrm{ON}$ & ON & ON & ON & $\mathrm{ON}$ & ON & $\mathrm{ON}$ \\
\hline & $\mathrm{ON}$ & ON & $\mathrm{ON}$ & $\mathrm{ON}$ & $\mathrm{ON}$ & $\mathrm{ON}$ & $\mathrm{ON}$ & ON & $\mathrm{ON}$ \\
\hline & $\mathrm{ON}$ & ON & ON & $\mathrm{ON}$ & ON & $\mathrm{ON}$ & $\mathrm{ON}$ & $\mathrm{ON}$ & $\mathrm{ON}$ \\
\hline & $\mathrm{ON}$ & ON & $\mathrm{ON}$ & $\mathrm{ON}$ & $\mathrm{ON}$ & $\mathrm{ON}$ & $\mathrm{ON}$ & ON & $\mathrm{ON}$ \\
\hline & ON & $\mathrm{ON}$ & ON & ON & ON & ON & $\mathrm{ON}$ & ON & $\mathrm{ON}$ \\
\hline & $\mathrm{ON}$ & ON & ON & ON & ON & ON & $\mathrm{ON}$ & ON & $\mathrm{ON}$ \\
\hline & ON & ON & ON & $\mathrm{ON}$ & ON & ON & $\mathrm{ON}$ & $\mathrm{ON}$ & $\mathrm{ON}$ \\
\hline & $\mathrm{ON}$ & ON & ON & $\mathrm{ON}$ & ON & ON & $\mathrm{ON}$ & $\mathrm{ON}$ & $\mathrm{ON}$ \\
\hline & ON & ON & & & & & & & \\
\hline LPOM-P & $\mathrm{ON}$ & ON & $\mathrm{ON}$ & ON & $\mathrm{ON}$ & $\mathrm{ON}$ & $\mathrm{ON}$ & ON & ON \\
\hline & ON & ON & $\mathrm{ON}$ & ON & ON & ON & $\mathrm{ON}$ & $\mathrm{ON}$ & $\mathrm{ON}$ \\
\hline & $\mathrm{ON}$ & ON & $\mathrm{ON}$ & ON & ON & $\mathrm{ON}$ & $\mathrm{ON}$ & ON & $\mathrm{ON}$ \\
\hline & ON & ON & ON & ON & ON & ON & $\mathrm{ON}$ & ON & $\mathrm{ON}$ \\
\hline & ON & ON & ON & ON & $\mathrm{ON}$ & ON & $\mathrm{ON}$ & ON & $\mathrm{ON}$ \\
\hline & ON & ON & ON & ON & ON & ON & ON & ON & $\mathrm{ON}$ \\
\hline & ON & ON & $\mathrm{ON}$ & ON & $\mathrm{ON}$ & ON & $\mathrm{ON}$ & ON & $\mathrm{ON}$ \\
\hline & $\mathrm{ON}$ & ON & $\mathrm{ON}$ & $\mathrm{ON}$ & ON & ON & $\mathrm{ON}$ & ON & $\mathrm{ON}$ \\
\hline & ON & ON & ON & ON & ON & ON & $\mathrm{ON}$ & ON & $\mathrm{ON}$ \\
\hline & ON & ON & ON & ON & $\mathrm{ON}$ & $\mathrm{ON}$ & $\mathrm{ON}$ & ON & $\mathrm{ON}$ \\
\hline & $\mathrm{ON}$ & ON & $\mathrm{ON}$ & $\mathrm{ON}$ & $\mathrm{ON}$ & ON & $\mathrm{ON}$ & ON & $\mathrm{ON}$ \\
\hline & $\mathrm{ON}$ & ON & ON & $\mathrm{ON}$ & ON & ON & ON & $\mathrm{ON}$ & $\mathrm{ON}$ \\
\hline & $\mathrm{ON}$ & ON & $\mathrm{ON}$ & $\mathrm{ON}$ & ON & ON & $\mathrm{ON}$ & ON & $\mathrm{ON}$ \\
\hline & ON & ON & ON & ON & ON & ON & $\mathrm{ON}$ & ON & $\mathrm{ON}$ \\
\hline & ON & ON & ON & ON & $\mathrm{ON}$ & ON & $\mathrm{ON}$ & ON & $\mathrm{ON}$ \\
\hline & $\mathrm{ON}$ & ON & $\mathrm{ON}$ & ON & $\mathrm{ON}$ & ON & $\mathrm{ON}$ & ON & $\mathrm{ON}$ \\
\hline & ON & ON & ON & ON & ON & ON & ON & $\mathrm{ON}$ & $\mathrm{ON}$ \\
\hline & ON & ON & ON & ON & ON & ON & $\mathrm{ON}$ & ON & $\mathrm{ON}$ \\
\hline & ON & ON & ON & ON & $\mathrm{ON}$ & ON & $\mathrm{ON}$ & ON & $\mathrm{ON}$ \\
\hline & ON & ON & ON & $\mathrm{ON}$ & $\mathrm{ON}$ & ON & $\mathrm{ON}$ & ON & $\mathrm{ON}$ \\
\hline & ON & ON & ON & $\mathrm{ON}$ & $\mathrm{ON}$ & ON & $\mathrm{ON}$ & ON & $\mathrm{ON}$ \\
\hline & $\mathrm{ON}$ & ON & ON & $\mathrm{ON}$ & ON & ON & ON & ON & $\mathrm{ON}$ \\
\hline & ON & ON & ON & ON & $\mathrm{ON}$ & ON & $\mathrm{ON}$ & ON & $\mathrm{ON}$ \\
\hline & $\mathrm{ON}$ & ON & $\mathrm{ON}$ & $\mathrm{ON}$ & $\mathrm{ON}$ & $\mathrm{ON}$ & $\mathrm{ON}$ & ON & $\mathrm{ON}$ \\
\hline & $\mathrm{ON}$ & ON & ON & $\mathrm{ON}$ & $\mathrm{ON}$ & ON & $\mathrm{ON}$ & ON & $\mathrm{ON}$ \\
\hline & $\mathrm{ON}$ & ON & ON & ON & $\mathrm{ON}$ & ON & $\mathrm{ON}$ & ON & $\mathrm{ON}$ \\
\hline & ON & ON & ON & ON & ON & ON & ON & ON & $\mathrm{ON}$ \\
\hline & $\mathrm{ON}$ & ON & ON & $\mathrm{ON}$ & $\mathrm{ON}$ & ON & ON & $\mathrm{ON}$ & $\mathrm{ON}$ \\
\hline & $\mathrm{ON}$ & ON & $\mathrm{ON}$ & $\mathrm{ON}$ & $\mathrm{ON}$ & $\mathrm{ON}$ & $\mathrm{ON}$ & ON & $\mathrm{ON}$ \\
\hline & $\mathrm{ON}$ & ON & $\mathrm{ON}$ & $\mathrm{ON}$ & $\mathrm{ON}$ & ON & $\mathrm{ON}$ & ON & $\mathrm{ON}$ \\
\hline & ON & ON & ON & ON & ON & ON & ON & ON & $\mathrm{ON}$ \\
\hline & ON & ON & ON & ON & ON & ON & ON & ON & $\mathrm{ON}$ \\
\hline & $\mathrm{ON}$ & ON & $\mathrm{ON}$ & $\mathrm{ON}$ & $\mathrm{ON}$ & ON & ON & $\mathrm{ON}$ & $\mathrm{ON}$ \\
\hline & ON & ON & & & & & & & \\
\hline RPOM-P & ON & ON & $\mathrm{ON}$ & $\mathrm{ON}$ & $\mathrm{ON}$ & $\mathrm{ON}$ & $\mathrm{ON}$ & ON & $\mathrm{ON}$ \\
\hline & ON & ON & $\mathrm{ON}$ & ON & ON & ON & $\mathrm{ON}$ & ON & $\mathrm{ON}$ \\
\hline & ON & ON & ON & ON & ON & ON & ON & ON & $\mathrm{ON}$ \\
\hline & $\mathrm{ON}$ & ON & ON & $\mathrm{ON}$ & $\mathrm{ON}$ & ON & $\mathrm{ON}$ & ON & $\mathrm{ON}$ \\
\hline & $\mathrm{ON}$ & ON & ON & $\mathrm{ON}$ & $\mathrm{ON}$ & $\mathrm{ON}$ & $\mathrm{ON}$ & ON & ON \\
\hline
\end{tabular}




\begin{tabular}{|c|c|c|c|c|c|c|c|c|c|}
\hline & ON & ON & $\mathrm{ON}$ & ON & ON & ON & $\mathrm{ON}$ & ON & $\mathrm{ON}$ \\
\hline & ON & $\mathrm{ON}$ & $\mathrm{ON}$ & $\mathrm{ON}$ & $\mathrm{ON}$ & $\mathrm{ON}$ & $\mathrm{ON}$ & ON & $\mathrm{ON}$ \\
\hline & ON & ON & ON & ON & ON & ON & $\mathrm{ON}$ & ON & $\mathrm{ON}$ \\
\hline & $\mathrm{ON}$ & ON & ON & $\mathrm{ON}$ & ON & ON & ON & $\mathrm{ON}$ & $\mathrm{ON}$ \\
\hline & ON & ON & $\mathrm{ON}$ & $\mathrm{ON}$ & ON & ON & $\mathrm{ON}$ & ON & $\mathrm{ON}$ \\
\hline & $\mathrm{ON}$ & ON & ON & ON & $\mathrm{ON}$ & $\mathrm{ON}$ & $\mathrm{ON}$ & ON & $\mathrm{ON}$ \\
\hline & ON & ON & ON & $\mathrm{ON}$ & ON & ON & ON & ON & $\mathrm{ON}$ \\
\hline & ON & ON & ON & ON & ON & ON & ON & $\mathrm{ON}$ & $\mathrm{ON}$ \\
\hline & $\mathrm{ON}$ & ON & $\mathrm{ON}$ & $\mathrm{ON}$ & $\mathrm{ON}$ & $\mathrm{ON}$ & $\mathrm{ON}$ & ON & $\mathrm{ON}$ \\
\hline & $\mathrm{ON}$ & ON & $\mathrm{ON}$ & $\mathrm{ON}$ & ON & $\mathrm{ON}$ & $\mathrm{ON}$ & $\mathrm{ON}$ & $\mathrm{ON}$ \\
\hline & $\mathrm{ON}$ & ON & ON & ON & ON & ON & $\mathrm{ON}$ & ON & $\mathrm{ON}$ \\
\hline & $\mathrm{ON}$ & $\mathrm{ON}$ & $\mathrm{ON}$ & $\mathrm{ON}$ & $\mathrm{ON}$ & $\mathrm{ON}$ & $\mathrm{ON}$ & ON & $\mathrm{ON}$ \\
\hline & $\mathrm{ON}$ & ON & ON & $\mathrm{ON}$ & ON & ON & $\mathrm{ON}$ & ON & $\mathrm{ON}$ \\
\hline & $\mathrm{ON}$ & ON & $\mathrm{ON}$ & $\mathrm{ON}$ & $\mathrm{ON}$ & $\mathrm{ON}$ & $\mathrm{ON}$ & ON & $\mathrm{ON}$ \\
\hline & ON & ON & ON & ON & ON & ON & ON & ON & $\mathrm{ON}$ \\
\hline & $\mathrm{ON}$ & ON & ON & ON & ON & ON & $\mathrm{ON}$ & ON & $\mathrm{ON}$ \\
\hline & ON & ON & ON & $\mathrm{ON}$ & ON & ON & $\mathrm{ON}$ & ON & $\mathrm{ON}$ \\
\hline & ON & ON & ON & $\mathrm{ON}$ & ON & ON & ON & $\mathrm{ON}$ & $\mathrm{ON}$ \\
\hline & $\mathrm{ON}$ & ON & $\mathrm{ON}$ & $\mathrm{ON}$ & $\mathrm{ON}$ & $\mathrm{ON}$ & ON & $\mathrm{ON}$ & $\mathrm{ON}$ \\
\hline & ON & ON & ON & ON & ON & ON & ON & $\mathrm{ON}$ & $\mathrm{ON}$ \\
\hline & ON & ON & $\mathrm{ON}$ & ON & ON & ON & $\mathrm{ON}$ & ON & $\mathrm{ON}$ \\
\hline & $\mathrm{ON}$ & ON & $\mathrm{ON}$ & $\mathrm{ON}$ & $\mathrm{ON}$ & $\mathrm{ON}$ & $\mathrm{ON}$ & ON & $\mathrm{ON}$ \\
\hline & $\mathrm{ON}$ & ON & ON & $\mathrm{ON}$ & ON & $\mathrm{ON}$ & $\mathrm{ON}$ & $\mathrm{ON}$ & $\mathrm{ON}$ \\
\hline & $\mathrm{ON}$ & ON & $\mathrm{ON}$ & $\mathrm{ON}$ & $\mathrm{ON}$ & $\mathrm{ON}$ & $\mathrm{ON}$ & ON & $\mathrm{ON}$ \\
\hline & ON & $\mathrm{ON}$ & ON & ON & ON & ON & $\mathrm{ON}$ & ON & $\mathrm{ON}$ \\
\hline & $\mathrm{ON}$ & ON & ON & ON & ON & ON & $\mathrm{ON}$ & ON & $\mathrm{ON}$ \\
\hline & ON & ON & ON & $\mathrm{ON}$ & ON & ON & $\mathrm{ON}$ & $\mathrm{ON}$ & $\mathrm{ON}$ \\
\hline & $\mathrm{ON}$ & ON & ON & $\mathrm{ON}$ & ON & ON & $\mathrm{ON}$ & $\mathrm{ON}$ & $\mathrm{ON}$ \\
\hline & ON & ON & & & & & & & \\
\hline LDOM-N & $\mathrm{ON}$ & ON & $\mathrm{ON}$ & ON & $\mathrm{ON}$ & $\mathrm{ON}$ & $\mathrm{ON}$ & ON & ON \\
\hline & $\mathrm{ON}$ & ON & ON & $\mathrm{ON}$ & ON & ON & ON & ON & $\mathrm{ON}$ \\
\hline & ON & ON & ON & $\mathrm{ON}$ & ON & ON & $\mathrm{ON}$ & ON & $\mathrm{ON}$ \\
\hline & ON & ON & ON & ON & ON & ON & $\mathrm{ON}$ & ON & $\mathrm{ON}$ \\
\hline & ON & ON & ON & ON & ON & ON & $\mathrm{ON}$ & ON & $\mathrm{ON}$ \\
\hline & ON & ON & ON & ON & ON & ON & ON & ON & $\mathrm{ON}$ \\
\hline & ON & ON & $\mathrm{ON}$ & ON & $\mathrm{ON}$ & ON & $\mathrm{ON}$ & ON & $\mathrm{ON}$ \\
\hline & $\mathrm{ON}$ & ON & $\mathrm{ON}$ & ON & ON & ON & $\mathrm{ON}$ & ON & $\mathrm{ON}$ \\
\hline & ON & ON & ON & ON & ON & ON & $\mathrm{ON}$ & ON & $\mathrm{ON}$ \\
\hline & ON & ON & ON & ON & $\mathrm{ON}$ & $\mathrm{ON}$ & $\mathrm{ON}$ & ON & $\mathrm{ON}$ \\
\hline & $\mathrm{ON}$ & ON & $\mathrm{ON}$ & $\mathrm{ON}$ & $\mathrm{ON}$ & ON & $\mathrm{ON}$ & ON & $\mathrm{ON}$ \\
\hline & $\mathrm{ON}$ & ON & ON & ON & $\mathrm{ON}$ & ON & $\mathrm{ON}$ & ON & $\mathrm{ON}$ \\
\hline & $\mathrm{ON}$ & ON & $\mathrm{ON}$ & $\mathrm{ON}$ & ON & ON & $\mathrm{ON}$ & ON & $\mathrm{ON}$ \\
\hline & ON & ON & ON & ON & ON & ON & $\mathrm{ON}$ & ON & $\mathrm{ON}$ \\
\hline & ON & ON & ON & ON & $\mathrm{ON}$ & ON & $\mathrm{ON}$ & ON & $\mathrm{ON}$ \\
\hline & $\mathrm{ON}$ & ON & $\mathrm{ON}$ & ON & $\mathrm{ON}$ & ON & $\mathrm{ON}$ & ON & $\mathrm{ON}$ \\
\hline & $\mathrm{ON}$ & ON & ON & ON & ON & ON & ON & $\mathrm{ON}$ & $\mathrm{ON}$ \\
\hline & ON & ON & ON & ON & ON & ON & $\mathrm{ON}$ & ON & $\mathrm{ON}$ \\
\hline & ON & ON & ON & ON & $\mathrm{ON}$ & ON & $\mathrm{ON}$ & ON & $\mathrm{ON}$ \\
\hline & ON & ON & ON & $\mathrm{ON}$ & $\mathrm{ON}$ & ON & $\mathrm{ON}$ & ON & $\mathrm{ON}$ \\
\hline & ON & ON & ON & $\mathrm{ON}$ & $\mathrm{ON}$ & ON & ON & ON & $\mathrm{ON}$ \\
\hline & $\mathrm{ON}$ & ON & ON & $\mathrm{ON}$ & ON & ON & ON & ON & $\mathrm{ON}$ \\
\hline & ON & ON & ON & ON & $\mathrm{ON}$ & ON & $\mathrm{ON}$ & ON & $\mathrm{ON}$ \\
\hline & $\mathrm{ON}$ & ON & $\mathrm{ON}$ & $\mathrm{ON}$ & $\mathrm{ON}$ & $\mathrm{ON}$ & $\mathrm{ON}$ & ON & $\mathrm{ON}$ \\
\hline & $\mathrm{ON}$ & ON & ON & $\mathrm{ON}$ & $\mathrm{ON}$ & ON & $\mathrm{ON}$ & ON & $\mathrm{ON}$ \\
\hline & $\mathrm{ON}$ & ON & ON & ON & $\mathrm{ON}$ & ON & $\mathrm{ON}$ & ON & $\mathrm{ON}$ \\
\hline & ON & ON & ON & ON & ON & ON & ON & ON & $\mathrm{ON}$ \\
\hline & $\mathrm{ON}$ & ON & ON & $\mathrm{ON}$ & $\mathrm{ON}$ & ON & ON & $\mathrm{ON}$ & $\mathrm{ON}$ \\
\hline & $\mathrm{ON}$ & ON & $\mathrm{ON}$ & $\mathrm{ON}$ & $\mathrm{ON}$ & $\mathrm{ON}$ & $\mathrm{ON}$ & ON & $\mathrm{ON}$ \\
\hline & $\mathrm{ON}$ & ON & $\mathrm{ON}$ & $\mathrm{ON}$ & $\mathrm{ON}$ & ON & $\mathrm{ON}$ & ON & $\mathrm{ON}$ \\
\hline & ON & ON & ON & ON & ON & ON & ON & ON & $\mathrm{ON}$ \\
\hline & ON & ON & ON & ON & ON & ON & ON & ON & $\mathrm{ON}$ \\
\hline & $\mathrm{ON}$ & ON & $\mathrm{ON}$ & $\mathrm{ON}$ & $\mathrm{ON}$ & ON & ON & $\mathrm{ON}$ & $\mathrm{ON}$ \\
\hline & ON & ON & & & & & & & \\
\hline RDOM-N & $\mathrm{ON}$ & ON & $\mathrm{ON}$ & $\mathrm{ON}$ & $\mathrm{ON}$ & $\mathrm{ON}$ & $\mathrm{ON}$ & ON & $\mathrm{ON}$ \\
\hline & ON & ON & $\mathrm{ON}$ & $\mathrm{ON}$ & ON & ON & $\mathrm{ON}$ & ON & $\mathrm{ON}$ \\
\hline & ON & ON & ON & ON & ON & ON & ON & ON & $\mathrm{ON}$ \\
\hline & $\mathrm{ON}$ & ON & ON & $\mathrm{ON}$ & $\mathrm{ON}$ & ON & $\mathrm{ON}$ & ON & $\mathrm{ON}$ \\
\hline & $\mathrm{ON}$ & ON & ON & $\mathrm{ON}$ & ON & $\mathrm{ON}$ & $\mathrm{ON}$ & ON & ON \\
\hline
\end{tabular}




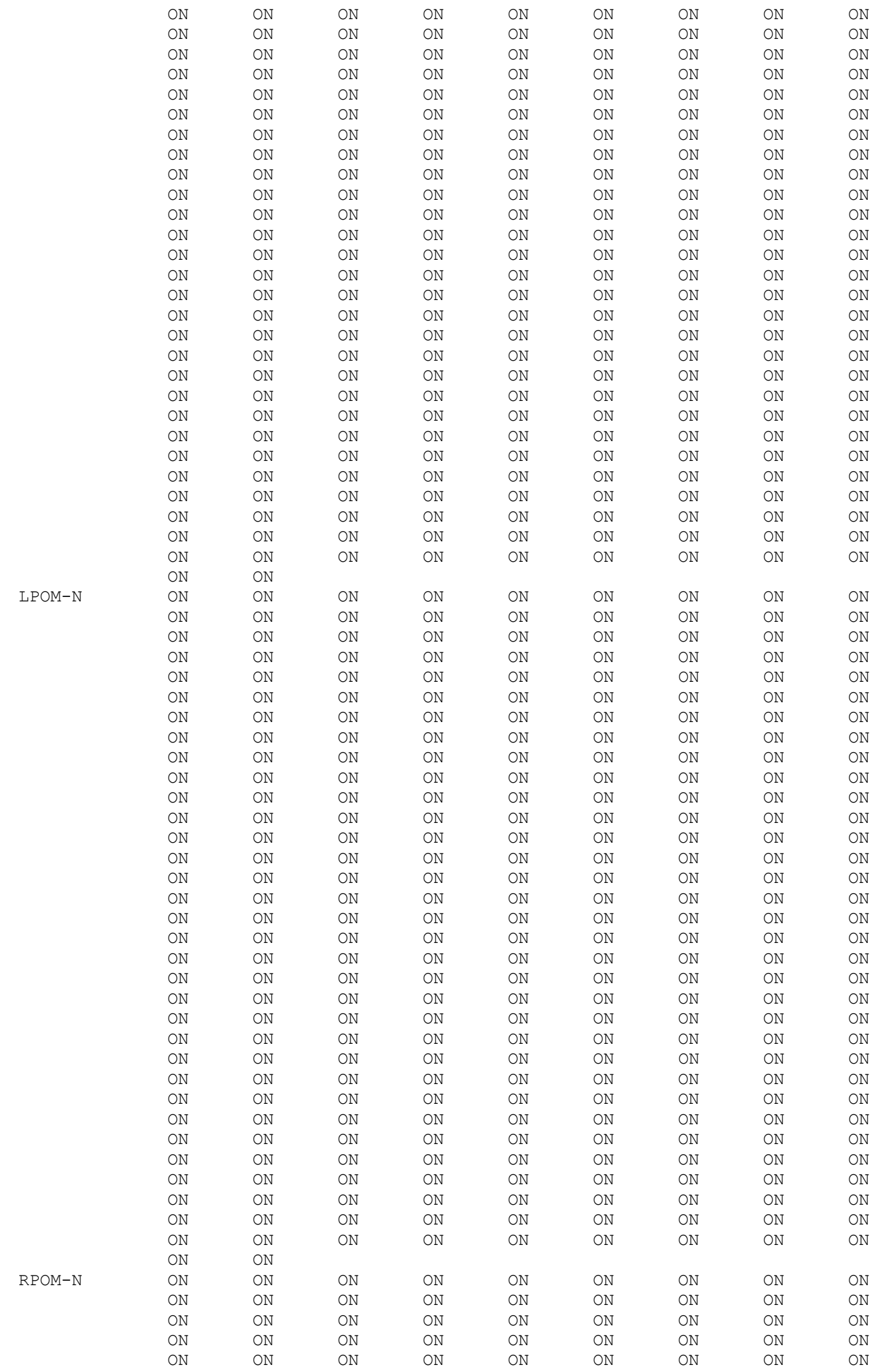




\begin{tabular}{|c|c|c|c|c|c|c|c|c|c|}
\hline & ON & ON & ON & ON & ON & ON & ON & ON & ON \\
\hline & ON & ON & ON & ON & ON & ON & ON & ON & ON \\
\hline & ON & ON & ON & ON & ON & ON & ON & ON & ON \\
\hline & ON & ON & ON & ON & $\mathrm{ON}$ & ON & ON & ON & ON \\
\hline & ON & ON & ON & ON & ON & ON & ON & ON & ON \\
\hline & ON & ON & ON & ON & $\mathrm{ON}$ & ON & ON & ON & ON \\
\hline & ON & ON & ON & ON & ON & ON & ON & ON & ON \\
\hline & ON & ON & ON & ON & ON & ON & ON & ON & ON \\
\hline & ON & ON & ON & ON & ON & ON & ON & ON & ON \\
\hline & ON & ON & ON & ON & ON & ON & ON & ON & ON \\
\hline & ON & ON & ON & ON & ON & ON & ON & ON & ON \\
\hline & ON & ON & ON & ON & ON & ON & ON & ON & ON \\
\hline & ON & ON & ON & ON & ON & ON & ON & ON & ON \\
\hline & ON & ON & ON & ON & ON & ON & ON & ON & ON \\
\hline & ON & ON & ON & ON & ON & ON & ON & ON & ON \\
\hline & ON & ON & ON & ON & ON & ON & ON & ON & ON \\
\hline & ON & ON & ON & ON & ON & ON & ON & ON & ON \\
\hline & ON & ON & ON & ON & $\mathrm{ON}$ & ON & ON & ON & ON \\
\hline & ON & ON & ON & ON & ON & ON & $\mathrm{ON}$ & ON & ON \\
\hline & ON & ON & ON & ON & ON & ON & ON & ON & ON \\
\hline & ON & ON & ON & ON & ON & ON & ON & ON & ON \\
\hline & ON & ON & ON & ON & ON & ON & ON & ON & ON \\
\hline & ON & ON & ON & ON & ON & ON & ON & ON & $\mathrm{ON}$ \\
\hline & ON & ON & ON & ON & $\mathrm{ON}$ & ON & ON & ON & ON \\
\hline & $\mathrm{ON}$ & ON & $\mathrm{ON}$ & $\mathrm{ON}$ & ON & ON & $\mathrm{ON}$ & ON & $\mathrm{ON}$ \\
\hline & ON & ON & $\mathrm{ON}$ & ON & $\mathrm{ON}$ & ON & ON & ON & ON \\
\hline & $\mathrm{ON}$ & ON & ON & ON & $\mathrm{ON}$ & ON & $\mathrm{ON}$ & ON & ON \\
\hline & ON & ON & $\mathrm{ON}$ & $\mathrm{ON}$ & ON & ON & ON & ON & ON \\
\hline & ON & ON & & & & & & & \\
\hline $\mathrm{CDT} \mathrm{CON}$ & CDTBRC & CDTBRC & CDTBRC & CDTBRC & CDTBRC & CDTBRC & CDTBRC & CDTBRC & CDTBRC \\
\hline TDS & $\begin{array}{l}\text { ON } \\
\text { ON }\end{array}$ & $\mathrm{ON}$ & $\mathrm{ON}$ & $\mathrm{ON}$ & $\mathrm{ON}$ & $\mathrm{ON}$ & $\mathrm{ON}$ & $\mathrm{ON}$ & $\mathrm{ON}$ \\
\hline Gen1 & $\begin{array}{l}\text { ON } \\
\text { ON }\end{array}$ & ON & ON & ON & $\mathrm{ON}$ & ON & $\mathrm{ON}$ & ON & ON \\
\hline Gen2 & $\begin{array}{l}\text { ON } \\
\text { ON }\end{array}$ & ON & $\mathrm{ON}$ & ON & $\mathrm{ON}$ & ON & $\mathrm{ON}$ & ON & ON \\
\hline Gen3 & $\begin{array}{l}\text { ON } \\
\text { ON }\end{array}$ & ON & $\mathrm{ON}$ & ON & $\mathrm{ON}$ & ON & $\mathrm{ON}$ & ON & ON \\
\hline Gen 4 & $\begin{array}{l}\text { OFF } \\
\text { OFF }\end{array}$ & $\mathrm{OFF}$ & $\mathrm{OFF}$ & $\mathrm{OFF}$ & $\mathrm{OFF}$ & $\mathrm{OFF}$ & $\mathrm{OFF}$ & $\mathrm{OFF}$ & $\mathrm{OFE}$ \\
\hline Gen 5 & $\begin{array}{l}\text { OFF } \\
\text { OFF }\end{array}$ & OFF & $\mathrm{OFF}$ & $\mathrm{OFF}$ & OFF & $\mathrm{OFF}$ & $\mathrm{OFF}$ & OFF & OFF \\
\hline Gen 6 & $\begin{array}{l}\mathrm{OFF} \\
\mathrm{OFF}\end{array}$ & OFF & $\mathrm{OFF}$ & $\mathrm{OFF}$ & OFF & $\mathrm{OFF}$ & $\mathrm{OFF}$ & $\mathrm{OFF}$ & OFF \\
\hline Gen 7 & $\begin{array}{l}\mathrm{OFF} \\
\mathrm{OFF}\end{array}$ & $\mathrm{OFF}$ & $\mathrm{OFF}$ & OFF & $\mathrm{OFF}$ & $\mathrm{OFF}$ & $\mathrm{OFF}$ & $\mathrm{OFF}$ & OFF \\
\hline Gen 8 & $\begin{array}{l}\mathrm{OFF} \\
\mathrm{OFF}\end{array}$ & $\mathrm{OFF}$ & $\mathrm{OFF}$ & $\mathrm{OFF}$ & $\mathrm{OFF}$ & $\mathrm{OFF}$ & $\mathrm{OFF}$ & $\mathrm{OFF}$ & $\mathrm{OFF}$ \\
\hline Gen 9 & $\begin{array}{l}\text { OFF } \\
\text { OFF }\end{array}$ & $\mathrm{OFF}$ & $\mathrm{OFF}$ & $\mathrm{OFF}$ & $\mathrm{OFF}$ & $\mathrm{OFF}$ & $\mathrm{OFF}$ & $\mathrm{OFF}$ & OFF \\
\hline Gen10 & $\begin{array}{l}\mathrm{OFF} \\
\mathrm{OFF}\end{array}$ & $\mathrm{OFF}$ & $\mathrm{OFF}$ & $\mathrm{OFF}$ & $\mathrm{OFF}$ & $\mathrm{OFF}$ & $\mathrm{OFF}$ & $\mathrm{OFF}$ & $\mathrm{OFE}$ \\
\hline Gen11 & $\begin{array}{l}\text { OFF } \\
\text { OFF }\end{array}$ & $\mathrm{OFF}$ & $\mathrm{OFF}$ & $\mathrm{OFF}$ & $\mathrm{OFF}$ & $\mathrm{OFF}$ & $\mathrm{OFF}$ & $\mathrm{OFF}$ & $\mathrm{OFE}$ \\
\hline ISS 1 & $\begin{array}{l}\text { OFF } \\
\text { OFF }\end{array}$ & OFF & $\mathrm{OFF}$ & OFF & OFF & $\mathrm{OFF}$ & $\mathrm{OFF}$ & $\mathrm{OFF}$ & OFF \\
\hline ISS2 & $\begin{array}{l}\mathrm{ON} \\
\mathrm{ON}\end{array}$ & ON & $\mathrm{ON}$ & $\mathrm{ON}$ & ON & ON & $\mathrm{ON}$ & ON & ON \\
\hline $\mathrm{PO} 4$ & $\begin{array}{l}\text { ON } \\
\text { ON }\end{array}$ & ON & ON & ON & ON & ON & $\mathrm{ON}$ & ON & ON \\
\hline $\mathrm{NH} 4$ & $\begin{array}{l}\text { ON } \\
\text { ON }\end{array}$ & ON & ON & ON & $\mathrm{ON}$ & ON & $\mathrm{ON}$ & ON & ON \\
\hline NO3 & $\begin{array}{l}\text { ON } \\
\text { ON }\end{array}$ & ON & ON & ON & $\mathrm{ON}$ & ON & $\mathrm{ON}$ & ON & $\mathrm{ON}$ \\
\hline DS I & $\begin{array}{l}\mathrm{OFF} \\
\mathrm{OFF}\end{array}$ & $\mathrm{OFF}$ & OFF & $\mathrm{OFF}$ & $\mathrm{OFF}$ & $\mathrm{OFF}$ & $\mathrm{OFF}$ & $\mathrm{OFF}$ & $\mathrm{OFF}$ \\
\hline PSI & OFF & $\mathrm{OFF}$ & OFF & $\mathrm{OFF}$ & OFF & $\mathrm{OFF}$ & OFF & OFF & OFF \\
\hline
\end{tabular}

333 


\begin{tabular}{|c|c|c|c|c|c|c|c|c|c|}
\hline \multirow{2}{*}{$\mathrm{FE}$} & \multicolumn{9}{|l|}{$\mathrm{OFF}$} \\
\hline & $\mathrm{OFF}$ & $\mathrm{OFF}$ & $\mathrm{OFF}$ & $\mathrm{OFF}$ & $\mathrm{OFF}$ & $\mathrm{OFF}$ & $\mathrm{OFF}$ & $\mathrm{OFF}$ & $\mathrm{OFF}$ \\
\hline & \multicolumn{9}{|l|}{$\mathrm{OFF}$} \\
\hline LDOM & $\begin{array}{l}\text { ON } \\
\text { ON }\end{array}$ & ON & $\mathrm{ON}$ & $\mathrm{ON}$ & ON & ON & ON & ON & $\mathrm{ON}$ \\
\hline \multirow[t]{2}{*}{$\mathrm{RDOM}$} & ON & ON & ON & ON & ON & ON & ON & ON & $\mathrm{ON}$ \\
\hline & ON & & & & & & & & \\
\hline \multirow[t]{2}{*}{ LPOM } & ON & ON & $\mathrm{ON}$ & ON & $\mathrm{ON}$ & ON & $\mathrm{ON}$ & ON & $\mathrm{ON}$ \\
\hline & ON & & & & & & & & \\
\hline \multirow[t]{2}{*}{$\mathrm{RPOM}$} & ON & $\mathrm{ON}$ & ON & ON & ON & ON & ON & ON & ON \\
\hline & ON & & & & & & & & \\
\hline \multirow[t]{2}{*}{ BOD1 } & ON & ON & $\mathrm{ON}$ & ON & ON & ON & $\mathrm{ON}$ & ON & $\mathrm{ON}$ \\
\hline & ON & & & & & & & & \\
\hline \multirow[t]{2}{*}{ BOD2 } & ON & ON & $\mathrm{ON}$ & ON & ON & ON & $\mathrm{ON}$ & $\mathrm{ON}$ & ON \\
\hline & ON & & & & & & & & \\
\hline \multirow[t]{2}{*}{ BOD3 } & ON & ON & ON & ON & ON & ON & ON & ON & ON \\
\hline & ON & & & & & & & & \\
\hline \multirow[t]{2}{*}{ BOD 4} & ON & $\mathrm{ON}$ & ON & ON & ON & ON & ON & ON & $\mathrm{ON}$ \\
\hline & ON & & & & & & & & \\
\hline BOD5 & ON & ON & ON & ON & ON & $\mathrm{ON}$ & ON & ON & $\mathrm{ON}$ \\
\hline & ON & & & & & & & & \\
\hline BOD 6 & ON & ON & ON & ON & ON & ON & $\mathrm{ON}$ & ON & $\mathrm{ON}$ \\
\hline & ON & & & & & & & & \\
\hline BOD 7 & ON & ON & ON & ON & ON & ON & ON & ON & $\mathrm{ON}$ \\
\hline & ON & & & & & & & & \\
\hline BOD8 & ON & ON & ON & ON & $\mathrm{ON}$ & ON & ON & $\mathrm{ON}$ & ON \\
\hline & ON & & & & & & & & \\
\hline BOD 9 & ON & ON & ON & ON & $\mathrm{ON}$ & ON & $\mathrm{ON}$ & ON & $\mathrm{ON}$ \\
\hline & ON & & & & & & & & \\
\hline BOD10 & ON & ON & ON & ON & ON & ON & ON & ON & ON \\
\hline & ON & & & & & & & & \\
\hline BODP1 & ON & ON & $\mathrm{ON}$ & ON & ON & ON & ON & ON & ON \\
\hline & ON & & & & & & & & \\
\hline BODP2 & ON & ON & ON & ON & ON & ON & ON & ON & ON \\
\hline & ON & & & & & & & & \\
\hline BODP3 & ON & $\mathrm{ON}$ & ON & ON & $\mathrm{ON}$ & ON & $\mathrm{ON}$ & ON & $\mathrm{ON}$ \\
\hline & ON & & & & & & & & \\
\hline BODP 4 & ON & ON & ON & ON & ON & ON & ON & ON & $\mathrm{ON}$ \\
\hline & ON & & & & & & & & \\
\hline BODP5 & ON & ON & ON & ON & ON & ON & ON & ON & $\mathrm{ON}$ \\
\hline & ON & & & & & & & & \\
\hline BODP 6 & ON & ON & ON & ON & ON & ON & ON & ON & ON \\
\hline & ON & & & & & & & & \\
\hline BODP7 & ON & ON & ON & ON & ON & ON & ON & ON & ON \\
\hline & ON & & & & & & & & \\
\hline BODP8 & ON & ON & $\mathrm{ON}$ & ON & $\mathrm{ON}$ & ON & ON & ON & $\mathrm{ON}$ \\
\hline & ON & & & & & & & & \\
\hline BODP9 & ON & ON & ON & ON & ON & ON & ON & ON & $\mathrm{ON}$ \\
\hline & ON & & & & & & & & \\
\hline BODP10 & ON & ON & ON & ON & ON & ON & ON & ON & $\mathrm{ON}$ \\
\hline & ON & & & & & & & & \\
\hline BODN1 & ON & ON & ON & ON & ON & ON & ON & ON & $\mathrm{ON}$ \\
\hline & ON & & & & & & & & \\
\hline BODN2 & ON & ON & $\mathrm{ON}$ & ON & $\mathrm{ON}$ & ON & $\mathrm{ON}$ & ON & ON \\
\hline & ON & & & & & & & & \\
\hline BODN3 & ON & ON & ON & ON & ON & ON & ON & ON & $\mathrm{ON}$ \\
\hline & ON & & & & & & & & \\
\hline BODN4 & ON & $\mathrm{ON}$ & ON & ON & $\mathrm{ON}$ & ON & $\mathrm{ON}$ & ON & ON \\
\hline & ON & & & & & & & & \\
\hline BODN5 & ON & ON & ON & ON & ON & ON & $\mathrm{ON}$ & ON & ON \\
\hline & ON & & & & & & & & \\
\hline BODN6 & ON & ON & ON & ON & ON & ON & ON & ON & $\mathrm{ON}$ \\
\hline & ON & & & & & & & & \\
\hline BODN7 & ON & $\mathrm{ON}$ & ON & ON & $\mathrm{ON}$ & ON & ON & $\mathrm{ON}$ & ON \\
\hline & ON & & & & & & & & \\
\hline BODN8 & ON & ON & ON & ON & $\mathrm{ON}$ & $\mathrm{ON}$ & $\mathrm{ON}$ & ON & $\mathrm{ON}$ \\
\hline & ON & & & & & & & & \\
\hline DN9 & ON & ON & ON & ON & ON & ON & ON & ON & ON \\
\hline
\end{tabular}




\begin{tabular}{|c|c|c|c|c|c|c|c|c|c|}
\hline & $\mathrm{ON}$ & & & & & & & & \\
\hline BODN1 0 & $\begin{array}{l}\text { ON } \\
\text { ON }\end{array}$ & $\mathrm{ON}$ & $\mathrm{ON}$ & ON & $\mathrm{ON}$ & $\mathrm{ON}$ & $\mathrm{ON}$ & $\mathrm{ON}$ & $\mathrm{ON}$ \\
\hline ALG1 & $\begin{array}{l}\text { ON } \\
\text { ON }\end{array}$ & $\mathrm{ON}$ & ON & $\mathrm{ON}$ & $\mathrm{ON}$ & ON & ON & ON & $\mathrm{ON}$ \\
\hline ALG2 & $\begin{array}{l}\mathrm{OFF} \\
\mathrm{OFF}\end{array}$ & $\mathrm{OFF}$ & $\mathrm{OFF}$ & OFF & $\mathrm{OFF}$ & $\mathrm{OFF}$ & $\mathrm{OFF}$ & $\mathrm{OFF}$ & $\mathrm{OFF}$ \\
\hline DO & $\begin{array}{l}\text { ON } \\
\text { ON }\end{array}$ & $\mathrm{ON}$ & ON & $\mathrm{ON}$ & $\mathrm{ON}$ & ON & $\mathrm{ON}$ & ON & $\mathrm{ON}$ \\
\hline TIC & $\begin{array}{l}\mathrm{ON} \\
\mathrm{ON}\end{array}$ & $\mathrm{ON}$ & ON & $\mathrm{ON}$ & $\mathrm{ON}$ & ON & ON & ON & ON \\
\hline ALK & $\begin{array}{l}\mathrm{ON} \\
\mathrm{ON}\end{array}$ & $\mathrm{ON}$ & ON & $\mathrm{ON}$ & ON & ON & ON & ON & ON \\
\hline $\mathrm{Z} 001$ & $\begin{array}{l}\text { ON } \\
\text { ON }\end{array}$ & ON & $\mathrm{ON}$ & $\mathrm{ON}$ & ON & ON & ON & $\mathrm{ON}$ & $\mathrm{ON}$ \\
\hline LDOM-P & $\begin{array}{l}\mathrm{ON} \\
\mathrm{ON}\end{array}$ & $\mathrm{ON}$ & $\mathrm{ON}$ & ON & $\mathrm{ON}$ & ON & $\mathrm{ON}$ & ON & ON \\
\hline $\mathrm{RDOM}-\mathrm{P}$ & $\begin{array}{l}\text { ON } \\
\text { ON }\end{array}$ & $\mathrm{ON}$ & ON & $\mathrm{ON}$ & ON & ON & ON & ON & $\mathrm{ON}$ \\
\hline LPOM-P & $\begin{array}{l}\mathrm{ON} \\
\mathrm{ON}\end{array}$ & $\mathrm{ON}$ & $\mathrm{ON}$ & $\mathrm{ON}$ & ON & ON & ON & ON & ON \\
\hline $\mathrm{RPOM}-\mathrm{P}$ & $\begin{array}{l}\text { ON } \\
\text { ON }\end{array}$ & $\mathrm{ON}$ & ON & $\mathrm{ON}$ & ON & ON & $\mathrm{ON}$ & ON & ON \\
\hline LDOM-N & $\begin{array}{l}\mathrm{ON} \\
\mathrm{ON}\end{array}$ & $\mathrm{ON}$ & ON & $\mathrm{ON}$ & $\mathrm{ON}$ & ON & ON & ON & ON \\
\hline $\mathrm{RDOM}-\mathrm{N}$ & $\begin{array}{l}\text { ON } \\
\text { ON }\end{array}$ & $\mathrm{ON}$ & ON & $\mathrm{ON}$ & ON & ON & ON & $\mathrm{ON}$ & ON \\
\hline LPOM-N & $\begin{array}{l}\mathrm{ON} \\
\mathrm{ON}\end{array}$ & $\mathrm{ON}$ & ON & $\mathrm{ON}$ & $\mathrm{ON}$ & ON & ON & ON & $\mathrm{ON}$ \\
\hline $\mathrm{RPOM}-\mathrm{N}$ & $\begin{array}{l}\mathrm{ON} \\
\mathrm{ON}\end{array}$ & ON & $\mathrm{ON}$ & $\mathrm{ON}$ & $\mathrm{ON}$ & $\mathrm{ON}$ & $\mathrm{ON}$ & $\mathrm{ON}$ & ON \\
\hline CPR CON & CPRBRC & CPRBRC & CPRBRC & CPRBRC & CPRBRC & CPRBRC & CPRBRC & CPRBRC & CPRBRC \\
\hline TDS & $\begin{array}{l}O F F \\
O F F\end{array}$ & $\mathrm{OFF}$ & $\mathrm{OFF}$ & $\mathrm{OFF}$ & $\mathrm{OFF}$ & OFF & $\mathrm{OFF}$ & $\mathrm{OFF}$ & OFF \\
\hline Gen1 & $\begin{array}{l}\text { OFF } \\
\text { OFF }\end{array}$ & $\mathrm{OFF}$ & $\mathrm{OFF}$ & $\mathrm{OFF}$ & $\mathrm{OFF}$ & $\mathrm{OFF}$ & $\mathrm{OFF}$ & $\mathrm{OFF}$ & $\mathrm{OFF}$ \\
\hline Gen2 & $\begin{array}{l}\mathrm{OFF} \\
\mathrm{OFF}\end{array}$ & $\mathrm{OFF}$ & $\mathrm{OFF}$ & $\mathrm{OFF}$ & $\mathrm{OFF}$ & $\mathrm{OFF}$ & $\mathrm{OFF}$ & OFF & $\mathrm{OFF}$ \\
\hline Gen3 & $\begin{array}{l}\mathrm{OFF} \\
\mathrm{OFF}\end{array}$ & OFF & $\mathrm{OFF}$ & $\mathrm{OFF}$ & $\mathrm{OFF}$ & $\mathrm{OFF}$ & $\mathrm{OFF}$ & $\mathrm{OFF}$ & $\mathrm{OFF}$ \\
\hline Gen 4 & $\begin{array}{l}\text { OFF } \\
\text { OFF }\end{array}$ & $\mathrm{OFF}$ & $\mathrm{OFF}$ & $\mathrm{OFF}$ & $\mathrm{OFF}$ & $\mathrm{OFF}$ & $\mathrm{OFF}$ & $\mathrm{OFF}$ & $\mathrm{OFF}$ \\
\hline Gen5 & $\begin{array}{l}\mathrm{OFF} \\
\mathrm{OFF}\end{array}$ & $\mathrm{OFF}$ & $\mathrm{OFF}$ & $\mathrm{OFF}$ & $\mathrm{OFF}$ & $\mathrm{OFF}$ & $\mathrm{OFF}$ & $\mathrm{OFF}$ & $\mathrm{OFF}$ \\
\hline Gen 6 & $\begin{array}{l}\mathrm{OFF} \\
\mathrm{OFF}\end{array}$ & $\mathrm{OFF}$ & $\mathrm{OFF}$ & $\mathrm{OFF}$ & $\mathrm{OFF}$ & $\mathrm{OFF}$ & $\mathrm{OFF}$ & $\mathrm{OFF}$ & $\mathrm{OFF}$ \\
\hline Gen7 & $\begin{array}{l}\text { OFF } \\
\text { OFF }\end{array}$ & $\mathrm{OFF}$ & OFF & OFF & OFF & OFF & $\mathrm{OFF}$ & OFF & $\mathrm{OFF}$ \\
\hline Gen 8 & $\begin{array}{l}\text { OFF } \\
\text { OFF }\end{array}$ & $\mathrm{OFF}$ & $\mathrm{OFF}$ & $\mathrm{OFF}$ & $\mathrm{OFF}$ & $\mathrm{OFF}$ & $\mathrm{OFF}$ & $\mathrm{OFF}$ & $\mathrm{OFF}$ \\
\hline Gen 9 & $\begin{array}{l}\text { OFF } \\
\text { OFF }\end{array}$ & $\mathrm{OFF}$ & $\mathrm{OFF}$ & $\mathrm{OFF}$ & $\mathrm{OFF}$ & $\mathrm{OFF}$ & $\mathrm{OFF}$ & $\mathrm{OFF}$ & $\mathrm{OFF}$ \\
\hline Gen10 & $\begin{array}{l}\text { OFF } \\
\text { OFF }\end{array}$ & OFF & OFF & OFF & OFF & $\mathrm{OFF}$ & $\mathrm{OFF}$ & OFF & $\mathrm{OFF}$ \\
\hline Gen11 & $\begin{array}{l}O F F \\
O F F\end{array}$ & $\mathrm{OFF}$ & $\mathrm{OFF}$ & $\mathrm{OFF}$ & $\mathrm{OFF}$ & $\mathrm{OFF}$ & $\mathrm{OFF}$ & $\mathrm{OFF}$ & $\mathrm{OFF}$ \\
\hline ISS1 & $\begin{array}{l}\text { OFF } \\
\text { OFF }\end{array}$ & $\mathrm{OFF}$ & $\mathrm{OFF}$ & $\mathrm{OFF}$ & $\mathrm{OFF}$ & $\mathrm{OFF}$ & $\mathrm{OFF}$ & $\mathrm{OFF}$ & OFF \\
\hline ISS2 & $\begin{array}{l}\mathrm{OFF} \\
\mathrm{OFF}\end{array}$ & $\mathrm{OFF}$ & $\mathrm{OFF}$ & $\mathrm{OFF}$ & $\mathrm{OFF}$ & $\mathrm{OFF}$ & $\mathrm{OFF}$ & $\mathrm{OFF}$ & $\mathrm{OFF}$ \\
\hline $\mathrm{PO} 4$ & $\begin{array}{l}\mathrm{OFF} \\
\mathrm{OFF}\end{array}$ & OFF & OFF & OFF & $\mathrm{OFF}$ & $\mathrm{OFF}$ & $\mathrm{OFF}$ & $\mathrm{OFF}$ & $\mathrm{OFF}$ \\
\hline NH 4 & $\begin{array}{l}\text { OFF } \\
\text { OFF }\end{array}$ & $\mathrm{OFF}$ & $\mathrm{OFF}$ & $\mathrm{OFF}$ & $\mathrm{OFF}$ & $\mathrm{OFF}$ & $\mathrm{OFF}$ & $\mathrm{OFF}$ & $\mathrm{OFF}$ \\
\hline NO3 & $\begin{array}{l}\text { OFF } \\
\text { OFF }\end{array}$ & OFF & OFF & OFF & OFF & OFF & $\mathrm{OFF}$ & OFF & $\mathrm{OFF}$ \\
\hline DSI & OFF & OFF & $\mathrm{OFF}$ & OFF & OFF & OFF & $\mathrm{OFF}$ & $\mathrm{OFF}$ & $\mathrm{OFF}$ \\
\hline
\end{tabular}




\begin{tabular}{|c|c|c|c|c|c|c|c|c|c|}
\hline & $\mathrm{OFF}$ & & & & & & & & \\
\hline PSI & $\begin{array}{l}\text { OFF } \\
\text { OFF }\end{array}$ & $\mathrm{OFF}$ & $\mathrm{OFF}$ & $\mathrm{OFF}$ & $\mathrm{OFF}$ & $\mathrm{OFF}$ & $\mathrm{OFF}$ & $\mathrm{OFF}$ & $\mathrm{OFF}$ \\
\hline $\mathrm{FE}$ & $\begin{array}{l}\text { OFF } \\
\text { OFF }\end{array}$ & $\mathrm{OFF}$ & $\mathrm{OFF}$ & $\mathrm{OFF}$ & $\mathrm{OFF}$ & $\mathrm{OFF}$ & $\mathrm{OFF}$ & $\mathrm{OFF}$ & $\mathrm{OFF}$ \\
\hline LDOM & $\begin{array}{l}O F F \\
\text { OFF }\end{array}$ & $\mathrm{OFF}$ & $\mathrm{OFF}$ & $\mathrm{OFF}$ & $\mathrm{OFF}$ & $\mathrm{OFF}$ & $\mathrm{OFF}$ & $\mathrm{OFF}$ & $\mathrm{OFF}$ \\
\hline $\mathrm{RDOM}$ & $\begin{array}{l}O F F \\
\text { OFF }\end{array}$ & $\mathrm{OFF}$ & $\mathrm{OFF}$ & $\mathrm{OFF}$ & $\mathrm{OFF}$ & $\mathrm{OFF}$ & $\mathrm{OFF}$ & $\mathrm{OFF}$ & $\mathrm{OFF}$ \\
\hline LPOM & $\begin{array}{l}\text { OFF } \\
\text { OFF }\end{array}$ & OFF & $\mathrm{OFF}$ & $\mathrm{OFF}$ & $\mathrm{OFF}$ & $\mathrm{OFF}$ & $\mathrm{OFF}$ & $\mathrm{OFF}$ & $\mathrm{OFF}$ \\
\hline $\mathrm{RPOM}$ & $\begin{array}{l}\text { OFF } \\
\text { OFF }\end{array}$ & $\mathrm{OFF}$ & $\mathrm{OFF}$ & $\mathrm{OFF}$ & $\mathrm{OFF}$ & $\mathrm{OFF}$ & $\mathrm{OFF}$ & $\mathrm{OFF}$ & $\mathrm{OFF}$ \\
\hline BOD1 & $\begin{array}{l}\text { OFF } \\
\text { OFF }\end{array}$ & OFF & $\mathrm{OFF}$ & $\mathrm{OFF}$ & $\mathrm{OFF}$ & $\mathrm{OFF}$ & $\mathrm{OFF}$ & $\mathrm{OFF}$ & $\mathrm{OFF}$ \\
\hline BOD2 & $\begin{array}{l}\text { OFF } \\
\text { OFF }\end{array}$ & $\mathrm{OFF}$ & $\mathrm{OFF}$ & $\mathrm{OFF}$ & $\mathrm{OFF}$ & $\mathrm{OFF}$ & $\mathrm{OFF}$ & $\mathrm{OFF}$ & OFF \\
\hline BOD3 & $\begin{array}{l}\text { OFF } \\
\text { OFF }\end{array}$ & $\mathrm{OFF}$ & $\mathrm{OFF}$ & $\mathrm{OFF}$ & $\mathrm{OFF}$ & $\mathrm{OFF}$ & $\mathrm{OFF}$ & $\mathrm{OFF}$ & $\mathrm{OFF}$ \\
\hline BOD 4 & $\begin{array}{l}\text { OFF } \\
\text { OFF }\end{array}$ & $\mathrm{OFF}$ & $\mathrm{OFF}$ & $\mathrm{OFF}$ & $\mathrm{OFF}$ & $\mathrm{OFF}$ & $\mathrm{OFF}$ & $\mathrm{OFF}$ & $\mathrm{OFF}$ \\
\hline BOD5 & $\begin{array}{l}O F F \\
O F F\end{array}$ & $\mathrm{OFF}$ & $\mathrm{OFF}$ & $\mathrm{OFF}$ & $\mathrm{OFF}$ & $\mathrm{OFF}$ & $\mathrm{OFF}$ & $\mathrm{OFF}$ & $\mathrm{OFF}$ \\
\hline BOD 6 & $\begin{array}{l}\text { OFF } \\
\text { OFF }\end{array}$ & $\mathrm{OFF}$ & $\mathrm{OFF}$ & $\mathrm{OFF}$ & $\mathrm{OFF}$ & $\mathrm{OFF}$ & $\mathrm{OFF}$ & $\mathrm{OFF}$ & $\mathrm{OFF}$ \\
\hline BOD7 & $\begin{array}{l}\mathrm{OFF} \\
\mathrm{OFF}\end{array}$ & $\mathrm{OFF}$ & $\mathrm{OFF}$ & $\mathrm{OFF}$ & $\mathrm{OFF}$ & $\mathrm{OFF}$ & $\mathrm{OFF}$ & $\mathrm{OFF}$ & $\mathrm{OFF}$ \\
\hline BOD8 & $\begin{array}{l}\text { OFF } \\
\text { OFF }\end{array}$ & $\mathrm{OFF}$ & OFF & $\mathrm{OFF}$ & $\mathrm{OFF}$ & $\mathrm{OFF}$ & $\mathrm{OFF}$ & $\mathrm{OFF}$ & $\mathrm{OFF}$ \\
\hline BOD9 & $\begin{array}{l}\text { OFF } \\
\text { OFF }\end{array}$ & $\mathrm{OFF}$ & $\mathrm{OFF}$ & $\mathrm{OFF}$ & $\mathrm{OFF}$ & $\mathrm{OFF}$ & $\mathrm{OFF}$ & $\mathrm{OFF}$ & OFF \\
\hline BOD10 & $\begin{array}{l}O F F \\
O F F\end{array}$ & $\mathrm{OFF}$ & $\mathrm{OFF}$ & $\mathrm{OFF}$ & $\mathrm{OFF}$ & $\mathrm{OFF}$ & $\mathrm{OFF}$ & $\mathrm{OFF}$ & $\mathrm{OFF}$ \\
\hline BODP1 & $\begin{array}{l}\text { OFF } \\
\text { OFF }\end{array}$ & $\mathrm{OFF}$ & $\mathrm{OFF}$ & $\mathrm{OFF}$ & $\mathrm{OFF}$ & $\mathrm{OFF}$ & $\mathrm{OFF}$ & $\mathrm{OFF}$ & OFF \\
\hline BODP2 & $\begin{array}{l}\text { OFF } \\
\text { OFF }\end{array}$ & OFF & $\mathrm{OFF}$ & $\mathrm{OFF}$ & $\mathrm{OFF}$ & $\mathrm{OFF}$ & $\mathrm{OFF}$ & $\mathrm{OFF}$ & $\mathrm{OFF}$ \\
\hline BODP3 & $\begin{array}{l}\text { OFF } \\
\text { OFF }\end{array}$ & $\mathrm{OFF}$ & $\mathrm{OFF}$ & $\mathrm{OFF}$ & $\mathrm{OFF}$ & $\mathrm{OFF}$ & $\mathrm{OFF}$ & $\mathrm{OFF}$ & OFF \\
\hline BODP 4 & $\begin{array}{l}\text { OFF } \\
\text { OFF }\end{array}$ & OFF & $\mathrm{OFF}$ & $\mathrm{OFF}$ & $\mathrm{OFF}$ & OFF & $\mathrm{OFF}$ & $\mathrm{OFF}$ & OFF \\
\hline BODP5 & $\begin{array}{l}\text { OFF } \\
\text { OFF }\end{array}$ & $\mathrm{OFF}$ & $\mathrm{OFF}$ & $\mathrm{OFF}$ & $\mathrm{OFF}$ & $\mathrm{OFF}$ & $\mathrm{OFF}$ & $\mathrm{OFF}$ & $\mathrm{OFF}$ \\
\hline BODP 6 & $\begin{array}{l}\text { OFF } \\
\text { OFF }\end{array}$ & $\mathrm{OFF}$ & $\mathrm{OFF}$ & $\mathrm{OFF}$ & $\mathrm{OFF}$ & $\mathrm{OFF}$ & $\mathrm{OFF}$ & $\mathrm{OFF}$ & $\mathrm{OFF}$ \\
\hline BODP 7 & $\begin{array}{l}\text { OFF } \\
\text { OFF }\end{array}$ & $\mathrm{OFF}$ & $\mathrm{OFF}$ & $\mathrm{OFF}$ & $\mathrm{OFF}$ & $\mathrm{OFF}$ & $\mathrm{OFF}$ & $\mathrm{OFF}$ & $\mathrm{OFF}$ \\
\hline BODP 8 & $\begin{array}{l}\text { OFF } \\
\text { OFF }\end{array}$ & $\mathrm{OFF}$ & $\mathrm{OFF}$ & $\mathrm{OFF}$ & $\mathrm{OFF}$ & $\mathrm{OFF}$ & $\mathrm{OFF}$ & $\mathrm{OFF}$ & $\mathrm{OFF}$ \\
\hline BODP 9 & $\begin{array}{l}\text { OFF } \\
\text { OFF }\end{array}$ & OFF & $\mathrm{OFF}$ & $\mathrm{OFF}$ & OFF & $\mathrm{OFF}$ & $\mathrm{OFF}$ & $\mathrm{OFF}$ & OFF \\
\hline BODP10 & $\begin{array}{l}\text { OFF } \\
\text { OFF }\end{array}$ & $\mathrm{OFF}$ & $\mathrm{OFF}$ & $\mathrm{OFF}$ & $\mathrm{OFF}$ & $\mathrm{OFF}$ & $\mathrm{OFF}$ & $\mathrm{OFF}$ & $\mathrm{OFF}$ \\
\hline BODN1 & $\begin{array}{l}\text { OFF } \\
\text { OFF }\end{array}$ & $\mathrm{OFF}$ & $\mathrm{OFF}$ & $\mathrm{OFF}$ & $\mathrm{OFF}$ & $\mathrm{OFF}$ & $\mathrm{OFF}$ & $\mathrm{OFF}$ & OFF \\
\hline BODN2 & $\begin{array}{l}\text { OFF } \\
\text { OFF }\end{array}$ & OFF & $\mathrm{OFF}$ & $\mathrm{OFF}$ & $\mathrm{OFF}$ & $\mathrm{OFF}$ & $\mathrm{OFF}$ & $\mathrm{OFF}$ & $\mathrm{OFF}$ \\
\hline BODN3 & $\begin{array}{l}\text { OFF } \\
\text { OFF }\end{array}$ & $\mathrm{OFF}$ & $\mathrm{OFF}$ & $\mathrm{OFF}$ & $\mathrm{OFF}$ & $\mathrm{OFF}$ & $\mathrm{OFF}$ & $\mathrm{OFF}$ & OFF \\
\hline BODN4 & $\begin{array}{l}\mathrm{OFF} \\
\mathrm{OFF}\end{array}$ & $\mathrm{OFF}$ & $\mathrm{OFF}$ & $\mathrm{OFF}$ & $\mathrm{OFF}$ & $\mathrm{OFF}$ & $\mathrm{OFF}$ & $\mathrm{OFF}$ & $\mathrm{OFF}$ \\
\hline BODN5 & $\begin{array}{l}\text { OFF } \\
\text { OFF }\end{array}$ & $\mathrm{OFF}$ & $\mathrm{OFF}$ & $\mathrm{OFF}$ & $\mathrm{OFF}$ & $\mathrm{OFF}$ & $\mathrm{OFF}$ & $\mathrm{OFF}$ & OFF \\
\hline BODN6 & $\begin{array}{l}\text { OFF } \\
\text { OFF }\end{array}$ & $\mathrm{OFF}$ & $\mathrm{OFF}$ & $\mathrm{OFF}$ & $\mathrm{OFF}$ & $\mathrm{OFF}$ & $\mathrm{OFF}$ & $\mathrm{OFF}$ & OFF \\
\hline BODN7 & $\begin{array}{l}\text { OFF } \\
\text { OFF }\end{array}$ & $\mathrm{OFF}$ & $\mathrm{OFF}$ & $\mathrm{OFF}$ & $\mathrm{OFF}$ & $\mathrm{OFF}$ & $\mathrm{OFF}$ & $\mathrm{OFF}$ & $\mathrm{OFF}$ \\
\hline BODN8 & $\mathrm{OFF}$ & $\mathrm{OFF}$ & $\mathrm{OFF}$ & $\mathrm{OFF}$ & $\mathrm{OFF}$ & $\mathrm{OFF}$ & $\mathrm{OFF}$ & $\mathrm{OFF}$ & $\mathrm{OFF}$ \\
\hline
\end{tabular}




\begin{tabular}{|c|c|c|c|c|c|c|c|c|c|}
\hline & $\mathrm{OFF}$ & & & & & & & & \\
\hline BODN9 & $\begin{array}{l}\mathrm{OFF} \\
\mathrm{OFF}\end{array}$ & $\mathrm{OFF}$ & $\mathrm{OFF}$ & $\mathrm{OFF}$ & $\mathrm{OFF}$ & $\mathrm{OFF}$ & $\mathrm{OFF}$ & $\mathrm{OFF}$ & $\mathrm{OFF}$ \\
\hline BODN10 & $\begin{array}{l}\mathrm{OFF} \\
\mathrm{OFF}\end{array}$ & $\mathrm{OFF}$ & $\mathrm{OFF}$ & $\mathrm{OFF}$ & $\mathrm{OFF}$ & $\mathrm{OFF}$ & $\mathrm{OFF}$ & $\mathrm{OFF}$ & $\mathrm{OFF}$ \\
\hline ALG1 & $\begin{array}{l}O F F \\
O F F\end{array}$ & $\mathrm{OFF}$ & $\mathrm{OFF}$ & $\mathrm{OFF}$ & $\mathrm{OFF}$ & $\mathrm{OFF}$ & $\mathrm{OFF}$ & $\mathrm{OFF}$ & $\mathrm{OFF}$ \\
\hline ALG2 & $\begin{array}{l}\mathrm{OFF} \\
\mathrm{OFF}\end{array}$ & $\mathrm{OFF}$ & $\mathrm{OFF}$ & $\mathrm{OFF}$ & $\mathrm{OFF}$ & $\mathrm{OFF}$ & $\mathrm{OFF}$ & $\mathrm{OFF}$ & $\mathrm{OFF}$ \\
\hline DO & $\begin{array}{l}O F F \\
O F F\end{array}$ & $\mathrm{OFF}$ & $\mathrm{OFF}$ & $\mathrm{OFF}$ & $\mathrm{OFF}$ & $\mathrm{OFF}$ & $\mathrm{OFF}$ & $\mathrm{OFF}$ & $\mathrm{OFF}$ \\
\hline TIC & $\begin{array}{l}\mathrm{OFF} \\
\mathrm{OFF}\end{array}$ & $\mathrm{OFF}$ & $\mathrm{OFF}$ & $\mathrm{OFF}$ & $\mathrm{OFF}$ & $\mathrm{OFF}$ & $\mathrm{OFF}$ & $\mathrm{OFF}$ & $\mathrm{OFF}$ \\
\hline ALK & $\begin{array}{l}O F F \\
O F F\end{array}$ & $\mathrm{OFF}$ & $\mathrm{OFF}$ & $\mathrm{OFF}$ & $\mathrm{OFF}$ & $\mathrm{OFF}$ & $\mathrm{OFF}$ & $\mathrm{OFF}$ & $\mathrm{OFF}$ \\
\hline Z001 & $\begin{array}{l}\text { OFF } \\
\text { OFF }\end{array}$ & OFF & $\mathrm{OFF}$ & $\mathrm{OFF}$ & $\mathrm{OFF}$ & $\mathrm{OFF}$ & $\mathrm{OFF}$ & $\mathrm{OFF}$ & $\mathrm{OFF}$ \\
\hline LDOM-P & $\begin{array}{l}O F F \\
O F F\end{array}$ & $\mathrm{OFF}$ & $\mathrm{OFF}$ & $\mathrm{OFF}$ & $\mathrm{OFF}$ & $\mathrm{OFF}$ & $\mathrm{OFF}$ & $\mathrm{OFF}$ & $\mathrm{OFF}$ \\
\hline $\mathrm{RDOM}-\mathrm{P}$ & $\begin{array}{l}\text { OFF } \\
\text { OFF }\end{array}$ & $\mathrm{OFF}$ & $\mathrm{OFF}$ & $\mathrm{OFF}$ & $\mathrm{OFF}$ & $\mathrm{OFF}$ & $\mathrm{OFF}$ & $\mathrm{OFF}$ & $\mathrm{OFF}$ \\
\hline LPOM-P & $\begin{array}{l}O F F \\
O F F\end{array}$ & $\mathrm{OFF}$ & $\mathrm{OFF}$ & $\mathrm{OFF}$ & $\mathrm{OFF}$ & $\mathrm{OFF}$ & $\mathrm{OFF}$ & $\mathrm{OFF}$ & $\mathrm{OFF}$ \\
\hline $\mathrm{RPOM}-\mathrm{P}$ & $\begin{array}{l}\text { OFF } \\
\text { OFF }\end{array}$ & $\mathrm{OFF}$ & $\mathrm{OFF}$ & $\mathrm{OFF}$ & $\mathrm{OFF}$ & $\mathrm{OFF}$ & $\mathrm{OFF}$ & $\mathrm{OFF}$ & $\mathrm{OFF}$ \\
\hline LDOM-N & $\begin{array}{l}O F F \\
O F F\end{array}$ & $\mathrm{OFF}$ & $\mathrm{OFF}$ & $\mathrm{OFF}$ & $\mathrm{OFF}$ & $\mathrm{OFF}$ & $\mathrm{OFF}$ & $\mathrm{OFF}$ & $\mathrm{OFF}$ \\
\hline $\mathrm{RDOM}-\mathrm{N}$ & $\begin{array}{l}\mathrm{OFF} \\
\mathrm{OFF}\end{array}$ & $\mathrm{OFF}$ & $\mathrm{OFF}$ & $\mathrm{OFF}$ & $\mathrm{OFF}$ & $\mathrm{OFF}$ & $\mathrm{OFF}$ & $\mathrm{OFF}$ & $\mathrm{OFF}$ \\
\hline LPOM-N & $\begin{array}{l}O F F \\
O F F\end{array}$ & $\mathrm{OFF}$ & $\mathrm{OFF}$ & OFF & $\mathrm{OFF}$ & $\mathrm{OFF}$ & $\mathrm{OFF}$ & $\mathrm{OFF}$ & $\mathrm{OFF}$ \\
\hline $\mathrm{RPOM}-\mathrm{N}$ & $\begin{array}{l}\mathrm{OFF} \\
\mathrm{OFF}\end{array}$ & $\mathrm{OFF}$ & $\mathrm{OFF}$ & $\mathrm{OFF}$ & $\mathrm{OFF}$ & $\mathrm{OFF}$ & $\mathrm{OFF}$ & $\mathrm{OFF}$ & OFF \\
\hline $\mathrm{EX} \quad \mathrm{COEF}$ & EXH2O & EXSS & EXOM & BETA & EXC & EXIC & & & \\
\hline WB 1 & 0.25000 & 0.20000 & 0.20000 & 0.45000 & $\mathrm{OFF}$ & $\mathrm{OFF}$ & & & \\
\hline WB 2 & 0.25000 & 0.20000 & 0.20000 & 0.45000 & $\mathrm{OFF}$ & $\mathrm{OFF}$ & & & \\
\hline WB 3 & 0.25000 & 0.20000 & 0.20000 & 0.45000 & $\mathrm{OFF}$ & $\mathrm{OFF}$ & & & \\
\hline WB 4 & 0.25000 & 0.20000 & 0.20000 & 0.45000 & $\mathrm{OFF}$ & $\mathrm{OFF}$ & & & \\
\hline WB 5 & 0.25000 & 0.20000 & 0.20000 & 0.45000 & $\mathrm{OFF}$ & $\mathrm{OFF}$ & & & \\
\hline WB 6 & 0.25000 & 0.20000 & 0.20000 & 0.45000 & $\mathrm{OFF}$ & $\mathrm{OFF}$ & & & \\
\hline WB 7 & 0.25000 & 0.20000 & 0.20000 & 0.45000 & $\mathrm{OFF}$ & OFF & & & \\
\hline WB 8 & 0.25000 & 0.20000 & 0.20000 & 0.45000 & $\mathrm{OFF}$ & OFF & & & \\
\hline WB 9 & 0.25000 & 0.20000 & 0.20000 & 0.45000 & $\mathrm{OFF}$ & $\mathrm{OFF}$ & & & \\
\hline ALG EX & $\begin{array}{r}\text { EXA } \\
0.20000\end{array}$ & $\begin{array}{r}\text { EXA } \\
0.20000\end{array}$ & EXA & EXA & EXA & EXA & & & \\
\hline ZOO EX & $\begin{array}{r}\text { EXZ } \\
0.20000\end{array}$ & EXZ & EXZ & EXZ & EXZ & EXZ & & & \\
\hline MACRO EX & $\begin{array}{r}\text { EXM } \\
0.01000\end{array}$ & EXM & EXM & EXM & EXM & EXM & & & \\
\hline GENERIC & CGQ10 & CGODK & CGIDK & CGS & & & & & \\
\hline CG 1 & 0.00000 & 0.00000 & 0.00000 & 0.00000 & & & & & \\
\hline CG 2 & 0.00000 & -1.0000 & 0.00000 & 0.00000 & & & & & \\
\hline CG 3 & 0.00000 & 0.00000 & 0.00000 & 0.00000 & & & & & \\
\hline CG 4 & 0.00000 & 0.00000 & 0.00000 & 0.00000 & & & & & \\
\hline CG 5 & 0.00000 & 0.00000 & 0.00000 & 0.00000 & & & & & \\
\hline CG 6 & 0.00000 & 0.00000 & 0.00000 & 0.00000 & & & & & \\
\hline CG 7 & 0.00000 & 0.00000 & 0.00000 & 0.00000 & & & & & \\
\hline CG 8 & 0.00000 & 0.00000 & 0.00000 & 0.00000 & & & & & \\
\hline CG 9 & 0.00000 & 0.00000 & 0.00000 & 0.00000 & & & & & \\
\hline CG 10 & 0.00000 & 0.00000 & 0.00000 & 0.00000 & & & & & \\
\hline CG 11 & 0.00000 & 0.00000 & 0.00000 & 0.00000 & & & & & \\
\hline S SOLIDS & SSS & SEDRC & TAUCR & & & & & & \\
\hline
\end{tabular}




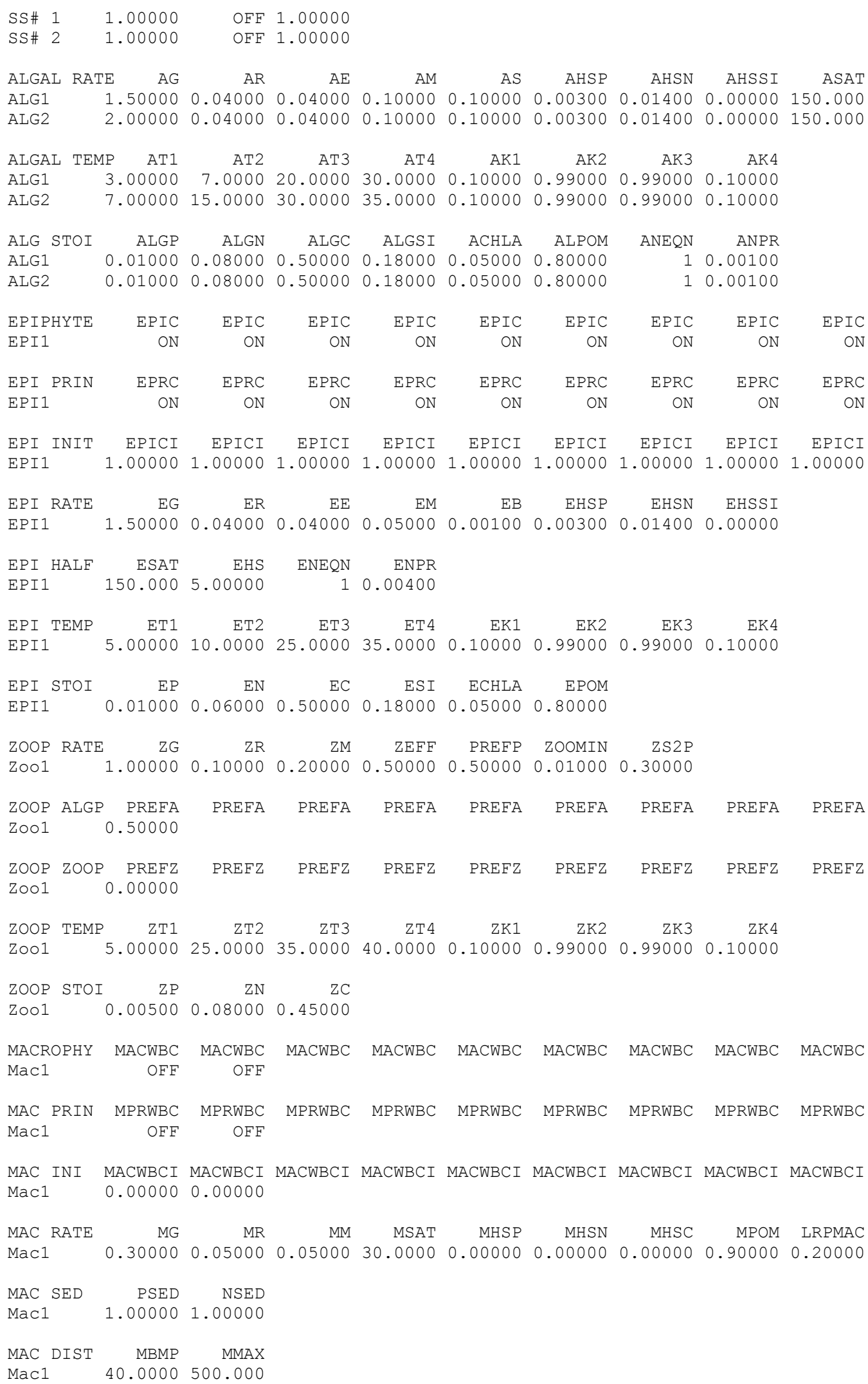




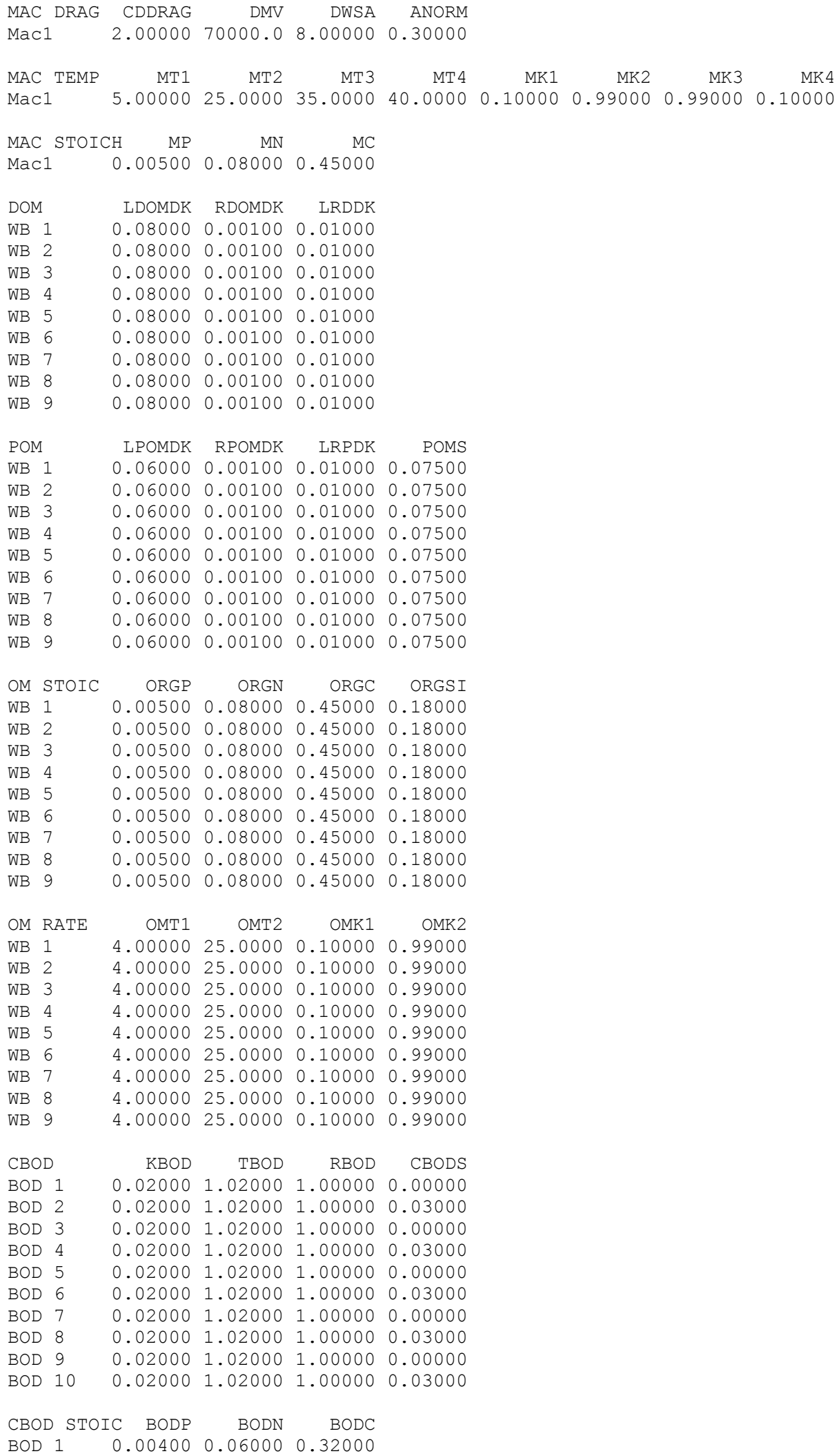




\begin{tabular}{|c|c|c|c|c|c|}
\hline$B O D$ & 2 & 0.00400 & 0.06000 & 0.32000 & \\
\hline$B O D$ & 3 & 0.00400 & 0.06000 & 0.32000 & \\
\hline BOD & 4 & 0.00400 & 0.06000 & 0.32000 & \\
\hline$B O D$ & 5 & 0.00400 & 0.06000 & 0.32000 & \\
\hline $\mathrm{BOD}$ & 6 & 0.00400 & 0.06000 & 0.32000 & \\
\hline BOD & 7 & 0.00400 & 0.06000 & 0.32000 & \\
\hline BOD & 8 & 0.00400 & 0.06000 & 0.32000 & \\
\hline$B O D$ & 9 & 0.00400 & 0.06000 & 0.32000 & \\
\hline $\mathrm{BOD}$ & 10 & 0.00400 & 0.06000 & 0.32000 & \\
\hline $\mathrm{PHO}$ & SPHOR & $\mathrm{PO} 4 \mathrm{R}$ & PARTP & & \\
\hline WB & 1 & 0.00100 & 0.00000 & & \\
\hline WB & 2 & 0.00100 & 0.00000 & & \\
\hline WB & 3 & 0.00100 & 0.00000 & & \\
\hline WB & 4 & 0.00100 & 0.00000 & & \\
\hline WB & 5 & 0.00100 & 0.00000 & & \\
\hline WB & 6 & 0.00100 & 0.00000 & & \\
\hline WB & 7 & 0.00100 & 0.00000 & & \\
\hline WB & 8 & 0.00100 & 0.00000 & & \\
\hline WB & 9 & 0.00100 & 0.00000 & & \\
\hline AMM & IONIUM & $\mathrm{NH} 4 \mathrm{R}$ & NH 4DK & & \\
\hline WB & 1 & 0.00100 & 0.80000 & & \\
\hline & 2 & 0.00100 & 0.80000 & & \\
\hline & 3 & 0.00100 & 0.80000 & & \\
\hline WB & 4 & 0.00100 & 0.80000 & & \\
\hline WB & 5 & 0.00100 & 0.80000 & & \\
\hline WB & 6 & 0.00100 & 0.80000 & & \\
\hline WB & 7 & 0.00100 & 0.80000 & & \\
\hline WB & 8 & 0.00100 & 0.80000 & & \\
\hline WB & 9 & 0.00100 & 0.80000 & & \\
\hline NH4 & RATE & NH4T1 & NH4T2 & NH4K1 & $\mathrm{NH} 4 \mathrm{~K} 2$ \\
\hline WB & 1 & 5.00000 & 25.0000 & 0.10000 & 0.99000 \\
\hline WB & 2 & 5.00000 & 25.0000 & 0.10000 & 0.99000 \\
\hline WB & 3 & 5.00000 & 25.0000 & 0.10000 & 0.99000 \\
\hline WB & 4 & 5.00000 & 25.0000 & 0.10000 & 0.99000 \\
\hline WB & 5 & 5.00000 & 25.0000 & 0.10000 & 0.99000 \\
\hline WB & 6 & 5.00000 & 25.0000 & 0.10000 & 0.99000 \\
\hline WB & 7 & 5.00000 & 25.0000 & 0.10000 & 0.99000 \\
\hline WB & 8 & 5.00000 & 25.0000 & 0.10000 & 0.99000 \\
\hline WB & 9 & 5.00000 & 25.0000 & 0.10000 & 0.99000 \\
\hline NIT & RATE & NO3DK & NO3S & FNO3SED & \\
\hline WB & 1 & 0.03000 & 0.00100 & 0.00000 & \\
\hline WB & 2 & 0.03000 & 0.00100 & 0.00000 & \\
\hline WB & 3 & 0.03000 & 0.00100 & 0.00000 & \\
\hline WB & 4 & 0.03000 & 0.00100 & 0.00000 & \\
\hline WB & 5 & 0.03000 & 0.00100 & 0.00000 & \\
\hline WB & 6 & 0.03000 & 0.00100 & 0.00000 & \\
\hline WB & 7 & 0.03000 & 0.00100 & 0.00000 & \\
\hline WB & 8 & 0.03000 & 0.00100 & 0.00000 & \\
\hline WB & 9 & 0.03000 & 0.00100 & 0.00000 & \\
\hline NO3 & B RATE & N03T1 & NO3T2 & NO3K1 & NO3K2 \\
\hline WB & 1 & 5.00000 & 25.0000 & 0.10000 & 0.99000 \\
\hline WB & 2 & 5.00000 & 25.0000 & 0.10000 & 0.99000 \\
\hline WB & 3 & 5.00000 & 25.0000 & 0.10000 & 0.99000 \\
\hline WB & 4 & 5.00000 & 25.0000 & 0.10000 & 0.99000 \\
\hline WB & 5 & 5.00000 & 25.0000 & 0.10000 & 0.99000 \\
\hline WB & 6 & 5.00000 & 25.0000 & 0.10000 & 0.99000 \\
\hline WB & 7 & 5.00000 & 25.0000 & 0.10000 & 0.99000 \\
\hline WB & 8 & 5.00000 & 25.0000 & 0.10000 & 0.99000 \\
\hline WB & 9 & 5.00000 & 25.0000 & 0.10000 & 0.99000 \\
\hline SIL & ICA & DSIR & PSIS & PSIDK & PARTSI \\
\hline WB & 1 & 0.10000 & 1.00000 & 0.30000 & 0.00000 \\
\hline WB & 2 & 0.10000 & 1.00000 & 0.30000 & 0.00000 \\
\hline
\end{tabular}




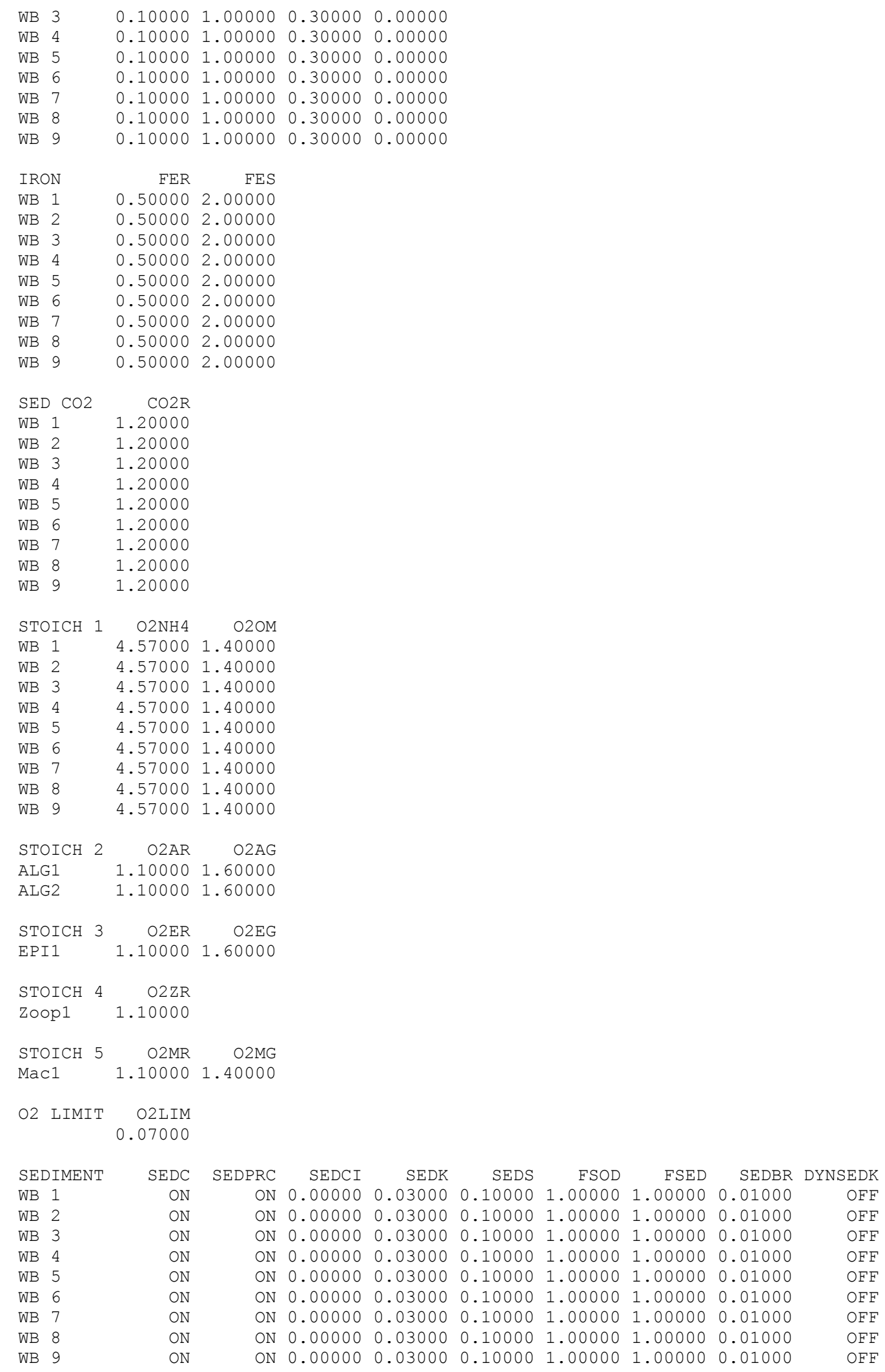




\begin{tabular}{|c|c|c|c|c|}
\hline SOD RATE & SODT1 & SODT2 & SODK1 & SODK2 \\
\hline WB 1 & 4.00000 & 25.0000 & 0.10000 & 0.99000 \\
\hline WB 2 & 4.00000 & 25.0000 & 0.10000 & 0.99000 \\
\hline 3 & 4.00000 & 25.0000 & 0.10000 & 900 \\
\hline WB & 4.00000 & 25.0000 & 0.10000 & 000 \\
\hline WB 5 & 4.00000 & 25.0000 & 0.10000 & 0.99000 \\
\hline WB & 4.00000 & 25.0000 & 0.10000 & 0.99000 \\
\hline 7 & 4.00000 & 25.0000 & 0.10000 & 0.99000 \\
\hline WB & 4.00000 & 25.0000 & 0.10000 & 0.99000 \\
\hline 9 & 4.00000 & 25.0000 & 0.10000 & 0.99000 \\
\hline
\end{tabular}

$S$ DEMAND SOD SOD SOD SOD SOD SOD SOD SOD SOD $\begin{array}{lllllllll}0.30000 & 0.30000 & 0.30000 & 0.30000 & 0.30000 & 0.30000 & 0.30000 & 0.30000 & 0.30000\end{array}$ $\begin{array}{lllllllll}0.30000 & 0.30000 & 0.30000 & 0.30000 & 0.30000 & 0.30000 & 0.30000 & 0.30000 & 0.30000\end{array}$

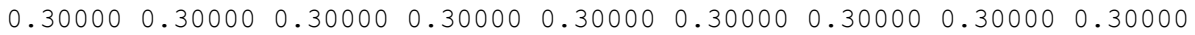

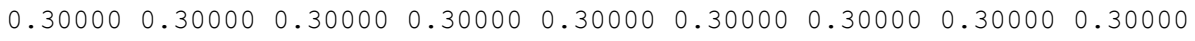
$\begin{array}{lllllllll}0.30000 & 0.30000 & 0.30000 & 0.30000 & 0.30000 & 0.30000 & 0.30000 & 0.30000 & 0.30000\end{array}$

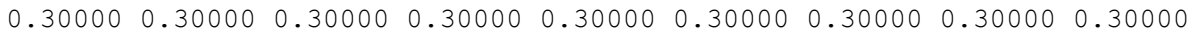
$\begin{array}{lllllllll}0.30000 & 0.30000 & 0.30000 & 0.30000 & 0.30000 & 0.30000 & 0.30000 & 0.30000 & 0.30000\end{array}$ $\begin{array}{lllllllll}0.30000 & 0.30000 & 0.30000 & 0.30000 & 0.30000 & 0.30000 & 0.30000 & 0.30000 & 0.30000\end{array}$ $\begin{array}{lllllllll}0.30000 & 0.30000 & 0.30000 & 0.30000 & 0.30000 & 0.30000 & 0.30000 & 0.30000 & 0.30000\end{array}$

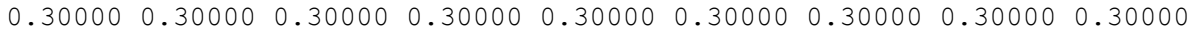
$\begin{array}{lllllllll}0.30000 & 0.30000 & 0.30000 & 0.30000 & 0.30000 & 0.30000 & 0.30000 & 0.30000 & 0.30000\end{array}$ $\begin{array}{lllllllll}0.30000 & 0.30000 & 0.30000 & 0.30000 & 0.30000 & 0.30000 & 0.30000 & 0.30000 & 0.30000\end{array}$

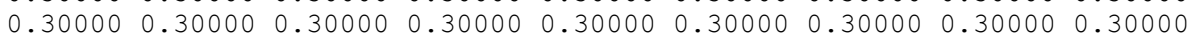

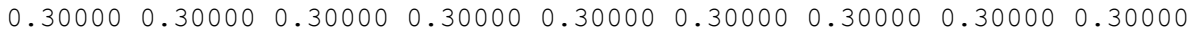
$0.30000 \quad 0.30000 \quad 0.300001 .900001 .900001 .900001 .900001 .900001 .90000$ 1.900001 .900001 .900001 .900001 .900001 .900001 .900001 .900001 .90000 1.900001 .900001 .900001 .900001 .900001 .900001 .900001 .900001 .90000

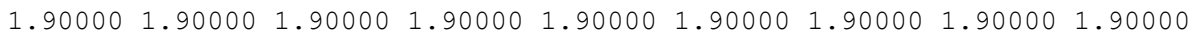
1.900001 .900001 .900001 .900001 .900001 .900001 .900001 .900001 .90000

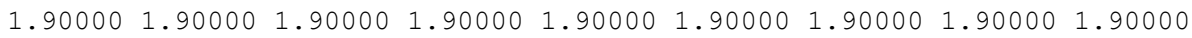
1.900001 .900001 .900001 .900001 .900001 .900001 .900001 .900001 .90000 1.900001 .900001 .900001 .900001 .900001 .900001 .900001 .900001 .90000 $\begin{array}{lllllllll}0.30000 & 0.30000 & 0.30000 & 0.30000 & 0.30000 & 0.30000 & 0.30000 & 0.30000 & 0.30000\end{array}$

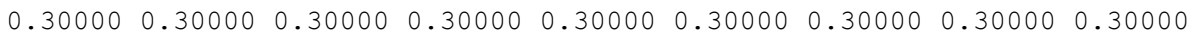
$0.30000 \quad 0.30000 \quad 0.30000 \quad 0.30000 \quad 0.30000 \quad 0.30000 \quad 0.30000 \quad 0.30000 \quad 0.30000$ $\begin{array}{lllllllll}0.30000 & 0.30000 & 0.30000 & 0.30000 & 0.30000 & 0.30000 & 0.30000 & 0.30000 & 0.30000\end{array}$ $\begin{array}{lllllllll}0.30000 & 0.30000 & 0.30000 & 0.30000 & 0.30000 & 0.30000 & 0.30000 & 0.30000 & 0.30000\end{array}$

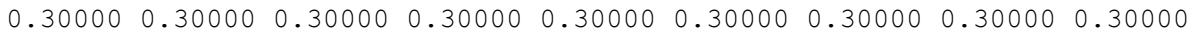
$\begin{array}{llllllllll}0.30000 & 0.30000 & 0.30000 & 0.30000 & 0.30000 & 0.30000 & 0.30000 & 0.30000 & 0.30000\end{array}$ $\begin{array}{lllllllll}0.30000 & 0.30000 & 0.30000 & 0.30000 & 0.30000 & 0.30000 & 0.30000 & 0.30000 & 0.30000\end{array}$ $\begin{array}{lllllllll}0.30000 & 0.30000 & 0.30000 & 0.30000 & 0.30000 & 0.30000 & 0.30000 & 0.30000 & 0.30000\end{array}$ $0.30000 \quad 0.30000 \quad 0.30000 \quad 0.30000 \quad 0.30000 \quad 0.30000 \quad 0.30000 \quad 0.30000 \quad 0.30000$

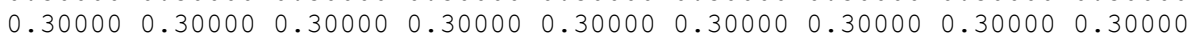

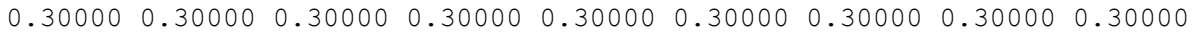

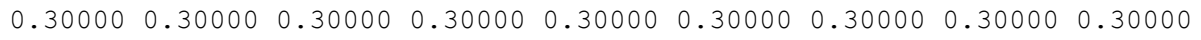
$0.30000 \quad 0.30000 \quad 0.30000 \quad 0.30000 \quad 0.30000 \quad 0.30000 \quad 0.30000$

\begin{tabular}{|c|c|c|c|c|c|c|}
\hline REAERATION & TYPE & $\mathrm{EQN \#}$ & COEF1 & COEF2 & COEF3 & $\operatorname{COEF} 4$ \\
\hline WB 1 & RIVER & 7 & 0.00000 & 0.00000 & 0.00000 & 0.00000 \\
\hline WB 2 & RIVER & 7 & 0.00000 & 0.00000 & 0.00000 & 0.00000 \\
\hline WB 3 & RIVER & 7 & 0.00000 & 0.00000 & 0.00000 & 0.00000 \\
\hline WB 4 & RIVER & 7 & 0.00000 & 0.00000 & 0.00000 & 0.00000 \\
\hline WB 5 & RIVER & 7 & 0.00000 & 0.00000 & 0.00000 & 0.00000 \\
\hline WB 6 & LAKE & 9 & 0.00000 & 0.00000 & 0.00000 & 0.00000 \\
\hline WB 7 & LAKE & 9 & 0.00000 & 0.00000 & 0.00000 & 0.00000 \\
\hline WB 8 & RIVER & 8 & 0.00000 & 0.00000 & 0.00000 & 0.00000 \\
\hline WB & RIVER & 8 & 0.00000 & 0.00000 & 0.00000 & 0.00000 \\
\hline
\end{tabular}

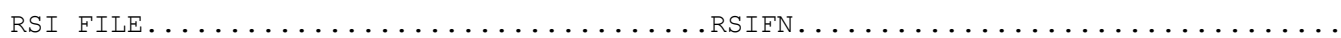
rsi.npt

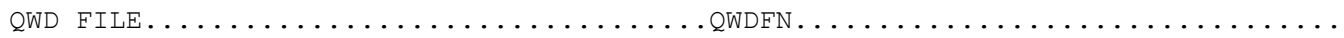
qwd.npt - not used

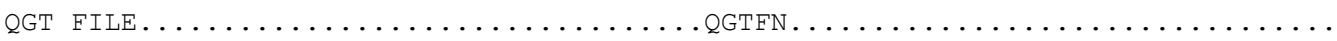
qgt.npt - not used 


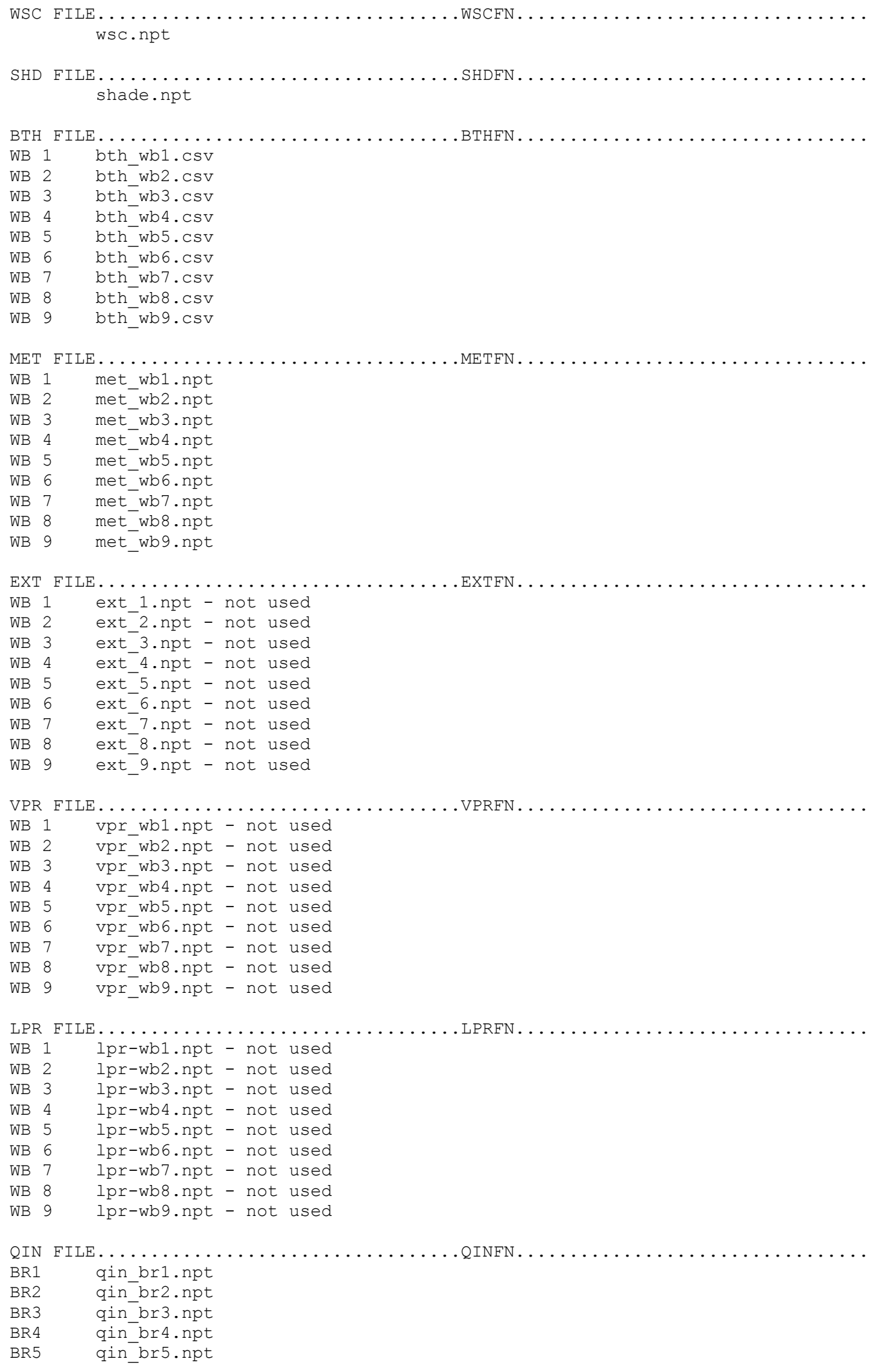




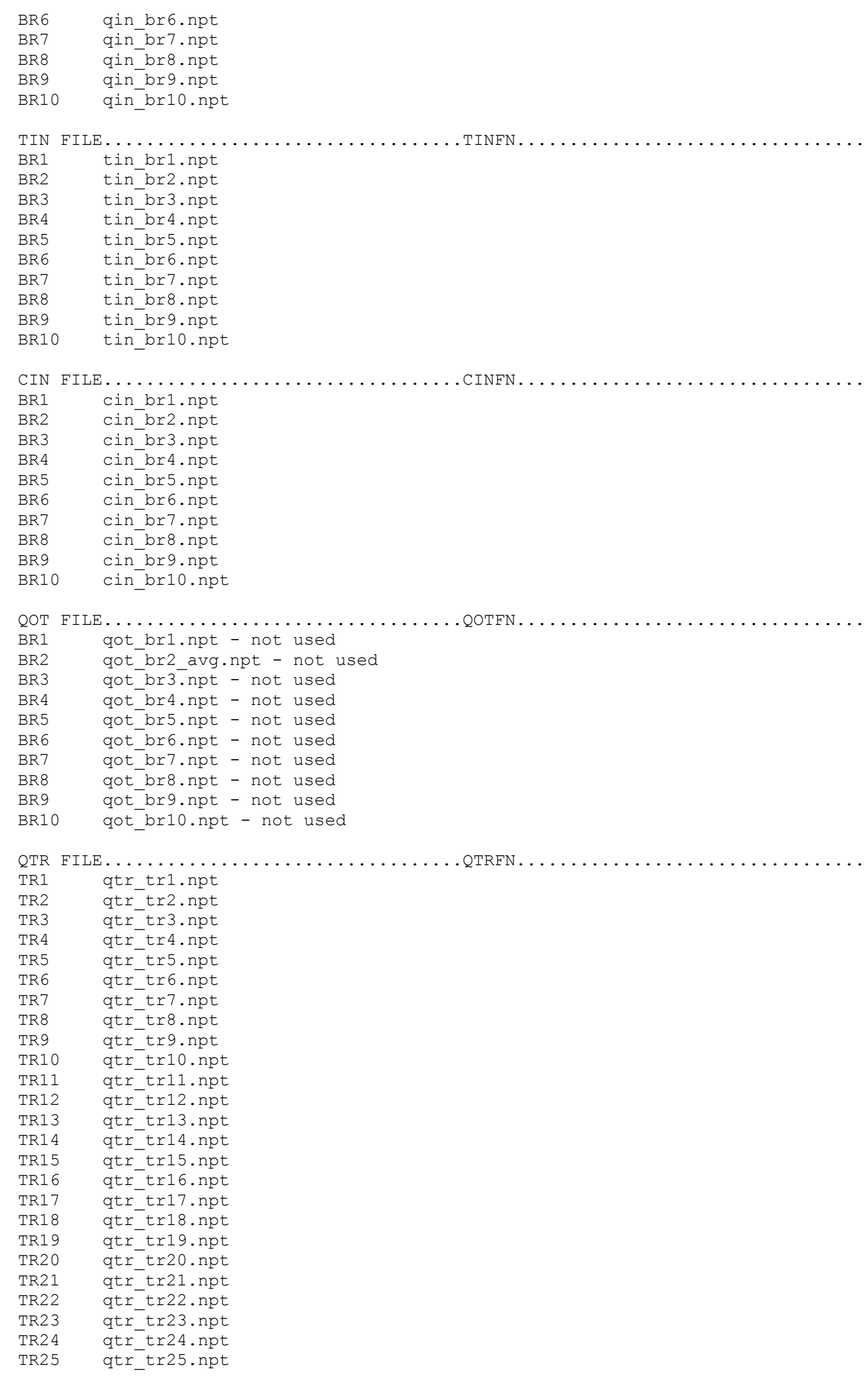




\begin{tabular}{|c|c|}
\hline TR26 & qtr_tr26.npt \\
\hline TR27 & qtr_tr27.npt \\
\hline TR28 & qtr_tr28.npt \\
\hline R29 & qtr_tr29.npt \\
\hline 3 & qtr_tr30.npt \\
\hline 3 & qtr $\operatorname{tr} 31 . \mathrm{npt}$ \\
\hline 32 & qtr_tr32.npt \\
\hline R3 & qtr_tr33.npt \\
\hline S & qtr_tr34.npt \\
\hline & qtr_tr35.npt \\
\hline & qtr_tr36.npt \\
\hline & qtr_tr37.npt \\
\hline & qtr_tr38.npt \\
\hline 3 & qtr_tr39.npt \\
\hline & qtr_tr $40 . n p t$ \\
\hline & qtr_tr $41 . n p t$ \\
\hline & qtr_tr $42 . n p t$ \\
\hline & qtr_tr43.npt \\
\hline 44 & qtr_tr $44 . n p t$ \\
\hline 4 & qtr_tr45.npt \\
\hline 4 & qtr_tr $46 . \mathrm{npt}$ \\
\hline & qtr_tr $47 . n p t$ \\
\hline & qtr_tr48.npt \\
\hline$R 49$ & qtr_tr49.npt \\
\hline 250 & qtr_tr50.npt \\
\hline 251 & qtr_tr51.npt \\
\hline 252 & qtr_tr52.npt \\
\hline TI & qtr_tr53.npt \\
\hline & qtr_tr54.npt \\
\hline TR55 & qtr_tr55.npt \\
\hline TR5 6 & qtr_tr56.npt \\
\hline TR57 & qtr_tr57.npt \\
\hline & qtr_tr58.npt \\
\hline & qtr_tr59.npt \\
\hline TR60 & qtr_tr60.npt \\
\hline TR61 & qtr_tr61.npt \\
\hline TR62 & qtr_tr $62 . n p t$ \\
\hline TR6. & qtr_tr63.npt \\
\hline & qtr_tr64.npt \\
\hline TR65 & qtr_tr65.npt \\
\hline TR6 6 & qtr_tr66.npt \\
\hline TR67 & qtr_tr67.npt \\
\hline TR6 & qtr_tr68.npt \\
\hline & qtr_tr69.npt \\
\hline & qtr_tr70.npt \\
\hline $\mathrm{TR}^{-}$ & qtr_tr $71 . n p t$ \\
\hline TR72 & qtr_tr72.npt \\
\hline TR7 & qtr_tr73.npt \\
\hline TR74 & qtr_tr74.npt \\
\hline & qtr_tr75.npt \\
\hline & qtr_tr76.npt \\
\hline TR77 & qtr_tr77.npt \\
\hline TR7 & qtr_tr78.npt \\
\hline TR79 & qtr_tr79.npt \\
\hline TR80 & qtr_tr80.npt \\
\hline & qtr_tr81.npt \\
\hline & qtr_tr $82 . n p t$ \\
\hline & qtr_tr83.npt \\
\hline TR84 & qtr_tr84.npt \\
\hline TR85 & qtr_tr85.npt \\
\hline TR8 6 & qtr_tr86.npt \\
\hline TR87 & qtr_tr87.npt \\
\hline & qtr_tr88.npt \\
\hline TR89 & qtr_tr89.npt \\
\hline & qtr_tr $90 . n p t$ \\
\hline & qtr_tr91.npt \\
\hline & qtr_tr92.npt \\
\hline & qtr_tr93.npt \\
\hline
\end{tabular}




\begin{tabular}{|c|c|}
\hline TR94 & qtr_tr94.npt \\
\hline TR95 & qtr_tr95.npt \\
\hline TR96 & qtr_tr96.npt \\
\hline TR97 & qtr_tr97.npt \\
\hline 298 & qtr_tr98.npt \\
\hline R99 & qtr tr99.npt \\
\hline TR100 & qtr_tr100.npt \\
\hline TR101 & qtr_tr101.npt \\
\hline TR102 & qtr_tr102.npt \\
\hline 103 & qtr_tr103.npt \\
\hline 104 & qtr $\operatorname{tr} 104 . \mathrm{npt}$ \\
\hline RR105 & qtr_tr105.npt \\
\hline TR106 & qtr_tr106.npt \\
\hline TR107 & qtr_tr107.npt \\
\hline R108 & qtr_tr108.npt \\
\hline 109 & qtr tr109.npt \\
\hline R110 & qtr_tr110.npt \\
\hline TR111 & qtr_tr111.npt \\
\hline TR112 & qtr_tr112.npt \\
\hline TR113 & qtr_tr113.npt \\
\hline RR114 & qtr_tr114.npt \\
\hline TR115 & qtr_tr115.npt \\
\hline TR116 & qtr_tr116.npt \\
\hline TR117 & qtr_tr117.npt \\
\hline TR118 & qtr_tr118.npt \\
\hline TR119 & qtr_tr119.npt \\
\hline TR120 & qtr_tr120.npt \\
\hline TR121 & qtr_tr121.npt \\
\hline TR122 & qtr_tr122.npt \\
\hline TR123 & qtr_tr123.npt \\
\hline TR124 & qtr_tr124.npt \\
\hline TR125 & qtr_tr125.npt \\
\hline TR126 & qtr_tr126.npt \\
\hline TR127 & qtr_tr127.npt \\
\hline TR128 & qtr_tr128.npt \\
\hline TR129 & qtr_tr129.npt \\
\hline TR130 & qtr_tr130.npt \\
\hline TR131 & qtr_tr131.npt \\
\hline TR132 & qtr_tr132.npt \\
\hline TR133 & qtr_tr133.npt \\
\hline TR134 & qtr_tr134.npt \\
\hline TR135 & qtr_tr135.npt \\
\hline TR136 & qtr_tr136.npt \\
\hline TR137 & qtr_tr137.npt \\
\hline TR138 & qtr_tr138.npt \\
\hline TR139 & qtr_tr139.npt \\
\hline TR140 & qtr_tr140.npt \\
\hline TR141 & qtr_tr141.npt \\
\hline TR142 & qtr_tr142.npt \\
\hline TR143 & qtr_tr143.npt \\
\hline TR144 & qtr_tr144.npt \\
\hline TR145 & qtr_tr145.npt \\
\hline TR146 & qtr_tr146.npt \\
\hline TR147 & qtr_tr147.npt \\
\hline TR148 & qtr_tr148.npt \\
\hline TR149 & qtr_tr149.npt \\
\hline TR150 & qtr_tr150.npt \\
\hline TR151 & qtr_tr151.npt \\
\hline TR152 & qtr_tr152.npt \\
\hline TR153 & qtr_tr153.npt \\
\hline TR154 & qtr_tr154.npt \\
\hline TR155 & qtr_tr155.npt \\
\hline TR156 & qtr_tr156.npt \\
\hline TR157 & qtr_tr157.npt \\
\hline TR158 & qtr_tr158.npt \\
\hline TR159 & qtr_tr159.npt \\
\hline TR160 & qtr_tr160.npt \\
\hline TR161 & qtr_tr161.npt \\
\hline
\end{tabular}




\begin{tabular}{|c|c|}
\hline R162 & qtr tr162.npt \\
\hline TR163 & qtr_tr163.npt \\
\hline TR164 & qtr_tr164.npt \\
\hline TR165 & qtr $\operatorname{tr165.npt}$ \\
\hline R166 & qtr $\operatorname{tr166.npt}$ \\
\hline R1 67 & qtr $\operatorname{tr} 167 . \mathrm{npt}$ \\
\hline R168 & qtr $\operatorname{tr168.npt}$ \\
\hline TR169 & qtr_tr169.npt \\
\hline TR170 & qtr $\operatorname{tr} 170 . \mathrm{npt}$ \\
\hline R171 & qtr_tr171.npt \\
\hline R172 & qtr $\operatorname{tr} 172 . \mathrm{npt}$ \\
\hline TR173 & qtr $\operatorname{tr173.npt}$ \\
\hline TR174 & qtr_tr174.npt \\
\hline TR175 & qtr $\operatorname{tr175.npt}$ \\
\hline TR176 & qtr_tr176.npt \\
\hline TR177 & qtr $\operatorname{tr} 177 . \mathrm{npt}$ \\
\hline TR178 & qtr $\operatorname{tr178.npt}$ \\
\hline TR179 & qtr_tr179.npt \\
\hline TR180 & qtr_tr180.npt \\
\hline TR181 & qtr $\operatorname{tr181.npt}$ \\
\hline TR182 & qtr $\operatorname{tr182} \cdot \mathrm{npt}$ \\
\hline TR183 & qtr $\operatorname{tr183.npt}$ \\
\hline TR184 & qtr $\operatorname{tr1} 184 . \mathrm{npt}$ \\
\hline TR185 & qtr_tr185.npt \\
\hline TR186 & qtr $\operatorname{tr186.npt}$ \\
\hline TR187 & qtr $\operatorname{tr} 187 . \mathrm{npt}$ \\
\hline TR188 & qtr $\operatorname{tr188.npt}$ \\
\hline TR189 & qtr $\operatorname{tr189} \mathrm{npt}$ \\
\hline TR190 & qtr_tr190.npt \\
\hline TR191 & qtr ${ }^{-} \operatorname{tr} 191 . \mathrm{npt}$ \\
\hline TR192 & atr ${ }^{-} \operatorname{tr} 192 . \mathrm{npt}$ \\
\hline TR193 & atr tr193.npt \\
\hline TR194 & qtr $\operatorname{tr194.npt}$ \\
\hline TR195 & qtr_tr195.npt \\
\hline TR196 & qtr_tr196.npt \\
\hline TR197 & atr $\operatorname{tr} 197 . \mathrm{npt}$ \\
\hline TR198 & qtr $\operatorname{tr198.npt}$ \\
\hline TR199 & qtr $\operatorname{tr199.npt}$ \\
\hline TR200 & qtr_tr200.npt \\
\hline TR201 & qtr tr201.npt \\
\hline TR202 & atr ${ }^{-}$tr202.npt \\
\hline TR203 & qtr tr203.npt \\
\hline TR204 & qtr $\operatorname{tr} 204 . \mathrm{npt}$ \\
\hline TR205 & qtr_tr205.npt \\
\hline TR206 & qtr $\operatorname{tr} 206 . \mathrm{npt}$ \\
\hline TR207 & qtr $\operatorname{tr} 207 . \mathrm{npt}$ \\
\hline TR208 & qtr $\operatorname{tr} 208 . \mathrm{npt}$ \\
\hline TR209 & qtr_tr209.npt \\
\hline TR210 & $\operatorname{tr} 210 . \mathrm{npt}$ \\
\hline TR211 & qtr_tr211.npt \\
\hline TR212 & qtr_tr212.npt \\
\hline TR213 & qtr $\operatorname{tr} 213 . \mathrm{npt}$ \\
\hline TR214 & qtr $\operatorname{tr} 214 . \mathrm{npt}$ \\
\hline TR215 & qtr $\operatorname{tr} 215 . \mathrm{npt}$ \\
\hline TR216 & qtr_tr216.npt \\
\hline TR217 & qtr $\operatorname{tr} 217 . \mathrm{npt}$ \\
\hline TR218 & qtr $\operatorname{tr} 218 . \mathrm{npt}$ \\
\hline TR219 & qtr tr219.npt \\
\hline TR220 & qtr $\operatorname{tr} 220 . \mathrm{npt}$ \\
\hline TR221 & qtr_tr221.npt \\
\hline TR222 & qtr_tr222.npt \\
\hline TR223 & qtr_tr223.npt \\
\hline TR224 & qtr $\operatorname{tr} 224 . \mathrm{npt}$ \\
\hline TR225 & qtr $\operatorname{tr} 225 . \mathrm{npt}$ \\
\hline TR226 & qtr $\operatorname{tr} 226 . \mathrm{npt}$ \\
\hline TR227 & qtr_tr227.npt \\
\hline TR228 & qtr_tr228.npt \\
\hline TR229 & atr $\operatorname{tr} 229 . \mathrm{npt}$ \\
\hline
\end{tabular}




\begin{tabular}{|c|c|}
\hline TR230 & qtr_tr230.npt \\
\hline TR231 & qtr_tr231.npt \\
\hline R232 & qtr_tr232.npt \\
\hline TR233 & qtr_tr233.npt \\
\hline TR234 & qtr_tr234.npt \\
\hline 235 & qtr_tr235.npt \\
\hline R236 & qtr_tr236.npt \\
\hline R237 & qtr_tr237.npt \\
\hline TR238 & qtr_tr238.npt \\
\hline TR239 & qtr_tr239.npt \\
\hline TR240 & qtr_tr240.npt \\
\hline TR241 & qtr_tr241.npt \\
\hline TR242 & qtr_tr242.npt \\
\hline TR243 & qtr_tr243.npt \\
\hline TR244 & qtr_tr244.npt \\
\hline TR245 & qtr_tr245.npt \\
\hline TR246 & qtr_tr246.npt \\
\hline TR247 & qtr_tr247.npt \\
\hline TR2 48 & qtr_tr248.npt \\
\hline TR249 & qtr_tr249.npt \\
\hline TR250 & qtr_tr250.npt \\
\hline TR251 & qtr_tr251.npt \\
\hline TR252 & qtr_tr252.npt \\
\hline TR253 & qtr_tr253.npt \\
\hline TR254 & qtr_tr254.npt \\
\hline TR255 & qtr_tr255.npt \\
\hline TR256 & qtr_tr256.npt \\
\hline TR257 & qtr_tr257.npt \\
\hline TR258 & qtr_tr258.npt \\
\hline TR259 & qtr_tr259.npt \\
\hline TR2 60 & qtr_tr260.npt \\
\hline TR261 & qtr_tr261.npt \\
\hline TR2 62 & qtr_tr262.npt \\
\hline TR263 & qtr_tr263.npt \\
\hline TR264 & qtr_tr264.npt \\
\hline TR2 65 & qtr_tr265.npt \\
\hline TR2 66 & qtr_tr266.npt \\
\hline TR2 67 & qtr_tr267.npt \\
\hline TR268 & qtr_tr268.npt \\
\hline TR2 69 & qtr_tr269.npt \\
\hline TR270 & qtr_tr270.npt \\
\hline TR271 & qtr_tr271.npt \\
\hline TR272 & qtr_tr272.npt \\
\hline TR273 & qtr_tr273.npt \\
\hline TR274 & qtr_tr274.npt \\
\hline TR275 & qtr_tr275.npt \\
\hline TR276 & qtr_tr276.npt \\
\hline TR277 & qtr_tr277.npt \\
\hline TR278 & qtr_tr278.npt \\
\hline TR279 & qtr_tr279.npt \\
\hline TR280 & qtr_tr280.npt \\
\hline TR281 & qtr_tr281.npt \\
\hline TR282 & qtr_tr282.npt \\
\hline TR283 & qtr_tr283.npt \\
\hline TR284 & qtr_tr284.npt \\
\hline TR285 & qtr_tr285.npt \\
\hline TR286 & qtr_tr286.npt \\
\hline TR287 & qtr_tr287.npt \\
\hline TR288 & qtr_tr288.npt \\
\hline TR289 & qtr_tr289.npt \\
\hline TR290 & qtr_tr290.npt \\
\hline TR291 & qtr_tr291.npt \\
\hline TR292 & qtr_tr292.npt \\
\hline TR293 & qtr_tr293.npt \\
\hline TR294 & qtr_tr294.npt \\
\hline TR295 & qtr_tr295.npt \\
\hline & qtr_tr296.npt \\
\hline TR297 & qtr_tr297.npt \\
\hline
\end{tabular}




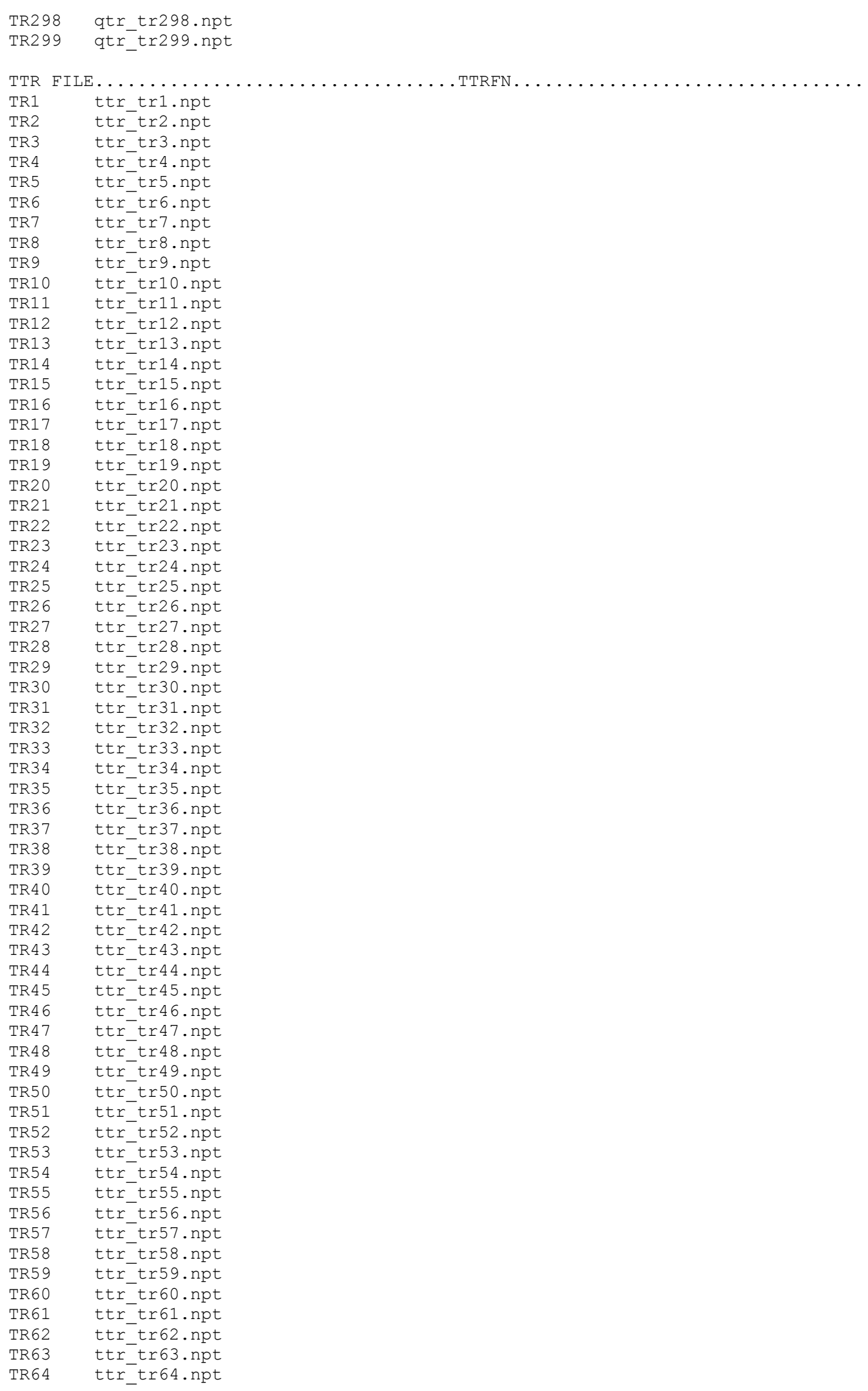




\begin{tabular}{|c|c|}
\hline TR65 & ttr_tr65.npt \\
\hline TR66 & ttr_tr66.npt \\
\hline TR67 & ttr_tr67.npt \\
\hline TR68 & ttr_tr68.npt \\
\hline RR69 & ttr_tr69.npt \\
\hline TR70 & ttr $\operatorname{tr} 70 . \mathrm{npt}$ \\
\hline TR71 & ttr_tr71.npt \\
\hline TR72 & ttr_tr72.npt \\
\hline TR73 & ttr_tr73.npt \\
\hline R74 & ttr_tr74.npt \\
\hline TR75 & ttr $\operatorname{tr} 75 . \mathrm{npt}$ \\
\hline TR76 & ttr_tr76.npt \\
\hline TR77 & ttr_tr77.npt \\
\hline TR78 & ttr_tr78.npt \\
\hline TR79 & ttr_tr79.npt \\
\hline TR80 & ttr_tr80.npt \\
\hline TR81 & ttr_tr81.npt \\
\hline TR82 & ttr_tr82.npt \\
\hline TR83 & ttr_tr83.npt \\
\hline TR84 & ttr_tr84.npt \\
\hline TR85 & ttr_tr85.npt \\
\hline TR8 6 & ttr_tr86.npt \\
\hline TR87 & ttr_tr87.npt \\
\hline TR88 & ttr_tr88.npt \\
\hline TR89 & ttr_tr89.npt \\
\hline TR90 & ttr_tr90.npt \\
\hline TR91 & ttr_tr91.npt \\
\hline TR92 & ttr_tr92.npt \\
\hline TR93 & ttr_tr93.npt \\
\hline TR94 & ttr_tr94.npt \\
\hline TR95 & ttr_tr95.npt \\
\hline TR96 & ttr_tr96.npt \\
\hline TR97 & ttr_tr97.npt \\
\hline TR98 & ttr_tr98.npt \\
\hline TR99 & ttr_tr99.npt \\
\hline TR100 & ttr_tr100.npt \\
\hline TR101 & ttr-tr101.npt \\
\hline TR102 & ttr_tr102.npt \\
\hline TR103 & ttr_tr103.npt \\
\hline TR104 & ttr_tr104.npt \\
\hline TR105 & ttr_tr105.npt \\
\hline TR106 & ttr-tr106.npt \\
\hline TR107 & ttr_tr107.npt \\
\hline TR108 & ttr_tr108.npt \\
\hline TR109 & ttr_tr109.npt \\
\hline TR110 & ttr_tr110.npt \\
\hline TR111 & ttr_tr111.npt \\
\hline TR112 & ttr_tr112.npt \\
\hline TR113 & tr113.npt \\
\hline TR114 & $\operatorname{tr} 114 . n p t$ \\
\hline TR115 & ttr_tr115.npt \\
\hline TR116 & ttr_tr116.npt \\
\hline TR117 & ttr_tr117.npt \\
\hline TR118 & ttr_tr118.npt \\
\hline TR119 & ttr_tr119.npt \\
\hline TR120 & ttr_tr120.npt \\
\hline TR121 & ttr_tr121.npt \\
\hline TR122 & ttr_tr122.npt \\
\hline TR123 & ttr_tr123.npt \\
\hline TR124 & ttr_tr124.npt \\
\hline TR125 & ttr_tr125.npt \\
\hline TR126 & ttr_tr126.npt \\
\hline TR127 & ttr_tr127.npt \\
\hline TR128 & ttr_tr128.npt \\
\hline TR129 & ttr_tr129.npt \\
\hline TR130 & ttr_tr130.npt \\
\hline TR131 & ttr_tr131.npt \\
\hline TR132 & ttr_tr132.npt \\
\hline
\end{tabular}




\begin{tabular}{|c|c|}
\hline TR133 & ttr_tr133.npt \\
\hline TR134 & ttr_tr134.npt \\
\hline TR135 & ttr_tr135.npt \\
\hline TR136 & ttr_tr136.npt \\
\hline R137 & ttr-tr137.npt \\
\hline R138 & ttr $\operatorname{tr138.npt}$ \\
\hline TR139 & ttr_tr139.npt \\
\hline TR140 & ttr_tr140.npt \\
\hline TR141 & ttr_tr141.npt \\
\hline R142 & ttr_tr142.npt \\
\hline TR143 & ttr- $\operatorname{tr143.npt}$ \\
\hline TR144 & ttr_tr144.npt \\
\hline TR145 & ttr_tr145.npt \\
\hline TR14 6 & ttr_tr146.npt \\
\hline TR147 & ttr_tr147.npt \\
\hline TR148 & ttr ${ }^{-} \operatorname{tr148.npt}$ \\
\hline TR149 & ttr_tr149.npt \\
\hline TR150 & ttr_tr150.npt \\
\hline TR151 & ttr_tr151.npt \\
\hline TR152 & ttr_tr152.npt \\
\hline TR153 & ttr_tr153.npt \\
\hline TR154 & ttr_tr154.npt \\
\hline TR155 & ttr_tr155.npt \\
\hline TR156 & ttr_tr156.npt \\
\hline TR157 & ttr_tr157.npt \\
\hline TR158 & ttr_tr158.npt \\
\hline TR159 & ttr_tr159.npt \\
\hline TR160 & ttr_tr160.npt \\
\hline TR161 & ttr_tr161.npt \\
\hline TR162 & ttr_tr162.npt \\
\hline TR163 & ttr_tr163.npt \\
\hline TR164 & ttr_tr164.npt \\
\hline TR165 & ttr_tr165.npt \\
\hline TR166 & ttr_tr166.npt \\
\hline TR167 & ttr_tr167.npt \\
\hline TR168 & ttr_tr168.npt \\
\hline TR169 & ttr_tr169.npt \\
\hline TR170 & ttr_tr170.npt \\
\hline TR171 & ttr_tr171.npt \\
\hline TR172 & ttr_tr172.npt \\
\hline TR173 & ttr_tr173.npt \\
\hline TR174 & ttr_tr174.npt \\
\hline TR175 & ttr_tr175.npt \\
\hline TR176 & ttr_tr176.npt \\
\hline TR177 & ttr_tr177.npt \\
\hline TR178 & ttr_tr178.npt \\
\hline TR179 & ttr_tr179.npt \\
\hline TR180 & ttr_tr180.npt \\
\hline TR181 & tr181.npt \\
\hline TR182 & ttr_tr182.npt \\
\hline TR183 & ttr_tr183.npt \\
\hline TR184 & ttr_tr184.npt \\
\hline TR185 & ttr_tr185.npt \\
\hline TR186 & ttr_tr186.npt \\
\hline TR187 & ttr_tr187.npt \\
\hline TR188 & ttr_tr188.npt \\
\hline TR189 & ttr_tr189.npt \\
\hline TR190 & ttr_tr190.npt \\
\hline TR191 & ttr_tr191.npt \\
\hline TR192 & ttr_tr192.npt \\
\hline TR193 & ttr_tr193.npt \\
\hline TR194 & ttr_tr194.npt \\
\hline TR195 & ttr_tr195.npt \\
\hline TR196 & ttr_tr196.npt \\
\hline TR197 & ttr_tr197.npt \\
\hline TR198 & ttr_tr198.npt \\
\hline TR199 & ttr_tr199.npt \\
\hline TR200 & ttr_tr200.npt \\
\hline
\end{tabular}




\begin{tabular}{|c|c|}
\hline RR201 & ttr_tr201.npt \\
\hline R202 & ttr_tr202.npt \\
\hline R203 & ttr- $\operatorname{tr203.npt}$ \\
\hline TR204 & ttr_tr204.npt \\
\hline TR205 & ttr_tr205.npt \\
\hline TR206 & ttr_tr206.npt \\
\hline R207 & ttr- $\operatorname{tr207.npt}$ \\
\hline R208 & ttr_tr208.npt \\
\hline TR209 & ttr-tr209.npt \\
\hline TR210 & ttr_tr210.npt \\
\hline TR211 & ttr- $\operatorname{tr211.npt}$ \\
\hline TR212 & ttr $\operatorname{tr} 212 . \mathrm{npt}$ \\
\hline TR213 & ttr_tr213.npt \\
\hline TR214 & ttr-tr214.npt \\
\hline TR215 & ttr_tr215.npt \\
\hline TR216 & ttr_tr216.npt \\
\hline TR217 & ttr_tr217.npt \\
\hline TR218 & ttr-tr218.npt \\
\hline TR219 & ttr tr219.npt \\
\hline TR220 & ttr_tr220.npt \\
\hline TR221 & ttr_tr221.npt \\
\hline TR222 & ttr_tr222.npt \\
\hline TR223 & ttr tr223.npt \\
\hline TR224 & ttr-tr224.npt \\
\hline TR225 & ttr_tr225.npt \\
\hline TR226 & ttr_tr226.npt \\
\hline TR227 & ttr_tr227.npt \\
\hline TR228 & ttr_tr228.npt \\
\hline TR229 & ttr_tr229.npt \\
\hline TR230 & ttr_tr230.npt \\
\hline TR231 & ttr_tr231.npt \\
\hline TR232 & ttr_tr232.npt \\
\hline TR233 & ttr_tr233.npt \\
\hline TR234 & ttr_tr234.npt \\
\hline TR235 & ttr_tr235.npt \\
\hline TR236 & ttr_tr236.npt \\
\hline TR237 & ttr_tr237.npt \\
\hline TR238 & ttr_tr238.npt \\
\hline TR239 & ttr_tr239.npt \\
\hline TR240 & ttr_tr240.npt \\
\hline TR241 & ttr_tr241.npt \\
\hline TR242 & $\operatorname{tr} 242 . n p t$ \\
\hline TR243 & ttr_tr243.npt \\
\hline TR24 4 & ttr_tr244.npt \\
\hline TR245 & ttr_tr245.npt \\
\hline TR246 & ttr_tr246.npt \\
\hline TR2 47 & $\operatorname{tr} 247 . n p t$ \\
\hline TR248 & ttr_tr248.npt \\
\hline TR249 & ttr_tr249.npt \\
\hline TR250 & ttr_tr250.npt \\
\hline TR251 & tr251.npt \\
\hline TR252 & $\operatorname{tr} 252 . n p t$ \\
\hline TR253 & ttr_tr253.npt \\
\hline TR254 & ttr_tr254.npt \\
\hline TR255 & ttr_tr255.npt \\
\hline TR256 & ttr_tr256.npt \\
\hline TR257 & tr257.npt \\
\hline TR258 & tr258.npt \\
\hline TR259 & ttr_tr259.npt \\
\hline TR260 & ttr_tr260.npt \\
\hline TR261 & ttr_tr261.npt \\
\hline TR262 & ttr_tr262.npt \\
\hline TR263 & ttr_tr263.npt \\
\hline TR264 & ttr_tr264.npt \\
\hline TR265 & ttr_tr265.npt \\
\hline TR2 66 & ttr_tr266.npt \\
\hline TR267 & ttr_tr267.npt \\
\hline TR268 & ttr $\operatorname{tr268.npt}$ \\
\hline
\end{tabular}




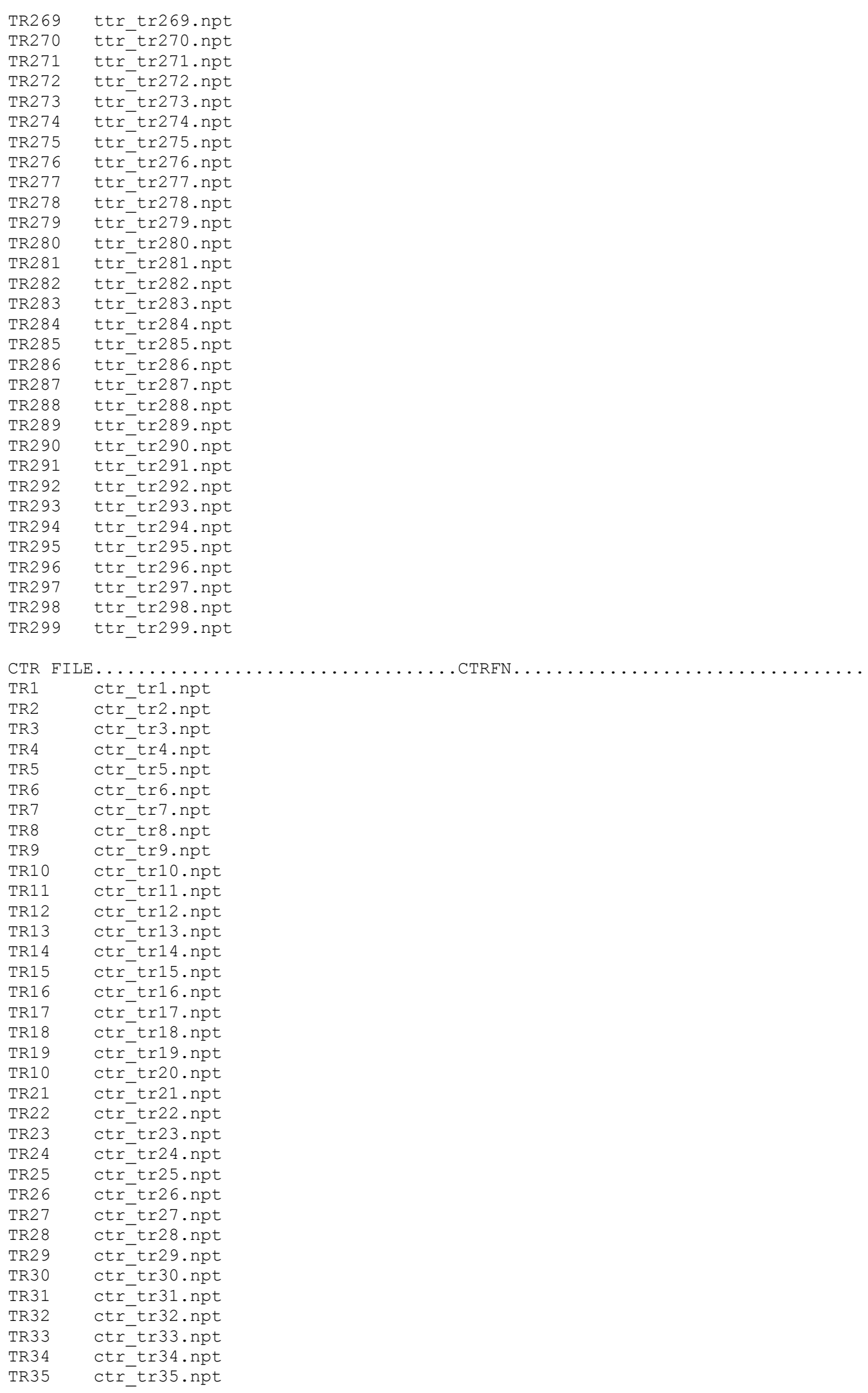




$\begin{array}{ll}\text { TR36 } & \text { ctr_tr36.npt } \\ \text { TR37 } & \text { ctr_tr37.npt } \\ \text { TR38 } & \text { ctr_tr38.npt } \\ \text { TR39 } & \text { ctr_tr39.npt } \\ \text { TR40 } & \text { ctr_tr40.npt } \\ \text { TR41 } & \text { ctr_tr41.npt } \\ \text { TR42 } & \text { ctr_tr42.npt } \\ \text { TR43 } & \text { ctr_tr43.npt } \\ \text { TR44 } & \text { ctr_tr44.npt } \\ \text { TR45 } & \text { ctr_tr45.npt } \\ \text { TR46 } & \text { ctr_tr46.npt } \\ \text { TR47 } & \text { ctr_tr47.npt } \\ \text { TR48 } & \text { ctr_tr48.npt } \\ \text { TR49 } & \text { ctr_tr49.npt } \\ \text { TR50 } & \text { ctr_tr50.npt } \\ \text { TR51 } & \text { ctr_tr51.npt } \\ \text { TR52 } & \text { ctr_tr52.npt } \\ \text { TR53 } & \text { ctr_tr53.npt } \\ \text { TR54 } & \text { ctr_tr54.npt } \\ \text { TR55 } & \text { ctr_tr55.npt } \\ \text { TR56 } & \text { ctr_tr56.npt } \\ \text { TR57 } & \text { ctr_tr57.npt } \\ \text { TR58 } & \text { ctr_tr58.npt } \\ \text { TR59 } & \text { ctr_tr59.npt } \\ \text { TR60 } & \text { ctr_tr60.npt } \\ \text { TR61 } & \text { ctr_tr61.npt } \\ \text { TR62 } & \text { ctr_tr62.npt } \\ \text { TR63 } & \text { ctr_tr63.npt } \\ \text { TR64 } & \text { ctr_tr64.npt } \\ \text { TR65 } & \text { ctr_tr65.npt } \\ \text { TR66 } & \text { ctr_tr66.npt } \\ \text { TR67 } & \text { ctr_tr67.npt } \\ \text { TR68 } & \text { ctr_tr68.npt } \\ \text { TR69 } & \text { ctr_tr69.npt } \\ \text { TR70 } & \text { ctr_tr70.npt } \\ \text { TR71 } & \text { ctr_tr71.npt } \\ \text { TR72 } & \text { ctr_tr72.npt } \\ \text { TR73 } & \text { ctr_tr73.npt } \\ \text { TR74 } & \text { ctr_tr74.npt } \\ \text { TR75 } & \text { ctr_tr75.npt } \\ \text { TR76 } & \text { ctr_tr76.npt } \\ \text { TR77 } & \text { ctr_tr77.npt } \\ \text { TR78 } & \text { ctr_tr78.npt } \\ \text { TR79 } & \text { ctr_tr79.npt } \\ \text { TR80 } & \text { ctr_tr80.npt } \\ \text { TR81 } & \text { ctr_tr81.npt } \\ \text { TR82 } & \text { ctr_tr82.npt } \\ \text { TR83 } & \text { ctr_tr83.npt } \\ \text { TR84 } & \text { ctr_tr84.npt } \\ \text { TR85 } & \text { ctr_tr85.npt } \\ \text { TR86 } & \text { ctr_tr86.npt } \\ \text { TR87 } & \text { ctr_tr87.npt } \\ \text { TR88 } & \text { ctr_tr88.npt } \\ \text { TR89 } & \text { ctr_tr89.npt } \\ \text { TR90 } & \text { ctr_tr90.npt } \\ \text { TR91 } & \text { ctr_tr91.npt } \\ \text { TR92 } & \text { ctr_tr92.npt } \\ \text { TR93 } & \text { ctr_tr93.npt } \\ \text { TR94 } & \text { ctr_tr94.npt } \\ \text { TR95 } & \text { ctr_tr95.npt } \\ \text { TR96 } & \text { ctr_tr96.npt } \\ \text { TR97 } & \text { ctr_tr97.npt } \\ \text { TR90 } & \text { ctr_tr98.npt } \\ \text { TR101 } & \text { ctr_tr99.npt } \\ \text { TR102 } & \text { ctr_tr100.npt } \\ \text { TR103 } & \text { ctr_tr102.npt } \\ \text { Tr_tr103.npt }\end{array}$




\begin{tabular}{|c|c|}
\hline RR104 & ctr_tr104.npt \\
\hline R105 & ctr_tr105.npt \\
\hline R106 & ctr_tr106.npt \\
\hline TR107 & ctr_tr107.npt \\
\hline TR108 & ctr-tr108.npt \\
\hline 109 & ctr_tr109.npt \\
\hline 2110 & ctr_tr110.npt \\
\hline R111 & ctr_tr111.npt \\
\hline TR112 & ctr_tr112.npt \\
\hline TR113 & ctr_tr113.npt \\
\hline TR114 & ctr_tr114.npt \\
\hline R115 & ctr_tr115.npt \\
\hline R116 & ctr_tr116.npt \\
\hline TR117 & ctr_tr117.npt \\
\hline TR118 & ctr_tr118.npt \\
\hline TR119 & ctr_tr119.npt \\
\hline RR120 & ctr_tr120.npt \\
\hline RR121 & ctr_tr121.npt \\
\hline TR122 & ctr_tr122.npt \\
\hline TR123 & ctr_tr123.npt \\
\hline TR124 & ctr_tr124.npt \\
\hline TR125 & ctr_tr125.npt \\
\hline TR126 & ctr_tr126.npt \\
\hline TR127 & ctr_tr127.npt \\
\hline TR128 & ctr_tr128.npt \\
\hline TR129 & ctr_tr129.npt \\
\hline TR130 & ctr_tr130.npt \\
\hline TR131 & ctr_tr131.npt \\
\hline TR132 & ctr_tr132.npt \\
\hline TR133 & ctr_tr133.npt \\
\hline TR134 & ctr_tr134.npt \\
\hline TR135 & ctr_tr135.npt \\
\hline TR136 & ctr_tr136.npt \\
\hline TR137 & ctr_tr137.npt \\
\hline TR138 & ctr_tr138.npt \\
\hline TR139 & ctr_tr139.npt \\
\hline TR140 & ctr_tr140.npt \\
\hline TR141 & ctr_tr141.npt \\
\hline TR142 & ctr_tr142.npt \\
\hline TR143 & ctr_tr143.npt \\
\hline TR144 & ctr_tr144.npt \\
\hline TR145 & ctr_tr145.npt \\
\hline TR146 & ctr_tr146.npt \\
\hline TR147 & ctr_tr147.npt \\
\hline TR148 & ctr_tr148.npt \\
\hline TR149 & tr149.npt \\
\hline TR150 & tr150.npt \\
\hline TR151 & ctr_tr151.npt \\
\hline TR152 & ctr_tr152.npt \\
\hline TR153 & ctr_tr153.npt \\
\hline TR154 & tr154.npt \\
\hline TR155 & tr155.npt \\
\hline TR156 & ctr_tr156.npt \\
\hline TR157 & ctr_tr157.npt \\
\hline TR158 & ctr_tr158.npt \\
\hline TR159 & ctr_tr159.npt \\
\hline TR1 60 & tr160.npt \\
\hline TR161 & ctr_tr161.npt \\
\hline TR1 62 & ctr_tr162.npt \\
\hline TR163 & ctr_tr163.npt \\
\hline TR1 64 & ctr_tr164.npt \\
\hline TR165 & ctr_tr165.npt \\
\hline TR166 & ctr_tr166.npt \\
\hline TR1 67 & ctr_tr167.npt \\
\hline TR168 & ctr_tr168.npt \\
\hline TR169 & ctr_tr169.npt \\
\hline TR170 & ctr_tr170.npt \\
\hline TR171 & ctr_tr171.npt \\
\hline
\end{tabular}




\begin{tabular}{|c|c|}
\hline R172 & ctr tr172.npt \\
\hline TR173 & ctr_tr173.npt \\
\hline TR174 & ctr_tr174.npt \\
\hline TR175 & ctr $^{-} \operatorname{tr} 175 . \mathrm{npt}$ \\
\hline R176 & ctr $\operatorname{tr} 176 . \mathrm{npt}$ \\
\hline R177 & $\mathrm{ctr}^{-} \operatorname{tr} 177 . \mathrm{npt}$ \\
\hline TR178 & $\mathrm{ctr}^{-} \operatorname{tr178.npt}$ \\
\hline TR179 & ctr_tr179.npt \\
\hline TR180 & $\operatorname{ctr}^{-} \operatorname{tr} 180 . \mathrm{npt}$ \\
\hline R181 & ctr_tr181.npt \\
\hline R182 & $\operatorname{ctr}^{-} \operatorname{tr182.npt}$ \\
\hline TR183 & $\operatorname{ctr}^{-} \operatorname{tr183.npt}$ \\
\hline TR184 & ctr-tr184.npt \\
\hline TR185 & ctr $^{-} \operatorname{tr185.npt}$ \\
\hline TR186 & ctr_tr186.npt \\
\hline TR187 & ctr $^{-} \operatorname{tr} 187 . \mathrm{npt}$ \\
\hline TR188 & ctr $^{-} \operatorname{tr188.npt}$ \\
\hline TR189 & ctr-tr189.npt \\
\hline TR190 & ctr $\operatorname{tr190.npt}$ \\
\hline TR191 & ctr_tr191.npt \\
\hline TR192 & ctr $^{-} \operatorname{tr192.npt}$ \\
\hline TR193 & ctr $^{-} \operatorname{tr193.npt}$ \\
\hline TR194 & ctr-tr194.npt \\
\hline TR195 & ctr_tr195.npt \\
\hline TR196 & $\operatorname{ctr}^{-} \operatorname{tr196.npt}$ \\
\hline TR197 & ctr $^{-} \operatorname{tr197.npt}$ \\
\hline TR198 & $\mathrm{ctr}^{-} \operatorname{tr198.npt}$ \\
\hline TR199 & ctr $^{-} \operatorname{tr199.npt}$ \\
\hline TR200 & ctr_tr200.npt \\
\hline TR201 & $\mathrm{ctr}^{-} \operatorname{tr201.\mathrm {npt}}$ \\
\hline TR202 & ctr ${ }^{-} \operatorname{tr} 202 . \mathrm{npt}$ \\
\hline TR203 & ctr tr203.npt \\
\hline TR204 & ctr $^{-} \operatorname{tr} 204 . \mathrm{npt}$ \\
\hline TR205 & ctr-tr205.npt \\
\hline TR206 & $\mathrm{ctr}^{-} \operatorname{tr206.\mathrm {npt}}$ \\
\hline TR207 & ctr $\operatorname{tr2} 207 . \mathrm{npt}$ \\
\hline TR208 & ctr $\operatorname{tr208.npt}$ \\
\hline TR209 & ctr $\operatorname{tr209} \mathrm{npt}$ \\
\hline TR210 & ctr_tr210.npt \\
\hline TR211 & ctr $^{-} \operatorname{tr} 211 . n p t$ \\
\hline TR212 & $\mathrm{ctr}^{-} \operatorname{tr} 212 \mathrm{npt}$ \\
\hline TR213 & ctr $\operatorname{tr} 213 . \mathrm{npt}$ \\
\hline TR214 & ctr $\operatorname{tr} 214 . \mathrm{npt}$ \\
\hline TR215 & ctr_tr215.npt \\
\hline TR216 & ctr ${ }^{-} \operatorname{tr} 216 . \mathrm{npt}$ \\
\hline TR217 & ctr $\operatorname{tr} 217 . \mathrm{npt}$ \\
\hline TR218 & ctr $\operatorname{tr} 218 . \mathrm{npt}$ \\
\hline TR219 & $\mathrm{ctr}^{-} \operatorname{tr219} \mathrm{npt}$ \\
\hline TR220 & $\operatorname{tr} 220 . \mathrm{npt}$ \\
\hline TR221 & $\operatorname{tr} 221 . n p t$ \\
\hline TR222 & ctr $\operatorname{tr} 222 . \mathrm{npt}$ \\
\hline TR223 & ctr $\operatorname{tr} 223 . \mathrm{npt}$ \\
\hline TR224 & ctr ${ }^{-} \operatorname{tr} 224 . \mathrm{npt}$ \\
\hline TR225 & ctr $\operatorname{tr} 225 . \mathrm{npt}$ \\
\hline TR226 & ctr $\operatorname{tr} 226 . \mathrm{npt}$ \\
\hline TR227 & ctr $\operatorname{tr} 227 . \mathrm{npt}$ \\
\hline TR228 & $\operatorname{ctr}^{-} \operatorname{tr} 228 . \mathrm{npt}$ \\
\hline TR229 & ctr ${ }^{-} \operatorname{tr} 229 . \mathrm{npt}$ \\
\hline TR230 & ctr $\operatorname{tr} 230 . \mathrm{npt}$ \\
\hline TR231 & ctr ${ }^{-} \operatorname{tr} 231 . \mathrm{npt}$ \\
\hline TR232 & ctr_tr232.npt \\
\hline TR233 & ctr $^{-} \operatorname{tr} 233 . \mathrm{npt}$ \\
\hline TR234 & $\mathrm{ctr}^{-} \operatorname{tr234} \mathrm{npt}$ \\
\hline TR235 & ctr $\operatorname{tr235}$.npt \\
\hline TR236 & ctr $\operatorname{tr} 236 . \mathrm{npt}$ \\
\hline TR237 & ctr $\operatorname{tr} 237 . \mathrm{npt}$ \\
\hline TR238 & $\mathrm{ctr}^{-} \operatorname{tr238.\mathrm {npt}}$ \\
\hline TR239 & $\mathrm{ctr}^{-} \operatorname{tr} 239 . \mathrm{npt}$ \\
\hline
\end{tabular}




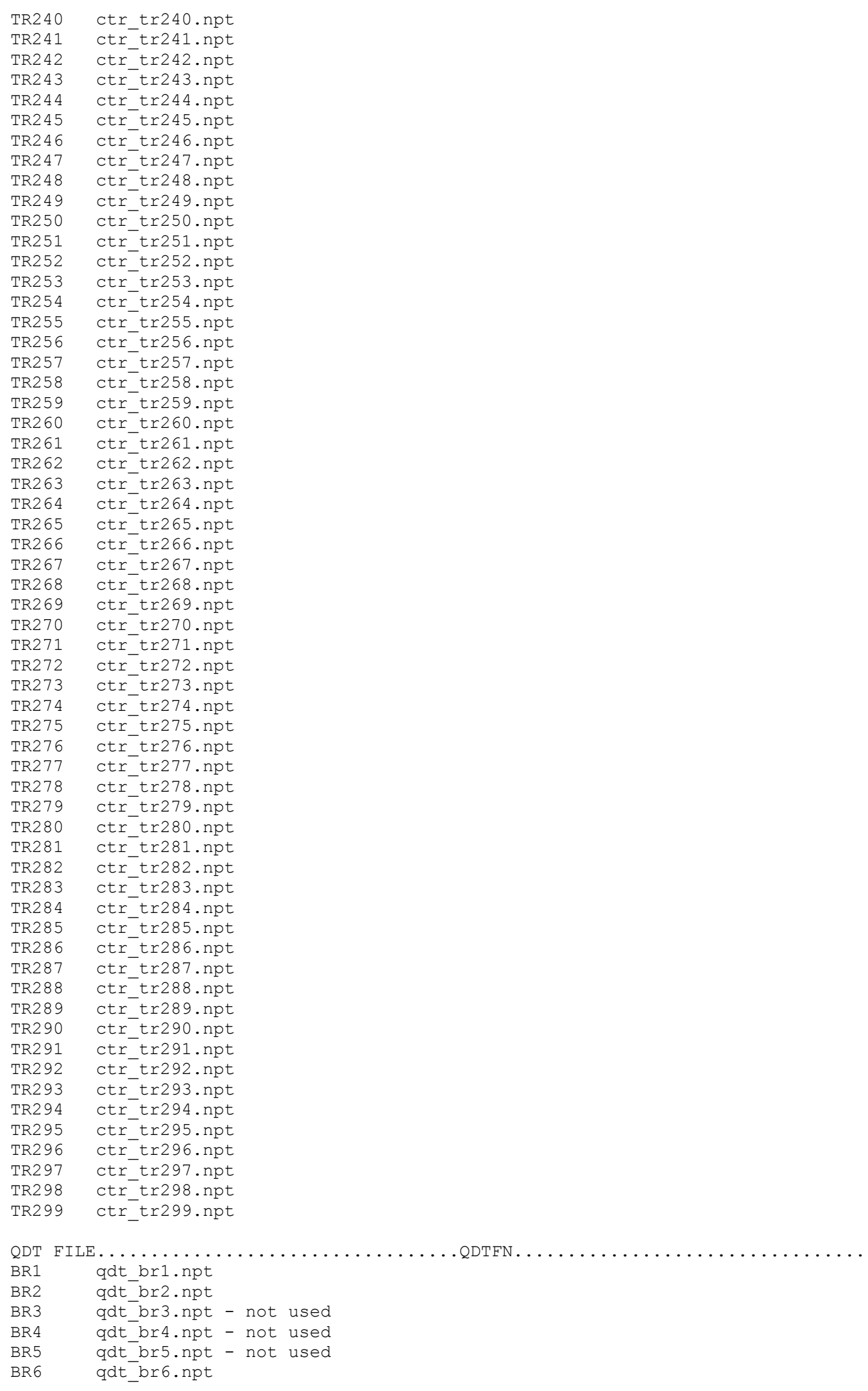




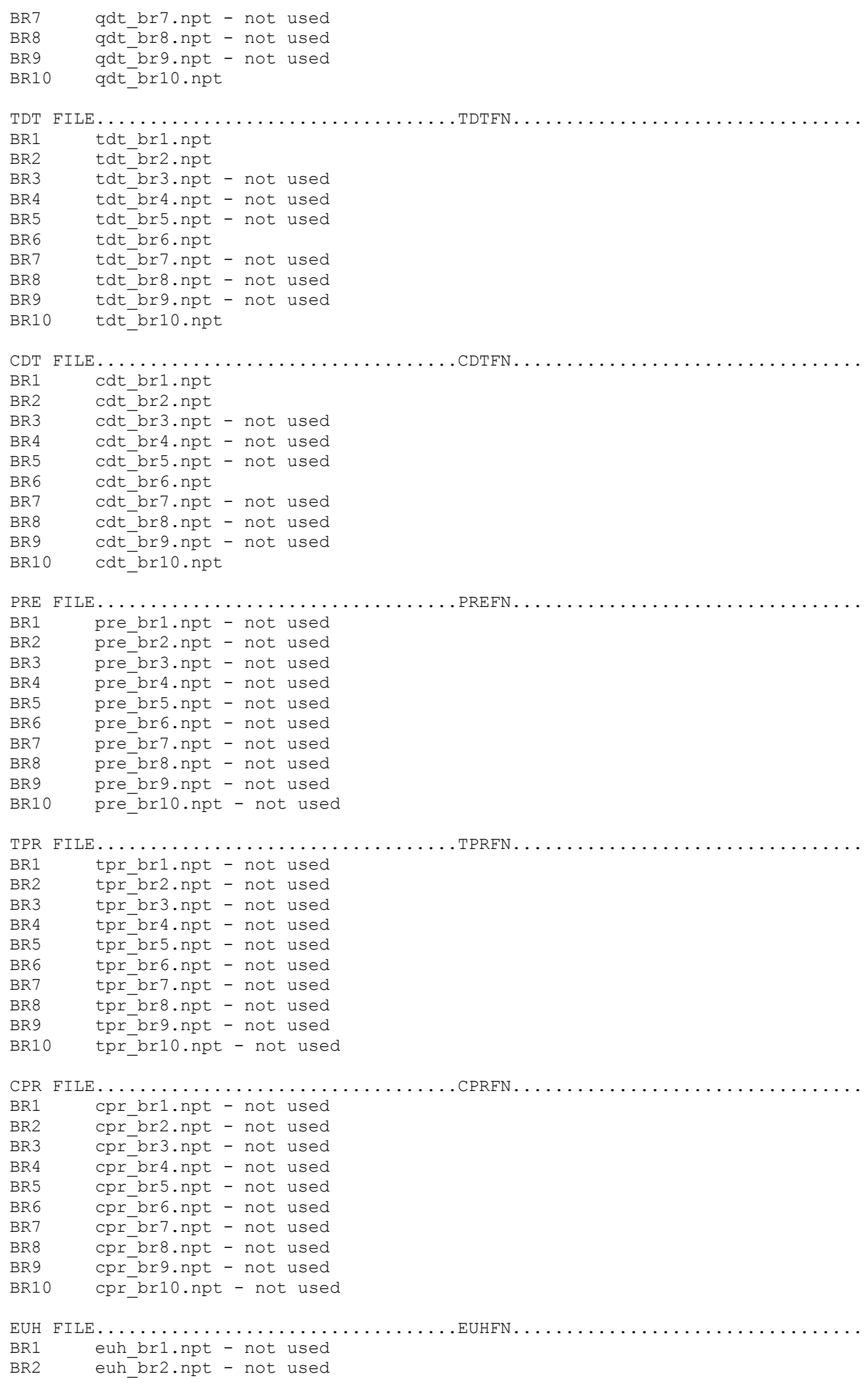




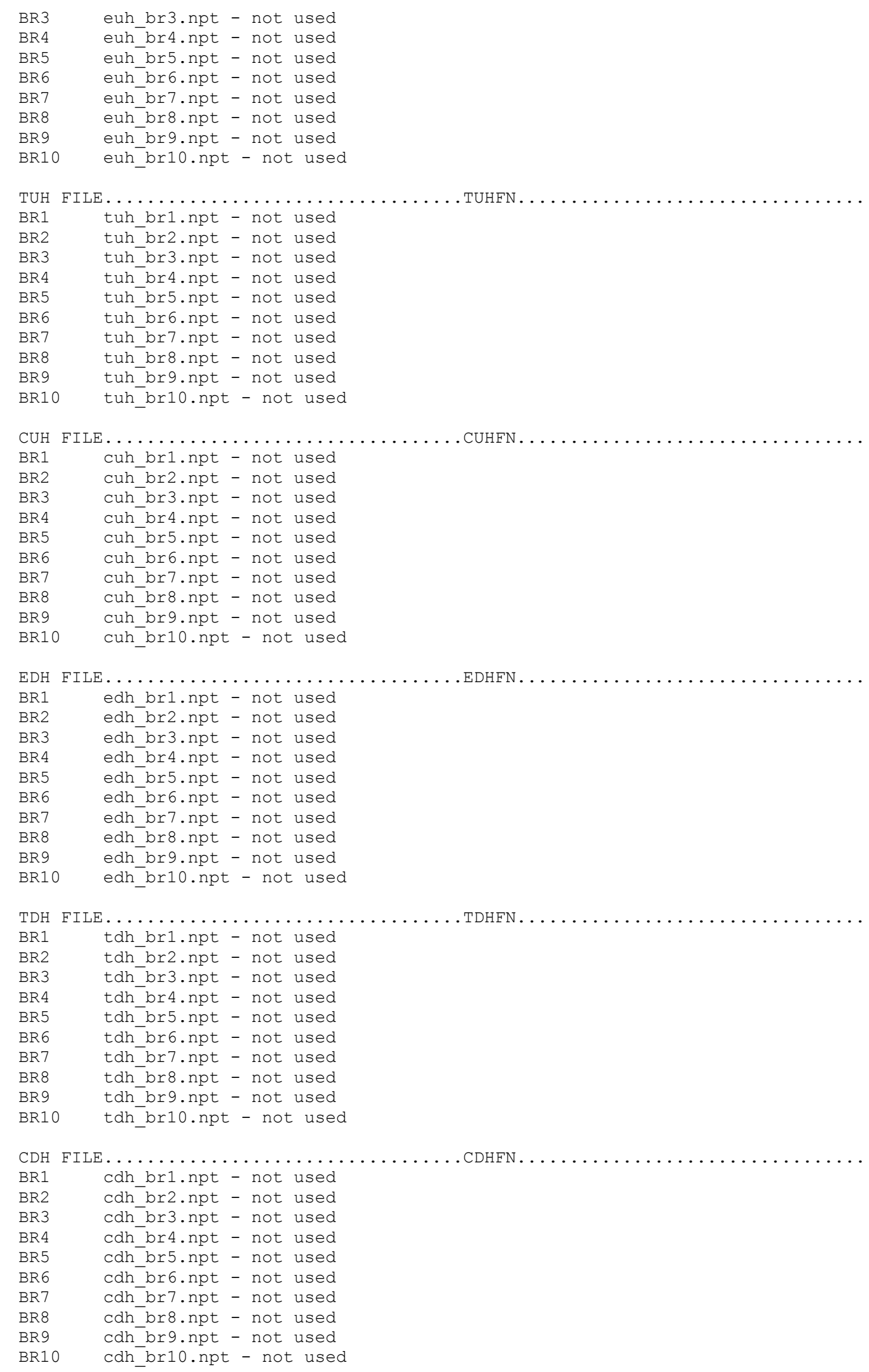




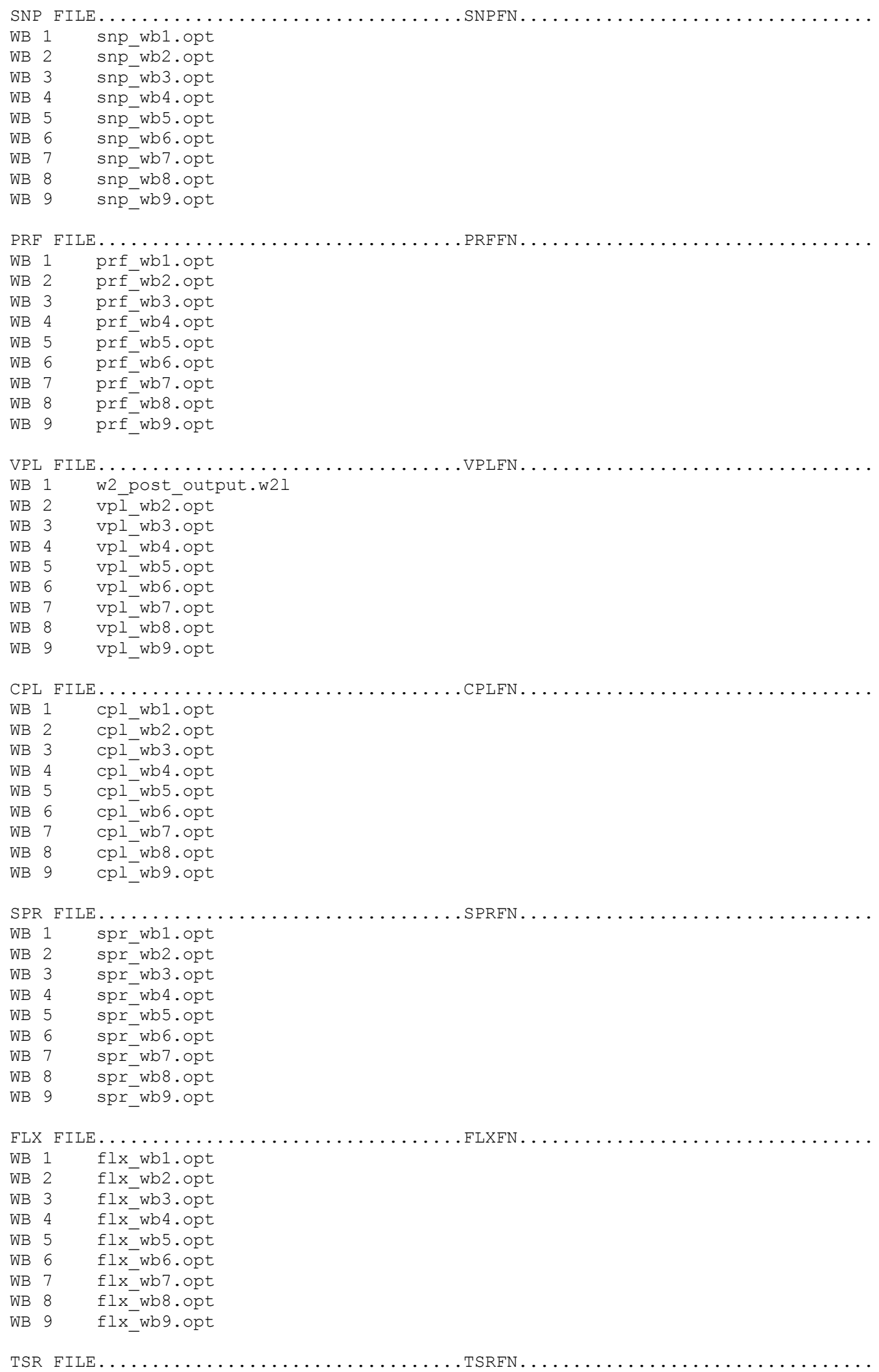


tsr.csv

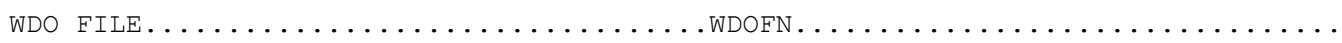
wdo.opt 